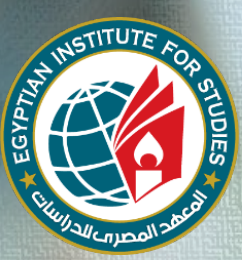

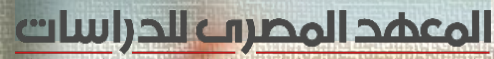
EGYPTIAN INSTITUTE FOR STUDIES

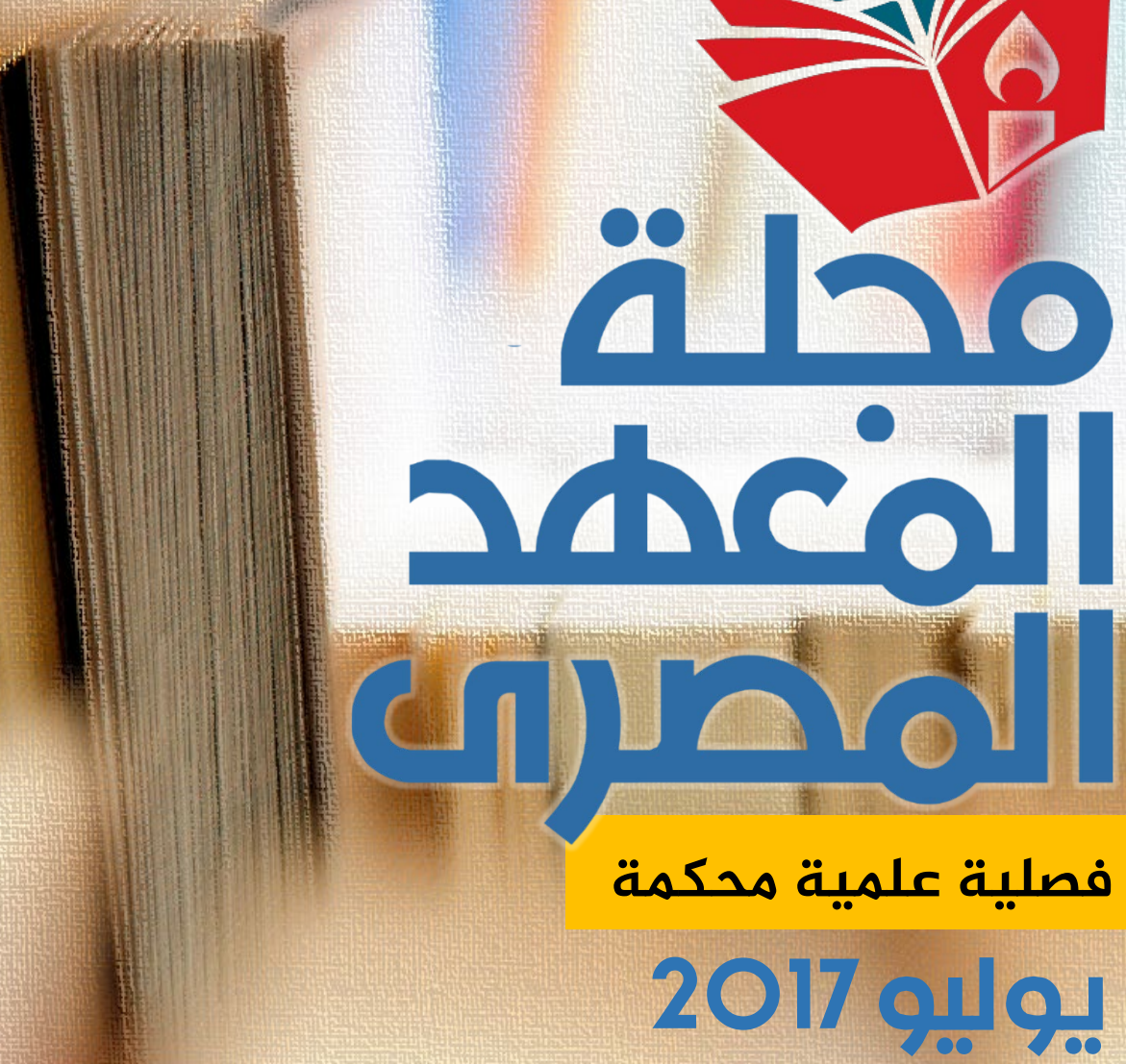

• ترامب بعد مائة يوم: المسسارات ولسسيناريوهات • البنية المؤسساسية لجماعة الإخموان: اقترلب تصاليلي

• الحركات الجهادية المصرية: حدود الدور

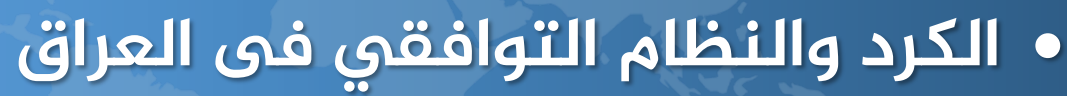

دصحص] • نهاية الحرب الباردة والنتنظير فهي النزراع الدولدي 


\section{مجلة المعهد المصر؟}

EIS PEERREVEWED J OURNAL

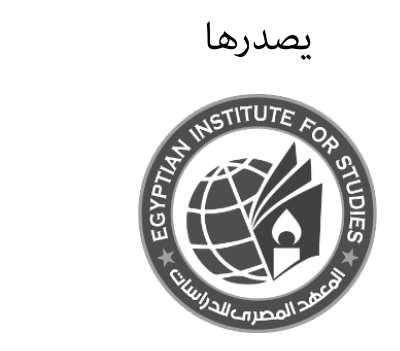

المعهد المصرى للدراسات EGYPTIAN INSTITUTE FOR STUDIES

$$
\text { رئيس المعهد }
$$

$$
\text { د. عمـــرو دراج }
$$

$$
\text { مدير المعهد }
$$

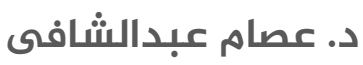

$$
\text { الهيئة الاستشارية }
$$

أد. نادية محمود مصطفى (مصر)

أد. سيف عبد الفتاح (مصـر) أد. محسن صـالح (فلسطين) (مداح)

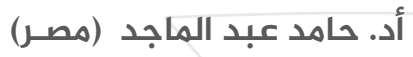
أد. محمد مختار الشنقيطي (موريتانيا) أد. وصفي عاشور أبوزيد (مصـر) أد. بوحنية قــوي (الجــزائر أد. رمضان يلدريم (تركـيا) أد. أشرف محمد دوابه (مصر يلرئ أد. أحمد ذكر الله (مصـر) أد. حسن حاج على (السودان) (ألسر) أد. عبد الناصر الجاسم (سوريا)

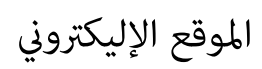

www.eipss-eg.org حسابات التواصل
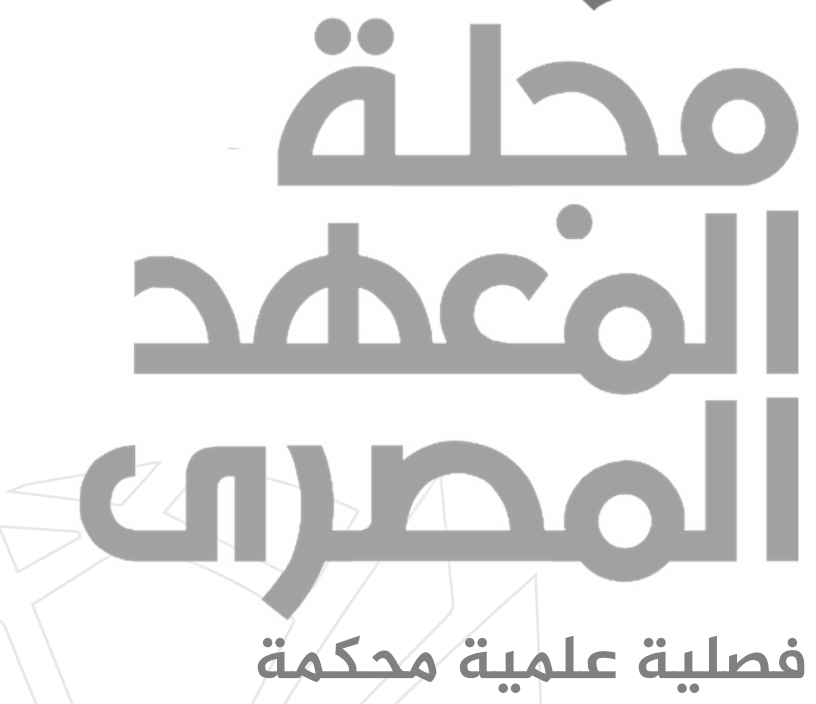

\section{العدح السابع 07- بيو لإيو 2017}

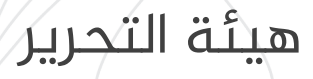

رئيس التحرير

د. عصام عبد الشافي

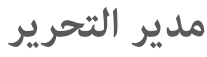

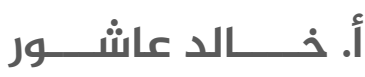




\section{مجلة المعهد المصري}

\section{Egypt institute J OURNAL}

مجلة علمية دولية محكمة، تصدر فصلياً، عن المعهد المصري للدراسات، تختصص

بنشر الدراسات والبحوث في مجال العلوم الاجتماعية والإنسانية.

An international peer-reviewed journal, published quarterly, by the

Egyptian Institute of Studies, specialized in publishing studies and

researches in the social and human sciences.

\begin{tabular}{|c|c|c|c|}
\hline \multicolumn{4}{|c|}{ الهيئة العلميـة } \\
\hline (اليمن) & د. هود أبو راس & (سوريا) & د. محمد رشيد \\
\hline (اليمن) & د. عبد الباقي شمسان & (سوريا) & د. عبد الحميد العواك \\
\hline (الجزائر) & د. وداد غزلاني & (توكيـا) & د. أحمد أويصال \\
\hline (فلسطين) & د. عدنان أبو عامر & (المغرب) & د. أنس بنعلال \\
\hline (تونس) & د. أنور الغربي & (المغرب) & د. سمر خمليشي \\
\hline (الجزائر) & د. بلخيرات حوسين & (المغرب) & د. نورة الحفيان \\
\hline (مصـر) & د. بدر حسن شافعي & (السودان) & د. إكرام صالح \\
\hline (مصر) & د. جمال ضلع & (تونس) & د. سكينة خضر اوي \\
\hline (العراق) & د. جاسم الشمري & (ليـيـيا) & د. ميلاد الحارثي \\
\hline
\end{tabular}

Bahçelievler, Yenibosna mah. 29 Ekim Cad. No:7 A2 Blok 3 Plaza, Kat: 6, D:64, Istanbul, Turkey. Mobile: +90 5466624446 Tel: +90 2122272262 Mail: journal@eipss-eg.org

\section{الناشر}

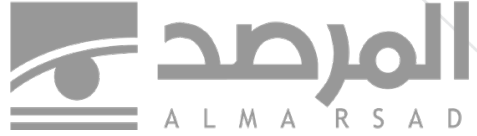

المرصد للنُشْر والصحافْة والإعلام ALMARSAD FOR PUBLISHING, PRESS \& MEDIA

29 Ekim Cad. No:7 A2 Blok 3 Plaza,

Kat: 6, D:64, Yenibosna mah.

Bahçelievler, Istanbul, Turkey.

Mobile: +90 5466624440

Tel: +902122272262

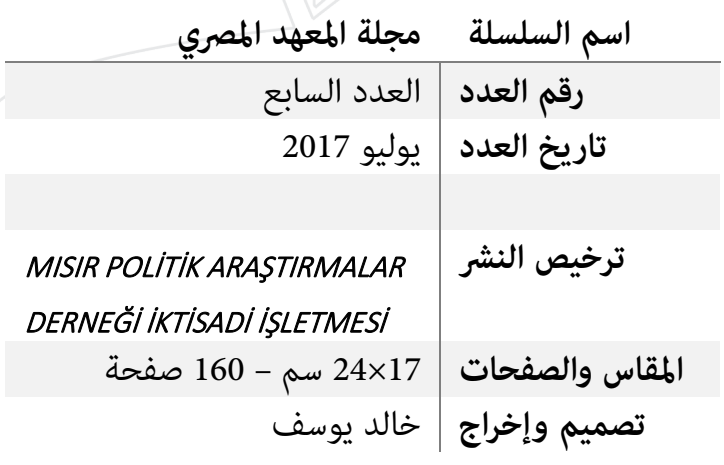

مجلة المعهد المصــــرى، المجلد الثاندي ، العدد السابع ، يوليو 2017 


\section{قواعد وضوابط النشر}

1- يجب ألا يتجاوز البحث المقدم للنشر (5000) كلمة، متضمنة الملخصين: العربي، والإنجليزي، والمراجع.

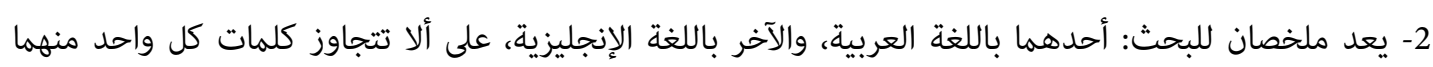

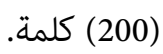

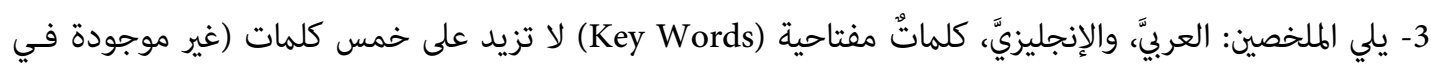

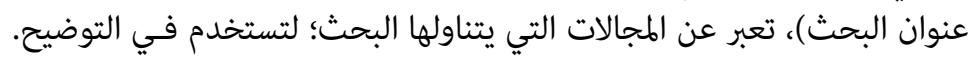

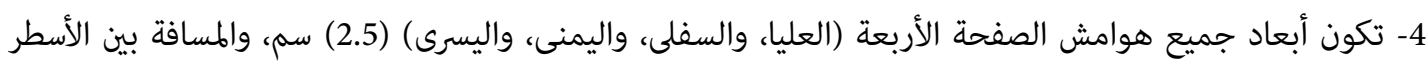

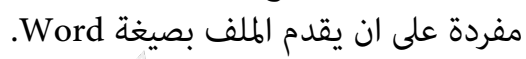

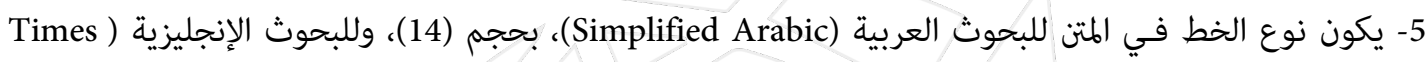

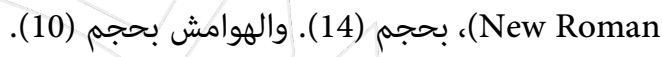
6- تستخدم الأرقام العربية (، Arabic...3-2-2) في (14). 7- يكون ترقيم صفحات البحث في منتصف أسفل الصفحة.

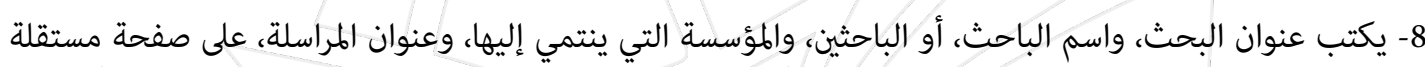

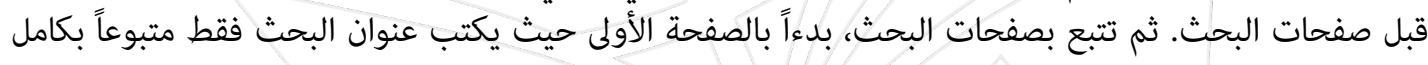

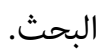

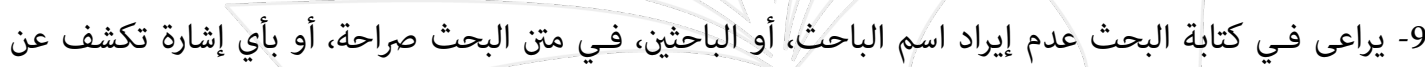

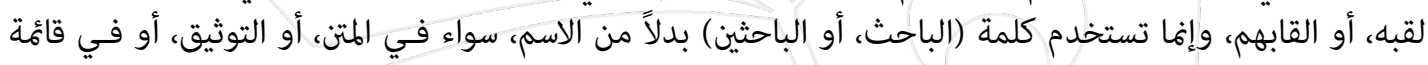
المراجع.

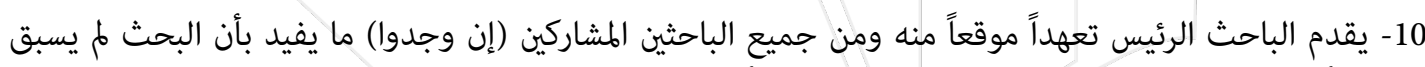

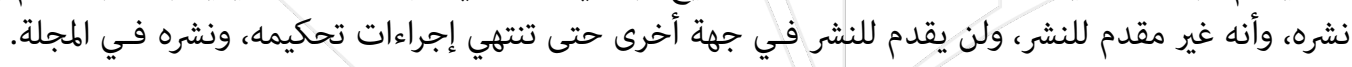

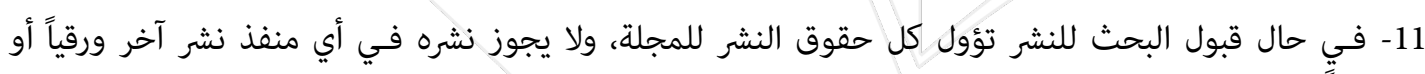
إلكترونياً، دون إذن كتابي من رئيس هيئة التحرير.

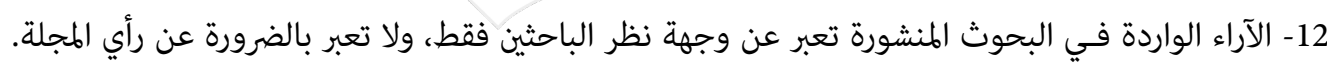

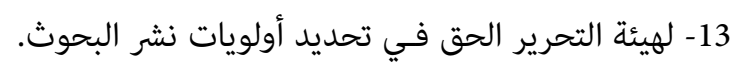
14- يتم تقديم البحوث إلكترونياً من خلال بريد المجلة الإلكتروني: journal@eipss-eg.org

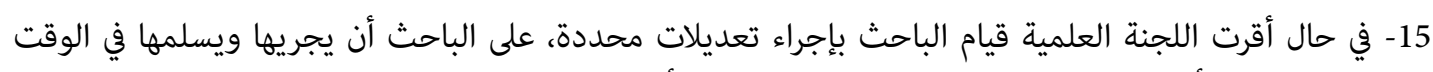

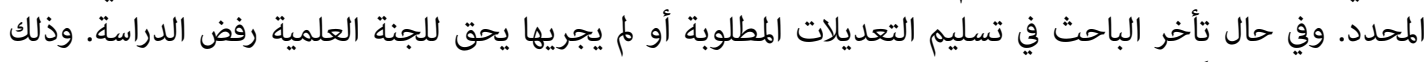
خلال مدة 15 يوماً من تاريخ إرسال التعديلات. 16- في حال قبول الدراسة، يتم توجيه خطاب رسمي للباحث، يشير الى قبول الدراسة، وتاريخ نشرها. 


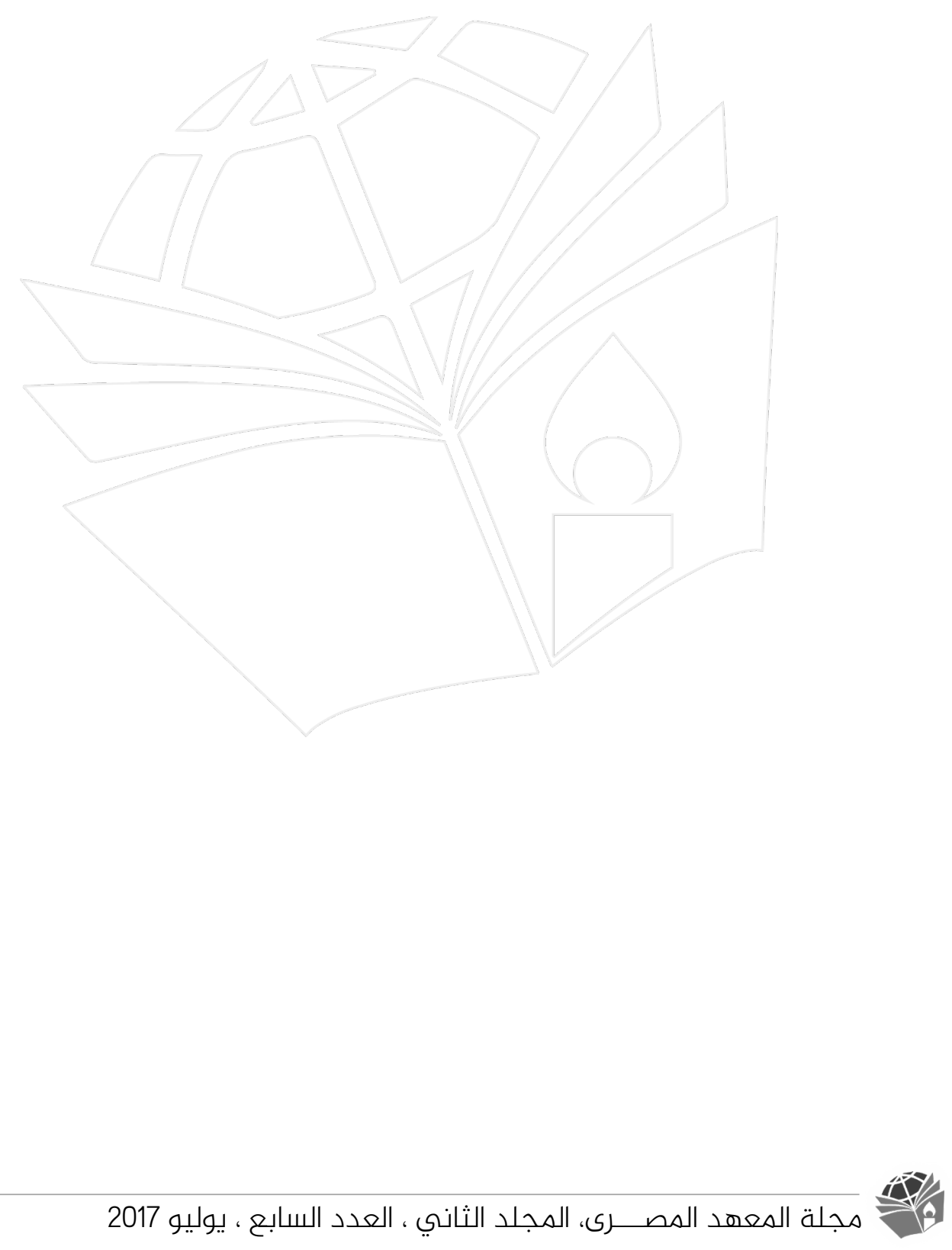




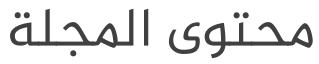

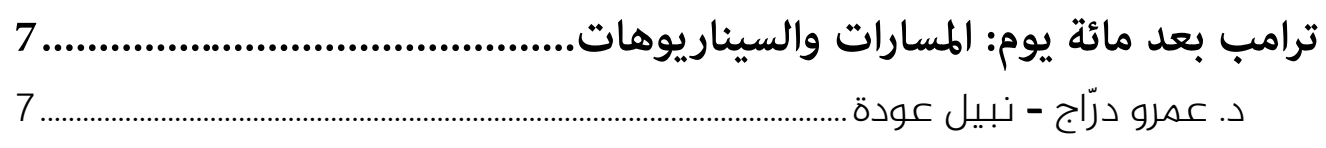

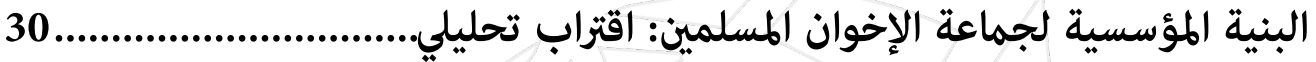
30 يمنسى سليمان.

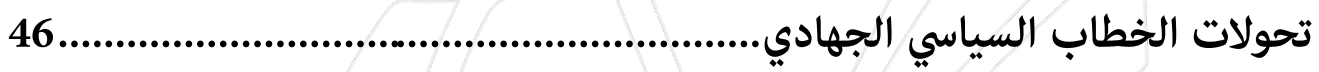
عبد الغني مزوز (الهغرب)..................................................................................

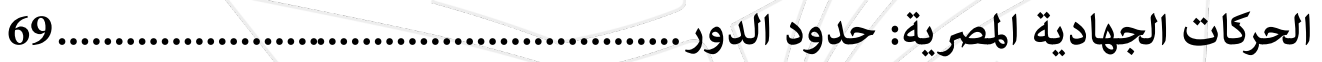
69.

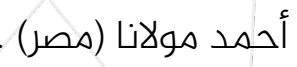

99 نهاية الحرب الباردة والتنظير في النزاع الدولي 99.

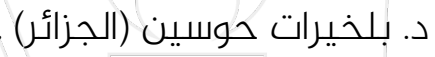

121

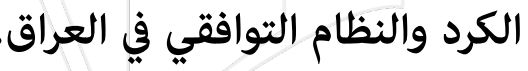
121

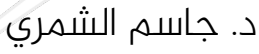

145 كيف تصنع رمزاً: باسم يوسف نموذجاً. 145

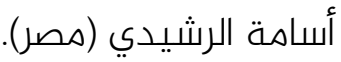




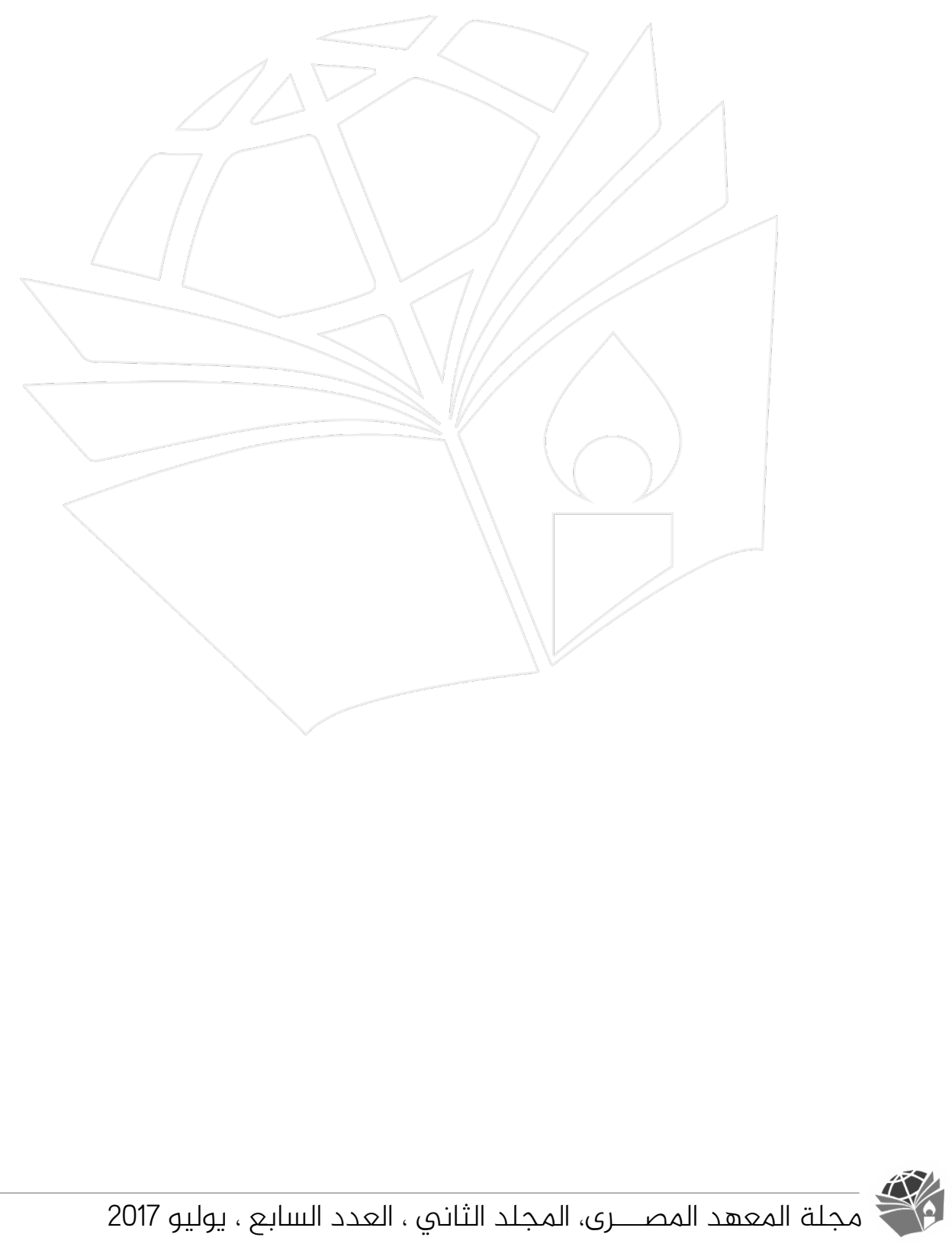




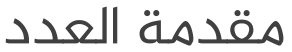

تضمن العدد السابع من مجلة المعهد المصري، يوليو 2017، عدداً من الدراسات السياسية والاستراتيجية، والاقتصادية والفكرية والقانونية والتي جاءت على على النحو التالي:

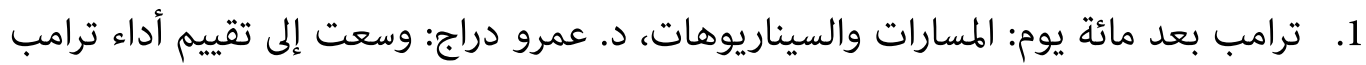

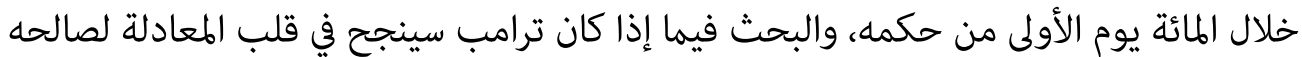

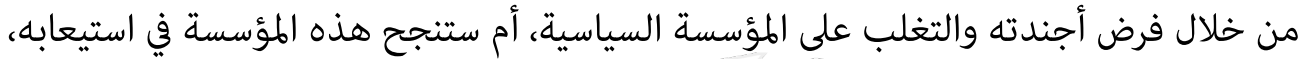

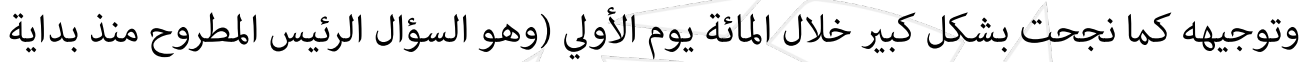

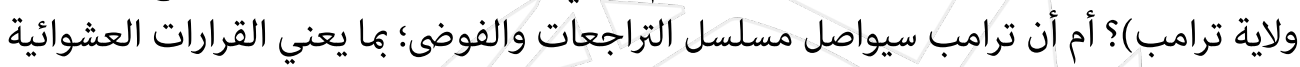

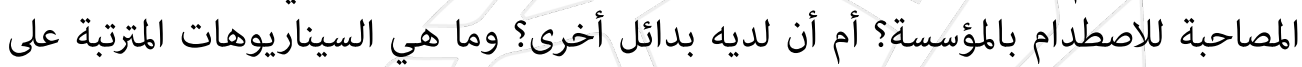

ذلك؟

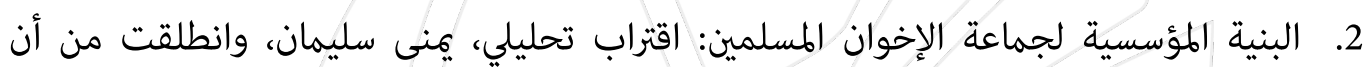

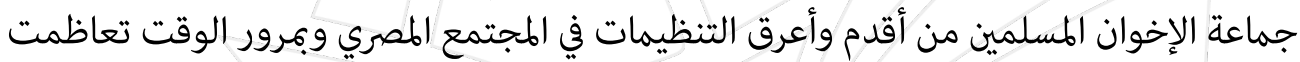

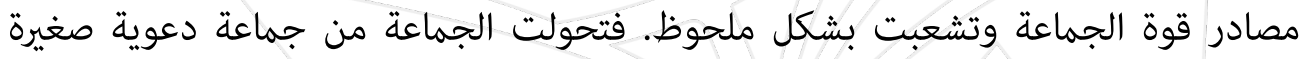

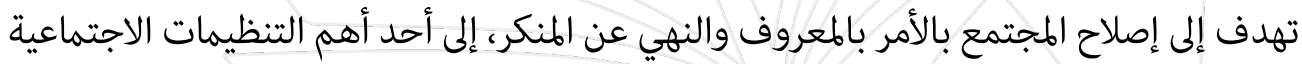

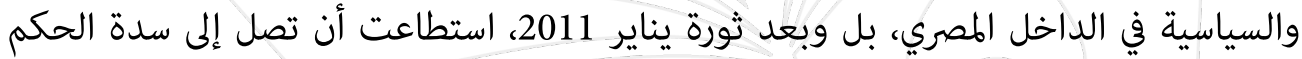

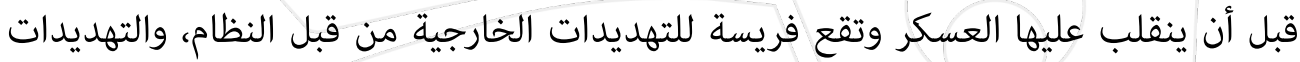

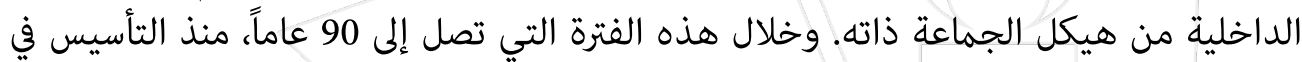

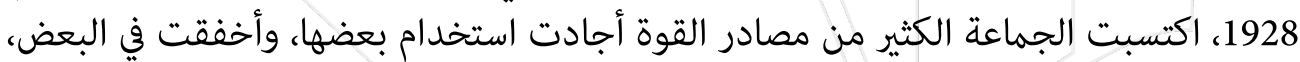

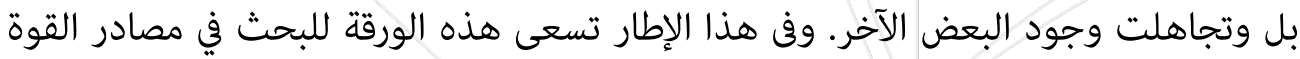

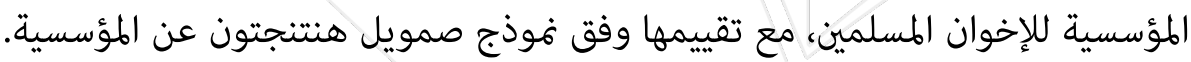

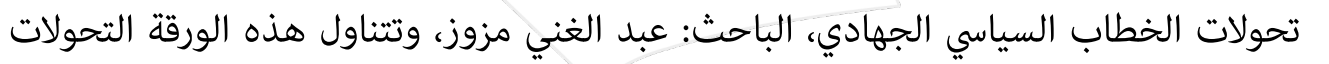

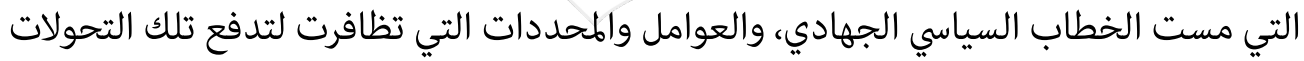

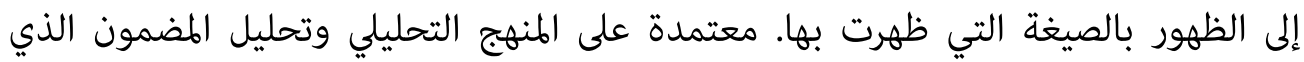

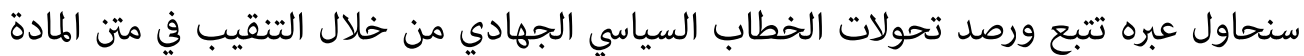

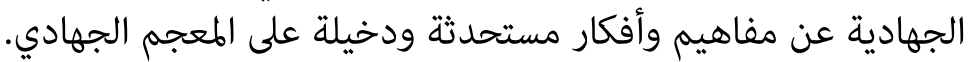

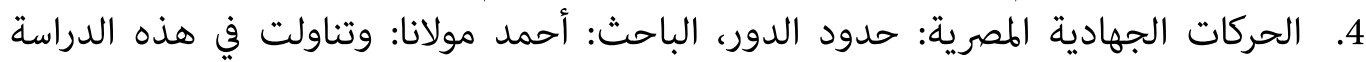

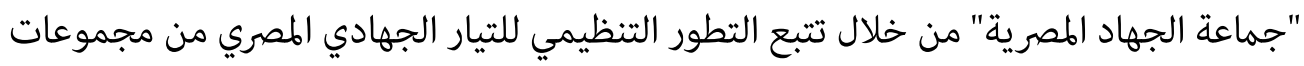

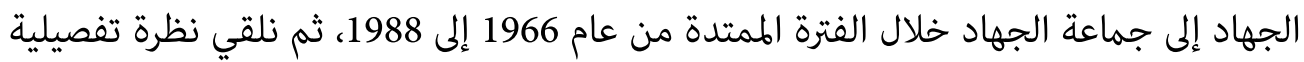

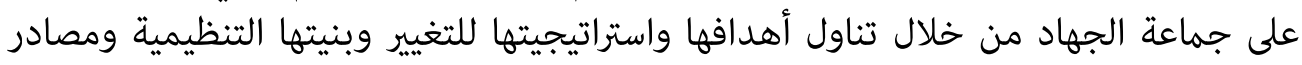

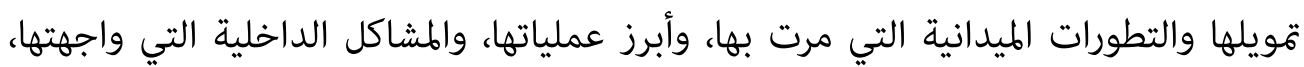




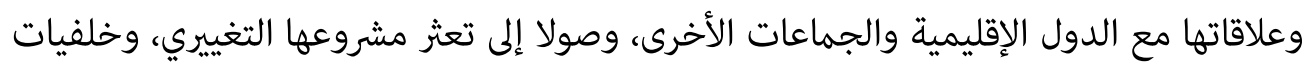

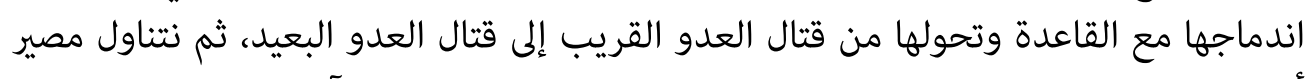

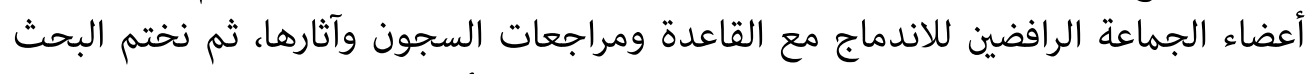
بتقييم إجمالي للتجربة. وقد اعتمدت في السرد التاريخي للأحداث على التهاء كتب قيادادات وكوادادر التيار الجهادي.

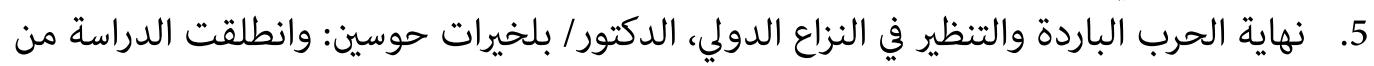

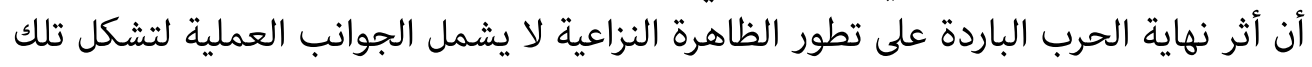

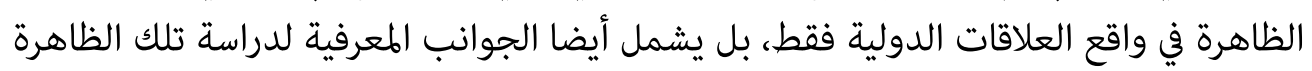

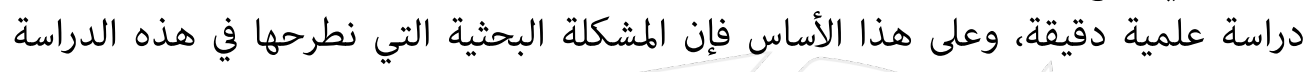

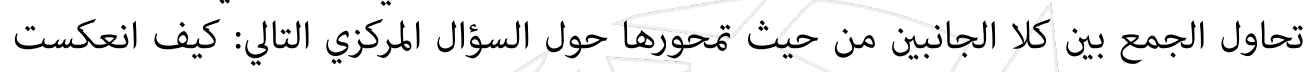

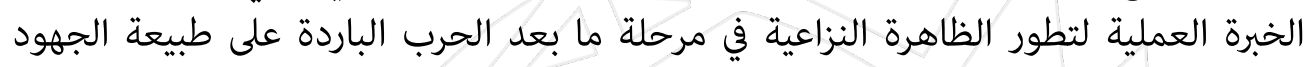

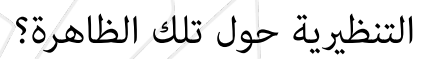

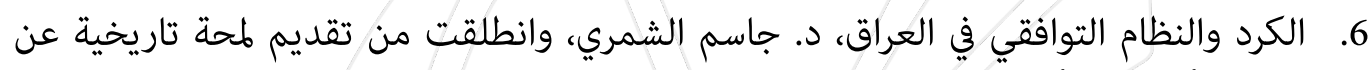

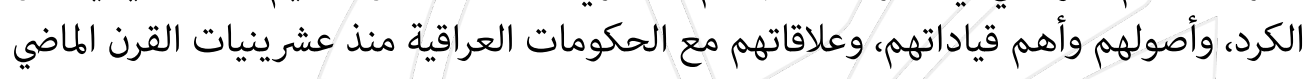

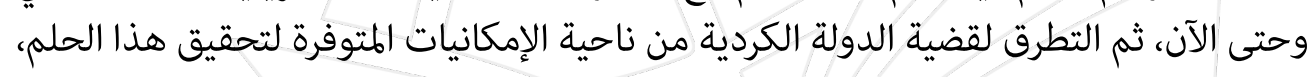

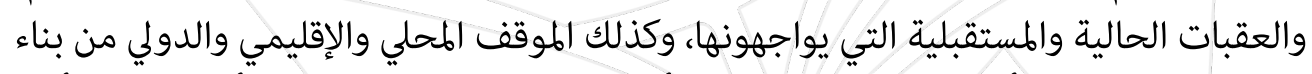

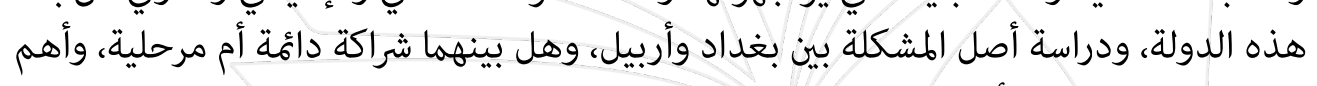

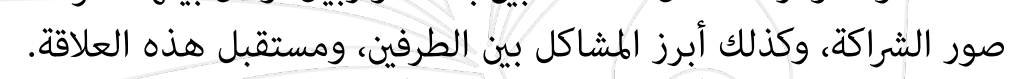

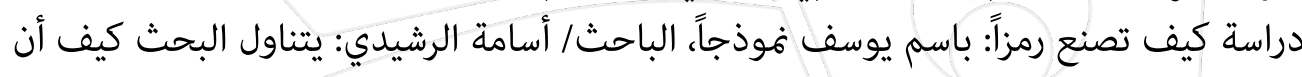

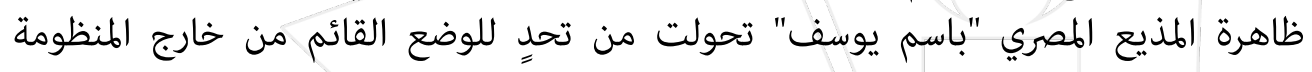

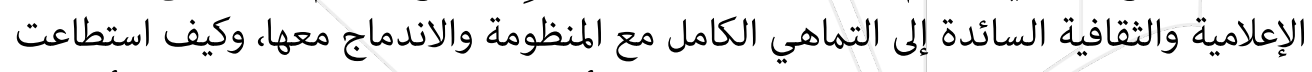

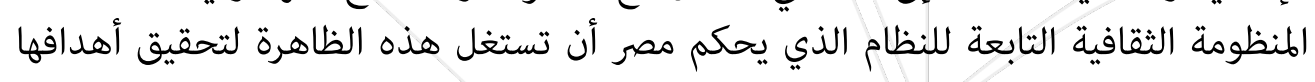

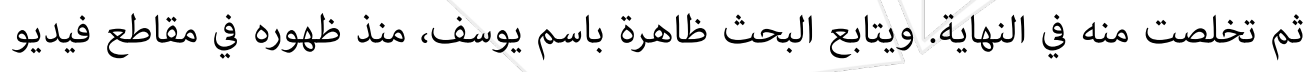

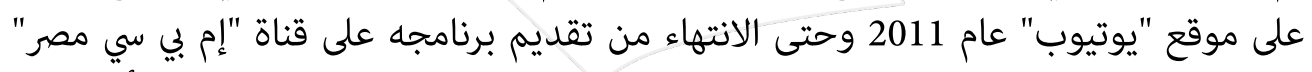

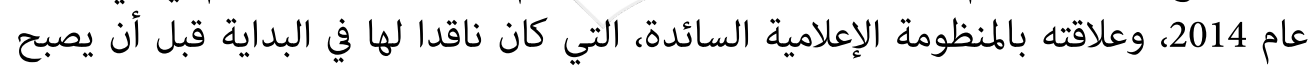

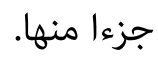




\section{مجلةٌ المعشد المصرات} EGYPT INSTITUTE JOURNAL

\section{ترامب بعد مائة يوم: المسارات والسيناريوهات}

$$
\text { ند عمرو درّاج }
$$

• •سياسي وأكاديمي مصري، رئيس المعهد المهري للدراسات السياسية والاستراتيجية، وزير التخطيط والتعاون الدولي في حكومة الرئيس 
"يبدو أنه في حالة من الفوضى الشخصية"1 هكذا وصفت زعيمة الأقلية الديمقراطية في مجلس النواب

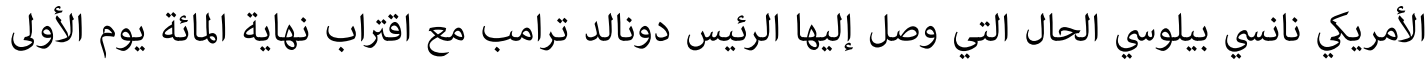

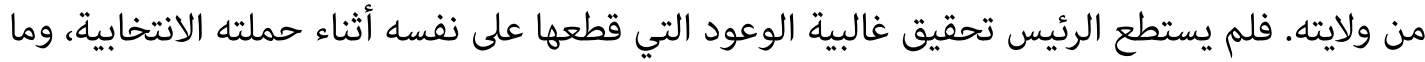

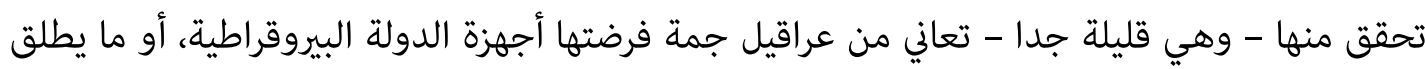

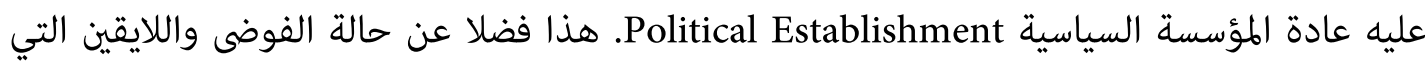
مازالت السمة البارزة لإدارته، حيث مل يستطع الرئيس ترامب الوصاسية الوصول إلى مقاربة واضحة يحسم بها

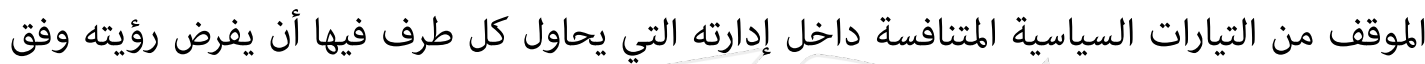
معادلة صفرية تهدف إلى تهميش أو حتى وأد الطرف الآخر.

$$
\text { أولاً: ترامب بين التخبط والفوضى: }
$$

هناك عدة مقاربات ممكنة لتفسير حالة التخبط والفوضى التي تواجهها إدارة ترامب. تتعلق إحدى هذه

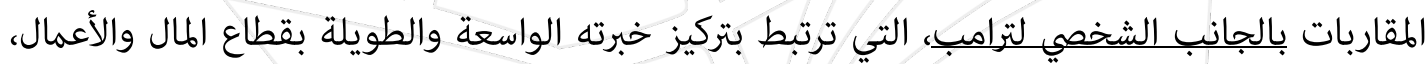

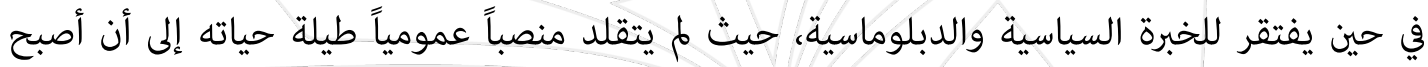

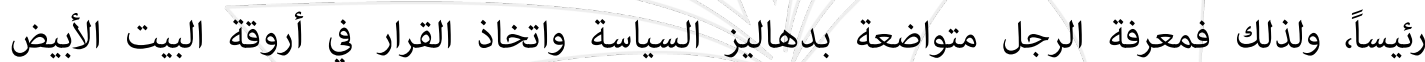

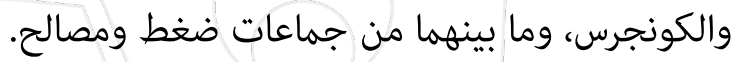

وهناك مقاربة أخرى متعلقة بالبنية الهيكلية لتحالفات ترامب السياسية، التي إلى الآن تظهر بحالة من التهات

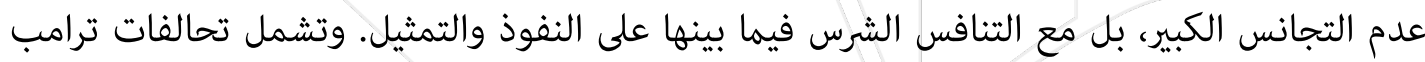

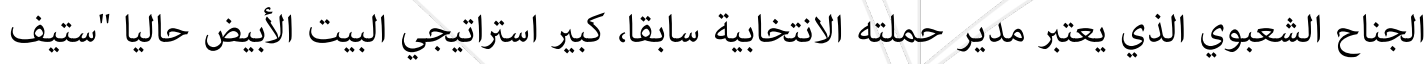

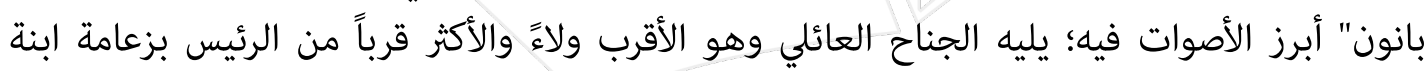

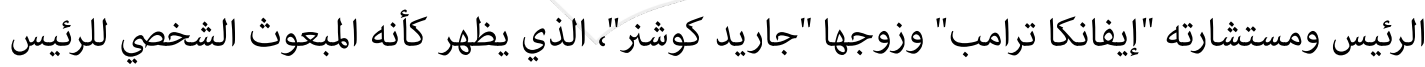
في الكثير من الملفات شديدة الحساسية مثل العلاقة مع الصين، مع المكسيك، والعلاقة مع الفلسطينيين كارين

1 see more; abby phillip and robert costa. trump remains the center of attention, but he's increasingly isolated politically. washington post, april 2, 2017. 
والإسرائيليين، وغيرها؛ وأخيرا هناك الجناح الحزبي الجمهوري التقليدي بزعامة جنرالات البيت الأبيض

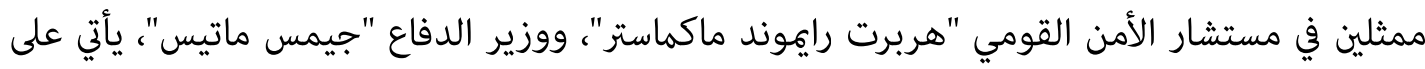

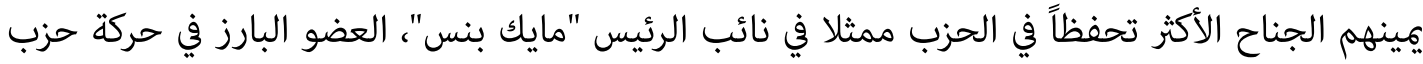
الشاي اليمينية المتشددة.

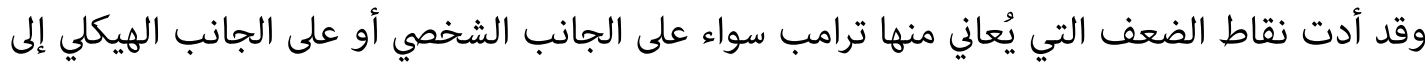

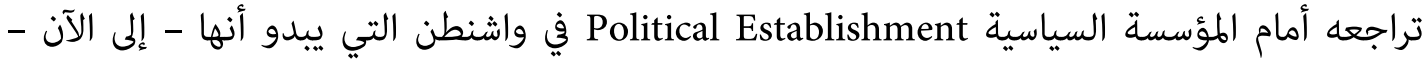
تتفوق عليه، وتجبره على التصرف مِقتضيات آلياتها وتراثها البيروقراطي.

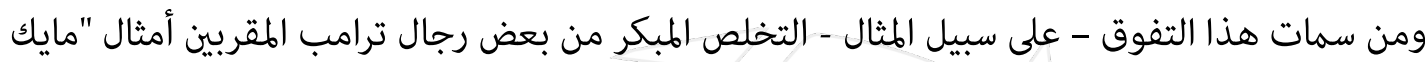

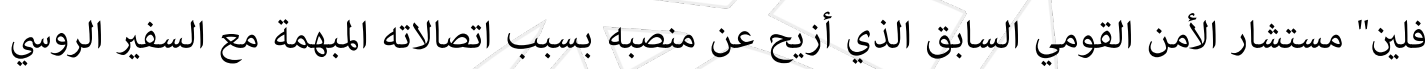

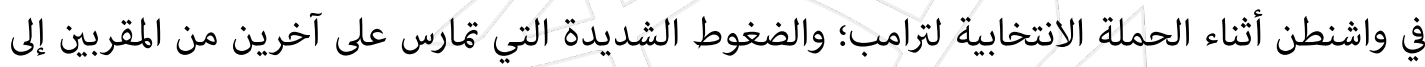

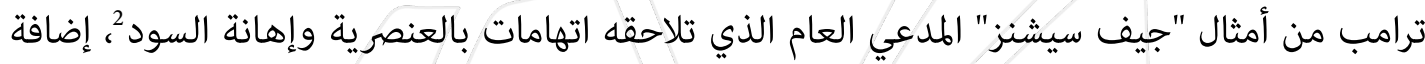

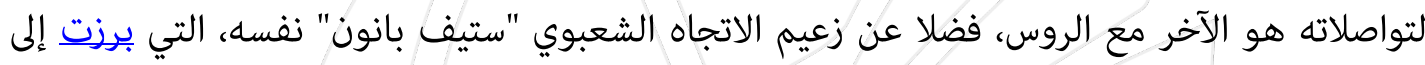

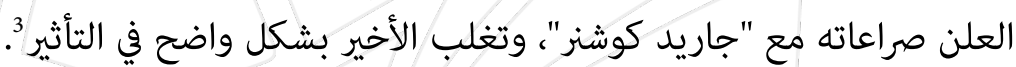

وقد أدى تراجع ترامب أمام المؤسسة السياسية إلى إخفاقه في تنفيذ أبرز الوعود التي قطعها على نفسه

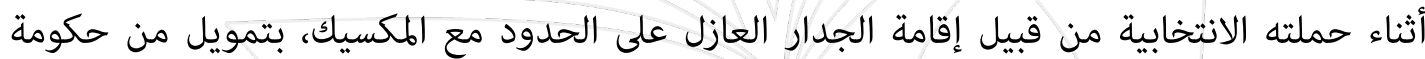

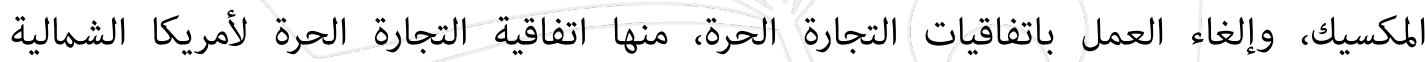

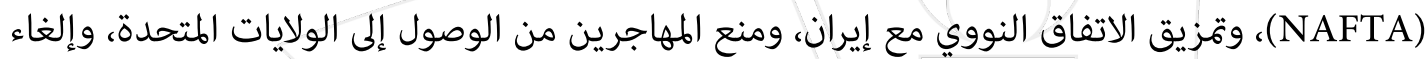

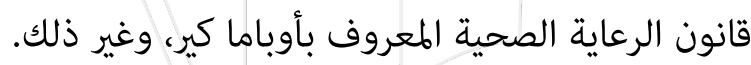
وعليه فإن السؤال المطروح الآن حول المستقبل، فضلا عن تقييم أداء ترامب خلال المائة يوم الأولى من

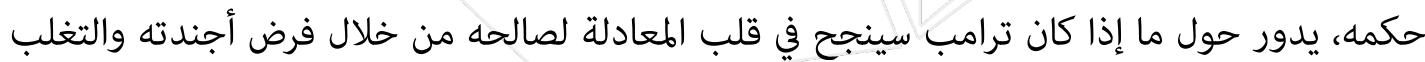

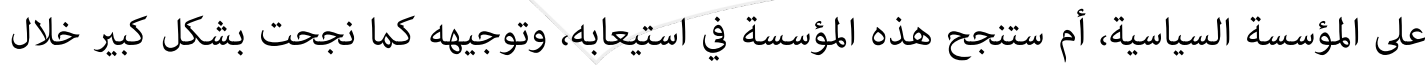

2 see more; jeff sessions, trump's new attorney general dogged by controversy. bbc news, march 2, 2017.

3 see more; jeremy w. peters and maggie haberman, trump fires warning shot in battle between bannon and kushner. new york time, april 7, 2017. 
المائة يوم الأولي (وهو السؤال الرئيس المطروح منذ بداية ولاية ترامب)؟ أم أن ترامب سيواصل مسلسل

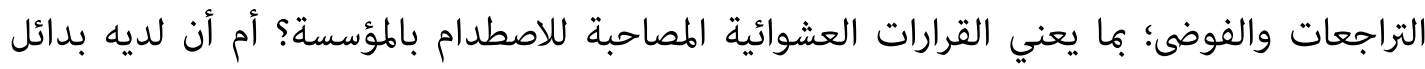

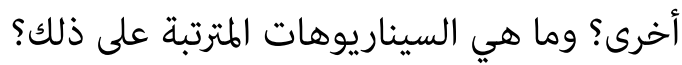

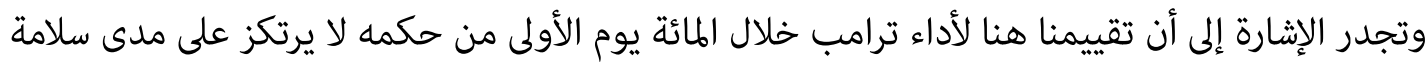

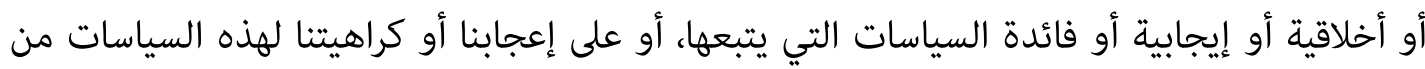

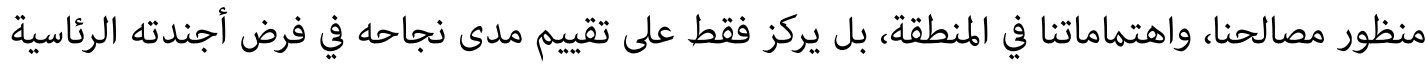

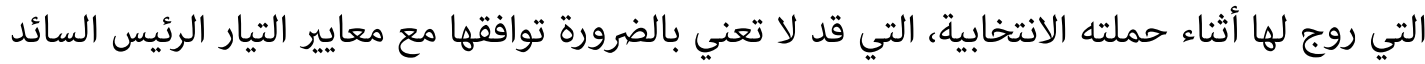

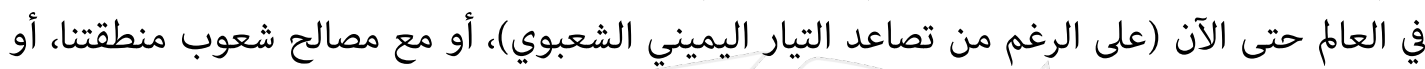

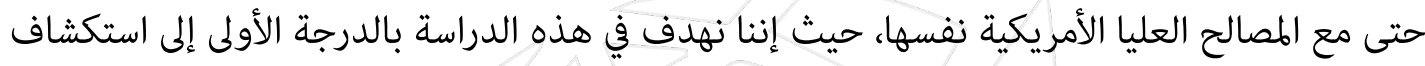

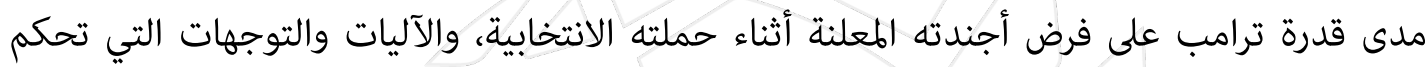

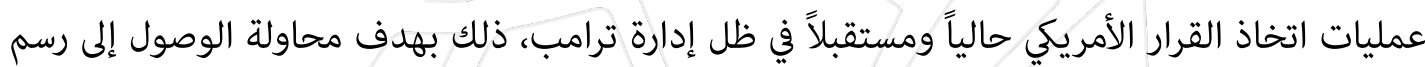

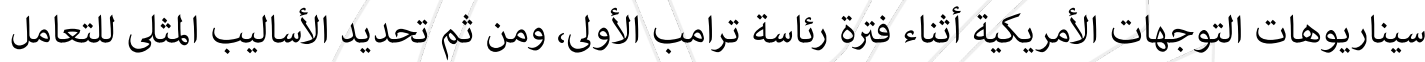
مع كل منها لاحقا.

ثانياً: ترامب بين البرجوازية والشعبوية من أبرز الاقترابات المهمة في فهم وتفسير سياسات الرئيس ترامب، محاولة تفكيك الإشكالية المتعلقة

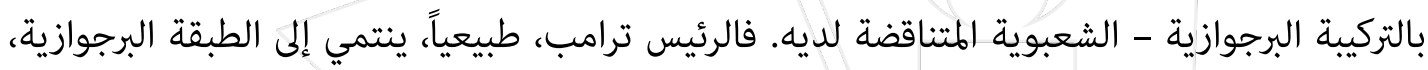

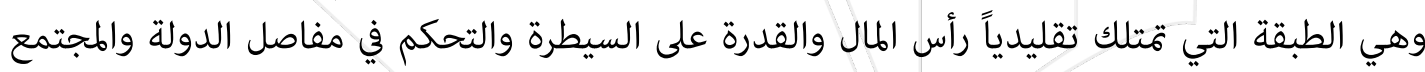

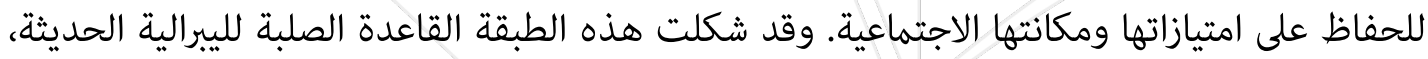

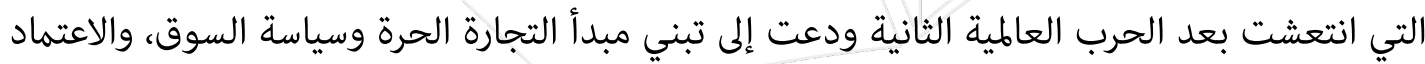

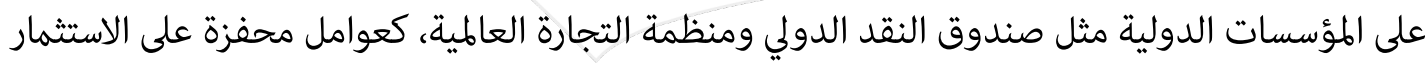

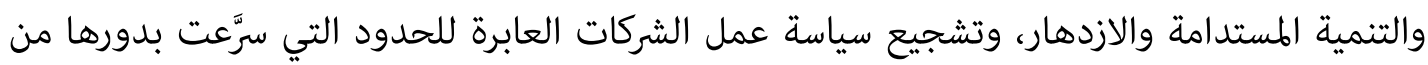
عملية العولة، التي أفضت لاحقاً إلى خلق عالم تسوده مستويات عالمالية عالية من الاندماج والاعتهاد المتبادل

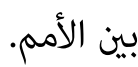

مع مرور الوقت شكلت هذه الطبقة البرجوازية عصب النخبة الحاكمة، ومع تكدس رأس المال في أيديها،

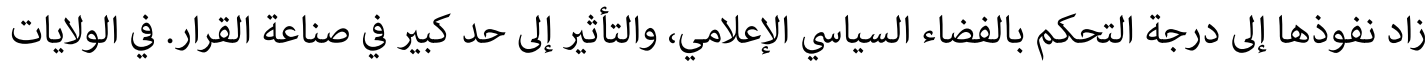

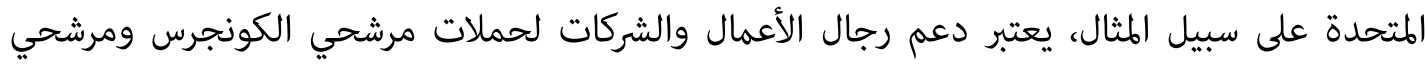

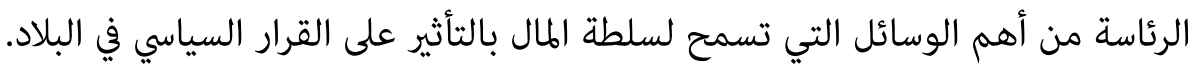


صدمت الأزمة المالية في العام 2008 النخبة البرجوازية والجماهير على حد سواء. فلم تكن نخب المال

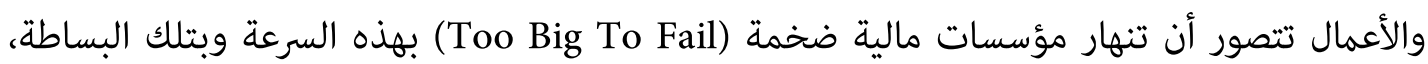

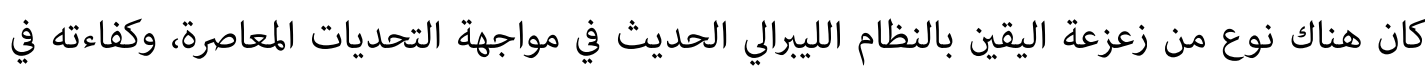

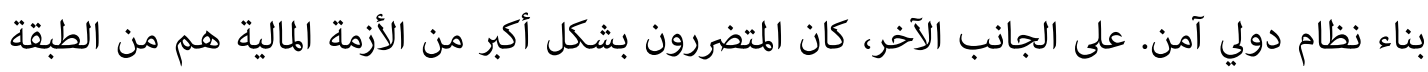

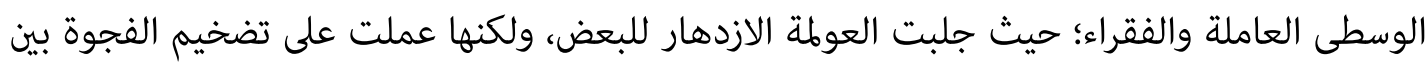
الفقراء والأغنياء، ولم تعد تلك المشاكل التي تصيب الاقتصاد الأمريكي بكعزل عن تدهور الحالة الاقتصادية للعمال في بيرو أو تايلاند على سبيل المثال.

أدى فشل السياسة المالية العالية لانتكاسة في الجهود المبذولة للقضاء على الفقر والبطالة، الأمر الذي

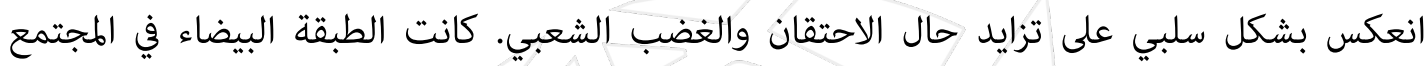

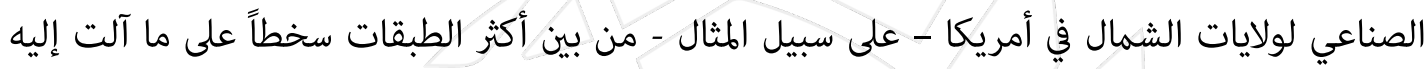

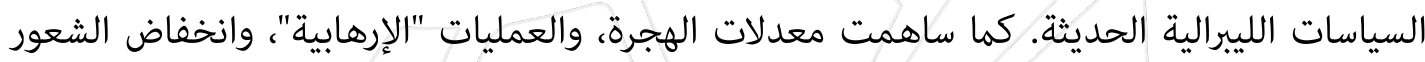

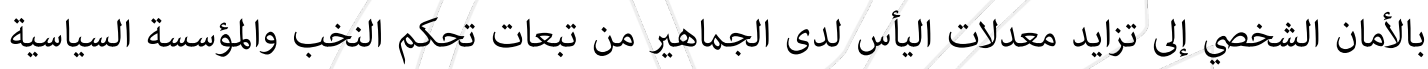

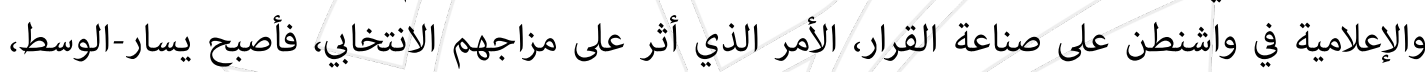
أيضا يمين الوسط، يفقد حاضنته الشعبية لصالح التيارات الأكثر يمينية وشعبوية. بالعودة إلى ترامب، فالرجل كون ثروته الهائلة التي تقدر حسب مجلة الأعمال الأمريكية فوربس، بثلثلاثة

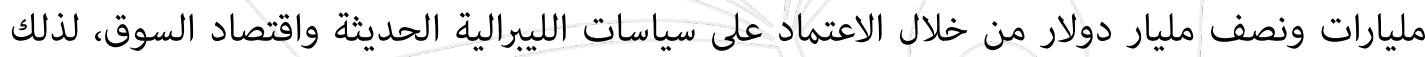

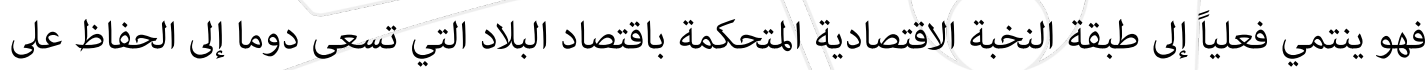

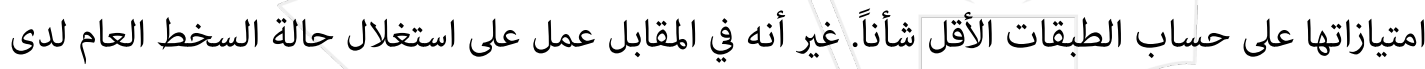

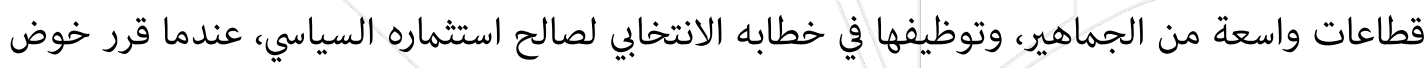
غمار المنافسة على منصب الرئاسة في الولايات المتحدة. كان ترامب من أولئك الذين يحسنون استغلال الفرصة ومعرفة مزاج السوق. كان يعرف كيف يتكلم بما

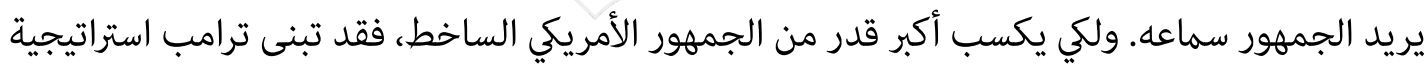
خطابية تقوم بالأساس على دعامتين: أولا، الحمائية الاقتصادية والاجتماعية. وثانياً الانعزالية السياسية 
والقومية، وقد تحورت مقاربته السياسية على الشعبوية الاقتصادية المحافظة ( conservative لeconomic populism الجمركي، من أجل العمل على تعزيز القطاعات الصناعية، في محاولة منه إلى ضمان تأييد سكان المقاطعات الصناعية في الشمال الأمريكي. أما أولئك القلقين على القيم الاجتماعية السائدة، فقد اتبع ترامب عقيد عقيدة Judo- "قومية تجعل من الهوية البيضاء العنصرية، التي تحافظ على القيم "المسيحية اليهودية

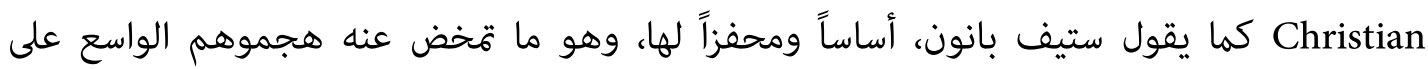
المهاجرين المسلمين والنساء والمثليين والسود (على الرغم من أن الكثير من سلوكياته الشخصية والتعبيرات التي يستخدمها قريبا من القيم التي ينادي بهاء).

إذن شََّّت الأيديولوجيا الشعبوية بشقيها الحمائي والانعزالي المنتج السياسي والخطاب الدعائي الذي استطاع ترامب توظيفه من أجل تعبئة الجمهور لغايات الفوز بالانتخابات الرئاسية. وبذلك يمثل ترامب ظاهرة نادرة في تاريخ الحركات الشعبوية؛ حيث لم يكن ترامب يوماً شعبوياً بالففهوم التقليدي القائم على فكرة ولادة القائد الشعبوي من رحم الجماهير (Bottom- Up approach)، بل كان ينتمي لعائلة عريقة من العائلات البرجوازية في منهاتن. بعبارة أخرى، لم يكن ترامب شعبوياً من حيث التكوين، ولكنه كان أفضل من غيره على الساحة في التعبير عن طموح طبقات عريضة من الشعب، تلك الغاضبة من السياسات غير العادلة لليبرالية الحديثة وهيمنة الدولة والكؤسسة السياسية على اتخاذ القرار، فالعبرة إذن، كانت في التعبير والخطاب لا في التكوين والأيديولوجيا، بل إن ترامب لم يعرف عنه حتى كونه جمهوري التوجه بالنظر للحزب الذي خاض انتخابات الرئاسة تحت رايته، فقد دعم في الماضي مرشحي رئاسة سابقين من كلا الحزبين: الجمهوري، والديمقراطي، دون أي توجه أيديولوجي واضح. فالئي الأيديولوجيا الوحيدة التي يؤمن بها ترامب كرجل أعمال فوذجي هي الربح فقط، وهذا ما سعى إليه ترامب وحققي، دوري ثالثاً: تراجعات ترامب: أوهام المرشح وحقائق الرئيس

نجح ترامب في توظيف الفضاء الشعبوي ليس بالفوز بترشيح الحزب الجمهوري وحسب، بل كذلك التغلب على المنافسة القوية ذات التاريخ السياسي العريق هيلاري كلينتون، والفوز بمنصب الرئاسة في الولايات المتحدة الأمريكية، وذلك بالاعتماد على خطاب شعبوي مختلف يحتوي سلسله من الوعود الانتخابية في إطار برنامج وعد بتنفيذه فور استلام السلطة. وقد وصف الكثيرون من المراقبين هذا الفوز بأنه حدث تاريخي بامتياز، ذلك أن ترامب لم يكن يملك أي رصيد من الخبرة السياسية، وهم يتلق دعما ماليا كبيرا لحملته الانتخابية عدا التمويل الذاتي، ولم يحظ بدعم كبير من قيادة الحزب بل الجمهوري، هذا

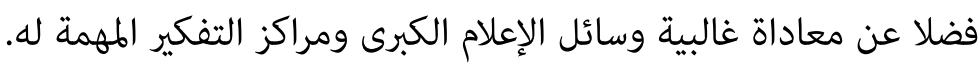


ومع ذلك فلم يستطع ترامب، حتى الآن على الأقل، أن يترجم هذا النجاح الاستثنائي في حملته الانتخابية

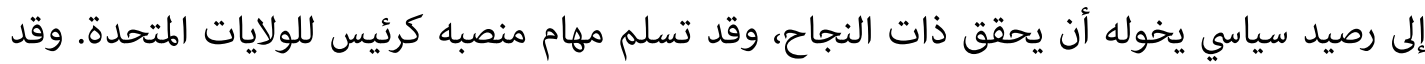

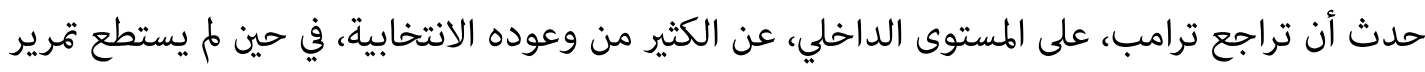

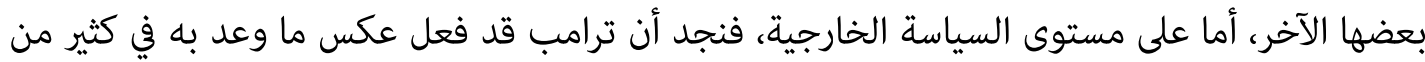
الأحيان.

أخفق ترامب - بداية - في تحقيق ما وعد به بخصوص إصلاح نظام الرعاية الصحية، وذلك من خلال

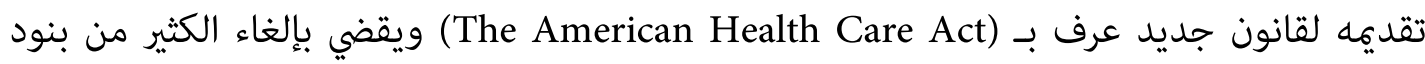
قانون الرعاية الصحية الذي كانت قد أقرته الإدارة السابقة واشتهر بـ Obamacare أو

.Care Act

ويستهدف القانون المقترح بشكل أساسي الإيرادات المالية لأوباما كير، بالإضافة إلى اقتراحه إجراء تعديلات كبيرة على قانون الرعاية الوطنية Medicaid (ستؤدي إلى تخفيض الانفاق الحكومي إلى حوالي 800 مليون

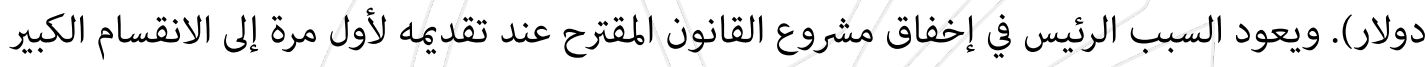

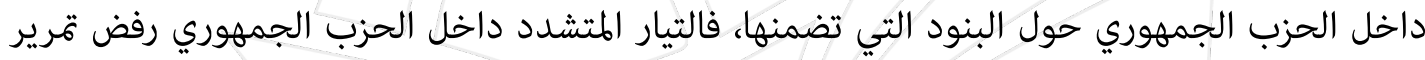

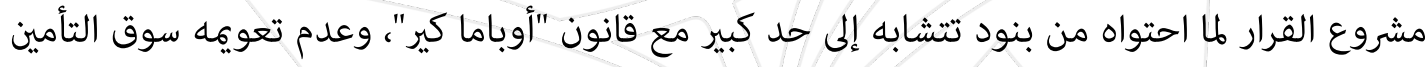

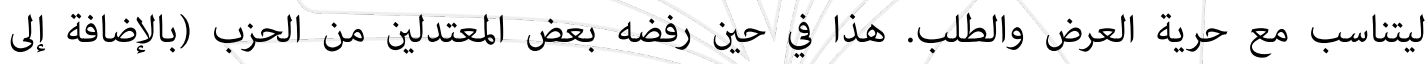

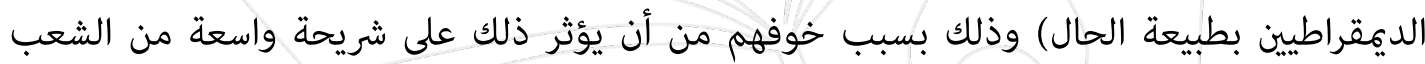

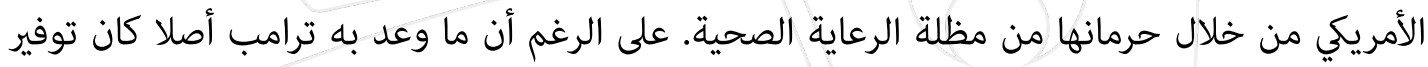

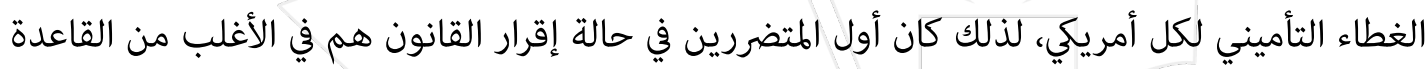

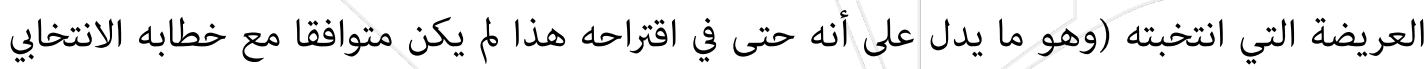

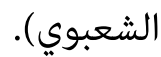
وقد شكل هذه الإخفاق ضربة موجعة لترامب من ناحيتين رئيسيتين؛ فمن ناحية ظهر الرئيس كأنه غير

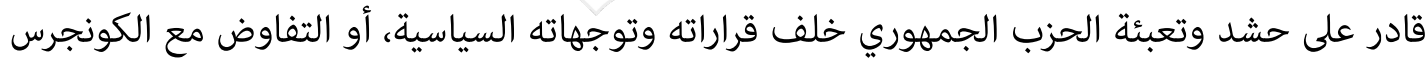

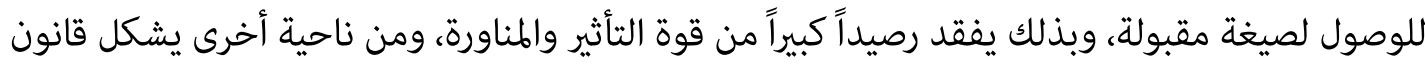

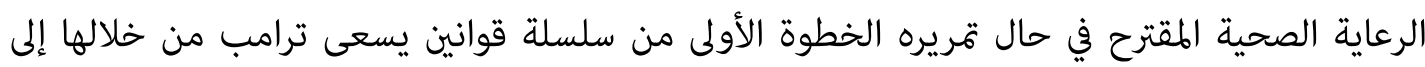

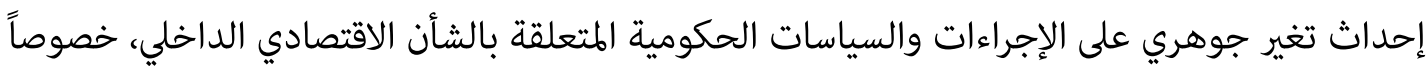

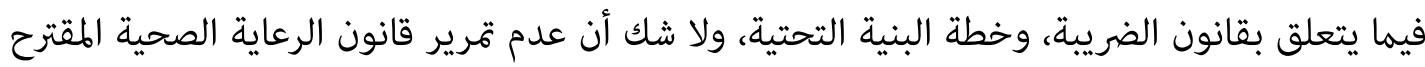

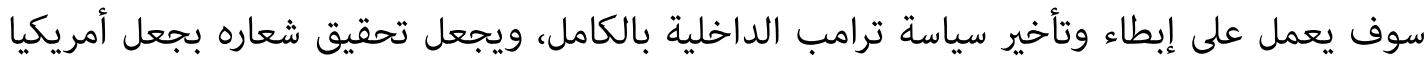

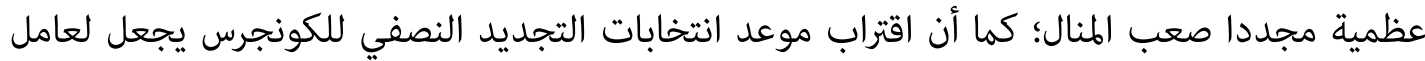
الوقت أهمية استثنائية. 
يدرك ترامب أهمية الوقت هنا، خصوصا للجمهوريين الذين يسعون للمحافظة على الأغلبية في

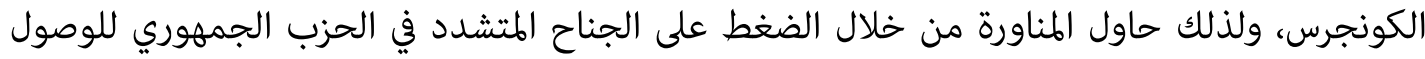

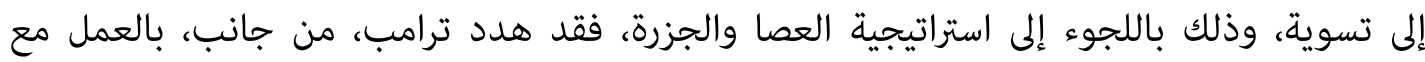

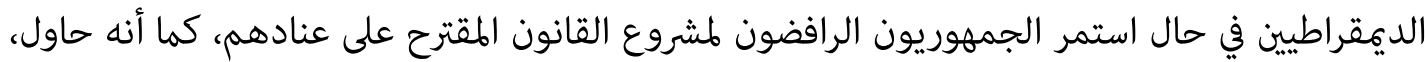

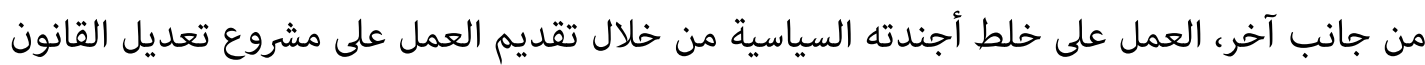
الضريبي الذي يفضله الجمهوريون بشكل كبير.

ولكنه عاد وتراجع عن ذلك لاحقا، بعد أن استمع لنصائح مستشاريهُ، حيث أكد مجدداً على أهمية

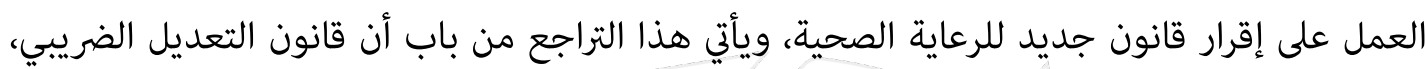

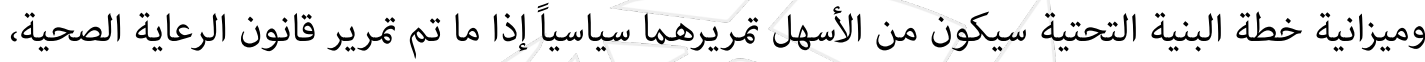

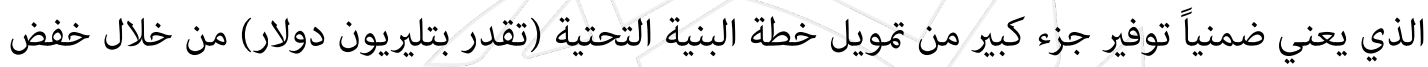

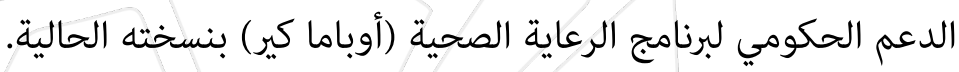
وقبل ذلك كان ترامب قد مني بإخفاق آخر يتعلق بحظر السفر إلى الولايات المتحدة، حيث وقع الرئيس

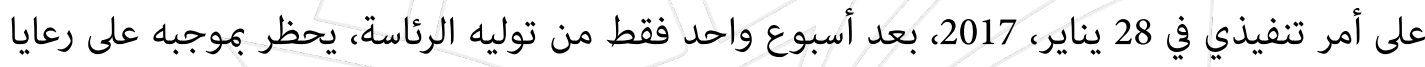

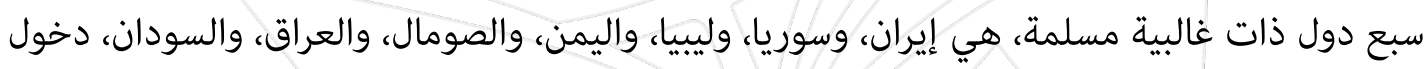

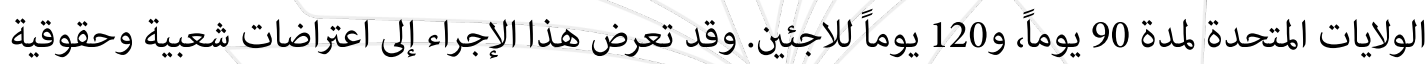

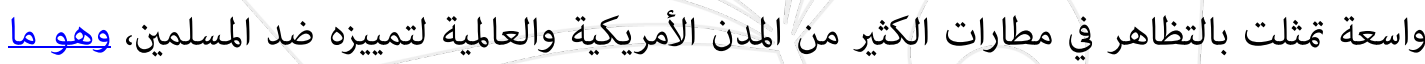
توافرت عليه بالفعل دلائل كثيرهة.

ولكن الاعتراض الأبرز جاء من القضاء الأمريكي؛ فبالرغم من أن ترامب قد جادل بأن الأمر التنفيذي يأتي

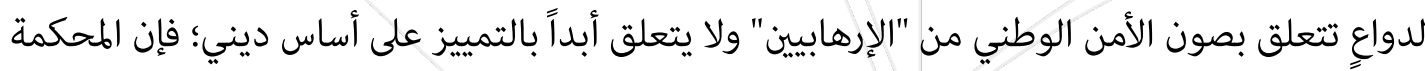

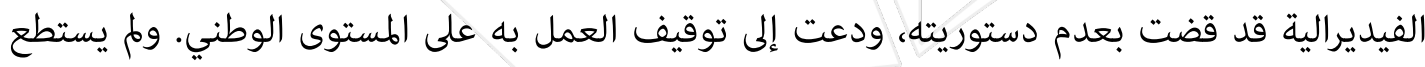

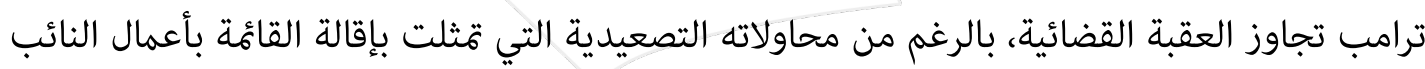

5 damian paletta and mike debonis. trump shifts course again, says health care repeal must precede tax overhaul. chicago times, april 12, 2017.

(6) للمزيد حول هذا الموضوع، انظر د. عمرو دراج، " سياسات ترامب: ضد الإخوان أم ضد الإسلام؟". المعهي المصري للدراسات السياسية والاستراتيجية، دراسات سياسية، 23 فبراير الإند الميري 2017. 
العام سالي ييتس لرفضها تنفيذ الأمر الرئاسي، فضلا عن تخفيف بعض بنود القرار بالسماح لحملة البطاقة

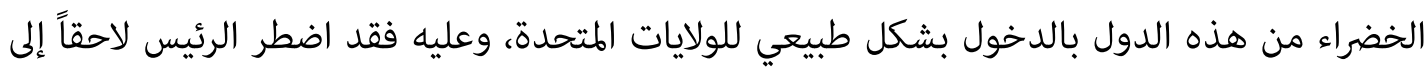

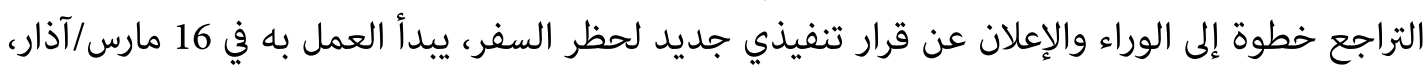
2017، ويتضمن تخفيف القيود المفروضة في القانون الأول، ويسقط من قائمة الحظر الحر الرئ الرعايا العراقيين.

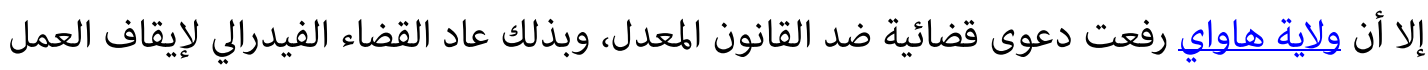
به مجددا بذريعة مخالفته الصريحة للدستور الأمريكي بإساءته للمسلمين. وفي هذا الإطار أيضا، تواترت الأنباء عن عزم الرئيس الأمريكي إصدار أمر تنفيذي آخر في أوائل فبراير

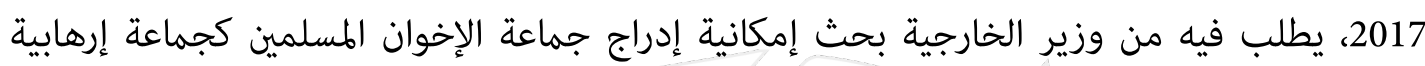

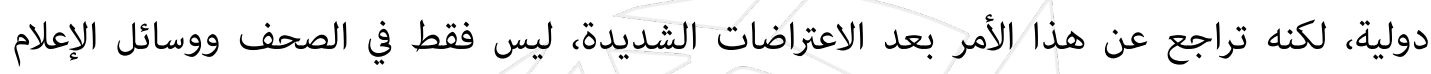

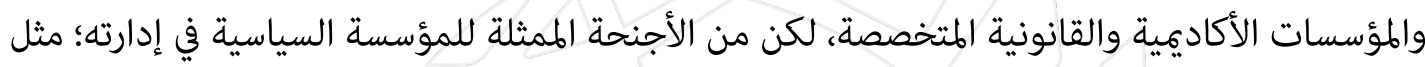
الخارجية والمخابرات، فضلاً عن مستشار الأمن القومي ماكماستر.

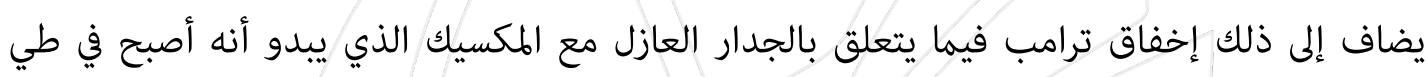

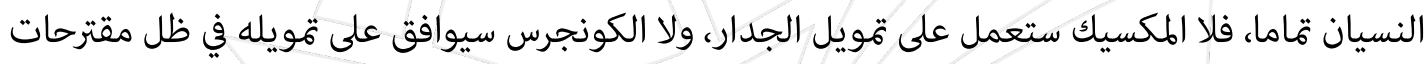

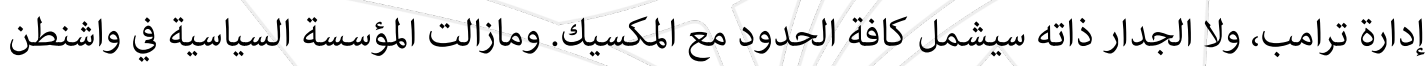

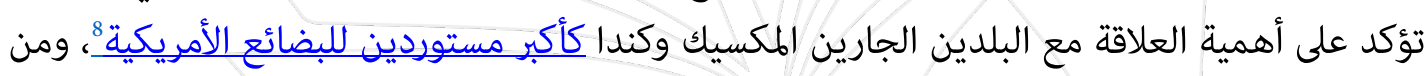
هنا وفي ذات السياق، فقد تراجع ترامب عن تهديداته بالخروج من اتفاقية التجارة الحرة لشمال أمريكا

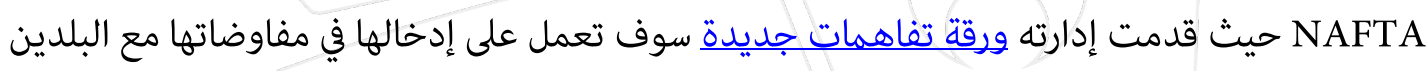

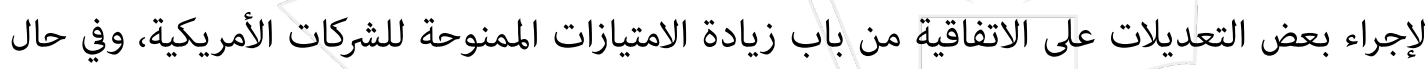

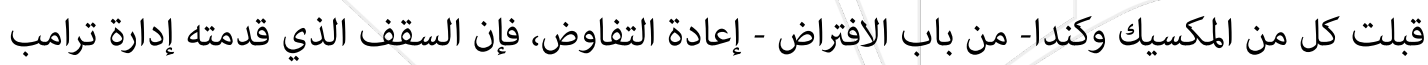

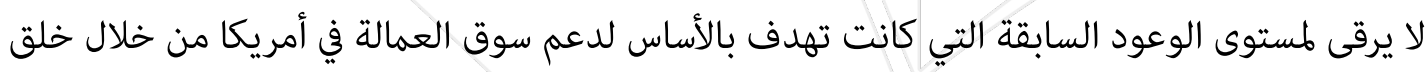

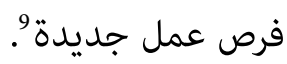

7 see more; steve almasy and darran simon. a timeline of president trump's travel bans. cnn, march 30, 2017. 8 see more; paul waldman. another trump promise bites the dust. washington post, march 31, 2017. 9 see more; greg sargent. why is trump flailing? because americans hate his agenda, and it's based on lies. washington post, april 3, 2017. 


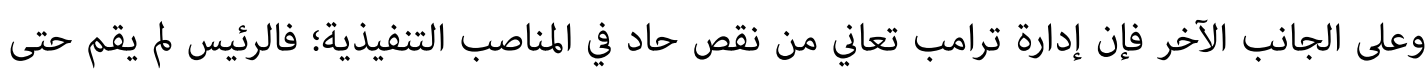

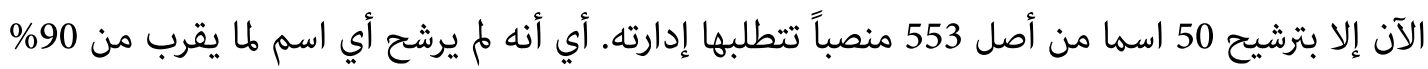

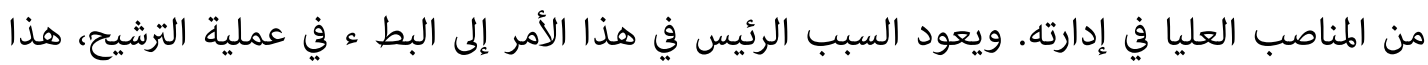

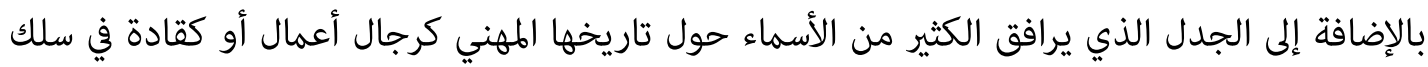

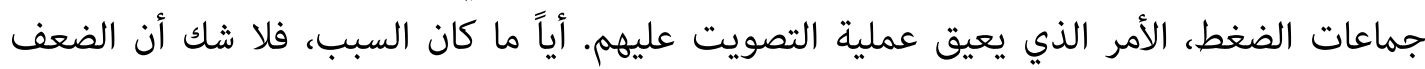

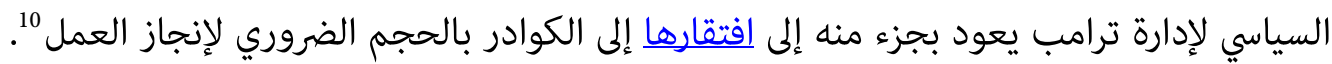

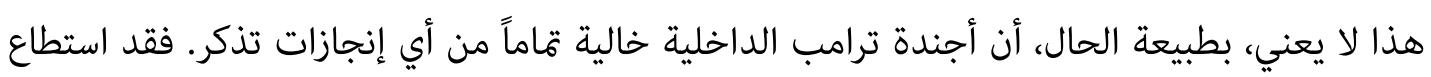

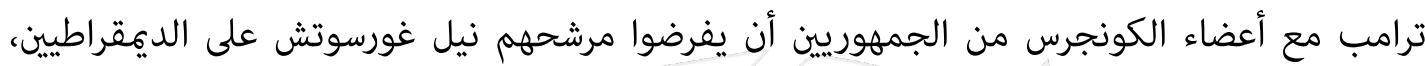

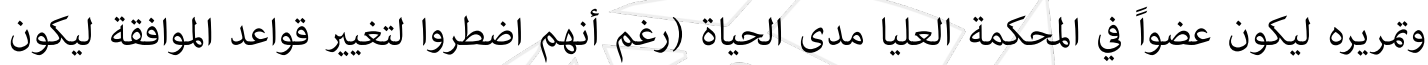
بالأغلبية البسيطة، وهو ما اصطلح على تسميته بالخيار النووي). ومن الجدير بالذكر هنا أن هذا النجاح يحسب بدرجة كبيرة منه إلى التنسيق والتفاهم بين كل من البيت

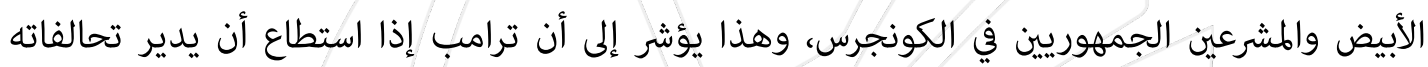

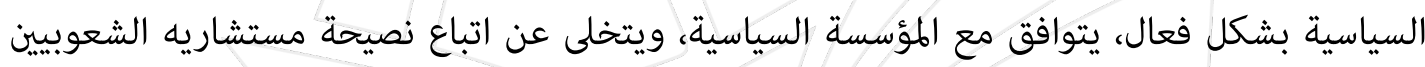

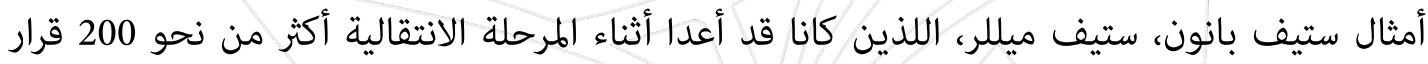

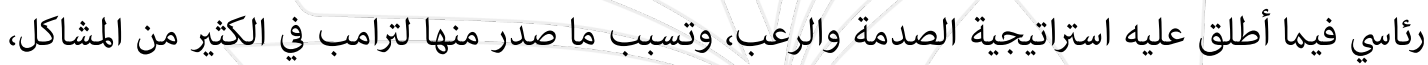

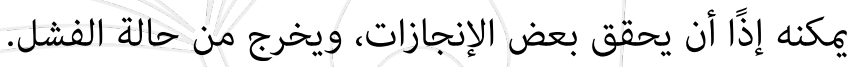
ومن هنا يمكن التنبؤ مثلا بأن تعديلات ترامب على قانون الضريبة من الممكن أن تر، وذلك لأنها تتسق

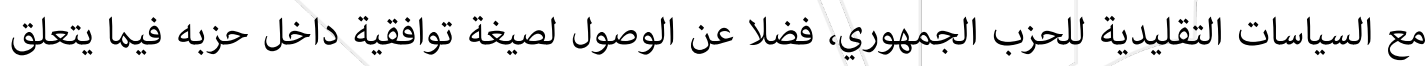
بـروع الرعاية الصحية، إلى غير ذلك.

إلا أننا، وفقاً للمعيار الذي وضعناه لتقييم ترامب في 100 يوم الأولى من رئاسته، من السهل أن نرى أنه

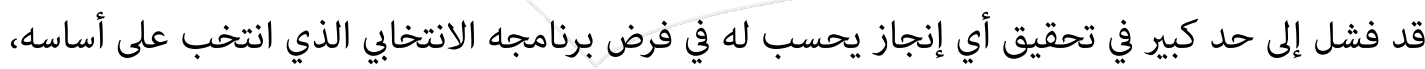

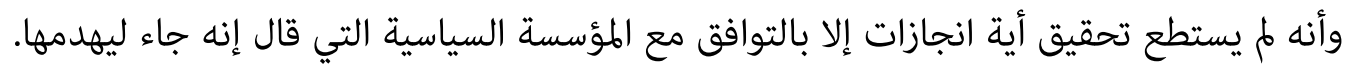

10 see more; david leonhardt. donald trump's first 100 days: the worst on record. new york time, april 26, 2017. 
رابعاً: شعبية ترامب والسقوط الحر

أثرت سلسلة إخفاقات ترامب، بالإضافة لحالة الاضطراب والفوضى التي سادت إدارته منذ توليه مقاليد منصبه إلى تهاوي شعبيته مسجلة أدنى مستوى في تاريخ الرؤساء الأمريكيين في فترة مماثله، فقد أظهر

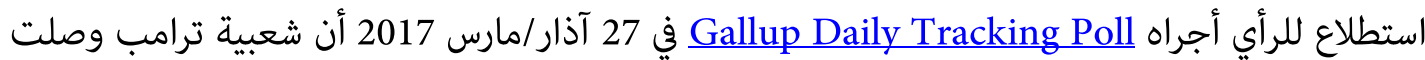
إلى 36\%"1 و إذا كان رؤساء سابقون من أمثال هاري ترومان، وليندون جونسون، وريتشارد نيكسون، وجيمي كارتر، ورونالد ريغان وحتى جورج بوش قد وصلوا لهذه النسبة المتدنية بعد فترة من توليهم،

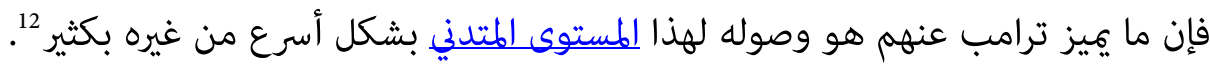
كما أظهرت النتائج أن نسبة الأمريكيين الذين يعتقدون أن ترامب يفي بوعوده قد تناقصت بشكل كبير، فبعد أن كانت تشكل ما نسبته 62\% في شهر شباط/فبراير، 2017 (بصرف النظر عن شعبيته)، تراجعت لتشكل ما نسبته 45\% فقط في شهر آذار/مارس، 2017. كما تدنت نسبة الأمريكيين الذين يعتقدون بأن ترامب صادق وجدير بالثقة من 42\% إلى 36\%.

في المقابل، لا توجد دلائل على أن شعبية ترامب قد تأثرت بين قاعدته الصلبة ممن صوتوا له في الانتخابات. حيث مازلت النسبة بين المؤيدين له - حسب استطلاع نشرته صحيفة الواشنطن بوست ثابتة عند سقف 94\% منهم. تصل هذه النسبة بين الجمهوريين عامة إلى 84\%. وعند سؤال أولئك الذين صوتوا له إذا ما كانوا يشعرون بالندم، أظهرت النتائج أن نسبة ضئيلة تصل إلى 2\% فقط هئ هي من تشعر إنى

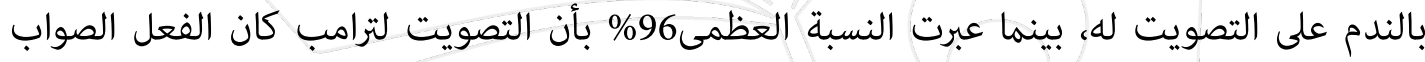
للقيام به. وعند السؤال إذا ما كانوا سوف يصوتون له في الانتخابات المقبلة، أظهرت النتائج أن نسبة عالية تصل إلى 96\% أيدت التصويت له مجددا، وهي نسبة أعلى من تلك التي عبرت عن تأييدها لهيلاري

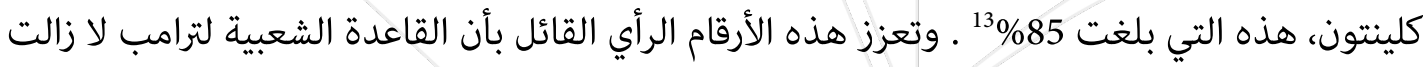
تقيمه بناء على ما يقوله، ليس على ما يفعله.

11 see more; "trump's approval rating drops to new low of 36\%", gallup, march 27, 2017.

12 see more; aaron blake. trump's first 100 days: a big failure, and a new low in the polls. washington post, march $27,2017$.

13 see more; dan balz and scott clement. nearing 100 days, trump's approval at record lows but his base is holding. washington post, april 23, 2017. 
في ذات السياق، أظهرت النتائج حول إذا ما تم الوفاء بتعهدات حملته الانتخابية، أن ترامب يقترب في

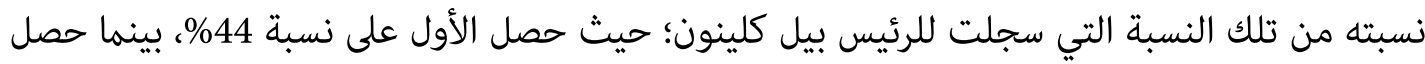

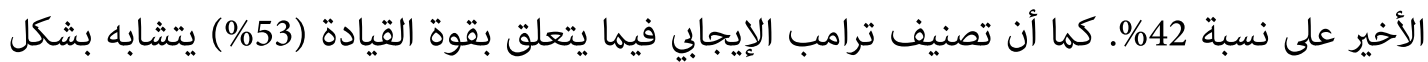

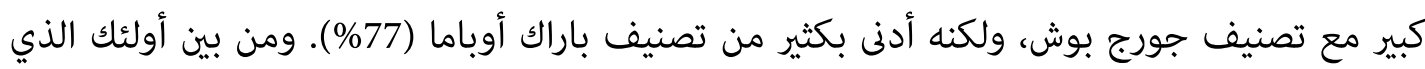

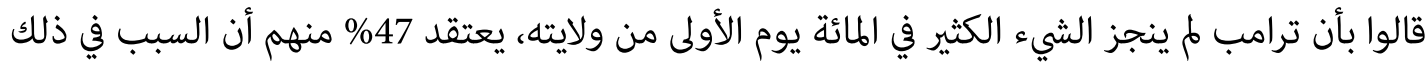

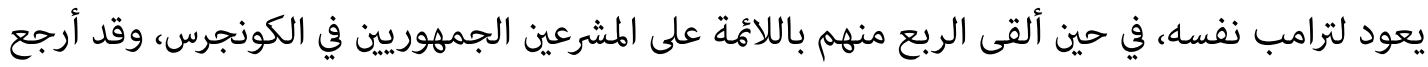

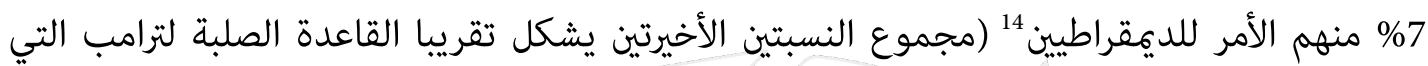
لازالت تصدقه، تقيمه بناء على أقواله لا أفعاله، تختلق له الأعذار). خامساً: استراتيجية الهروب للأمام راهن ترامب أثناء حملته الانتخابية على شعبيته، خطابه الشعبوي، وعلى قدرته ومهارته - أيضا - في

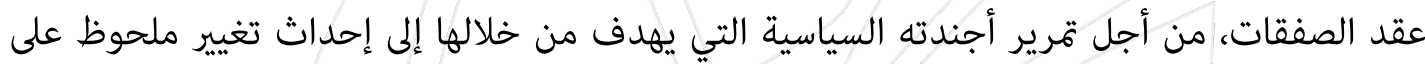

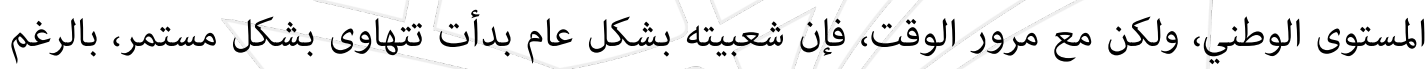

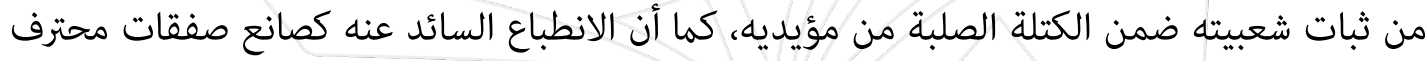

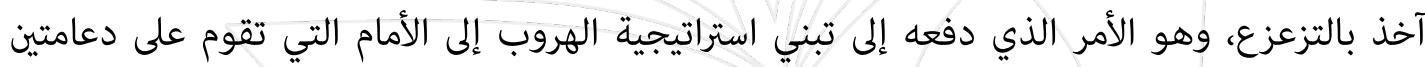
أساسيتين:

الأولي: سياسة الإيهام بالفوز سياسة الإيهام بالفوز؛ وذلك عن طريق شن حملة واسعة من الدعاية المنظمة للترويج للإنجازات الوهمية

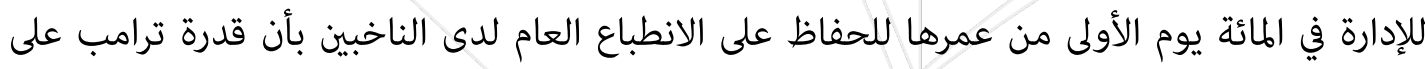

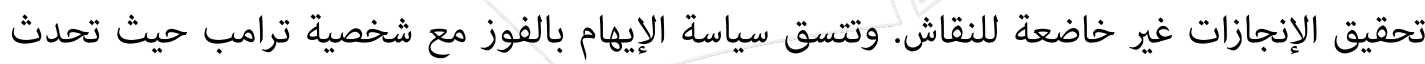

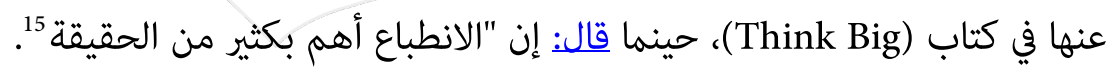

14 ibid.

15 see more; michael kruse. how trump succeeds without succeeding. politico magazine, april 23, 2017. 


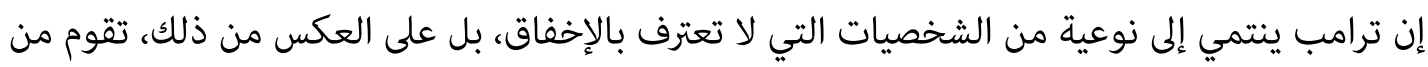

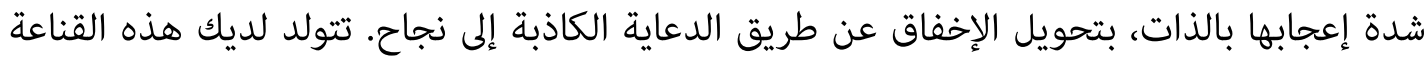

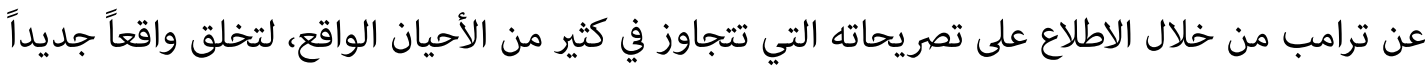

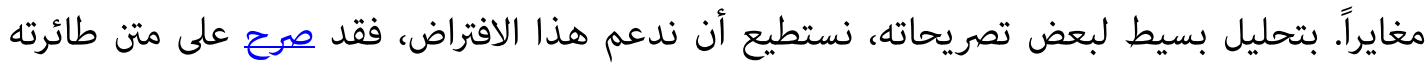

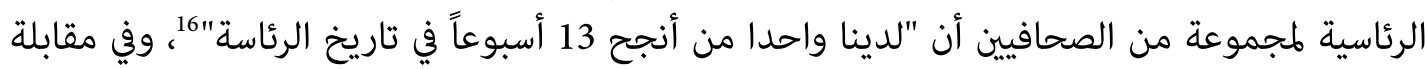

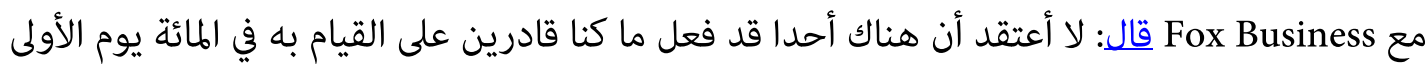

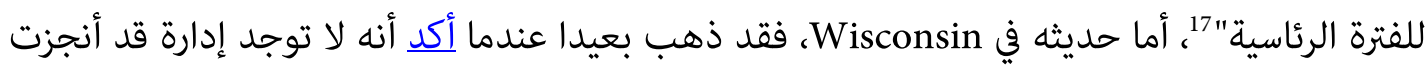

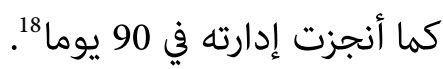

ولا يعد ادعاء النجاح بالأمر الطارئ على شخصية ترامب، بل هي خاصة قد صاحبته منذ بداية مشواره

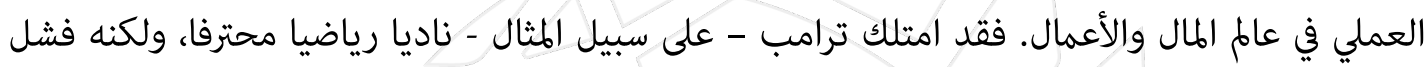

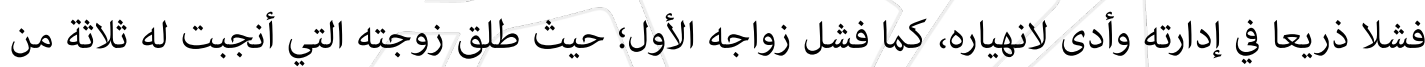

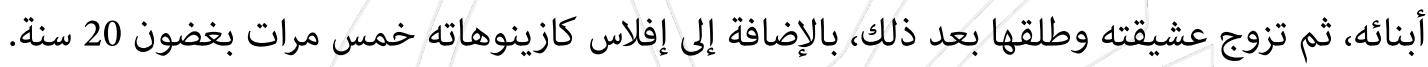

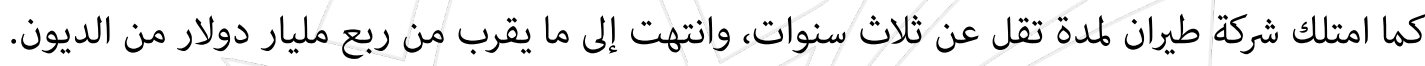

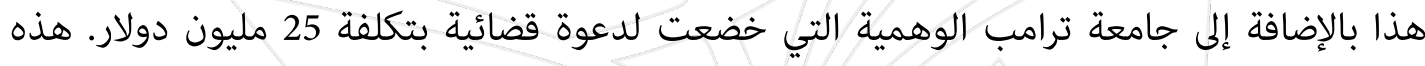

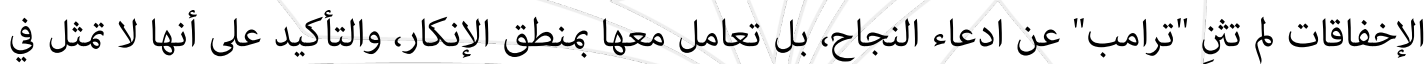
الحقيقية إلا نجاحِاً باهراً. فقد صرح للـ Financial Times بأنه "لا يخسر"، كما صرح لقناة ABC بأنه "م يفلس أبداً"19. يدرك

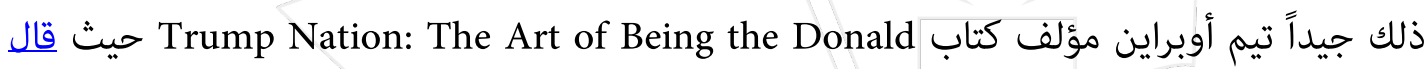

16 see more; josh dawsey. trump maintained pageantry as syria strikes unfolded. polotico, april 7, 2017.

17 see more; watch maria bartiromo's must-see interview with president trump on fox business network. fox insider, april 11, 2017.

18 see more; nolan d. mccaskill. trump issues bold new promises on health care, tax, infrastructure. politoco, april $18,2017$.

19 see more; george stephanopoulos. donald trump interview: transcript part two. abc news, apri; $19,2017$. 
بأن ترامب "لا يعد ناجحاً بالأمور التي يدعي أنه ناجح بها، ومع ذلك يككن القول بأنه المروج الأكثر نجاحاً

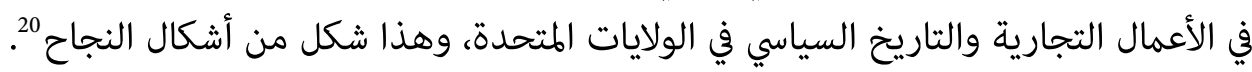
فيما يتعلق بالشأن السياسي، يستمر ترامب في السير على نفس المنهج. فهو يعتبر أن الحديث عن الإخفاق

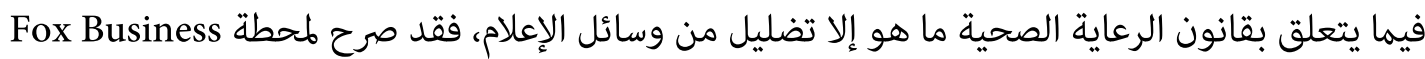

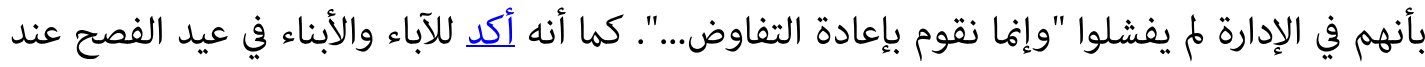

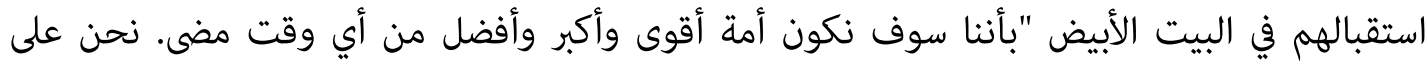
الطريق القويم، وأنتم تشاهدون ما يحدث".

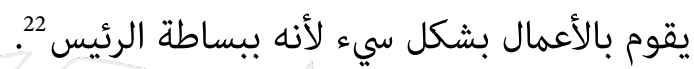

بعض المختصين بعلم النفس حاولوا أن يقدموا تفسيرات للدوافع النفسية التي تكمن وراء تصرفات

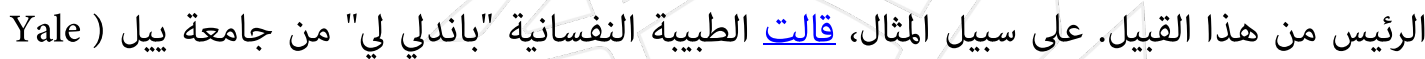
Make إن Mniversity America Great Again واقعية، يقوم باستغلال حالاتهم النفسية" ورفض.

من ناحيته قال الدكتور جيمس جيليغان، وهو أستاذ كبير في الطب النفسي في كلية الطب بجامعة

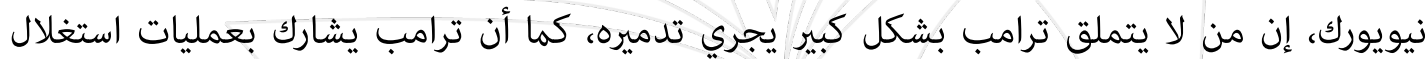

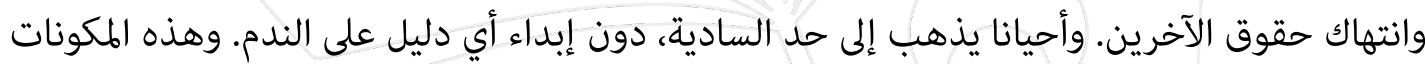

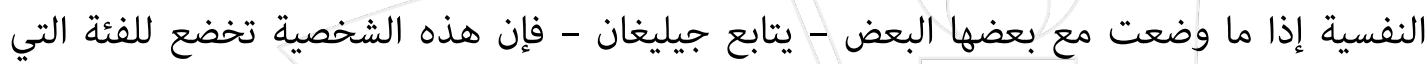

20 see more; michael kruse. he has made a career of convincing people that his failures were the exact opposite. can he pull it off again?, politico, april 23, 2017.

21 see more; south lawn. remarks by president trump and first lady melania trump at the 2017 white house easter egg roll. the white house, april 17, 2017.

22 see more; louis nelson. trump: 'i can't be doing so badly, because i'm president and you're not'. politico, march 23, 2017.

23 see more; gail sheehy. at yale, psychiatrists cite their 'duty to warn' about an unfit president. mail intelligencer, april 23, 2017. 
يتواجد فيها أناس أمثال هيتلر." 24 أما ريتشارد كوهين في مقالته في صحيفة واشنطن بوست فقد قال :

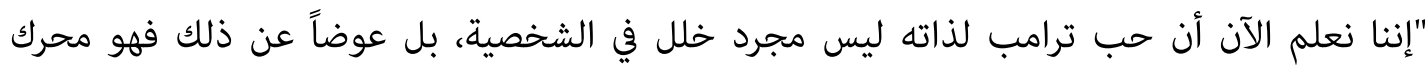

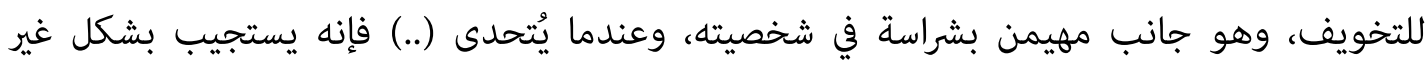
منطقي"

الثانية: سياسة تسعير الجبهات

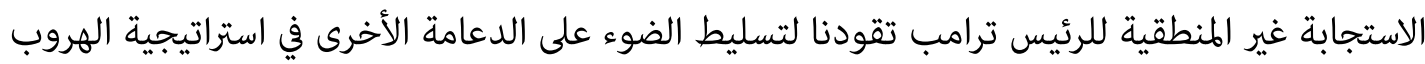

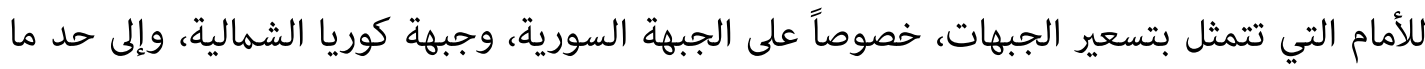

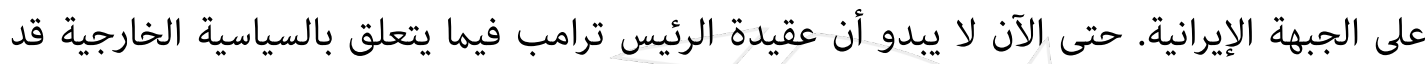

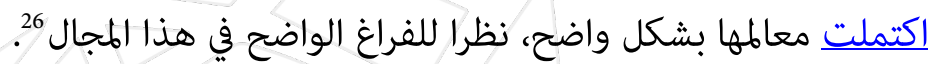

في أثناء حملته الانتخابية كان ترامب يدعو إلى تبني سياسة انعزالية Isolationist من خلال رفع شعار America First

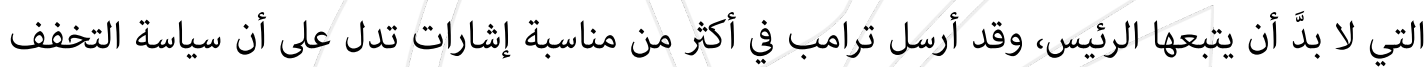

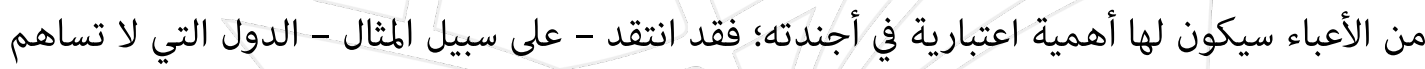

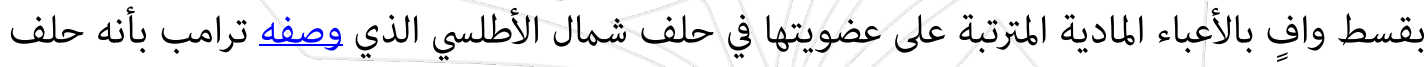

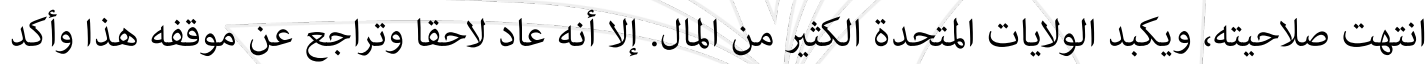

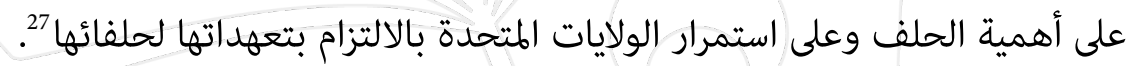

Non- مذا بالإضافة إلى أن ترامب كان يدعو أثناء حملته الانتخابية إلى تبني سياسة غير تدخلية

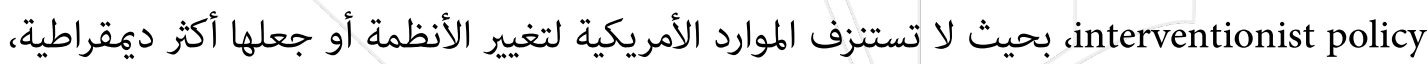

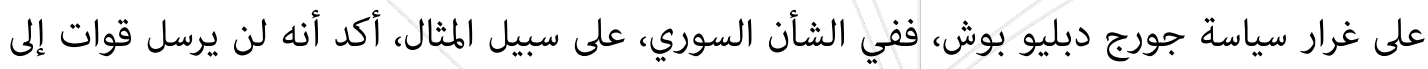

24 ibid.

25 see more; richard cohen. sean spicer's stalinist apparition. washington post, january 23, 2017.

للمزيد أنظر؛ د. عمرو دراج " إدارة ترامب والفراغ في السياسة الخارجية الأمريكية". المعهد المصري للدراسات السياسية والاستراتيجية، تقارير سياسية، 13 مارس 2017.

27 see more; jenna johnson. trump on nato: 'i said it was obsolete. it's no longer obsolete. washington post, april $12,2017$. 
سوريا. كما اعتبر ترامب أن " بشار" شريك محتمل في محاربة "الإرهاب"، وقبيل الضربة العسكرية على مطار الشعيرات بقليل، كانت المندوبة الأمريكية في الأمم المتحدة قد صرحت بأن بـأن أولوية سياسة الولايات المتحدة في سوريا لم تعد إزاحة بشار الأسد عن السلطة 28. هذا الموقف انقلب بشكل دراماتيكي عندما أصدر ترامب أوامره بتوجيه ضربة عسكرية تأديبية للنظام السوري بعيد هجوم الأخير الكيماوي على هلى المدنيين في خان شيخون.

مع ذلك لم يصدر موقف صريح من إدارة ترامب حول نيتها الجادة فيما يتعلق بالإطاحة بالأسد، وقد

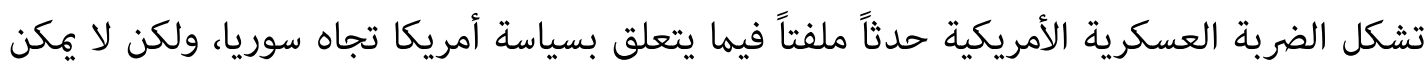

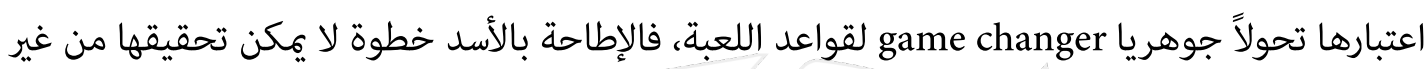
التفاهم مع كل من روسيا، وإيران، وهما الداعمان الرئيسيان للنظام السوري، وإلى الآن لا تلوح في الأفق بوادر على مثل هذا التفاهم في ظل حالة التصعيد ضد البلدين. إن التحرك ضد الأسد إذا ما تم فعلياً إدراجه ضمن الأولويات الأمريكية في المنطقة، فيجب أن يأتي ضمن استراتيجية كبرى للتعامل مع قضايا الشرق الأوسط من جانب، وروسيا من جانب آخر. لا يبدو إلى الآن

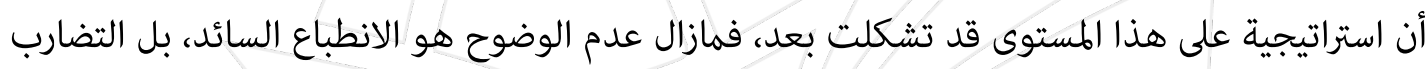
في بعض الأحيان، حول سياسة ترامب الشرق أوسطية. ربما يكون عدم الوضوح أو عدم القدرة على التنبؤ بسياسة الرئيس ترامب إجراء مقصودا في حد ذاته 29، كما صرح ترامب بذلك أكثر من مرة، ولكن هذه السياسة لا يمكن أن تشكل ضمانة لحماية المصالح الأمريكية في ظل حالة اللايقين التي تسود الفضاء السياسي العالكي

ينظر البعض إلى الضربة العسكرية من زاوية أخرى؛ فبالإضافة إلى بعدها الإنساني الذي حاولت إدارة ترامب الترويج له، إلا أنها في الحقيقية شكلت في توقيتها طوق نجاة لترامب الذي كان يعيش حالة من

28 see more; michelle nichols. u.s. priority on syria no longer focused on 'getting assad out': haley. reuters, march $27,2017$.

29 see more; noah bierman. trump is delivering on his promise to be unpredictable on foreign affairs. not everyone's convinced that's a good idea. los angeles times, december 16, 2016.

30 ibid 
القلق على شعبيته جراء الجمود الحاصل في أجندته الداخلية '31، هذا بالإضافة إلى أن التصعيد ضد حليف ترابف روسيا الأقوى في دمشق، يخطف الأضواء عن التحقيقات الجارية حول تورط ترامب ومستشاريه في التهاء

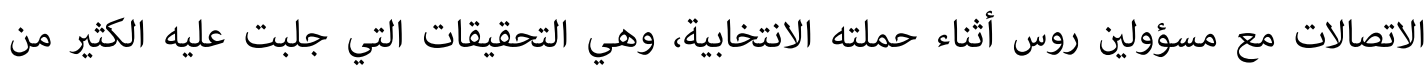

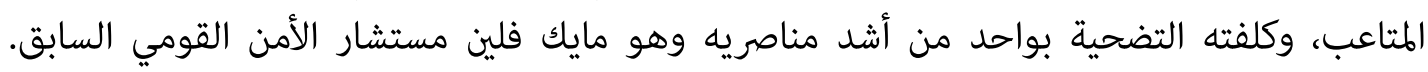

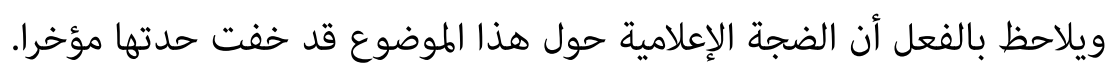

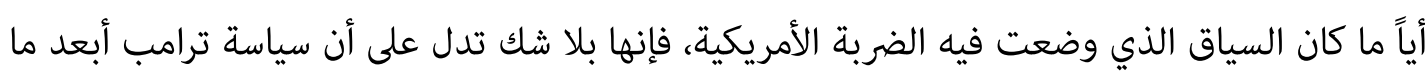

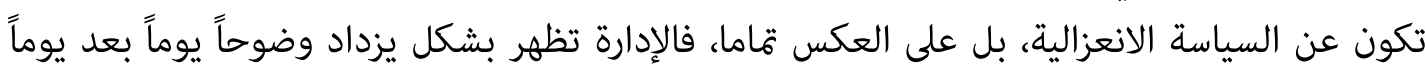

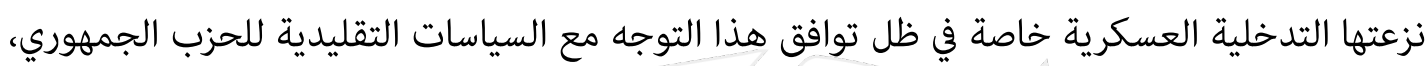

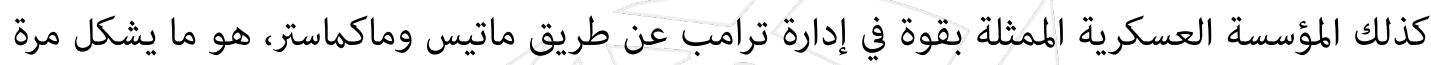
أخرى اختلافا جوهريا عن برنامج ترامب الانتخابي، وعن توجهات القاعدة الصلبة الصنة لمؤيديه.

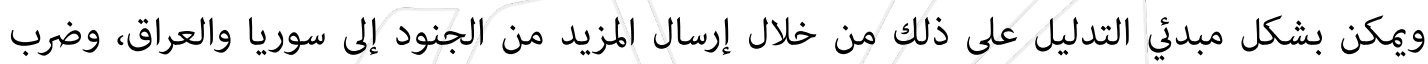

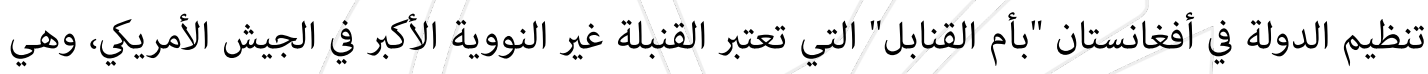

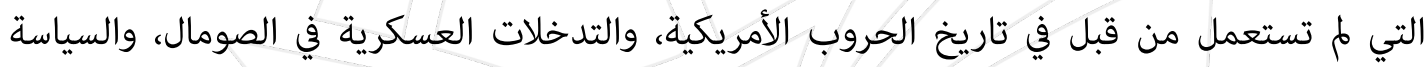
الجديدة في اليمن، الأهم من هذا كله هو التصعيد الخطير مع كوريا الشمالية. سادساً: سيناريوهات تعامل ترامب في المرحلة القادمة من خلال هذا الاستعراض، يكن طرح عدة سيناريوهات فيما يتعلق بتعامل ترامب مع المؤسسة السياسية، أو توجهات سياساته العامة في المرحلة المقبلة، وذلك على النعاض النحو التالي: السيناريو الأول: سيناريو الترويض: ذلك بأن تستمر المؤسسة السياسية بواشنطن في التحكم بالمسار الذي ينحاه الرئيس ترامب، الأمر الذي

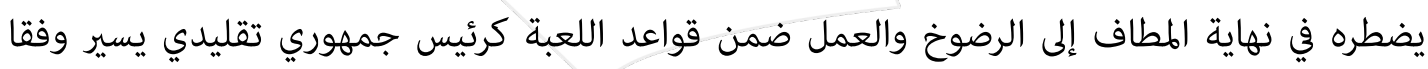

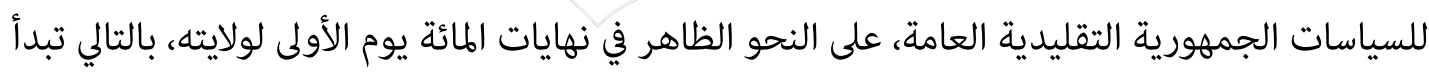

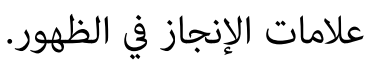

للمزيد انظر: عمرو دراج . "الضربة الأميركية: هروب ترامب إلى الأمام".امعهد المصري للدراسات السياسية والاستراتيجية، إبريل 7، 31 . 2017 


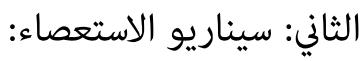

يكون ذلك من خلال استمرار الانسداد السياسي الداخلي برجوع الرئيس ترامب إلى تحدي المؤسسة

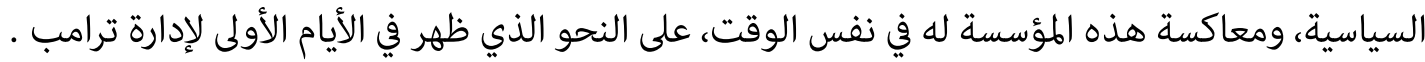
الثالث: سيناريو العسكرة والتدخلات الخارجية وذلك من خلال توجه ترامب بسبب الانغلاق الداخلي إلى الهروب للأمام بتصدير الأزمات خارجياً،

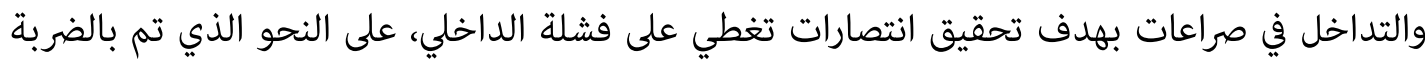
الموجهة لقاعدة الشعيرات في سوريا . الرابع: سيناريو التغلب وذلك من خلال نجاح الرئيس ترامب بفرض أجندته على المؤسسة السياسية، وتقويض أعمدتها بالتدريج على النحو الذي دعا إليه في أثناء حملته الانتخابية.

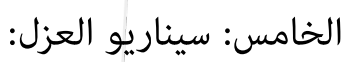

وذلك بالتخلص من الرئيس ترامب حتى قبل انتهاء ولايته الأولى، أو من خلال سحب البساط من تحت قدميه لحرمانه من فرص النجاح لدورة رئاسية ثانية.

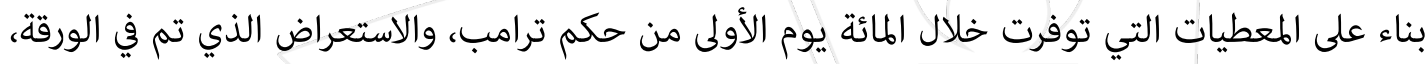

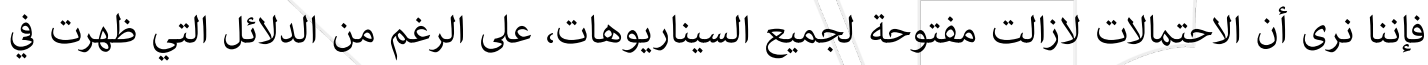

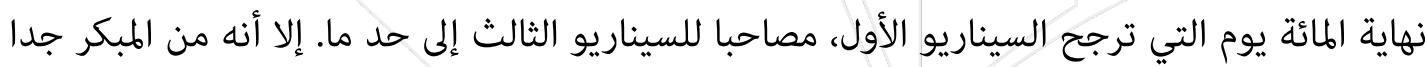

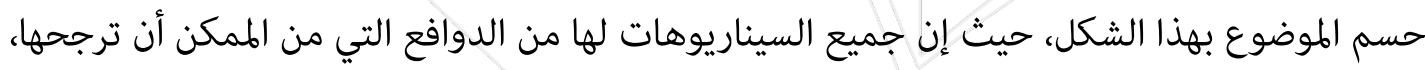

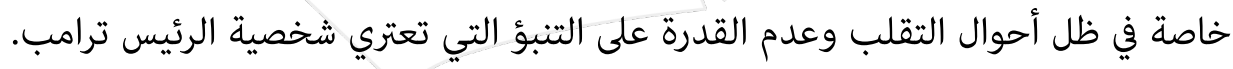
ويكتسب السيناريو الأول وهو سيناريو الترويض أهميته من خلال الدلائل والمؤشرات التي تتعلق

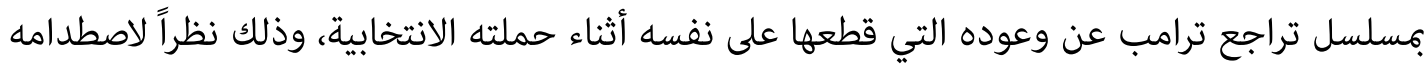

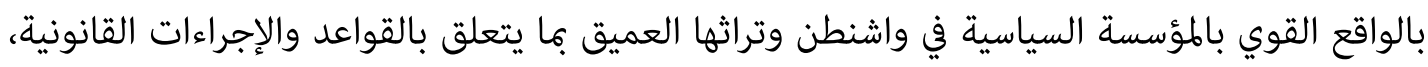

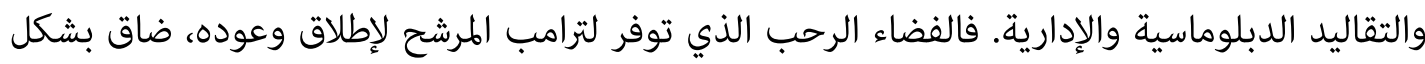

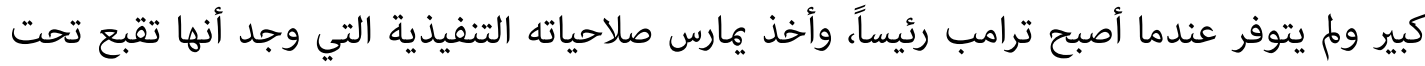

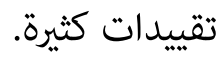


على الجانب الآخر، فإن المعركة المحتدمة داخل إدارة ترامب بين التيارات المتنازعة أصبحت قيل لصالح الفريق العائلي، والفريق الحزبي. وتراجع الفريق الشعبوي، وكلا الفريقين اللذين قيل الكفة لصالحهما

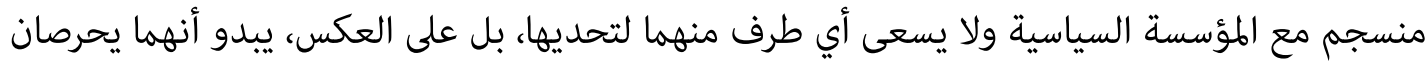
على العمل وفق مقتضياتها، وهو ما يعني في نهاية المطاف أن إدارة ترامب سوف تبقى ملى ملتزمة بالإطار المحدد للمؤسسة.

وقد بدأت إشارات جديدة لتبلور هذا التوجه في الظهور، يتمثل في الاتفاق داخل الحزب الجمهوري مؤخرا للتصويت في مجلس النواب لصالح وقف مشروع "أوباما كير"، في الاتفاق على اعتماد موازنة مؤقتة حتى شهر سبتمبر، لتجنب سيناريو ما يعرف ب "إغلاق الحكومة"، إلى غير ذلك.

ويُعضد هذا السيناريو أن ترامب يرى أنه مل يعاقب بعد من قاعدته الانتخابية التي لا زالت تدعمه بقوة،

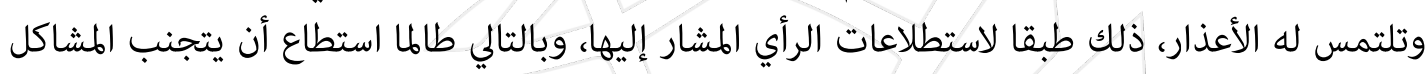
فإنه يحاول تحقيق الإنجازات بالتوافق مع المؤسسة، مع الاستمرار في استخدام الخطاب الذي يرضي مؤيديه (وهذا يتناسب مع براجماتيته ومنطلقاته للربح، وليست المدفوعة بالأيديولوجيا الثابتة). وسيستمر في هذا المسار لتحقيق بعض الإنجاز.

إلا أننا نرى أنه إذا حدث تحول ما في آراء مؤيديه، وبدأوا يفقدون الثقة به، فسيعود مرة أخرى إلى بعض السياسات الشعبوية والاصطدام بالمؤسسة للحفاظ على قاعدته الانتخابية، هذا هو السيناريو الثاني الذي

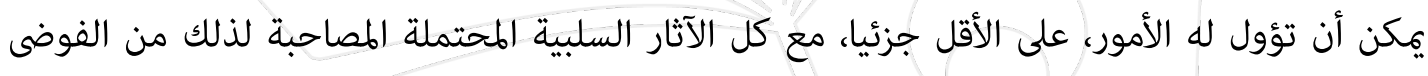
والاضطراب، إلا أن هذا لا ينتظر حدوثه، من وجهة نظرنا، في المدى القولئ القصير. أما سيناريو العسكرة فالدافع وراءه قد يكون أحد أمرين: أولهما، الاستعصاء الداخلي بحيث يسعى ترامب إلى ترحيل الأزمات الداخلية إلى الخارج من خلال الانخراط بشكل أكبر في الساحات الساخنة في آسيا والشرق الأوسط للحفاظ على شعبيته، والإبقاء على صورته كرجل قوي يفرض الإرادة الأمريكية على العالم. وثانيها، سيطرة الجنرالات على القرار السياسي فيما يتعلق بالسياسية الخارجية حتى الآن، في المدى المنظور، حيث يلاحظ تنامي دور كل من وزير الدفاع جيمس ماتيس، ومستشار الأمن القومي ماكماستر، مع بروز نجم نيكي هالي السفيرة الأمريكية لدى الأمم المتحدة، التي تعد من الصقور التي تؤمن بالقوة كوسيلة رئيسية في ممارسة السياسة الخارجية الأمريكية. ويمتلك كل من ماتيس وماكماستر خبرة طويلة

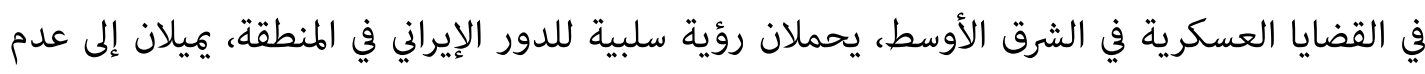
ترك المجال واسعا لروسيا في السيطرة على شئون المنطقة، كما يميلان بشكل عام لرؤية المؤسسة العسكرية في تبني مبدأ التدخلية وليس الانعزالية أو القيادة من الخلف (كما كان أوباما يفعل)، فضلا عن أن هذه هي الرؤية التقليدية للحزب الجمهوري، وهو ما يعني أن احتماليه زيادة انخراط الولايات المتحدة في 
المنطقة مجددا ستمتلك حظوظاً أوفر، خاصة أن فكرة إعادة الهيبة الأمريكية على الساحة الدولية من

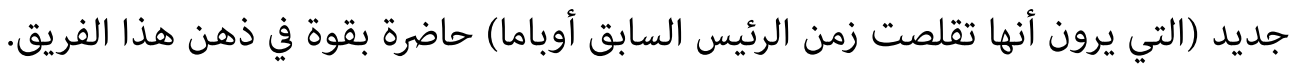
ويدعم هذا السيناريو اشتعال منطقة الشرق الأوسط بالكثير من القضايا الساخنة، التي لا تبدو هناك

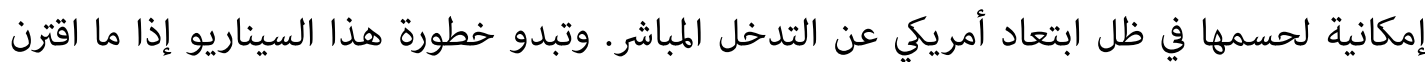

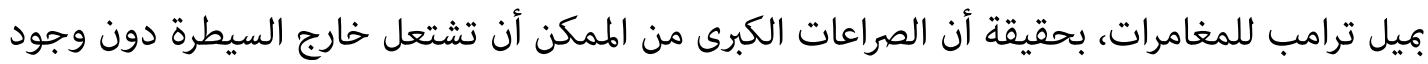

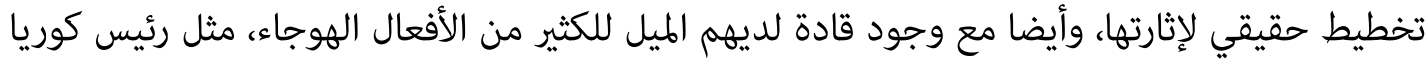

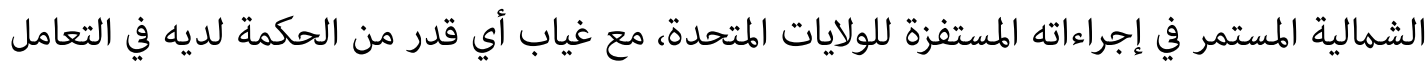

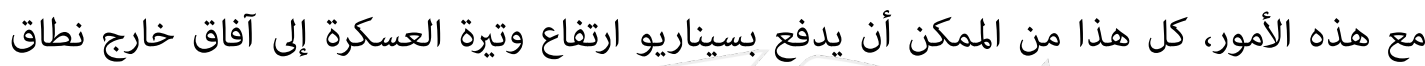
السيطرة إذا لم يتم اتخاذ خطوات جادة من الآن لنزع فتيل مثل هذه من النزاعات.

أما السيناريو الرابع، أي التغلب على المؤسسة، فهو مستبعد من واقع استقراء شخصية ترامب ودوافعه

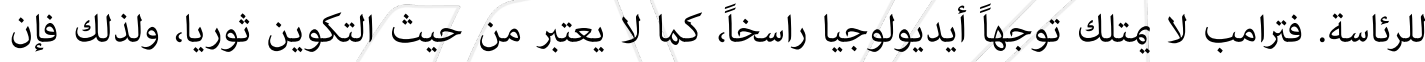

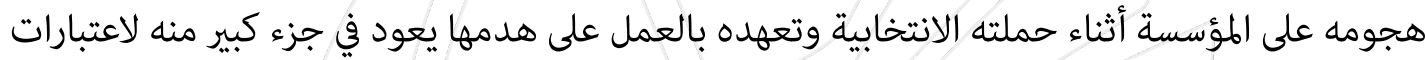

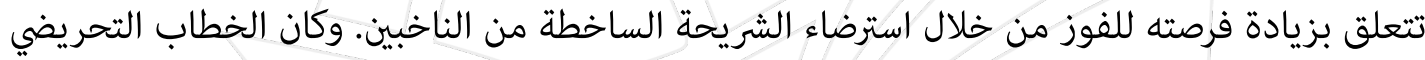

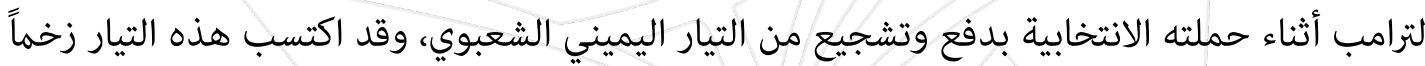

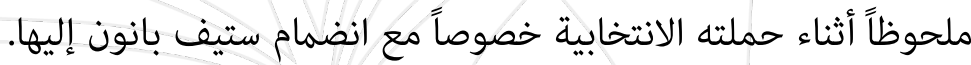
ولكن هذا الفريق أخذ في التراجع بعد أن تولى ترامب مهامه كرئيس، وفي الأوهن الأخيرة يتعرض بانون

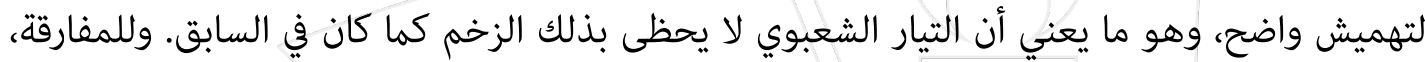

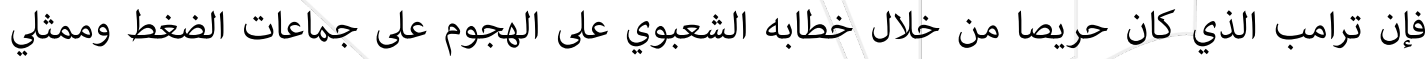

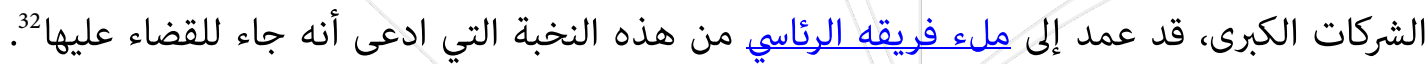

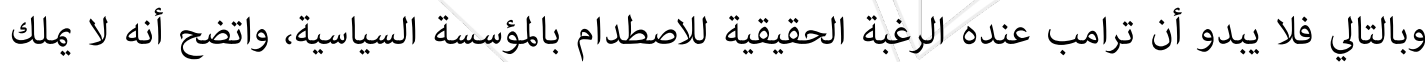

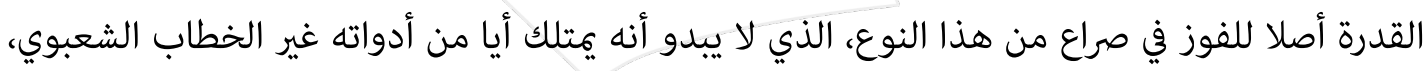

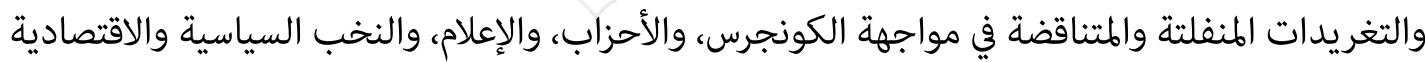

32 see more; eric lipton. trump campaigned against lobbyists, but now they're on his transition team. new york time, november 11, 2016. 
المؤثرة. وفي ضوء الانخفاض المستمر لشعبيته بشكل عام، عدا قاعدة مؤيديه الصلبة، مما يجعل هذا السيناريو مستبعدا إلى حد كبير في المدى المنظور.

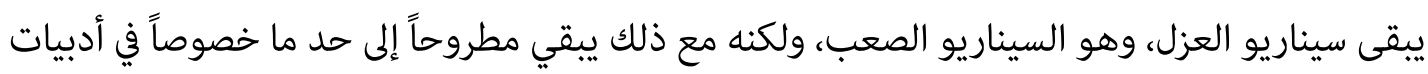

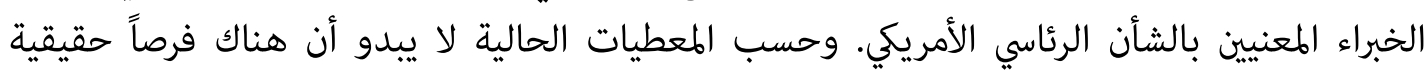

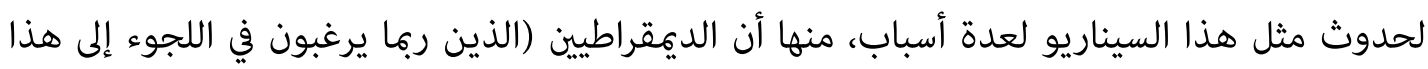

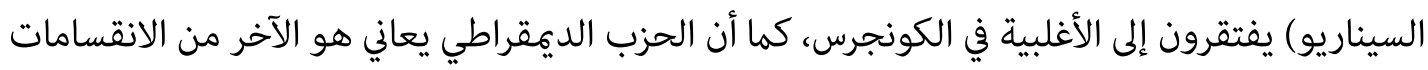

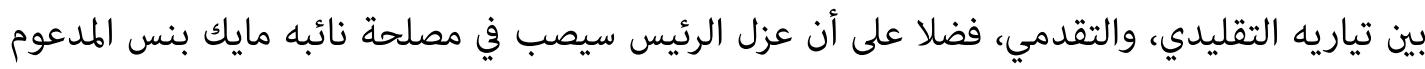

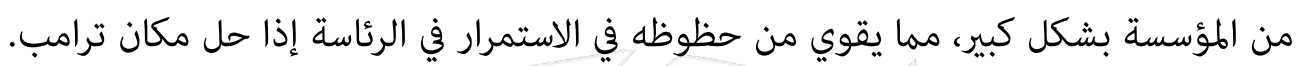

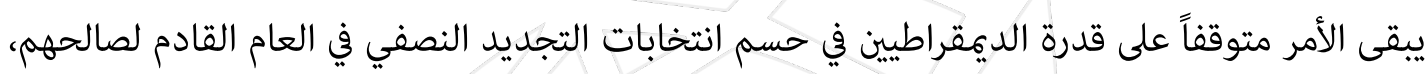

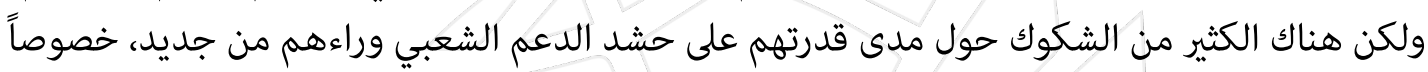

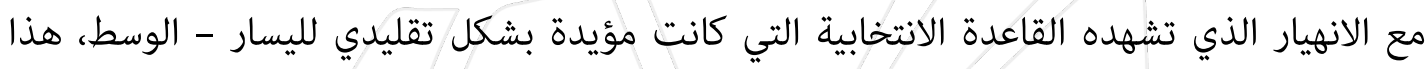

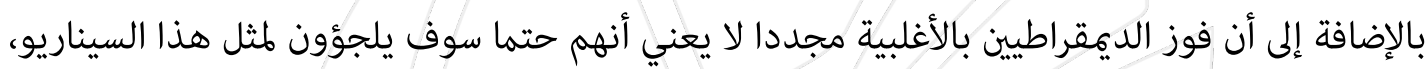

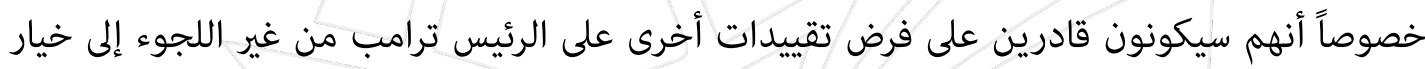
العزل، وذلك بشكل أفضل من مواجهة بينس كرئيس. إلا أننا يجب ألا نستبعد أن يأتي سيناريو العزل بإيعاز من داخل الحزب الجمهوري نفسه، خاصة من الجنا

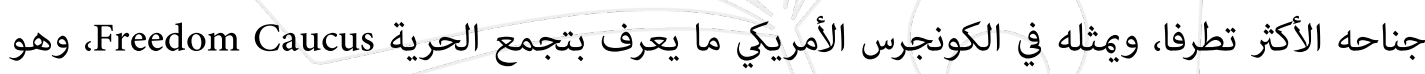

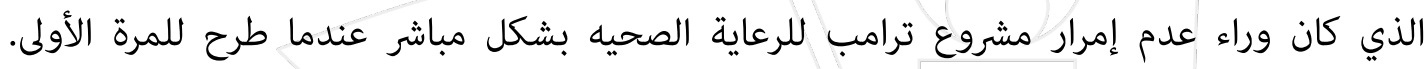

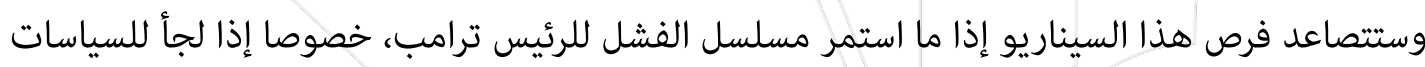

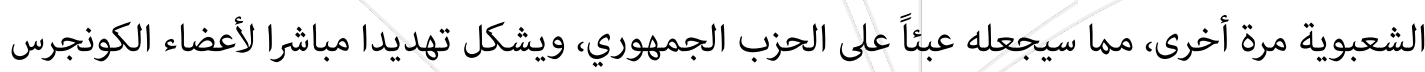

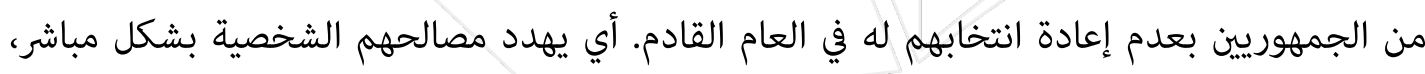

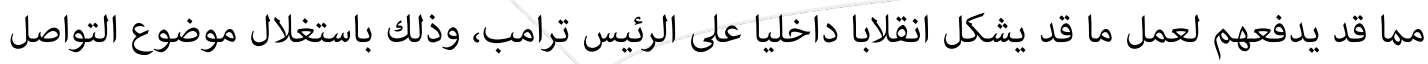

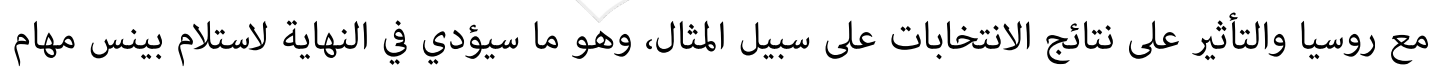

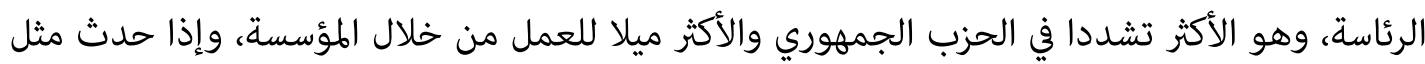

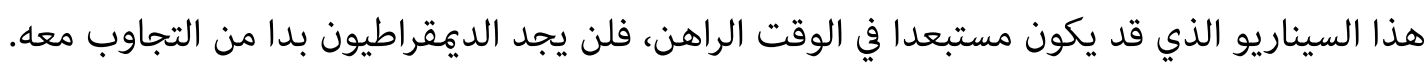

خلاصة

يشكل ترامب بحد ذاته ظاهرة في تاريخ السياسة الأمريكية الحديث، فمنذ أن أعلن ترشحه إلى أن فاز

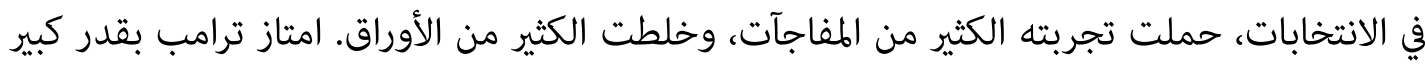




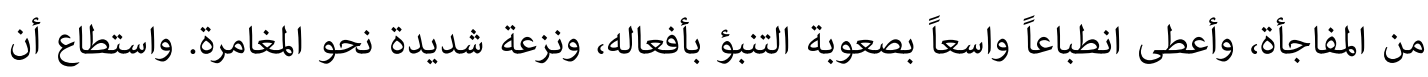

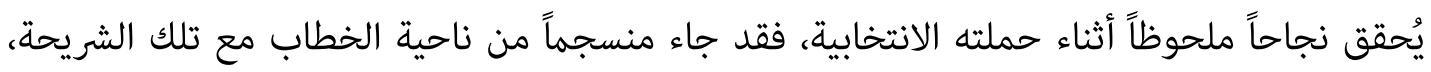

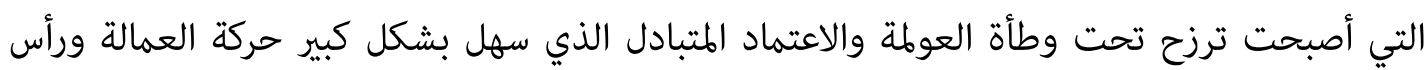

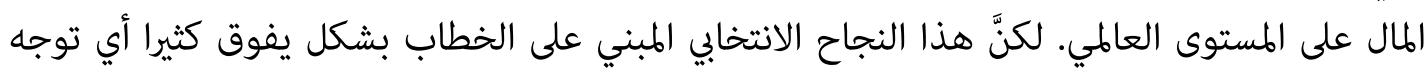

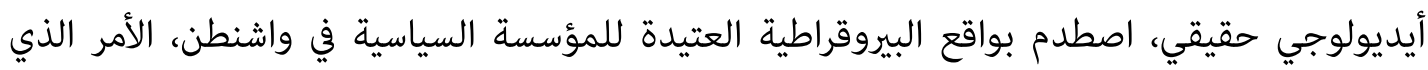

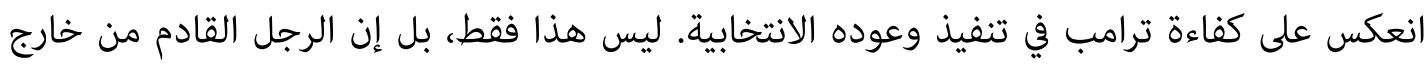

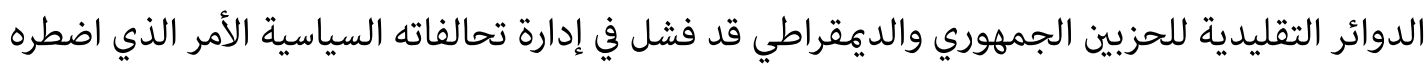
للرضوخ والتسليم بالأمر الواقع، على الأقل مرحلياً.

ومع ذلك تبقى للرئيس ترامب وإدارته بعض الخصائص التي يمتازون بها، فبالإضافة إلى حالة اللايقين،

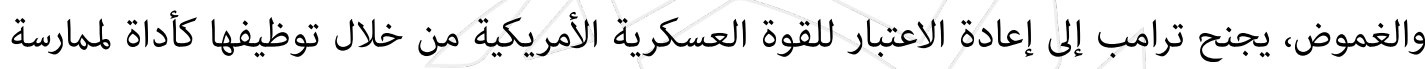

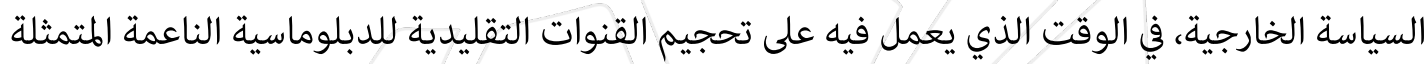

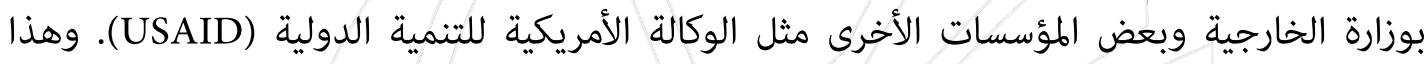

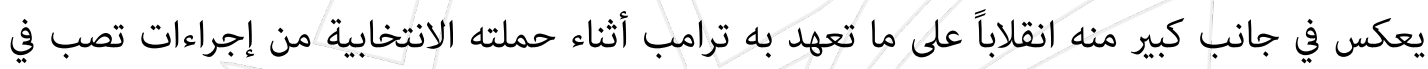

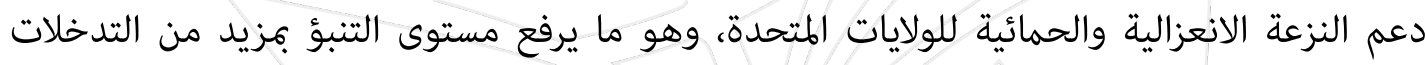

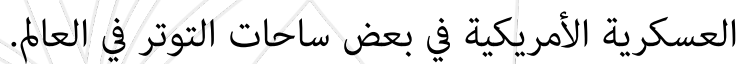

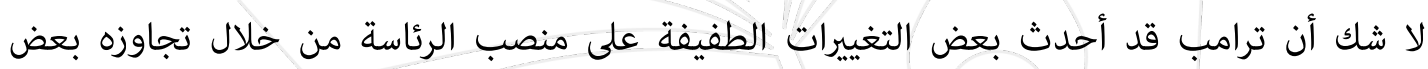

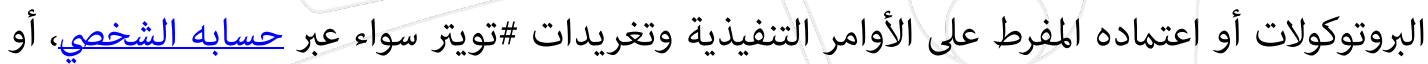

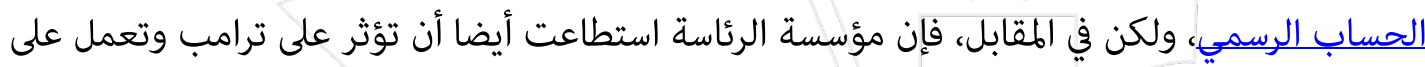

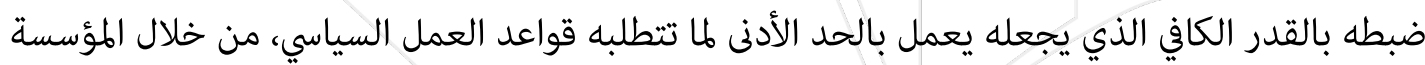

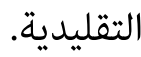
وإذا كانت السيناريوهات لستقبل إدارة ترامب مفتوحة على كافة الاحتمالات، فإن السيناريو الأقرب

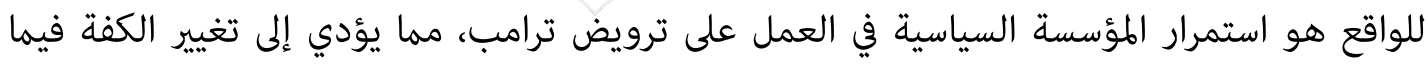

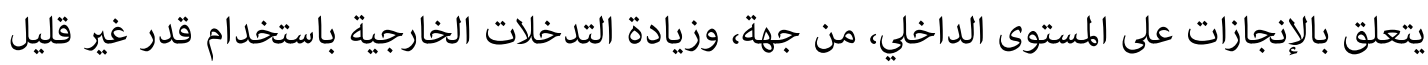

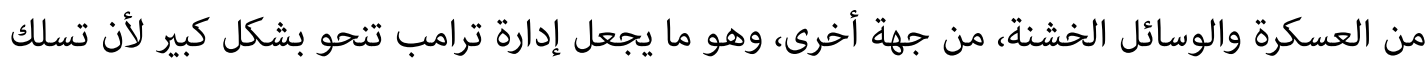

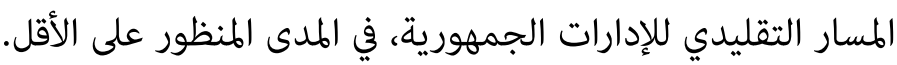




\section{مجلة المعشد المصرش} EGYPT INSTITUTE JOURNAL

\section{البنية المؤسسية لجماعة الإخوان المسلمين:}

$$
\text { اقتراب تحليلي }
$$


تعتبر جماعة الإخوان المسلمين من أقدم وأعرق التنظيمات في المجتمع المصري وبمرور الوقت تعاظمت مصادر قوة الجماعة وتشعبت بشكل ملحوظ. فتحولت الجماعة من جماعة دعوية صغيرة تهدف إلى إلى

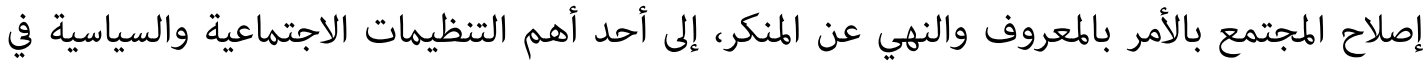

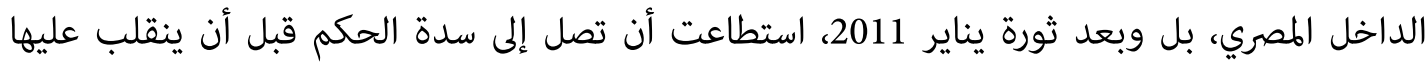

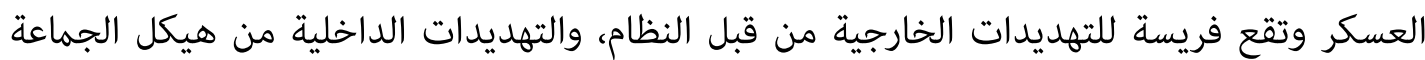
ذاته.

وخلال هذه الفترة التي تصل إلى 90 عاماً، منذ التأسيس في 1928، اكتسبت الجماعة الكثير من مصادر القوة أجادت استخدام بعضها، وأخفقت في البعض، بل وتجاهلت وجود البعام البعض مضد الآخر. وفى هذا الإطار تسعى هذه الورقة للبحث في مصادر القوة المؤسسية للإخوان المسلمين، مع تقييمها وفق فوذج صمويل هنتنجتون عن المؤسسية.

أولاً: النموذج النظري: معايير المؤسسية عند صمويل هنتنجتون: تعتبر القوة المؤسسية من أهم مصادر القوة التي يمكن أن قتتلكها أي منظمة أو مؤسسة وتعطيها الكثير من الميزات وعوامل القوة وتحميها من الكثير مما قد يعترضها من تحديات وعقبات. ونظرًا لأهميتها في الفوهات

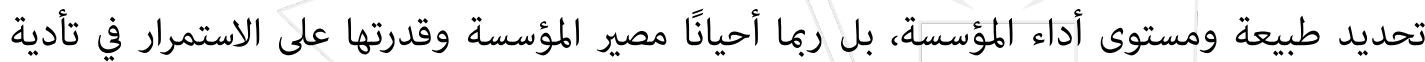
مهامها دون أن تتعرض للانكماش أو الاندثار.

وعلى المستوى النظري قدّم المفكر الأمريكي "صمويل هنتنجتون" في كتابه Political Order in" معايير المؤسسية السياسية للمنظمة أو للدولة، عبر محورين أساسيين: Changing Societies" الأول: نطاق أو مجال الدعم (scope of support): يعنى بهجال دعم المنظمة المدى الذي تحظى فيه

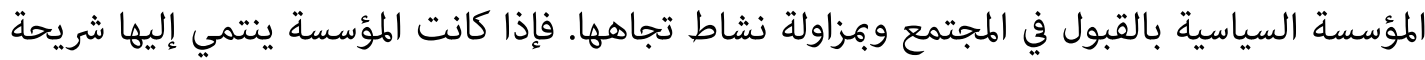
صغيرة من المجتمع فهي بذلك تعتبر ذات مجال أو نطاق محدود أما إذا كان ينتمي إليها شريحة كبيرة

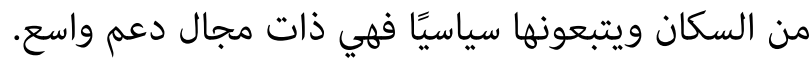

الثاني: مستوى المؤسسية (The level of institutionalization): ويعرفها على أنها العملية التي تكتسب من خلالها المنظمة القيمة والاستقرار. 
ويحدد هنتتتجتون لقياس مستوى المؤسسية أربعة معايير وهم التكيف، التعقيد، الاستقلال، التماسك:

1ـ التكيف (Adaptability):

التكيف مقابل الجمود هو أحد المعايير التي حددها هنتنجتون لقياس مستوى المؤسسية للمنظمة،

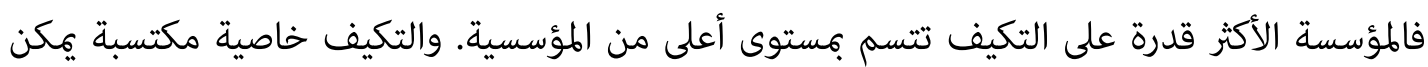
دراستها وفقا لعاملين هما التحديات التي تواجهها المؤسسة وعمر المؤسسة. فكلما كانت التحديات التي تقابل المنظمة أكثر، كلما كان تكيفها أعلى، وكلما كان عمر المؤسسة أطول،

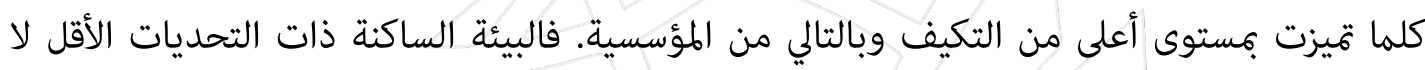
يكن أن تختبر مدي مؤسسية المنظمة ولا تعكس قدرتها على التعامل مع المتغيرات. فكل تحدي تواجهيه

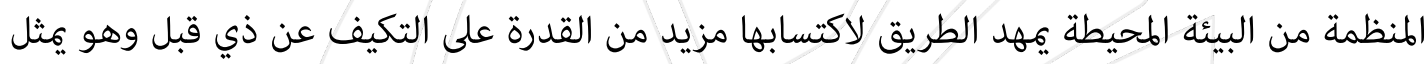
نجاحًا للمنظمة في تحقيق مستوى أعلى من التكيف وبالتالي من المؤسسية.

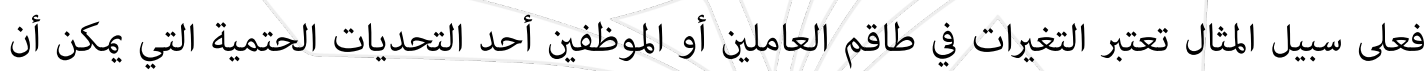

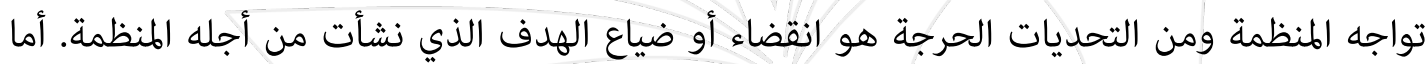

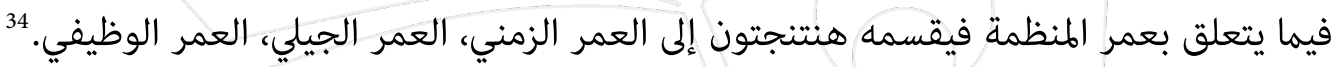
(أ) العمر الزمني: ويعني الزمن الذي استمر فيه عمل المنظمة، فكلما زاد هذا العمر كلما زادت قدرتها

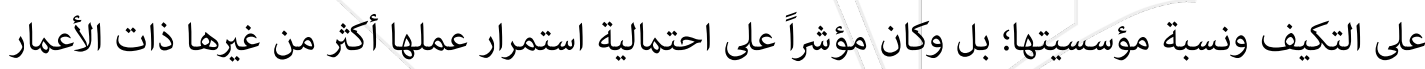
الأقصر نسبيًا.

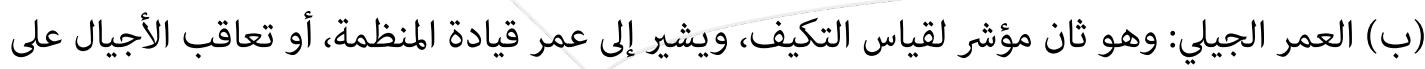

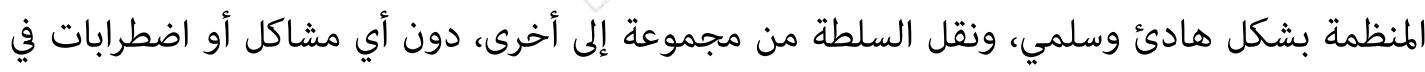

33Samuel Huntington, "Political order in changing societies", Yale University Press, New Haven and London, 1968, p. 12.

2Ibid, p. 13. 
عمل المنظمة واستقرارها. فالمنظمة التي مازال يقودها المؤسسون الأوائل لها لا تعبر عن مؤسسية عالية لعدم اختبار قدرتها على التكيف.

فالفجوة بين العمر الزمني والعمر الجيلي للمنظمة قد تُشكل تحديًا لعمل المنظمة يتمثل في التوتر الذي

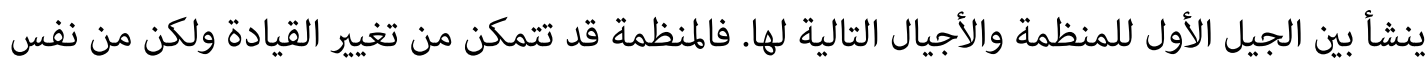

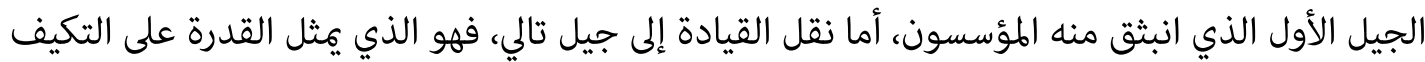

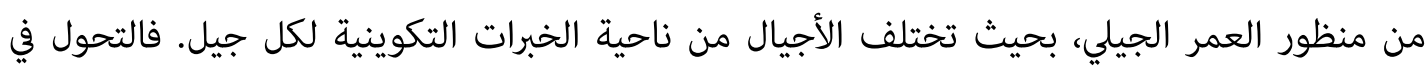
القيادة من جيل إلى آخر هو معيار العمر الجيلي للمنظمة دهيث. (ج) العمر الوظيفي للمنظمة والذي يتمثل في وظائف المنظمة؛ فعادة ما يكون للمنظمة وظيفة أو

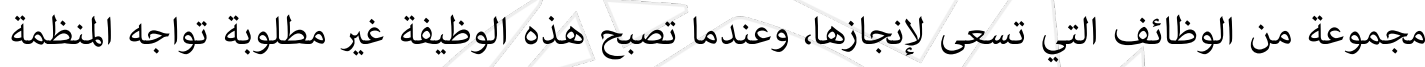

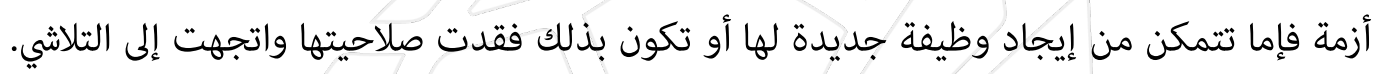
فالتكيف الوظيفي وليس التحديد أو التخصيص الوظيفي هو معيار قياس التكيف الصحيح فالمؤسسة لا

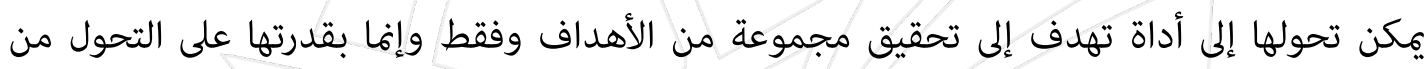

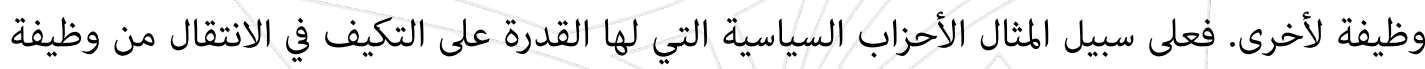

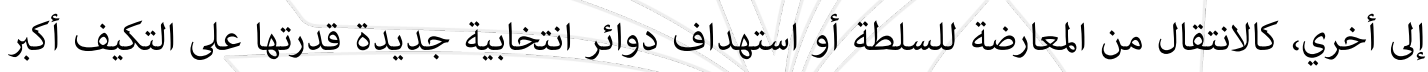
من غيرها.

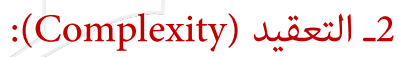

يعتبر صمويل هنتنجتون التعقيد مقابل البساطة أحد معايير قياس مستوى المؤسسية لدي أي منظمة.

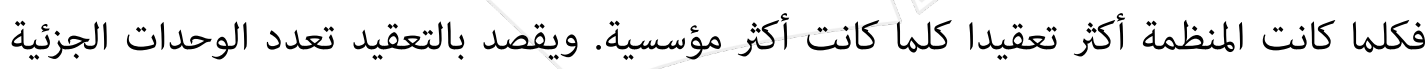

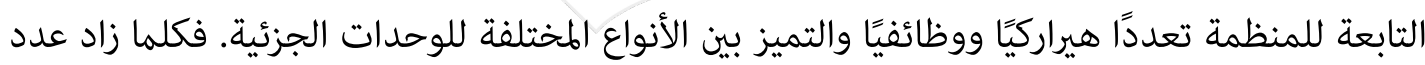

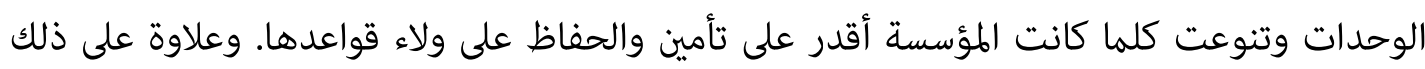

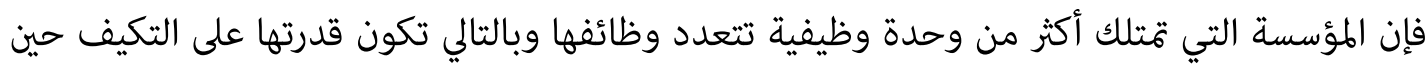


فقد أحد هذه الوظائف أكبر فبذلك تساعد خاصية التعقيد على تعزيز خاصية التكيف الوظيفي، ليس هذا فقط بل تخدم احتياجات جيل من المؤسسة وبذلك يتحقق التكيف الجيلي الذي أشار إليه سابقًا. خلاصة القول إن المؤسسات بسيطة التكوين تكون عرضة للاندثار بشكل أكبر من المؤسسات المعقدة

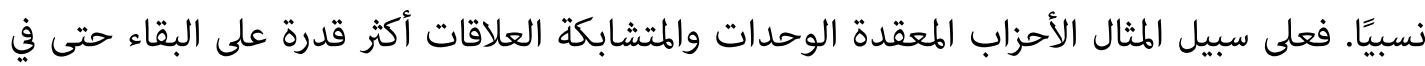

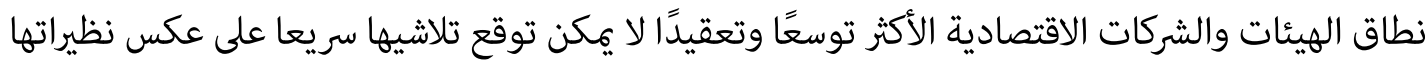
الصغيرة والبسيطة نسبيًا.

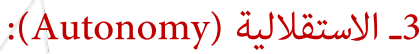

يقصد بها أن المؤسسة تعمل بشكل مستقل عن الهياكل الاجتماعية الأخرى وعن محددات السلوك

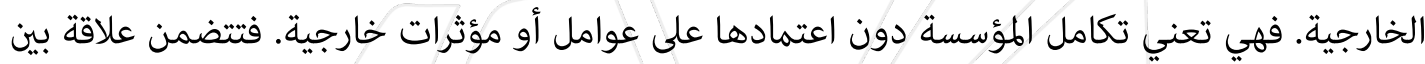

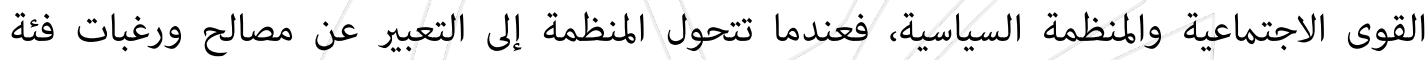

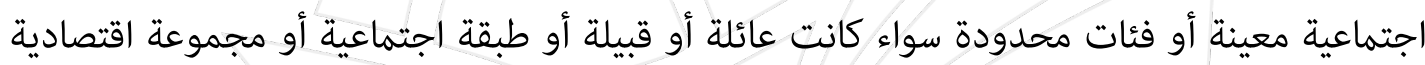
معينة فهي تفقد الاستقلالية والمؤسسية. فدرجة الاستقلال يكن تحديدها وفقًا لمدى اختصاصهم بمصالحهم وشؤونهم دون غيرهم من التكوينات

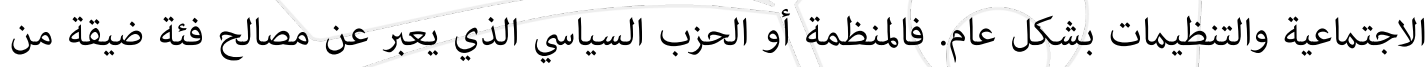

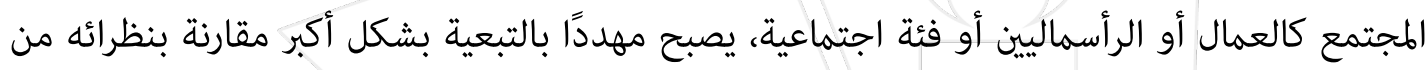

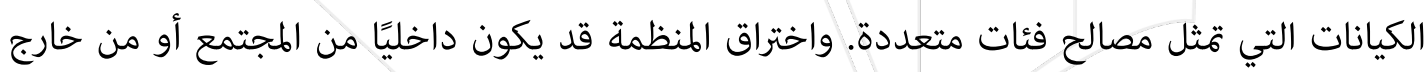

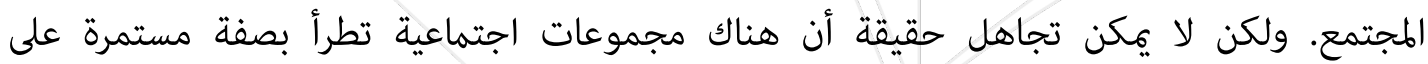

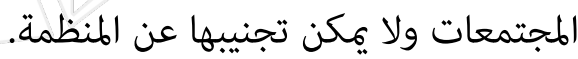

لكن يمكن ضمان الاستقلال عن طريق مجموعة من الإجراءات والوسائل التي تحد من تأثير الجماعات

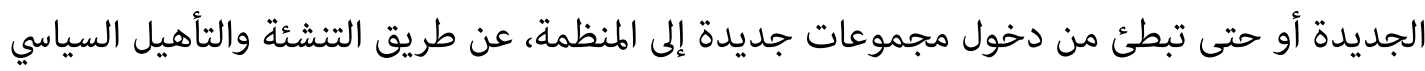

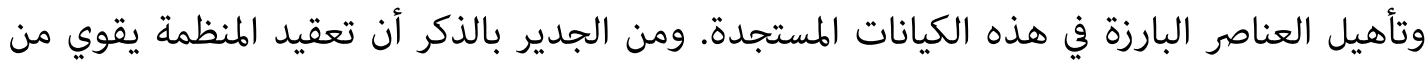




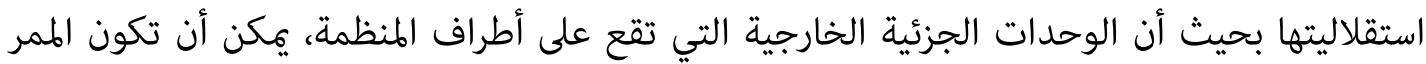
الذي يعبر من خلاله الأفراد الجدد الراغبين في الانضمام للمؤسسة.

4ـ التهاسك (Coherence):

تأتي خاصية التماسك مقابل التشتت، فكلما زاد مستوى التماسك في المؤسسة كلما زادت المؤسسية،

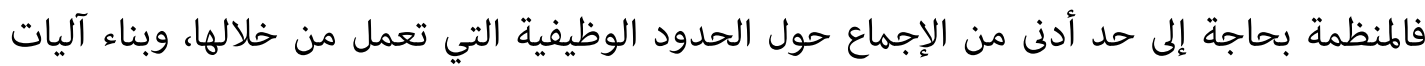

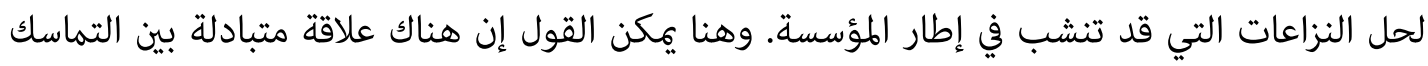

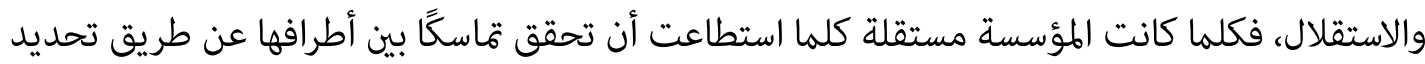
نوذج محدد يخدم مصالحها وأهدافها دون الحاجة إلى تأثيرات خارجية على سلوكها.

ثانياً: الهيكل المؤسسي لجماعة الإخوان المسلمين:

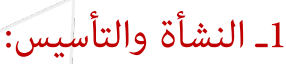

كانت بواكير نشأة الهيكل التنظيمي لجماعة الإخوان في الثلاثينات من القرن العشرين وتم وضع هيكل

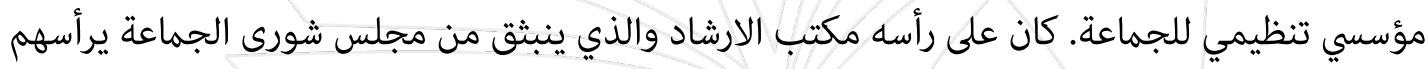

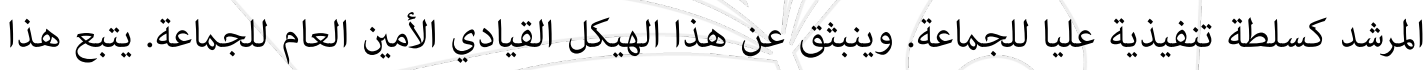

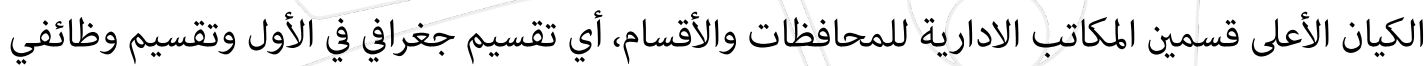

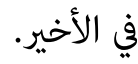

بحيث ينقسم المكتب الإداري للمحافظة إلى مكتب إداري للمحافظة ومجلس شورى المحافظة، وتبعًا

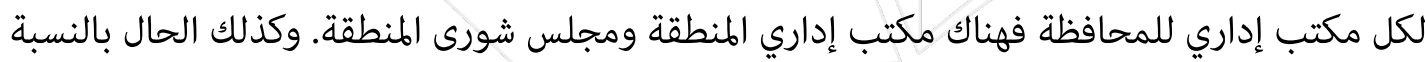
للشعب حتى يصل إلى آخر السلم التنظيمي وهو الأسر التي تتكون من مجموعة من الأفراد (من خمس إنس إنس إلى ست أفراد).

5 ibid, p.19-22.

6 ibid, p. 22 . 
ويتم تشكيل هذه المكاتب وفقًا للاقتراع الحر المباشر من قبل الأعضاء الذين ينتمون للجماعة بشكل

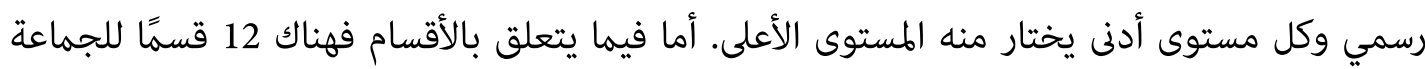

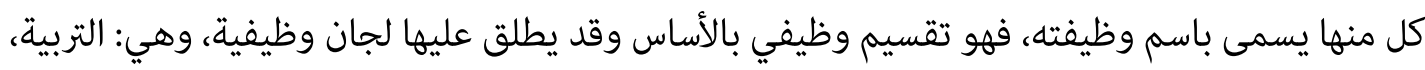

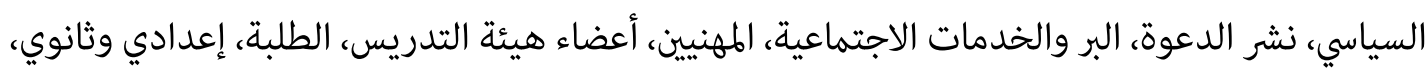

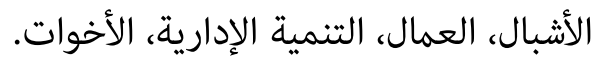
وظل هذا الهيكل المؤسسي قائًا وتشابكت أفراده وتعاظمت قواه تدريجيًا بحيث اكتسبت شكلًا أكثر

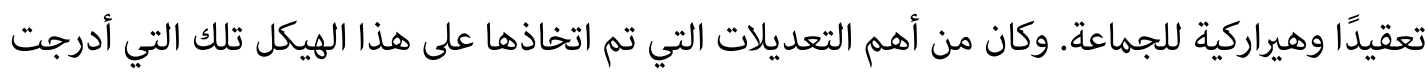

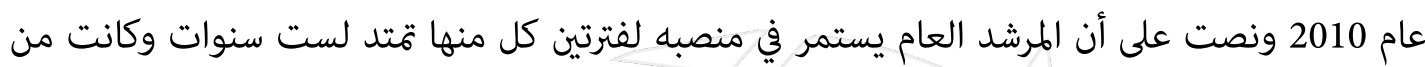
قبل قتتد مدى الحياة.

ولعل أهم التغيرات التي طرأت على الهيكل المؤسسي للجماعة، بالرغم من احتفاظه بالشكل السابق، إلا

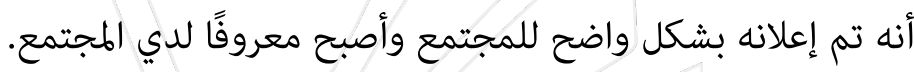

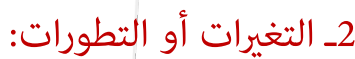

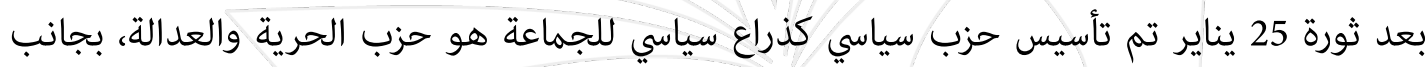
بعض المؤسسات الاجتماعية كالجمعيات الخيرية المشهرة التي كانت تابعة للجماعة بشكل تلاعل أو بآخر.

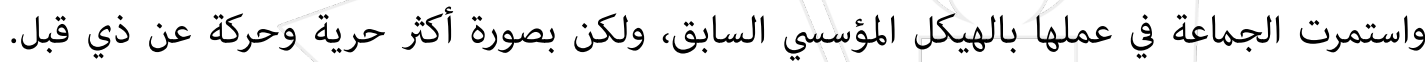

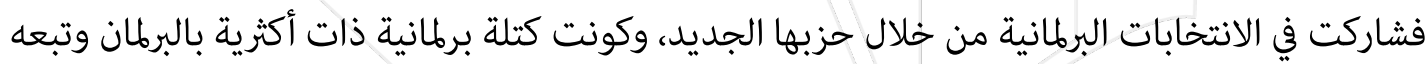

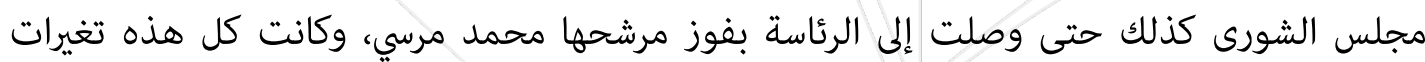

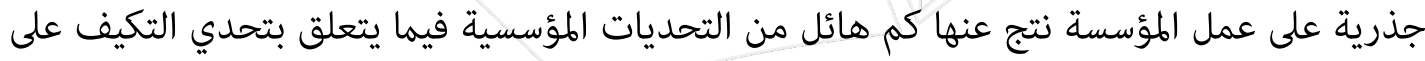
الأخص.

79 Bedford Row Report, "The History of the Muslim Brotherhood", London, 2 April 2015, www.9bri.com, Available on: http://9bri.com/wp-content/uploads/2015/04/Report-on-the-History-of-the-MuslimBrotherhood1.pdf, accessed date: 20 October 2015. 
حيث واجهت العديد من الأزمات التي كانت نتاج تحولها من المعارضة إلى السلطة وتغير وظائفها بشكل

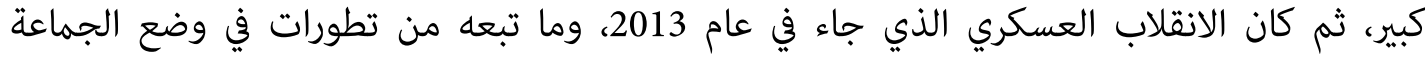

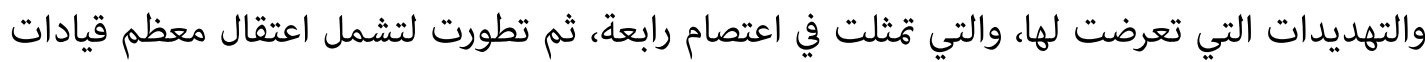

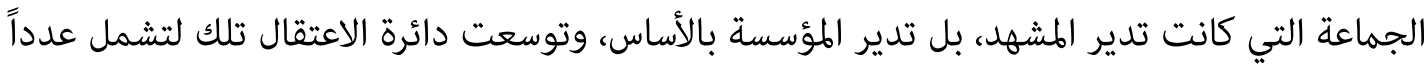

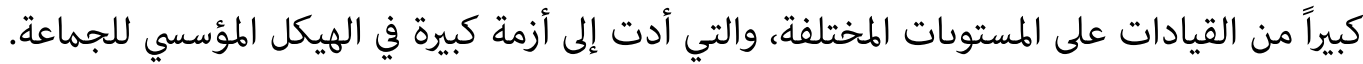
حيث أفرز أزمة مؤسسية، لاسيما فيما يخص اختيار القيادة الجديدة لإدارة الجماعة. بجانب مجموعة

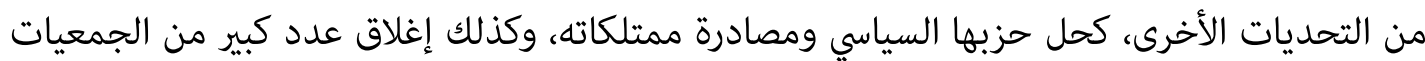

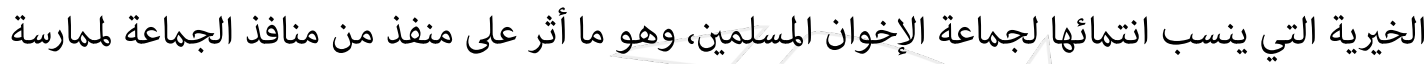

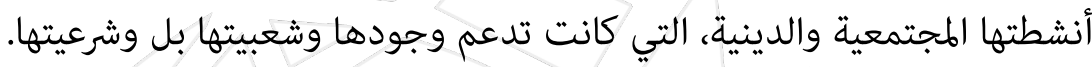
وكان من أهم التغيرات المؤسسية التي طرأت على التنظيم بعد اعتقال قياداته، ولاسيما الصفوف العليا

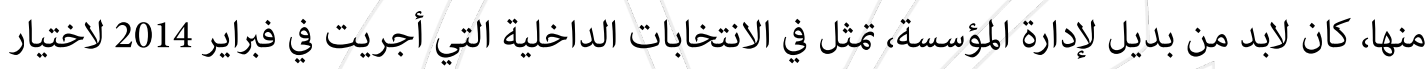

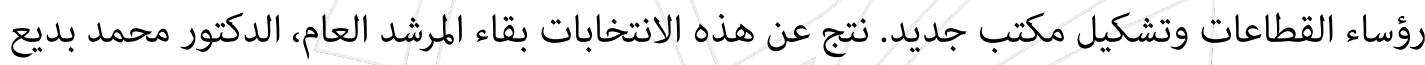

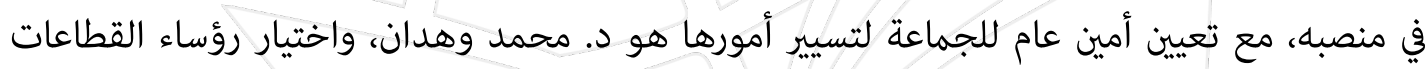

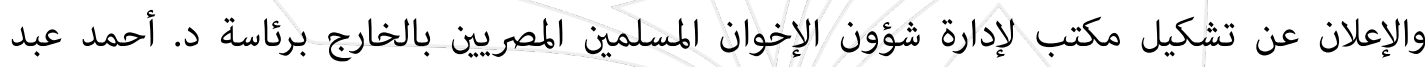

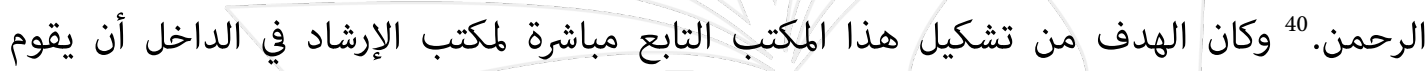
بالوظائف التي يتعثر على مكتب الإرشاد بالداخل القيام بها. وكان هذا التشكيل المؤسسي الجديد مصدراً لنزاع داخلي بين قيادات الجماعة من الجيل القديم التي

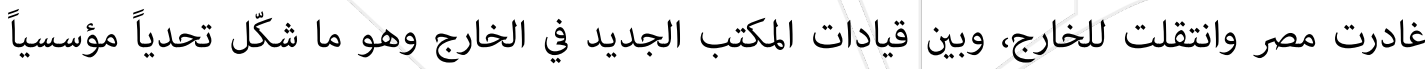
للجماعة، ظهرت ملامحه في عدة مؤشرات:

1ـ الاختلاف حول الدور: حيث يري البعض أن التشكيل الإداري الجديد يهدف إلى جعل المؤسسة أكثر

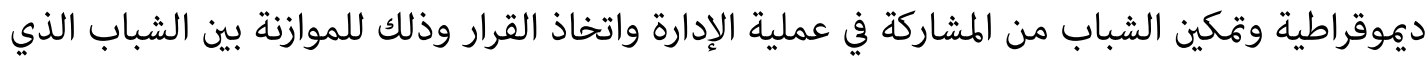

40 رصد، "الاخوان: الانتخابات الداخلية أجريت بعلم جميع أعضاء (الإرشاد والشورى)"، 28 مايو 2015، متاح على: تاريخ الدخول: 21 أكتوبر 2015.الرابط 41 عربي21 , "الاخوان: نحن لسنا ملائكة.. ونعد بتغييرات جذرية"، 25 إيريل 2015، متاح على الرابط, تاريخ الدخول: 21 أكتوبر 2015. 
يعمل على الأرض وبين المؤسسة وقيادتها2،، وفي المقابل يرى البعض أن هذا التشكيل هو انشقاق عن الجماعة، وخروج عن تقاليدها وعلى قيادتها الشرعية.

2ـ الاختلاف حول الإدارة: حيث نشب عن هذا التشكيل، نزاع بين طرفين كل منهما يريد أن يتولى مقاليد

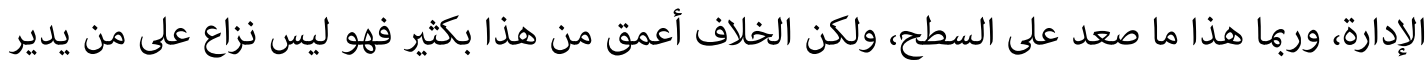

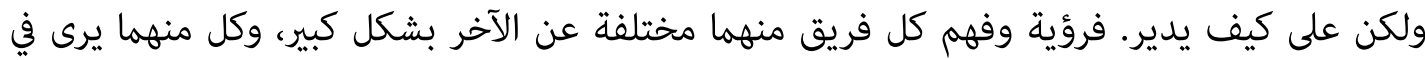
تصوره أنه الأصلح، ولعله بالفعل كذلك، ولكن كل بما يخدم تلك وفن الرؤى المتباينة.

3ـ الاختلاف على المنهج: حيث يرجع البعض هذا الاختلاف أنه اختلاف على طبيعة العمل الثوري. وآخرون

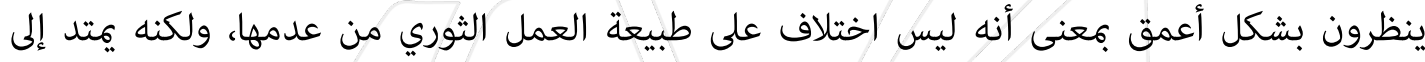
أهداف كل منهما، فالجيل القديم يسعى بشكل أكبر للحفاظ على ألى تقاليد وقواعد الجماعة ونظامها

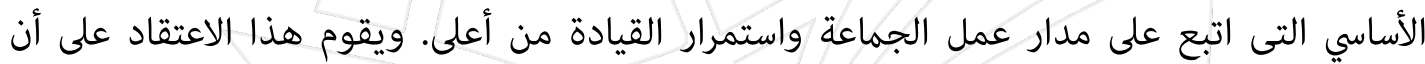

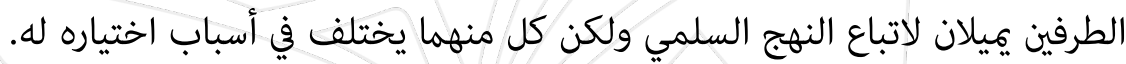
خلاصة القول إن الوضع المؤسسي الحالي لجماعة الاخوان يقابله عدد من التحديات المتمثلة في هذا

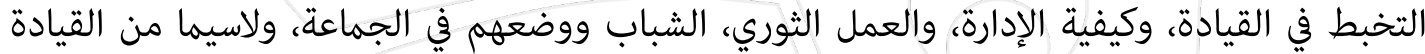
وكيفية رؤيتهم للأزمة والتعامل معها.

ثالثاً: نهوذج هنتنجتون والوضع المؤسسي للإخوان: بتطبيق نموذج هنتنجتون للوقوف على تقييم القوة المؤسسية لجماعة الإخوان المسلمين، يمكن القول بأن

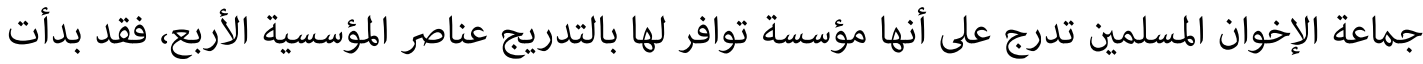

10 Georges Fahmi, "The Struggle for the leadership of Egypt's Muslim Brotherhood", Carnegie Center, 14 July 2015. 
على هيئة مجموعة من الأفراد وتتابعت مسيرتها تدريجيًا، حتى تحولت إلى مؤسسة بالمفهوم الذي عرضه

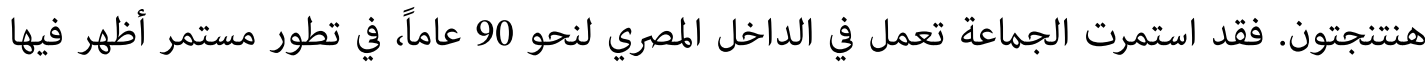

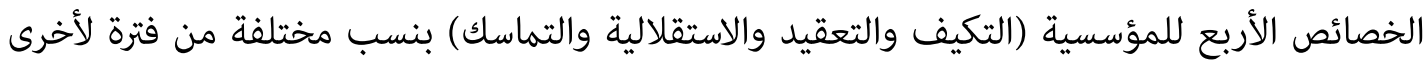

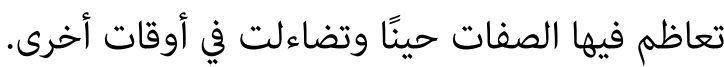

1ـ مدى تكيف جماعة الاخوان المسلمين:

التكيف يعتمد على عنصرين أساسيين هما التحديات التي تواجه المؤسسة وعمر المؤسسة، وقد برزت

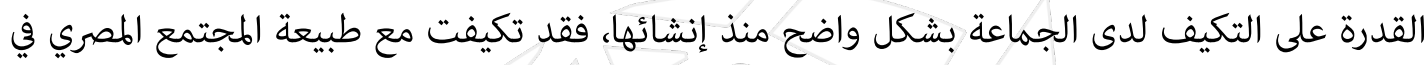

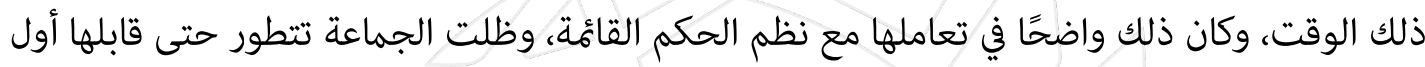

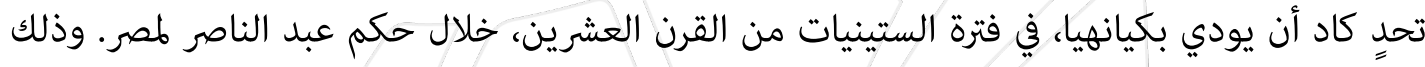

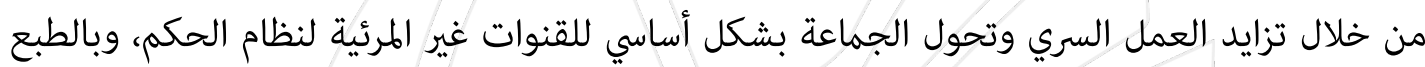
قل نشاطها، ولكن احتفظت بوجودها ولو بشكل رلو رمزي. ولكن قدرتها على مواجهة مثل هذا التحدي كان بمثابة علامة قوة ميزتها وانتقلت إلى المراحل التالية

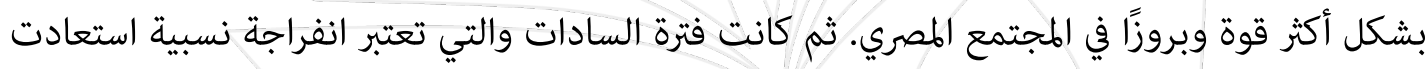

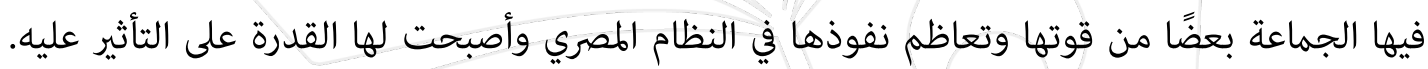

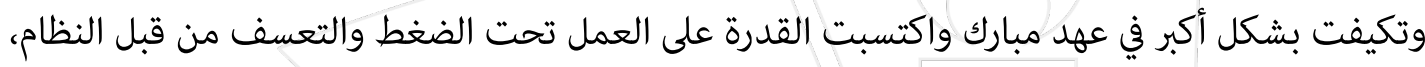

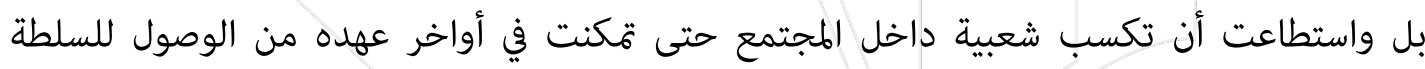

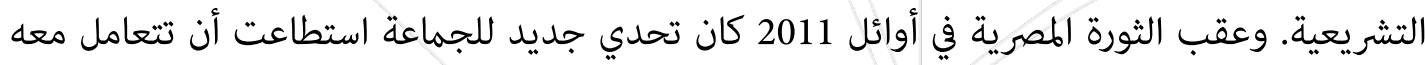

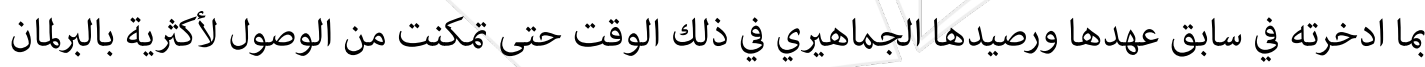

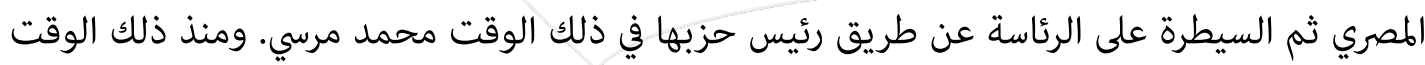

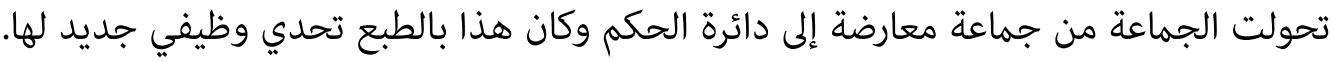
وتعددت التقييمات لهذه المرحلة بمميزاتها ومساوئها أيا كانت والتي لا مجال للاستفاضة فيها ولكن يكن

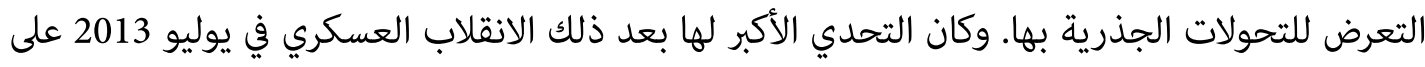

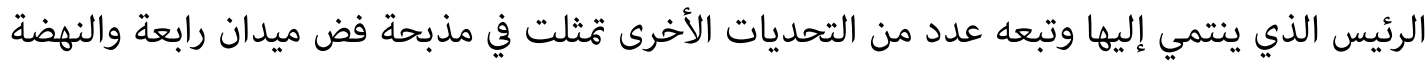

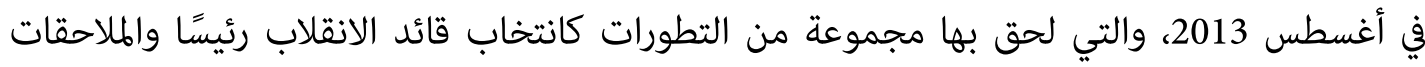

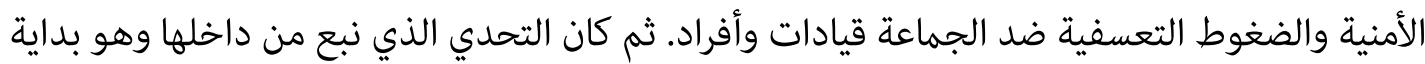


الانقسامات الداخلية في القيادة، وانقسامات الصف في توجهاتهم نحو القيادة تارة، ونحو الرؤية تجاه التعامل مع الوضع الحالي، تارة أخرى.

إن الثورة في حد ذاتها كان تحديًا لمؤسسة الإخوان ولكنها استطاعت أن تتعامل معه بالرغم من الأخطاء

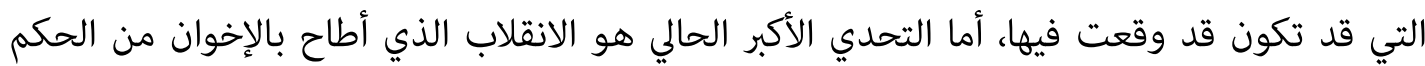

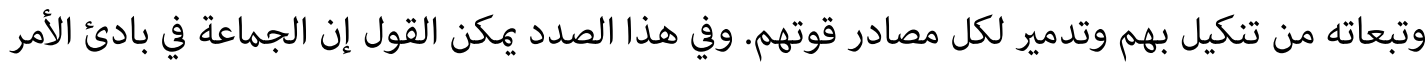

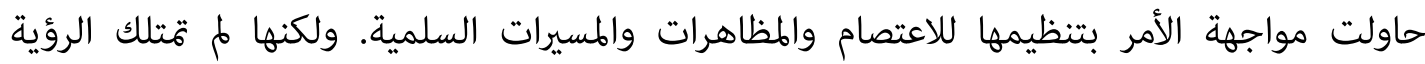

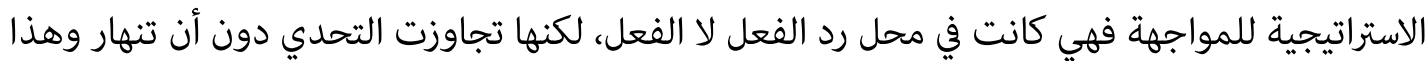
مؤشر قوة مؤسسية، فأزمة كهذه كان من الممكن أن تطيح بالجماعة قامَاًا. ثم جاء التحدي الأكبر في وسط تتابعات الانقلاب ألا وهو اعتقال الصف القيادي وبالتالي غياب القيادة

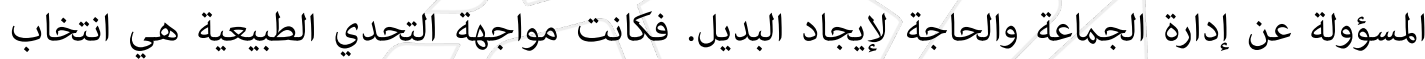

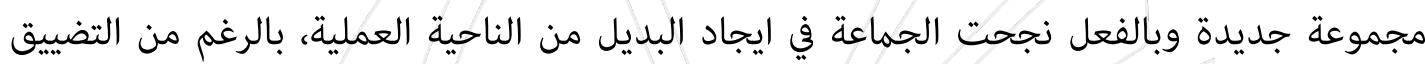

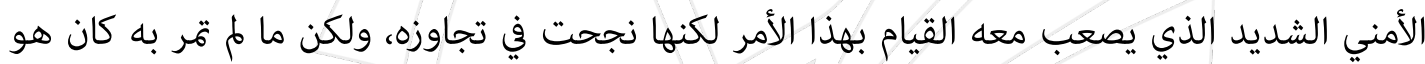

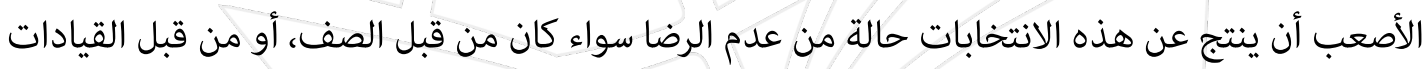

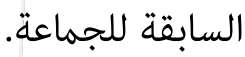

وقامت الجماعة بهجموعة من المحاولات لاحتواء الأزمة، ولكنها كانت مثثابة مسكنات وليست حل نهائي

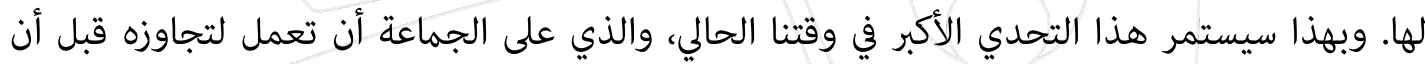
تتعثر في تحديات جديدة وسيصبح الأمر حينها أسوأ. أما فيما يتعلق بعمر المؤسسة، العمر الزمني للإخوان هو الفترة الزمنية التي استمرت فيها المؤسسة في

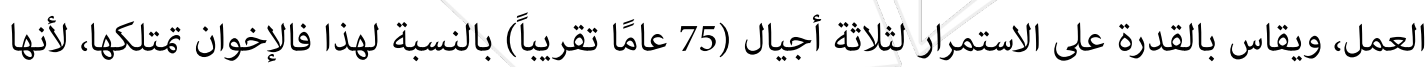

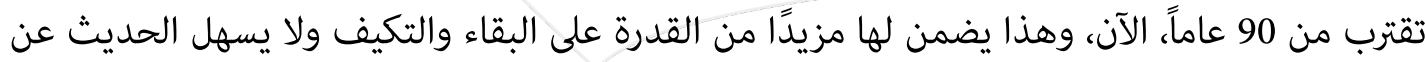

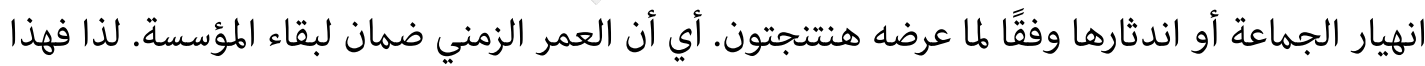
يعطي ميزة نسبية للجماعة. أما العمر الجيلي فيتعلق بتداول السلطة بين أجيال مختلفة من المؤسسة وليس مجرد تداولها وفقط.

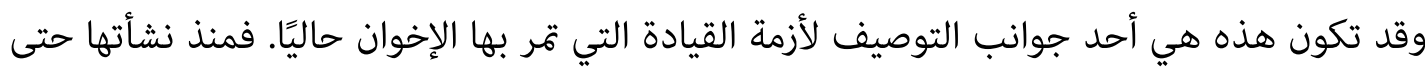

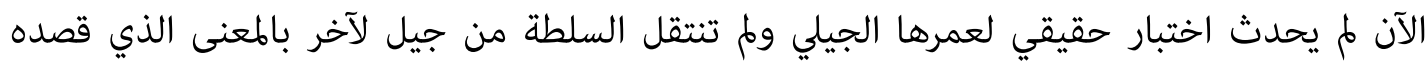

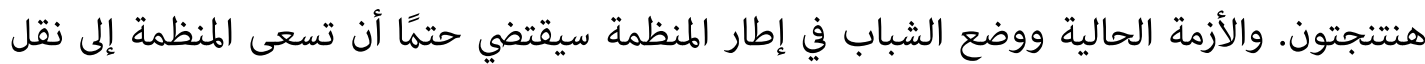


السلطة لأجيال جديدة منها، لأن الوضع الحالي سيؤدي إلى تآكل القدرة التكيفية لدي الجماعة. لذا يمكن القول إن العمر الجيلي نقطة ضعف لدى الجماعة حتى الآن تضغط عليها وتقوض من مؤسسيتها. أما بالنسبة للعمر الوظيفي فهو الآخر يواجه تحديًا من حين لآخر منذ توسع الجماعة في بدايتها كوظيفة

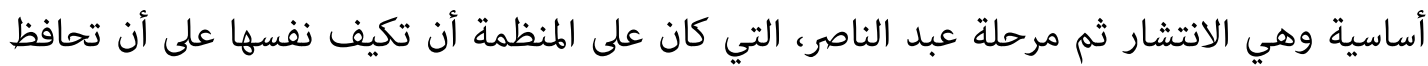

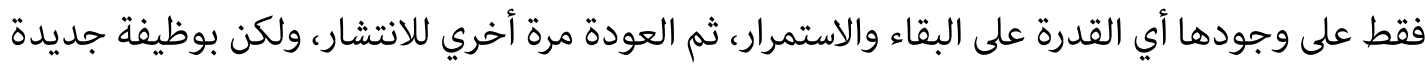

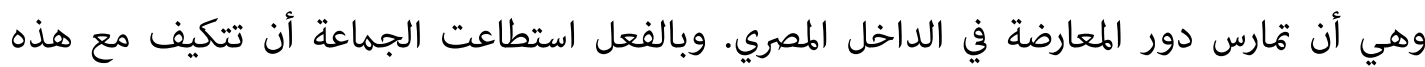
المتغيرات بشكل جيد نسبيًا واستطاعت أن تتعامل مع التحولات الوظيفية المارئ المتتابعة. ولكن منذ ثورة يناير، يمكن القول إن التحولات الوظيفية أصبحت مختلفة إلى حد كبير، كمًا وكيفًا من

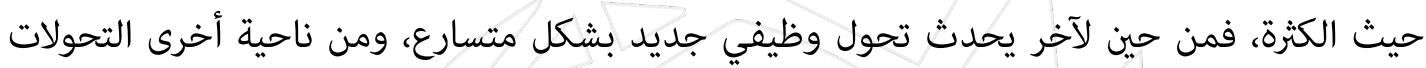

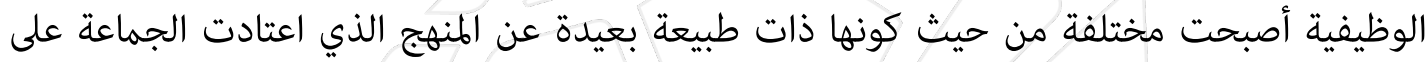

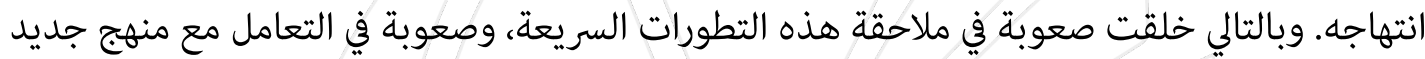
من الوظائف لم تعرفه في أدبياتها ولا تاريخها.

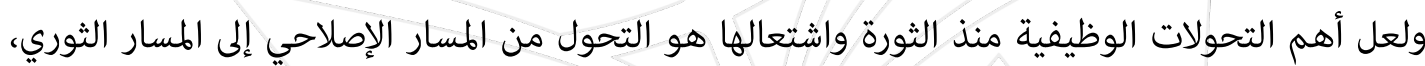

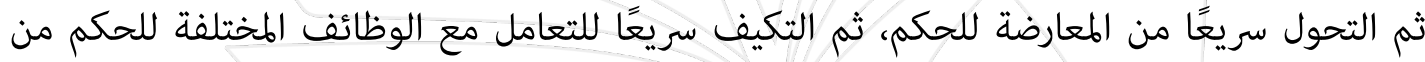

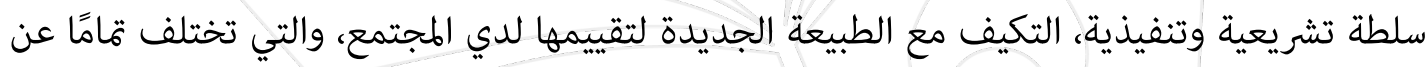
التقييم وهي في خانة المعارضة.

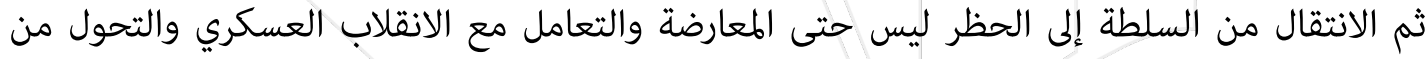

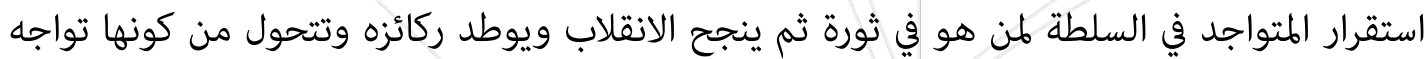

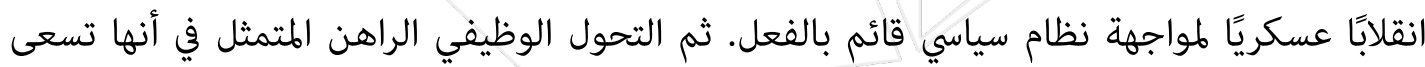

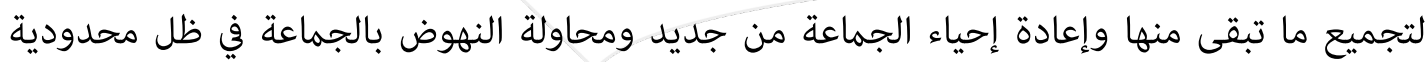

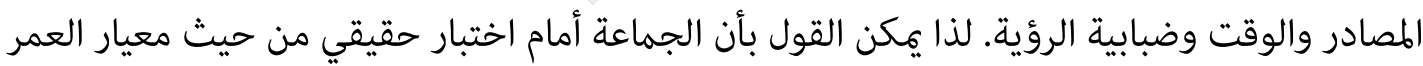
الوظيفي نجحت في اختبارات وظيفة سابقة ولكن الاختبار الحالي مختلف بشكل كبيه.

ومن هنا يمكن القول إن معيار التكيف عند الجماعة وفقًا للتحديات محل اختبار قد يضعف أو يقوي من قدرتها المؤسسية. أما وفقًا للعمر فالعمر الزمني يعطيها ميزة العيف واضحة بينما يكون العمر الجيلي عبئا

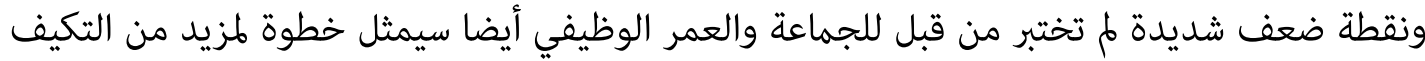
أو العكس، فملخص قياس قوتها هنا يجمع بين نقطة قوة ونقطة ضعف مازالت محل اختبار ونقطة ما 
2ـ مدي تعقيد جماعة الإخوان المسلمين:

الجماعة منذ نشأتها ويتزايد معدل تعقيدها تدريجيًا بمرور الوقت ويضاف إليها الوحدات الجزئية

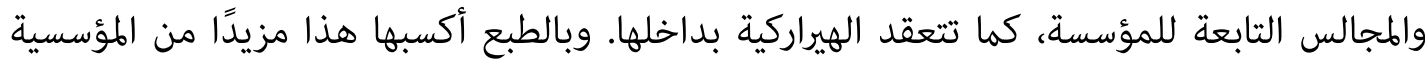

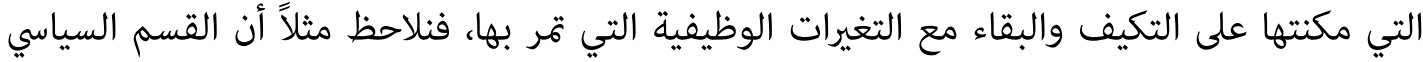

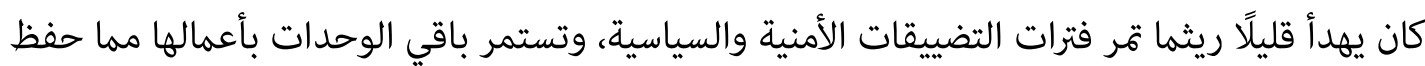

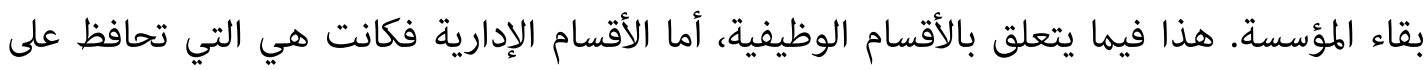

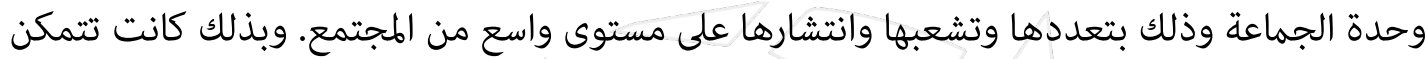

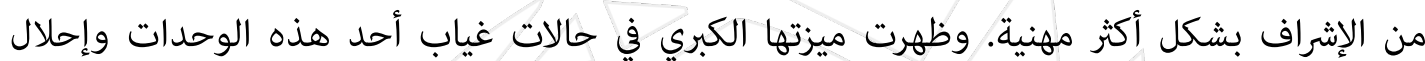
الوحدات التابعة محلها في حالة الاعتقالات السياسية وما إلى ذلك.

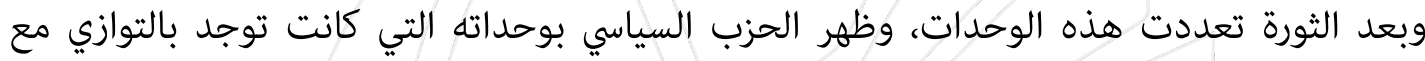

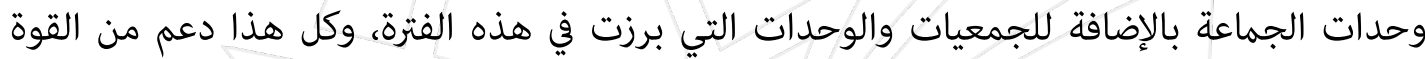
المؤسسية للجماعة بشكل كبير وظهر في تحركاتها داخل المجتمع، وفي الجانب السياسي بالأخص وحملاتلاتها لراتها الانتخابية والسياسية بغض النظر عن أي معيار أخر للتقييم بخلاف معيار المؤسسية.

ثم جاء الانقلاب بعد ذلك وتعرضت الجماعة لضغوطات شديدة في هذه المرحلة، وبدأت خاصية التعقيد

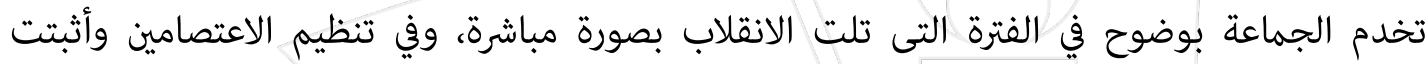

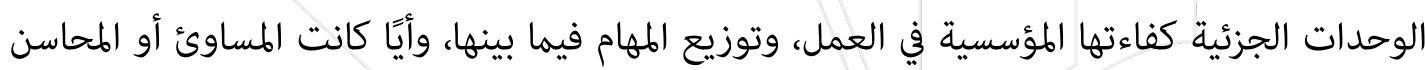

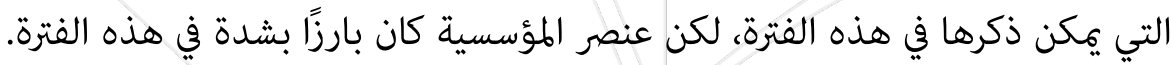
ثم جاءت مذبحة رابعة والنهضة والقبض على الكثير من أعضاء الهياكل الإدارية بل العديد من أعضاء

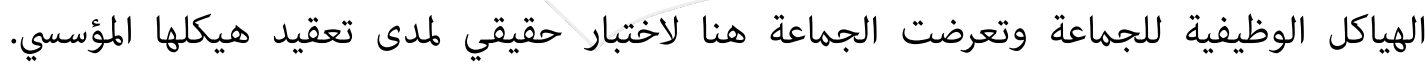

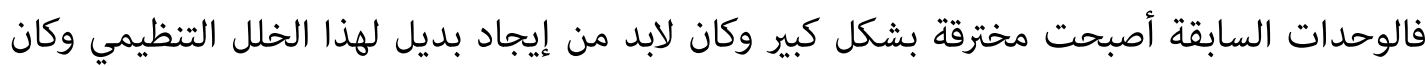
لابد من إعادة تشكيل الصف الداخلي من جديد. وبعد عدة أشهر بدأ التنظيم الداخلي في تدارك الصدمة ولعلها كانت عنيفة لأي مؤسسة وبدأت التشكيلات الداخلية في محاولة جديدة للإحياء من جديد بما فيها الوحدات الوظيفية والوحدات الإدارية.

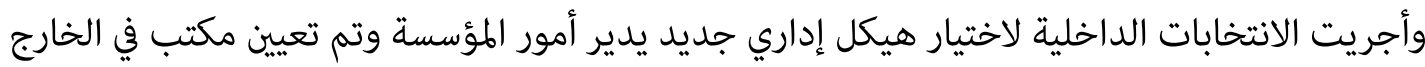

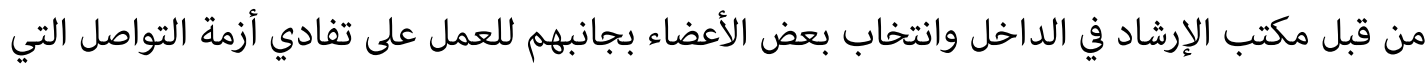
خلقها الوضع الأمني والسياسي في مصر. 
ويككن اعتبار هذا في محل تدعيم المؤسسية وتجنب الخلل المؤسسي، الناتج عن تحديات الظروف الراهنة،

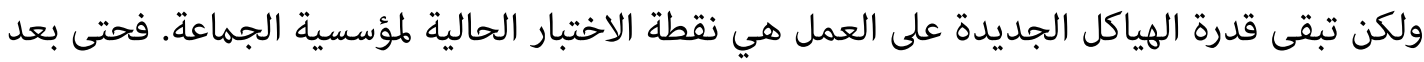

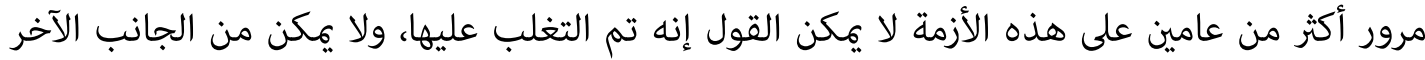

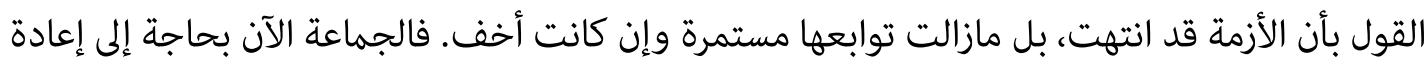

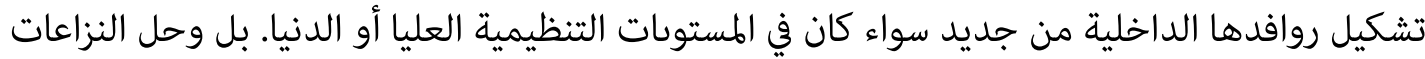
القائة في المستونات العليا.

3ـ مدى استقلالية جماعة الإخوان المسلمين:

تتمثل استقلالية المؤسسة في قدرتها على العمل بعيدًا عن تأثير الهياكل الاجتماعية المحيطة ومحددات

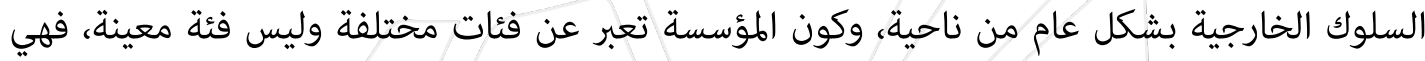

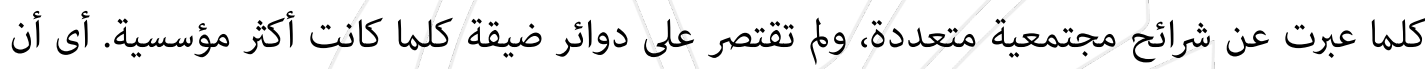

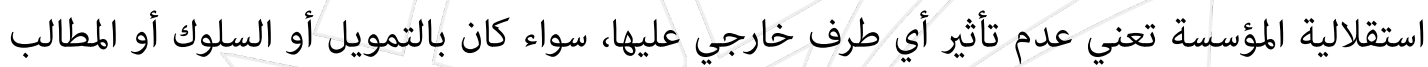
أو غيره.

وقد تتعت الجماعة باستقلالية بالفعل في التمويل بالرغم من كونه عنصر مختلف، ولكن يككن القول

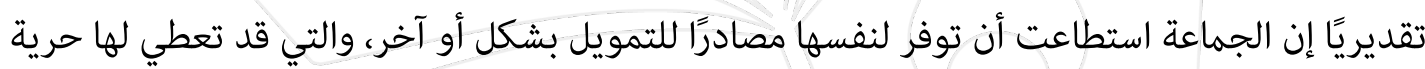

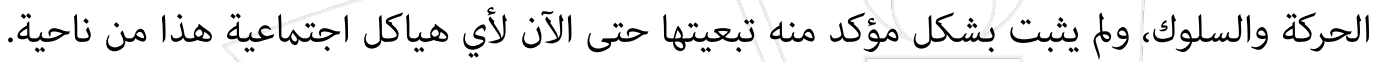
وعلى الجانب الآخر فإن التشكيل العضوي لجماعة الإخوان المسلمين مل ينطو على شريحة معينة من

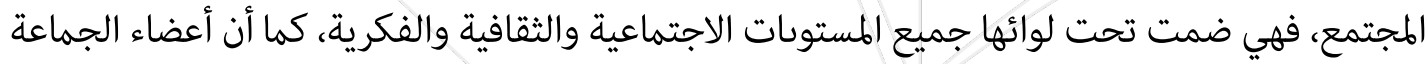

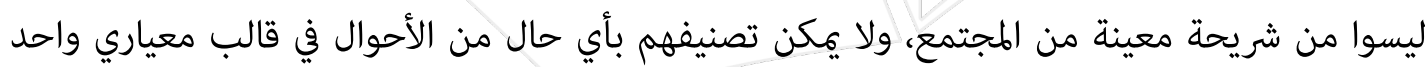

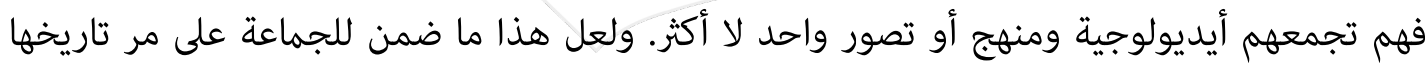
قدر كبير من الاستقلالية والمؤسسية.

كما أن تعقيد الجماعة وتعقيد اجراءات الانضمام للتنظيم كان من الأسباب التي حفظت للجماعة

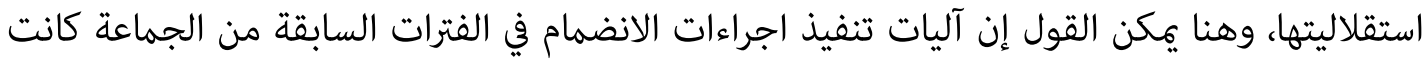

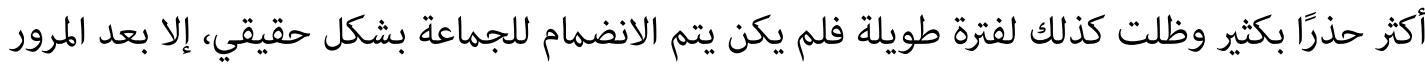

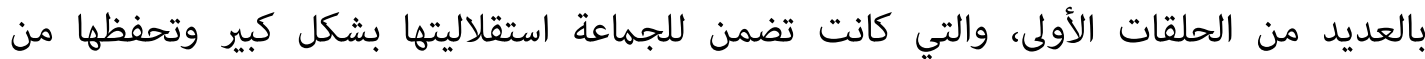
الانضمامات العشوائية للجماعة. 
وبالتدريج قل الالتزام بهذه الاجراءات، فأصبحت الجماعة عرضة لانضمام فئات كثيرة تختلف كثيرًا عما لإسا

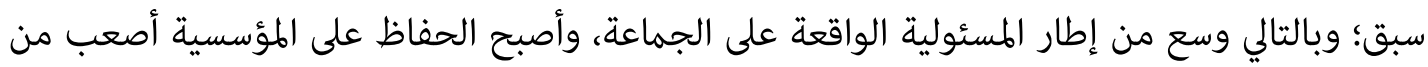

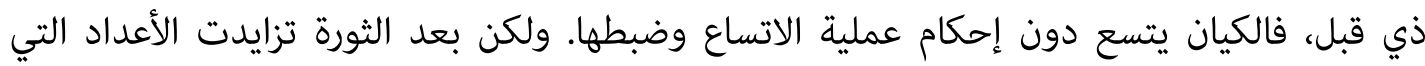

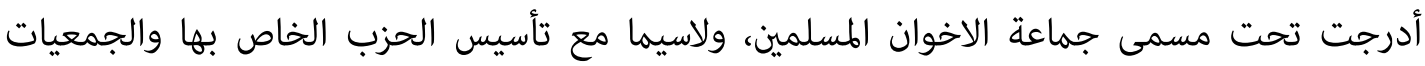
وأصبحت السيطرة عليها أصعب من ذي ذئ قبل. الاخوان

أما فيما يتعلق بالوضع الحالي فهو يمكن النظر إليه فيما يتعلق بالجماعات الخارجية وتأثيرها: الأول: هو الانضمام في تحالفات مع قوي سياسية وهياكل اجتماعية جديدة، ولكن على مستوى القيادة

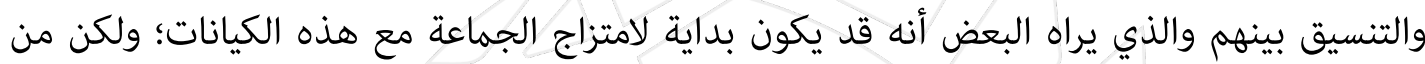
منظور آخر أن هذا فقط على مستوى القيادات ليس فيه أي اختراق للجماعة، حتى ولو كان مع كئ كيانات بعيدة عن توجه الجماعة بشكل جوهري فهو يككن تصنيفه على أنه مجرد تعاون لتحقيق غايات مشتركة.

الثاني: يتعلق بالتحاق الأفراد الجدد بالجماعة ولعل الظرف الحالي الذي قر به الجماعة قنن هذه العملية

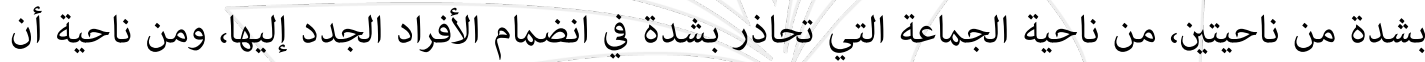

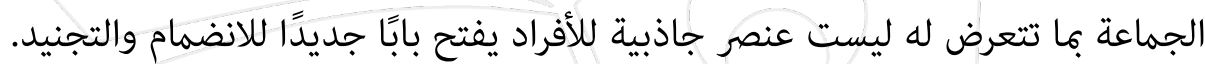
وهنا يمكن القول إنه بالنسبة لعنصر التنوع العضوي في الجماعة فهو قائم، ويعتبر ميزة نسبية للجماعة لا يصح إهمالها وعدم الانتفاع بها في تدعيم قواها المؤسسية بشكل خاص وقوت النها الشها الشاملة بشكل عام. 


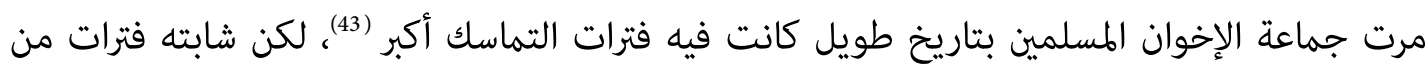
التشتت وشهدت الجماعة عدة انقسامات على مر تاريخها، وبعد الثورة مرت الجماعة بعدة اختلافات

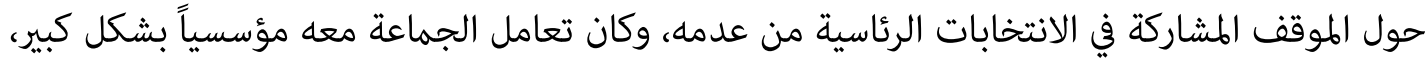

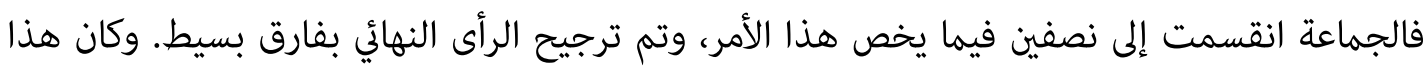

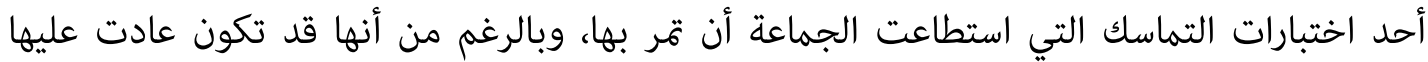
بسلبيات إلا أنها استطاعت تجاوزها بشكل عملي. وبعد الانقلاب ظهر تحدي غياب القيادة المتمثلة في مكتب الإرشاد وراء السجون، وكيفية تشكيل قيادة جديدة، وهنا تعرض معيار التماسك لاختبار شديد، فاختلفت قيادات الجماعة فيما بينها، فيما يخص

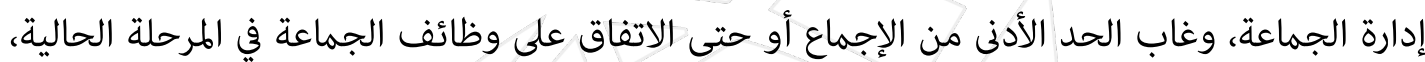

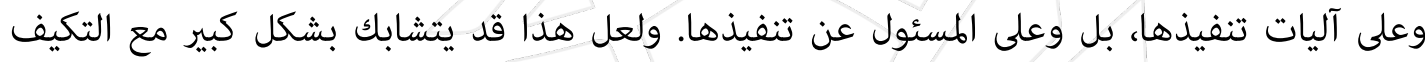
الوظيفي للجماعة (44).

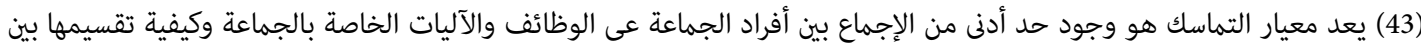

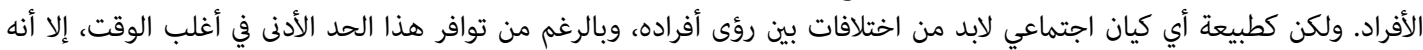

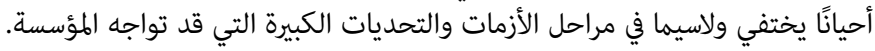
(44) الآراء الواردة تعبر عن آراء كاتبها، ولا تعبر بالضرورة عن "المعهد المصري للدراسات السياسية والاستراتيجية". 


\section{تحولات الخطاب السباسي الجهادي عبد الغني مزوز (المغرب) •}


يحتل مفهوم "الحاكمية" مكانة مركزية في البناء التنظيري للحركات الجهادية منذ نشأتها في ستينيات

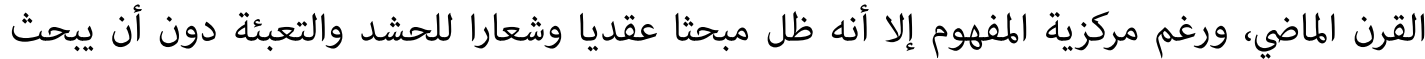

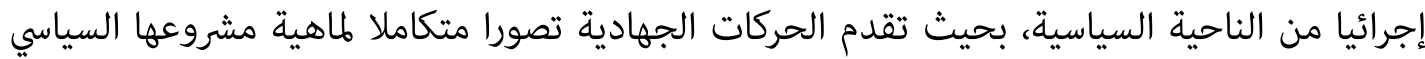

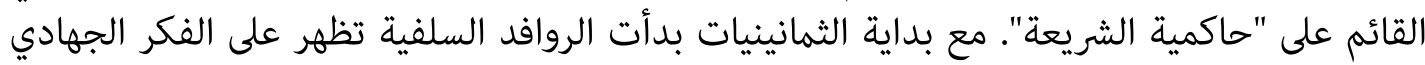

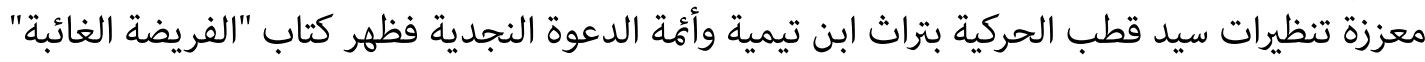

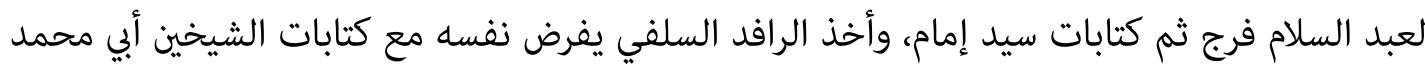

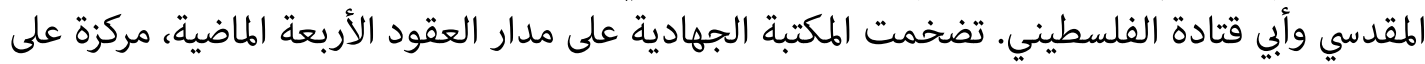

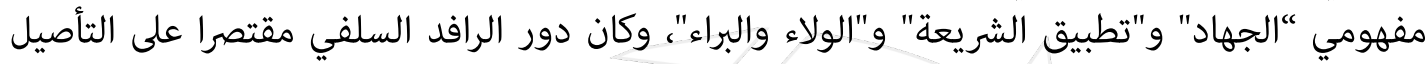

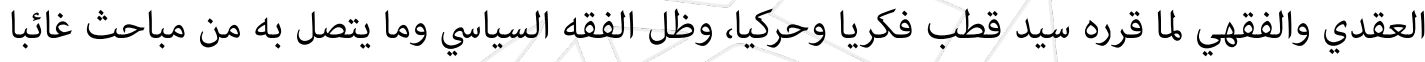

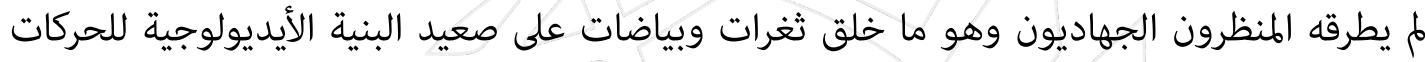

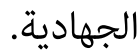

امتدت أزمات التيار الجهادي على البياضات التي خلفها غياب الفقه السياسي في أدبيات التيار، كما

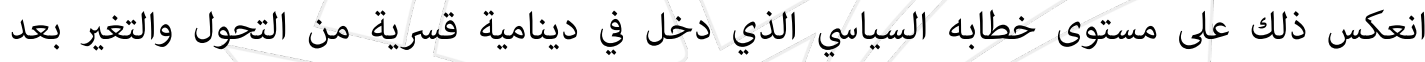
مستجدات ووقائع لم تكن في حسبانه فأربكته تنظيميا وأيديولوجيا.

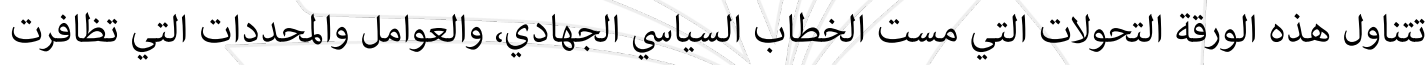

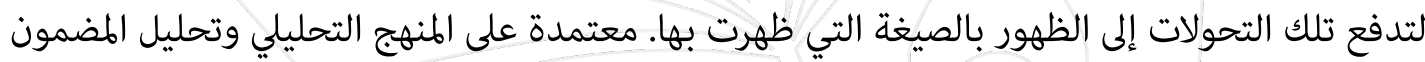

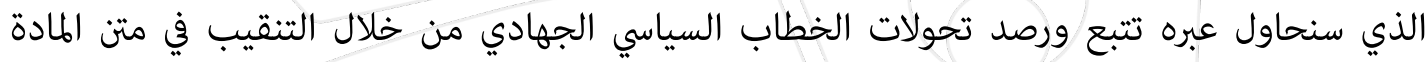

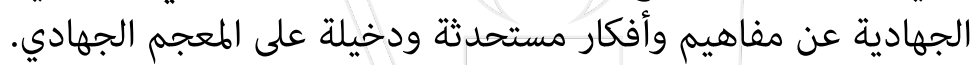

\section{تحديدات أولية}

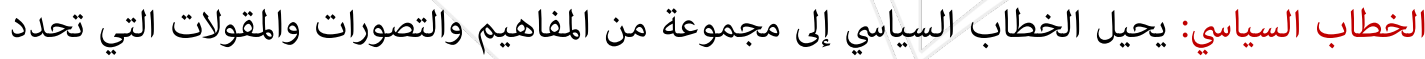
الممارسة السياسية شكلا ومضمونا، وتضبط المواقف والعلاقات بين مختلف الفاعلين داخل مجتمع ما. الجهاديون أو التيار الجهادي: نقصد بالتيار الجهادي ذلك التيار الذي تشكل في ستينيات القرن الهاضي

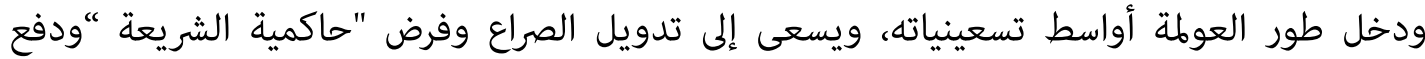

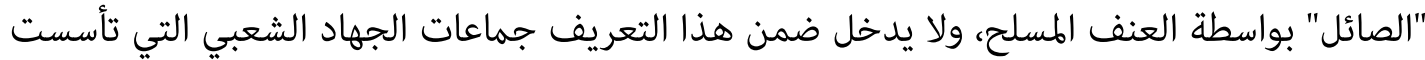

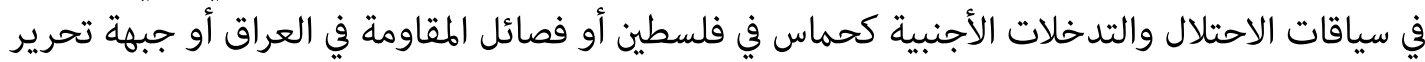

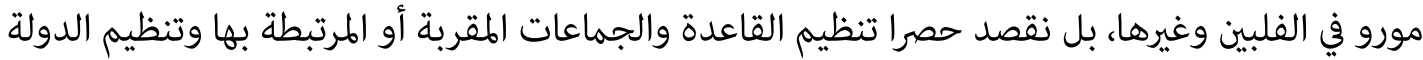


دينامية الخطاب السياسي الجهادي

بنى التيار الجهادي شرعيته الجهادية على وجوب التصدي للأوضاع الجاهلية القائمة في البلاد الإسلامية

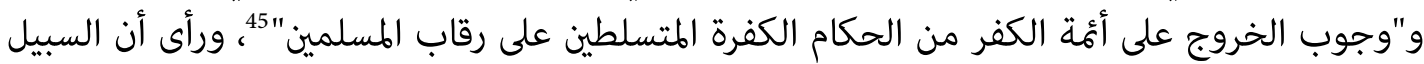

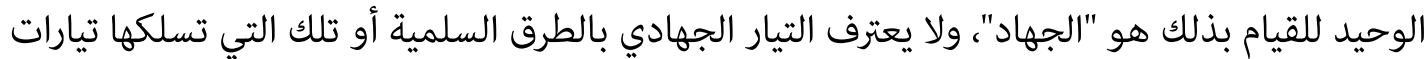

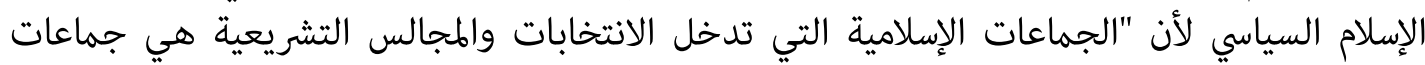

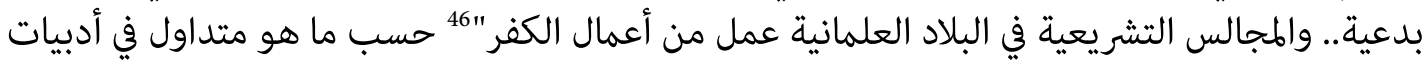
التيار.

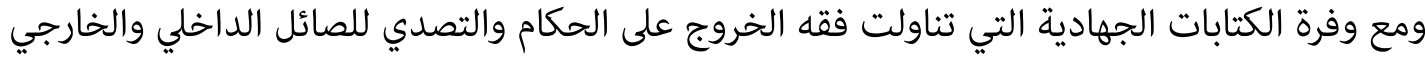

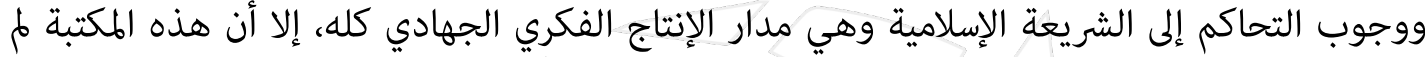

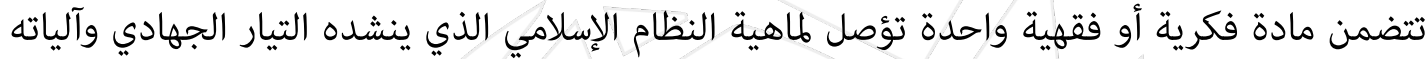

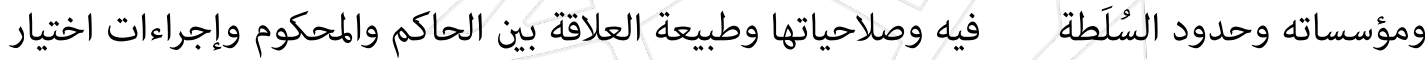

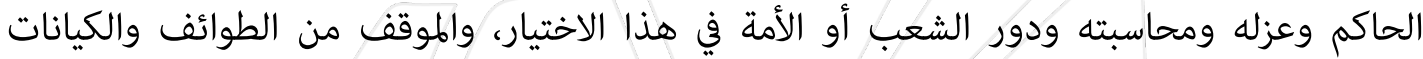

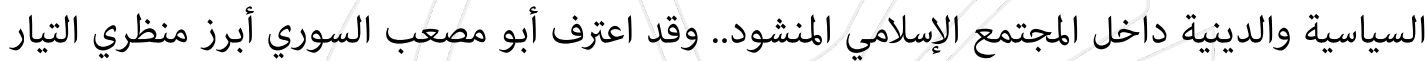

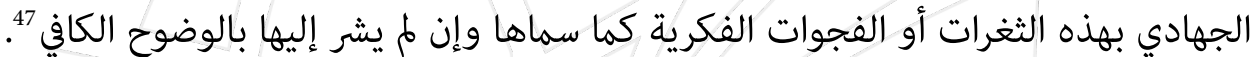
تناول المنظرون والكتاب الجهاديون مفاهيم "الطاغوت" و"تطبيق الشريعة" و"الحاكمية" و"البيعة"

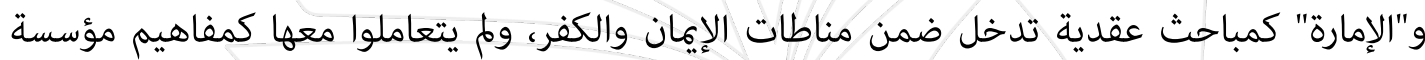

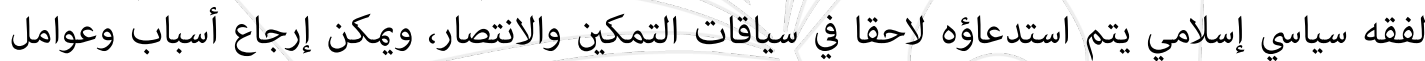
هذه القراءة العقدية المنغلقة إلى عدة أسباب:

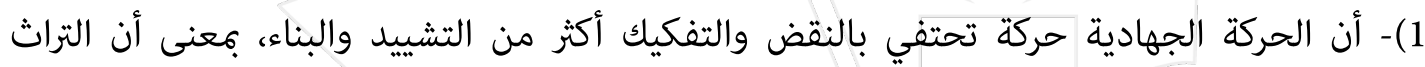

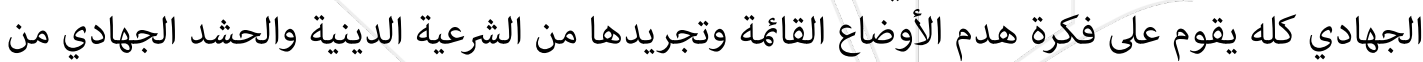

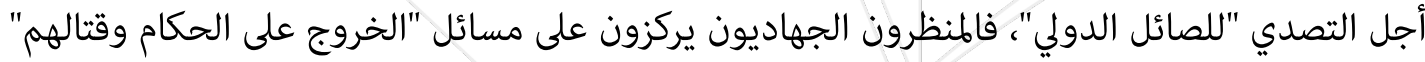

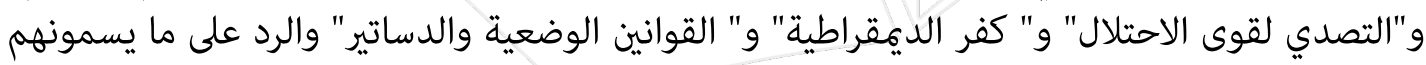

45 أبو محمد المقدسي، هذه عقيدتنا، 1997 الرابط

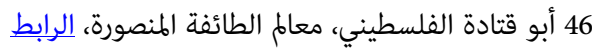

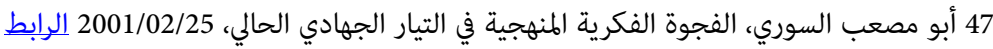




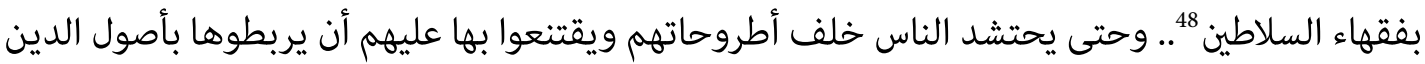

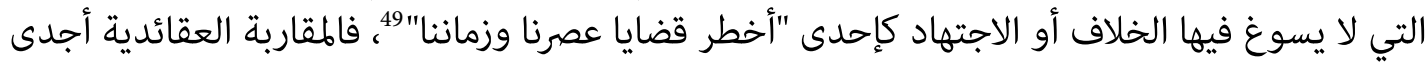
وأمتن كما أن المعتنقين لها يكون إيمانهم بالقضية أقوى وأرسخ.

2)- يدرك التيار الجهادي أن معركته طويلة وقد تستغرق عقودا، ومنذ أواسط التسعينيات حين عولم التهات

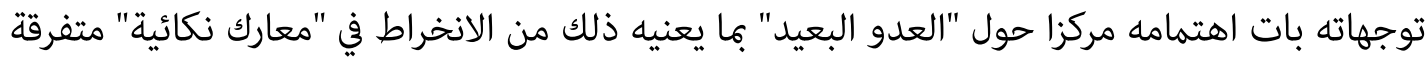

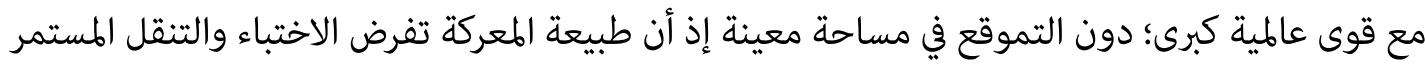

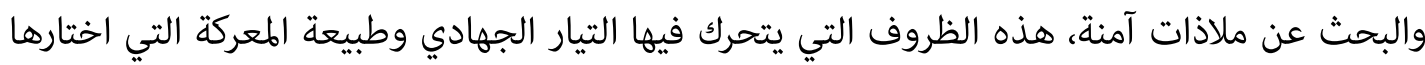

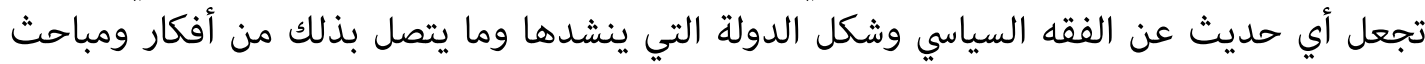

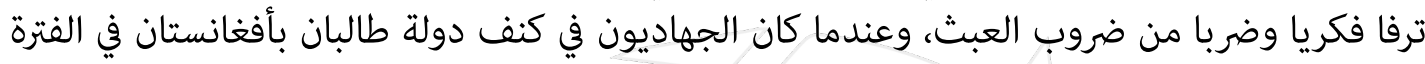

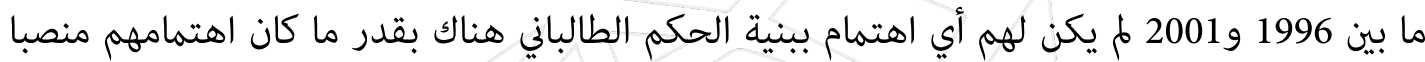
في تأمين معسكرات للتدريب وقواعد للانطلاق.

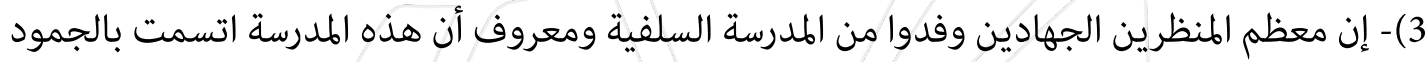

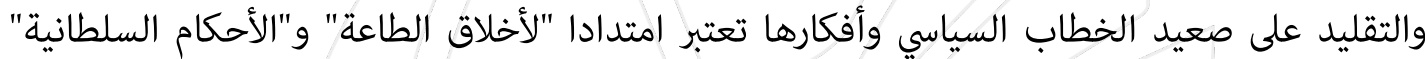

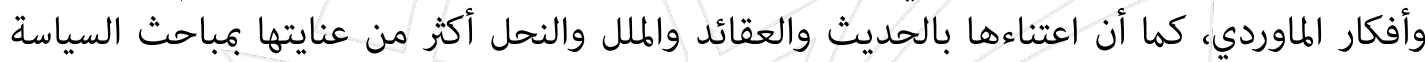

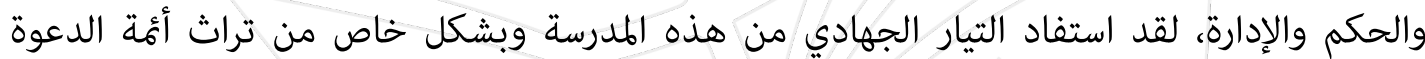

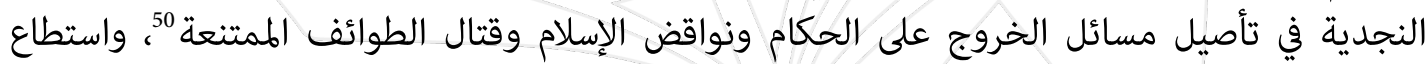

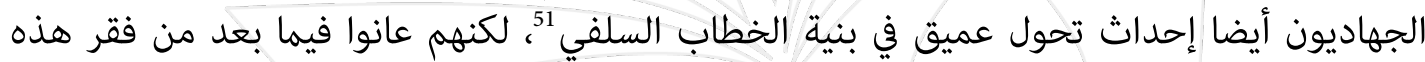

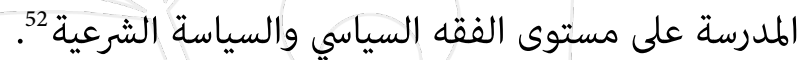

48 معظم كتابات المقدسي جاءت في إطار الرد على المخالفين مثل: "الديمقراطية دين" و"امتاع النظر في كشف شبهات مرجئة العصر" و"

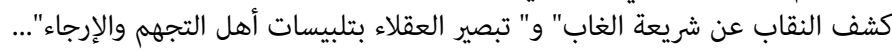
49 أيمن الظواهري، إعزاز راية الإسلام.. رسالة في تلازم الحاكمية والتوحيد، ص2 (نسخة إلكترونية) 50 يعتبر كتاب "ملة إبراهيم" لأبي محمد المقدسي كتابا تأسيسا في الفكر السلفي الجهادي وكله مبني على نقول واقتباسات من كتب إتبات الدعوة النجدية.

51 مروان شحادة، التحولات التي أحدثها تنظيم القاعدة في الخطاب السلفي، 2012/2/7 الرابط

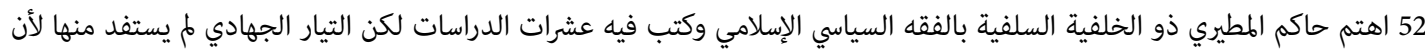

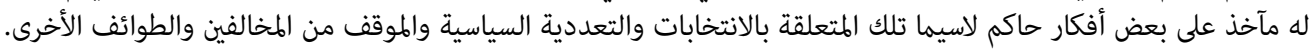


في السنوات الست الماضية عرف الخطاب السياسي الجهادي تحولات لافتة، وبدأ المنظرون الجهاديون

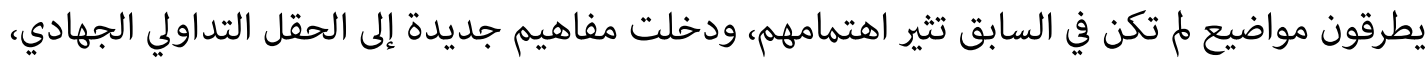

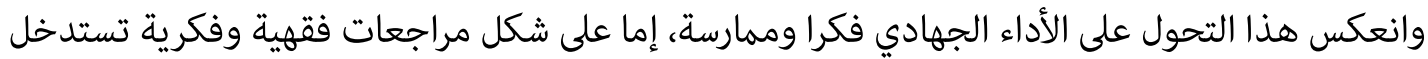

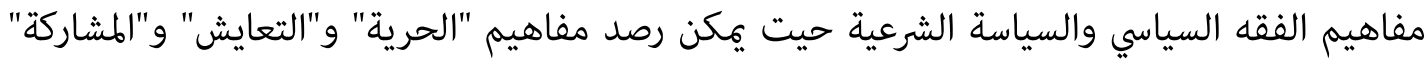

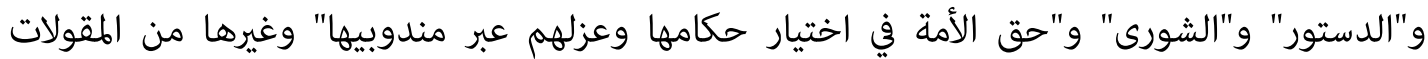

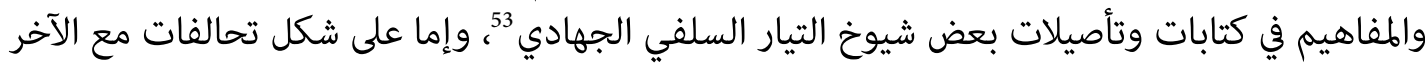

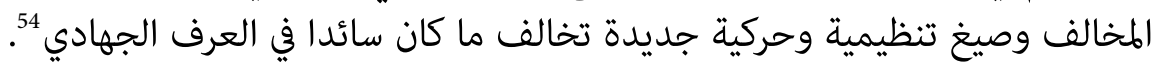

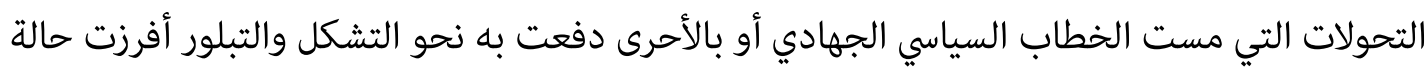

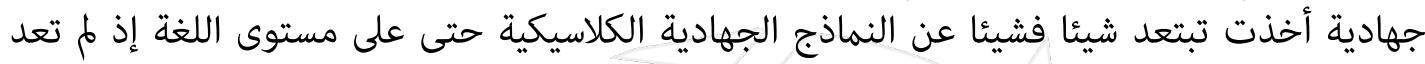

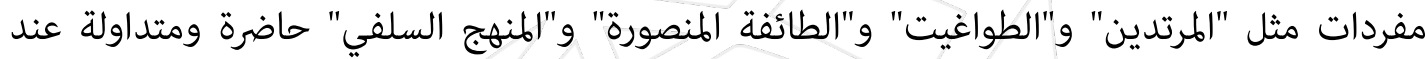

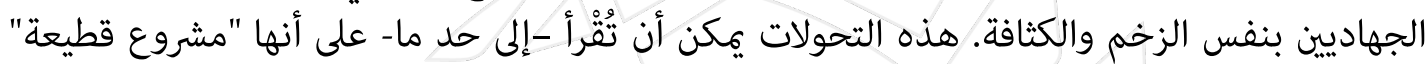

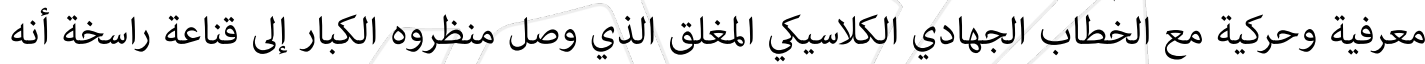

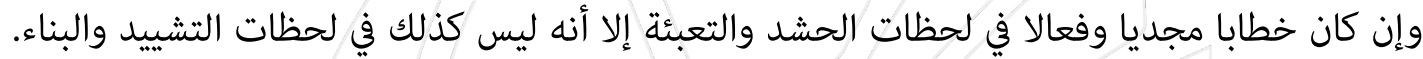

الخطاب السياسي الجهادي محددات التحول

دينامية الخطاب السياسي الجهادي مل تكن نتيجة عوامل ذاتية كامنة في بنية الخطاب واجتهادادات إتهات روادها،

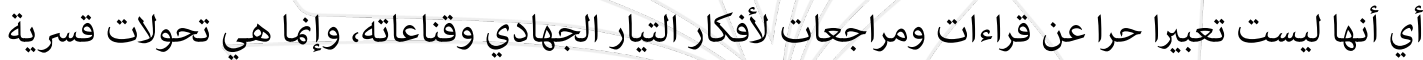

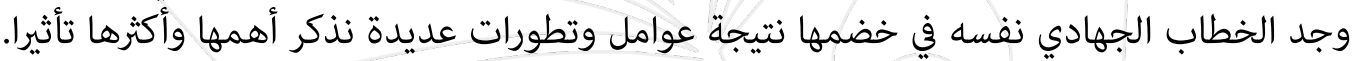

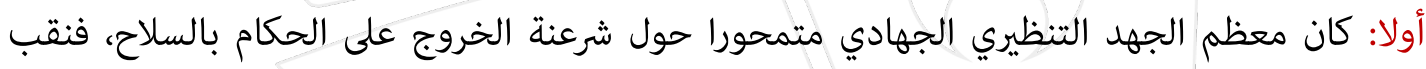

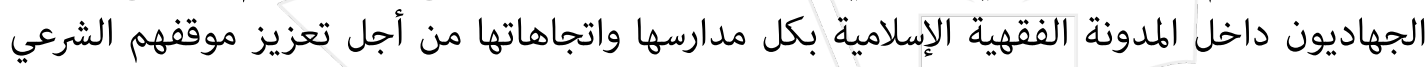

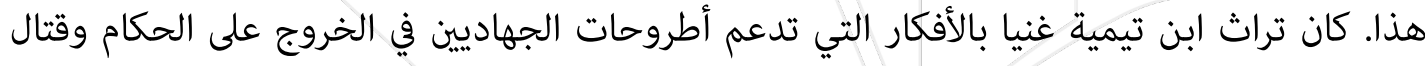

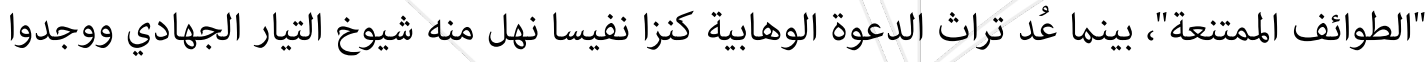

53 يكنن لأي متابع أن يلحظ حضور هذه المفاهيم بكثافة في سلسلة " رسائل الأمل والبشر لأهلنا في مصر" وسلسلة " الربيع الإسلامي"

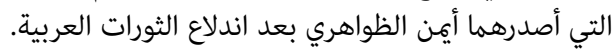

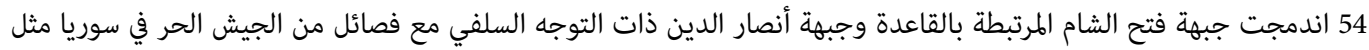

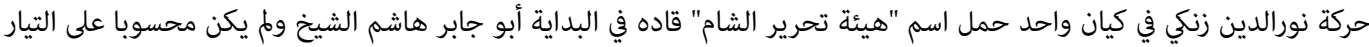

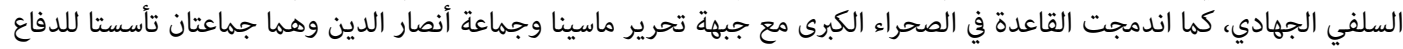

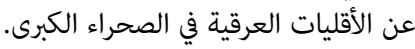


فيه ضالتهم. المقاربة العقدية الصارمة والمنغلقة كانت ضرورية من أجل مواجهة التأصيلات السلفية

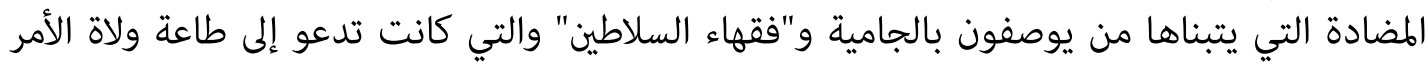

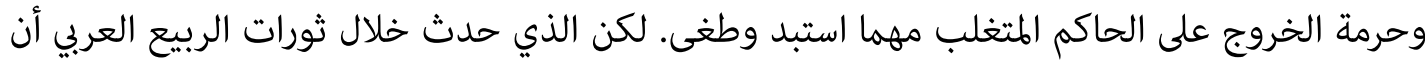

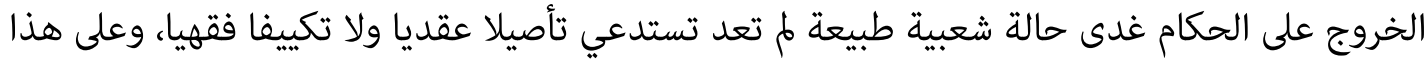

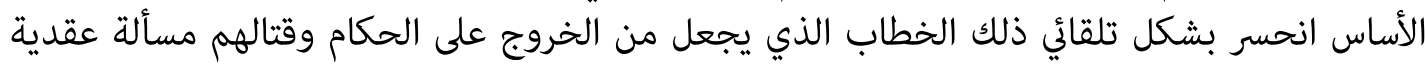

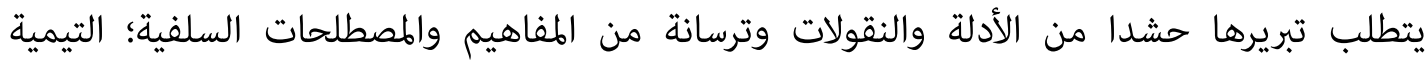

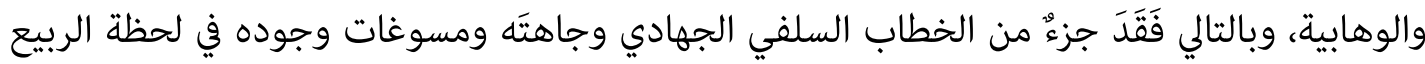

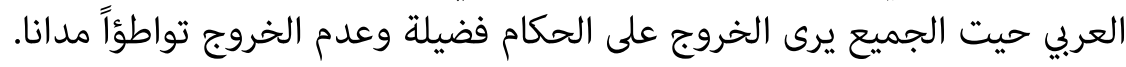

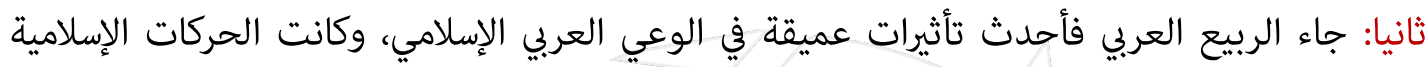

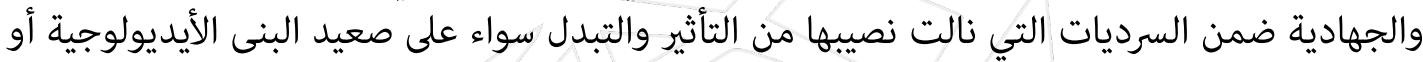

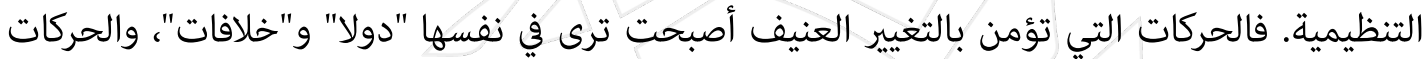

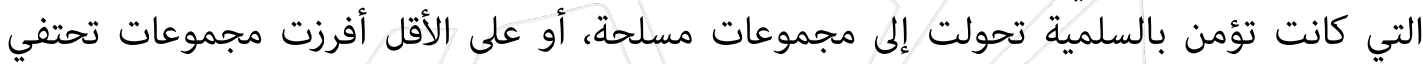
بالعنف والمقاومة المسلحة، وتلاشت الحركات الكبرى لحساب الخلايا والتجمعات الصغيرة الناشئة.

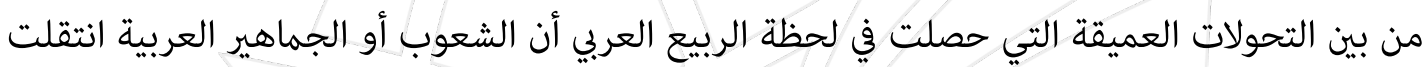

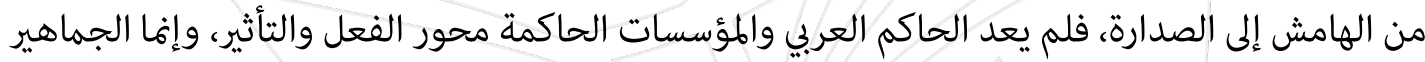

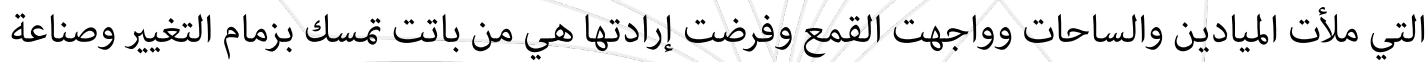

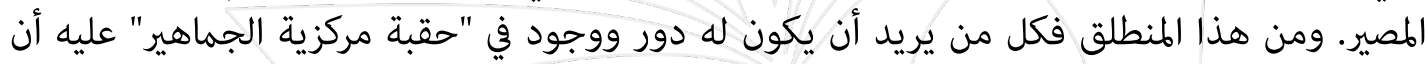

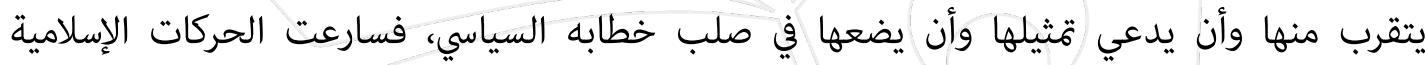

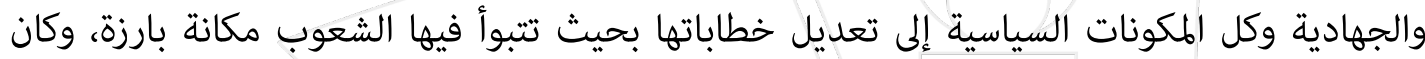

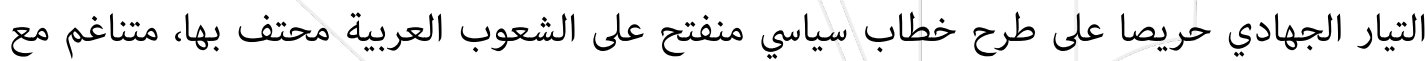

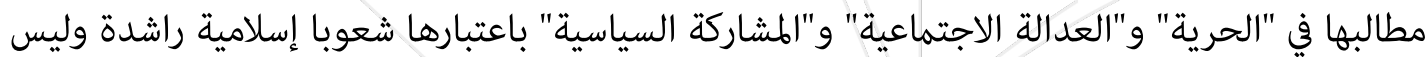
"رعية" أو "عواما" أو "غثناء" كما هو متداول في خطاعلة ولتهابه التقليدي.

ثالثا: كان إعلان أبي بكر البغدادي تأسيس "الدولة الإسلامية في العراق والشام" حدثا فارقا في تاريخ الحركة

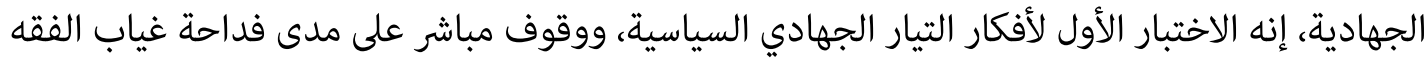

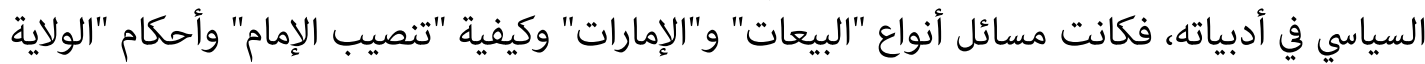

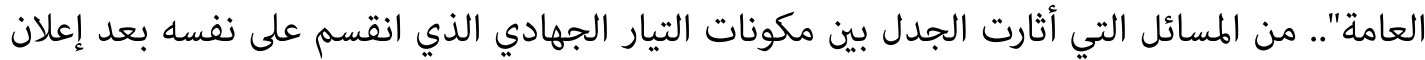

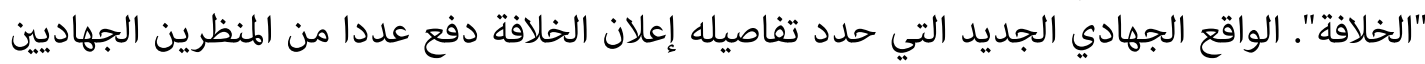

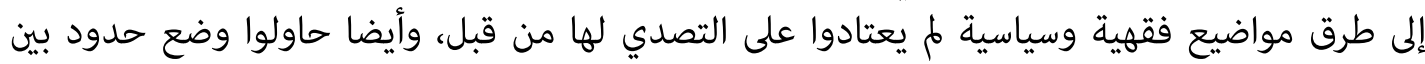

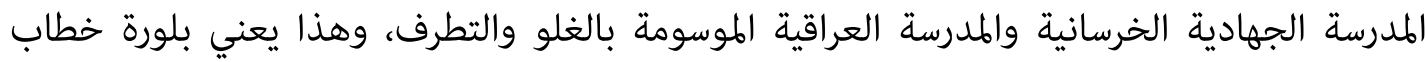




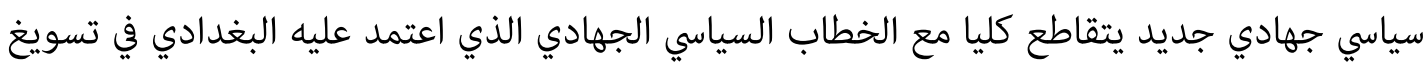
ما ذهب إليه من إعلان "الدولة الإسلامية" ثم "الخلافة"، وهذا ما ما سنبينه لاحقا.

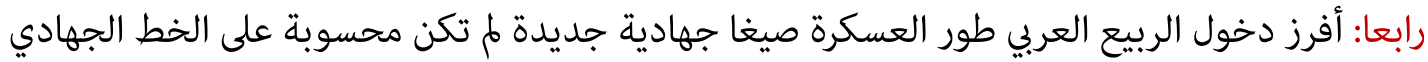

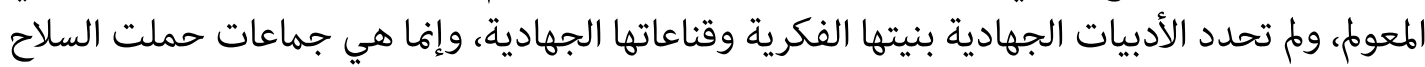

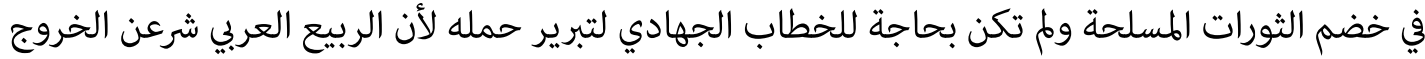

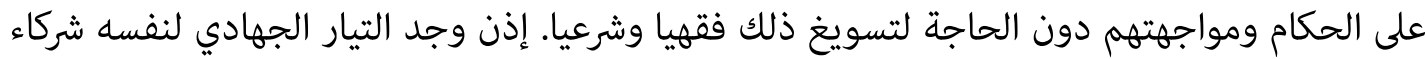

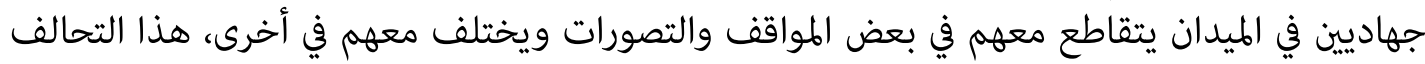

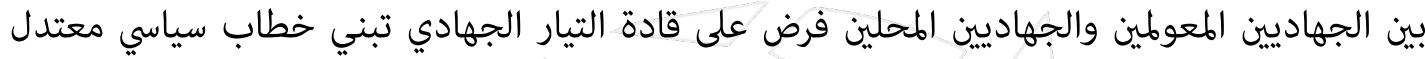

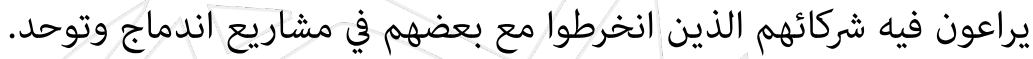

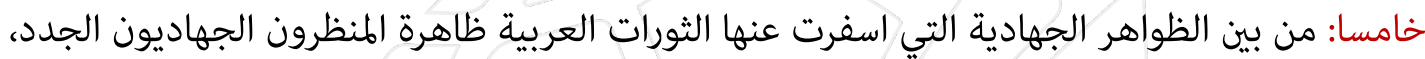

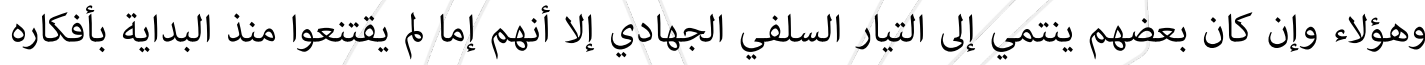

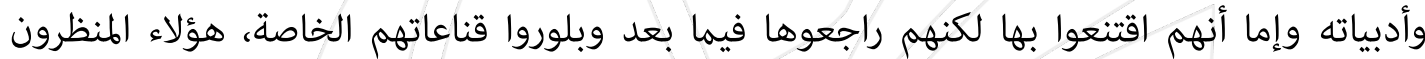

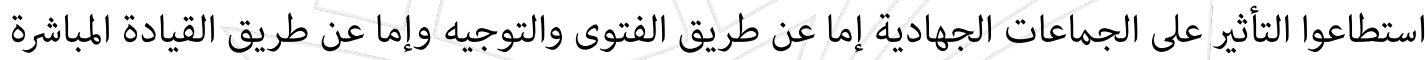

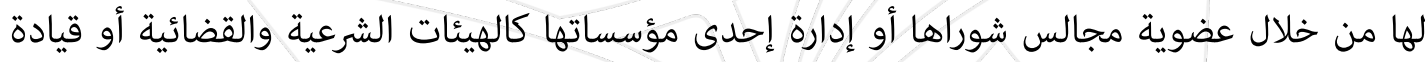

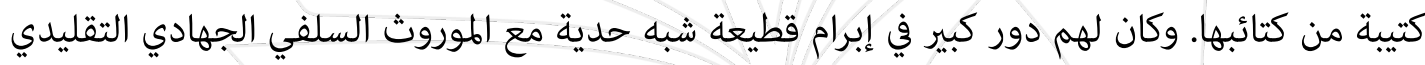

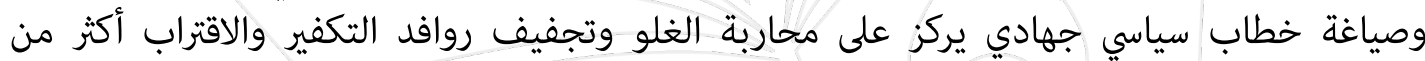

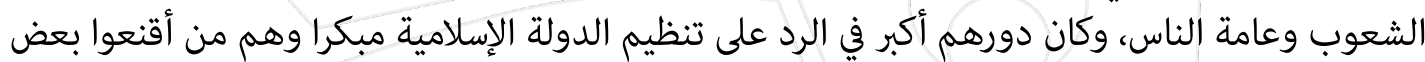

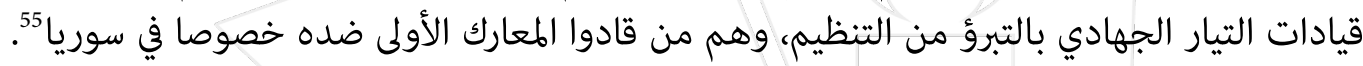

$$
\text { الخطاب السياسي الجهادي.. تجليات التحول }
$$

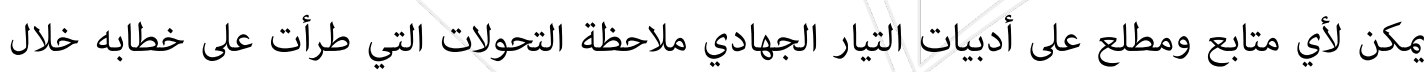

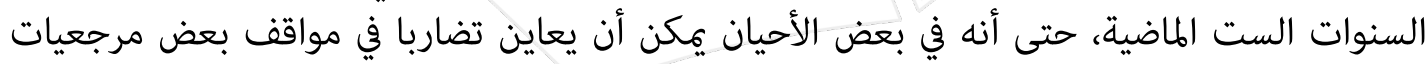

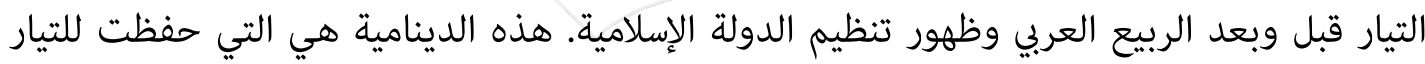

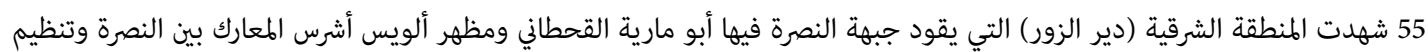

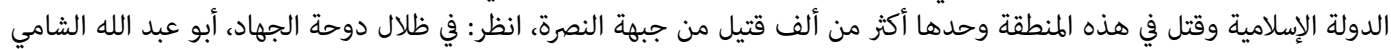

2016 ص: 197 (نسخة إلكترونية) 
تحولات الخطاب السياسي الجهادي

الجهادي وجوده وزخمه في وقت انحسرت فيه الخطابات الإسلامية الأخرى وظل صوت مرجعياته مسموعا ومؤثرا حتى اللحظة. 
الخطاب الجهادي قبل وبعد الربيع العربي: - البي:

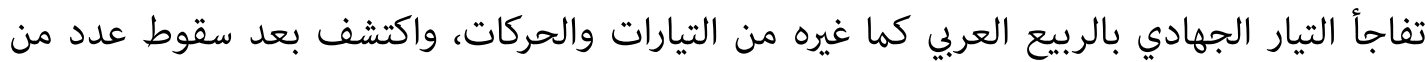

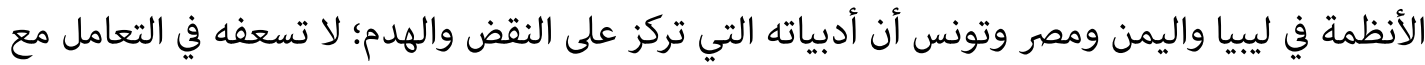

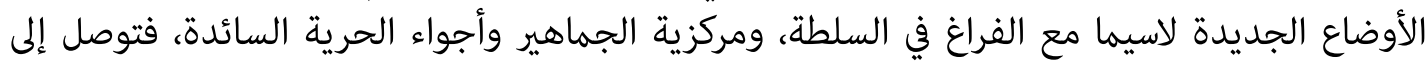

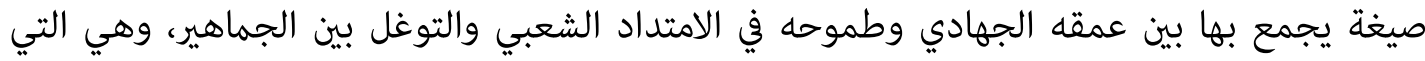

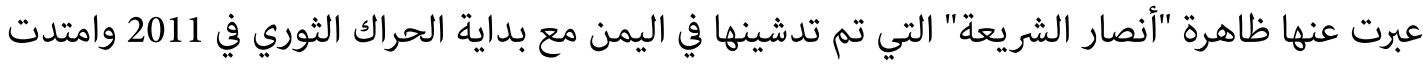

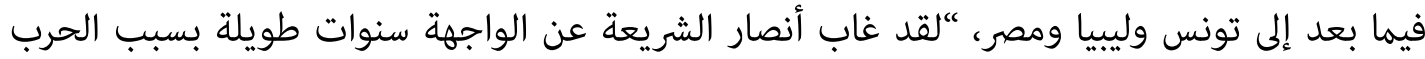

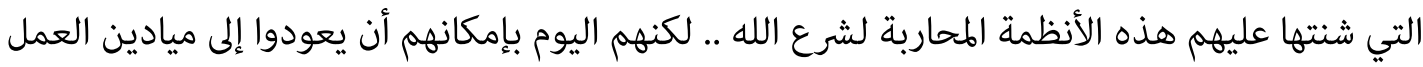

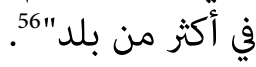

انخرطت جماعات أنصار الشريعة في الأنشطة الدعوية والخدمية والإغاثية في البلدان التي تأسست فيها،

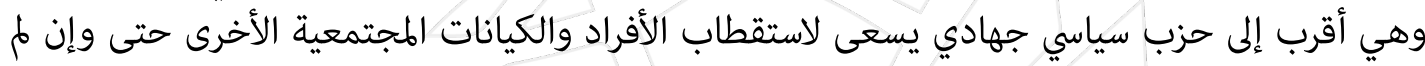
يتقاسم معها نفس القناعات

كان لافتا احتفاء قادة التيار الجهادي في خطاباتهم بالشعوب العربية أثناء الربيع العربي وتثمينهم

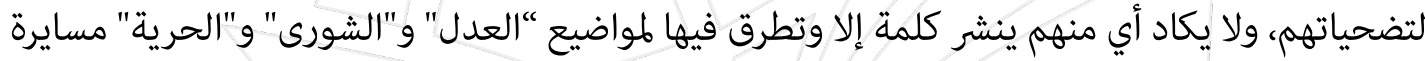

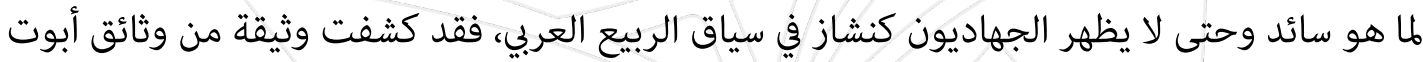

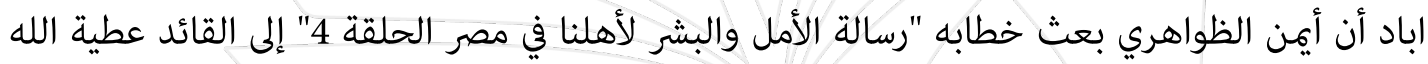

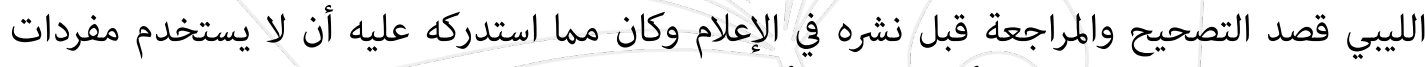

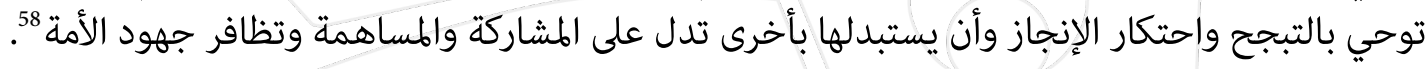

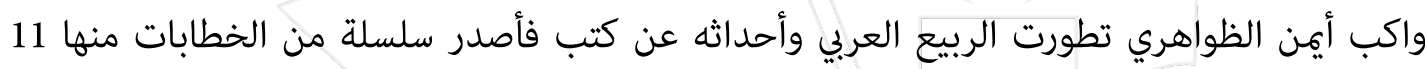

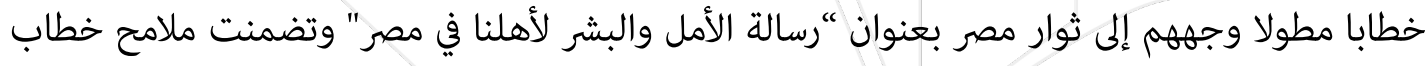

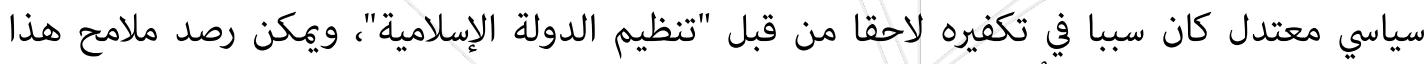

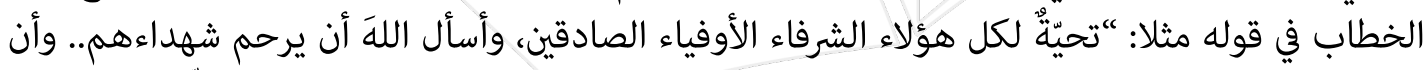

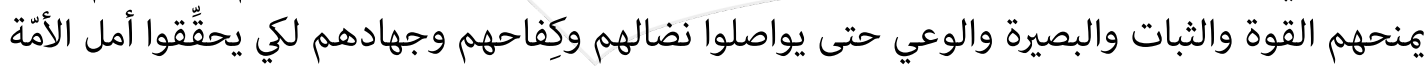

56 أبو المنذر الشنقيطي، نحن أنصار الشريعة ص 6 (نسخة إلكترونية) 57 بي بي سي عربي، من هم أنصار الشريعة في اليمن؟، 2012/3/7 الرابط

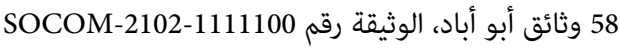




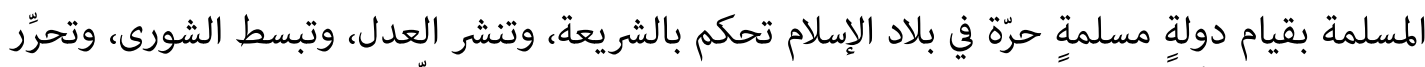

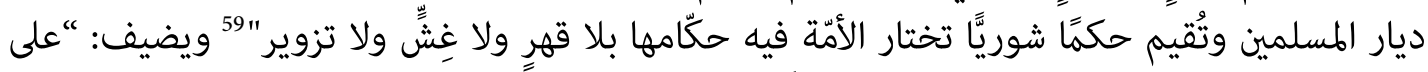

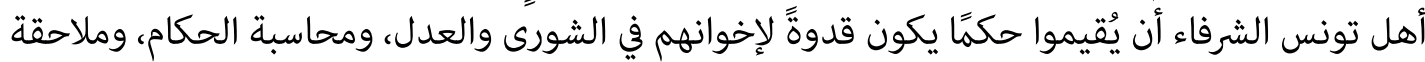

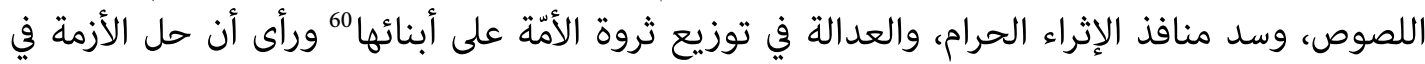

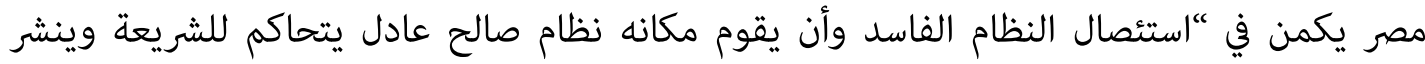

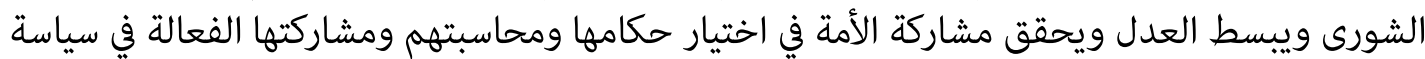

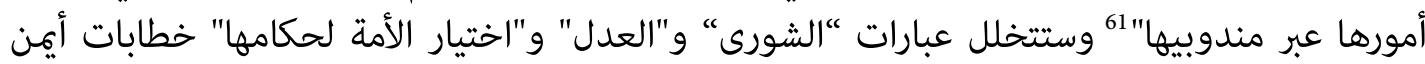

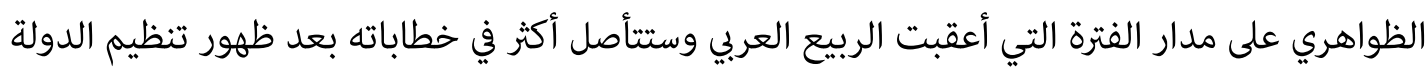
الإسلامية كما سنرى.

في الحلقة الخامسة من "رسالة الأمل والبشر لأهلنا في مصر" حث أيمن الظواهري من وصفهم بالشعبين

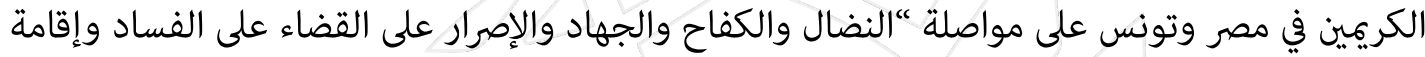

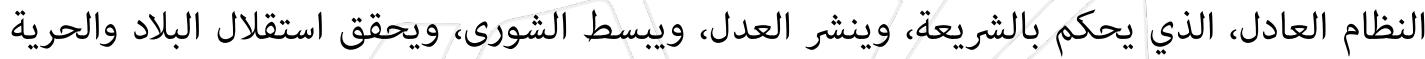

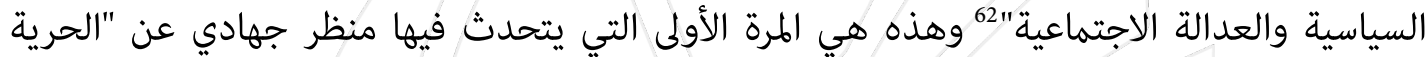

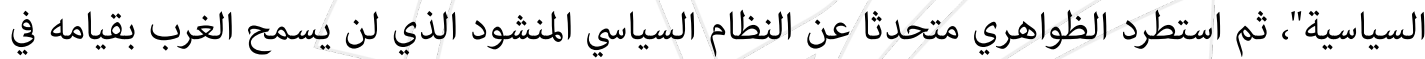

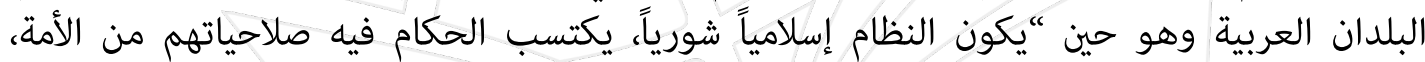
ويحاسبون أمامها، ويرفض وهو احتلال ديار المسلمين وسرقة ثرواتهم"

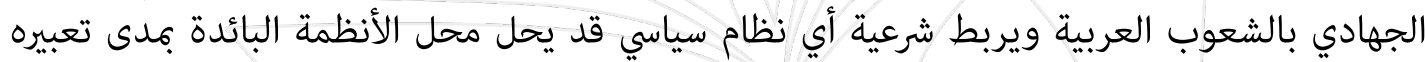
عن إرادتها ونيله لرضاها، وهذا التوجه لم يكن حاضرا من قبل فيل في أدبيات التيار الجهادي. وفي خضم معركة الدستور في مصر والجدل حول المادة الثانية أكد الظواهري على ضرورة التعائ الإصلاح القضائي

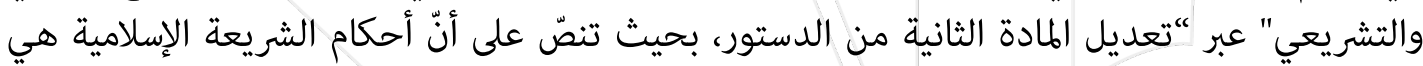

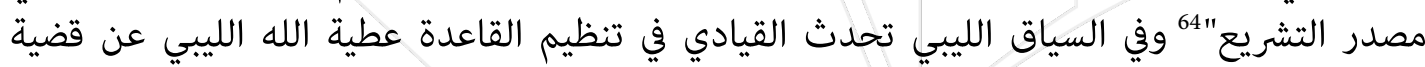

59 أيمن الظواهري، رسالة الأمل والبشر لأهلنا في مصر الحلقة الثالثة، 2011/2/28 الرابط 60

61 أيمن الظواهري، رسالة الأمل والبشر لأهلنا في مصر الحلقة الرابعة، 2011/3/4 الرابط 62 أيمن الظواهري، رسالة الأمل والبشر لأهلنا في مصر الحلقة الخامسة، 2011/4/16 الرابط 63 64 أيمن الظواهري، رسالة الأمل والبشر لأهلنا في مصر الحلقة السادسة، 2011/5/15 الرابط 


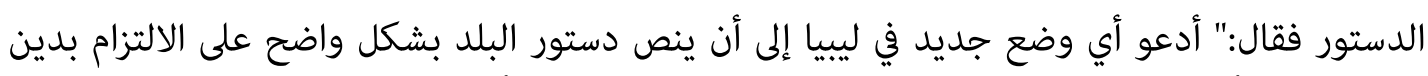

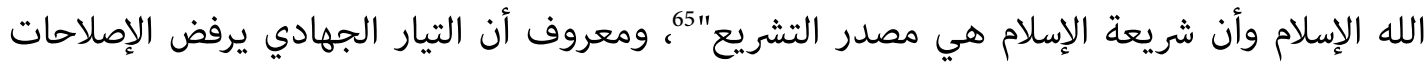

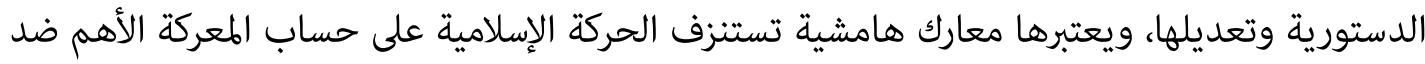

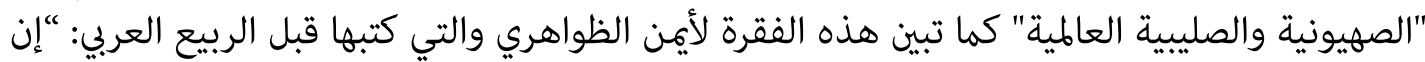

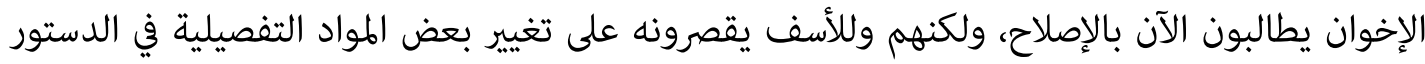

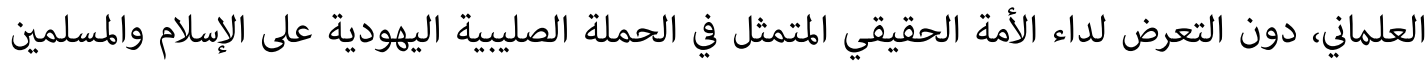

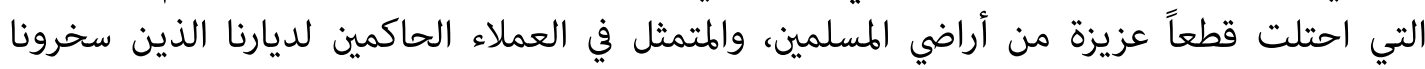
ومقدساتنا وثرواتنا لخدمة الصليبيين واليهود"

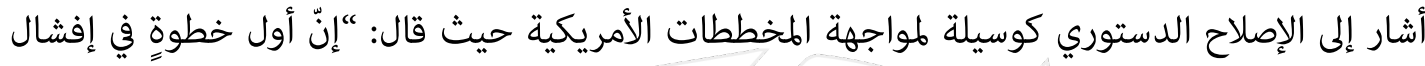

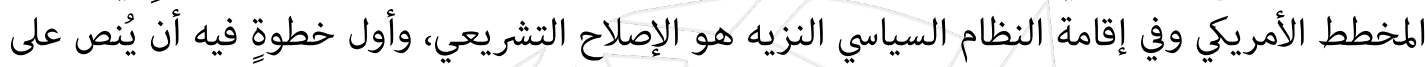
أن تكون الشريعة هي مصدر التشريع ويبطل كل ما يخالفها من مواد الدستور والقانون"

إذن، طرأت تحولات في الخطاب السياسي الجهادي وساهم الربيع العربي في بلورة بعضا من ملامحها،

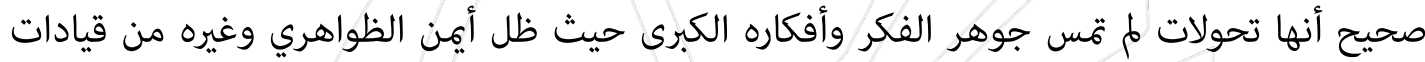

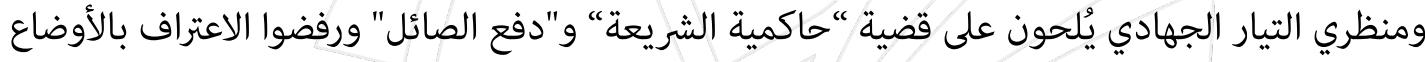

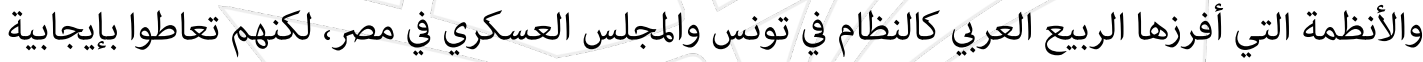
مع نظام محمد مرسي، وحكومة الإنقاذ الليبية. الخطاب السياسي الجهادي قبل وبعد تنظيم الدولة الإسلامية

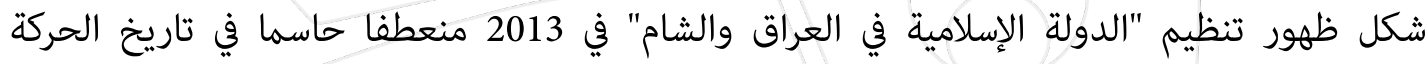

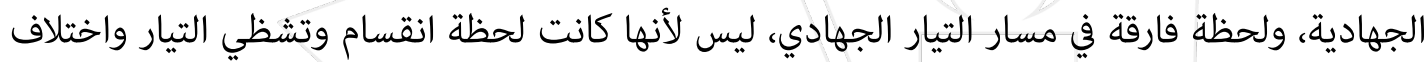

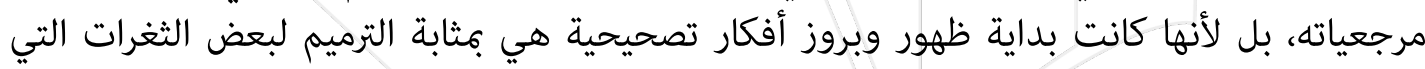

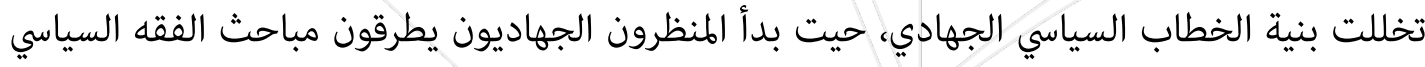
ويؤصلون لففاهيم لم تكن من قبل تثير الهتمامهم.

65 عطية الله الليبي، تحية لأهلنا في ليبيا، 2011/2/15 الرابط 66 أيمن الظواهري، الحصاد المر، الطبعة الثانية ص20 (نسخة إلكترونية)

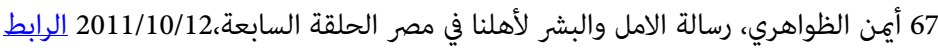




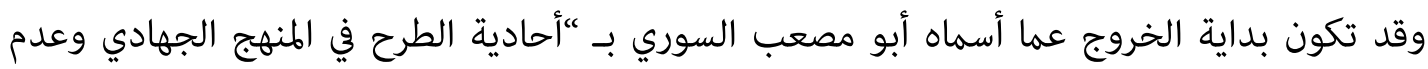

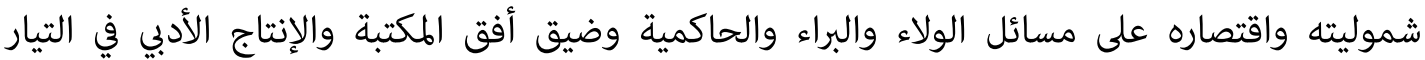

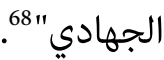

في سياق رفض مرجعيات التيار الجهادي لنمط الحكم و“"الخلافة، التي أعلنها البغدادي وردهم عليها

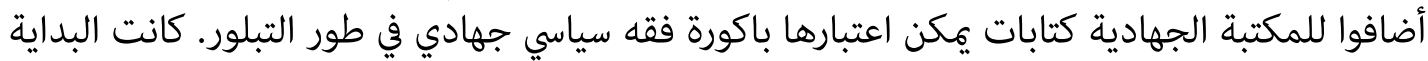

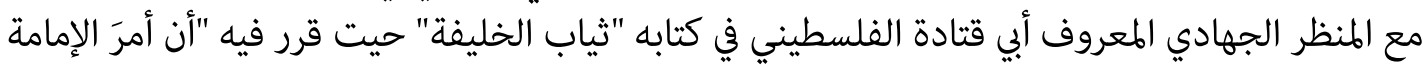

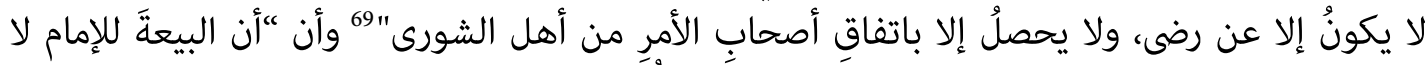

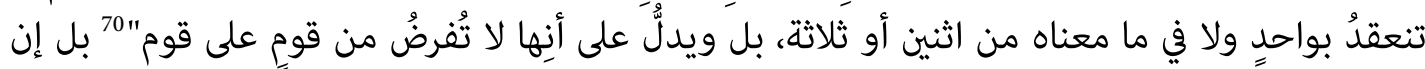

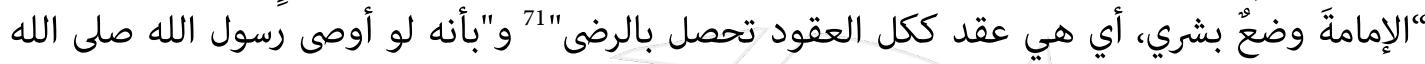

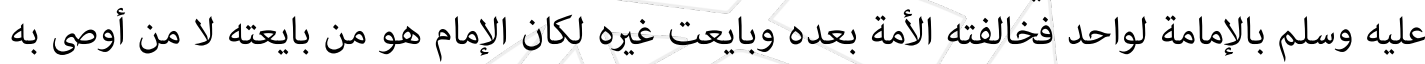

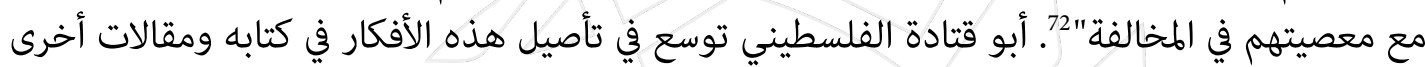

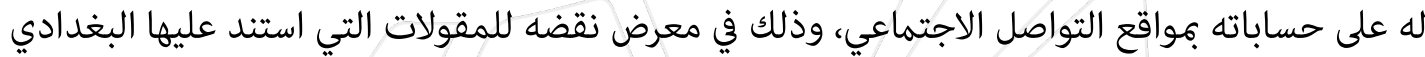

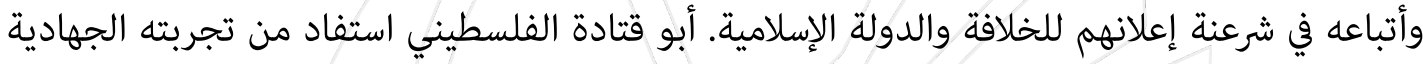

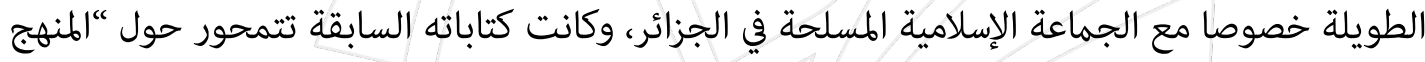

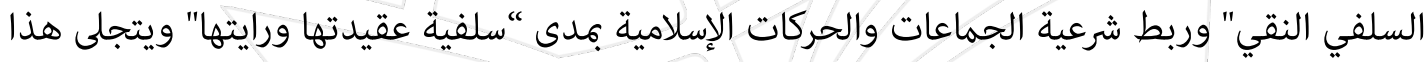

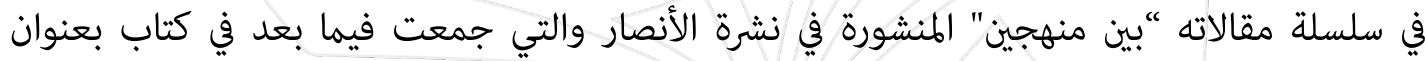

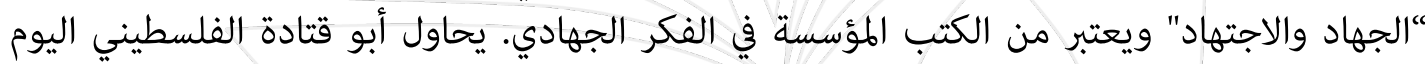

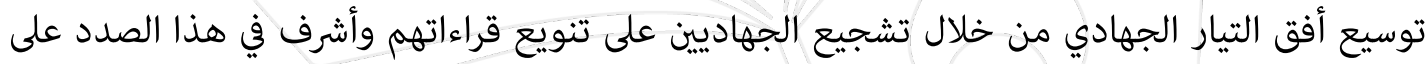

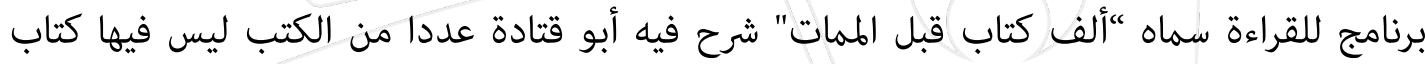

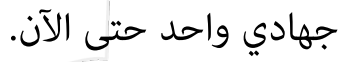

68 أبو مصعب السوري، دعوة المقاومة الإسلامية العالمية ص 846 (نسخة إلكترونية) 69 أبو قتادة الفلسطيني، ثياب الخليفة، ص23 (نسخة إلكترونية) 


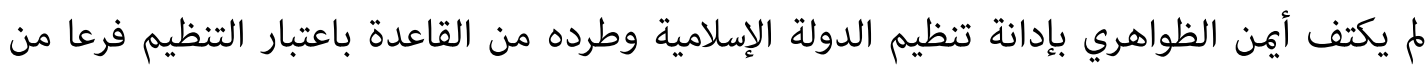

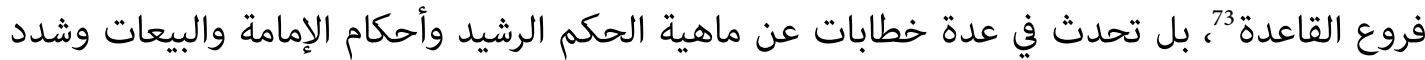

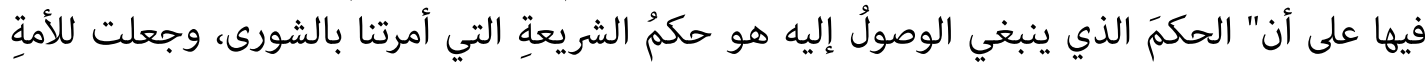

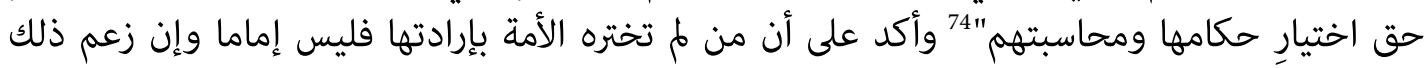

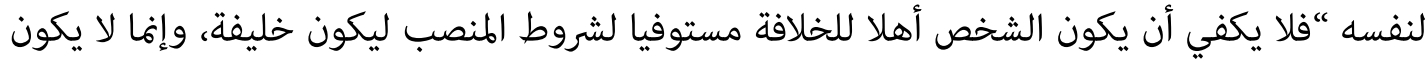
كذلك إلا باختيار المسلمين"

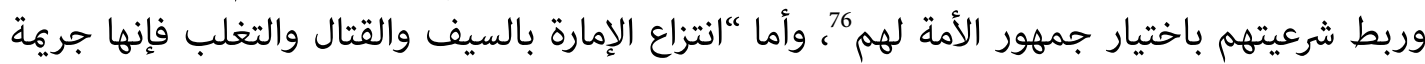

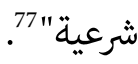

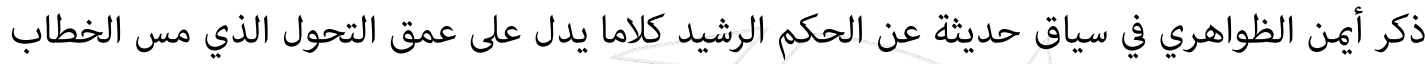

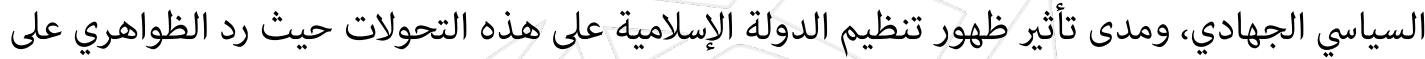

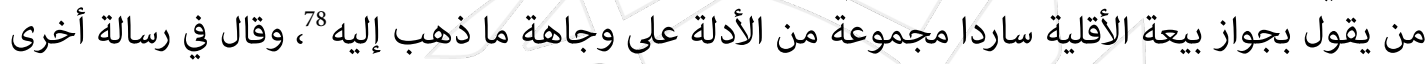

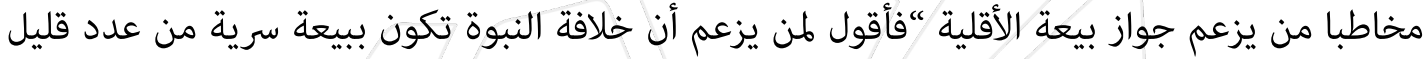

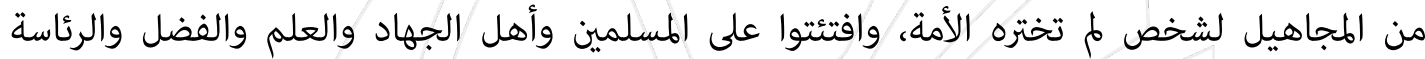

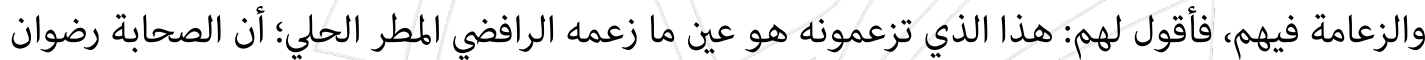

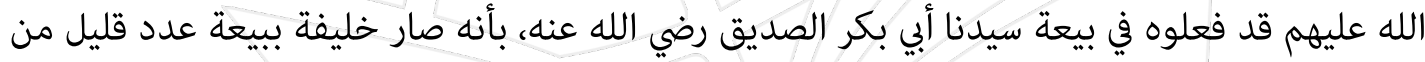

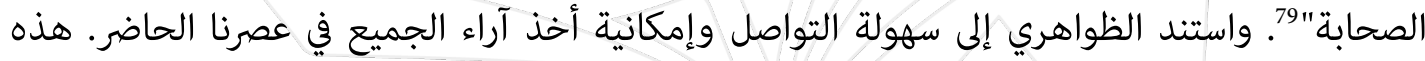

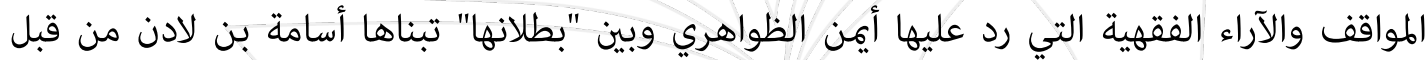

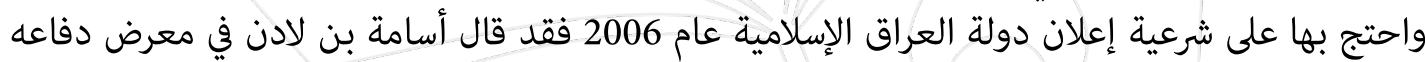

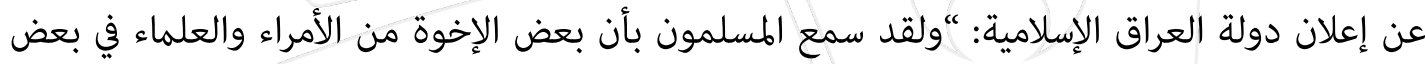

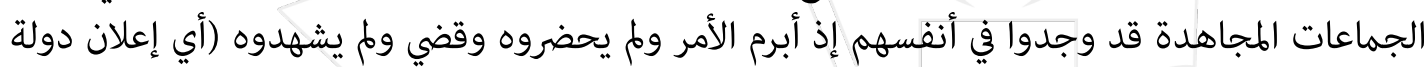

73 بيان جماعة قاعدة الجهاد بشأن العلاقة مع تنظيم الدولة الإسلامية في العراق والشام، 2014/2/3 الرابط

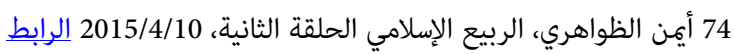

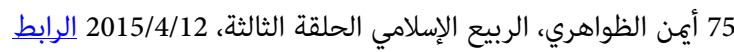
76 المصدر السابق 77 أين الظواهري، الربيع الإسلامي الحلقة الرابعة، 2015/10/6 الرابط 78 المصدر السابق 79 أيمن الظواهري، الربيع الإسلامي الحلقة الثالثة، 2015/4/12 الرابط 


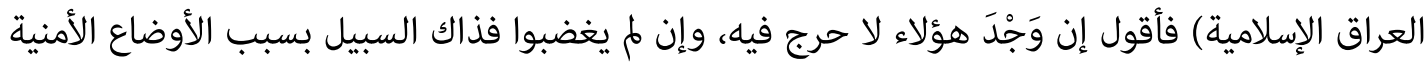

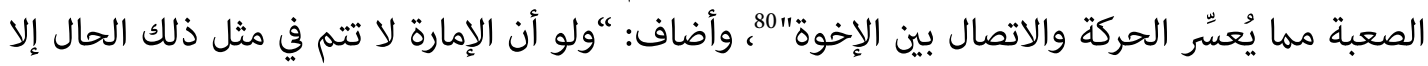

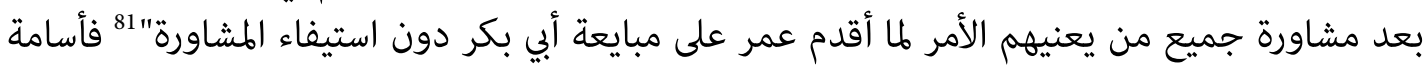

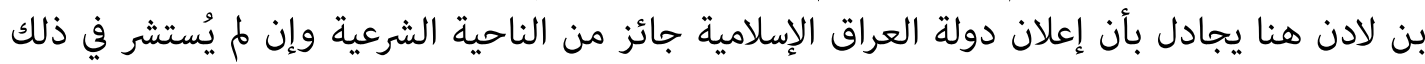

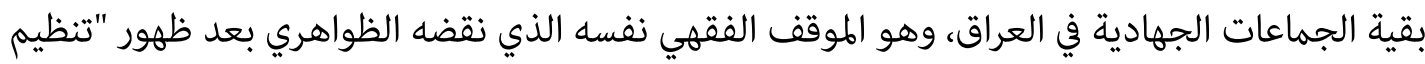

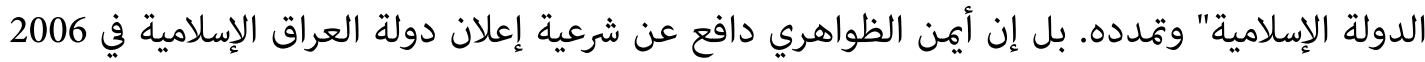

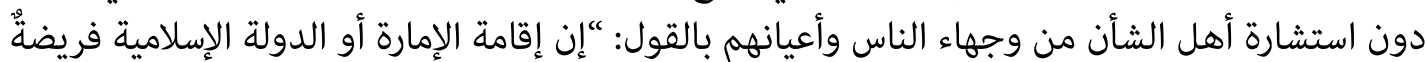

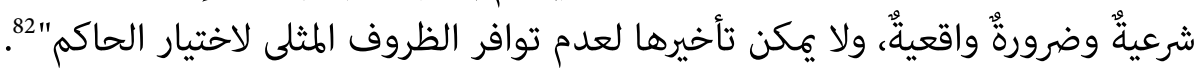

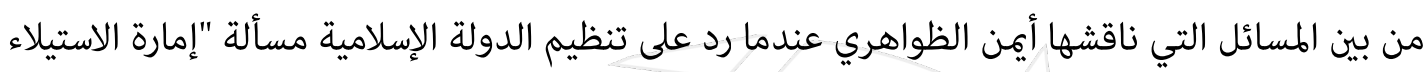

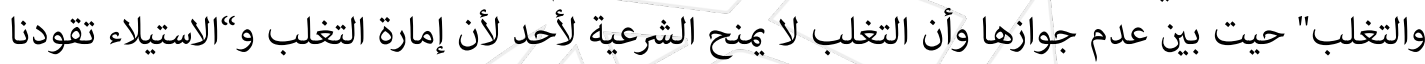

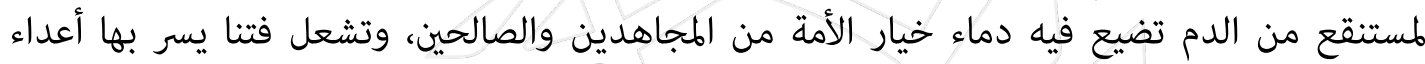

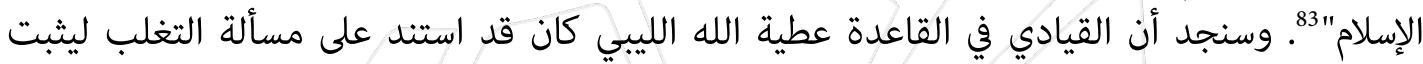

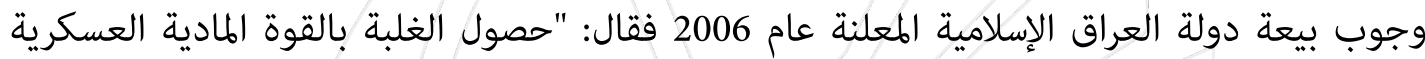

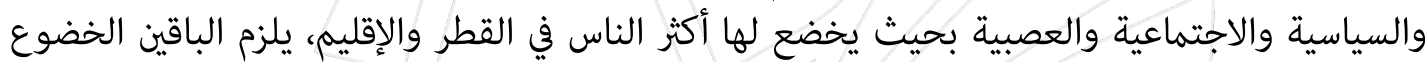

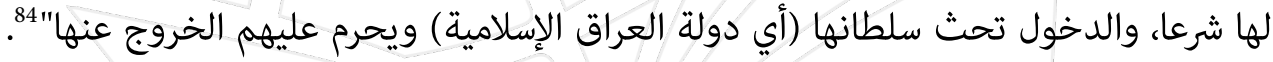
إذن، يبدو واضحا كيف أثر ظهور تنظيم الدولة الإسلامية (داعش) في بنية الفكر الجهادي، ودفع إدادئ

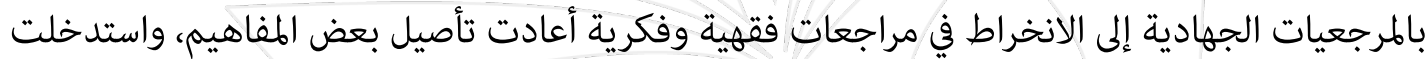

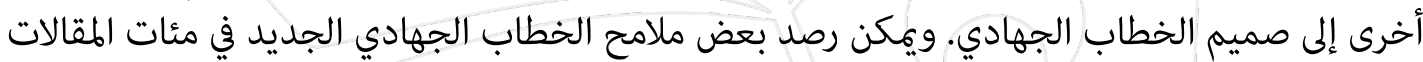
والكتب والنشرات والإصدارات التي كتبها الجهاديون ردا على تنظيم الدولة الإسلامية. دور الشركاء الجهاديين في تحولات الخطاب الجهادي

80 أسامة بن لادن، السبيل لإحباط المؤامرات، 2007/12/20 الرابط 81 المصدر نفسه

82 مؤسسة السحاب، اللقاء المفتوح مع أيمن الظواهري، 2008/4/4 الرابط 83 أيمن الظواهري، الربيع الإسلامي، الحلقة الرابعة، 2015/10/6 الرابط 84 عطية الله الليبي، كلمات في نصرة دولة العراق الإسلامية، الأعمال الكاملة، جمع وترتيب الزبير الغزي، ص515 (نسخة إلكترونية) 
عندما أعلن أبو بكر البغدادي عن دمج جبهة النصرة مع دولة العراق الإسلامية وتأسيس “بالدولة الإسلامية

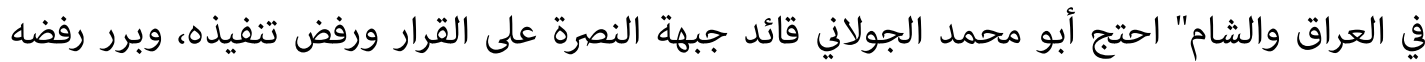

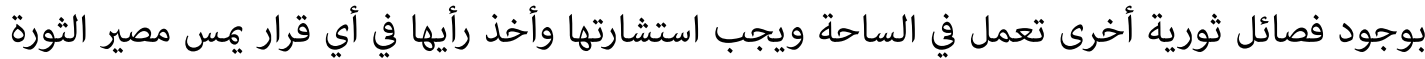

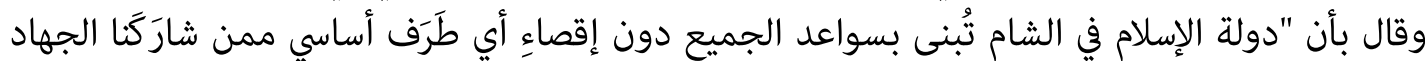

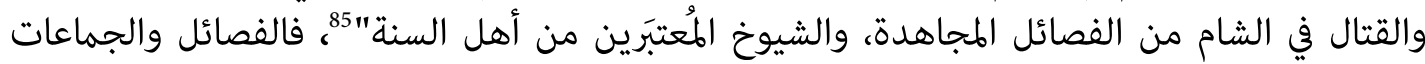

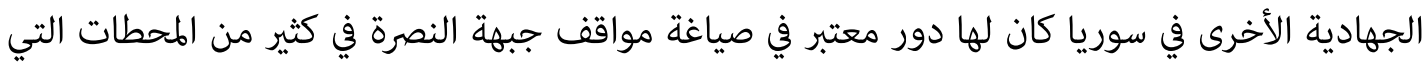

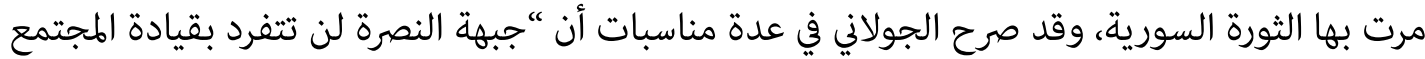

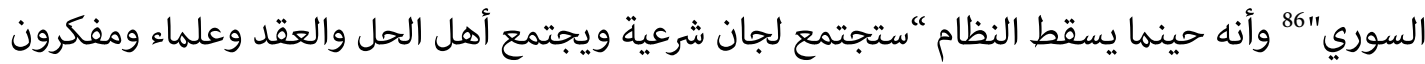

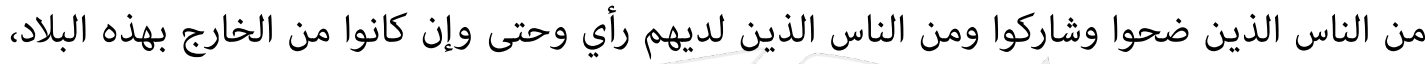

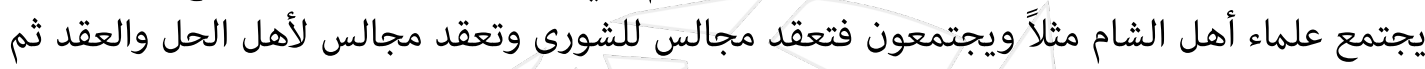
توضع خطة مناسبة لإدارة هذا البلد"

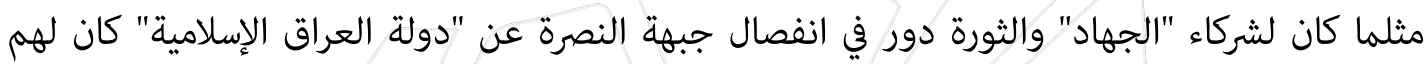

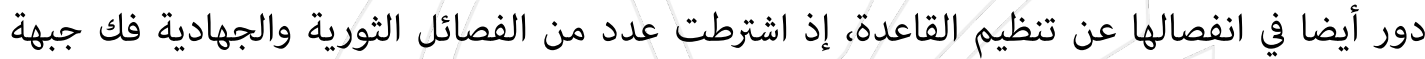

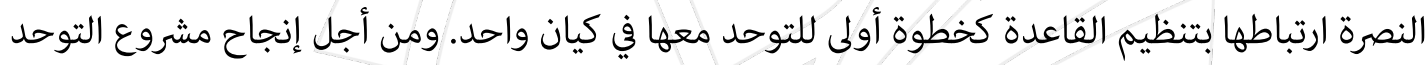

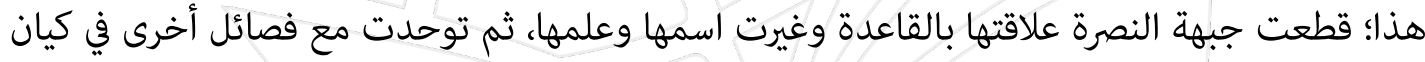

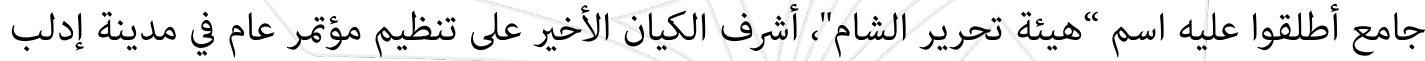

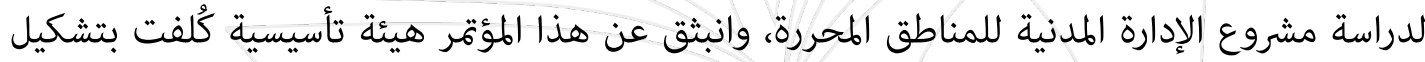

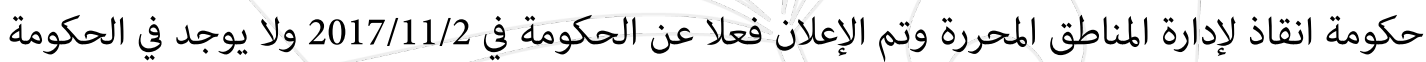

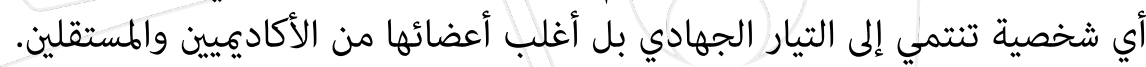

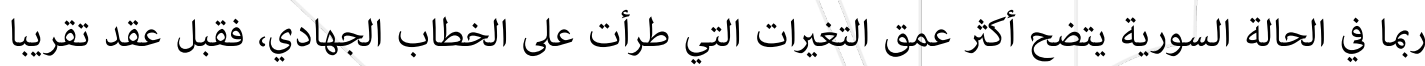

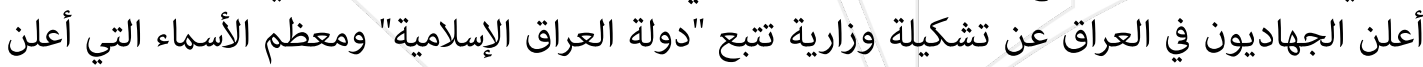

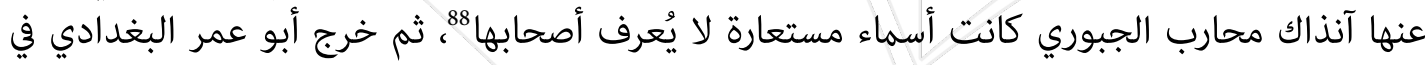

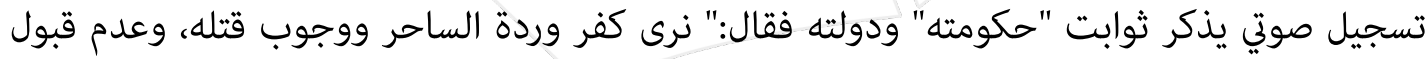

85 أبو محمد الجولاني، حول ساحة الشام، 2013/4/10 الرابط 86 قناة الجزيرة، لقاء مع أبي محمد الجولاني، 2013/12/19 الرابط 87 
توبته في أحكام الدنيا بعد القدرة عليه.. ونرى تحريم كل ما يدعو إلى الفاحشة ويدعو عليها كجهاز

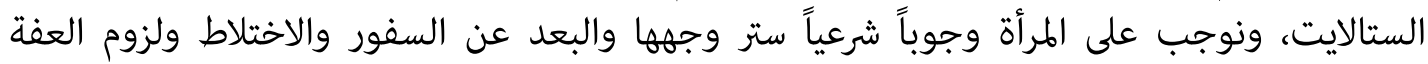

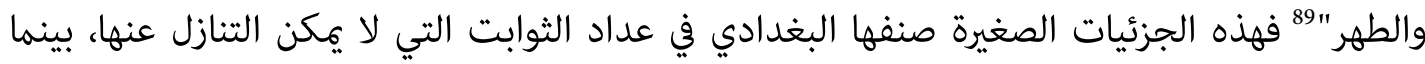

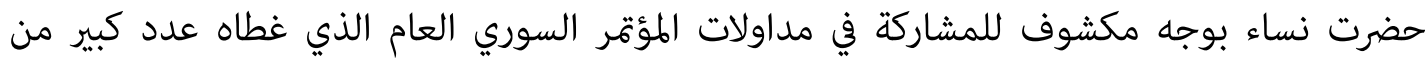

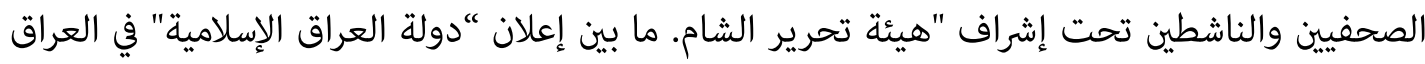

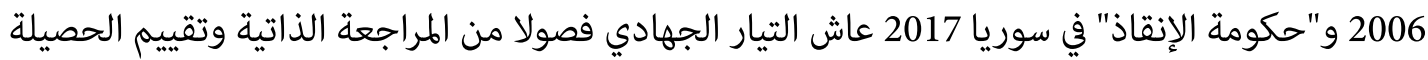

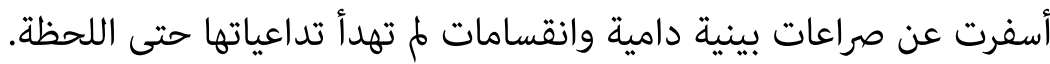

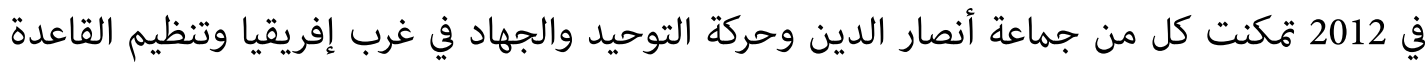

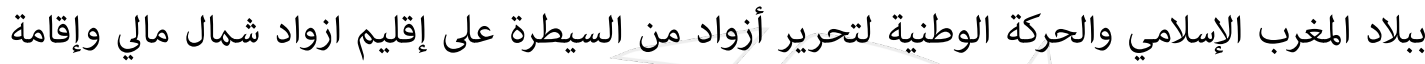

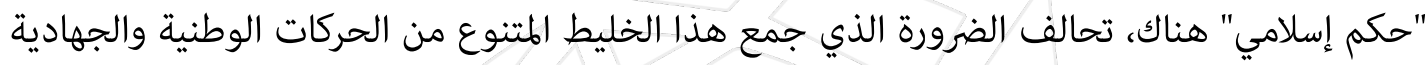

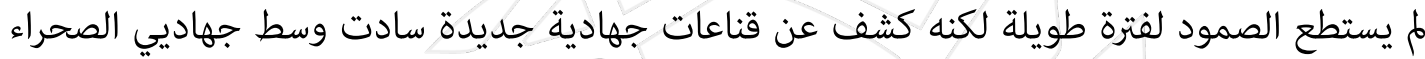

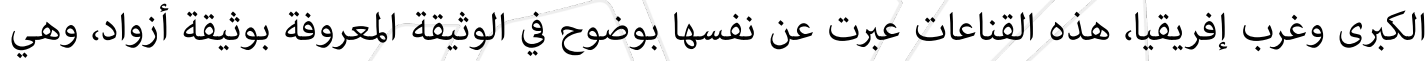

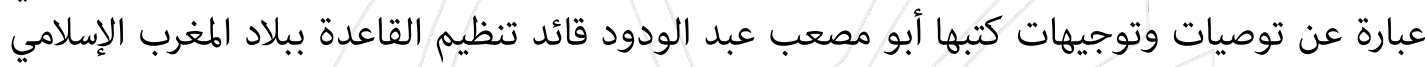

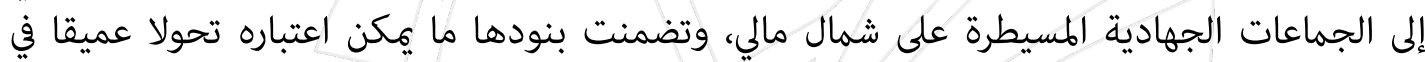

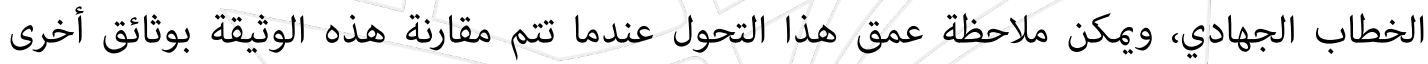
أصدرها تنظيم القاعدة ببلاد المغرب الإسلامي قبل ملادئ سنوات.

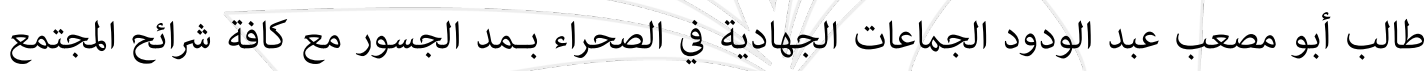

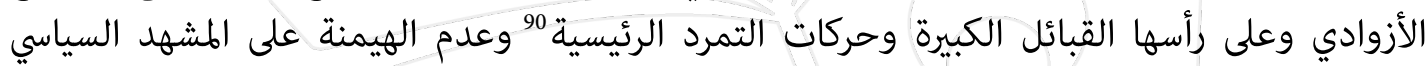

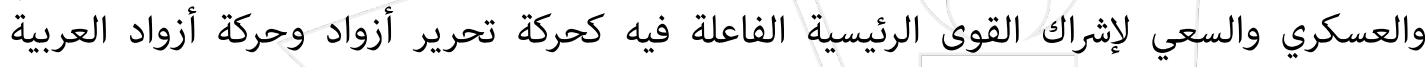

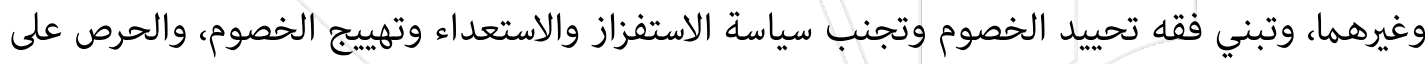

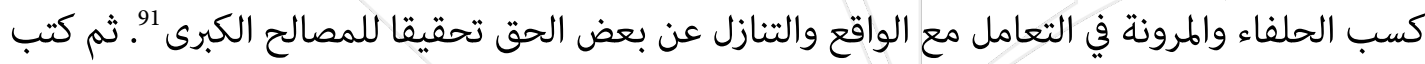

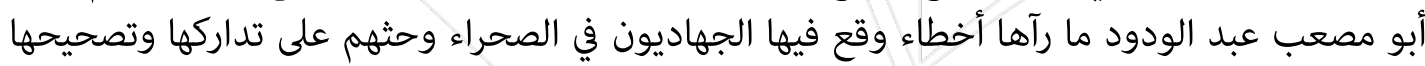

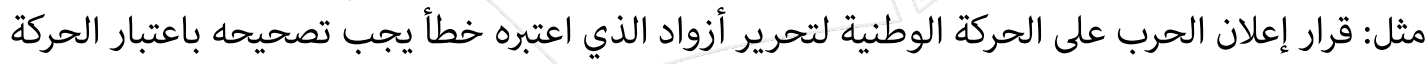

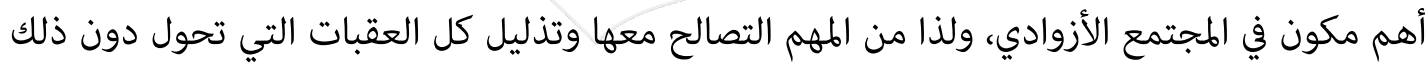

89 أبو عمر البغدادي، قل إني على بينة من ربي، 2007/3/13 الرابط

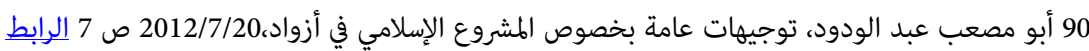
91 
"توحيدا للصف الأزوادي الداخلي"92، وأكد عبد الودود ضرورة التدرج في تطبيق الشريعة 93 ومراعاة

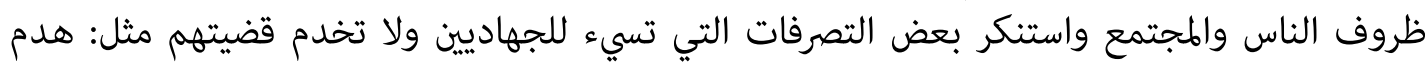

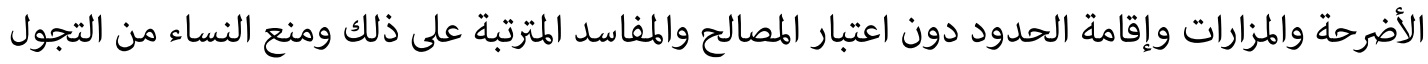

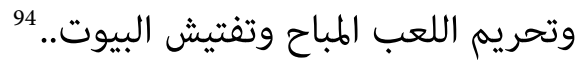

وردت فقرة في وثيقة أزواد المشار إليها تعكس بوضوح تأثير الشركاء الجهاديين في الخطاب السياسي

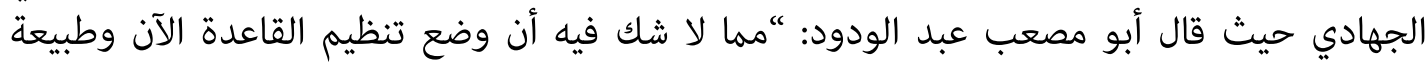

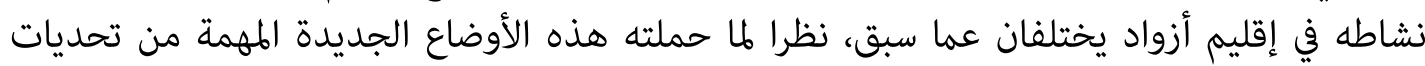

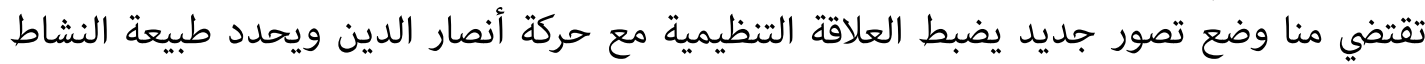

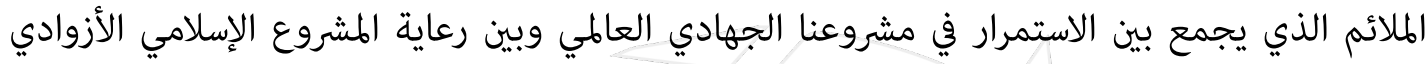

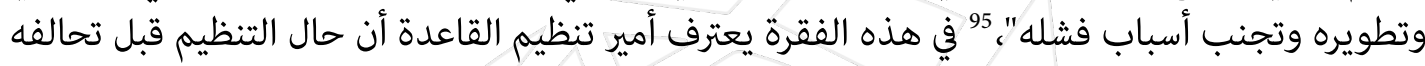

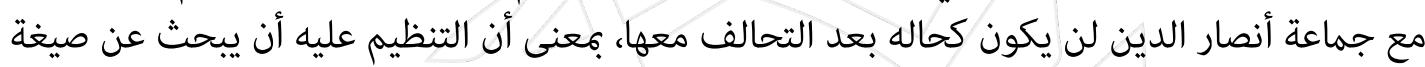

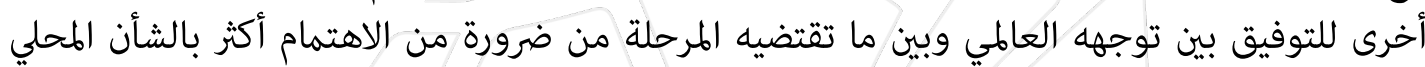

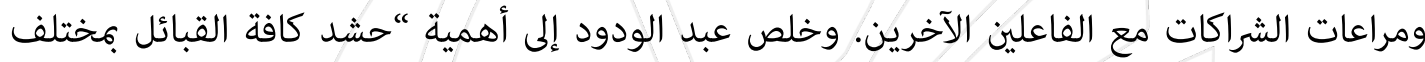

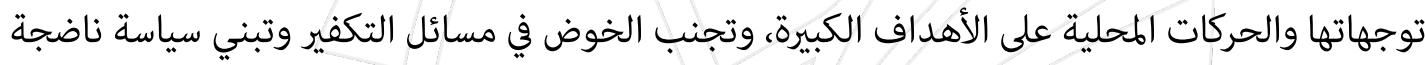

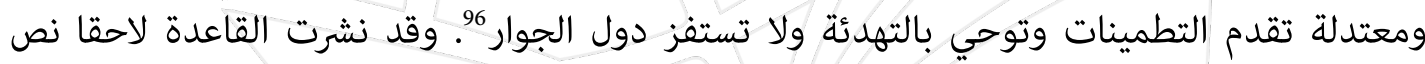

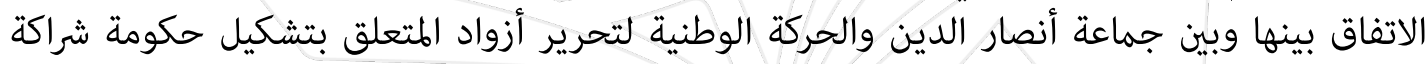
فيما بينهم تحدث القيادي في القاعدة (منطقة الصحراء الكبرى) عبد العزيز حبيب في حوار مطول عن الخطوط التها التها

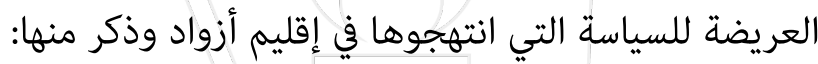

92 93 يتحفظ التيار الجهادي على مسألة التدرج في تطبيق الشريعة، أنظر مثلا: أيهن الظواهري، الحصاد المر، الطبعة الثانية ص61 (نسخة الكترونية)

94

95

96 المصدر السابق ص 13

97 مؤسسة الأندلس، رسالة وتوضيح من مؤسسة الأندلس للإنتاج الإعلامي، 2012/5/26 الرابط 
العتماد المذهب المالكي المدلل، ويقصد به عبد العزيز حبيب مواقف فقهاء المالكية المسنودة بالأدلة

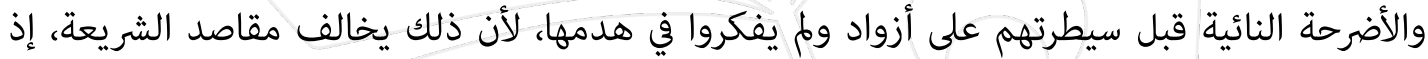

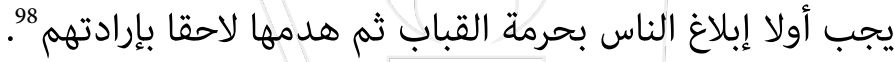

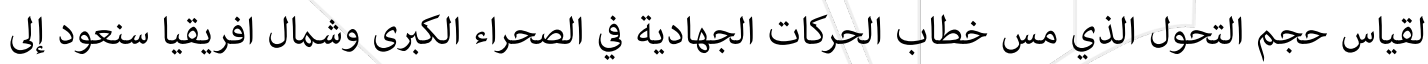

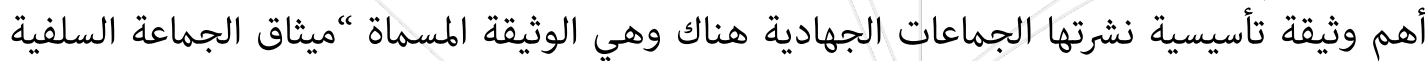

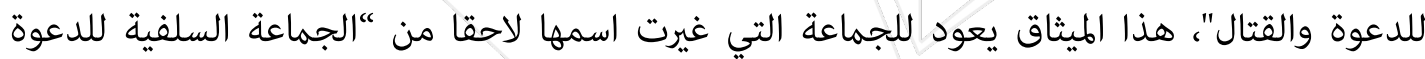

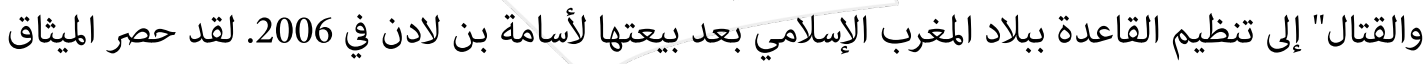

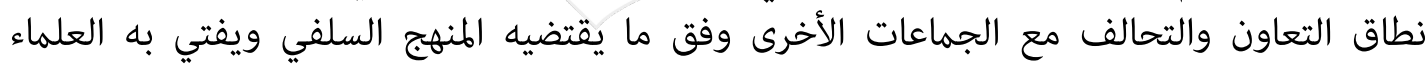

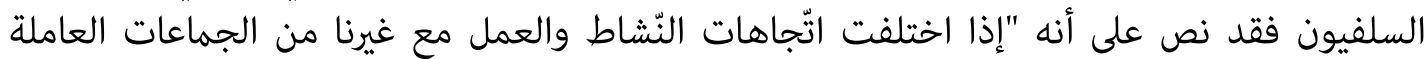

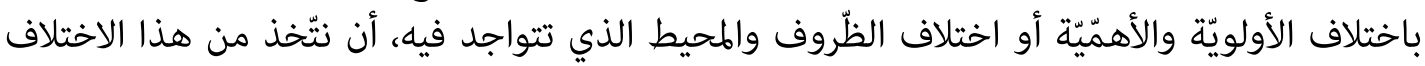


وسيلة تكامل وقوّة، بدل أن يكون سبب تطاحن وضعف، ما دام ذلك وفقا لمنهج السّلف، وفي إطار

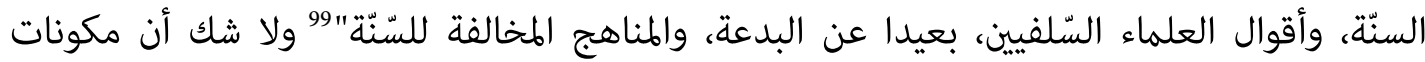

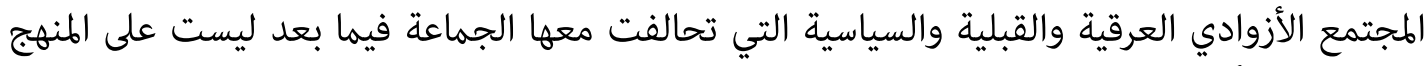
السلفي، كما أن الحركات التي دخلت معها في مشروع حكومة مؤقتة لا تدين كلها بالعقيدة السلفية العية العية.

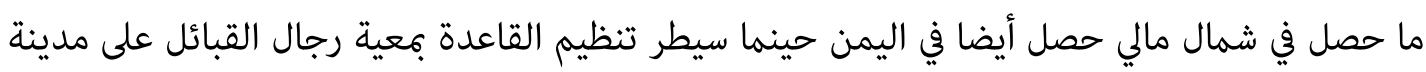

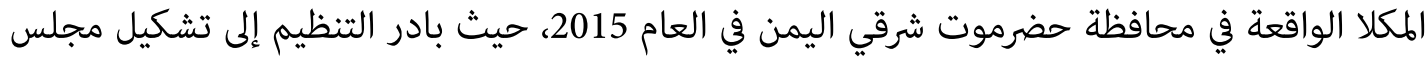

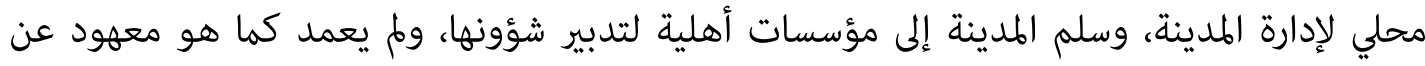

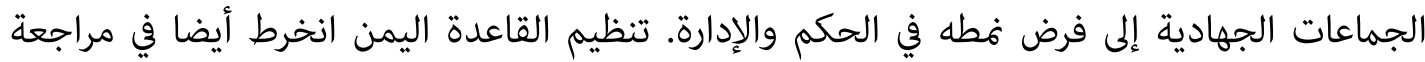

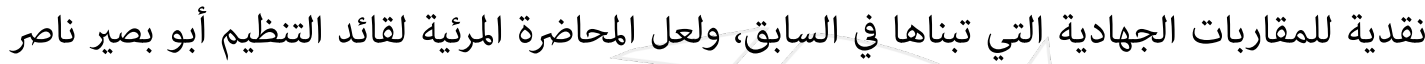

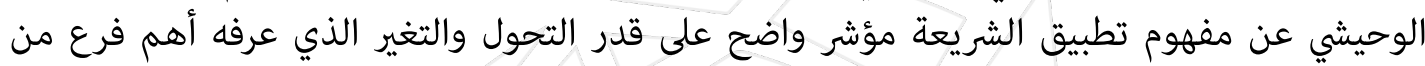

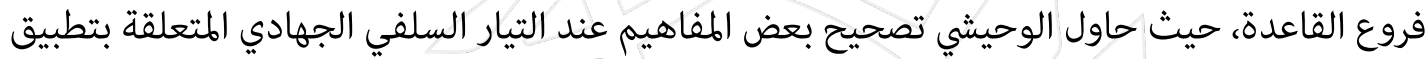

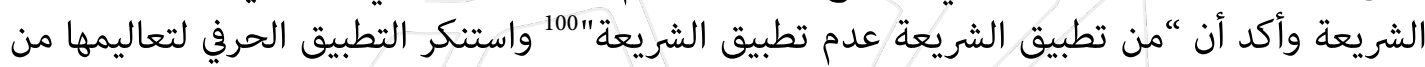

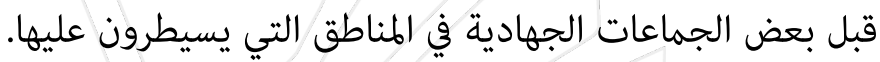

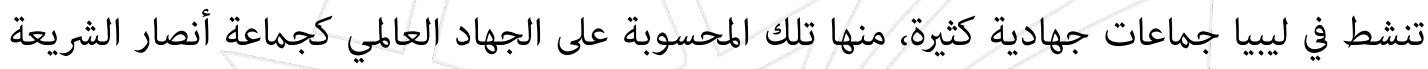

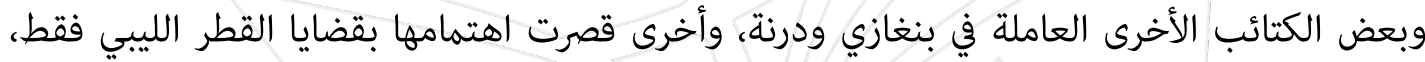

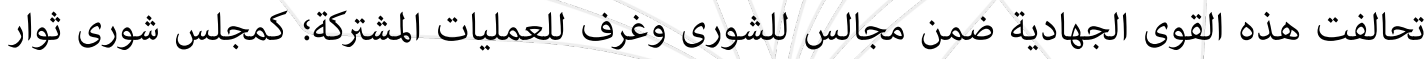

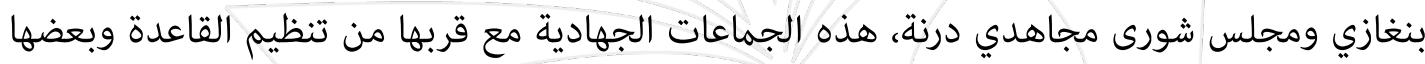

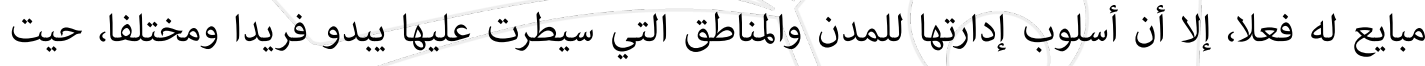

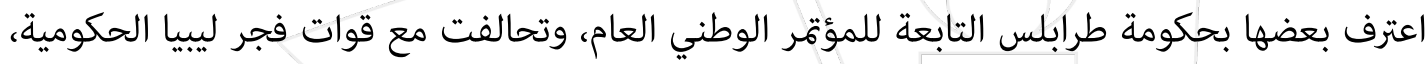

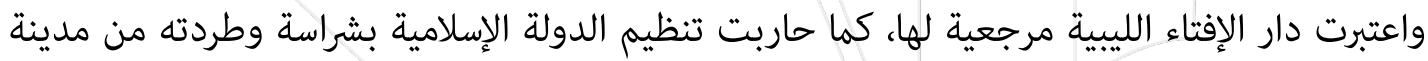
درنة وبعض المناطق الليبية الأخرى.

ا - المنظرون الجدد ودورهم في تحولات الخطاب الجهادي

99 ميثاق الجماعة السلفية للدعوة والقتال، (بدون تاريخ) ص12 الرابط 100 أبو بصير ناصر الوحيشي، مفهوم تطبيق الشريعة، 2015/7/22 الرابط 
عند مقاربتنا للظاهرة الجهادية وما يعتريها من تحولات لابد أن نشير إلى عامل مهم كان له دور محوري

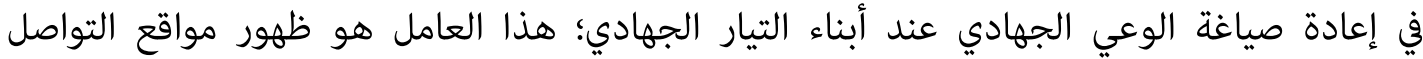

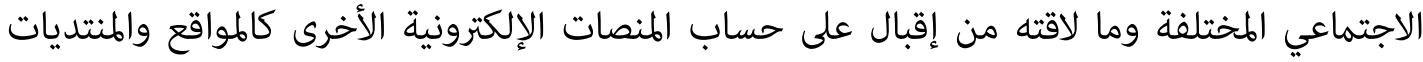

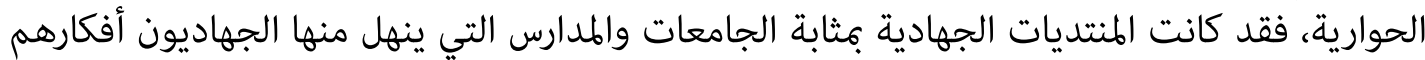

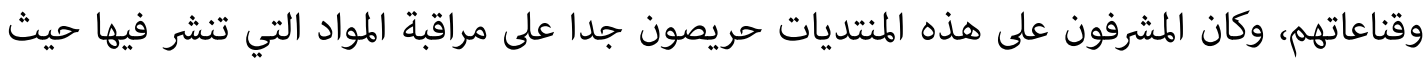

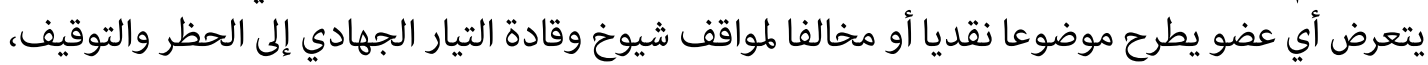

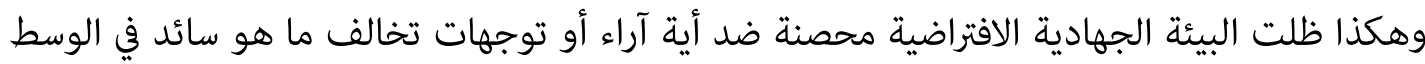
الجهادي. مع انتشار مواقع التواصل الاجتماعي وتراجع اهتمام رواد الانترنت بالمواقع والمنتديات وجد وجد إندان

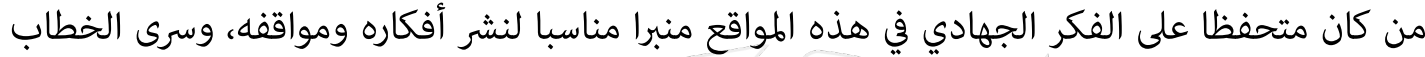
الجهادي النقدي فيها وحظي بتفاعل كبير من قبل روادها لاسيما المؤيدين منهم للحركة الجهادية. وجد المنظرون الجدد للتيار الجهادي في مواقع التواصل الاجتماعي فضاء لعرض أفكارهم وأطروحاتهم وساعدهم ذلك في خلق توجه جهادي تجرأ على نقد كبار شيوخ السلفية الجهادية والاستدراك عليهم،

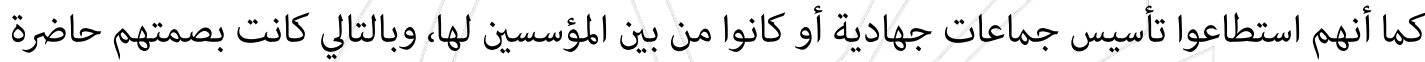

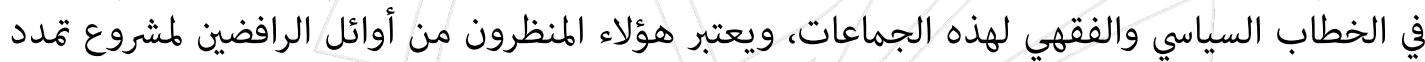

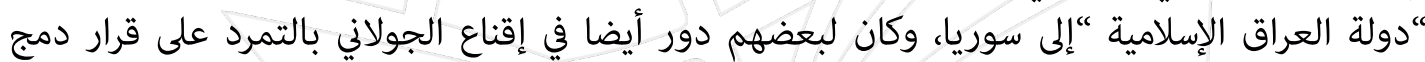

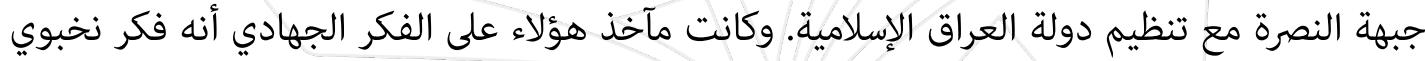
يصعب معه حشد الناس خلف قضاياه وأطروحاته، وأن روافد الغلو داخله ينبغي تجفيفها دواتها وحصارها،

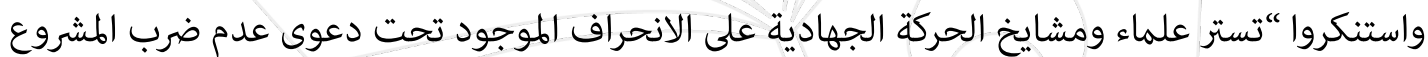

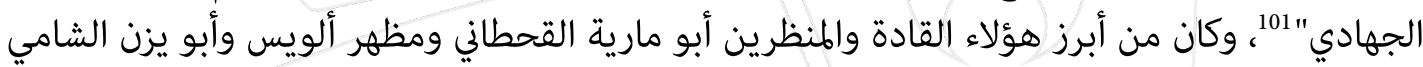

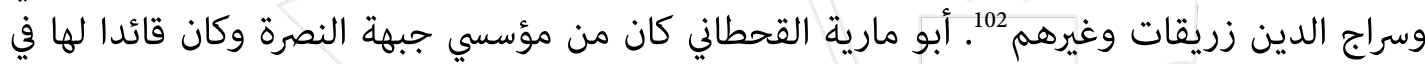

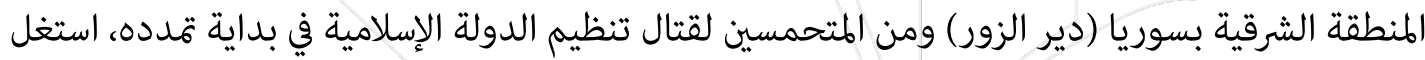
شبكات التواصل الاجتماعي لنشر أفكاره وآراءه عن تنظيم الدولة والحركة الجهادية عموما، خاض معاض معارك

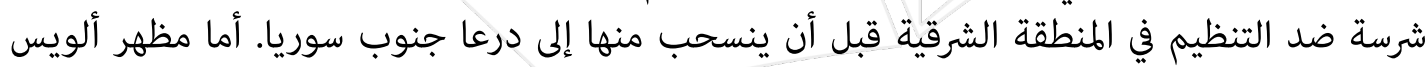
فقد كان رفيقا للقحطاني في المنطقة الشرقية وتقاسما القناعات نفسها حول التيار الجهادي، نقض مض مظهر ألويس مبادئ الغلو والتكفير في كتابه المشهور “العلامات الفارقة في كشف دين المارقة “وهاجم فيه

101 مظهر ألويس، العلامات الفارقة في كشف دين المارقة، ص38 (نسخة إلكترونية)

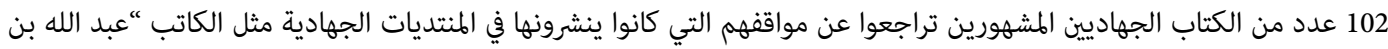

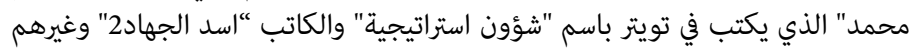


شيوخ التيار الجهادي لأنهم مل يبينوا حقيقة الخوارج بنفس القدر الذي بينوا فيه حقيقة المرجئة 103.

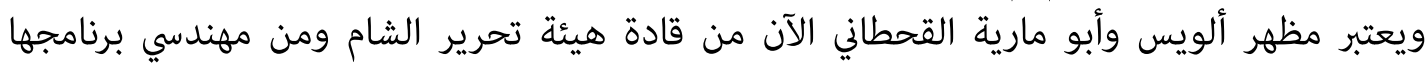
الجهادي الموسوم بالاعتدال والانفتاح.

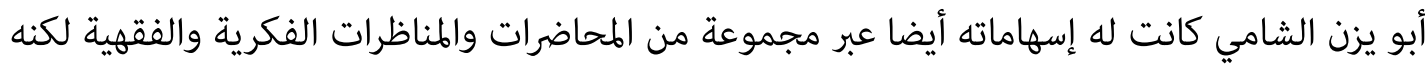

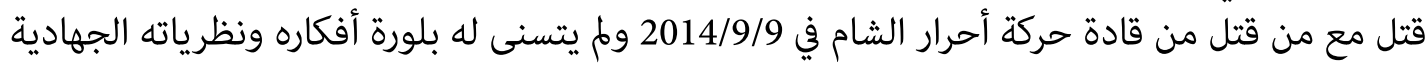

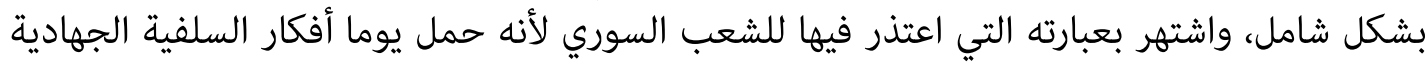

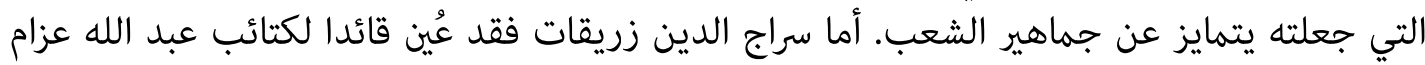

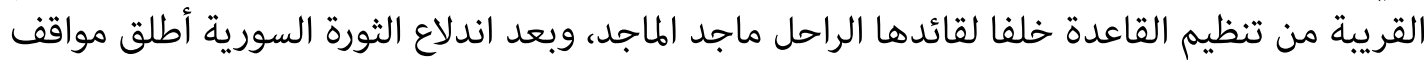
ناقدة للتيار الجهادي عبر حساباته على مواقع التواصل الاجتماعي.

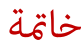

تبدو تحولات الخطاب السياسي الجهادي في سوريا عميقة وراسخة وأشد بروزا وتجليا، لأن عوامل

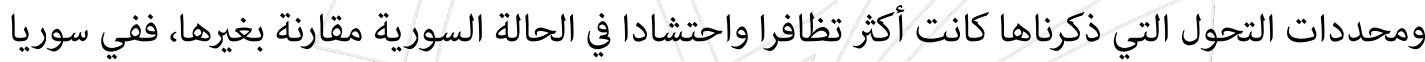

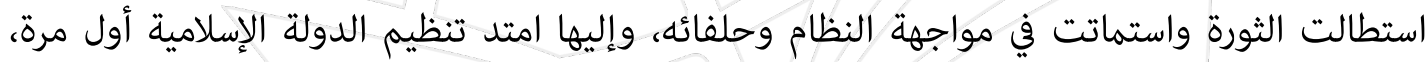

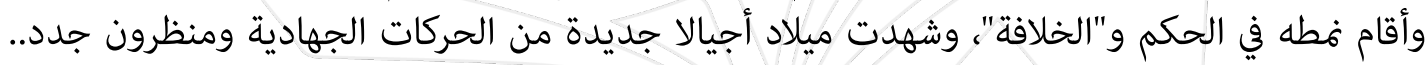

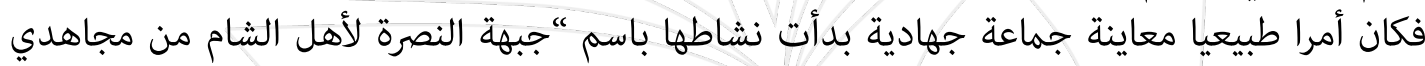

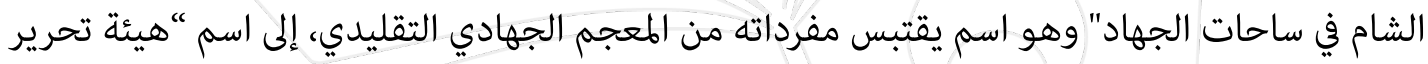

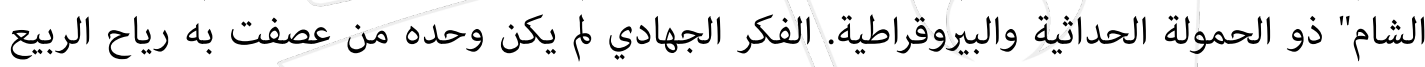

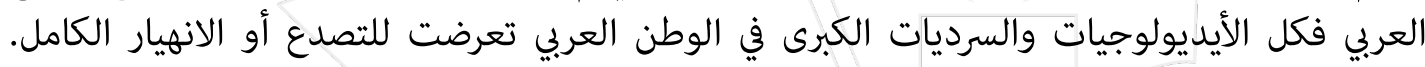

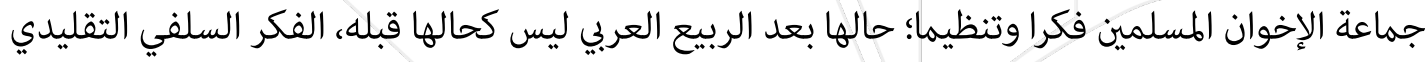

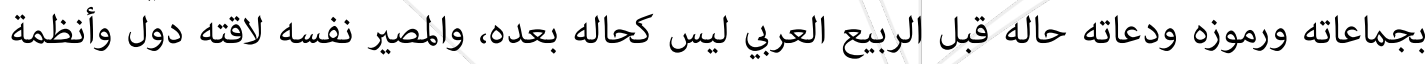

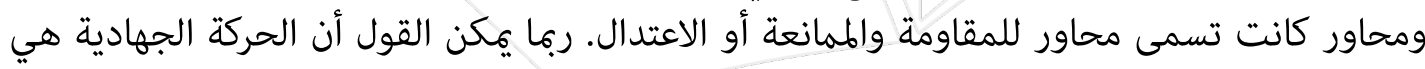

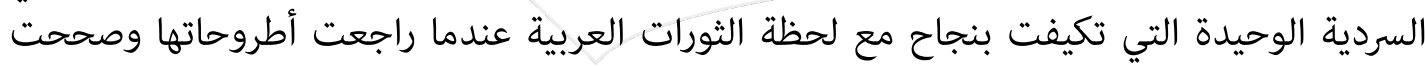

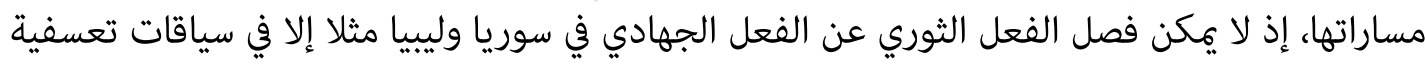

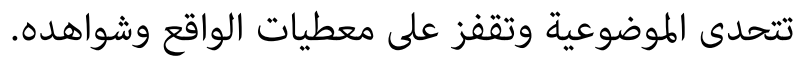




\section{مجلة المعهد المصرات}

EGYPT INSTITUTE JOURNAL

\section{الحركات الجهادية المصربية: حدود الدور \\ • أحمد مولانا (هصر)}


عاد التيار الجهادي ليبرز في المشهد المصري مع تصاعد حملات القمع عقب الانقلاب العسكري في

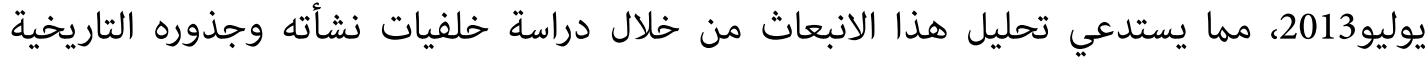

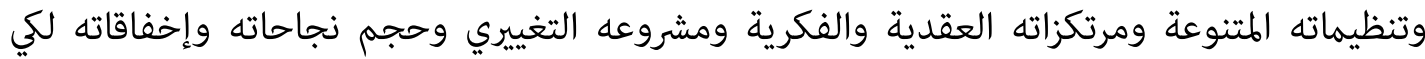
نتمكن من استشراف مستقبله وتقييم مستوى تأثيره على الأوضاع بكصر.

سنتناول في هذه الدراسة "جماعة الجهاد المصرية" من خلال تتبع التطور التنظيمي للتيار الجهادي

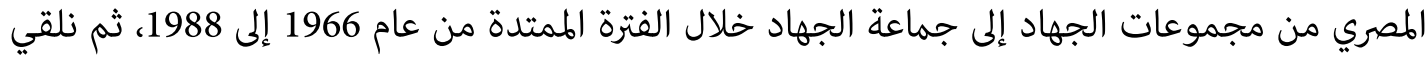

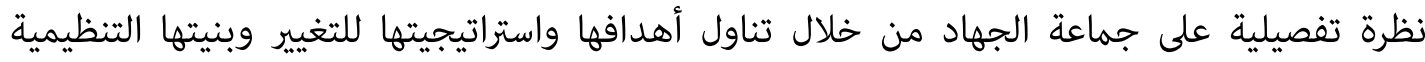

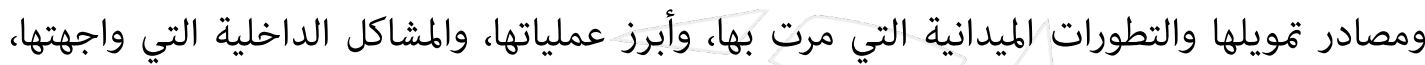

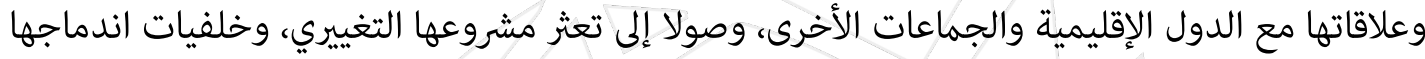

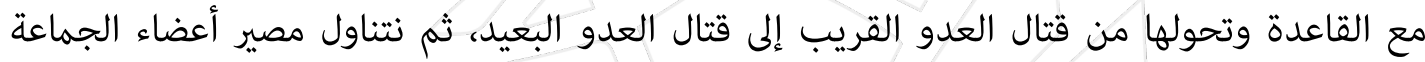

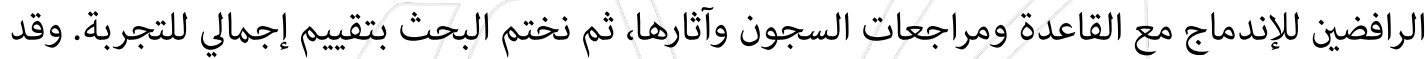

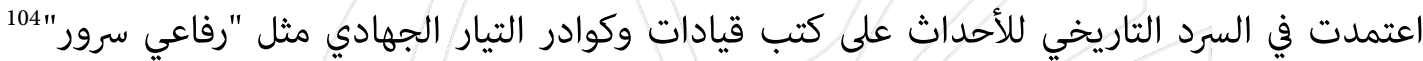

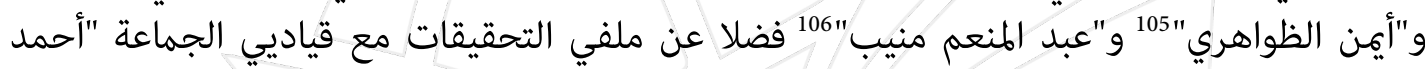
سلامة مبروك" 107 و"أحمد النجار"

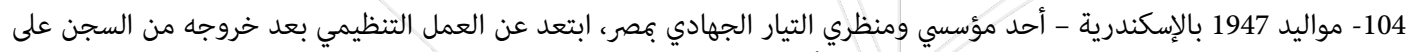
خلفية حادث اغتيال السادات، واتجه للكتابة والتنظير، وتُوفي عام

105 - مواليد 1951 بالقاهرة، خريج طب القصر العيني، وأمير جماعة الجهاد منذ عام 1993 وصولا لإندماجها مع تنظيم القاعدة. 106 - اعتقل على خلفية حادث اغتيال السادات، ثم انضم إلى جماعة الجهاد، واُعتقل مجددا من من عادئ عام العمل التنظيمي وأصدر عدة كتب عن الحركات الإسلامية، ويعمل حاليف اليا كصحفي.

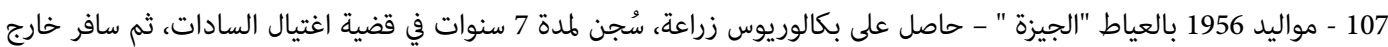

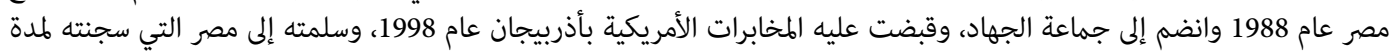

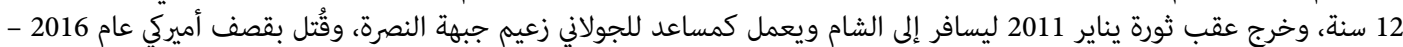
وملف التحقيق معه عام 1999 في مصر غير منشور.

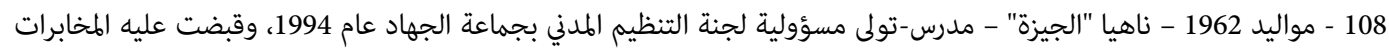

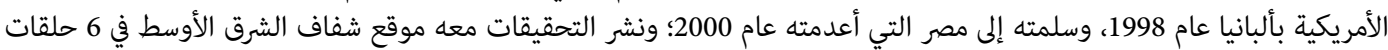

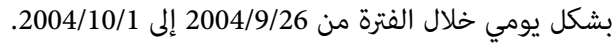


المحور الأول: من مجموعات الجهاد إلى جماعة الجهاد (1977-19MM): لم ينشأ التيار الجهادي على هيئة تنظيم موحد بل على شكل مجموعات متعددة تأسست بداية من عام

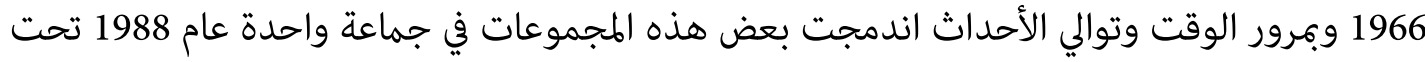
اسم "جماعة الجهاد المصرية"

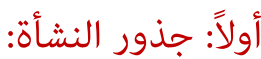

في عام1965 دشن النظام الناصري موجة قمع جديدة ضد جماعة الإخوان المسلمين توجت بإعدام الاستاذ سيد قطب ورفيقيه "محمد هواش وعبد الفتاح اسماعيل" عام 1966، بينما نجت جماعة أنصار السنة من القمع لهامشية تأثيرها وبعدهما عن همدو الصدام مع النظام الناصري.

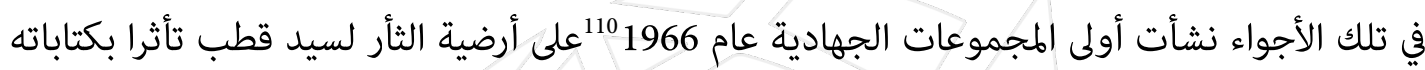

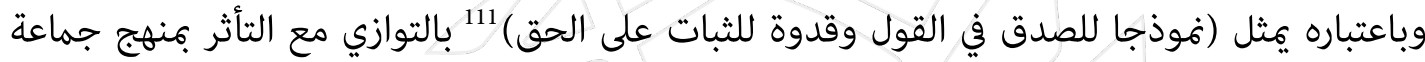
أنصار السنة المتمثل في الاهتمام (بعقيدة التوحيد، وبالتعامل المباشر مع النصوص الشرعية، وبالقراءة في

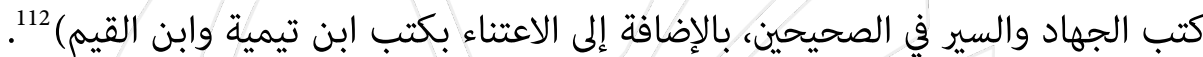
وتشكلت المجموعة من عدة شباب من طلبة الثانوية العامة من أبرزهم (اسماعيل طنطاوي، رفاعي

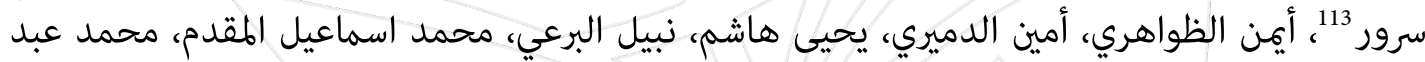

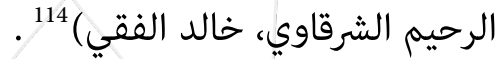
وتبنت المجموعة مبدأ الانقلاب العسكري كوسيلة للتغيير لأن (النظام الحاكم يحكم بالقوة والقمع ويسد أي منفذ للتغيير السلمي) 115 فدفعت بعض عناصرها للالتحاق بالجيش، ونجحت في ضم (ضابط الجيش

109 - عبد المنعم منيب -دليل الحركات الإسلامية المصرية-ص103 مكتبة مدبولي-ط1

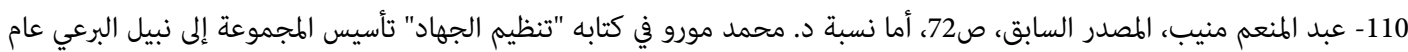

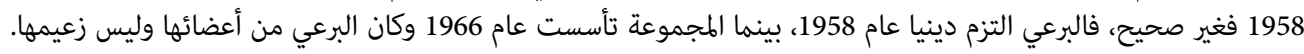

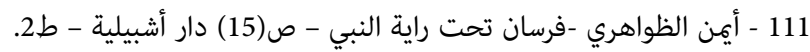
112 - رفاعي سرور - التصور السياسي للحركة الإسلامية - ص (264،265) - نسخة إلكترونية. 113- رفاعي سرور كان طالبا بالتعليم الصناعي.

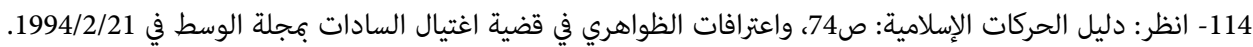

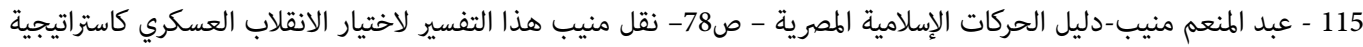
للتغيير عن نبيل البرعي ومصطفى يسري من مؤسسي التيار الجهادي بمصرك. 
عصام القمري، وتكن القمري من تجنيد العديد من ضباط الجيش مثل عبد العزيز الجمل وسيد

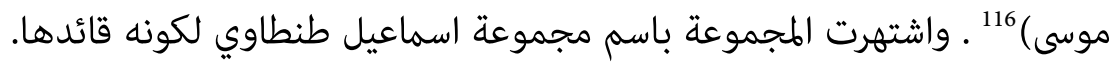
واعتمدت المجموعة (منهجا للدراسات الشرعية يستند إلى المنهج السلفي وكتابي "معالم في الطريق -في

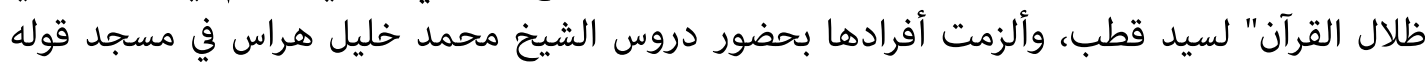

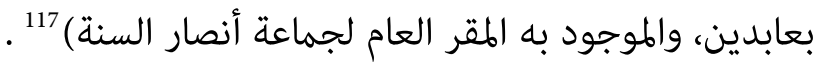

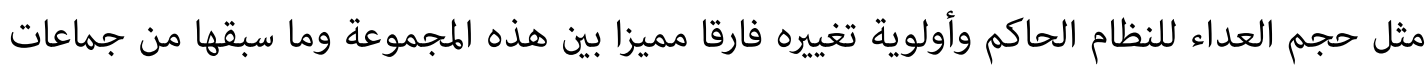

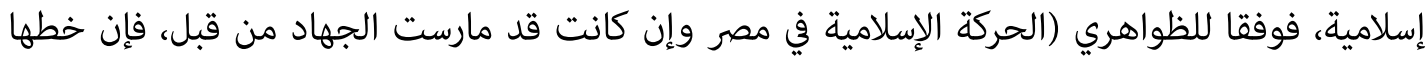

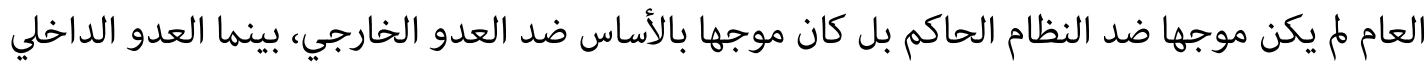

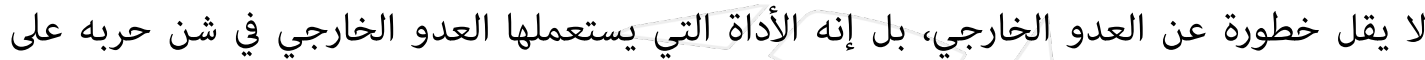
الإسلام) ألمان

أي أن تلك المجموعة الجهادية جمعت بين منطلقين

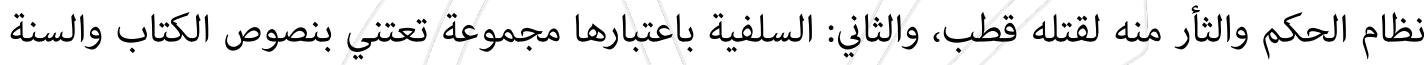
وفهم السلف لهما. ثم وقعت هزيمة 1967 وخفت وطأة القهر الناصري وأتيحت مساحة أوسع للدعوة والانتشار، فاندمجت أندات

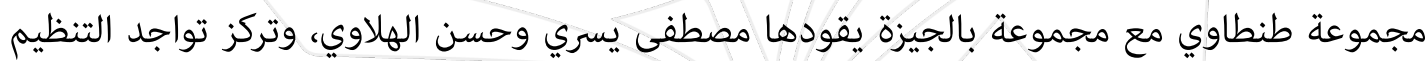
بمحافظات القاهرة والاسكندرية والجيزة.

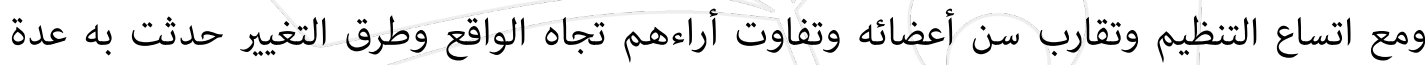

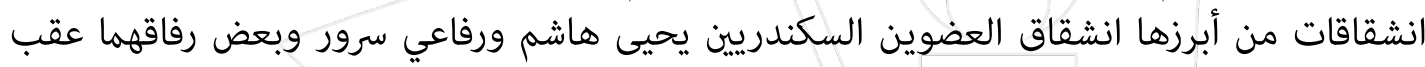

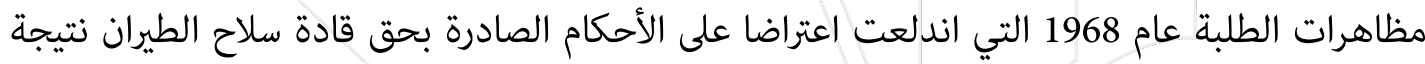

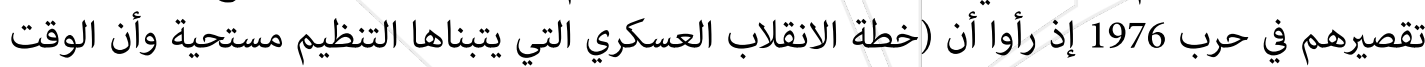

116 - حوار جريدة الحياة مع أيمن الظواهري، ونشره المكتب الإعلامي لجماعة الجهاد عام1993.

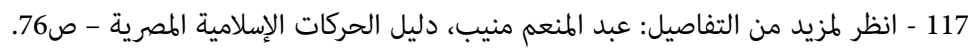

118- أيمن الظواهري - فرسان تحت راية النبي - ص (13، 14).

119- رفاعي سرور-التصور السياسي ص278، عبد المنعم منيب-دليل الحركات الإسلامية ص 75. 
مناسب لكشف حقيقة عبدالناصر ونظامه للناس بعد الهزيمة، واقترح يحيى هاشم القيام بشروع تغييري

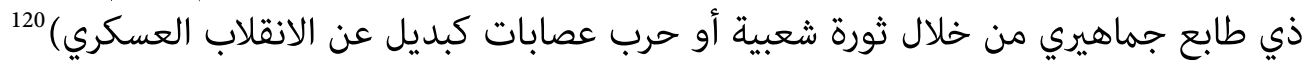
دفعت تلك الانشقاقات مجموعة مصطفى يسري إلى العمل بشكل منفرد تجنبا للمشاكل الداخلية التي

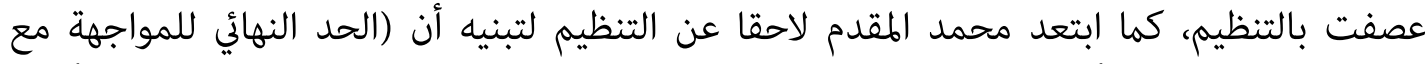

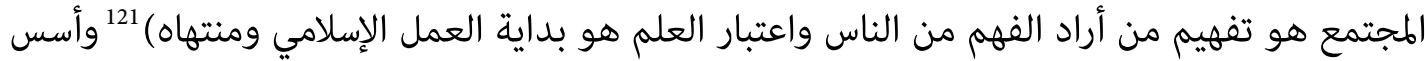
الدعوة السلفية بالإسكندرية عام1974 لتمثل تطبيقا لرؤيته، بينما اختار أغلب عناصر التنظيم (المواجهة

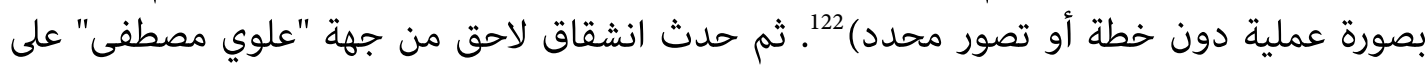

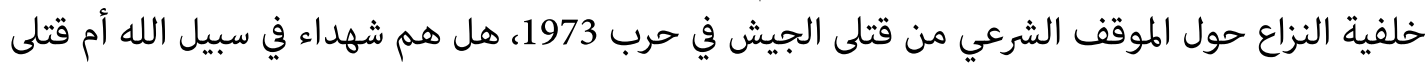
تحت راية الطاغوت.

شكل موت (عبد الناصر عام 1970 موتا لبادئه) 123 ومثل تولي السادات للحكم (بداية لتحول سياسي

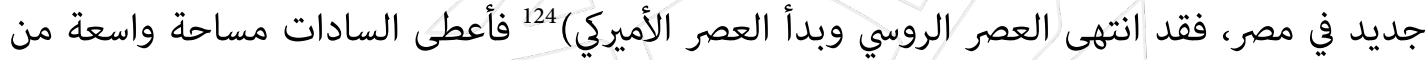

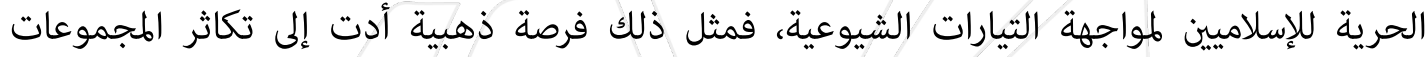
الجهادية وانتشار أفكارها (كرد فعل نفسي لأهوال الناصرية.. والخوف من تكرارها معهم) ثم وفد إلى مصر عام 1971 القيادي الفلسطيني ذي الخلفية الإخوانية (صالح سرية) ليعمل موظفا بالجامعة العربية 26. وأسس تنظيما جديدا يسعى للقيام بانقلاب عسكري. والتقى بإسماعيل طنطاوي ويحيى هاشم وفم ينجح في ضمهما لتنظيمه لرفض طنطاوي إرجاء حسم الخلافات في مسائل عقدية

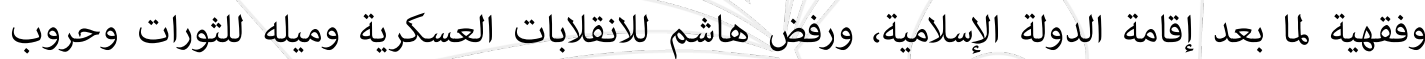

120 - ملزيد من التفصيل: عبد المنعم منيب -دليل الحركات الإسلامية -ص (79-81). 121 - رفاعي سرور -التصور السياسي- ص266. 122 - المصدر السابق. 123 - أيمن الظواهري-فرسان تحت راية النبي - ص17. - المعن. 124 125- رفاعي سرور-التصور السياسي للحركة الإسلامية -ص277 126 - حصل صالح سرية على الدكتوراه في التربية وعمل موظفا منظمة التربية والثقافة والعلوم التابعة للجامعة العربية. 
العصابات، بينما نجح سرية في ضم مجموعة مصطفى يسري إلى تنظيمه ونفذ محاولة انقلاب اشتهرت

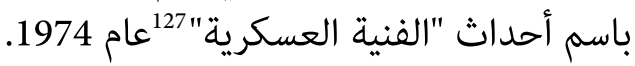

ورغم بساطة الخطة وفشلها إلا أن خطورتها تكمن في كونها أول خطة انقلاب يقوم بها إسلاميون تدخل

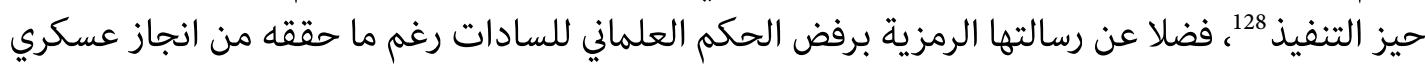
وسياسي وإعلامي في حرب أكتوبر.

وعلى وقع تداعيات التحقيقات في قضية الفنية هرب اسماعيل طنطاوي خارج البلاد وقاد عصام القمري

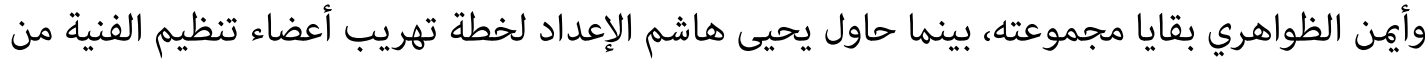

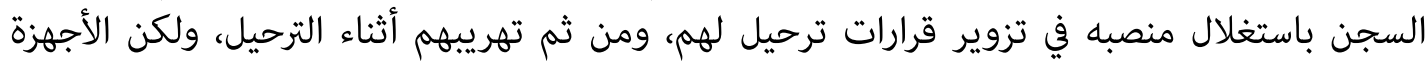

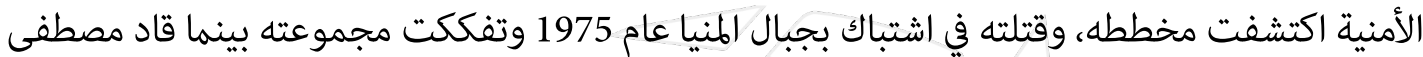

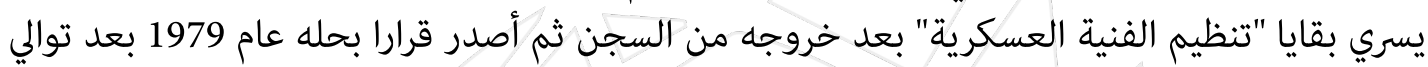

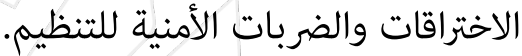

وبرز من بين كوادر تنظيم "مصطفى يسري" المنحل المهندس محمد عبد السلام فرج الذي قرر مواصلة

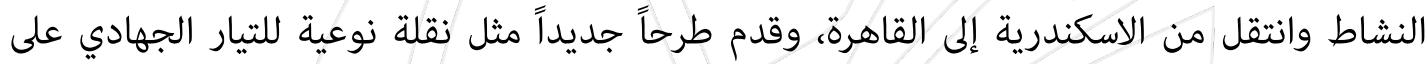
المستويين الفكري والتنظيمي:

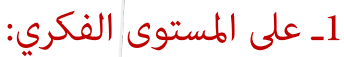

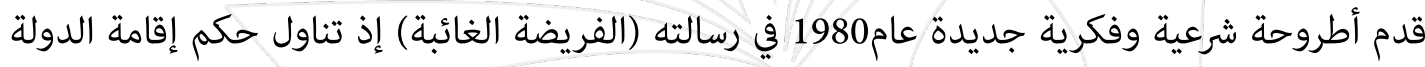

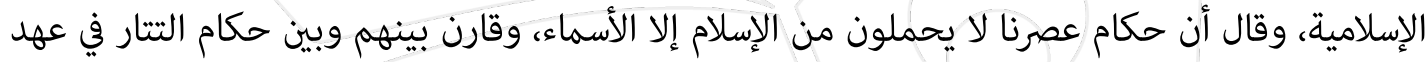

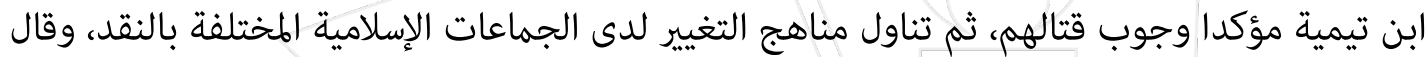

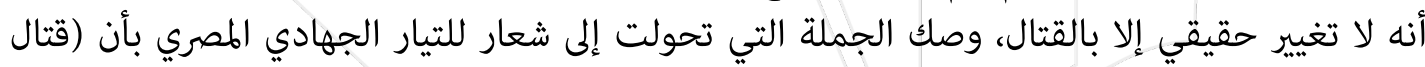

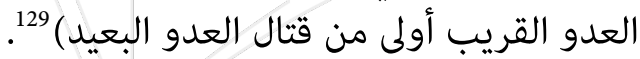

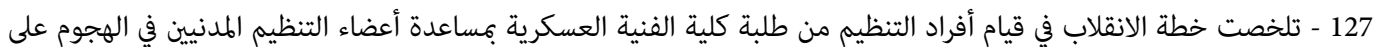

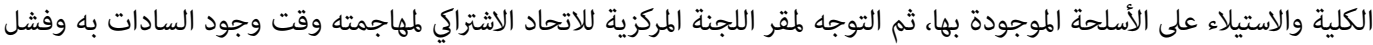

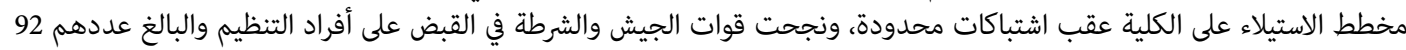
شخص، وأعدم كلا من صالح سرية وكارم الأناضولي الطالب بكلية الفنية الفية العسكرية. 128 - رفاعي سرور-التصور السياسي: ص279، 280 129 - محمد عبد السلام فرج -الفريضة الغائبة -ص15-نسخة إلكترونية. 


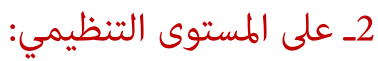

اقتنع فرج بنظرية عبود الزمر 130 القائلة بأن (الانقلاب العسكري لابد أن تصحبه تحركات شعبية مؤيدة

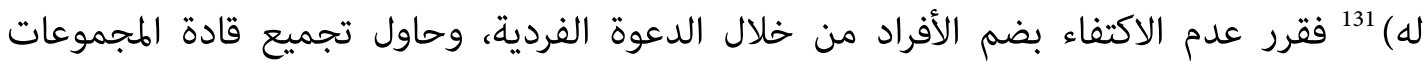

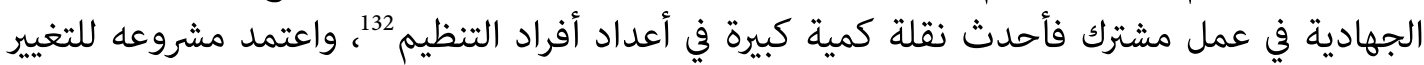

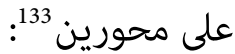

الأول: تكوين مجموعات عسكرية من أفراد الجيش بغرض القيام بانقلاب عسكري. الثاني: إعداد مجموعات مدنية تدعم الانقلاب العسكري لحظة وقوعه. في تلك الآونة تصاعدت إجراءات السادات القمعية، فعقب عقده لاتفاقية كامب ديفيد عام 1978 أصدر

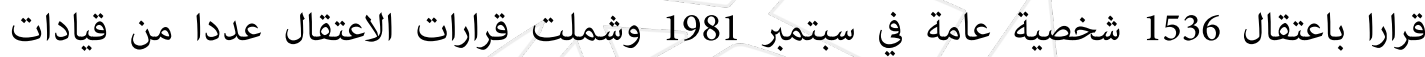

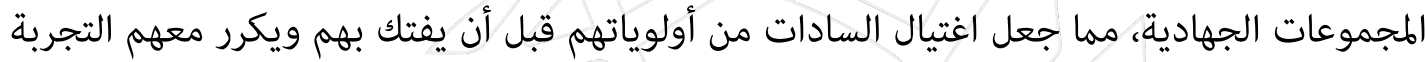

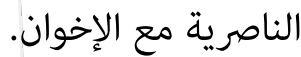

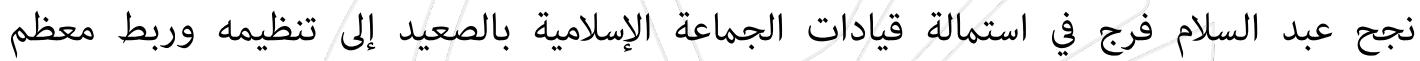

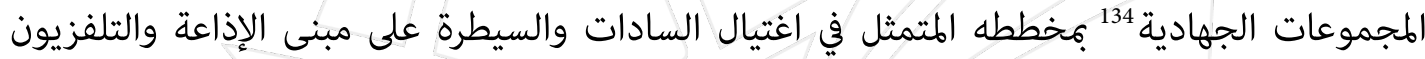

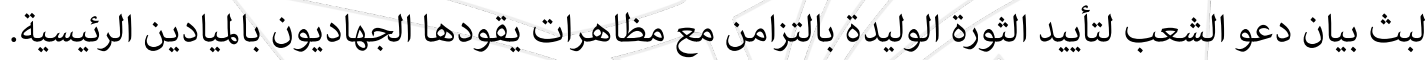

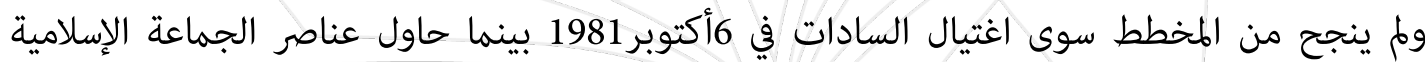

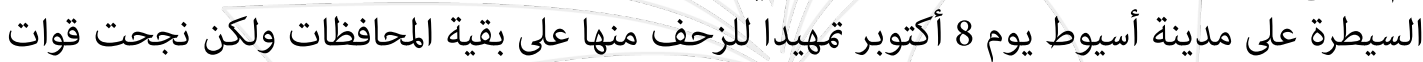
الصاعقة والشرطة في السيطرة على المدينة عقب اشتباكات دامينة.

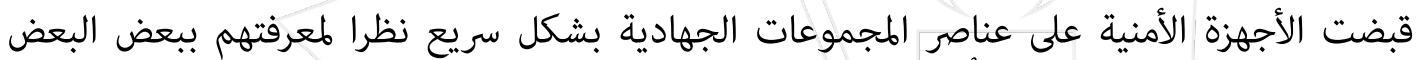

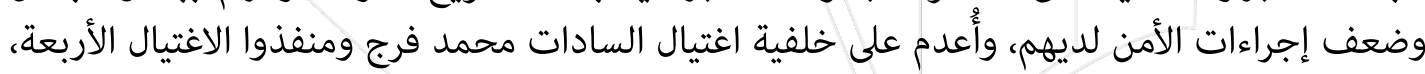
بينما تفاوتت الأحكام على بقية الأعضاء ما بين البراءة والمؤبد متضمنة الستئ السجن 3 سنوات، وتشكل في

130 - عبود الزمر كان مقدما بالمخبرات الحربية، وانضم إلى مجموعة طارق الزمر عام 1978، وتعرف على فرج عام1979. 131 - عبد المنعم منيب -التنظيم والتنظير - صبر 11-مكتبة مدبولي ط1. 132 - بلغ عدد المتهمين عام 1981 في قضية الجهاد الكبرى 302 فرد بينما بلغ عدد المتهمين عامبئية في في قضية الفنية 92 فرد. 133 - انظر: عبد المنعم منيب-دليل الحركات الإسلامية ص87، 88. 134- شاركت في أحداث 1981 مجموعة سامل الرحال ومجموعة نبيل المغربي ومجموعة الجماعة الإسلامية بالصعيد مع بعض أفراد من مجموعة اسماعيل طنطاوي. 
السجن هيكل تنظيمي يضم المجموعات الجهادية المتنوعة، وضم مجلس شورى التنظيم كلا من (أيمن

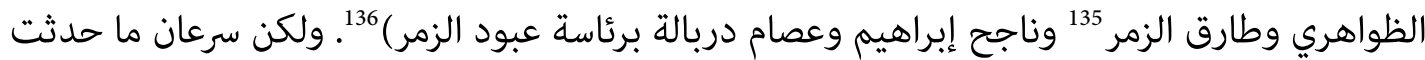

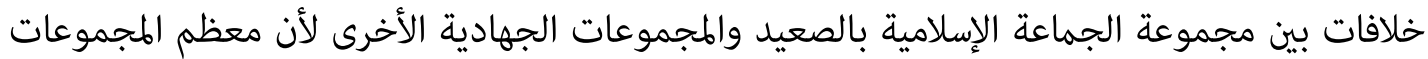

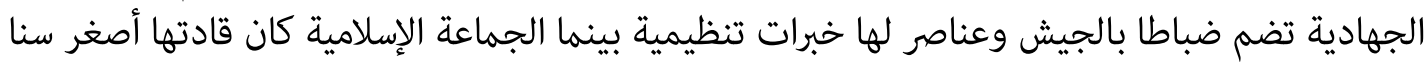

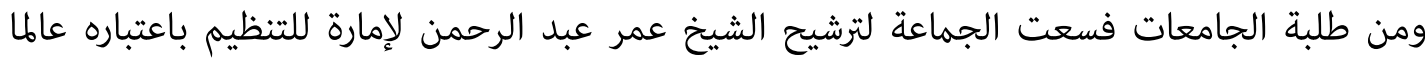

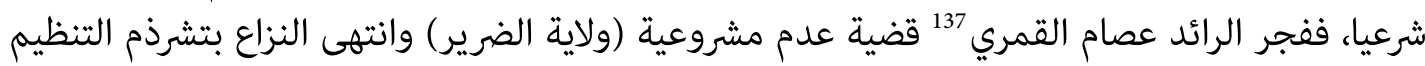

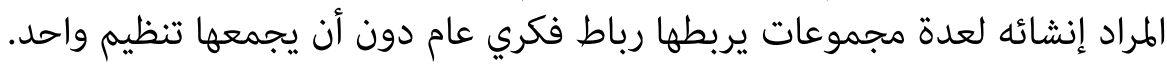

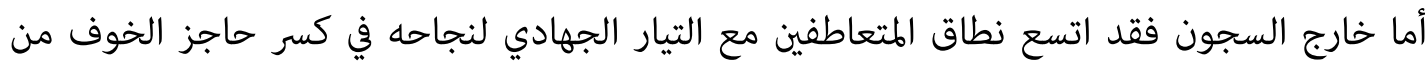

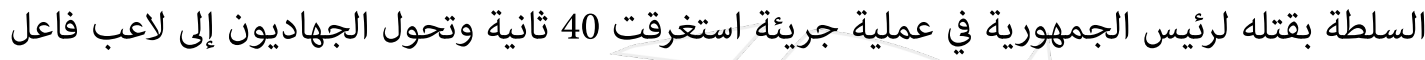

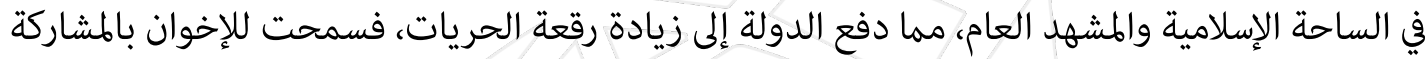
في الانتخابات النيابية عام 1984، وزادت رقعة الدروس الدينية بالتلفزيون الدهادية الرسمي.

أدت تداعيات اغتيال السادات إلى انتقال الجهاديين المصريين من حيز المحلية إلى العالمية، ففي عام 1984

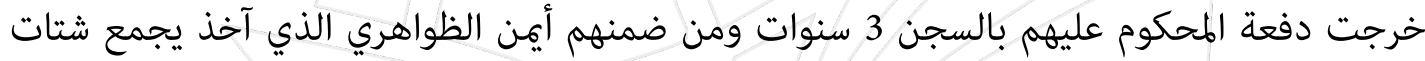

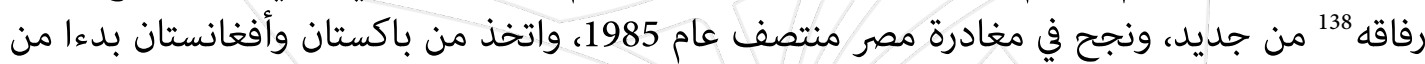

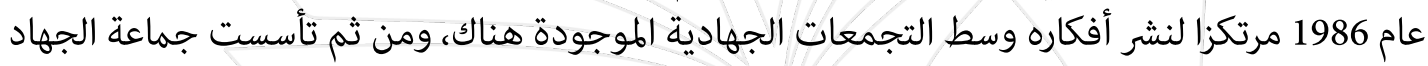

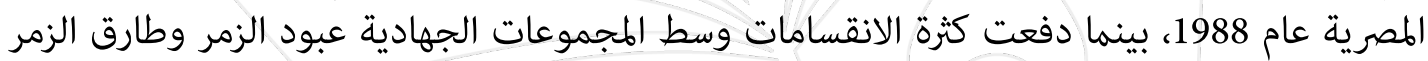

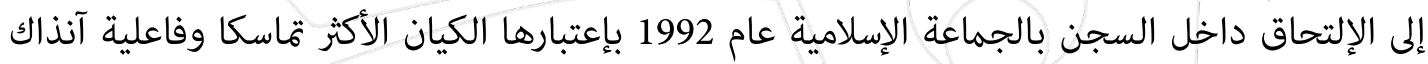


وذلك عقب فشل محاولاتهما في تشكيل جبهة 139 تضم كافة المجموعات الجهادية بالساحة فضلا عن جماعة الإخوان

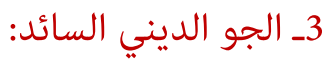

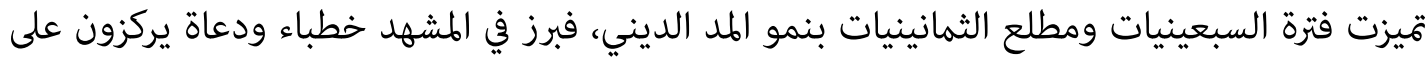

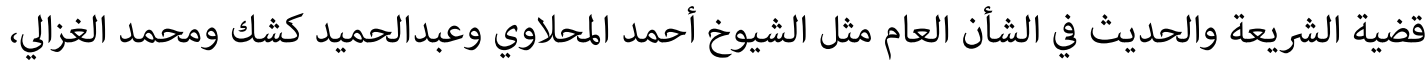

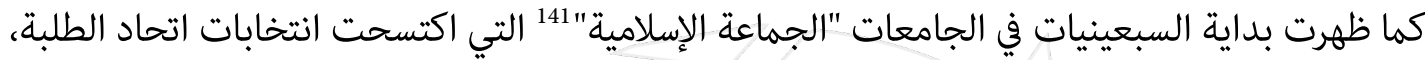

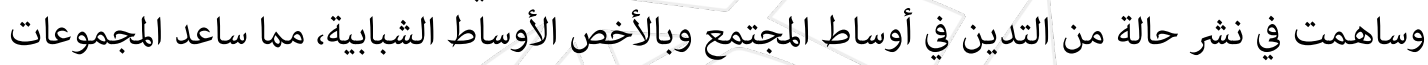
الجهادية على اجتذاب العديد من الشباب عقب تكثيفها النشاط الدعوي بالمساجد والجامعات، كما التشرت آنذاك كتب سيد قطب التي مثلت مرجعية للتيار الجهادي، فضلا عن تدوين أولى الأطروحات الجهادية مثل " رسالة الإيمان" لصالح سرية، و"الفريضة الغائبة" لمحمد عبدالسلام فرج.

المحور الثاني: جماعة الجهاد رؤية من الداخل(19MM-12001): تأسست جماعة الجهاد المصرية نهاية عام 1988 في بيشاور بباكستان من خلال دمج بقايا مجموعة

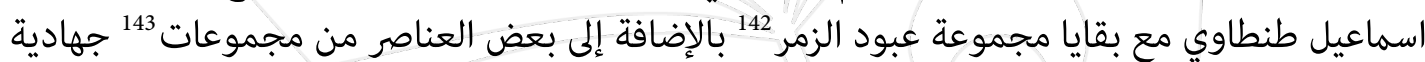
أخرى. أولاً: أفكار جماعة الجهاد وأهدافها:

139 - سبق لعبود إصدار وثيقة بعنوان (مشروع الجبهة الإسلامية) دعا فيها إلى اندماج الجماعة الإسلامية وجماعة الجهاد والإخوان في

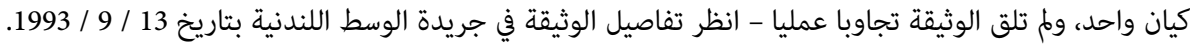
140 - اعترافات أحمد سلامة في التحقيقات معه - ص27. 141 - سأفرد الجماعة الإسلامية ببحث منفرد بإذن الله. 142 - مثل مجدي سامل وعادل السوداني وأحمد سلامة. 143 - مثل عادل عبد القدوس الذي كان ينتمي إلى مجموعة عبد الرؤوف أيمر الجيوش المعروفة باسم مجموعة شبرا. 
رأت جماعة الجهاد أن (الكفار يتسلطون على بلاد المسلمين سواء بالاحتلال المباشر أو من خلال الأنظمة

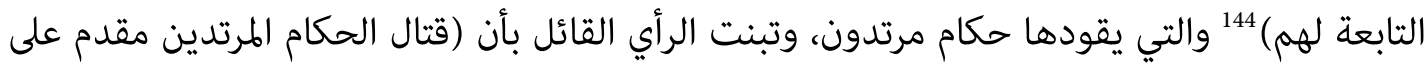

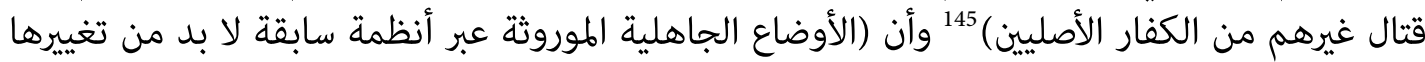

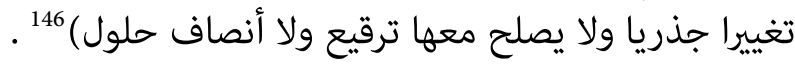

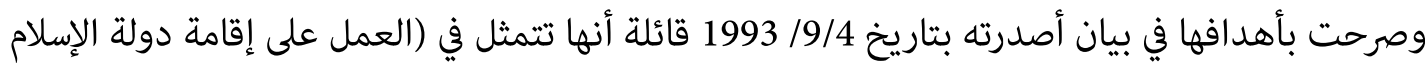

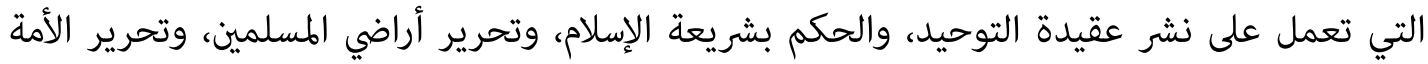

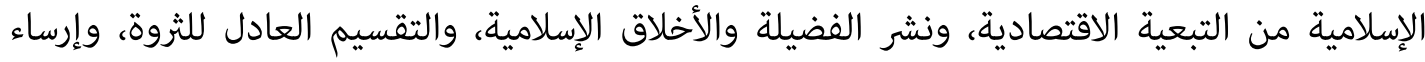

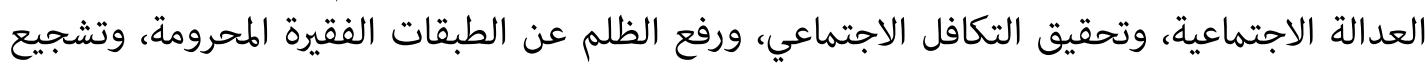

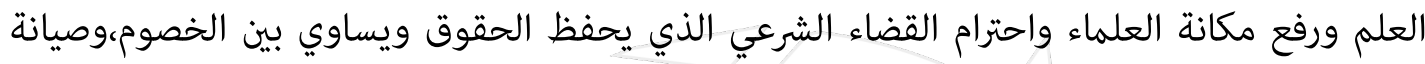

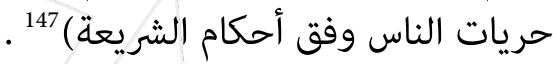

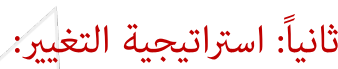

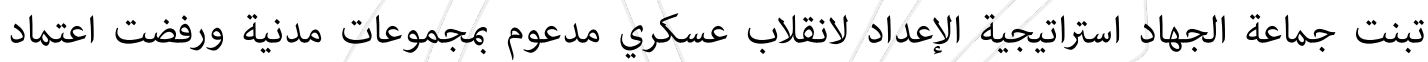

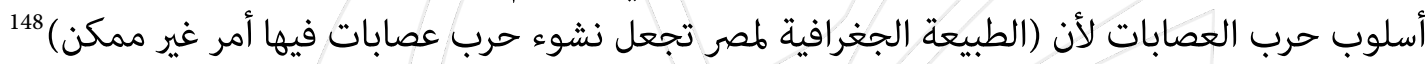

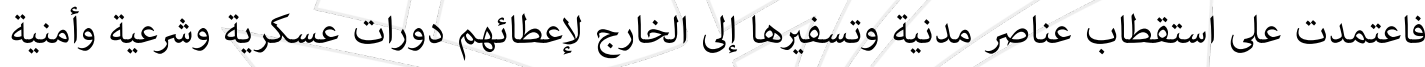

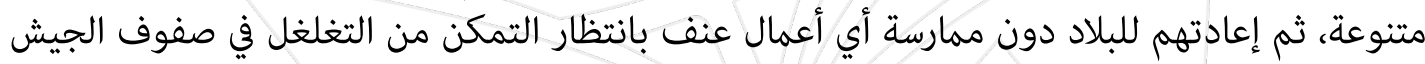
لتنفيذ انقلاب عسكري تدعمه المجموعات إنمار المدنية السابق إعدادها.

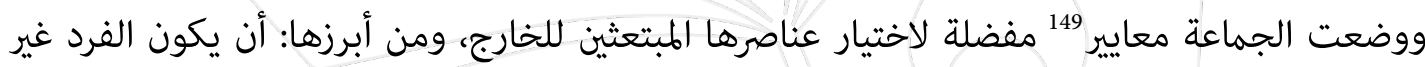
مرصود أمنيا وله سابقة في العمل الجماعي وسليم بدنيا ومتسما بالطاعة ويفضل أنسار أن يكون عازيا.

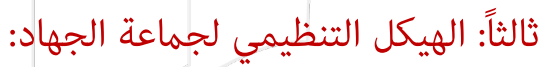

144 -انظر: عبد القادر عبد العزيز-العمدة في إعداد العدة-ص 24 - نسخة إلكترونية. 145 - المصدر السابق ص320. 146 - الحلقة الثانية من اعترافات أحمد النجار-مصد سابق.

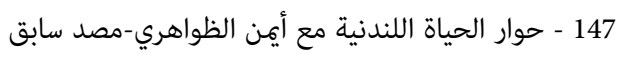
148 - أيمن الظواهري -فرسان تحت راية النبي -ص 93. 149 - اعترافات أحمد سلامة - ص17. 
مر الهيكل التنظيمي للجماعة بتغيرات متتالية وفقا لتطورات الأحداث، وقد تشكل أول هيكل تنظيمي

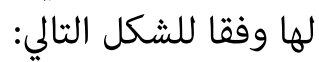
ترأس الجماعة أمير يعاونه نائب، وتولى الإمارة د. سيد إمام ${ }^{150}$ باعتباره أكثر أعضائها تحصيلا للعلم الشرعي بينما قادها فعليا وتنظيميا د. أيمن الظواهري، الإهارة واعتمدت الجيد الجماعة في تسيير أمورها على مجلسين: الأول: مجلس الشورى، ويختص بدراسة سياسة الجماعة وأنشطتها وبحث المشكلات التي تواجهها وكيفية حلها. الثاني: المجلس التأسيسي ويضم 8 لجان تباشر العمل التنظيمي، ويتم التنسيق بينها بإشراف أمير التنظيم، وهي: 1ـ اللجنة السياسية: تختص بدراسة الأوضاع السياسية دوليا وإقليميا ومحليا، ورسم سياسة الجماعة ويشرف عليها أيمن الظواهري.

2ـ اللجنة العسكرية: تختص بالإعداد لإنشاء معسكرات لتدريب عناصر الجماعة، وانشاء خلايا تابعة الجاء

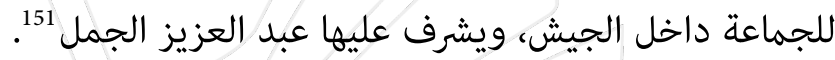

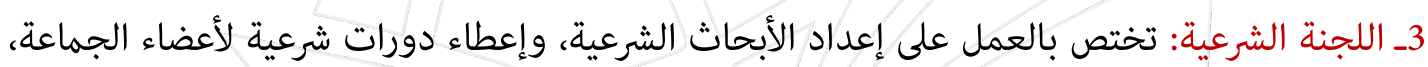
ويشرف عليها سيد إمام

4ـ اللجنة الأمنية والعمل الخاص: تختص بأمن وسلامة عناصر الجماعة، وحمايتها من الاختراقات، وإعطاء

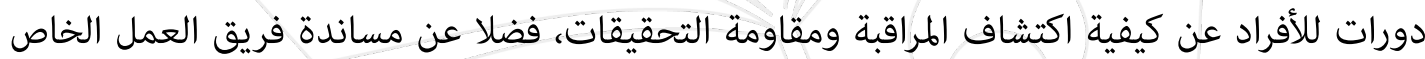

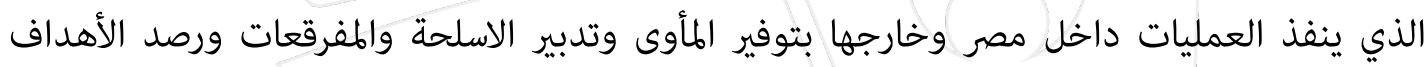

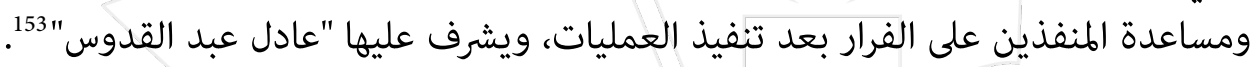

150 - سيد إمام وأيمن الظواهري كانا رفيقين بكلية الطب بجامعة القاهرة ومن أعضاء مجموعة اسماعيل طنطاوي. 151 - رائد سابق بالجيش، ترك الجماعة لاحقا عام 1993 والتحق بتنظيم القاعدة ثم تركه، اعتقل باليمن عام 2003، وسُلم إلى مصر عام 20004، وخرج من السجن عقب الثورة، ثم سافر إلى الشام. 152 - مواليد 1950 ببني سويف - طبيب بشري-ترك إمارة الجماعة عام 1993، ثم اعتقل باليمن أكتوبر 2001، وسُلم إلى مصر عام 2004، وخرج من السجن عام 2011. 153 - حصل على حكم بالبراءة في قضية اغتيال السادات ثم صدر ضده حكمان بالإعدام غيابيا في قضيتي "عاطف صدقي والعائدون من ألبانيا “وطلب حق اللجوء السياسي بالنمسا عام 153 
5ـ لجنة التنظيم المدني: تختص بمتابعة أعضاء الجماعة وإعداد قاعدة بيانات تشمل المعلومات المتوافرة

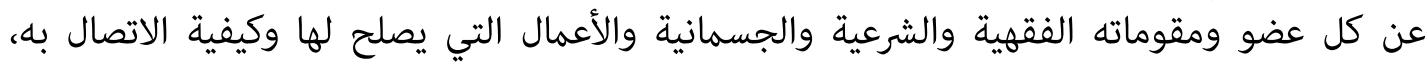
ويشرف عليها "أحمد سلامة".

6ـ لجنة الوثائق: تختص بتوفير الأوراق الرسمية والمزورة من بطاقات وجوازات سفر وتأشيرات وشهادات عسكرية، ويشرف عليها "مدين محمود". 7ـ اللجنة الاعلامية: تتولى نشر وتوزيع مطبوعات الجماعة وأبحاثها وبياناتها، كما أنشئ مركز النور

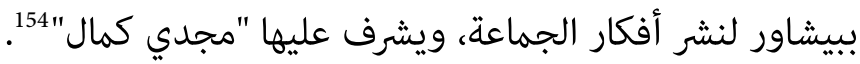

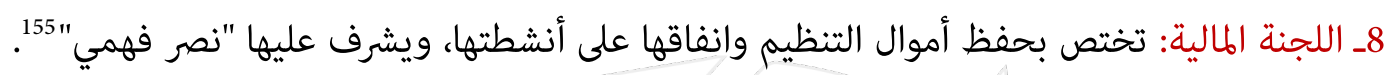
رابعاً: مصادر التمويل

اعتمدت الجماعة في توفير الأموال اللازمة لأنشطتها على تبرع أعضاءها بعشرة بالمائة من رواتبهم، فضلا

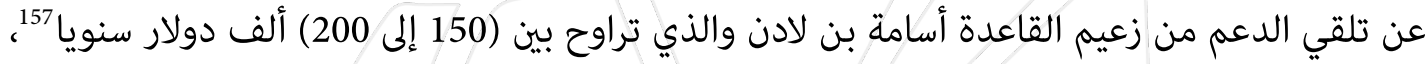

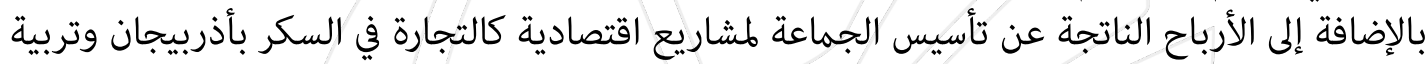

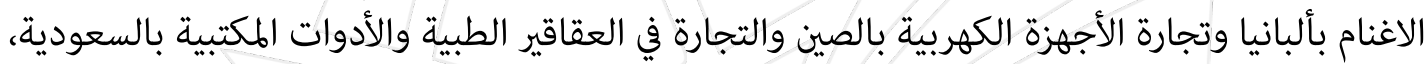
وترميم المساكن القديمة بلندن. خامساً: منهج الدعوة والاصدارات

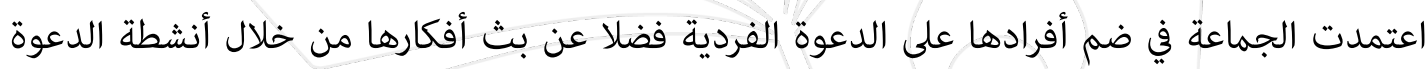

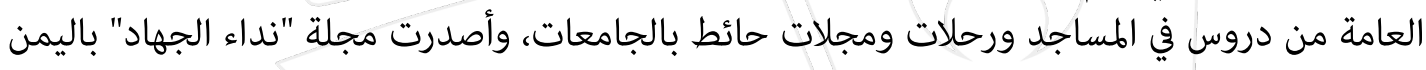

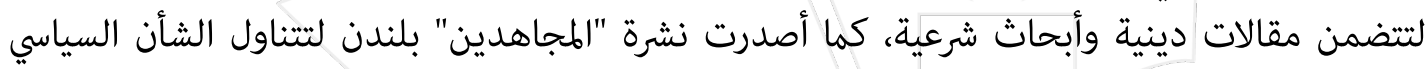

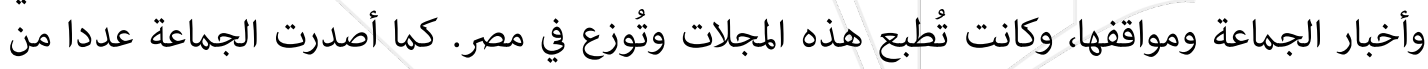

154 - من بني سويف، سُجن في قضية اغتيال السادات، وعقب خروجه من السجن سافر باكستان، وقبضت عليه السلطات الأردنية عام

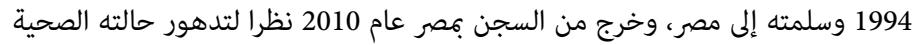
155 - قُتل بغارة أمريكية في أفغانستان عام 2001. 156 - انظر الحلقة الأولى من اعترافات أحمد النجار -مصدر سابق.

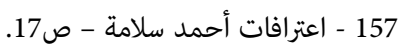
158 - انظر الحلقة الثالثة من اعترافات أحمد النجار - مصدر سابق. 
الكتب والرسائل التي كتب معظمها سيد إمام باسم حركي هو "عبد القادر عبد العزيز" من أبرزها:

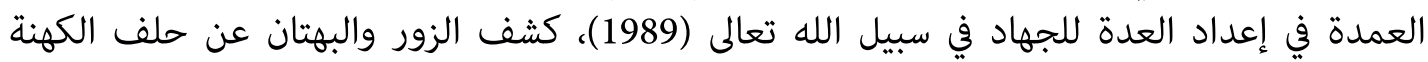

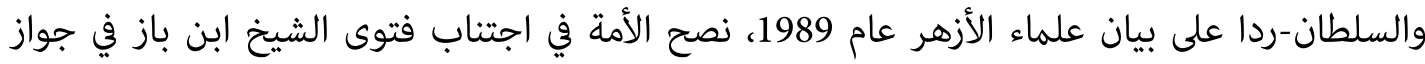

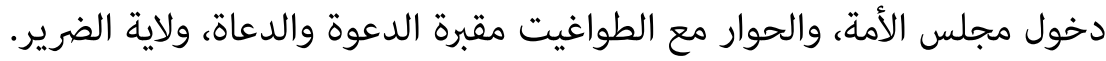

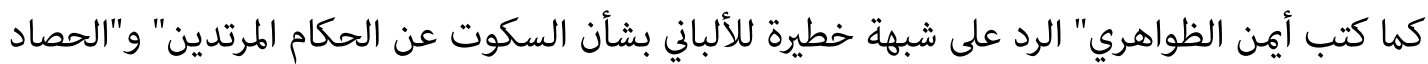

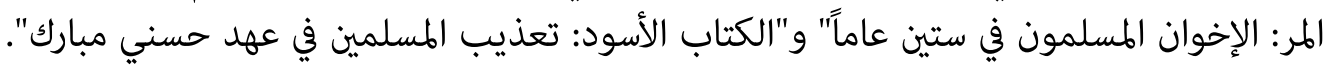

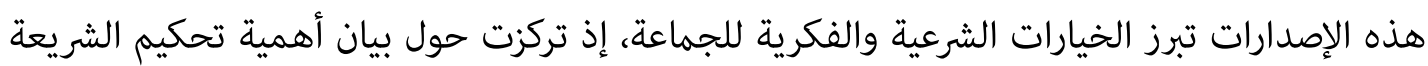

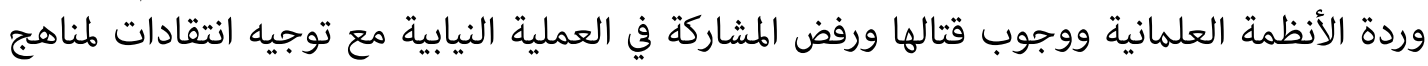
التغيير لدى الجماعات الإسلامية الأخرى.

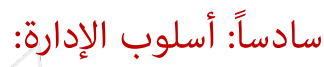

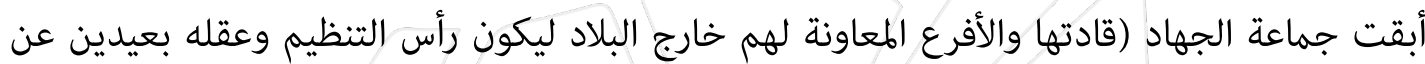

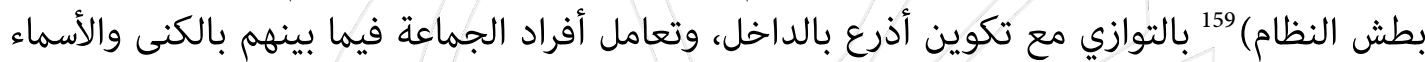

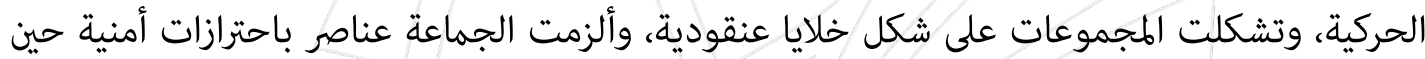

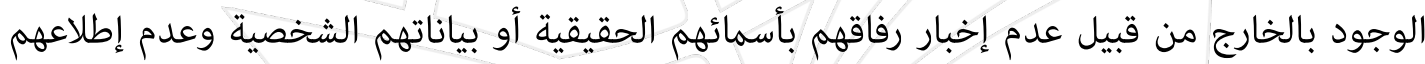
على جوازاتهم المزورة. سابعاً: المسار العملي لجماعة الجهاد: المستوى الأول: الإعداد العسكري: بدأت الجماعة تعد أفرادها على محورين: الأول: تدريب القيادات وتأسيس المعسكرات:

في نهاية عام 1988 بدأت الجماعة بتسفير عناصرها القيادية إلى باكستان عن طريق اليمن والسعودية وتركيا لتلقي دورات عسكرية بمعسكر الفاروق التابع لتنظيم القاعدة. وتستغرق مدة التدريب 3 شهور 
يتمرن فيها المتدرب على استخدام الأسلحة الخفيفة والمتوسطة والطبوغرافيامن وصناعة المتفجرات، ثم

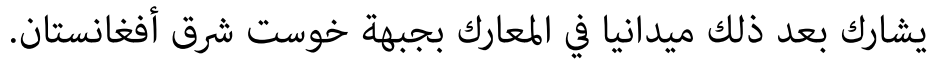

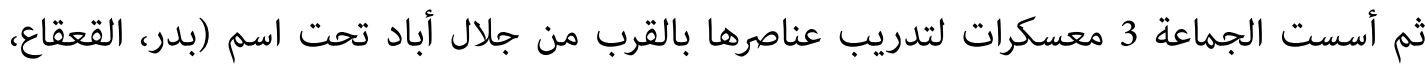

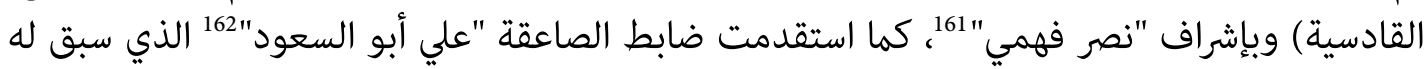

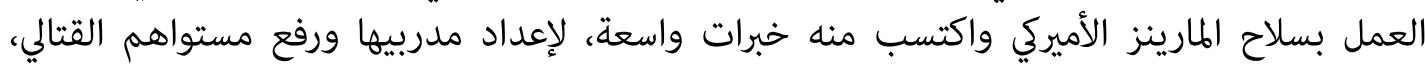

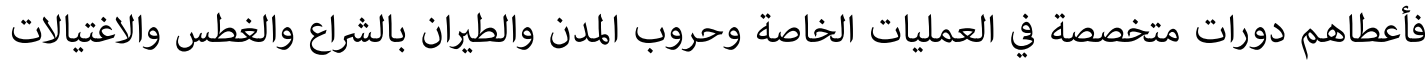

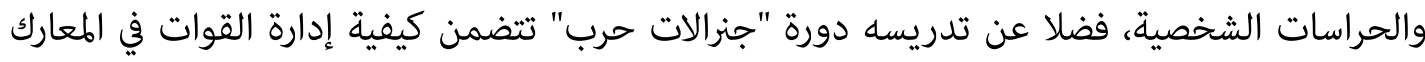
وقراءة الخرائط وتنظيم الكتائب والسرايا والفصائل. تصرئ. الثاني: تسفير العناصر المدنية للتدريب بالخارج:

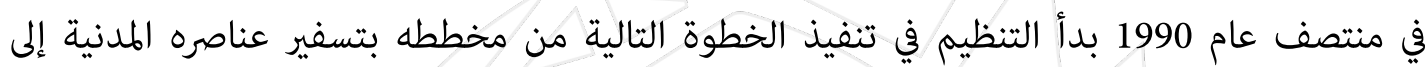
باكستان وأفغانستان للتدريب، بعد أن انتهى من إنشاء معسكراته وإعداد مدربيه خلال الفيد الفترة السابقة.

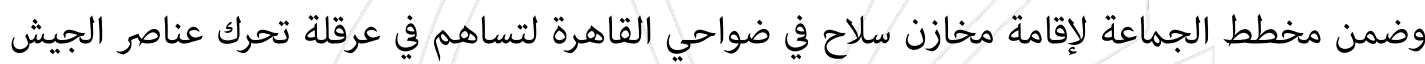

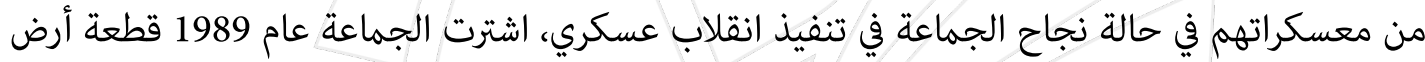

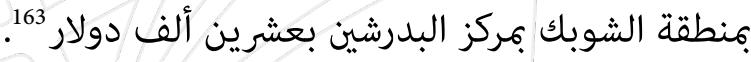

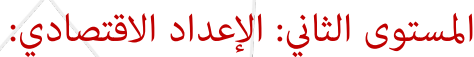

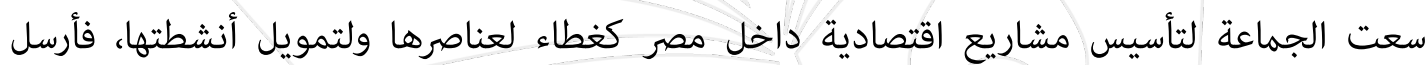

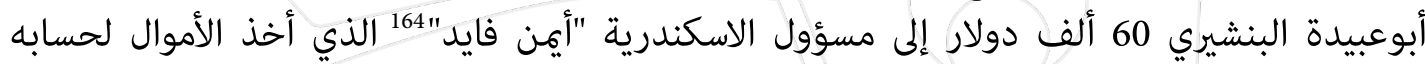

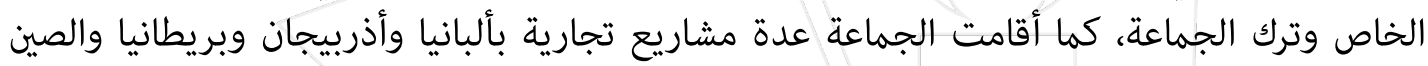

160 - الطبوغرافيا تشمل قراءة الخرائط وتحديد الاتجاهات. 161 - قتل بغارة أمريكية على أفغانستان عام 2001.

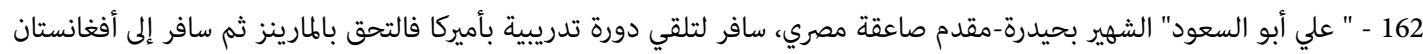

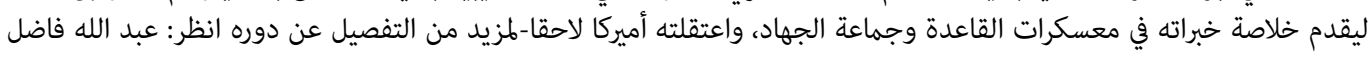
هارون - حرب على الإسلام - ج1 - صلئس(313-328). 163 - ملف التحقيق مع أحمد سلامة-ص 17. 164 - ملف التحقيق مع أحمد سلامة-ص18، 36. 
والسعودية، كما اشترت لجنة الوثائق مطبعة في باكستان لطبع المنشورات والاصدارات الخاصة بالجماعة، ولاستخدامها في تزوير جوازات السفر. المستوي الثالث: قتتين البناء الداخلي والانتشار داخل مصر وخارجها: أقامت الجماعة بباكستان مضيفة لعناصرها يقيمون بها، ويتلقون فيها دورات متنوعة فأعطاهم أيمن

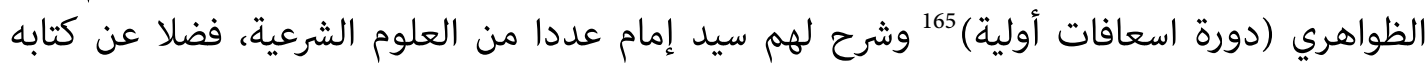

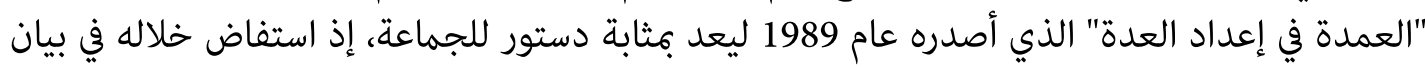

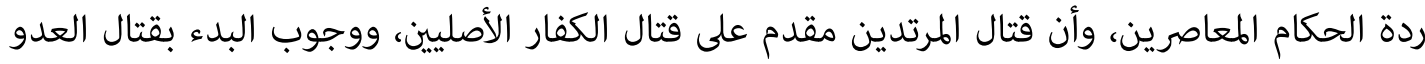

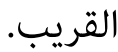

ونجحت الجماعة في تكوين عدة مجموعات بالداخل المصري من أبرزها: مجموعة أبو زعبل بقيادة

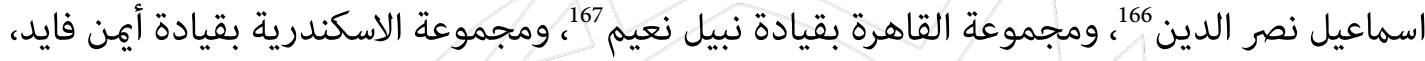

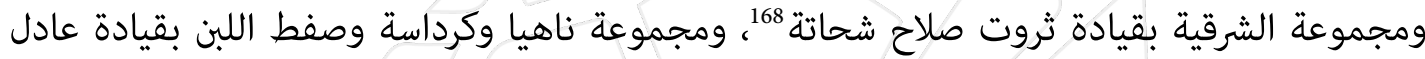

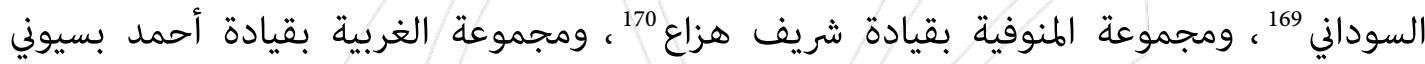
دويدار '، ومجموعة بني سويف بقيادة مجدي كمال. ونجح "ثروت صلاح" في دعوة عدد من الأفراد لينضموا إلى الجماعة منهم زميله المحامي “هاني لهاني

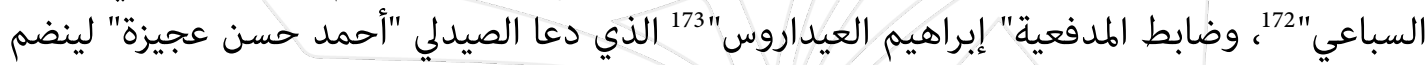

165

166 - مهندس، اعتنق الفكر الجهادي على يد نبيل نعيم عام امنيد 1980، وحكم عليه بالسجن 15 سنة في قضية طلائع الفتح، وأيد داخل السجن وثيقة "ترشيد العمل الجهادي" التي طرحها سيد إمام عام الفي يل نيل نعيم عادي 2007.

167 -سجن عدة مرات، وبلغ أخر اعتقال له قرابة 19 سنة، انقلب داخل السجن على جماعة الجهاد، وخرج عقب ثورة يناير.

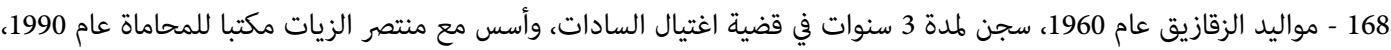

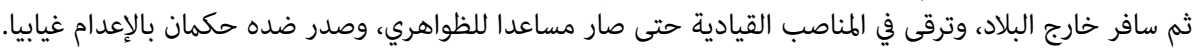
169 - أعدم في قضية خان الخليلي.

170 - شيخ سلفي من شبين الكوم، تقارب مع جماعة الجهاد، واعتقل مدة طويلة، وسافر إلى الشام للمشاركة في الثورة السورية. 171 - مواليد 1956 - ميت حبيش مركز طنطا-هرب من مصر مطلع التسعينيات، وتولى مسؤولية محطة اليمن، وترك الجماعة عقب تحالفها مع القاعدة، وقُتل على يد الأمن اليمني عام 2007. 172 - مواليد 1960 بالقناطر الخيرية-محامي-هرب من مصر مطلع التسعينات وصار عضوا باللجنة الإعلامية للجماعة.

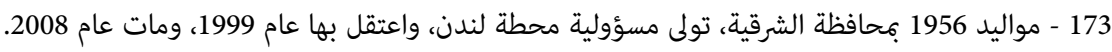




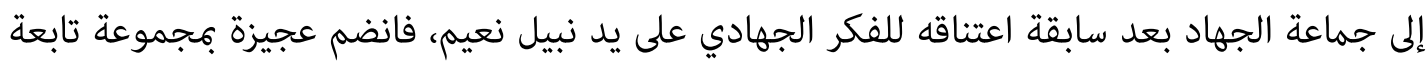

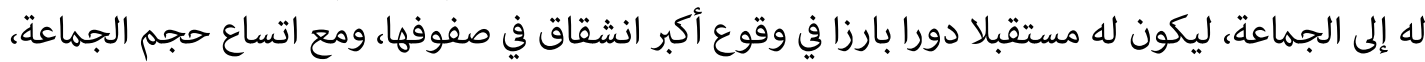

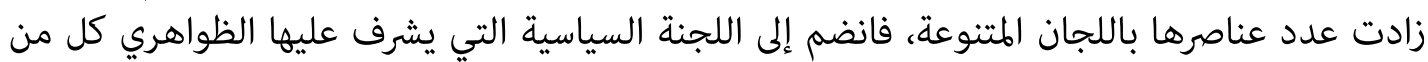
أحمد عجيزة ورفيقه ايهاب صقدر عادها بالجان المتنوعة

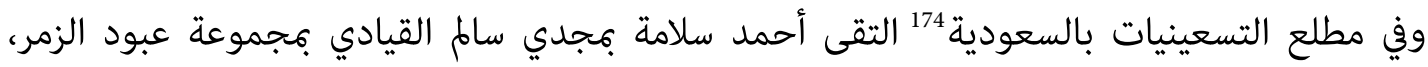

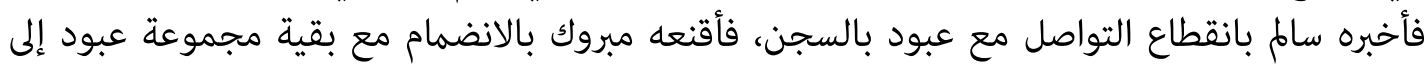

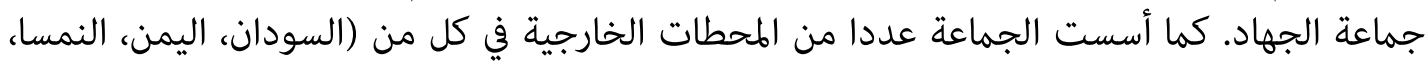

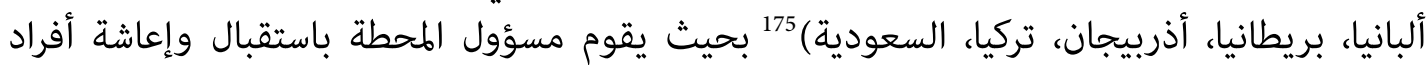

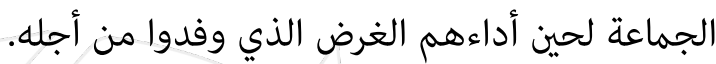


المستوى الرابع: كيفية التواصل مع أفراد الجماعة

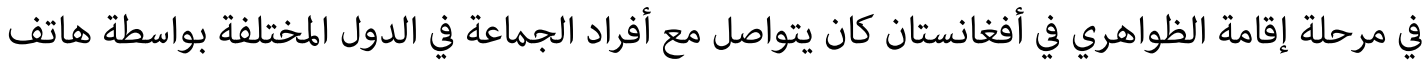

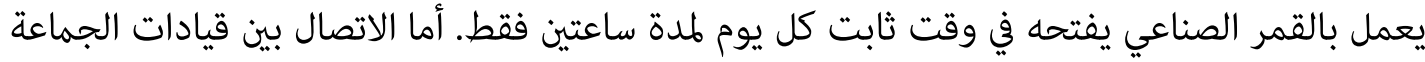

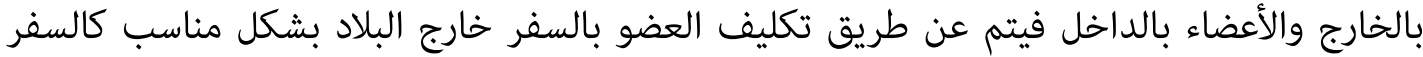
للحج والعمرة، أو عن طريق التليفونات والرسائل البريدية والفاكس. المستوى الخامس: العلاقات الخارجية والرحيل إلى السودان واليمن:

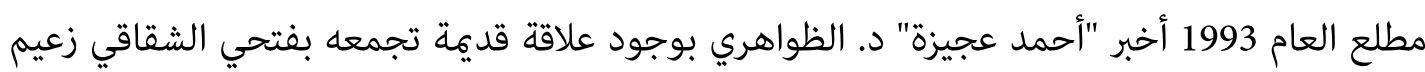

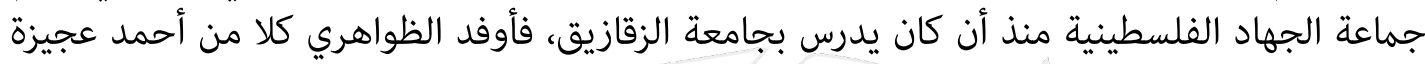

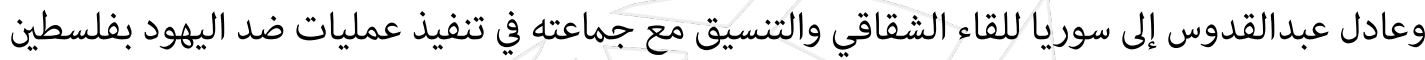

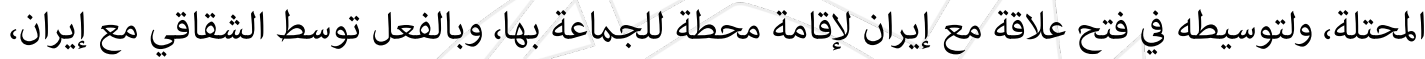

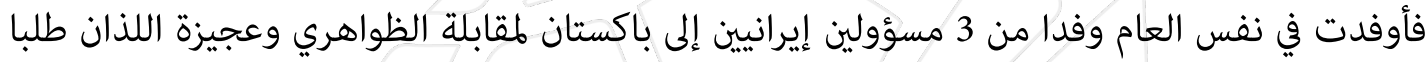

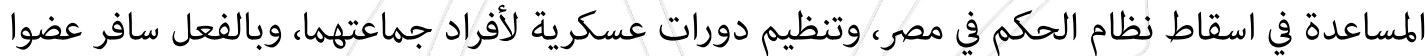

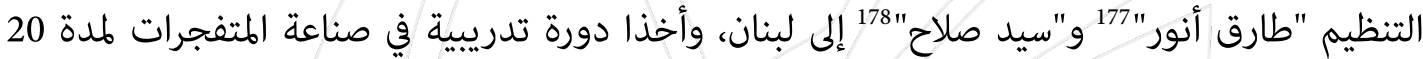
يوم في معسكرات حزب الله 179.

ومع مطلع عام 1992 وتحول الساحة الأفغانية لساحة حرب أهلية، تزايد تضييق باكستان على الجهاديين

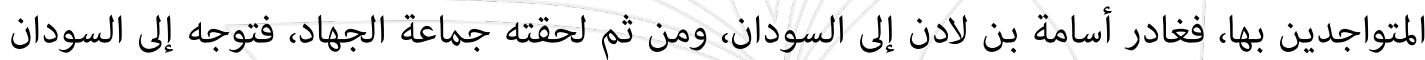

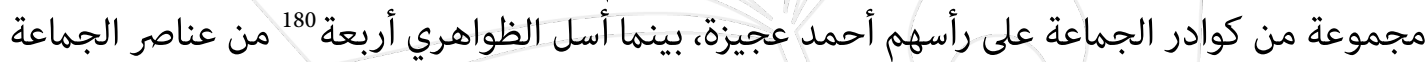

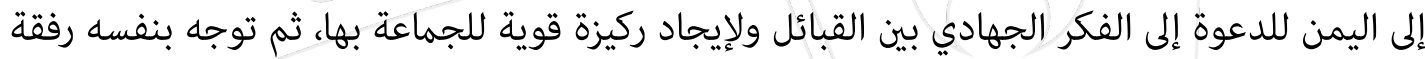
بعض مساعديه للإقامة باليمن.

176 - اعترافات مسؤول محطة ألبانيا "شوقي سلامة" بجريدة الوسط اللندنية 18 / 10 / 2001-والحلقة الثالثة من اعترافات أحمد النجار. 177 - قُتل بغارة أمريكية على أفغانستان عام 2001. 178 - أعدم في قضية محاولة اغتيال عاطف صدقي. 179 - ملف التحقيقات مع أحمد سلامة: ص43، 44. 180 - هم "ناجي الخولي-صفوت عثمان-أسامة صديق-عاطف أبو جبل". 


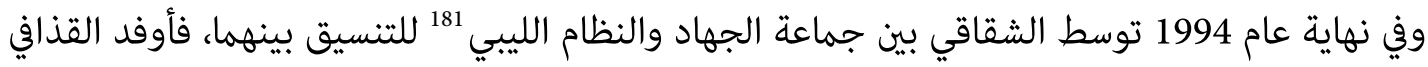

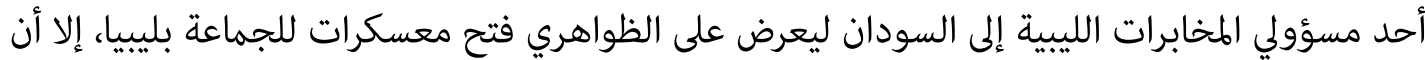

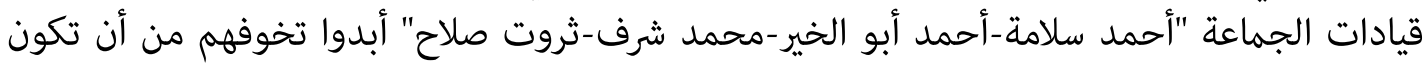
هذه مكيدة من القذافي للقبض عليهم وتسليمهم للنظام المصرئ أحمدي.

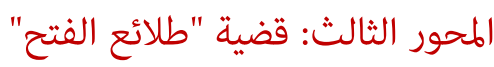

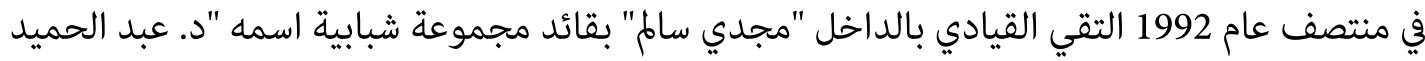

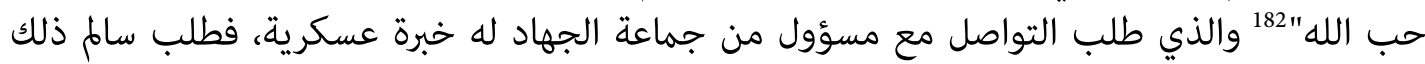

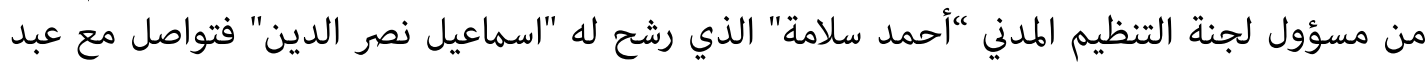
الحميد.

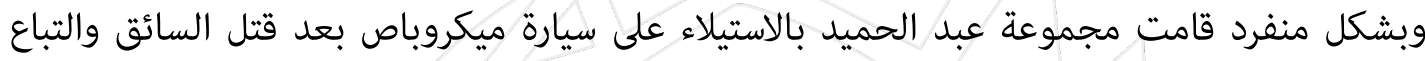

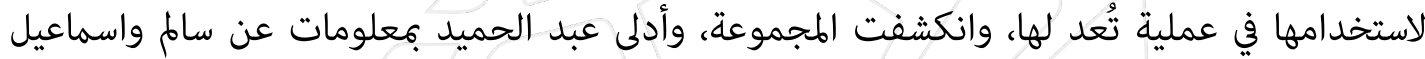

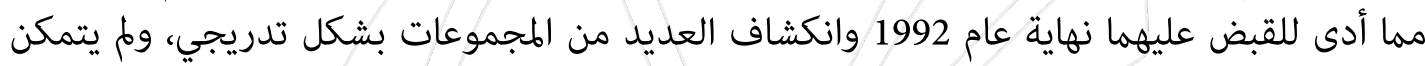

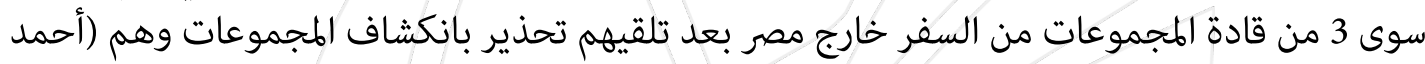

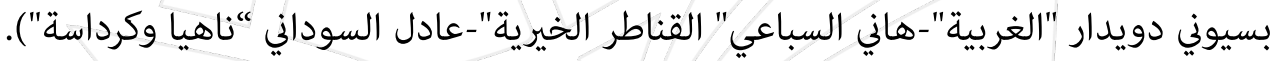
وبحلول منتصف عام 1993 بلغ عدد المقبوض عليهم 1000 فرد، تم تقديم 800 للمحاكمات في 5 قضايا

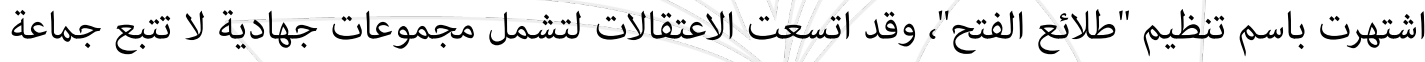

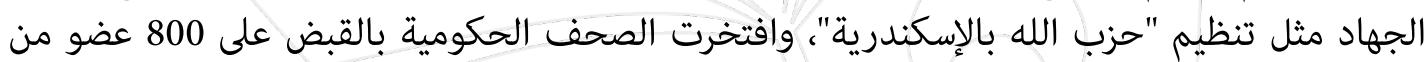
جماعة الجهاد دون إطلاقهم طلقة واحدة. انفجرت المشاكل الداخلية بالجماعة عقب سقوط معظم عناصرها داخل مصر بيد الأجهزة الأمنية،

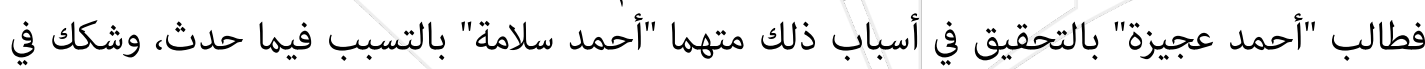

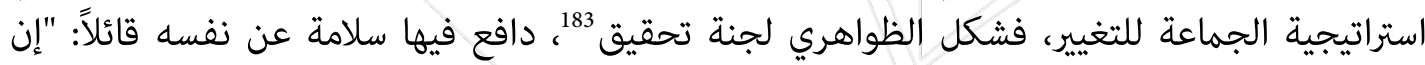

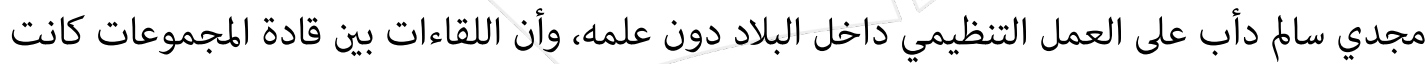
تتم وفقا للاحترازات الأمنية المتبعة، وأنه سارع عقب التب القبض البلاد دون على وأن سالم ونصر الدين إلى إبلاغ بقية قادة المعادة

181 - ملف التحقيقات مع أحمد سلامة: ص63.

182 - أعدم على خلفية حادث قتل السائق والتباع. 183 - ملف التحقيقات مع أحمد سلامة: ص(46-48). 
المجموعات بضرورة مغادرة البلاد حفاظا عليهم وعلى مجموعاتهم، وطلب سلامة الاستقالة من مسؤولية لجنة العمل المدني، ووافق قادة الجماعة على طلبه".

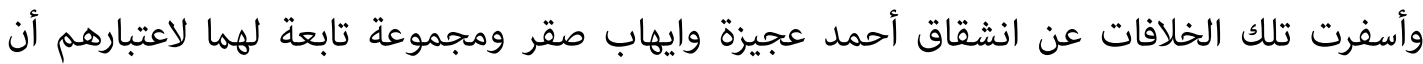

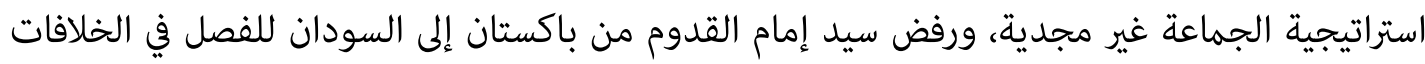

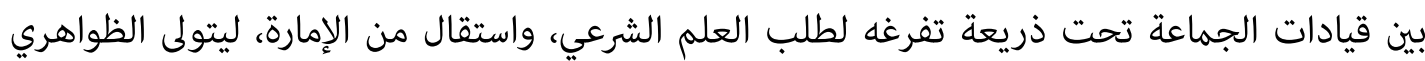

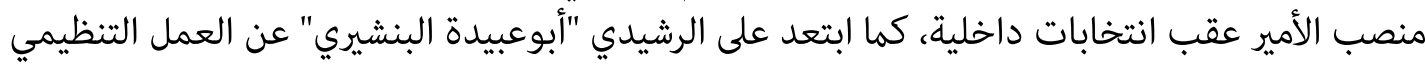

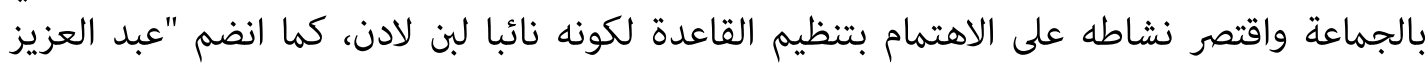
الجمل" مسؤول اللجنة العسكرية إلى تنظيم القاعدة.

المحور الرابع: إعادة الهيكلة الأولى مسولى

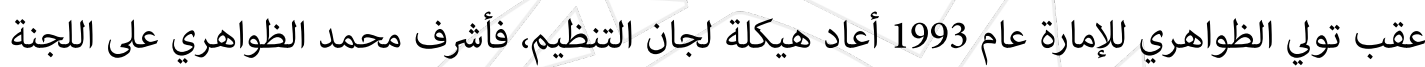

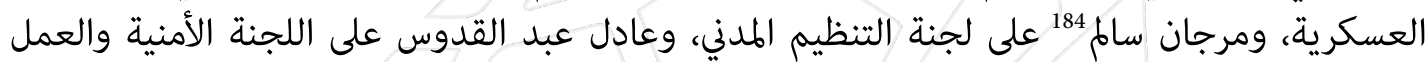

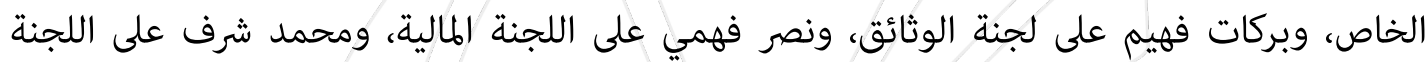

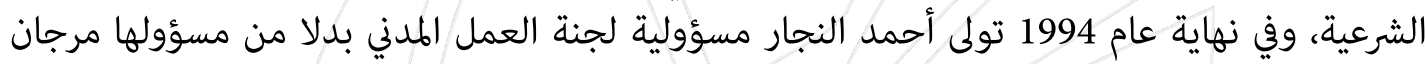
سالم الذي تولى مسؤولية اللجنة الشرعية بدلا من محمد شرف.

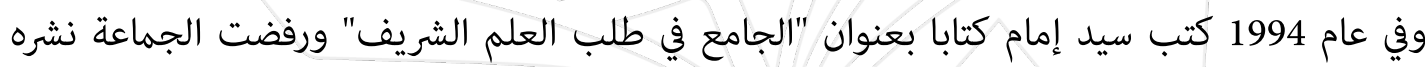

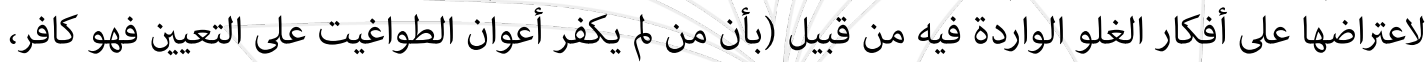

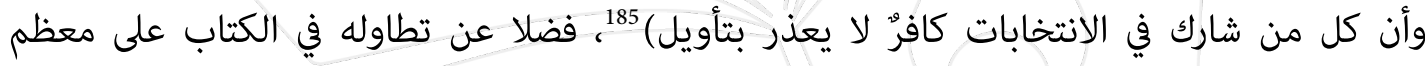

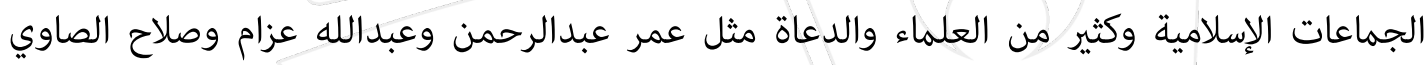

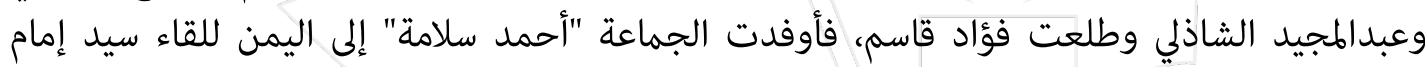

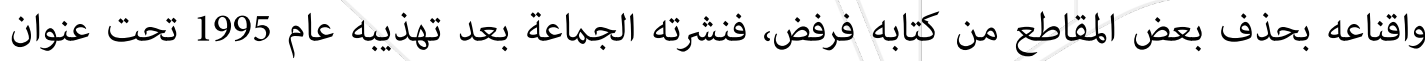

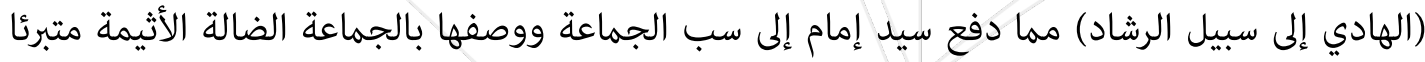

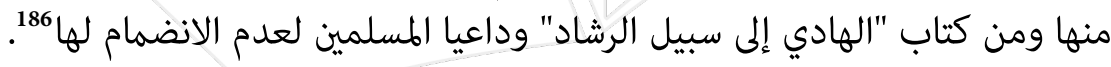

184 - اعتقلته باكستان بمنطقة وزيرستان عام 2009 وسلمته إلى مصر، وخرج من السجن بعد ثورة يناير 2011، وأعيد القبض عليه في نوفمبر 2013، ومات بسجن العقرب عام 185 - أين الظواهري -إصدار مرئي بعنوان "اللقاء المفتوح - الجزء الأول" أصدرته مؤسسة سحاب عام2013. 186 - انظر: عبد القادر عبد العزيز-مقدمة الطبعة الثانية لكتاب الجامع في طلب العلم الشريف: ص10، 11. 
وعقب انكشاف معظم مجموعات الجماعة داخل مصر، تعرض الظواهري إلى ضغوط من مساعديه

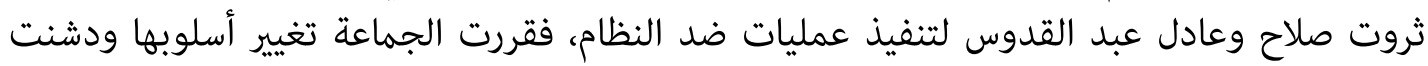

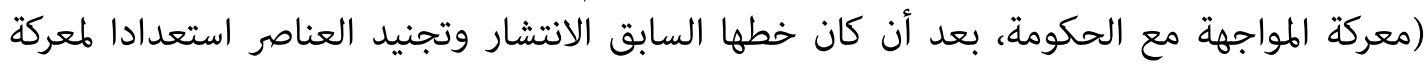
التغيير)

المحور الخامس: مرحلة استهداف الشخصيات السياسية:

دخلت الجماعة هذه المعركة حسب الظواهري من أجل (المحافظة على إرادة القتال وإفشال حملة

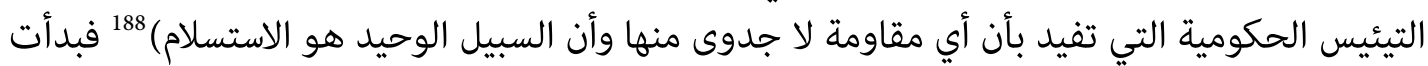

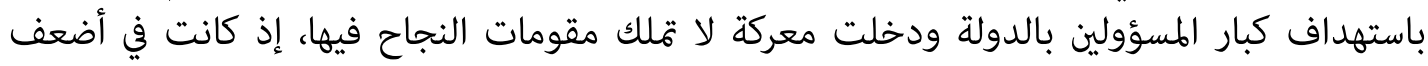

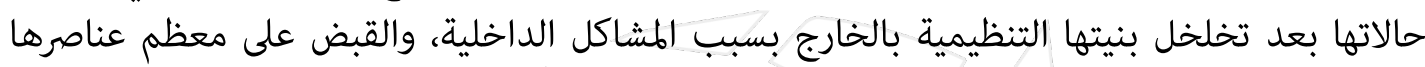
بالداخل. 1- م- وزير الداخلية حسن الألفي: استهدفت لجنة العمل الخاص موكب وزير الداخلية حسن الألفي بدراجة نارية مفخخة في

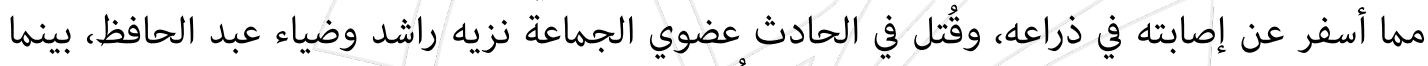

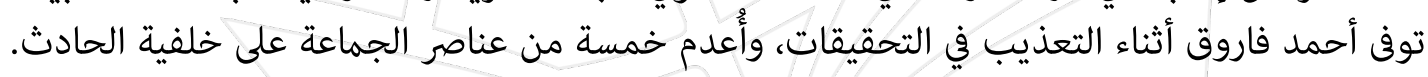
2ـ رئيس الوزراء عاطف صدقي

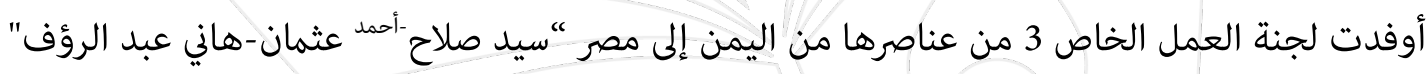

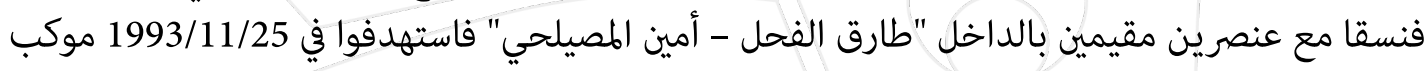

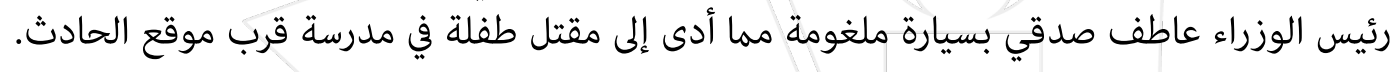

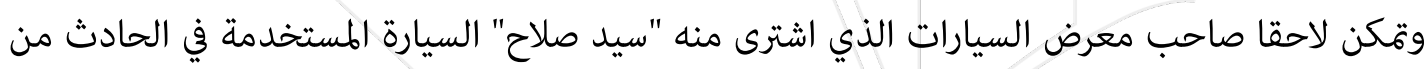

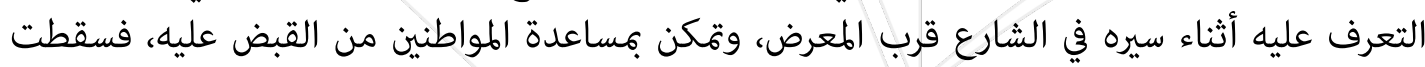

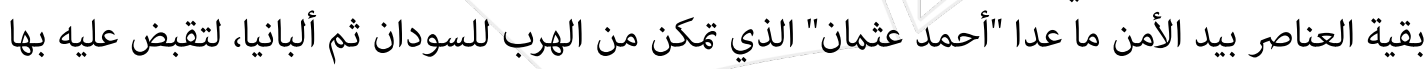

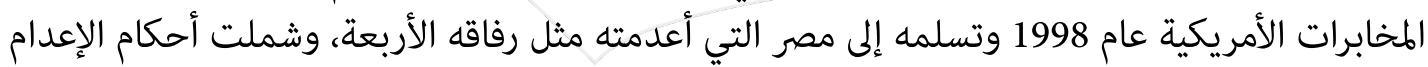


الغيابي "ياسر السري" مسؤول لجنة الإعلام الذي نشر بيانا بمسؤولية الجماعة عن العملية. وقبل أن يدلي

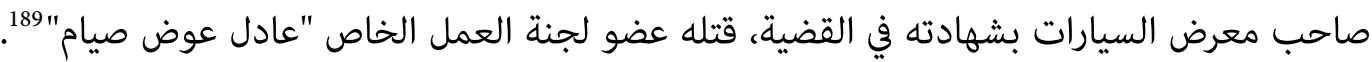

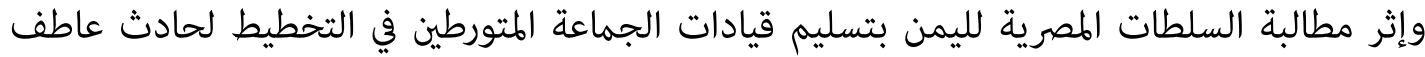

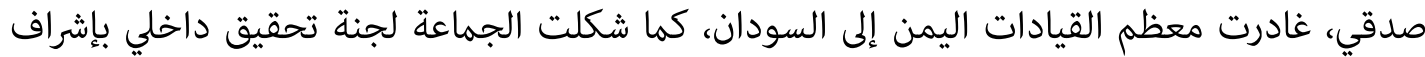

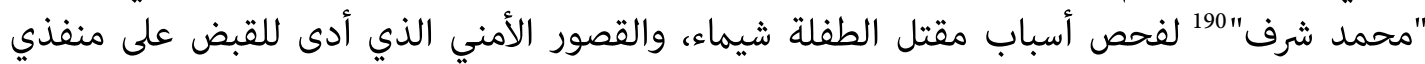

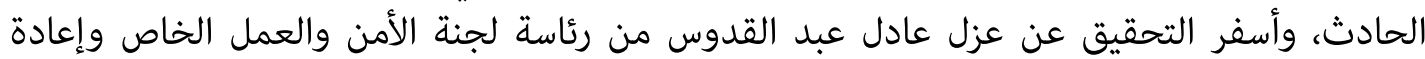

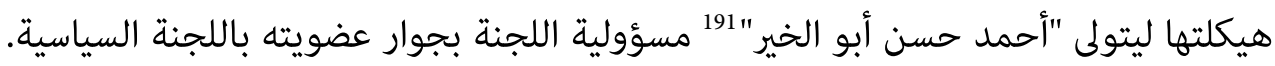

كما أوفد الظواهري كلا من هاني السباعي وياسر السري إلى لندن ليحصلا على اللجوء السياسي بها، ويتوليا

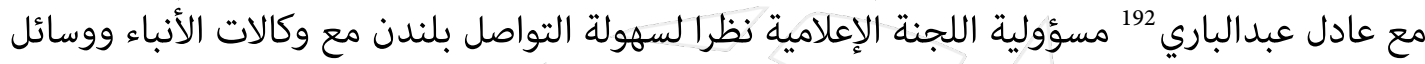

الإعلام.

3ـ مخططان لاغتيال حسني مبارك

وضعت اللجنة العسكرية بالجماعة مخططا لاستهداف "حسني مبارك" في قاعدة رأس التين بالإسكندرية

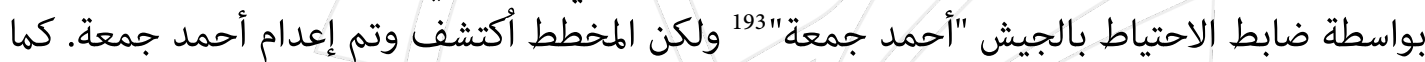

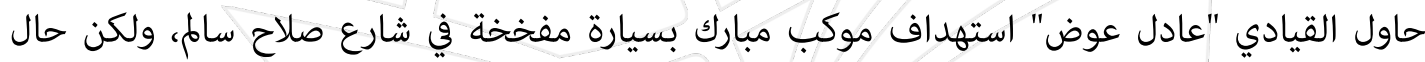
تغيير مسار الموكب دون نجاح المخطط.

189 - قُتل باشتباك مع الشرطة في منطقة المنيب عام 1994.

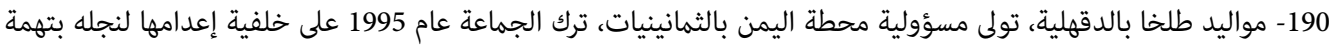

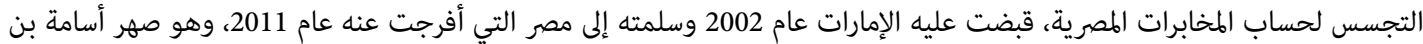
لادن إذ أن حمزة بن أسامة متزوج من حفيدته.

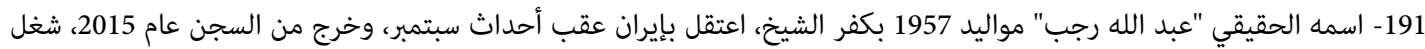
منصب نائب أمير تنظيم القاعدة، واغتيل بغارة أمريكية بالشام عام 2017.

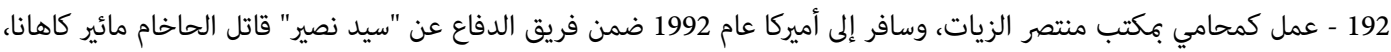

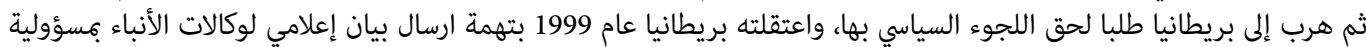

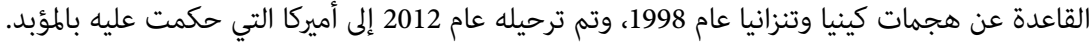


المحور السادس: ايقاف العمليات

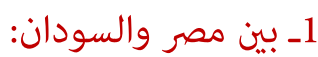

إثر نجاح مسؤول الأمن بالسفارة المصرية في السودان في تجنيد نجلي أحد قيادات تنظيم القاعدة وجماعة إداء

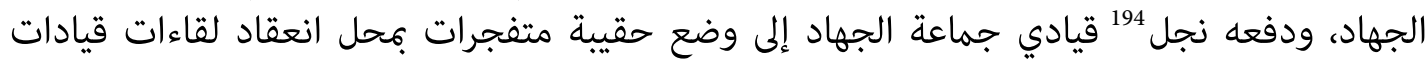

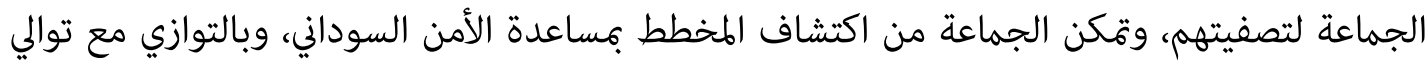

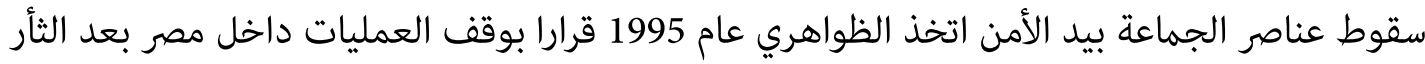

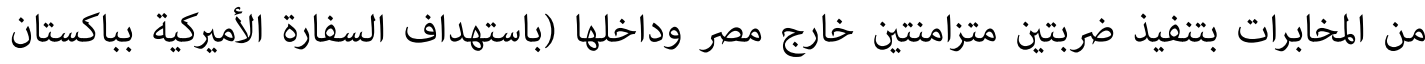

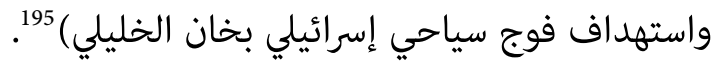
وملا عجزت مجموعة التنفيذ عن استهداف السفارة الأميركية استهدفت السفارة المصرية 196 بإسلام أباد

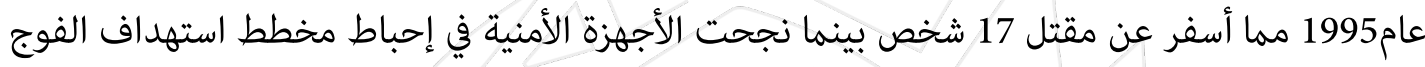

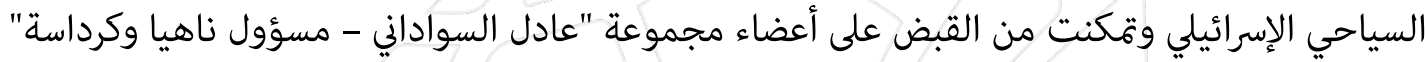

القائين على تنفيذ المخطط. 2ـ الرحيل إلى أذربيجان

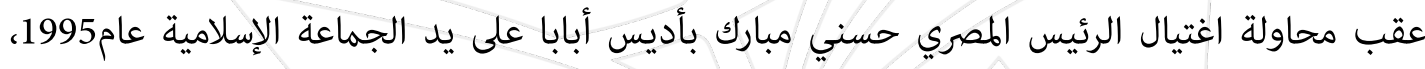

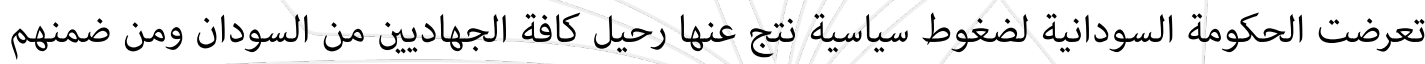

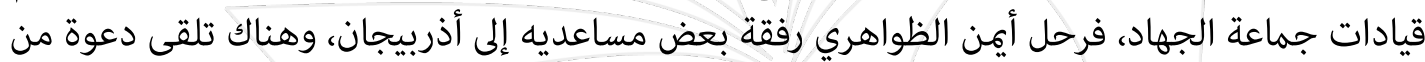

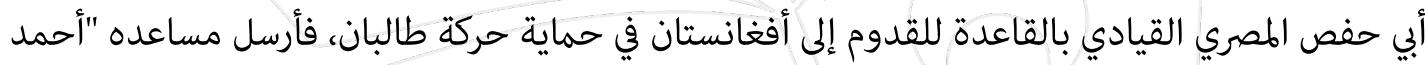

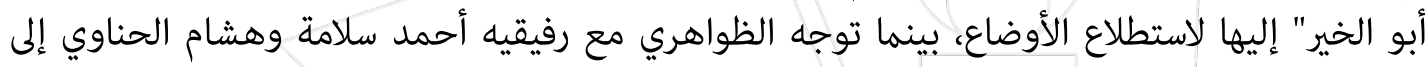

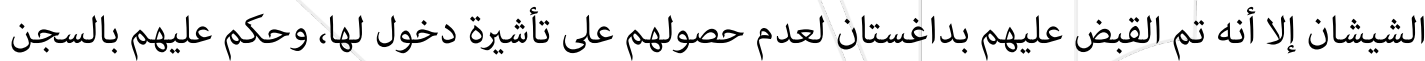

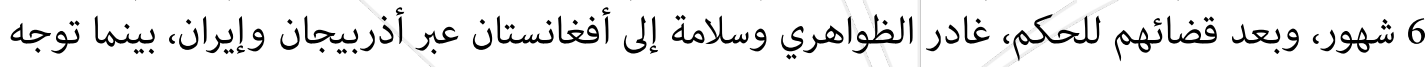

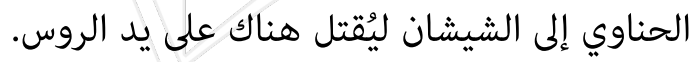

194 - اسمه "مصعب محمد شرف" - أعدمت الجماعة الشابين إثر محاكمة داخلية بإشراف مسؤول اللجنة الشرعية "مرجان سالم". 195 - أيمن الظواهري-فرسان تحت راية النبي -ص (185-188). 196 - نفذ الحادث محمد حسن عبد الفتاح وأيمن عبد الرازق بعد ارسالهما من السودان إلى باكستان عبر اليمن. 197 - إثر تزايد الصراعات السياسية بألبانيا انتقل أحمد سلامة منها إلى أذربيجان وأسس محطة للتنظيم عام 1995. 
3ـ العودة إلى أفغانستان والبحث عن حلفاء:

وصل الظواهري ورفيقاه ثروت صلاح وأحمد سلامة إلى أفغانستان في أغسطس 1997، وأرسلوا إلى بقية عناصر الجماعة عن (استعداد بن لادن لكفالة عناصر التنظيم بأفغانستان وإعطاء كل أسرة ما ما يعادل

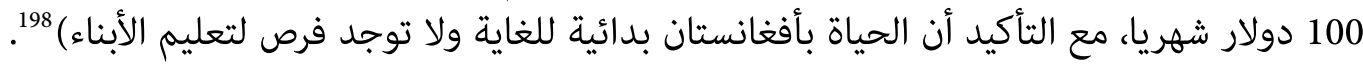
ونتيجة لتعثر جماعة الجهاد في تحقيق أهدافها، ومرورها بأزمة مالية حادة، وسقوط عناصرها داخل مصر

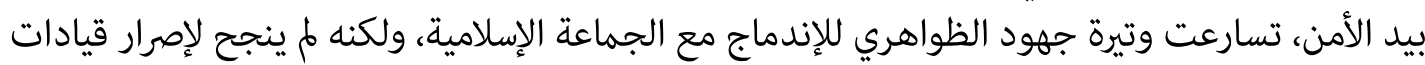

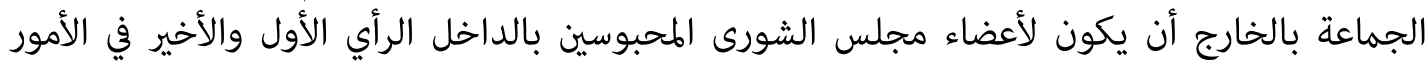

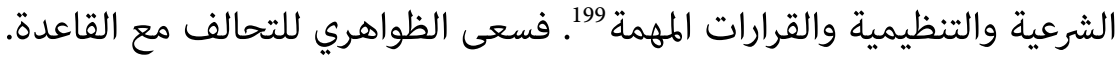

اتفق زعيم القاعدة بن لادن مع الظواهري ومع قيادي الجماعة الإسلامية المصرية "إسلام الغمري" ممثلا

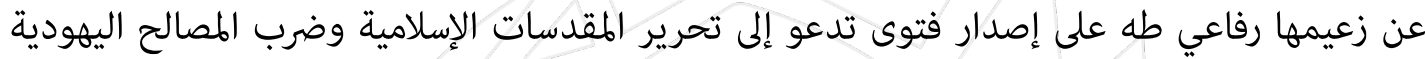

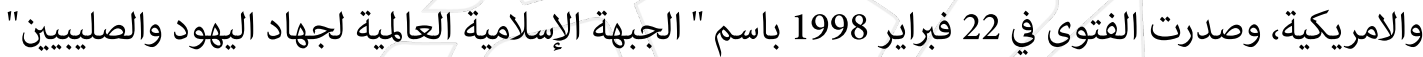
ولكن سرعان ما سحب رفاعي طه توقيعه عقب تعرضه لضغوط من قيادات الجماعة داخل السجون،

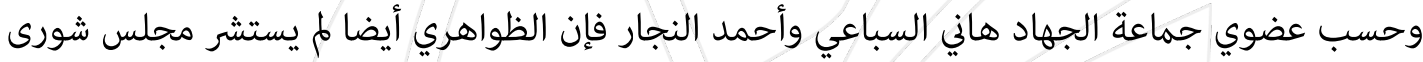

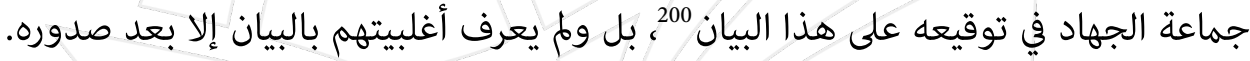
الهحور السابع: إعادة الهيكلة الثانية 201:

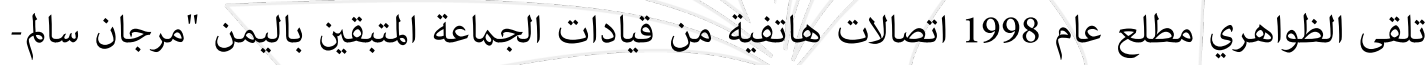

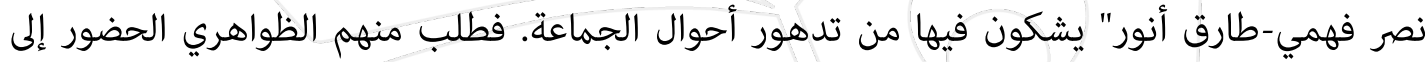

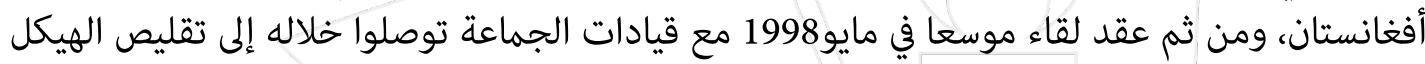
التنظيمي للجماعة ليشمل 4 لجان فقط هي: لجنة الوثائق بإشراف بركات فئ فهيم، ولجنة فئة التنظيم المداني

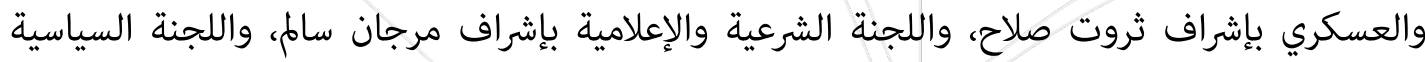
والاتصالات الخارجية والمالية بإشراف أحمد حسن أبو الخير.

198 - اعترافات أحمد النجار - الحلقة الأولى-موقع شفاف الشرق الأوسط بتاريخ 26 / 2004/9. 199 - انظر -أيمن الظواهري-فرسان تحت راية النبي -ص (310-312). 200 - حوار هاني السباعي مع جريدة الحياة اللندنية بتاريخ 2002/9/4-اعترافات أحمد النجار "الحلقة الثانية". 201 - ملف التحقيقات مع أحمد سلامة: ص(80-86). 
كما اتفقوا على تعيين بركات فهيم نائبا للظواهري، ووافقوا على الانضمام إلى الجبهة الإسلامية العالهية

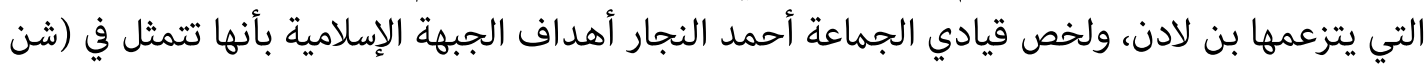

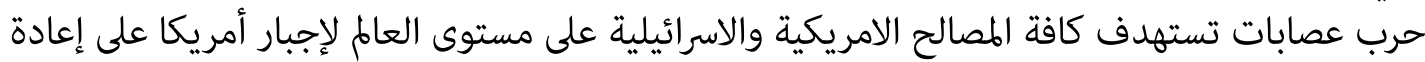

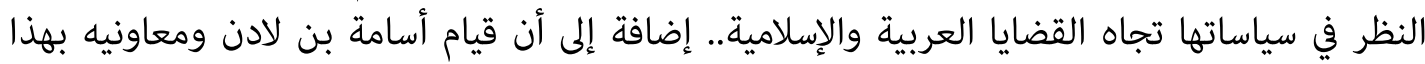

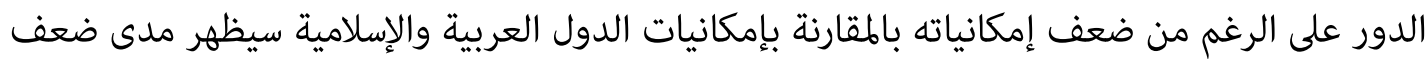

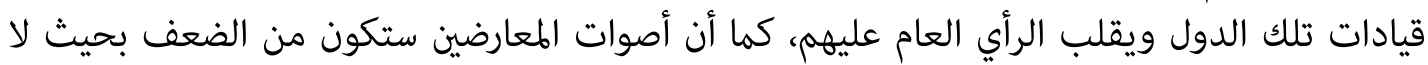

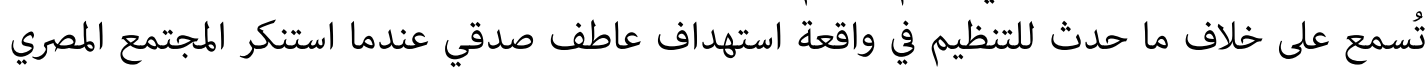

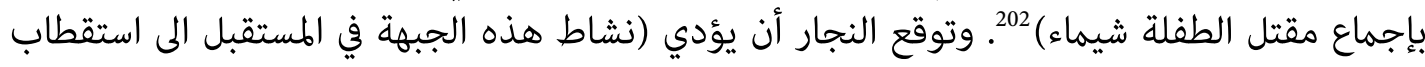

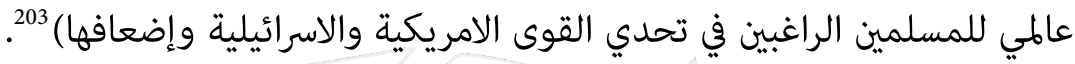

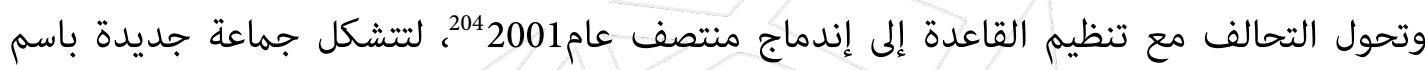

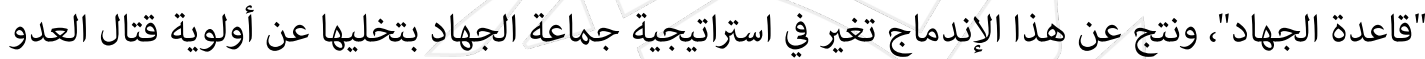

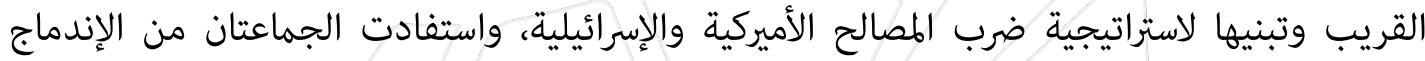
بتعاون كوادرهما معا وتقليص نقاط ضعف كل منهما. المحور السابع: تبعات التحالف ثم الاندماج مع القاعدة: عقب إعلان تحالف ثم اندماج جماعة الجهاد مع تنظيم القاعدة تعرضت قيادات الجماعة لحملة مطاردة

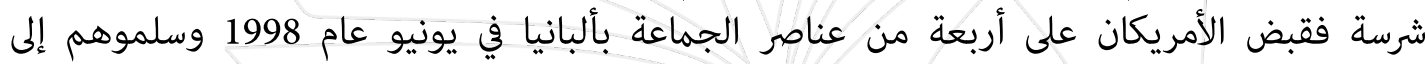

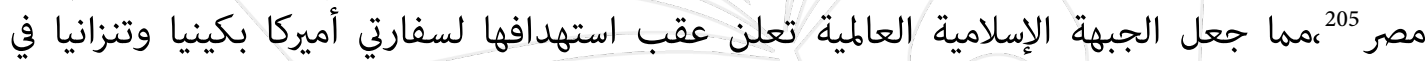

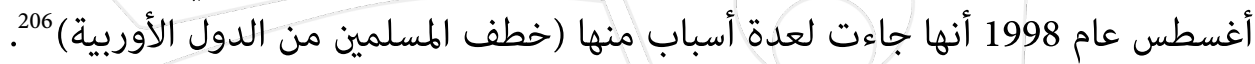

202 - الطفلة شيماء تلميذة قتلت إثر إصابتها في انفجار سيارة مفخخة استهدف موكب رئيس الوزراء عاطف صدقي. 203 - الحلقة الثانية من ملف التحقيقات مع أحمد النجار - مصدر سابق.

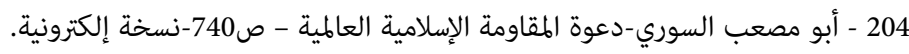

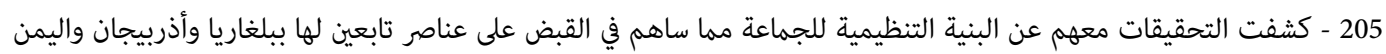
والكويت والإمارات، وقتت محاكمة 107 فرد منهم 44 حضوريا في قضية التهية اشتهرت باسم "العائدون من ألبانيا". 206 - ملف التحقيقات مع أحمد سلامة: ص84. 
كما قبضت المخابرات الأمريكية في يوليو 1998 على " أحمد سلامة مبروك" بأذربيجان أثناء تواجده بها

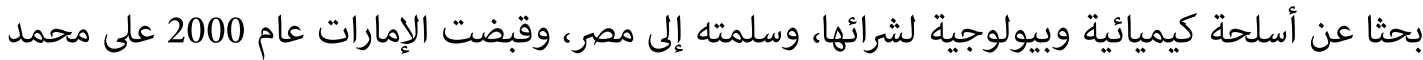
الظواهري وسلمته لمصر.

ويذكر سيمور هيرش في كتابه "القيادة العمياء"207أن الإدارة الأمريكية قامت باختطاف وتسليم 70

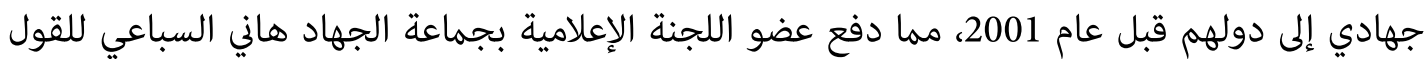

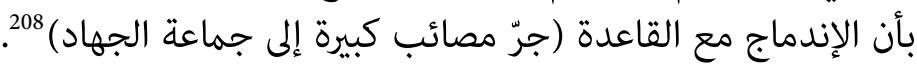
المحور الثامن: بقايا جماعة الجهاد والمنشقين عنها (2001-2011) خارج مصر تلاشت جماعة الجهاد بعد إندماج الظواهري وعدد من كوادر الجماعة مع تنظيم القاعدة، إنداء

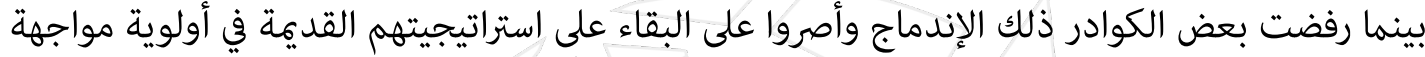

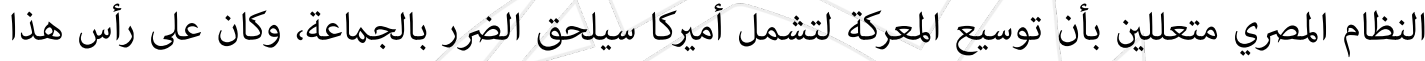

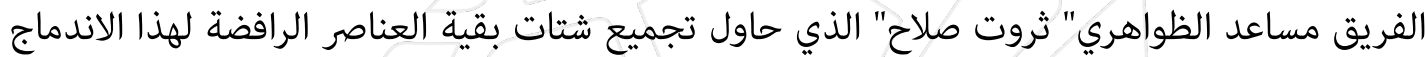

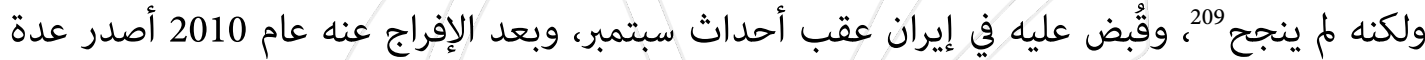
بيانات باسم "جماعة الجهاد" يُعبر فيها عن مواقفه مثل بيان بيانه الصادر دعمه للثورة المصرية، فضلا عن بيان لاحق عام 2012 دعا فيه لانتخاب عن محابه محمد مرسي للرئاسة. وعقب أحداث 11 سبتمبر تعرض أعضاء جماعة الجهاد بما فيهم المنشقون عنها لحملة مطاردة عالمية، إكباء

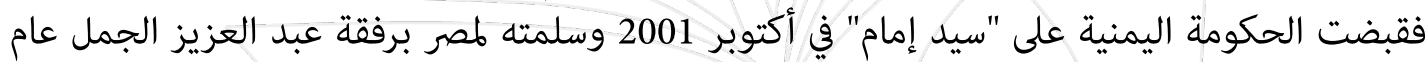

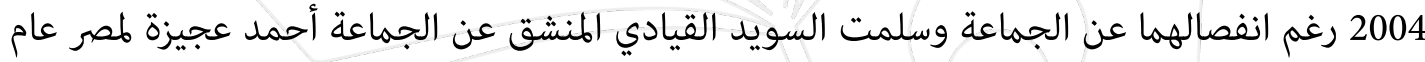

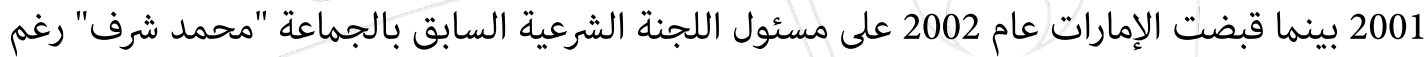
انفصاله عنها منذ عام 1995 وسلمته لمصر.

207 - سيمور هيرش-القيادة العمياء - ص61 - الدار العربية للعلوم - ط1. 208 - حوار هاني السباعي مع جريدة الحياة اللندنية بتاريخ 2002/9/4.

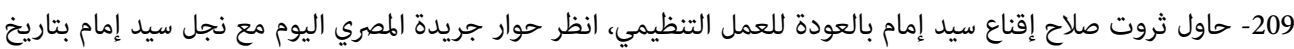

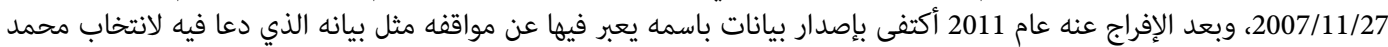

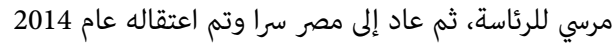
210 - نشره مركز المقريزي بلندن الذي يشرف عليه هاني السباعي. 
وتفككت جماعة الجهاد داخل السجون، وصار كل فرد منها معبر عن نفسه فقط وكتب سيد إمام عام

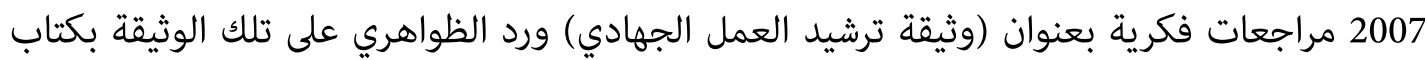

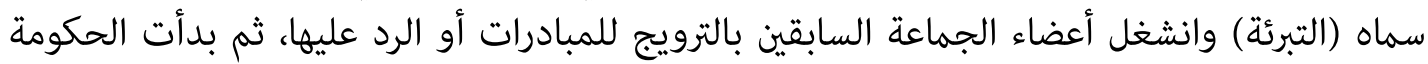

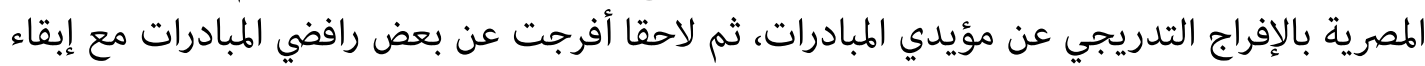

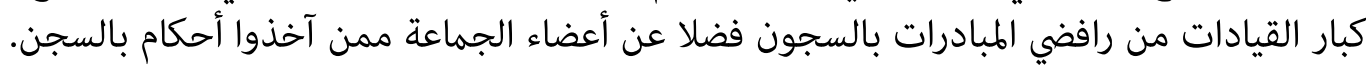

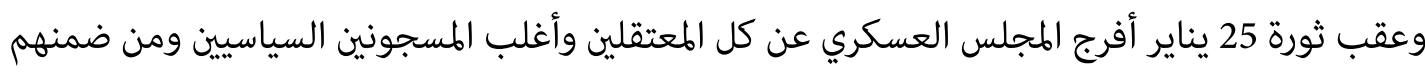

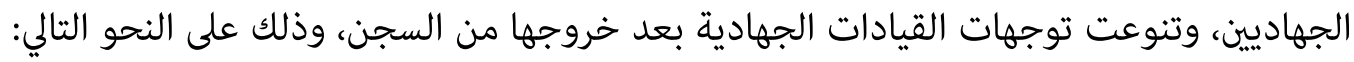

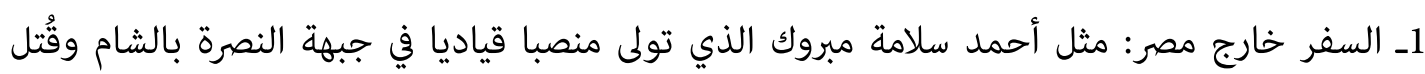
بغارة أمريكية بالشام عام

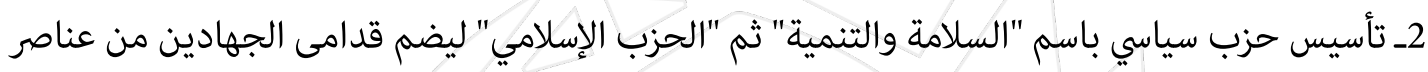

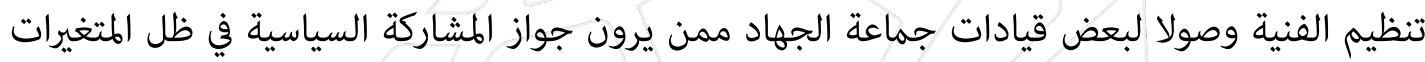
الجديدة مثل صالح جاهين ومجدي سالم.

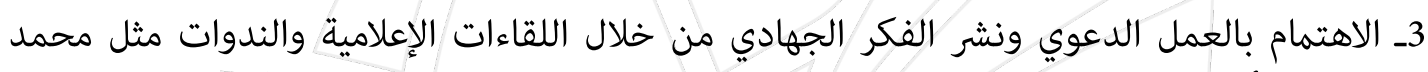

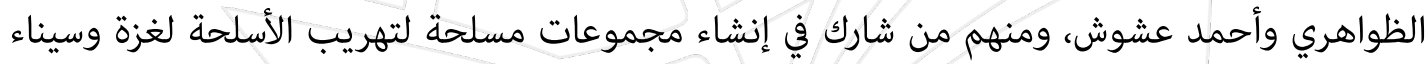

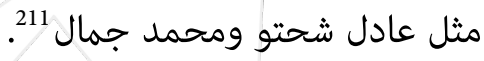
4ـ الانتكاس والانضمام للثورة المضادة ودعم الانقلاب العسكري مثل نبيل نعيم. 5ـ تصفية الحسابات مع الرفاق القدامى من خلال الهجوم الدائم عليهم في الفضائيات والصحف مثل مئم سيد إمام. وعقب الانقلاب العسكري اعتقلت الأجهزة الأمنية أغلب من بقي بهصر من القيادات الجهادية السابقة كمحمد الظواهري

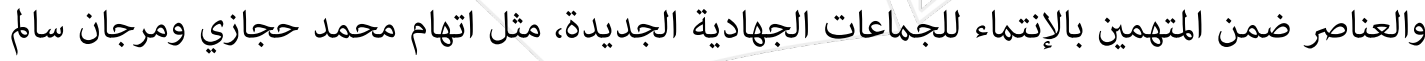

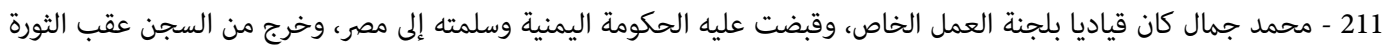

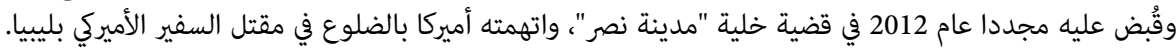


في قضية أنصار بيت المقدس، واتهام أسامة جبريل 213 في قضية أجناد مصر²، واتهام الشحات أبو سبحة 214 في قضية "أنصار الشريعة". الهحور التاسع: تقييم تجربة جماعة الجهاد من خلال السرد التاريخي السابق يمكن تقييم تجربة التيار الجهادي في بواكير نشأته وبالأخص جماعة

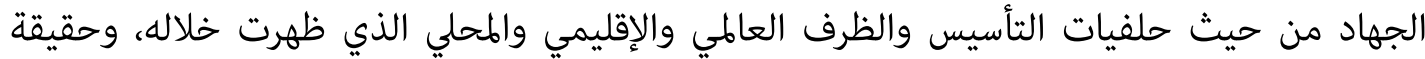

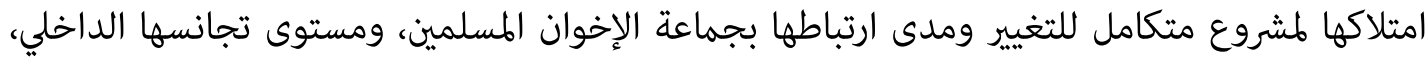
ونظرتها للدولة وعلاقتها بالمجتمع، وطبيعة أطروحاتها، والسمات العامة لعناصرها، وحجم نجاحاتهاتها وإخفاقاتها في النقاط التالية: 1-نشأت التجربة الجهادية الأولى في ظل نظام إقليمي متماسك ودول قومية قوية تحكم قبضتها على

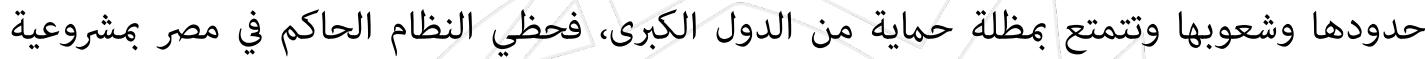

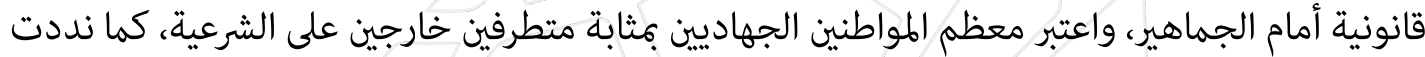

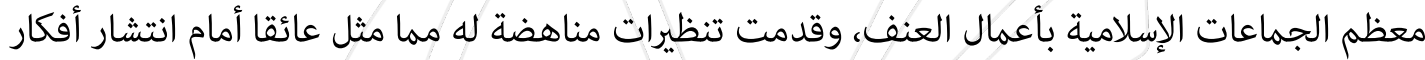
الجهاديين وأدى لافتقادهم إلى حاضنة شعبية قوية تقدم لهم الدعم المالي والبشري الذي يكفل الاستمرار. 2-تأسست المجموعات الجهادية الأولى على قاعدة الثأر من النظام الحاكم القمعي دون إمتلاكها لشروع

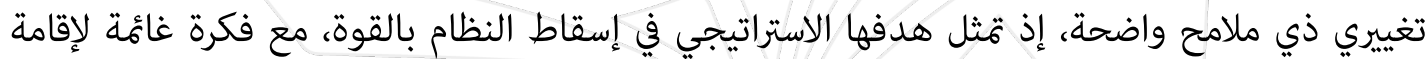

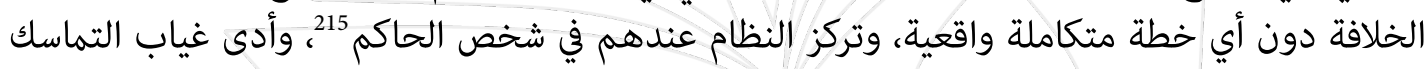

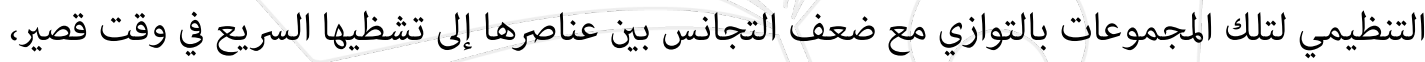
بينما أدت فترات السجن القصيرة إلى تازج بعض الأفراد وتكوينهم عقب خروجهم من السجوات السون بؤر عمل جديدة أكثر رسوخا. 3-تايز التيار الجهادي عن جماعة الإخوان وارتباطه بما حدث لها، إذ نشأت الحالة الجهادية وتطورت كحركة صدامية تتبنى حتمية المواجهة وتنبذ منهج جماعة الإخوان السلمي، وتعتبر قيادات جماعة إعة

213 - أحد عناصر جماعة الجهاد، اعتقل مدة طويلة في عهد مبارك على خلفية تدربه بأفغانستان. 214 - من عناصر جماعة الجهاد بمحافظة الشرقية، وسبق اعتقاله لمدة 15 سنة وأفرج عنه عام 2010، وقبض عليه مجددا مع نجليه عام 
الإخوان بثثابة عقبة أمام تطور المشروع الجهادي لاختلاف المناهج والمهارسات وأطروحات التغيير ${ }^{216}$

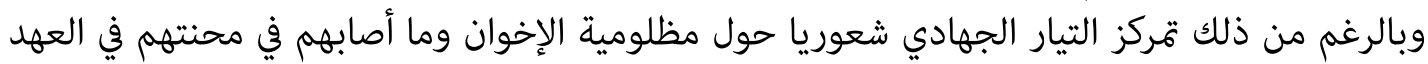

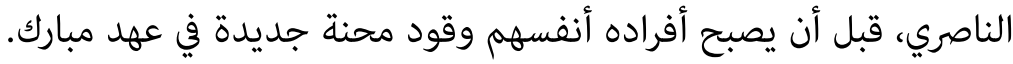

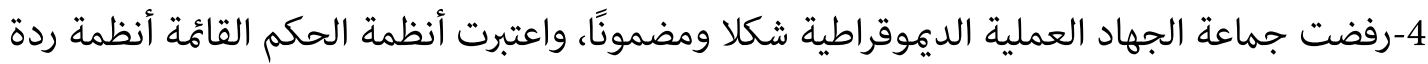

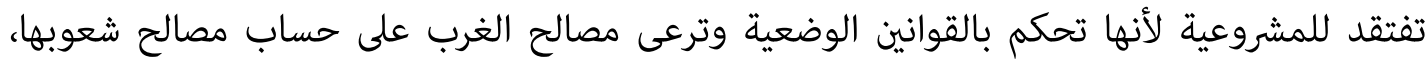

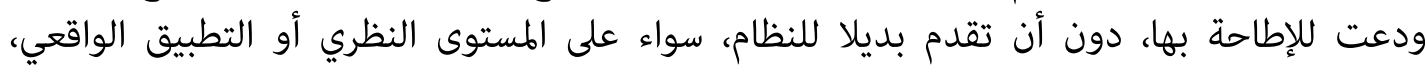

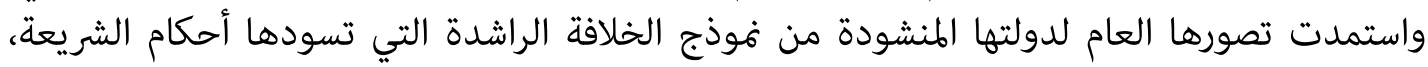

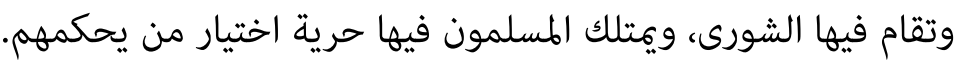

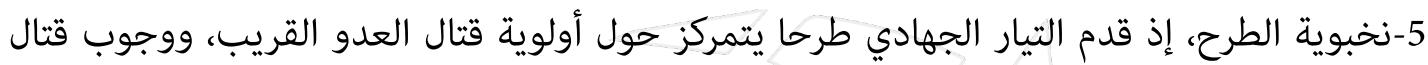

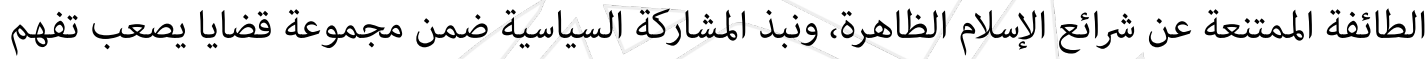

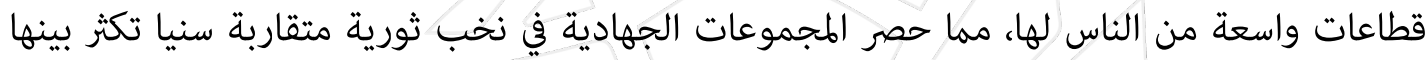
النقاشات الفكرية والشرعية ومن ثم الانشقاقات والنزاعات.

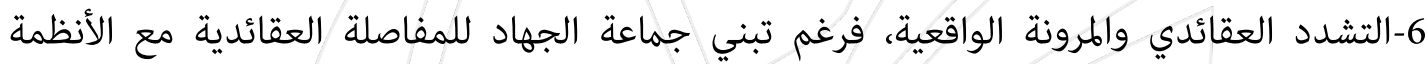

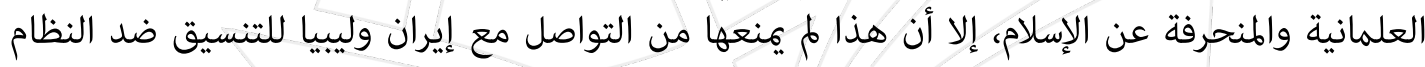
المصري الذي مثل لهم خصما مشتركا.

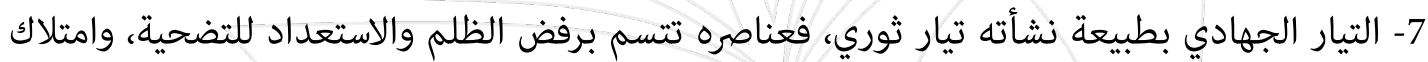

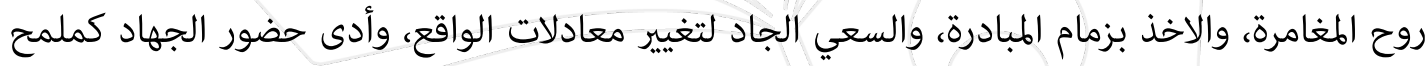

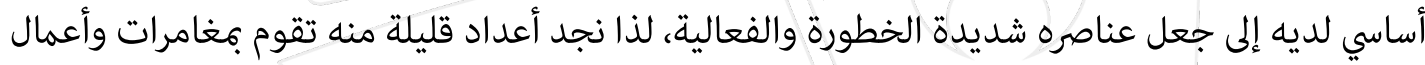

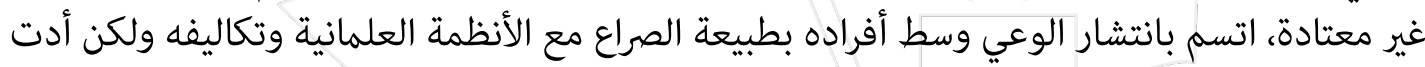

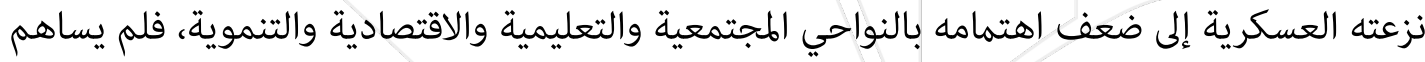
بأي أطروحات نظرية في تلك المجالات.

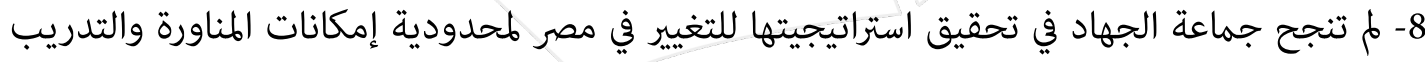

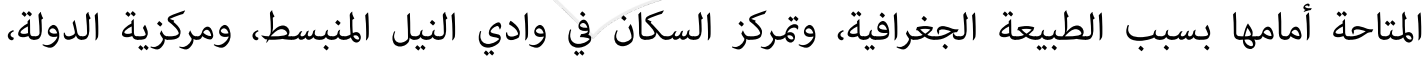

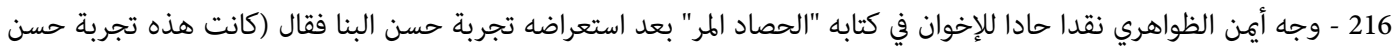

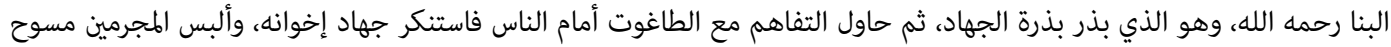

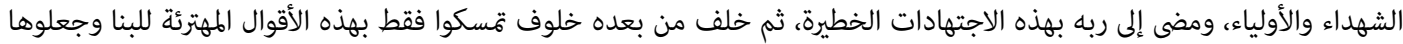

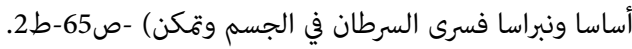


وسيطرتها القوية على المدن الكبرى والوادي، فضلا عن ضعف التمويل لافتقاد الجماعة لمصادر دعم إدماد

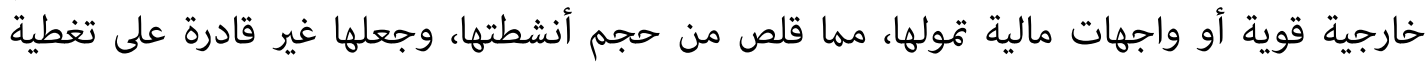

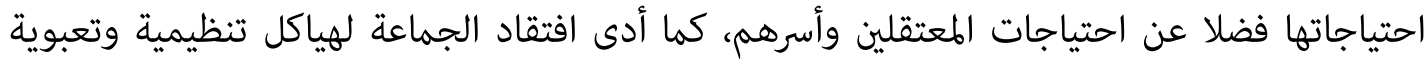

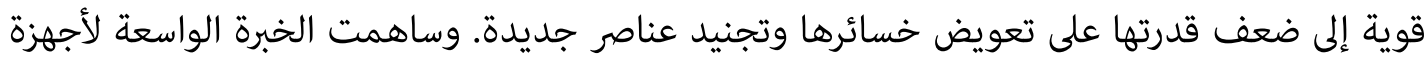

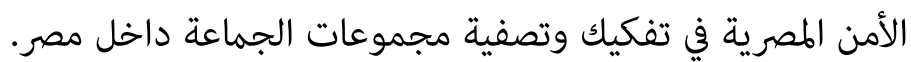

9- نجح التيار الجهادي في إحياء حالة المواجهة بعد القمع الناصري، وتمكن من استغلال الساحات

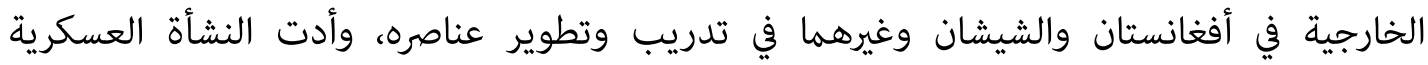

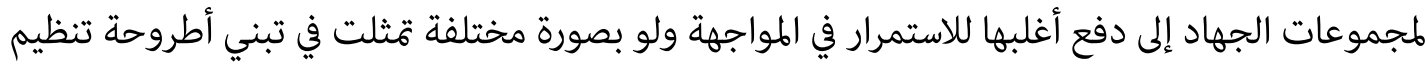

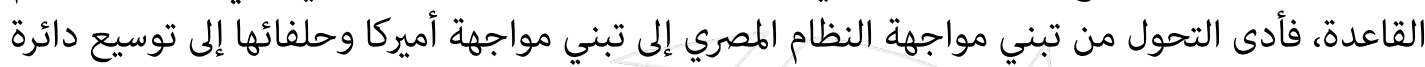

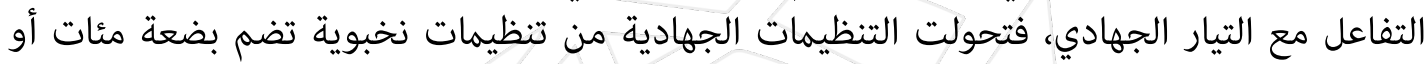

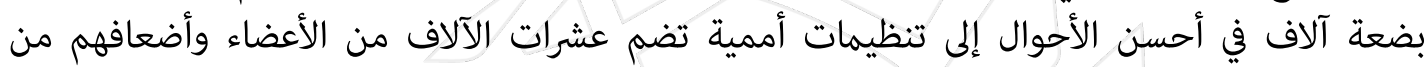

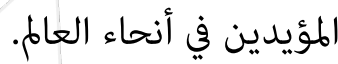

خاتة

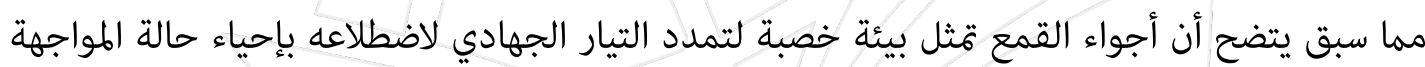

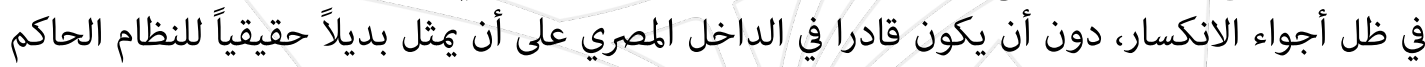

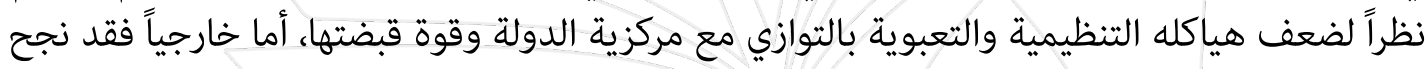

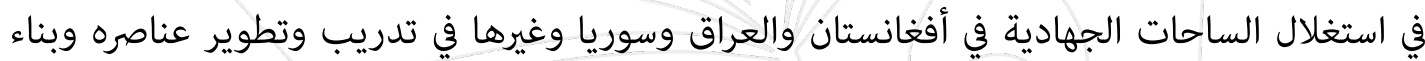
بؤر عمل جديدة أعاقت جهود محاصرته وتصفيته وساهمت في نشر أفران أفكاره. 


\section{نهاية الحرب الباردة والتنظير في النزاع الدولي \\ د. بلخيرات حوسين (الجزائر)}


تعتبر الظاهرة النزاعية من الظواهر المركزية في الحياة الاجتماعية بصورة عامة ولذا فإن تناول هذه الذانهان

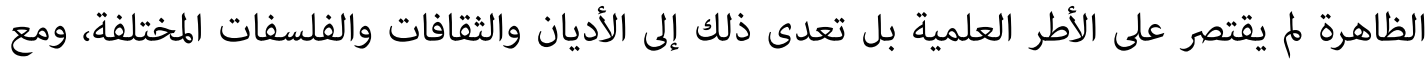

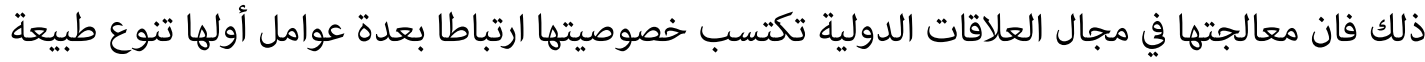

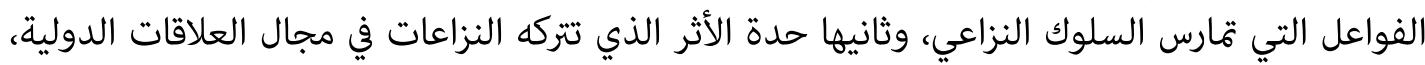

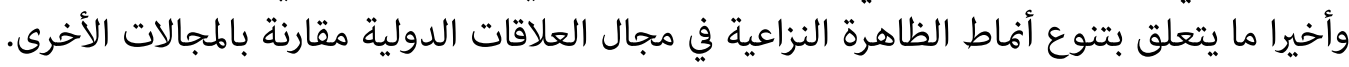

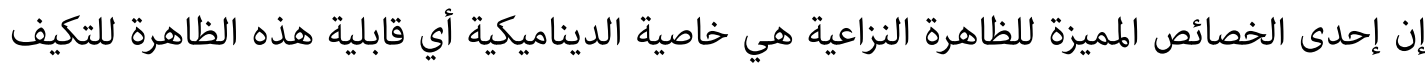

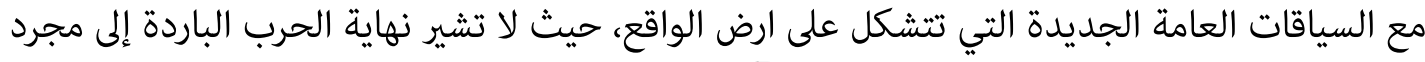

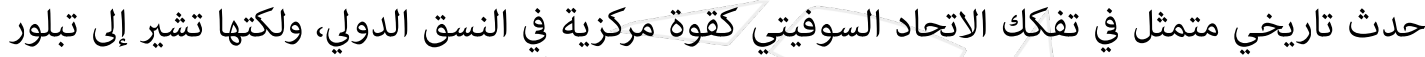

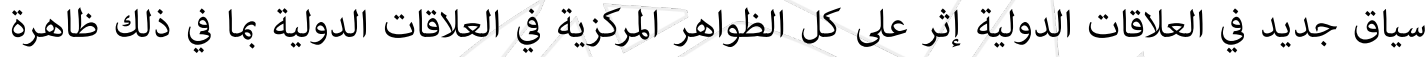

النزاع الدولي عمليا ونظريا.

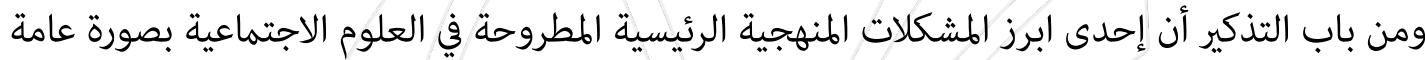

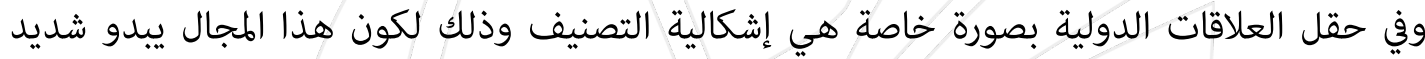

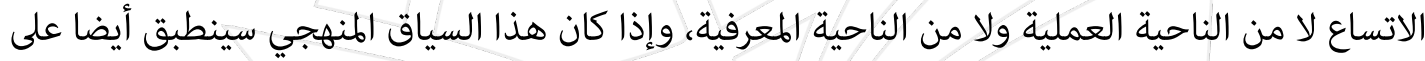

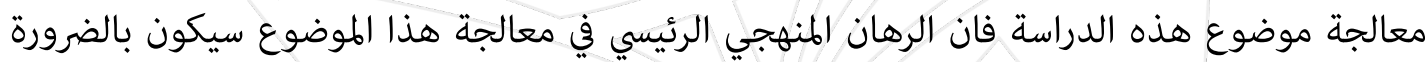

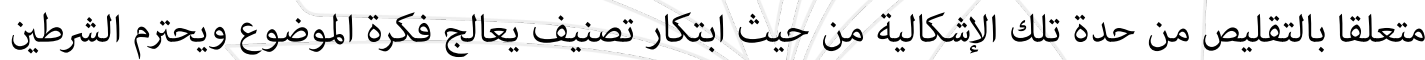

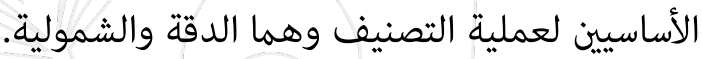

إن إثر نهاية الحربة الباردة على تطور الظاهرة النزاعية كما ذكرنا سابقا لا يشمل الجوانب العملية لتشكل التها

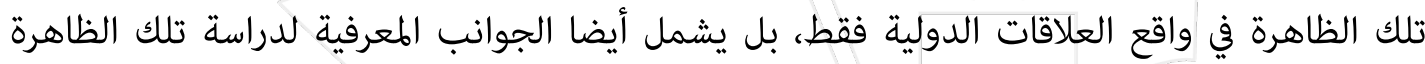

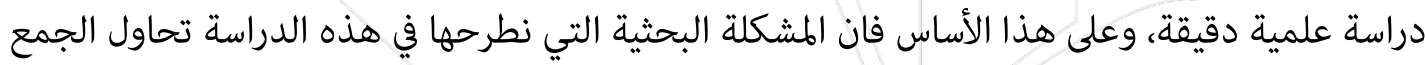

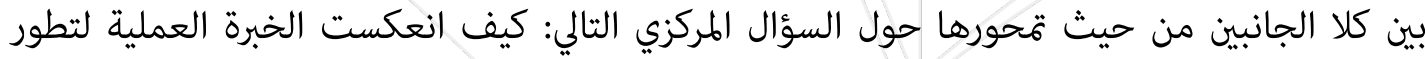

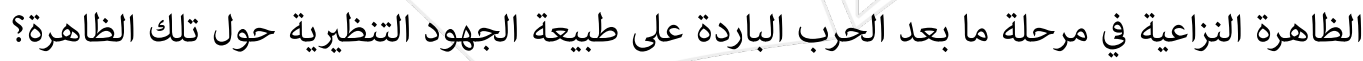
ولعالجة هذه الإشكالية فإننا نطرح الفرضية المركزية التالية: لا تشير التطورات في جهود التنظير للظاهرة

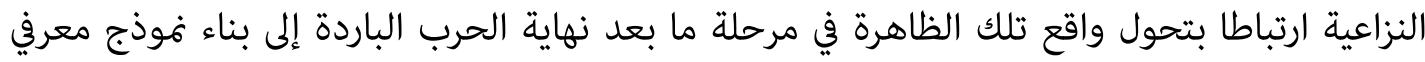

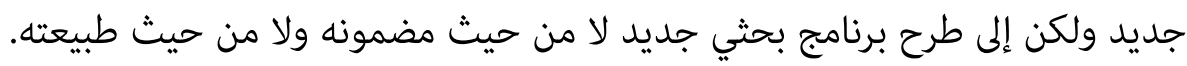

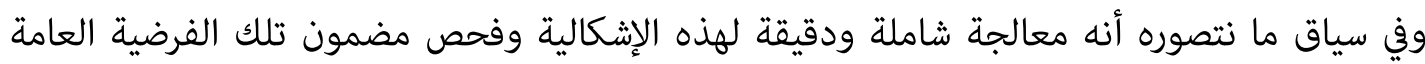

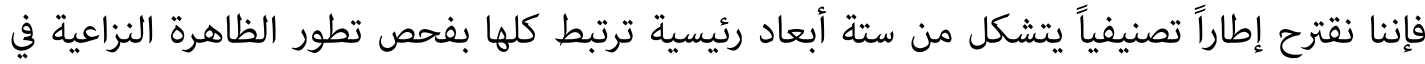
مرحلة ما بعد نهاية الحرب الباردة: البعد الانطولجي والمقصود به طبيعة التطور في الجوانب الكمية والنوعية لظاهرة النزاع الدولي. 
البعد الابستمولجي: والذي يعني مدى تطور الخفية المعرفية التي نعالج الظاهرة النزاعية انطلاقا منها. البعد الايتمولوجي: أي منظومة المفاهيم المركزية المعبرة عن ظاهرة النزاع الدولي ومدى تطورها. البعد الميتادولوجي: أي الخلفية المنهجية التي تطور من خلالها التنظير حول ظاهرة النزاع الدولي. البعد الاكسيولجي: أي مدى تحول منظومة القيم التي نبني من خلالها مواقفنا اتجاه الظاهرة النزاعية.

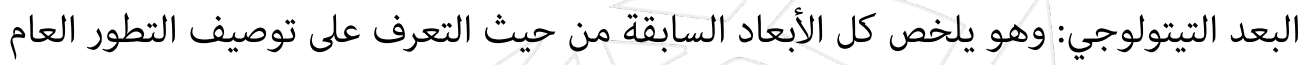
الذي حدث في التنظير للظاهرة النزاعية بعد نهاية الحرب الباردة.

المحور الاول -النزاع: الظاهرة والمفهوم

بالرغم من خصوصية تشكل الظاهرة النزاعية في كل مجال إلى أن هذه الظاهرة هي ظاهرة مركزية في

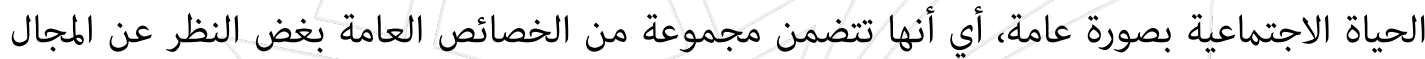

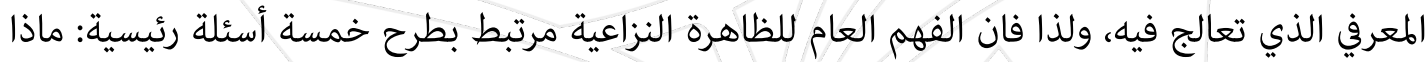

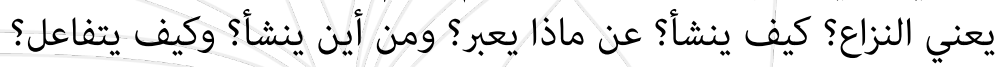
أولاً: ماذا يعني النزاع؟ النئ

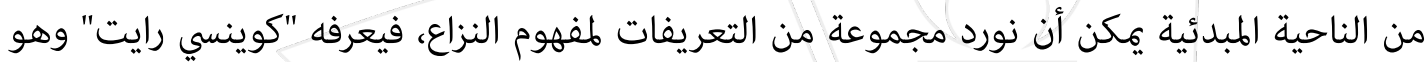

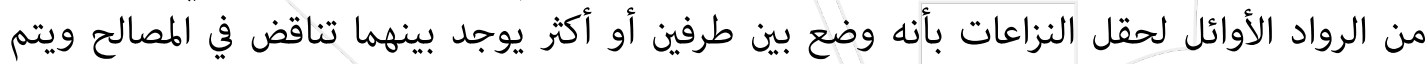

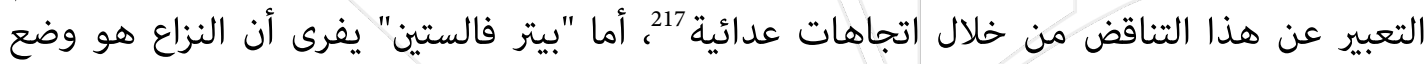

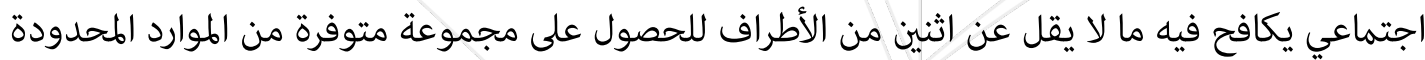

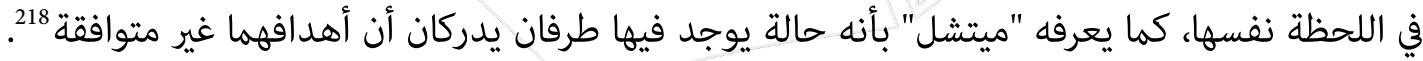

217 Wright Quincy. "The Nature of Conflict". In .Burton, john and Dukes, Frank: Conflict: Readings in Management and Resolution. US: The Macmillan Press LTD. 1990.P15

218 Mitchell ,Christopher Roger.The Structure of International Conflict. London:Macmillan. 1981. 


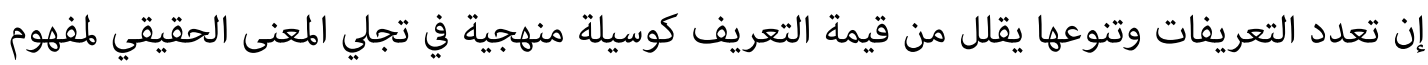

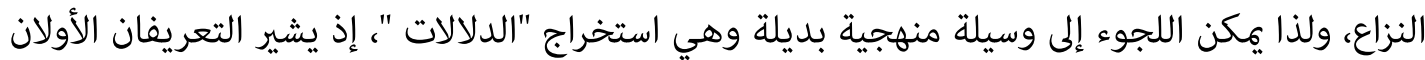

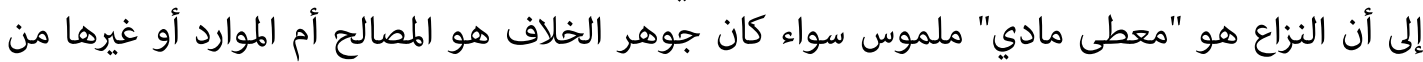

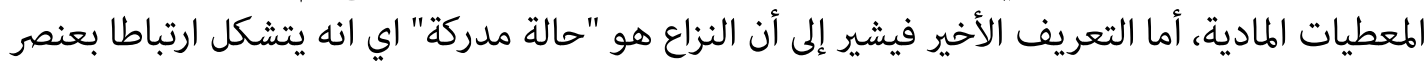

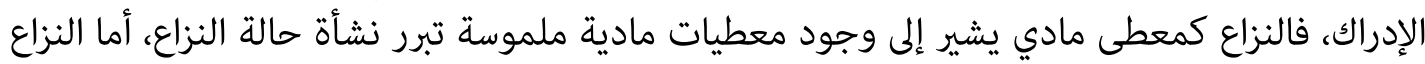

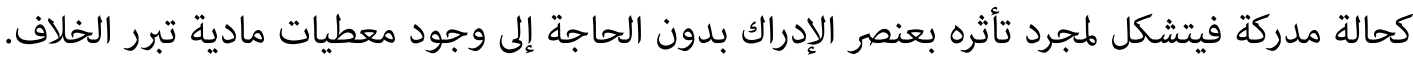

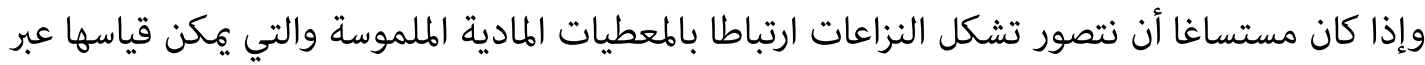

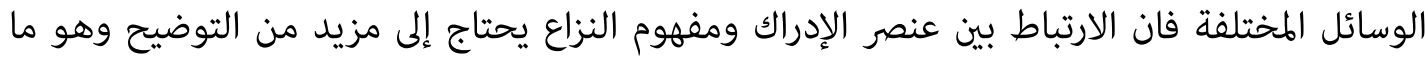

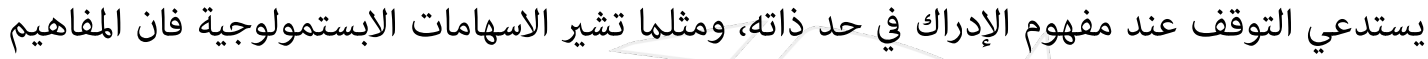

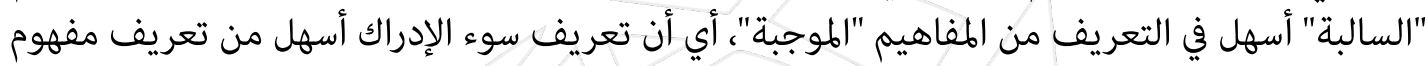

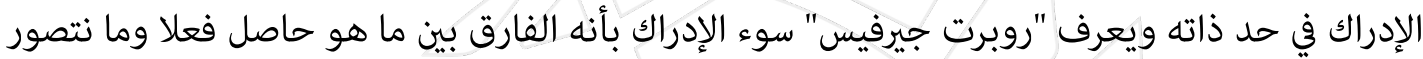

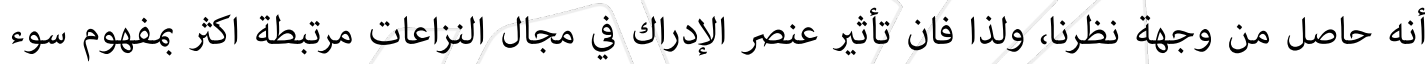
الادراك في حد ذاته وهو يشمل الاعتبارات التالية:219

1-سوء الإدراك في نوايا الفاعلين: فمن جهة لا يمكن أن تتوفر في جميع الأحوال قرائن يمكن الاعتماد عليها

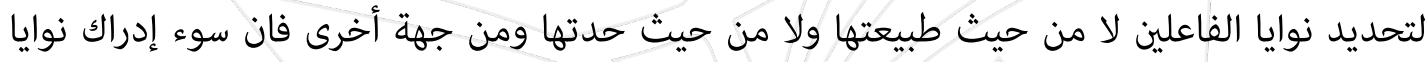

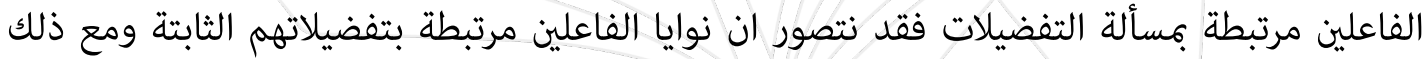

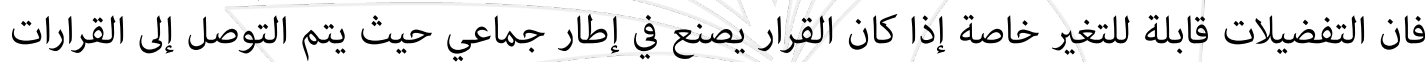

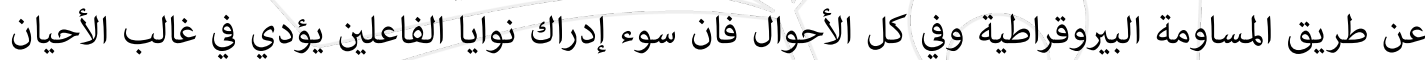
إلى تشكل النزاعات.

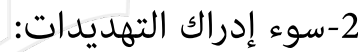
وهو يشمل من جهة المبالغة في تقدير قدرات المنافسين كما يشمل المبالغة في تقدير نظرتهم العدائية

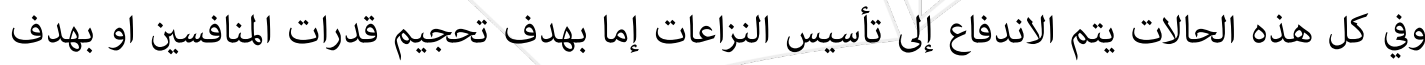
تقليص نزعتهم العدائية.

219 Robert, Jervis. War and Misperception. The Journal of Interdisciplinary History .Vol. 18. No.Spring1998. pp $660-686$ 
3-سوء إدراك ومسألة الاستهداف: أي المبالغة في اعتبار الذات محلا للاستهداف من طرف الآخرين وهذا

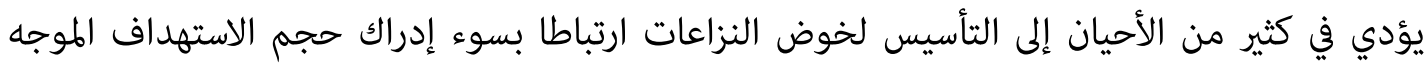

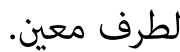

ثانياً: كيف ينشأ النزاع؟

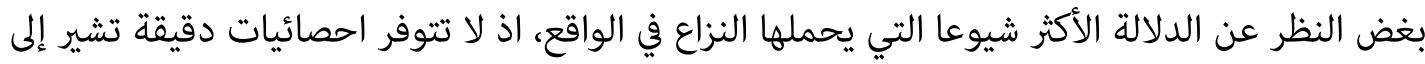

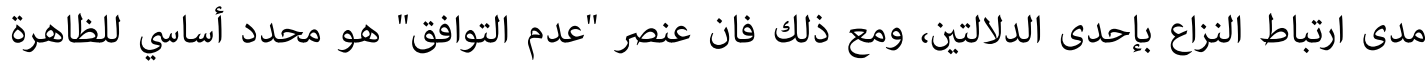

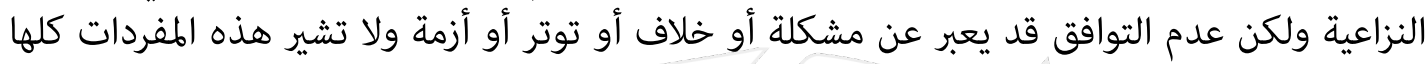

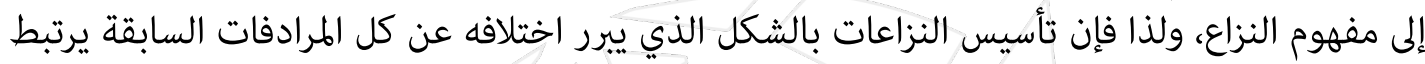

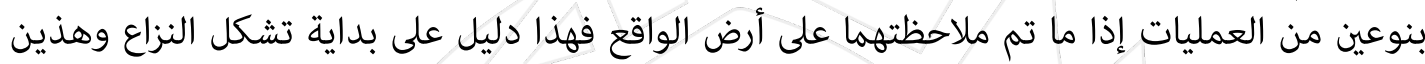
النوعين من العمليات كما حددهما "فيشر" هما العمليات المعيارية والعملئ إنماتيات العمات الإدراكية:220 أ-العمليات المعيارية: وهي تعني كيفية التأسيس لخوض النزاع وتشمل: - تكون الحالة المزاجية السلبية: فالمزاج هو الداعم للمواقف العدائية او التوفيقية ويعني تشكل المزاج السلبي فقدان الأطراف للاستعداد للتعامل الايجابي مع بعضهم البها هو البعض.

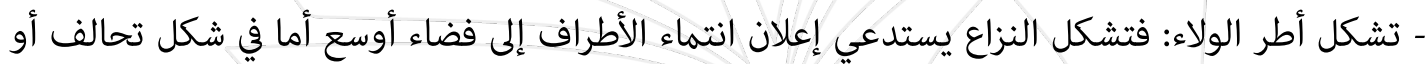

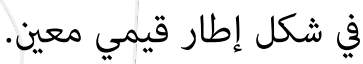
- خلق الالتزامات البنيوية: أي كل طرف يطرح أشياء لا يكنه التنازل عنها والتي تبرر موقفه تحفزه

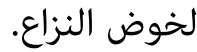

ب-العمليات الإدراكية: وهي تعني كيفية التفكير في النزاع وتشمل:

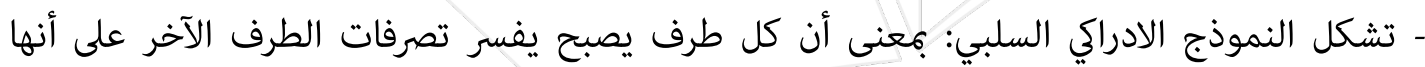
تصرفات سلبية بغض النظر على أنها تحمل هذه الني الصفة فعلا. 
- الانغلاق المعلوماتي: كل طرف يصبح لا يملك الاستعداد لتقبل المعلومات المناقضة لموقفه النزاعي بحيث ان كل معلومة تعارض الموقف النزاعي يتم تجاهلها.

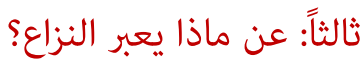
إن تظظهر النزاعات على ارض الواقع لا تعكس بعدا واحد ولكنها تعكس مثلما يشير كلمان دائما أربع أبعاد أساسية: 221 1-النزاع كوسيلة لتلبية الحاجات ودرأ المخاوف: إذ قد تتشكل الظاهرة النزاعية على ارض الواقع عنداتها

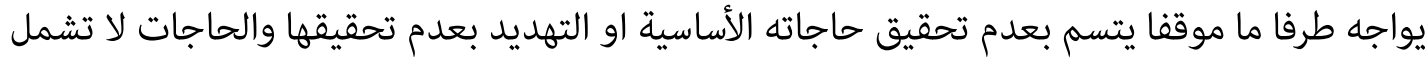

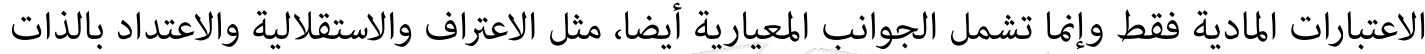

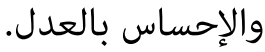

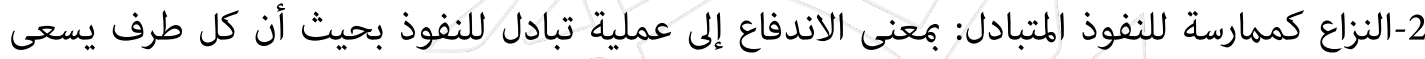

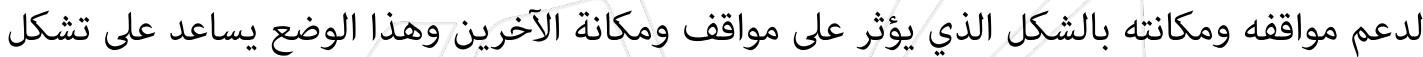

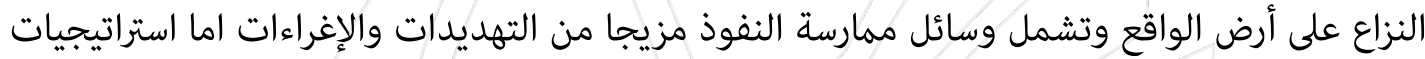

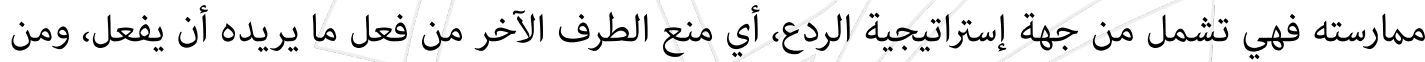

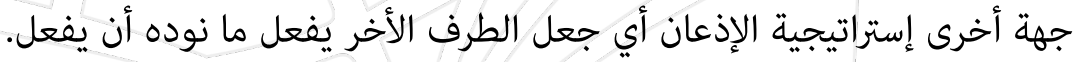

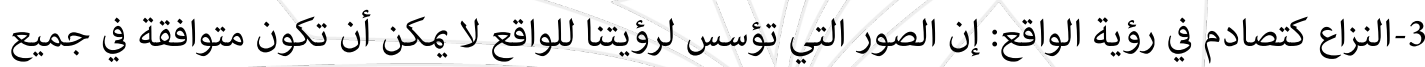

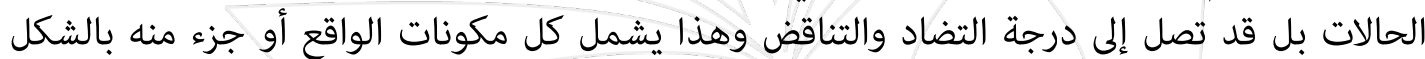

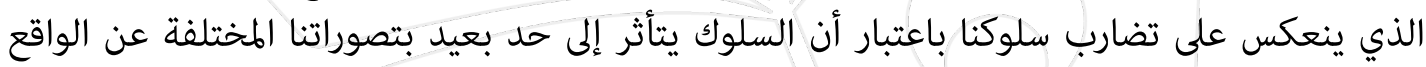
وهو ما يؤسس لتشكل النزاعات. 4-النزاع هو انعكاس طبيعي للسياق السائد: بمعنى ان خصائص بعض السياقات السيات التي يوجد فيها الفاعلون

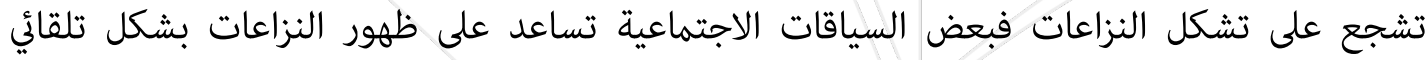
وطبيعي. رابعاً: من أين ينشأ النزاع؟

221 Kelman.H.C.Social-psychlogical dimensions of international conflict .(Washington: United States Institute of Peace). 1997. Pp 220-237 
إن تحديد أبعاد الظاهرة النزاعية - كما ورد سابقا-يبدو في غاية الأهمية إذا ما أردنا التعرف عما تعكسه النها

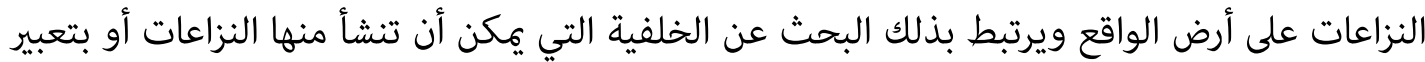

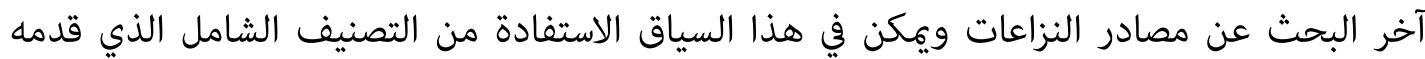

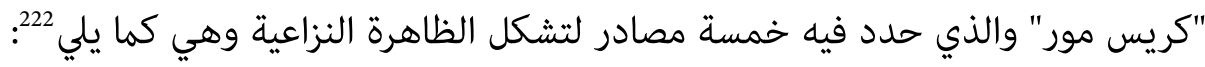
1-مصادر النزاعات المرتبطة بالعلاقات: قد تنشأ اما بسبب سوء الفهم، أو ضعف التواصل، أو السلوكيات السلبية المتكررة - مادرات

2-مصادر النزاعات مرتبطة بالقيم: وتنشا اما بسبب اختلاف معايير تقييم الأفكار او السلوكيات او اختلاف الانتماء.

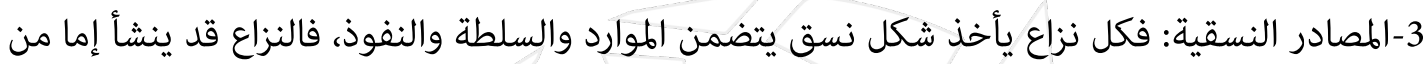

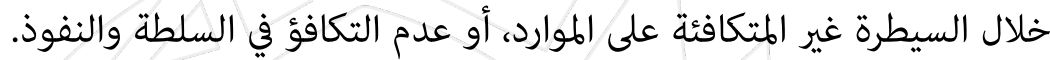

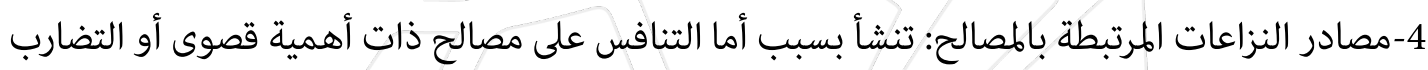
في الاستراتيجيات العملية لتحقيق مصالح ثانوية. 5-مصادر النزاعات المرتبطة بالمعلومات: تنشأ إما بسبب قلة المعلومات - التضليل - الاختلاف في تفسير المعلومات-الاختلاف في وجهات النظر النزاتر خامساً: كيف يتفاعل النزاع؟

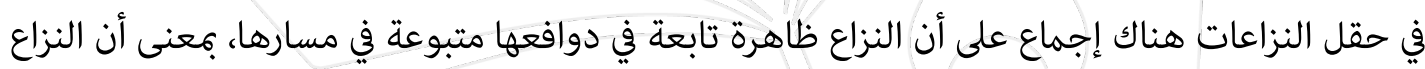

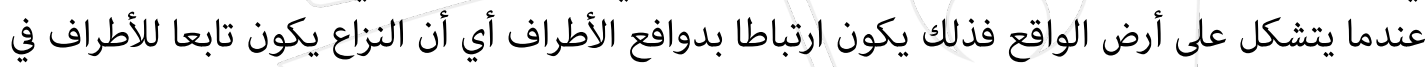

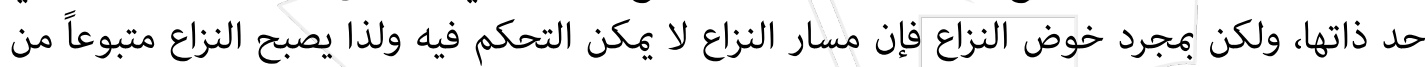

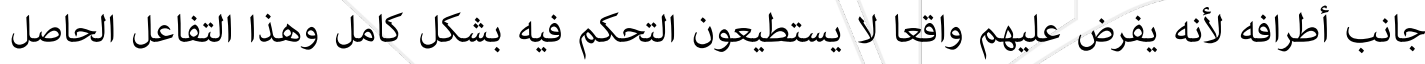
يستدعي التوقف عند مكونات الظاهرة النزاعية.

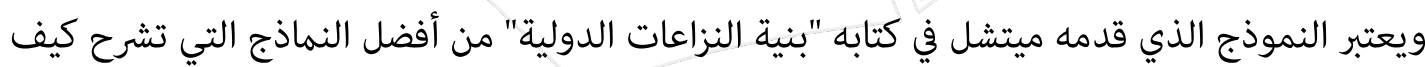

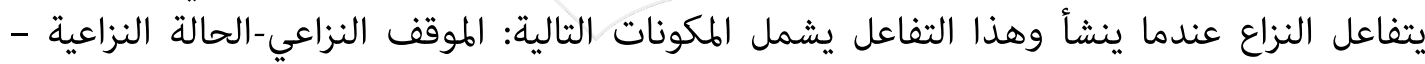

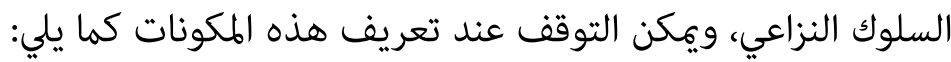


1-الحالة النزاعية: هي الوضع العام الذي يوجد فيه النزاع ويتم قياسها بناء على اتساعها على أساس عدد

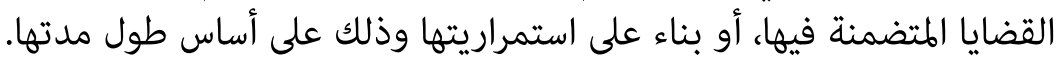

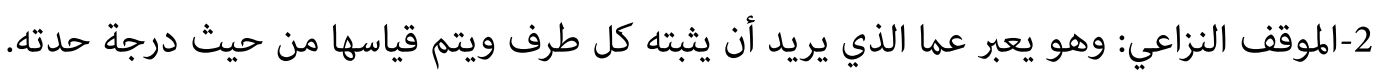
3-السلوك النزاعي: وهو يعني ما الذي يفعله كل طرف اتجاه الآخر ويتم قياسها بالنجاح أو الفشل. هذه المكونات تتفاعل مع بعضها البعض كلها بالشكل التالي:

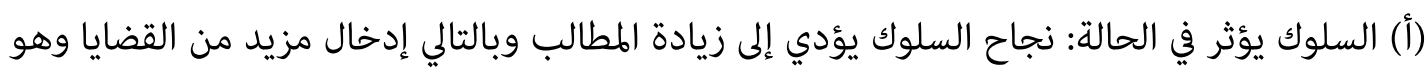
ما يؤثر على اتساع الحالة النزاعية. (ب) الموقف يؤثر في الحالة: كل ما كان الموقف النزاعي حادا كل ما ادى ذلك إلى طول مدة النزاع وبالتالي استمرارية الحالة النزاعية.

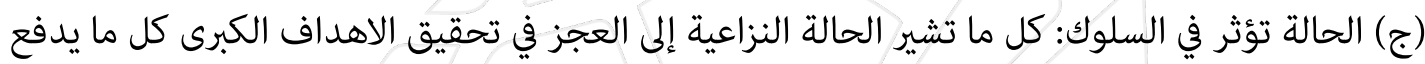

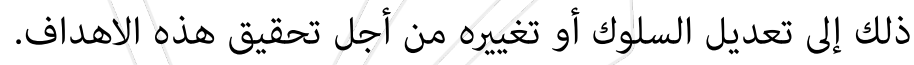
(د) السلوك يؤثر في الموقف: نجاح السلوك يؤدي إلى التحفز، أما الفشل فيؤدي إلى الرغبة في الانتقام وفي الحالتين تتأثر حدة الموقف النزاعي.

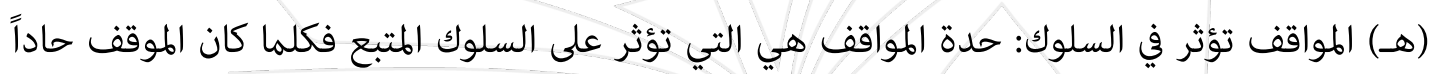

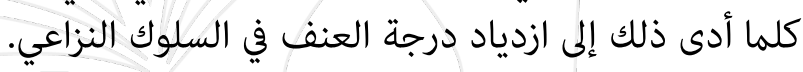
(و) الحالة تؤثر في المواقف: كلما طالت مدة النزاع كلما أدى ذلك إلى ازدياد انعدام الثقة وبالتالي حدة الموقف النزاعي.

المحور الثاني: البعد الانطولوجي لتطور الظاهرة النزاعية بعد الحرب الباردة

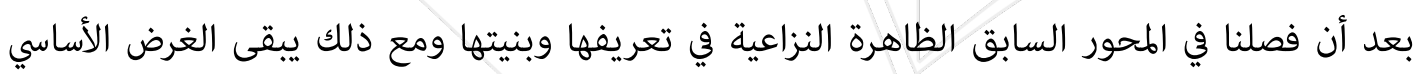

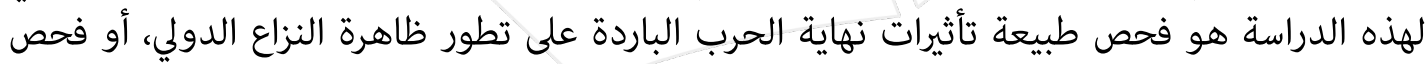

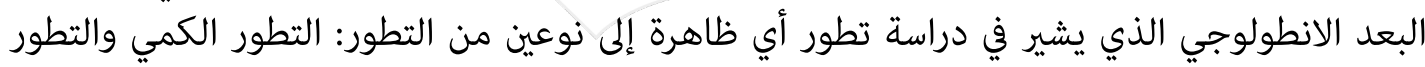

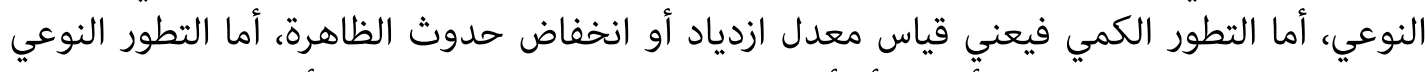

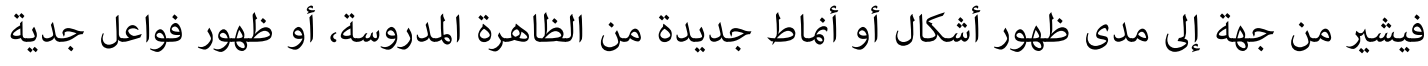


تارس الظاهرة، أو تبلور فضاء جديد تارس فيه الظاهرة، او ارتباط الظاهرة بعوامل جديدة وإذا طبقنا

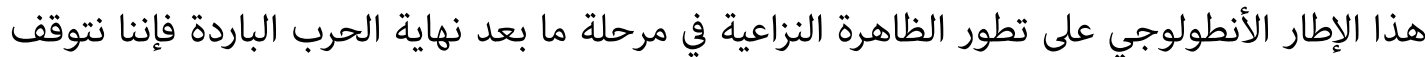
عن المضامين التالية:

أ-بالنسبة للتطور الكمي يلاحظ انخفاض معدل الظاهرة النزاعية بين الدول وخاصة في مظهرها الأكثر

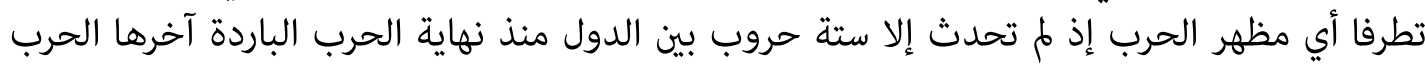

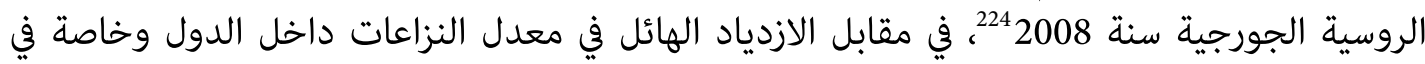

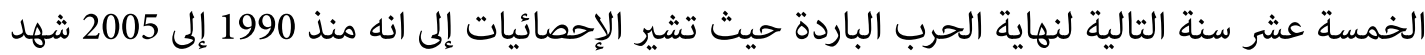
العالم 57 صراعا داخليا في 45 دولة في مختلف أنحاء العالم كانت حكومة الدول أحد أطراف النزاع. بـ- أما بالنسبة للتطور النوعي فقد شمل كل الجوانب المشار اليها سابقا فقد أصبحت الظاهرة النزاعية

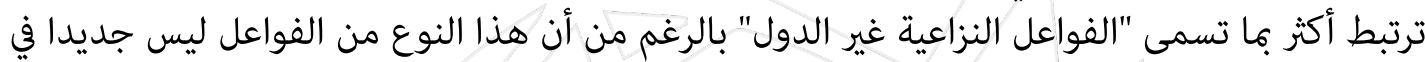

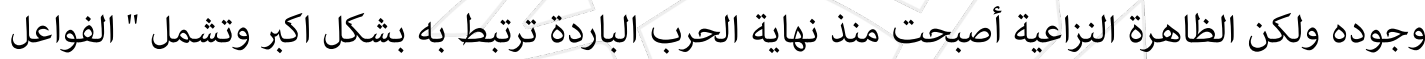

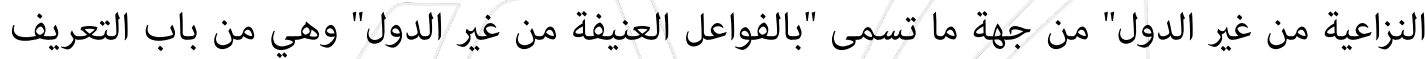
"جماعة منظمة ذات بنية أساسية للقيادة تعمل خارج سيطرة الدولة اعنية وتستخدم القوة لتحقيق أهدافهاه 226، كما تشمل من جهة أخرى ما تسمى ب" جماعات العنف الخاصة" وهي تشير إلى الجماعات التي تلجا اليها الدول لخوض الحروب كبديل لعنصرها البشري أو بهدف خلق خلق نزاعات اتهات داخلية تبرر التدخل الخارجي وخاصة من طرف الدول الكبر ى 227. وشمل التطور النوعي أيضا تبلور البيئة الداخلية للدول باعتبارها الفضاء الأساسي الذي تارس فيه الظاهرة

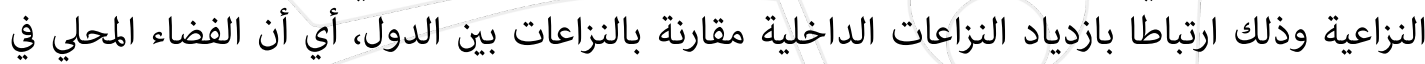

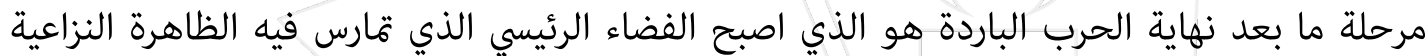

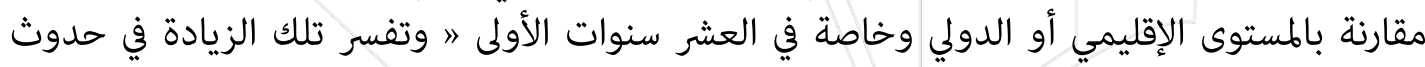

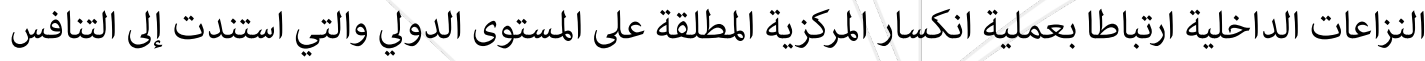

224 Richard Ned Lebow.Why Nations Fight:Past and Future Motives for War. (Cambridge University press).2010 225 "World Refugees Statistics: Refugees and Asylum Eeekers World wide".World Refugees .2005. p6-7

226 شهرا زاد ادمام. الفواعل العنيفة من غير الدول: دراسة في الاطر المفاهيمية والنظرية. مجلة سياسات عربية. ع8. (الدوحة: المركز

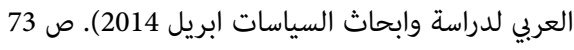

227 Mary Kaldor .New and Old Wars: Organizev Violance in a Global Era. The Amirerican Political Science Review.Vol.95.No.2.Jun2001 


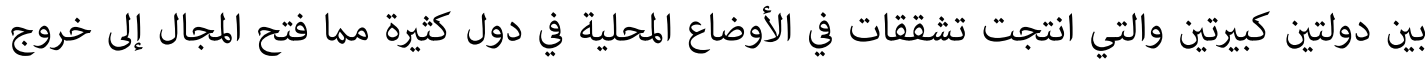

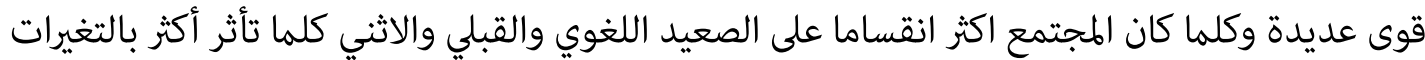

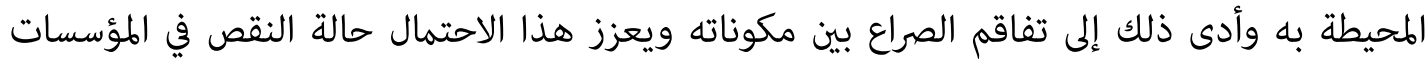

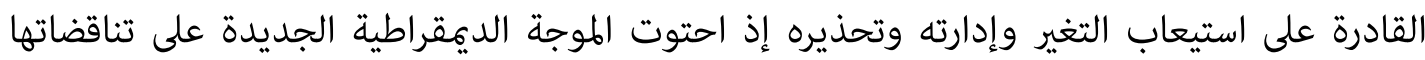

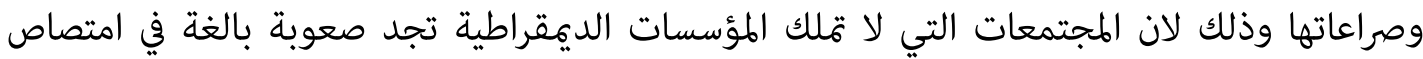
العنف الذي يرافق العملية الديمقراطية «ـ.

كما يشير التطور النوعي أيضا إلى ظهور أشكال وأفاط جديدة للظاهرة النزاعية والتي تتمثل اساسا فيما

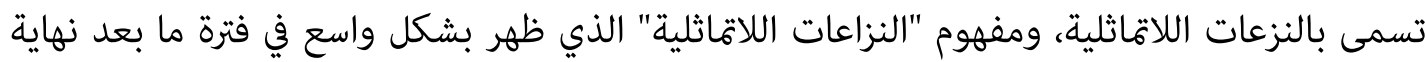

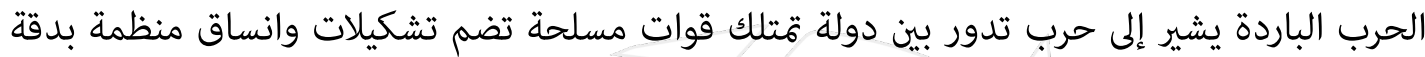

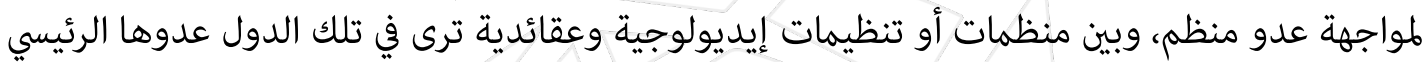

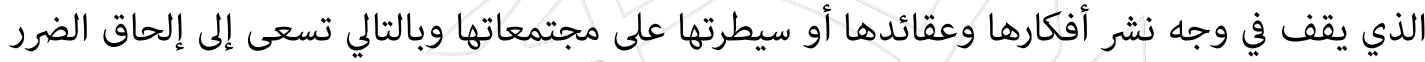

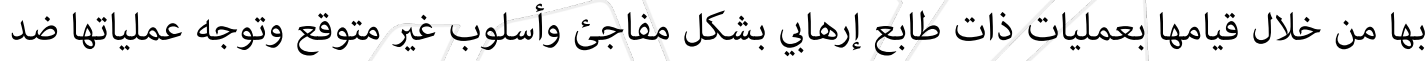

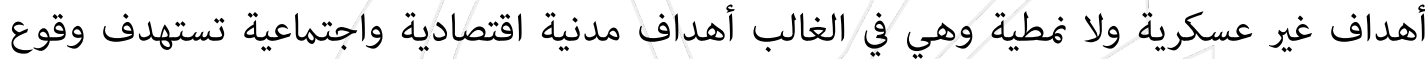

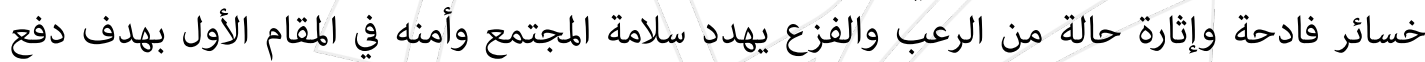

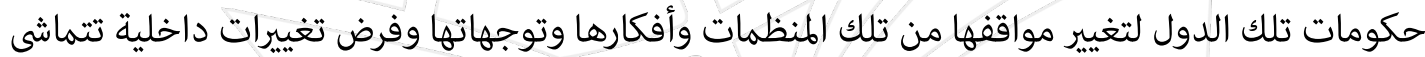
مع تلك التوجهات.

وتلك المنظمات لا تملك قوات منظمة يمكن مواجهتها ولا قواعد واضحة يكن مئن استهدافها ولكنها تعتمد

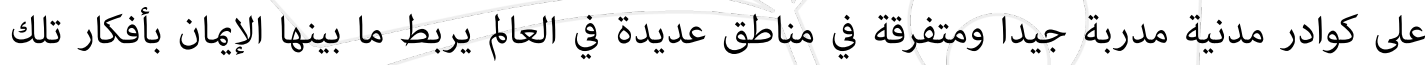

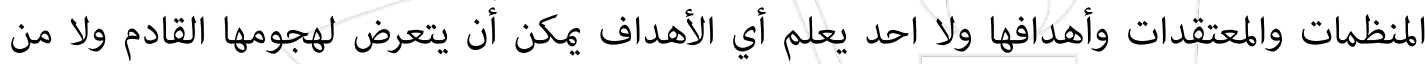

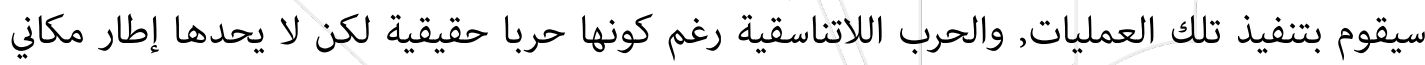

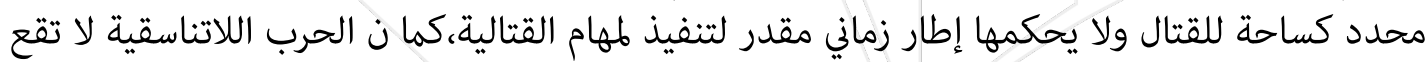

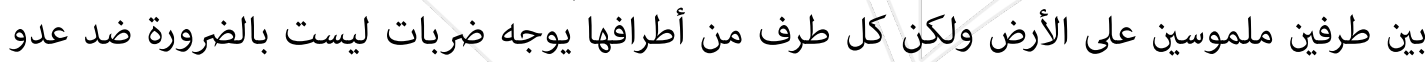

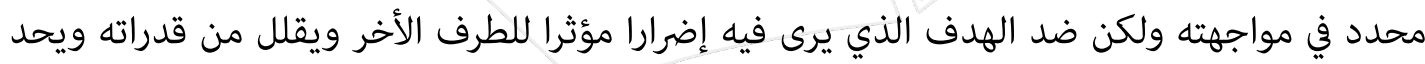

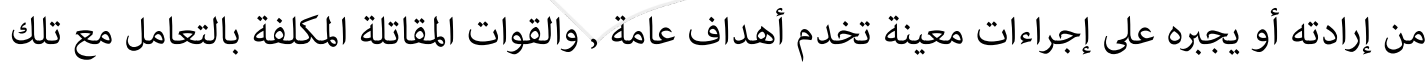

228 شفيق ناظم الغبرا. النزاعات وحلها: إطلالة على المفاهيم والأدييات. مجلة المستقبل العربي ـ العدد71. (بيروت: مركز درايات الوحدة

العربية ).ماين 1993.ص ناطم الغرا.

229 انظر: عادل سليمان. الثورة في الشؤون العسكرية: التداعيات والانعكاسات الدولية والإقليمية. (القاهرة: المركز الدولي للدراسات

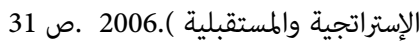


التنظيمات تستهدف عادة قواعدها ومراكزها ومناطق اختفائها وأيضا من يعتقد انه يحتضنها ويسهل

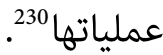

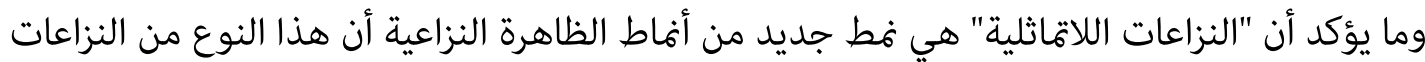
يستند إلى مرتكزات تختلف تقاما عن مرتكزات النزاعات النيات التقليدية وهذا يشمل:

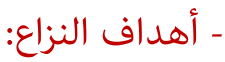

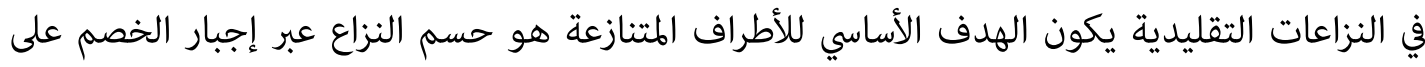

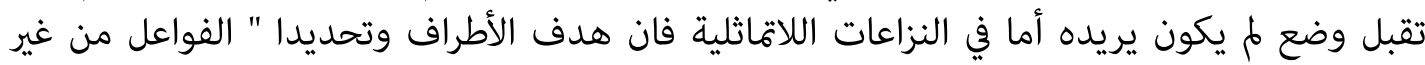

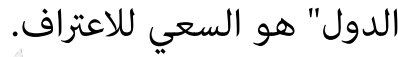

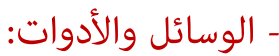

في النزاعات التقليدية عادة ما تستخدم الأسلحة العسكرية الثقيلة لكن خوض النزاعات اللاتاثلية لا يحتاج إلى هذا النوع من الأسلحة.

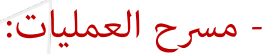
في النزاع التقليدي يكون ميدان النزاع مقيد بكساحة جغرافية محددة اما في النزاعات اللاقاثلية فان ميدان النزاع يكون مفتوحا.

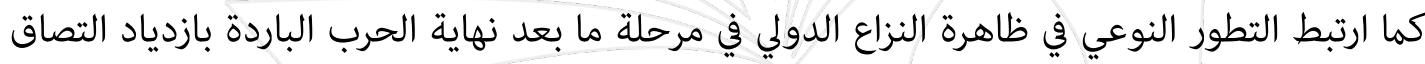

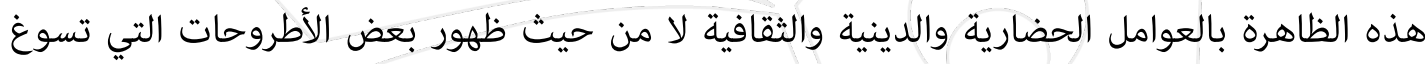

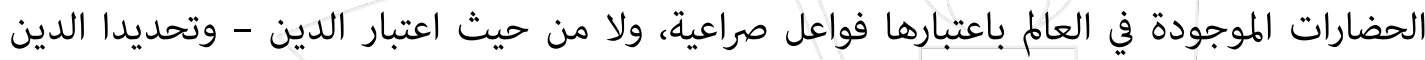

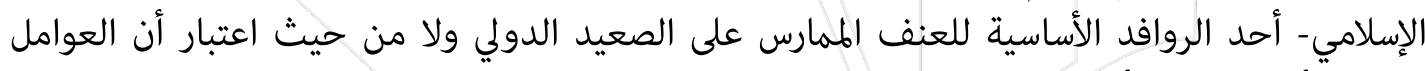

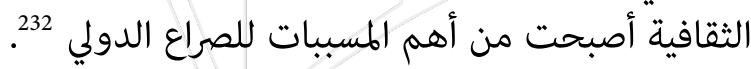

230 نفس المرجع. ص 34

231 Wayman, Frank". Rivalries: Recurrent Disputes and Explaining War". In John Vasquez (ed) What Do We Know _ About War? Lanham, MD: Rowman and Littlefield, 2000:pp 219234

232 انظر حول هذه الجزئية كل من: - عصام عبد الشافي. البعد الديني في العلاقات الدولية: الماهية والتأثير.(الإسكندرية: منشورات مكتبة الإسكندرية ـ 2014.) 


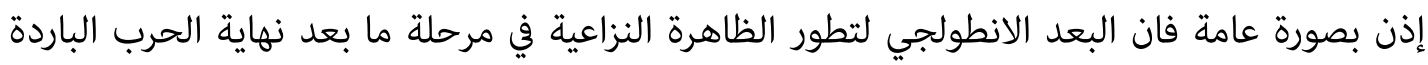

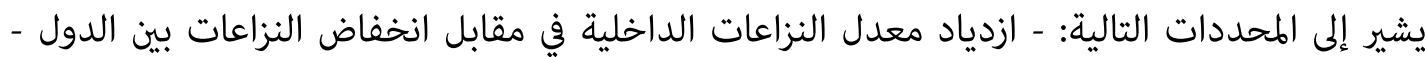

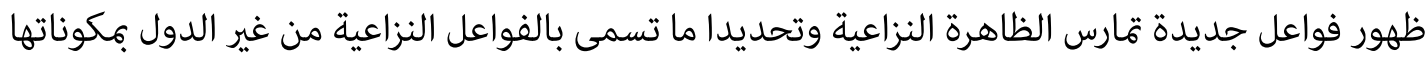

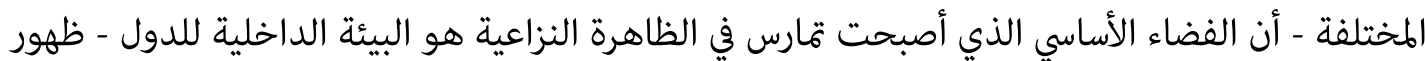

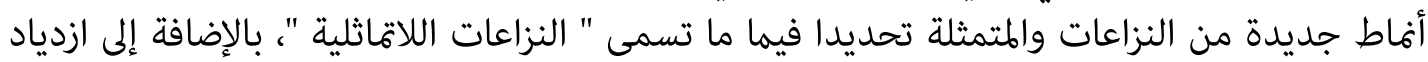
ارتباط الظاهرة النزاعية بالعوامل الثقافية والدينية والحضارية.

المحور الثالث: البعد الابستمولوجي لتطور الظاهرة النزاعية بعد الحرب الباردة:

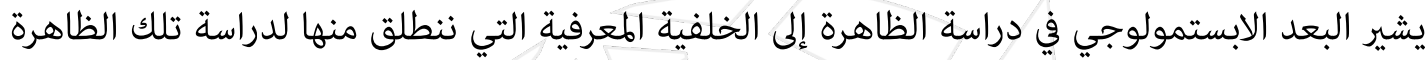

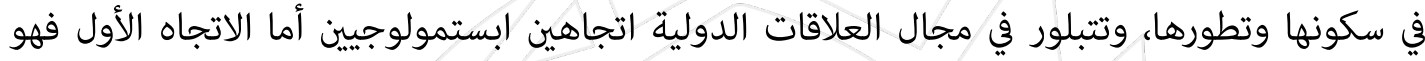

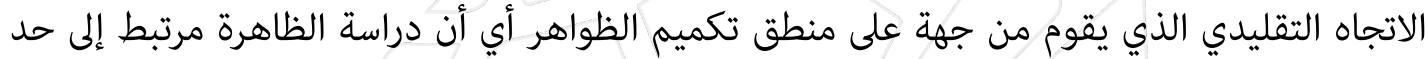

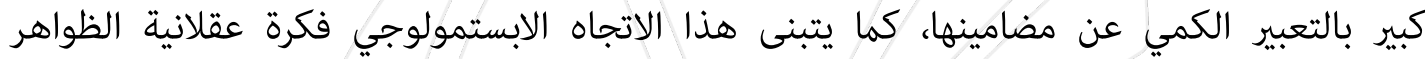

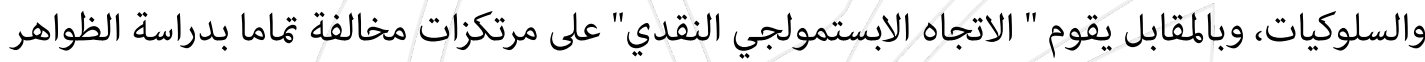

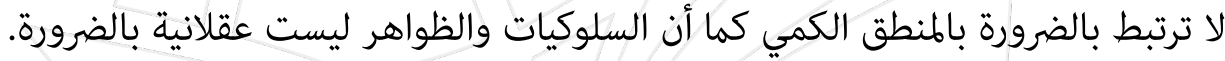
إن إحدى التطورات المهمة التي حدثت في تطور الظاهرة النزاعية في مرحلة ما بعد نهاية الحرب الباردة

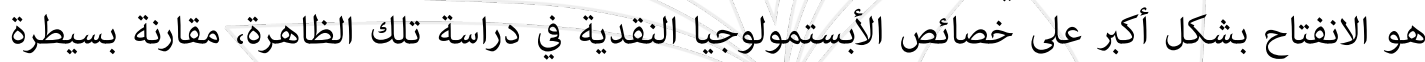
الأبستمولوجيا التقليدية في مراحل سابقة وهذا الأصنا التحول يبرر من خلال:

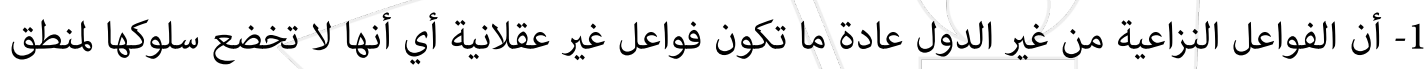

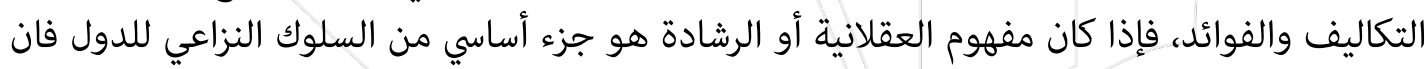

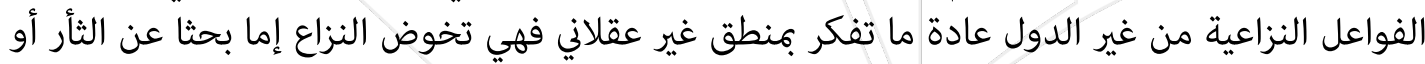

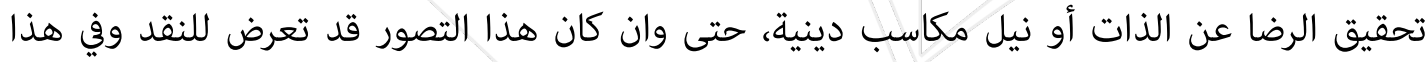

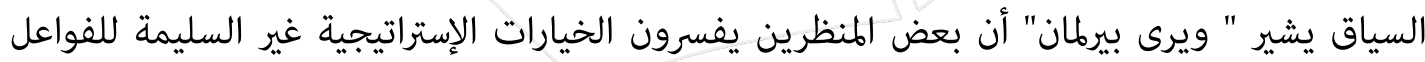

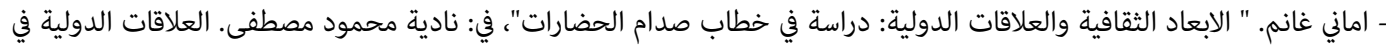
عام متغير: منظورات ومداخل مقارنة.ج3 ـ القاهرة: مركز الحضارة للدراسات السياسية. 
العنيفة من غير الدول ارتباطا بمحددات غير عقلانية كالثقافة والدين والايديولوجيا وان هدف الفاعل هو تحقيق غاية دينية وليس دنيوية"

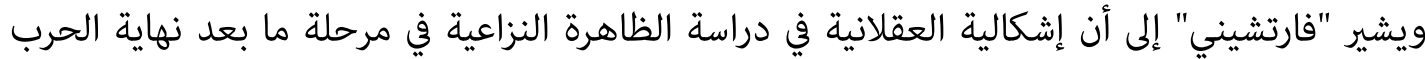

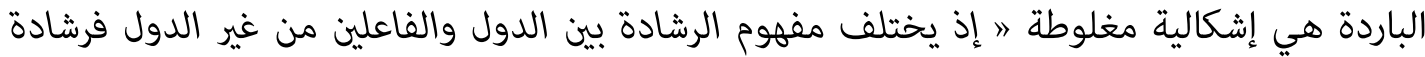
صانع السياسة الخارجية في الدولة تعنى أن يسعى لتعظيم منافعها المادية المتوقعة من تفاعلاتها الدولية،

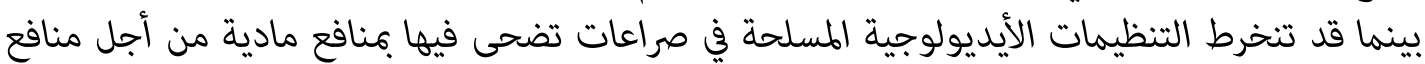

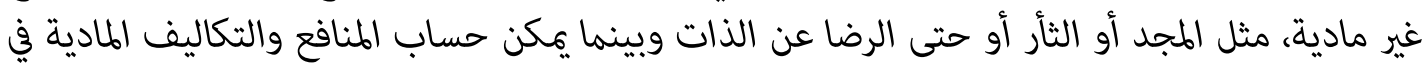

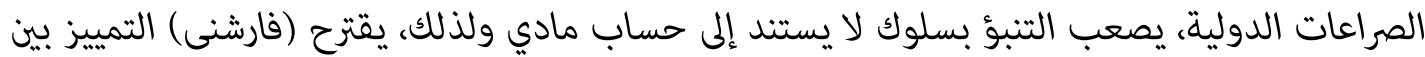
رشادة القيم التي تعمل القوى المتصارعة على تعظيمها من جهة، ورشادة المصالح التي تستخدمها في مئي

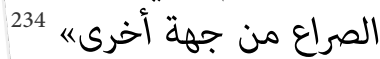

2-أن الفواعل من غير الدول والتي تعتبر الأكثر ارتباطا مهمارسة الظاهرة النزاعية في مرحلة ما بعد نهاية الحرب الباردة هي فواعل غامضة لا يكن بسهولة توفير معطيات كمية حولها، ولذا فان دراسة السلوك

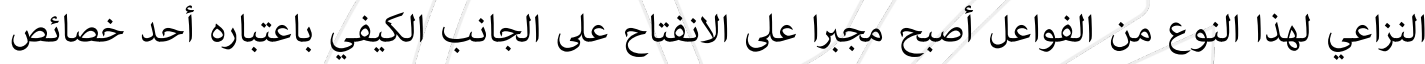

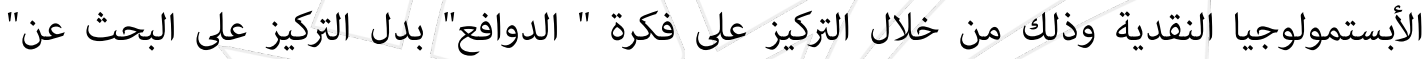
القدرات".

الهحور الرابع: البعد الايتمولجي لتطور الظاهرة النزاعية بعد الحرب الباردة يشير البعد الايتمولجي في دراسة ظاهرة اجتماعية ما في سكونها او تطورها إلى منظومة المفاهيم المعبرة

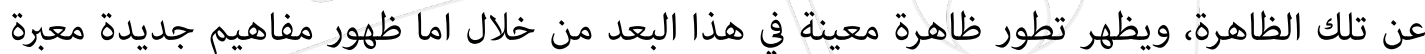

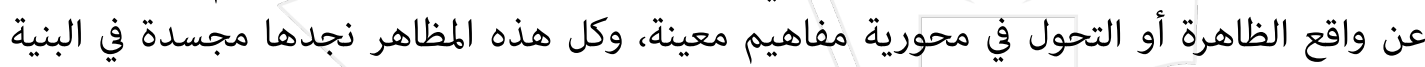

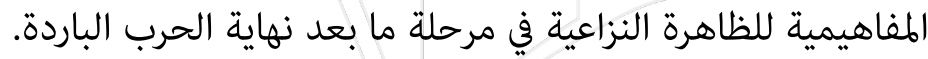
1-ظهور مفاهيم جديدة معبرة عن واقع الظاهرة النزاعية: ونركز في هذا السياق على ثلاثة مفاهيم:

233 Wendy Parlman.A Composite Actor A pproach to Conflict Behavior .in: Chenoweth .Erika. and Andria Lawrence.eds. Rethinking Violence: State and Non Actors in Conflict. Cambridge: Belfar Center for Science and International Affairs.2010

234 احمد علي سالم. عن الحرب والسلام: مراجعة لأدبيات الصراع الدولي. مجلة السياسة الدولية. ع 170. اكتوبر 2007. ص 115 


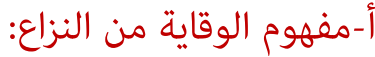

إن الاهتمام بالمنع الوقائي من النزعات جاء مرتبطا في سياق طرح وسائل جديدة لحماية النظام في

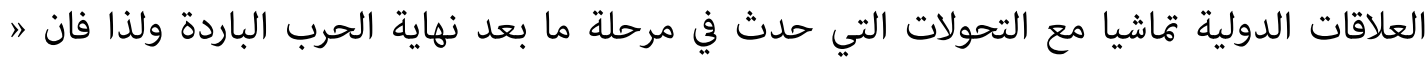

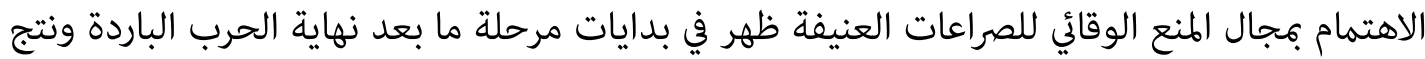

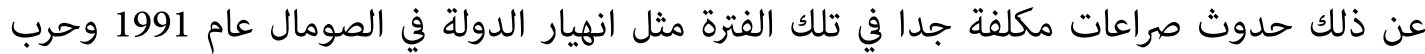

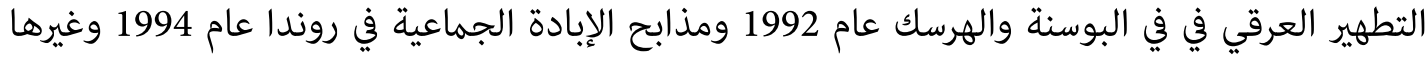

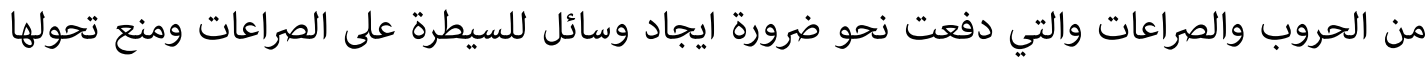

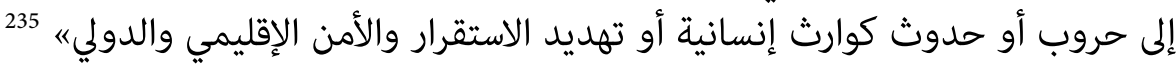

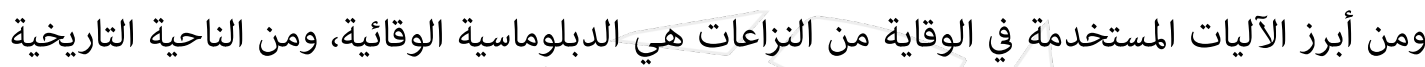

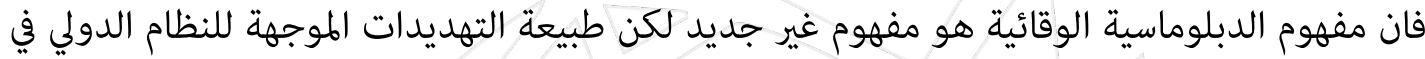

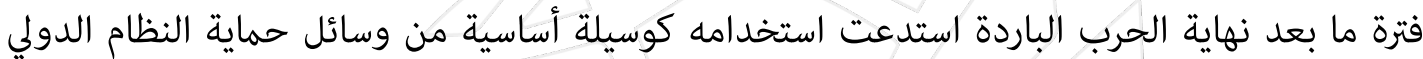

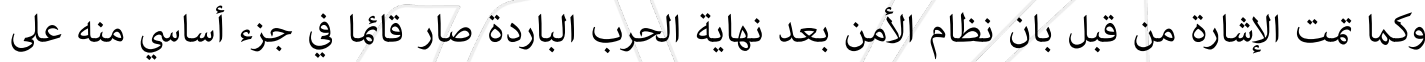

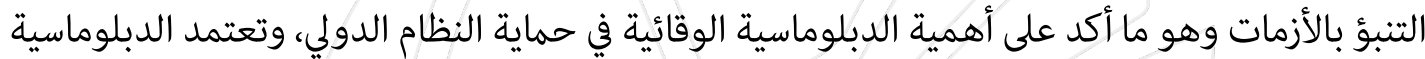

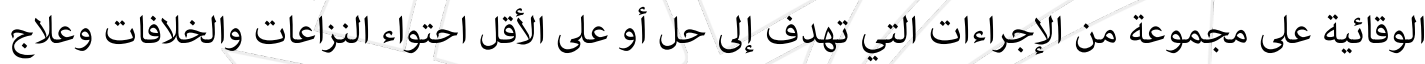
بعض أنواع التهديدات وذلك بطرق من الاجراعة التية.

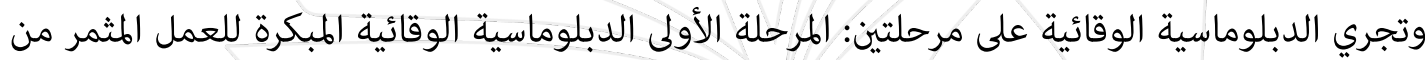

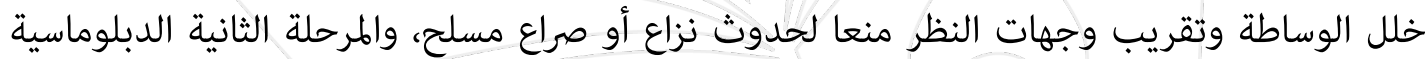

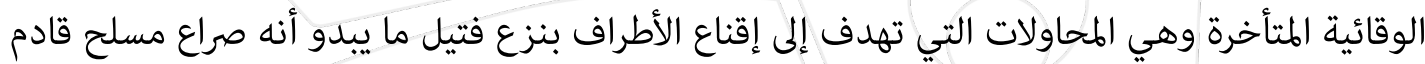

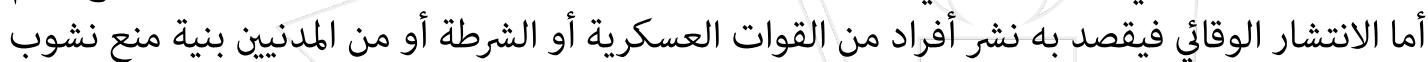

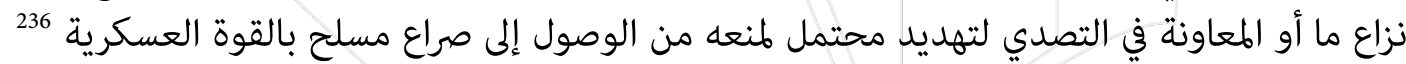

235 سامي ابراهيم الخزندار. ادارة الصراعات وفض المنازعات: إطار نظري .(الدوحة: مركز الجزيرة للدراسات.)2014. ص 238 George, Alexander L., Strategies for Preventive Diplomacy and Conflict Resolution (Political Science and 236 


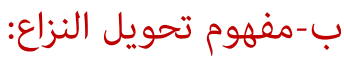

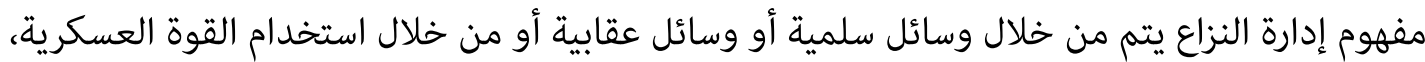

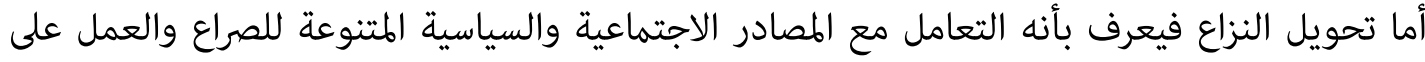

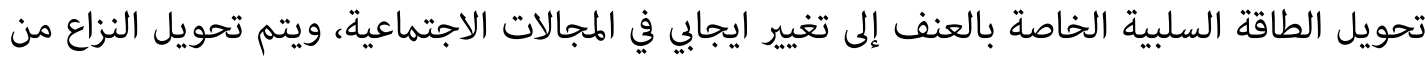

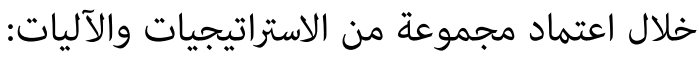

إنضاج النزاع: من خلال تحسيس الأطراف بخطورة الاستمرار في خوض النزاع أو بصورة عامة في

$$
\text { عدم الجدوى من الاستمرار فيه. }
$$

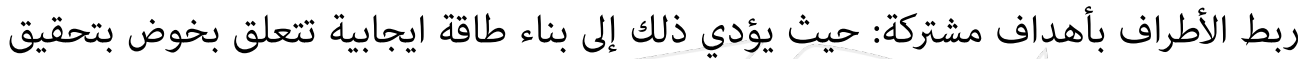

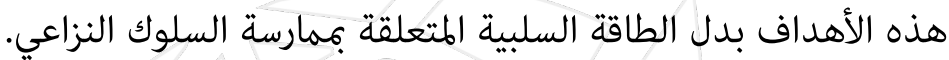
تعديل بنية النزاع: سواء من خلال تعديل موازين القوى بين الأطراف أو دفع الأطراف إلى إعادة تعريف مصالحهم. 237

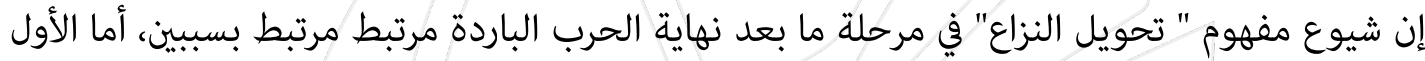

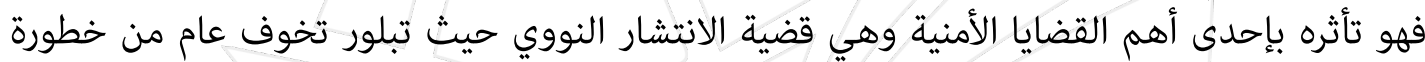

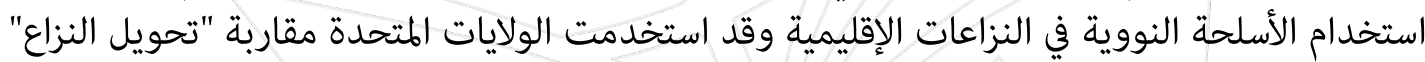

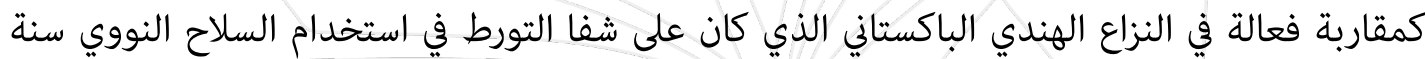

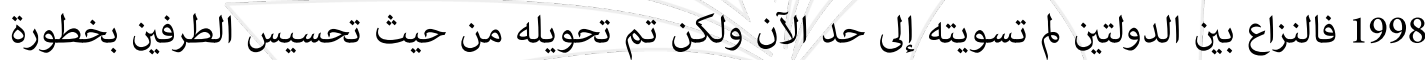

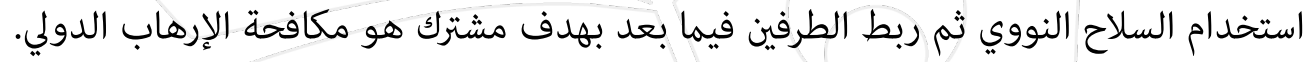
كما ارتبط شيوع مفهوم " تحويل النزاع" في مرحلة ما بعد نهاية الحرب الباردة من خلال التعامل معه التها

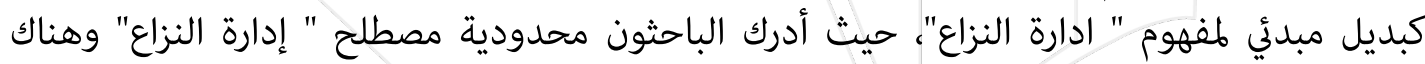

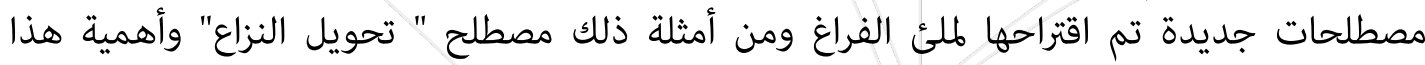

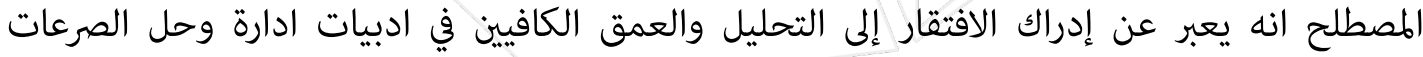
التقليدية.

(ed.). Dictionary of Conflict Resolution .(San Francisco: Jorrey-Bass Publisher .1999 pp120- Douglas H. Yorn237 


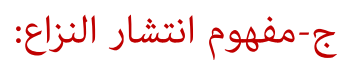

بحكم أن الفضاء الأساسي الذي أصبحت تتبلور فيه الظاهرة النزاعية هو ظاهرة البيئة الداخلية لدول

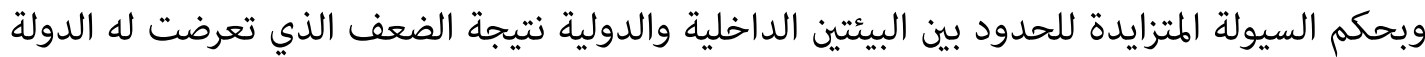

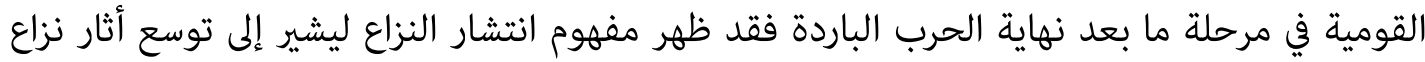

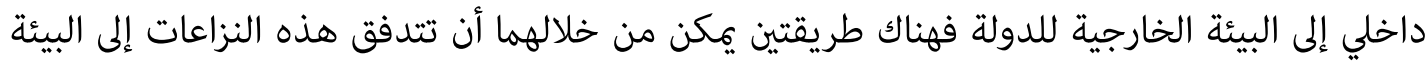

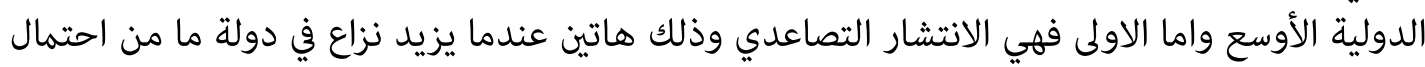

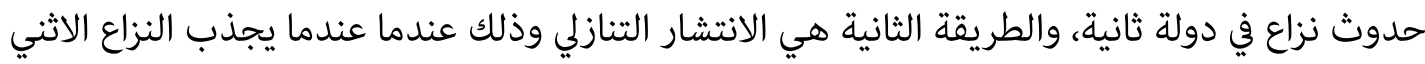

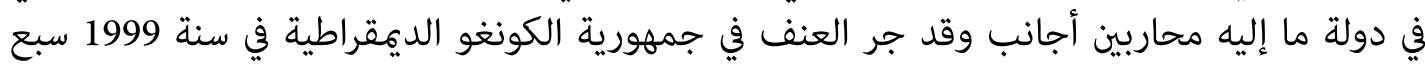

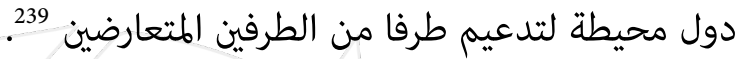

2-تغير القيمة المركزية لبعض املفاهيم المركزية في حقل النزاعات:

ومنها بشكل خاص مفهوم "إدارة النزاع" والذي ارتبطت قيمته المركزية في التنظير للظاهرة النزاعية قبل نهاية الحرب الباردة بالعوامل التالية: 240

- تجاوز النزعة المثالية لحقل النزاعات: فأي حقل معرفي في العلوم الاجتماعية تسيطر عليه في بداياته

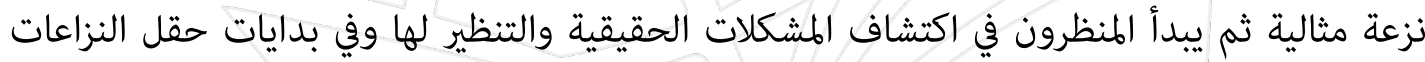

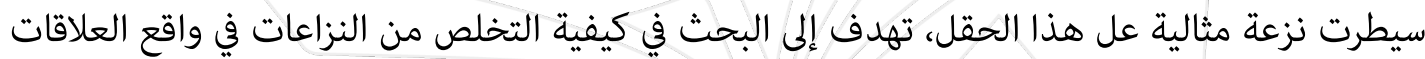

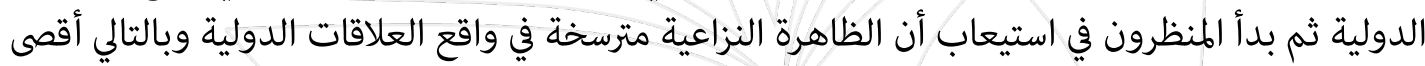

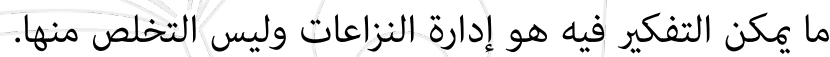

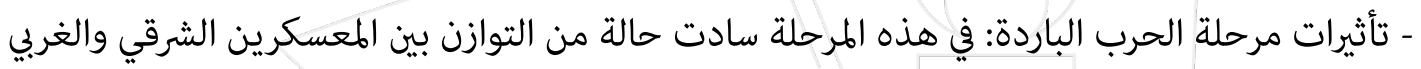

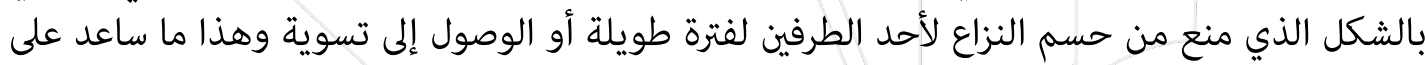

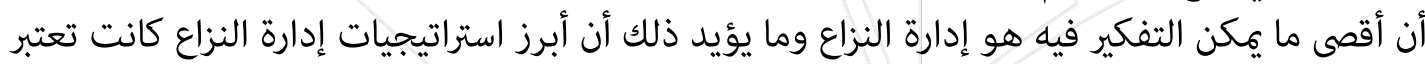

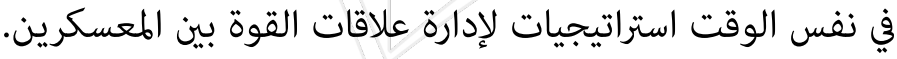

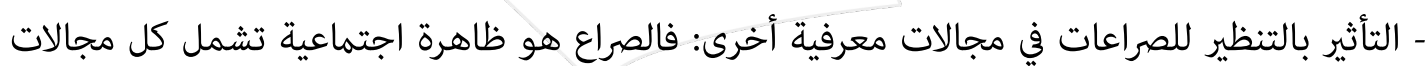

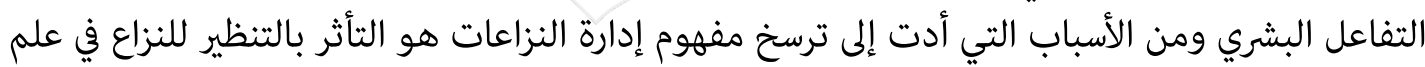




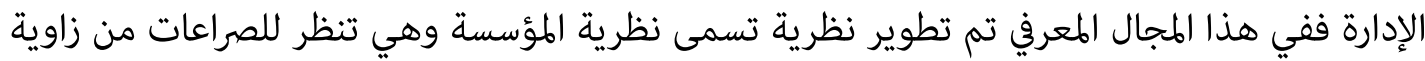

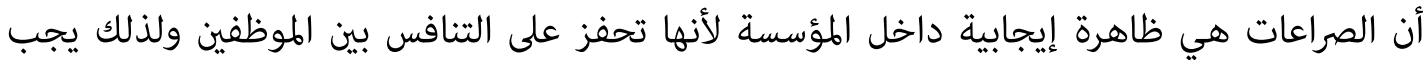
الإبقاء على حد معين من النزاعات بين الموظفين والعمل على إنها إدارته.

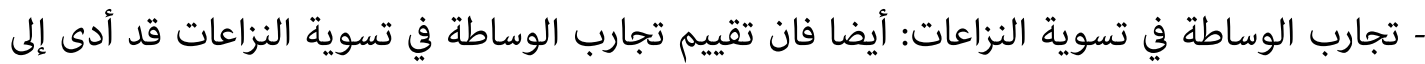

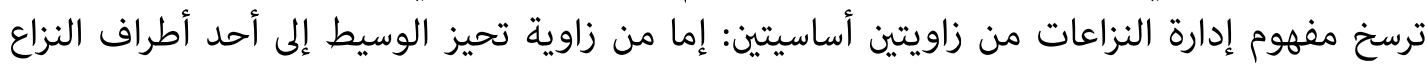

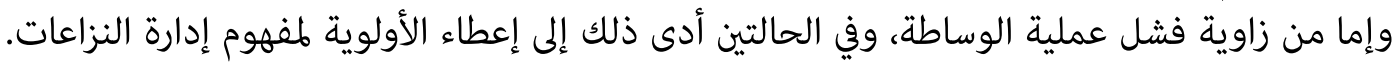
ومع ذلك فقد تعرض مفهوم إدارة النزاع إلى مراجعة عميقة باعتباره مفهوما مركزيا في حقل النزعات

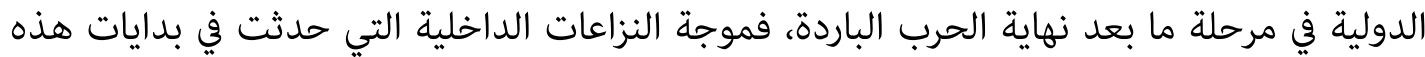

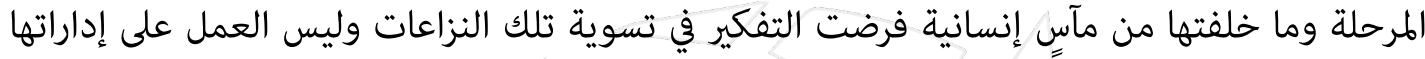

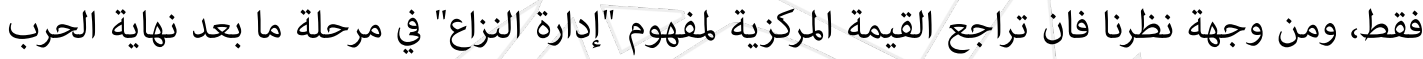
الباردة يرجع للأسباب التالية:

1-آثار النزاعات الداخلية بعد نهاية الحرب الباردة: فموجة النزاعات الداخلية التي اندلعت في مرحلة ما

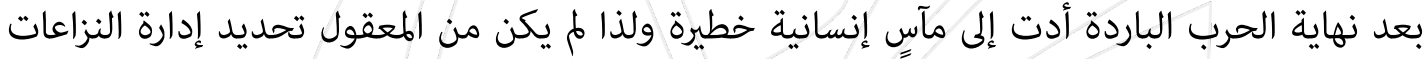
كهدف نهائي لها بل ضرورة التفكير في تسويتها.

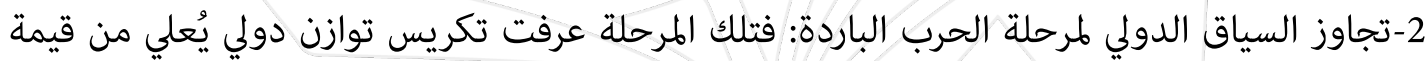

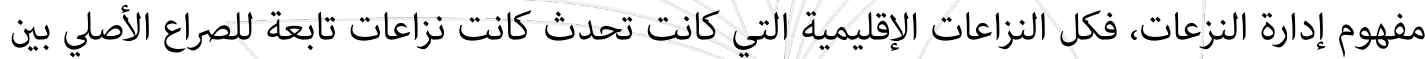

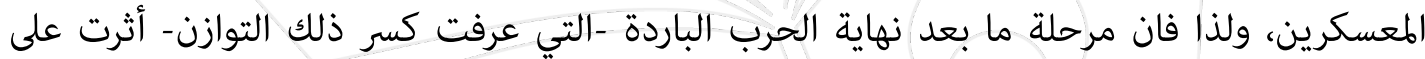

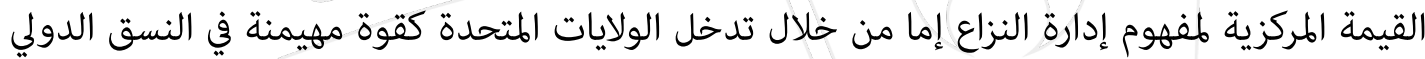
لحسم بعض الصراعات، أو في الضغط الدلى القراع القوى الإقليمية لتسوية نزاعاتها.

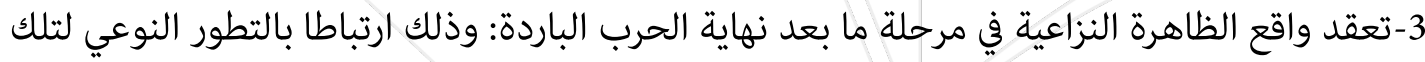

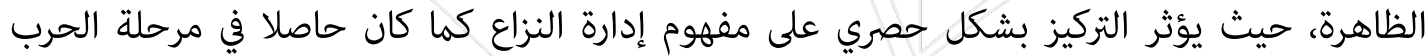
الباردة على تطور التنظير حول الظاهرة النزاعية.

المحور الخامس: البعد الميتادولوجي لتطور الظاهرة النزاعية بعد الحرب الباردة

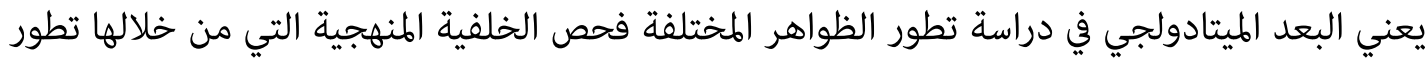

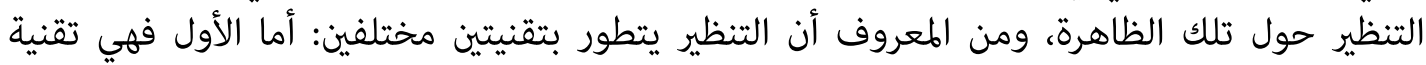

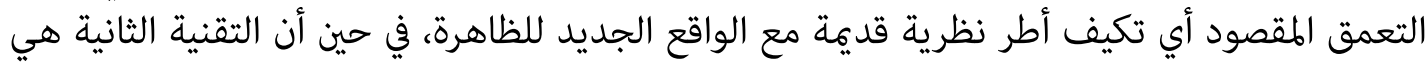

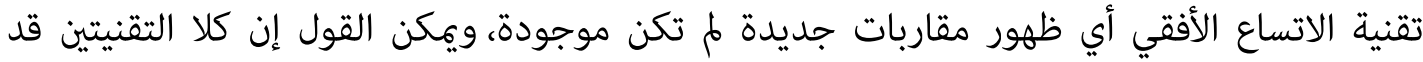

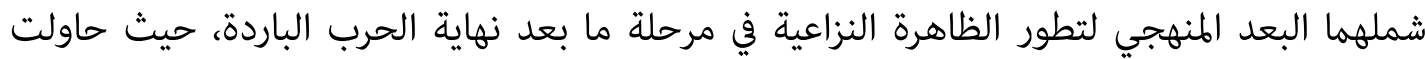

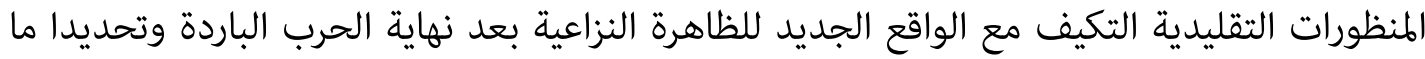

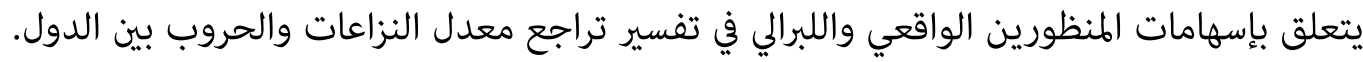


أما المنظور الواقعي فيفسر هذا الواقع الجديد من خلال التركيز على التحول في بنية النظام الدولي والتي

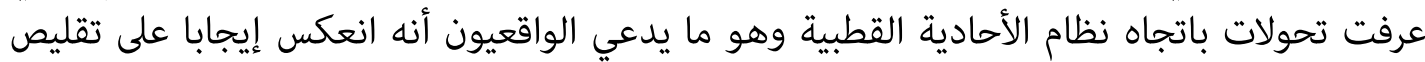

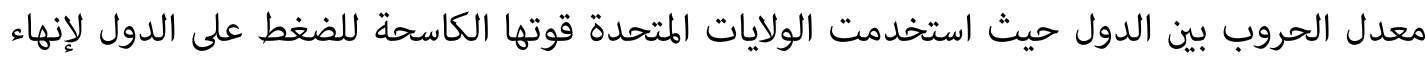

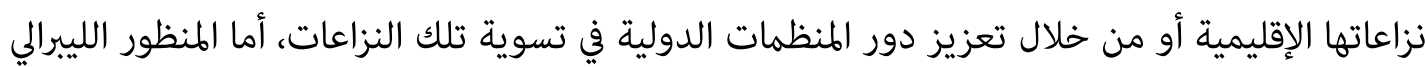

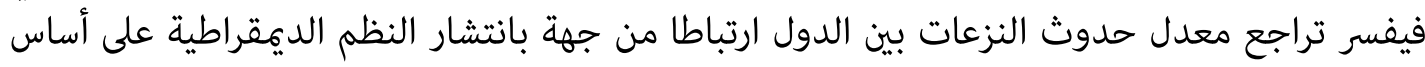

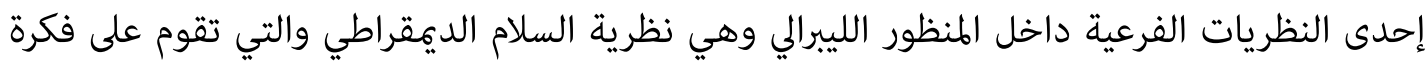

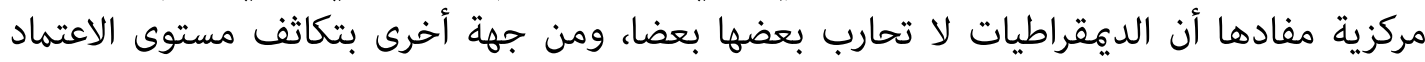

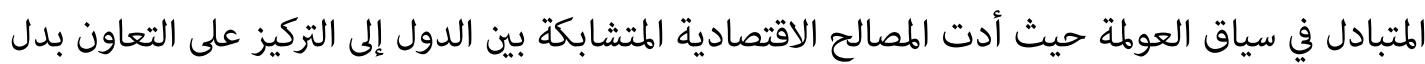

الصراع.

أما تقنية الاتساع الأفقي فتبرز من خلال ظهور أطر نظرية جديدة تحاول تفسير واقع الظاهرة النزاعية

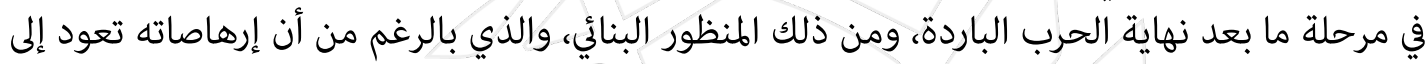

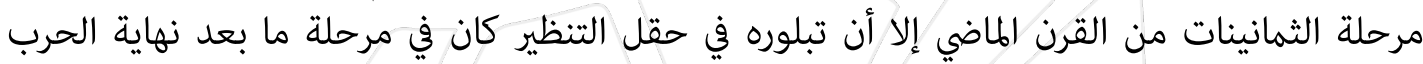
الباردة وبصورة عامة كان هناك عاملان رئيسيان حفزت على صعود البنائية في حقل التنظير:(241)

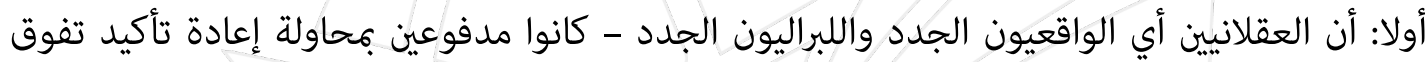

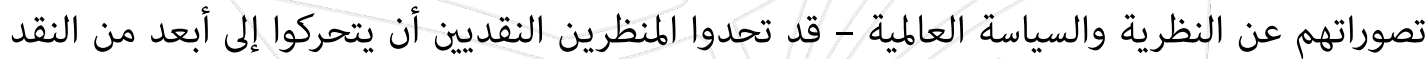

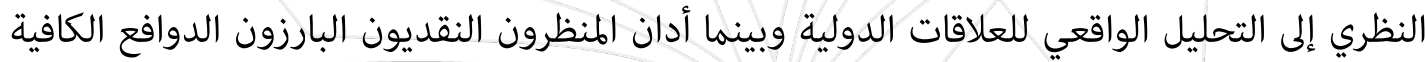

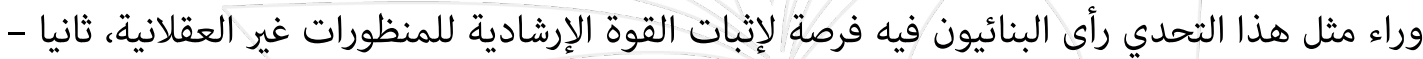

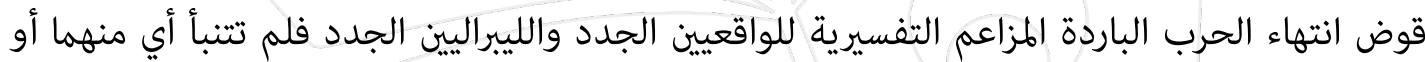

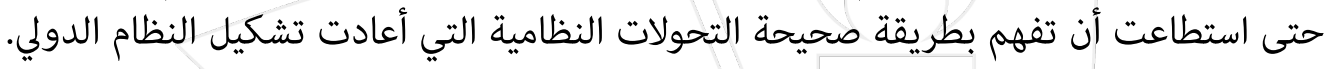

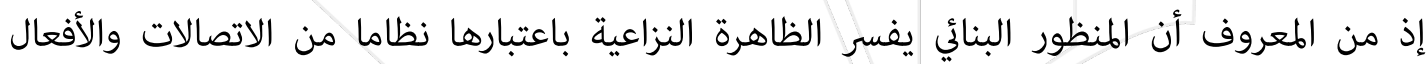

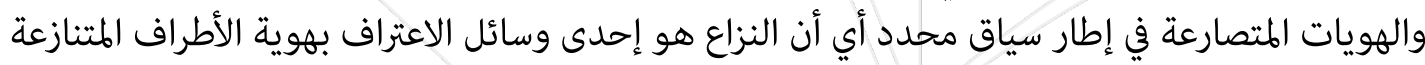

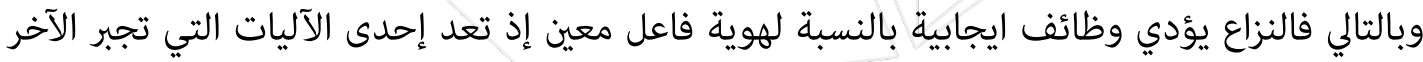

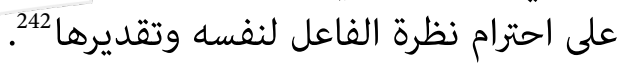

241 Christian Reus- Smit. Constructivism.In Theories of International Relations .eds Andrew Linklater.Scott Burchill.(.Deakin University).1996

242 Dan. Reiter.Exploring the Bargaining Mode of War .Avlaible at: http: // socsci.colorado.edu/ blimes / retier \%20\% Bargaining 20\%model $20 \%$ war.pdf 


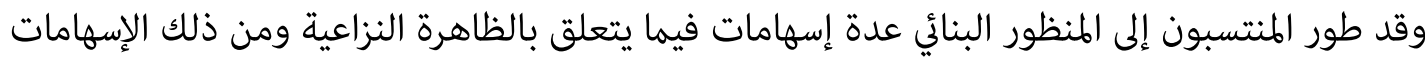

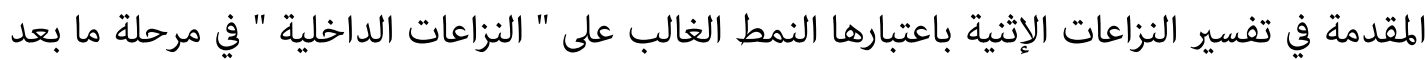

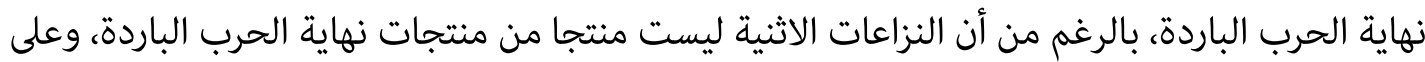

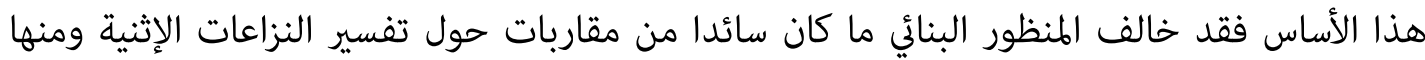

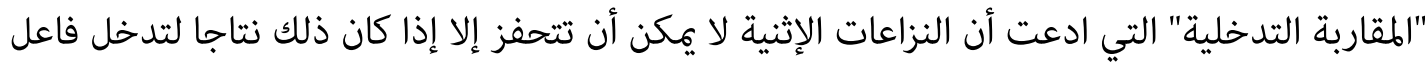

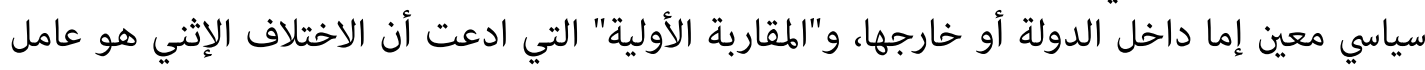

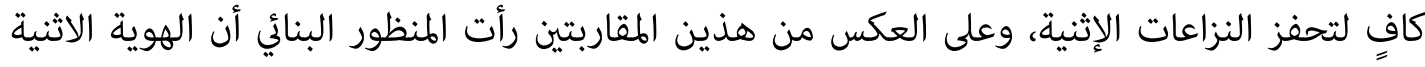

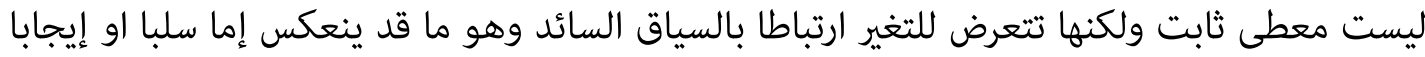

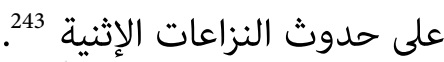

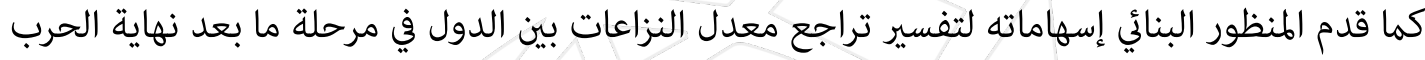

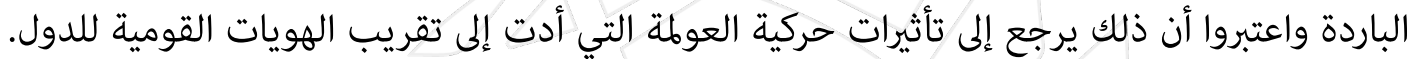
ومن المقاربات الجديدة التي ظهرت لتفسر واقع الظاهرة النزاعية بعد نهاية الحرب الباردة هي مقاربة

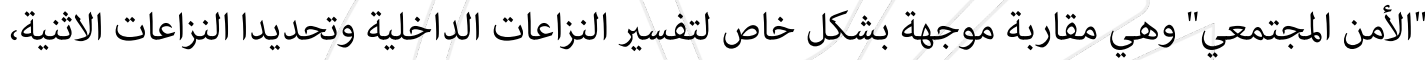

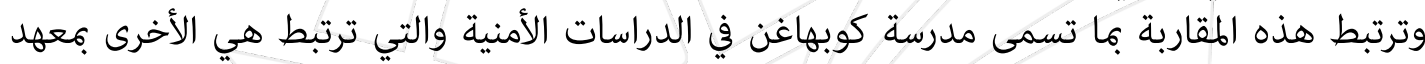

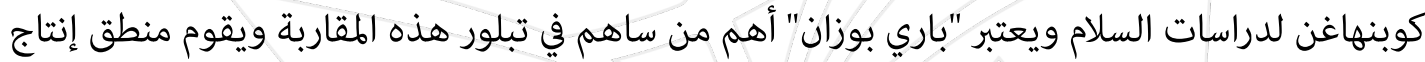

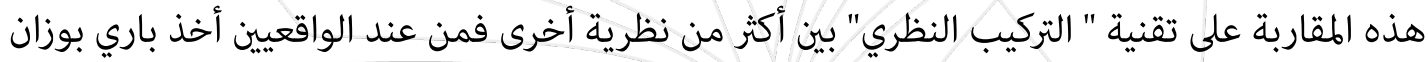

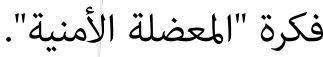

وبالنسبة إليه فإنه مثل ما أن المعضلة الأمنية الدولية تنشأ نتيجة عدم وجود سلطة مركزية تفرض قيودا

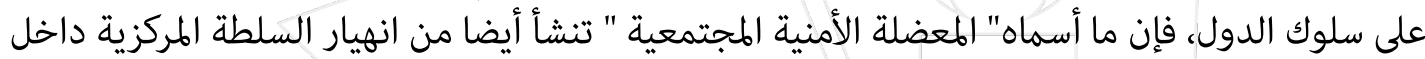

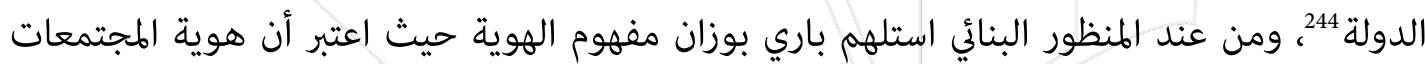

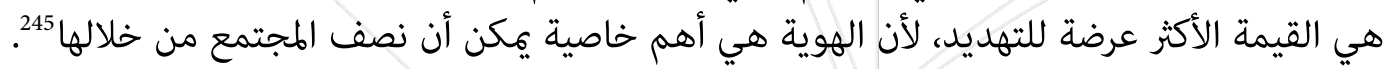

243 Amir,Pasic."Culture,Identity,and Security".Rockefelcer Brothers Fund.NY.1998.P10

244 عادل زقاع ـ المعضلة الأمنية المجتمعية: خطاب الامننة وصناعة السياسة العامة. مجلة دفاتر السياسة والقانون. ع 5. جوان 2015.

16 ص

245 Bill Mcsweeney, ,Review:Identiti and Security: Buzan and the Co penhagen . School".Review of Internatio,al Studies.Vol. 22. No.1. Jan. 1996 . 
بالإضافة إلى ذلك ظهرت مقاربة صدام الحضارات كمحاولة للتنظير إلى الأبعاد الحضارية للصراع الدولي

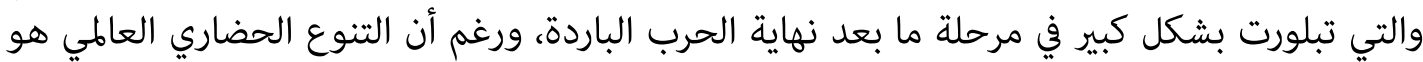

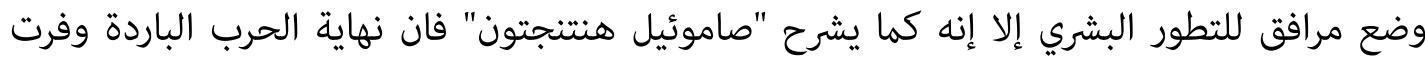
اللحظة التاريخية المناسبة لتسويغ الحضارات المختلفة كفواعل صراعية المائه

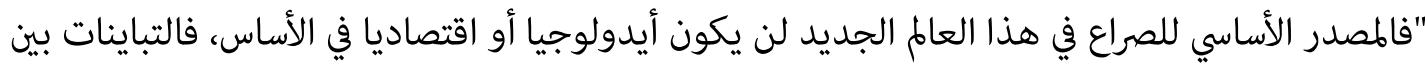

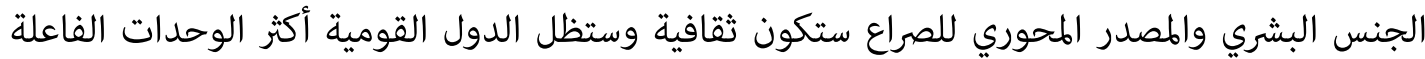

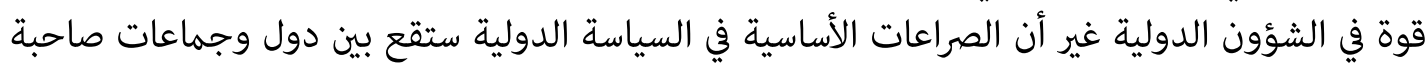

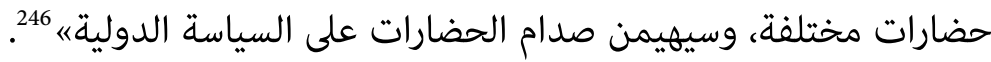
وبالمحصلة فان البعد الميتادولوجي لتطور الظاهرة النزاعية في مرحلة ما بعد نهاية الحرب الباردة يشير النير النيا

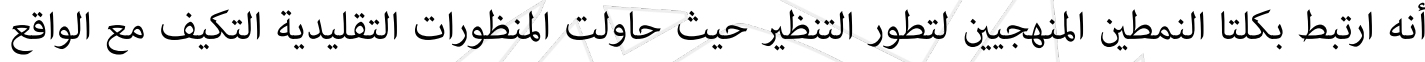

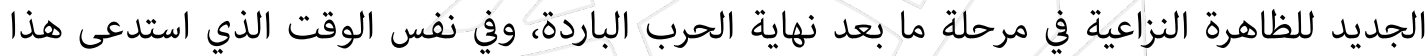

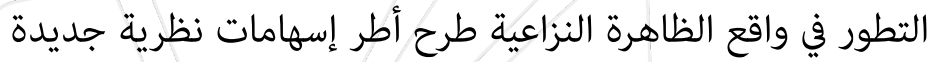

المحور السادس: البعد الاكسيولجي لتطور الظاهرة النزاعية بعد نهاية الحرب الباردة

يعبر البعد الاكسيولجي عن طبيعة المنظومة القيمة التي ننظر بها للظاهرة النزاعية، ويمكن القول إنه

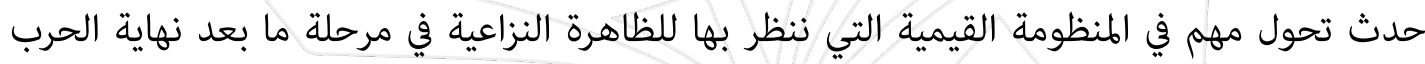

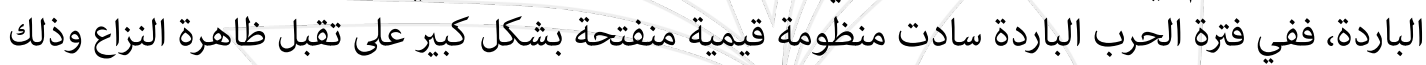

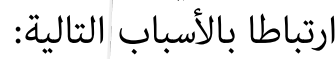

- إن السياق العام للعلاقات الدولية في تلك الفترة كان سياقاً نزاعياً محوره الأساسي التنافس على تشكيل التهيل

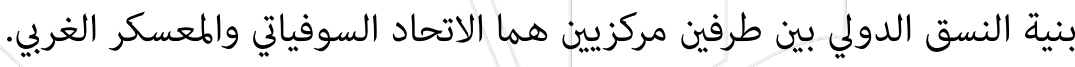

- إن خطاب المنظور الواقعي في العلاقات الدولية هو الخطاب النظري الأكثر رواجا في تلك الفئ الفترة وهذا

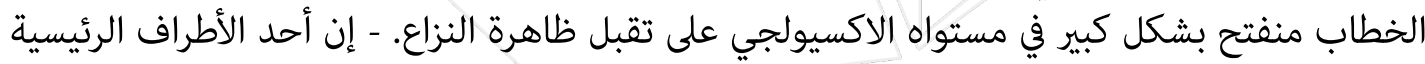

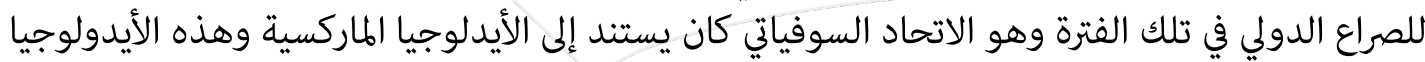
منفتحة بشكل كبير على ظاهرة الصراع بل تعتبره هو الأصل في العلاقات الدواتئ الدولية.

246 صامويل هنتنجتون، الإسلام والغرب: آفاق الصدام. ترجمة مجدي شرشر (القاهرة: مكتبة مدبولي، 1995) ص 7. 


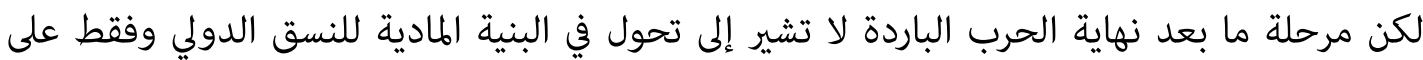

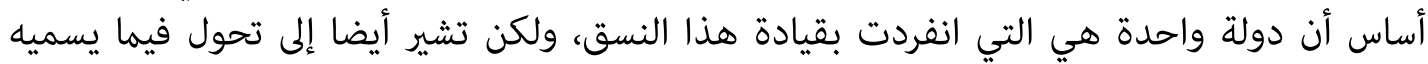

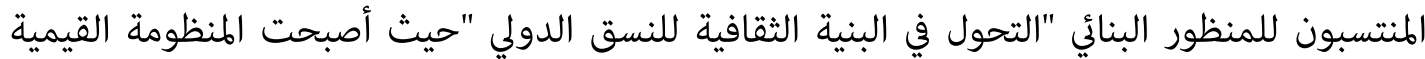

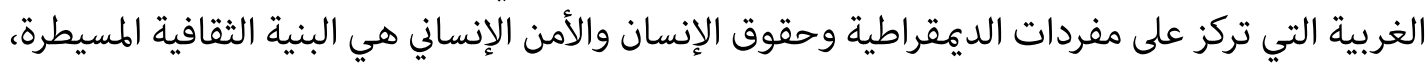

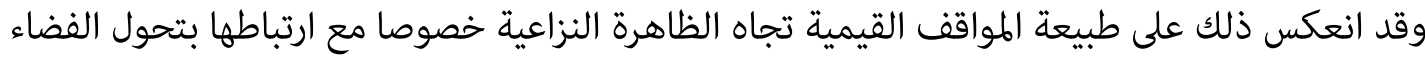

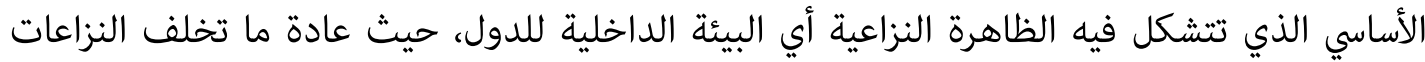

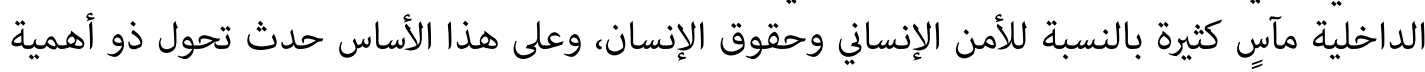

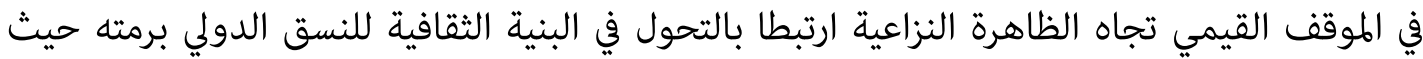
أصبح هناك انفتاح أكثر على "استهجان" الظاهرة النزاعية نظرا لما تخلفه من مآسِ إنسانية كبيرة.

بالرغم من كل التطورات العملية والنظرية على الظاهرة النزاعية في مرحلة ما بعد نهاية الحرب الباردة

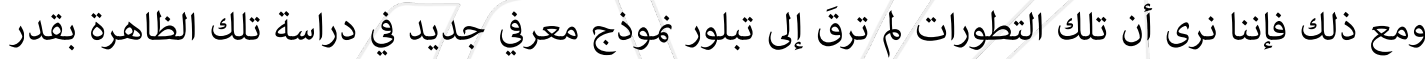
ما أدت إلى تبلور برنامج بحثي جديد ضمن ذلك إنك السياق.

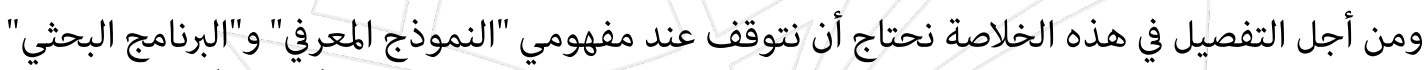

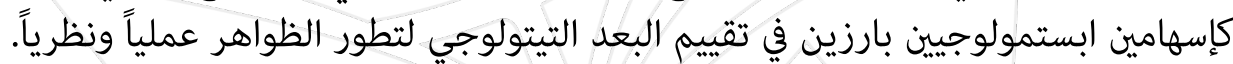

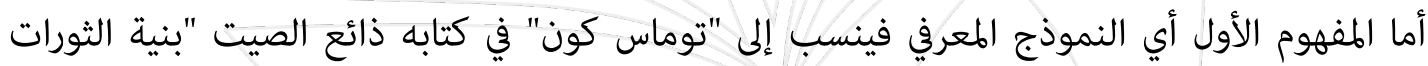

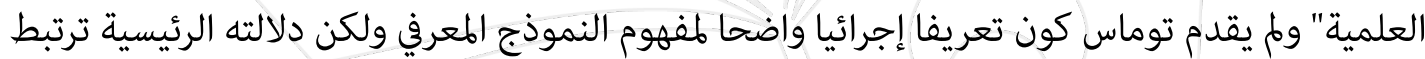

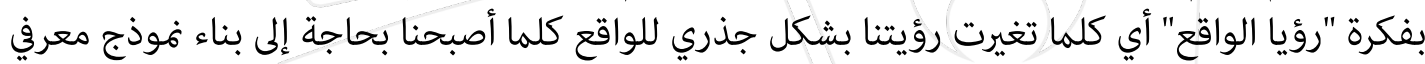
جديد 247.

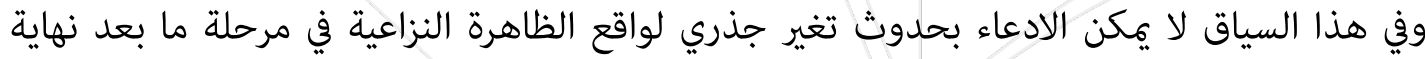

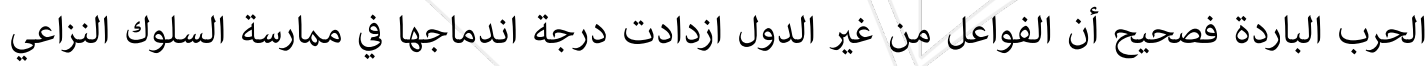

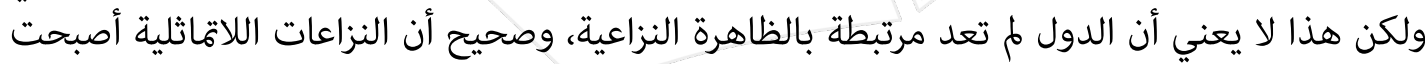

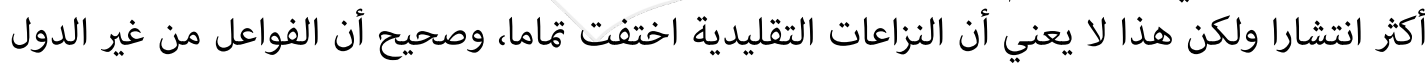

247 Kuhn ,Thomas S.The Structure of Scientific Revolution.3rd ed. (Chicago: University of Chicago).1996. 
منفتحة بشكل أكبر على السلوك غير العقلاني ولكن هذا لا يعني أن الظاهرة النزاعية تتحول إلى ظاهرة

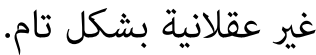

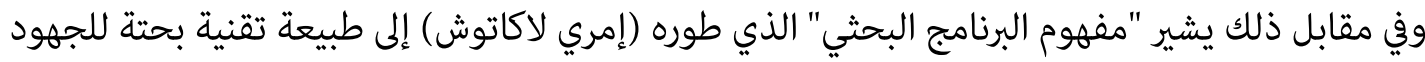

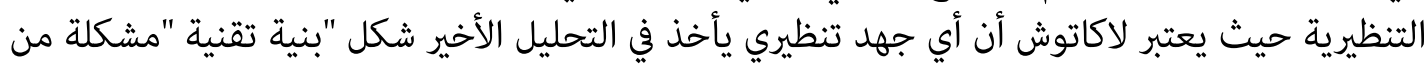

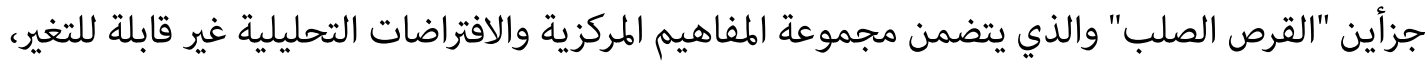
أما الجزء الحزام الواقعي "الحالات الإمبريقية" ويفرق (لاكاتوش) بين نوعين من التحول التهول في البرامج البحثية:

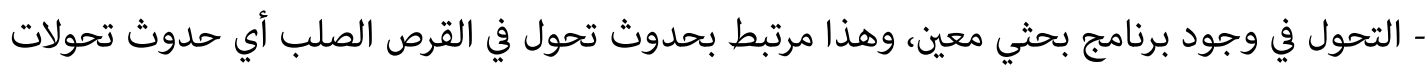

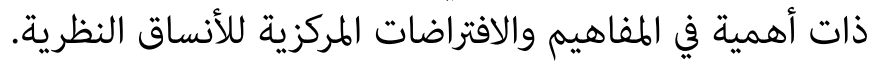

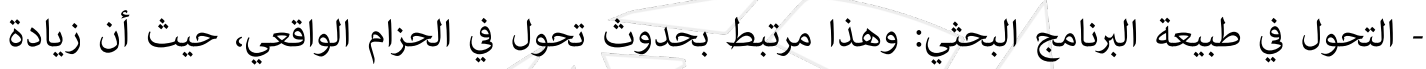

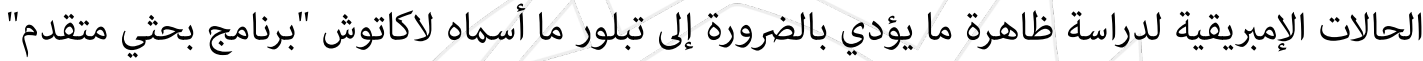

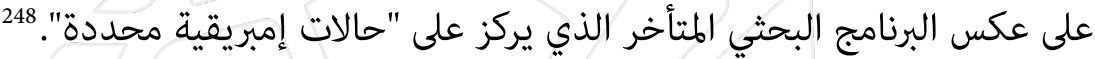

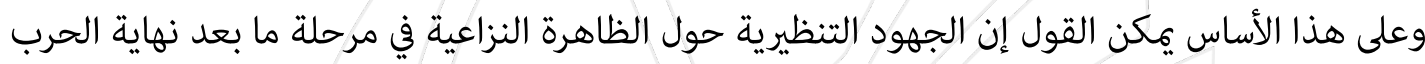
الباردة تشير إلى تبلور برنامج بحثي جديد وهذا يستند إلى إلى الاعتبارات التالية:

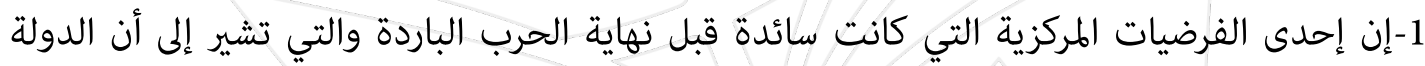

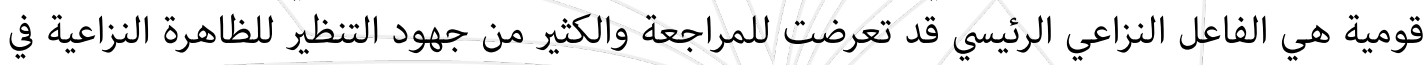

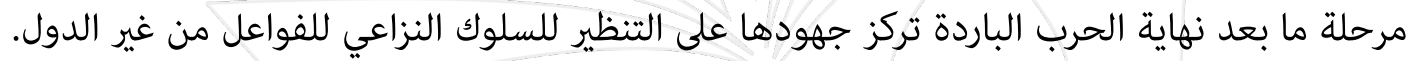
2-إن مفهوم إدارة النزاع الذي كان المفهوم المركزي في مراحل سابقة قد تعرض للمراجعة سواء في دلالاته

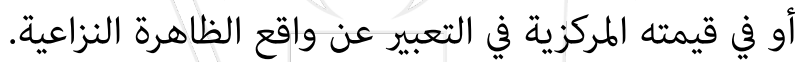

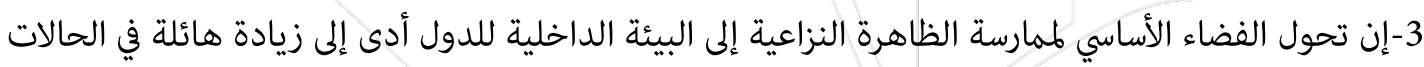
الإمبريقية المدروسة ما انعكس على "تقدمية" البرنامج البحثي للجهود التنظيرية حول الظاهية الناهرة النزاعية.

248 انظر حول البرنامج البحثي عنند لاكاتوش: امري لاكاتوش. فلسفة العلوم: برامج الأبحاث العلمية. ترجمة ماهر عبد القادر محمد علي.(بيروت: دار الفارابي.) 1975 


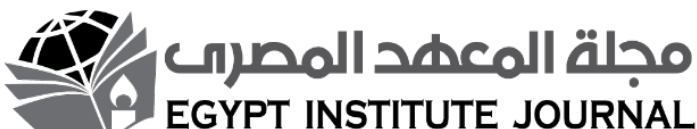

الكرد والنظام التوافقي في العراق

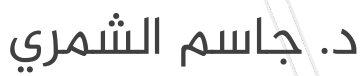


مقدمة:

اتسمت العلاقات بين كثير من الأطراف المساهمة في العملية السياسية في العراق بعد عام 2003، بأنها

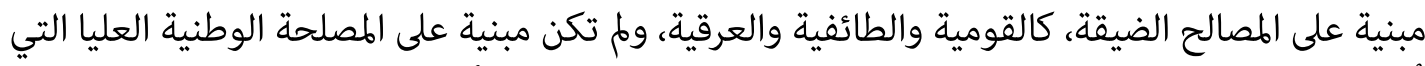

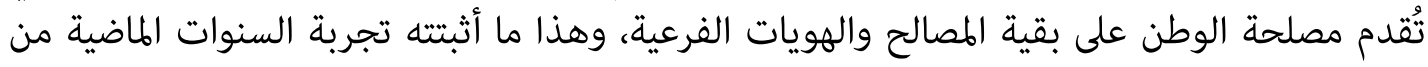
عمر العملية السياسية. والكتل السياسية الكردية - على اختلاف توجهاتها- تُشُّل محورًا مهمًا في عراق ما بعد 2003، سواء أكان ذلك على المستوى السياسي، أم الأمني.

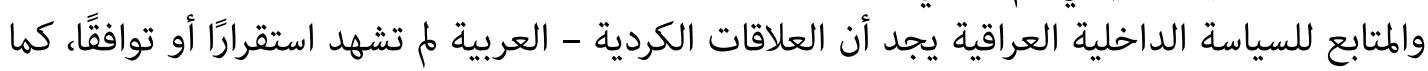

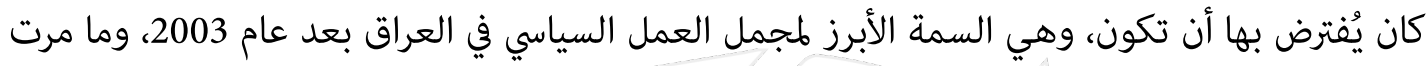

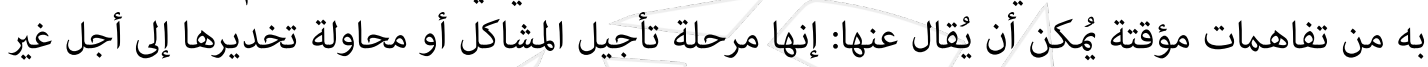

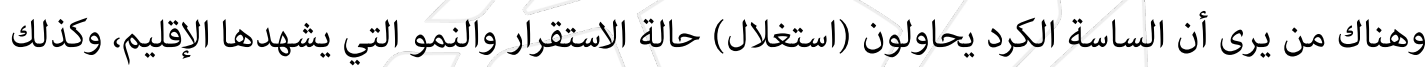

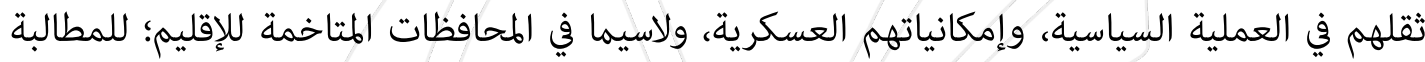

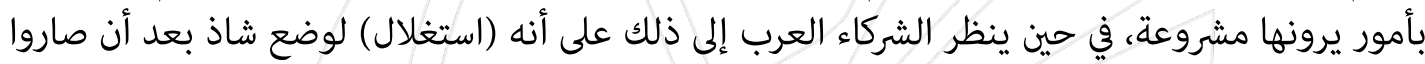

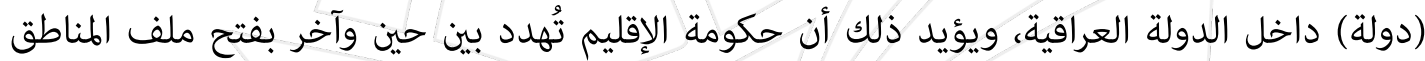

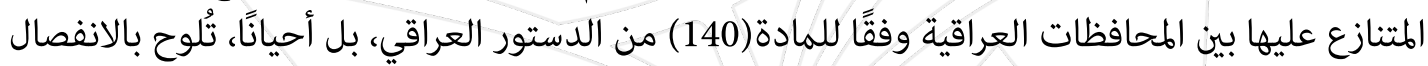

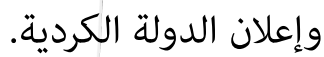

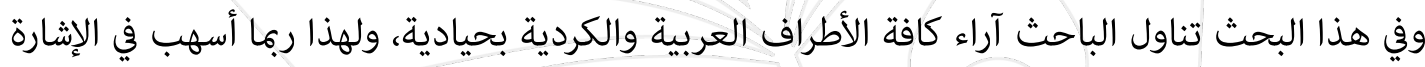

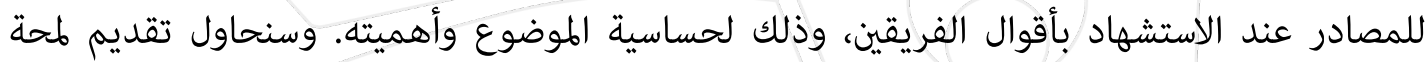

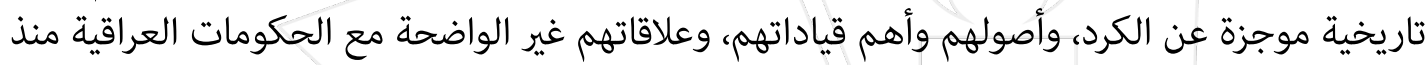

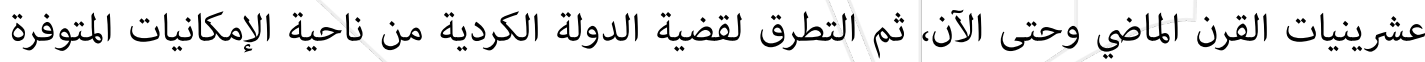

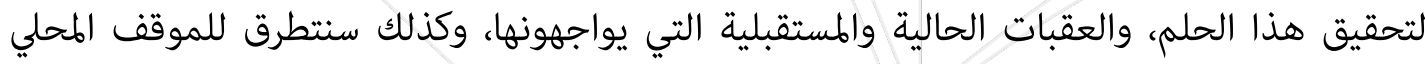

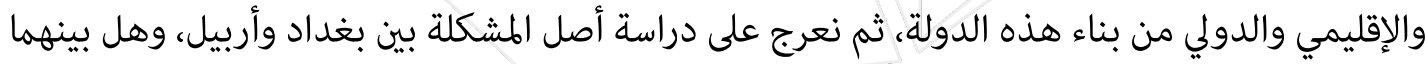

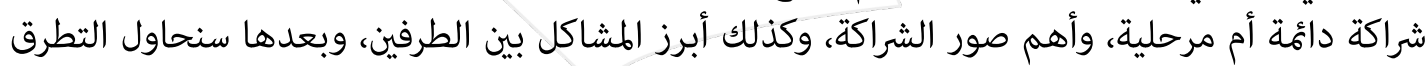

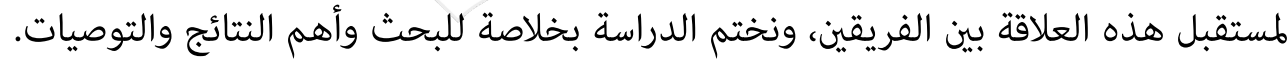

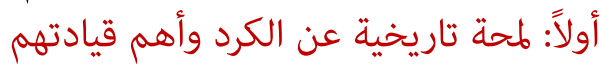

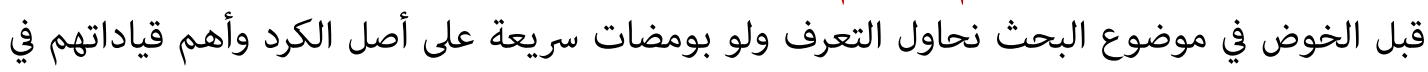

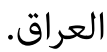


اختلف المؤرخون في إعطاء الفصول الأولى من تاريخ الكرد وأصولهم ومنشأهم (249)؛ والكرد يصنفون من ألناء

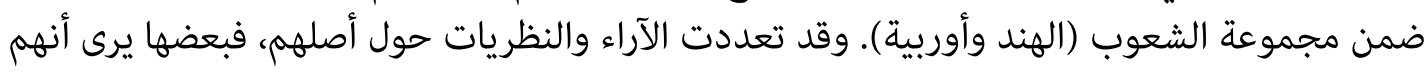

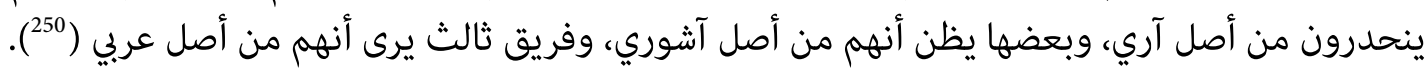

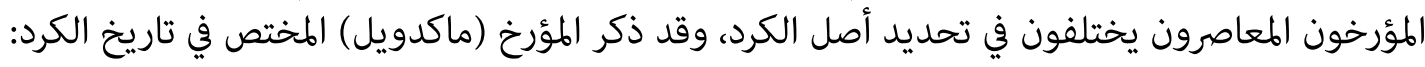

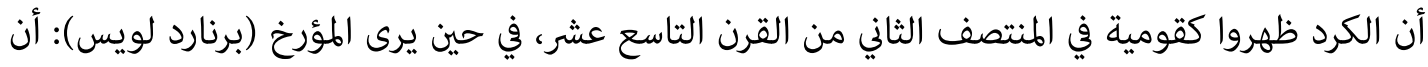

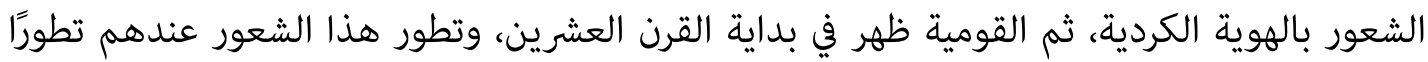

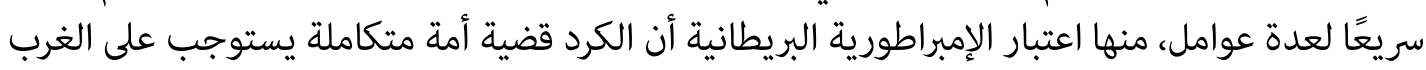
الدفاع عنها (251). ونشأت ((بين الكرد في أوائل القرن العشرين فكرة القومية الكردية؛ كردٍ فعل تجاه القوميات التركية

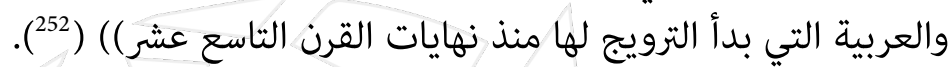

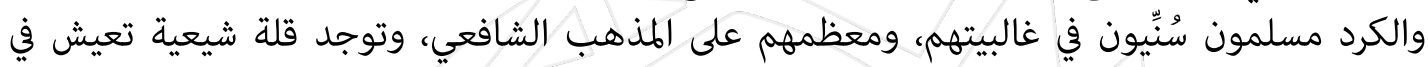

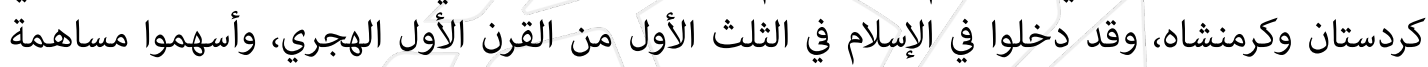

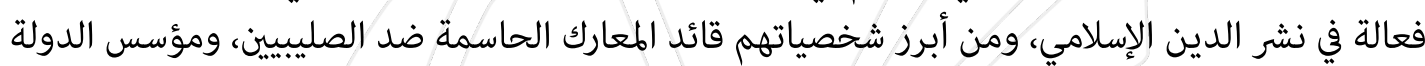

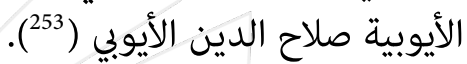

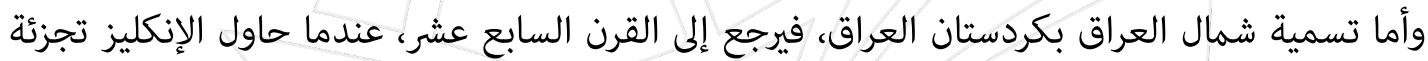

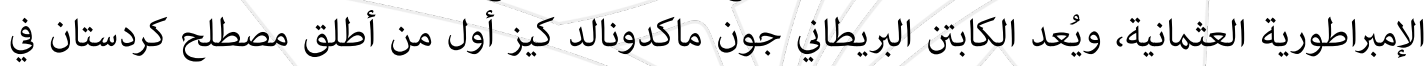

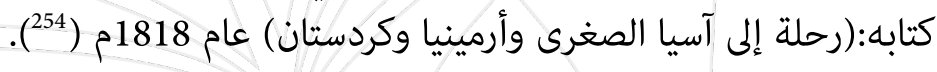

(249) لقد أثبتت الدراسات والبحوث الأنثرلوبولجية والأثنولوجية بالأدلة القاطعة أن الكرد من أصل آري. انظر: تاج النارئ الدين، أحمد، الأكراد:

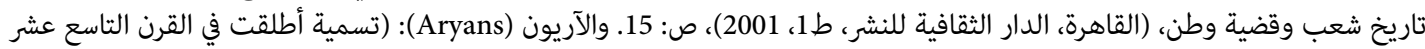

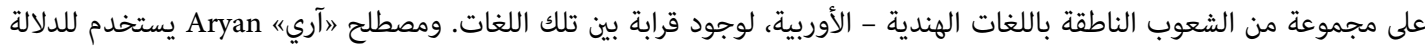

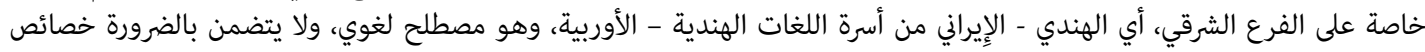

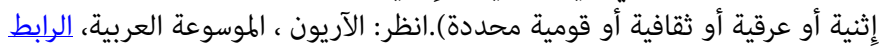

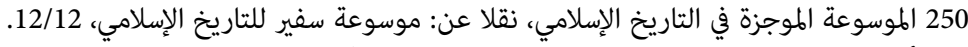

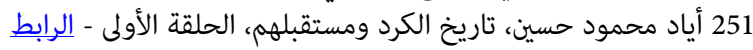

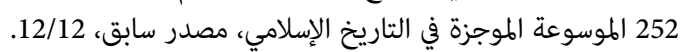

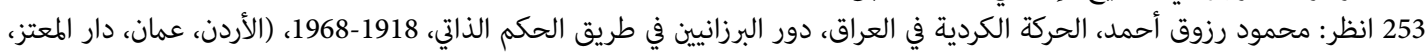

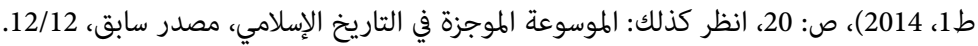

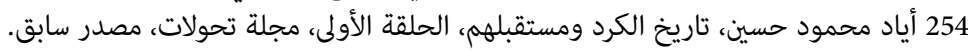


ويقدر عدد السكان بحافظات الإقليم الأربع أربيل والسليمانية ودهوك وحلبجة (5255) بأكثر من (5.2)

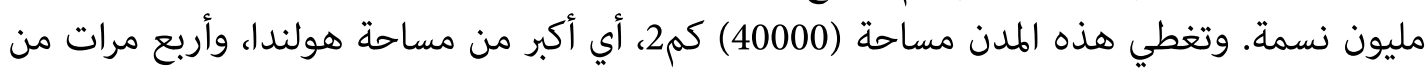

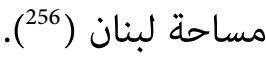

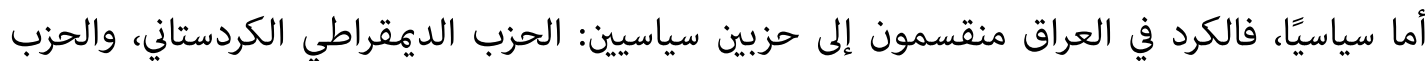

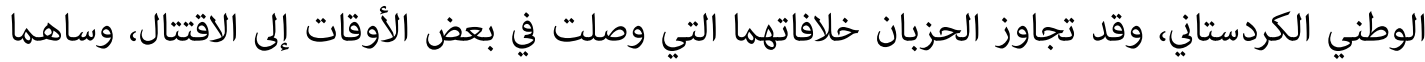

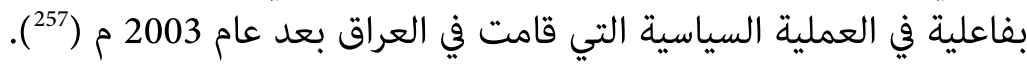

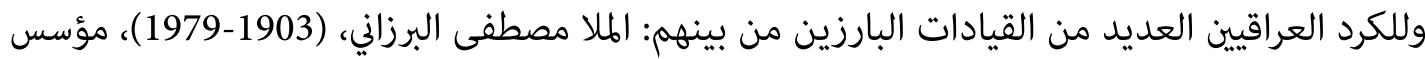

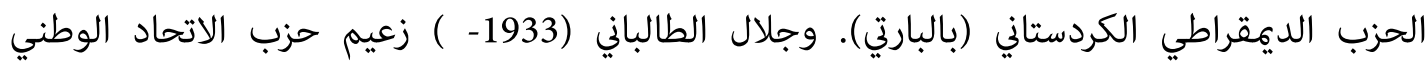

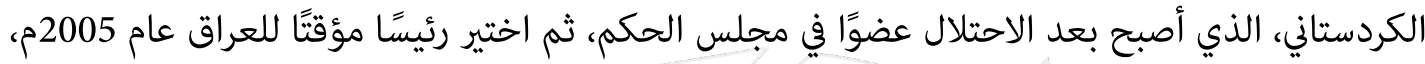

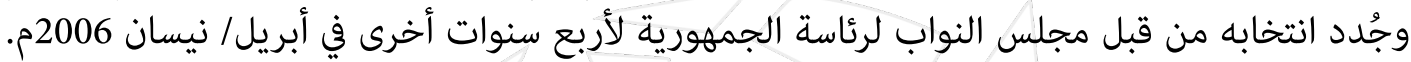

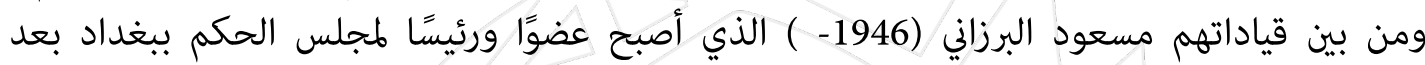

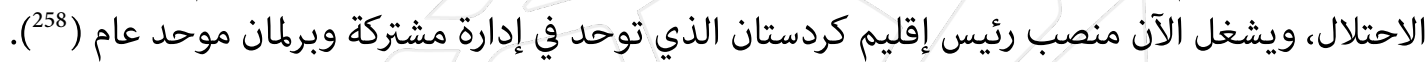

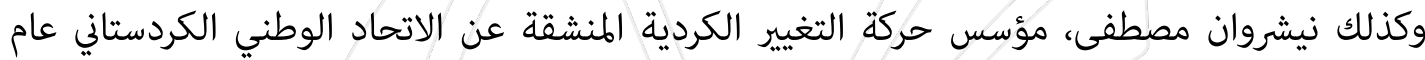
2006م (259 (259).

ثانياً: مراحل العلاقات الكردية مع الحكومات العرات العراقية شهدت العلاقات العربية (العراقية) - الكردية تطورات العات كبيرة منذ بدات العاتية العاتية العات القرن الماضي، ويمكننا تحديد

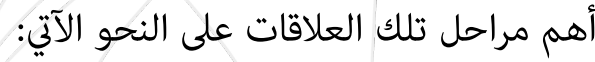
- في 1930 - 1933 شارك ملا مصطفى البرزاني في مقاتلة القوات العات العراقية المدعومة من البريطانيين، لكن

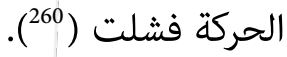

255 في (31 كانون الأول 2013)، وافق مجلس الوزراء العراقي على طلب حكومة الإقليم بجعل قضاء حلبجة محافظة جديدة في الإقليم

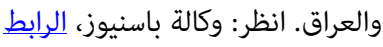

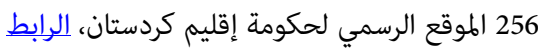

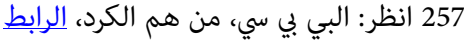

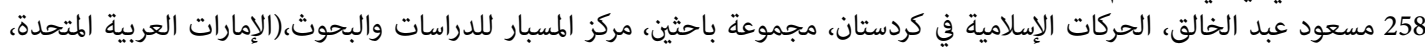

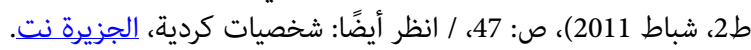

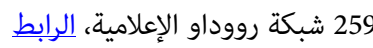

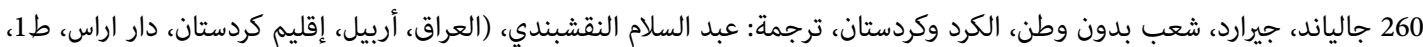


- في عام 1943 استثمر الكرد الحرب العالية الثانية ليعلنوا ثورتهم التي قادها مصطفى البرزاني في منطقة برزان، واستطاع الجيش العراقي القضاء عليها عام 1945م (261). - في عام 1945 عاد البرزاني لقاتلة القوات العراقية، لكن حركته انتهت ليتوجه بعدها لكهاباد الإيرانية

- في عام 1961، عاد البرزاني لقتال الحكومة (263 (203). - في أوائل عام 1970 قام الكرد بثورة مسلحة عندما كان صدام حسين نائبًا لرئيس الجمهورية، البكر، وفشلت ثورتهم عام 1975م (264). - في عام 1976 بدأ الطالباني حركة مسلحة ضد السلطة المركزية، واستمرت حتى الحرب العراقية الإيرانية

- في تسعينيات القرن الماضي (شارك الكرد في الحملة الأمريكية للإطاحة بنظام صدام حسين كطريقة

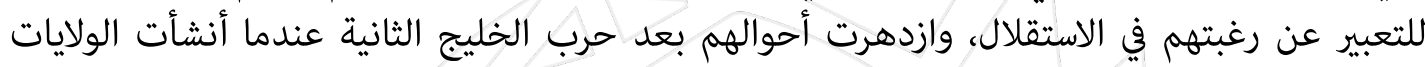

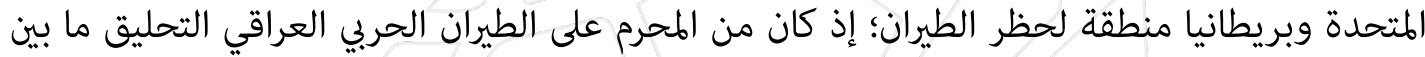

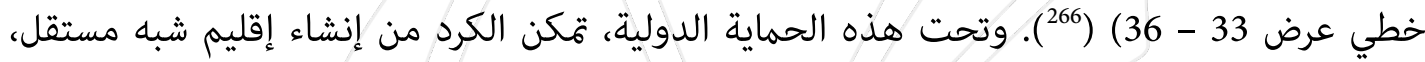
رغم عدم استطاعتهم الاستغناء الكامل عن حكومة بغداد (35) (267).

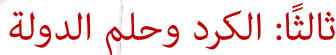
مل يكن مفهوم الدولة الحديثة قد ظهر لدى الكرد أو وصلت أفكاره المنطقة حتى نهايات القرن التاسع

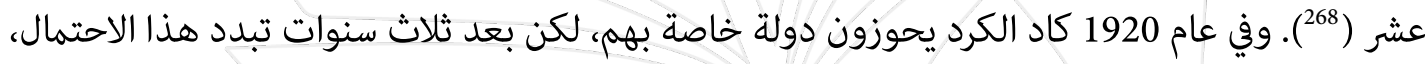

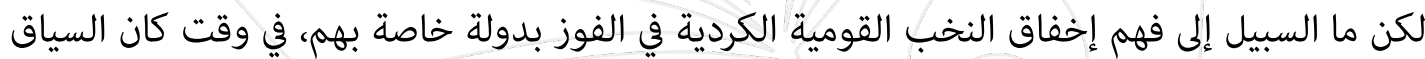
الدولي يبدو مواتيًا على وقع تقطيع أوصال السلطنة العثمانية وبحث القوى الغربية عن حلفاء محلية مليين.

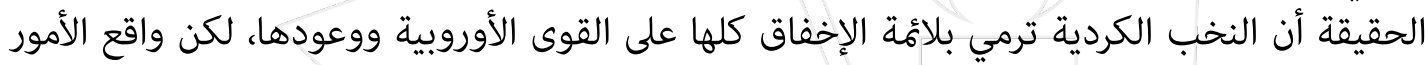
أكثر تعقيدًا وتركيبًا، والسبيل إلى جواب مركب هو الى احتساب عدة عوامل خارجية الإبفاب (مصالح الغربيين

261 هادي حسن عليوي، الدولة الكردية، وتقسيم العراق، كتابات.

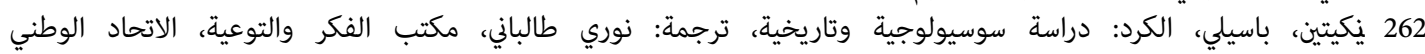

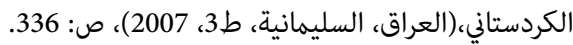

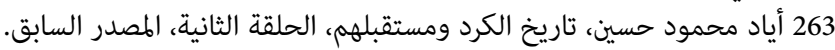

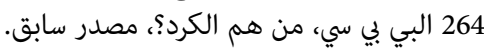
265 شخصيات كردية، الجزيرة نت، من مصدر، مصدر سابق. 266 انظر: البي بي سي، من هم الجزية الكردي، مصدر سمدر سابق. 267 المصدر سابق. 268 لقاء مكي، الدولة الكردية هل من فرصة، الجزيرة نت. 
المتباينة، وانتصارات مصطفى كمال العسكرية) وداخلية (انقسام اللجان الكردية) ومسارات تاريخية

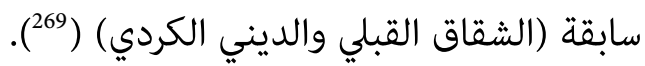
وقد (نعى العديد من الكرد دولتهم خلال الذكرى السنوية المئوية لاتفاقية (سايكس بيكو)، الموقعة في

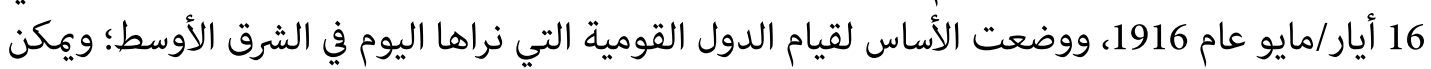
القول بأنه لا توجد مجموعة عرقية واحدة تبغض هذا العات الاتفاق أكثر من الكرد، فهم يعتبرون صياغة الدول

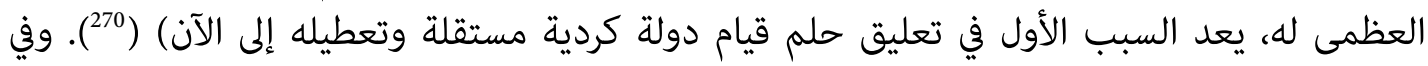
1919م أعلن الشيخ محمود الحفيد تشكيل حكومة كردستان الجنوبية بعد مساندة الإنكليز له،

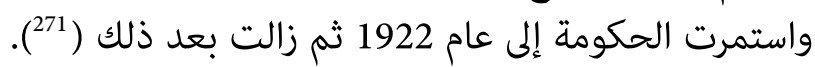
وفي مطلع القرن العشرين (بدأ الكثير من الكرد التفكير في تكوين دولة مستقلة، باسم كردستان، وإن وبعد

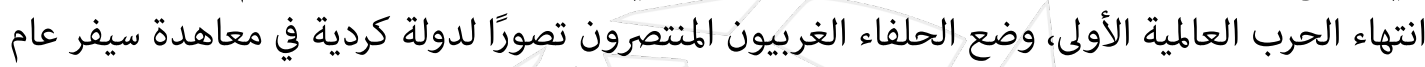

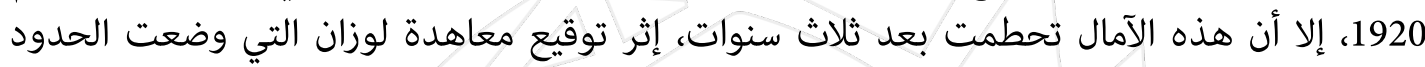
الحالية لدولة تركيا، بشكل لا يسمح بوجود دولة كردية) (272).

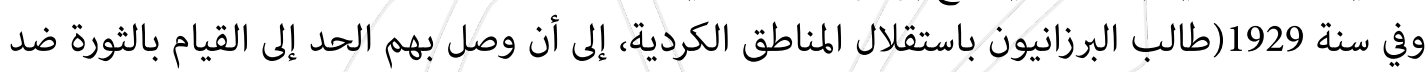

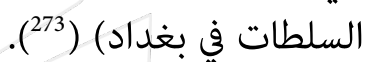
والواقع أن (جمهورية مهاباد) هي أول دولة كردية تأسست في إيران، في بr من كانون الثاني/يناير عام 197ا إلا أنها فشلت وسقطت سريعًا. والجمهورية المهابادية كانت من الأخطاء القاتلة للقيادة الكردية، التي لم تتحسب للظروف المحلية والدولية والإقليمية (274).

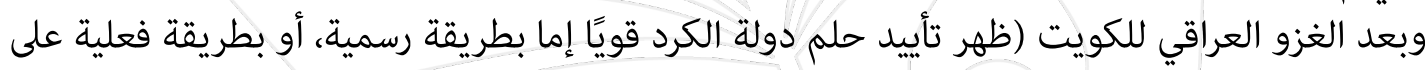

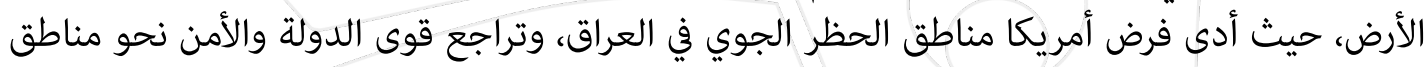

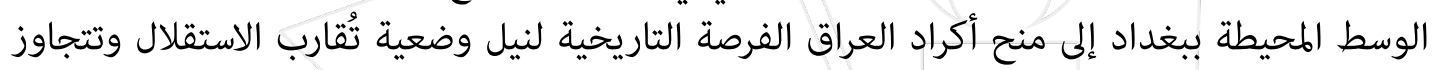

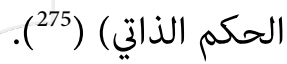

269 جوردي تيجيل، كيف تبدّدت فرصة إنشاء الدولة الكرديّة في 1920؟ صحيفة الحياة اللندنية نقلًا عن"ليستواره الفرنسية، وتيجيل أستاذ

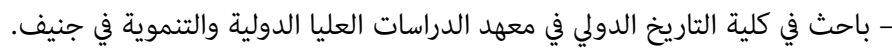

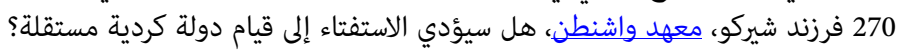

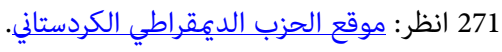
272 البي بي سي، من هم الكرد، مصدر سابق. 273

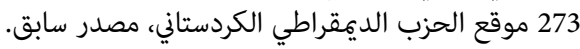

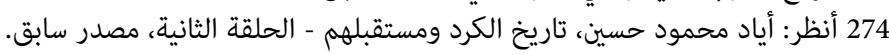

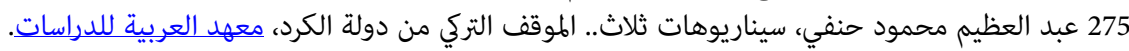


وبعد الاحتلال الأمريكي للعراق عام 2003، مل يتوقف الساسة الكرد عن التهديد وترديد دعواتهم لتكوين

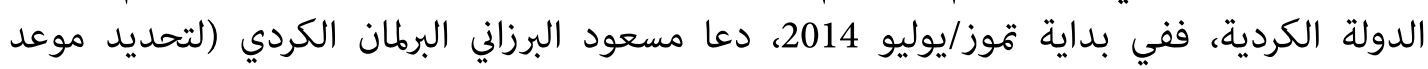

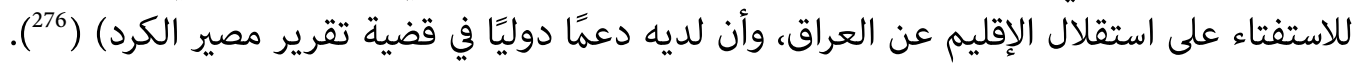

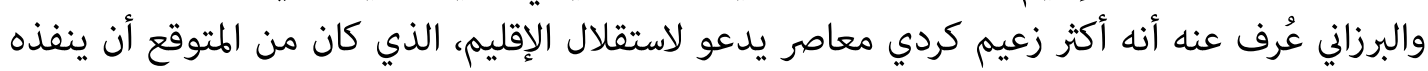

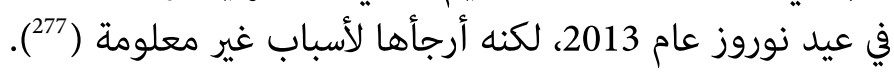

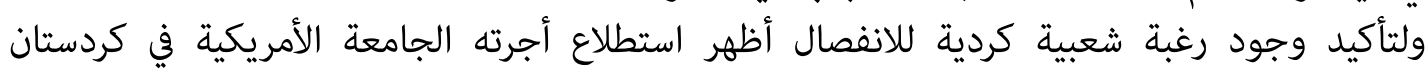
(AUDK)

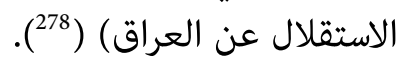
وفي نهاية أيلول/سبتمبر 2016، أكد رئيس مجلس الأمن في الإقليم مسرور البرزاني لصحيفة (واشنطن

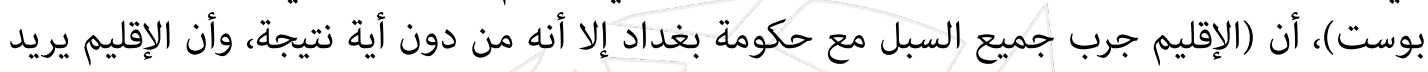

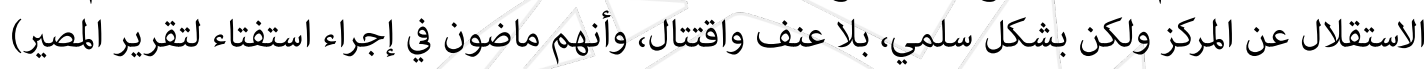

إن الذي يجعل مشروع استقلال كردستان يشق طريقه بصلابة إلى الأمام أكثر، هو دخول الأحزاب

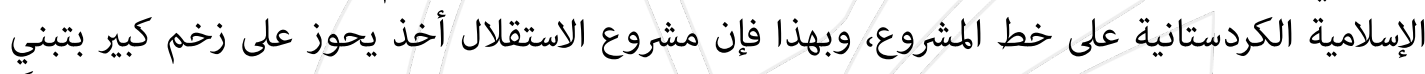

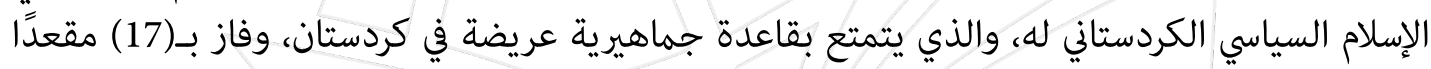

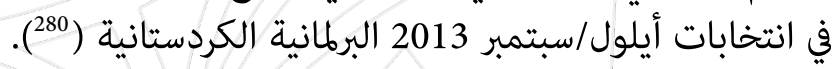

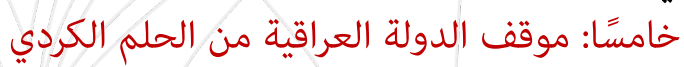

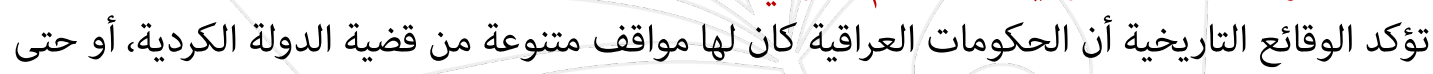

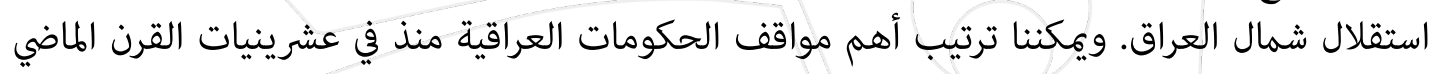
وحتى اليوم على النحو الآتي: - في عام 1920 تشكلت حكومل النومة الآني: عراقية مؤقتة تحت الرعاية البريطانية، وتم الاتفاق على ترشيح الأمير

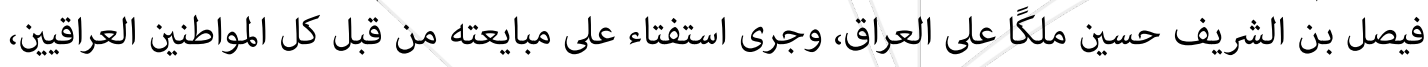

276 الجزيرة نت، كردستان العراق. هل تقرير المصير ممكن؟ 277 أنظر: شخصيات كردية، الجزيرة نت، مصدر سابق. 280 انظر: عبد الغني علي يحيى، هل آن الأوان لإعلان استقلال كردستان؟ ميدل ائل إيت أونلاين، http: //www.middle-east-online.com/?id=174588 
لكن الكرد العراقيين لم يشاركوا في الاستفتاء، ومع ذلك فإن كل ما تحقق للعرب تحقق للأكراد، ومن ضمن ذلك المشاركة في الحكم.

- وجاء دستور ثورة 14 قوز 1958 لينص على: (أن العرب والكرد شركاء في هذا الوطن)، وعاد الملا

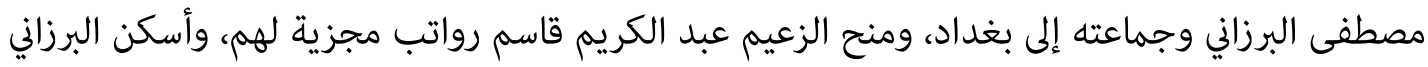

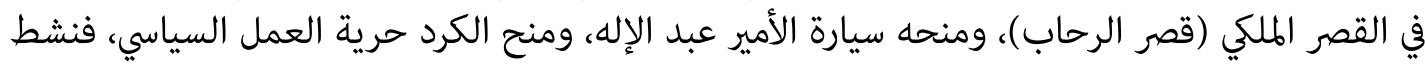

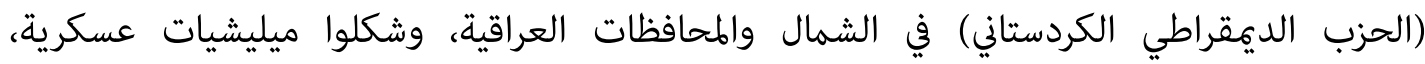

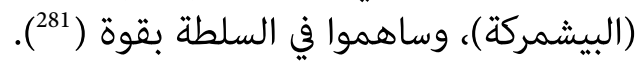
- في عهد الأخوين عبد السلام عارف وعبد الرحمن عارف (تشرين الثاني 1963ـ قموز 1968)، استمرت حالة الحرب واللا حرب بين الحركة الكردية والحكومات العراقية المتعاقبة، وفشلت كل الاتفاقيات بين الطرفين. - وبعد نجاح انقلاب حزب البعث بتموز 1968، استمر الكرد في الإجراءات المناوئة للحكومة واندلع قتال

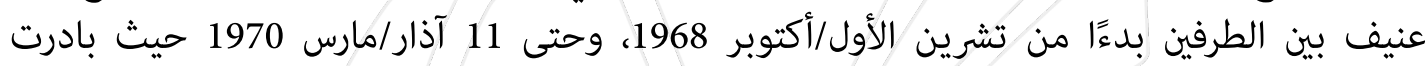
الحكومة إلى إعلان بيان 11 آذار/مارس، الذي يُقننن حقوق النين الكرد القومية على مستوى الدولة، ويشعرهم

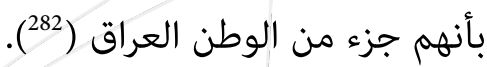
- في عام 1970 اتفق حزب البعث الحاكم والحركة الكردية على منحهم الحكم الذاتي خلال أربع سنوات، وطبقت كل فقرات الاتفاق، لكن الكرد رفضوا تنفيذ آخر بند في إعلان الحكم الذاتي في 11 آذار

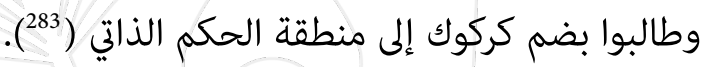

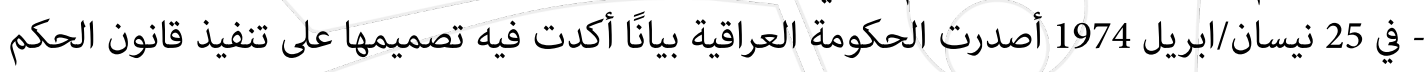
الذاتي، وأنها لن تتفاوض ثانية مع البرزاني، وعادت الحرب بحلول آب/أغسطس 1974 بيسن بين الجانبين (284).

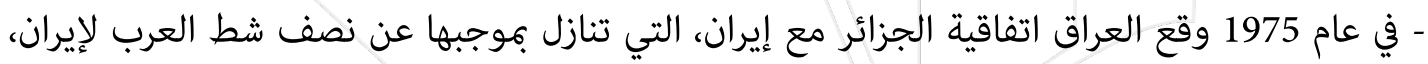
مقابل عدم دعمها للبرازاني (285).

281 انظر: هادي حسن عليوي، الدولة الكردية.. وتقسيم العراق، كتابات، مصدر سابق.

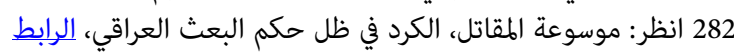

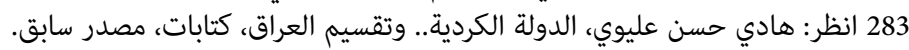

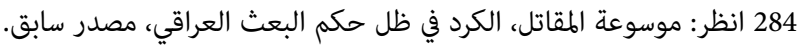

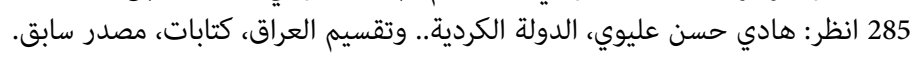


- في عام 1995، أراد العراق أن يُنهي قضية الكرد نهائًًا بإعطائهم الاستقلال، فقد ذكر مكرم الطالباني

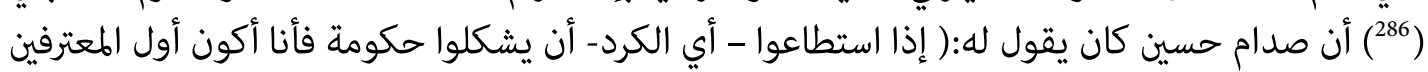

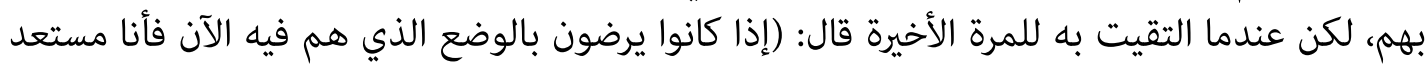

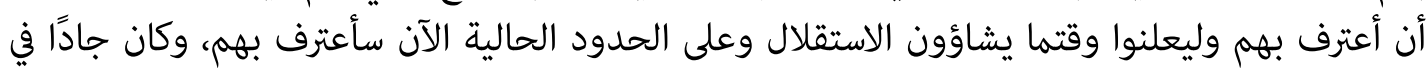

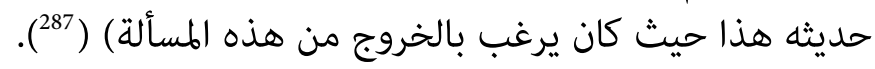
- بعد الاحتلال الأمريكي للعراق عام

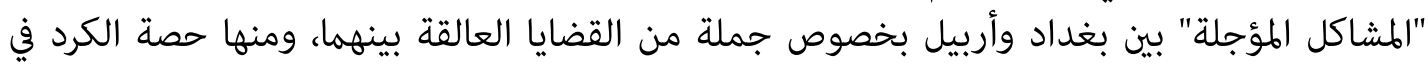
الموازنة، والمناطق المتنازع عليها، وغيرها.

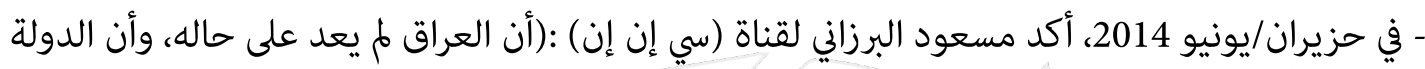

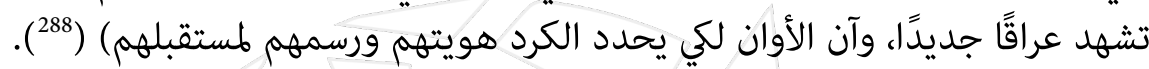

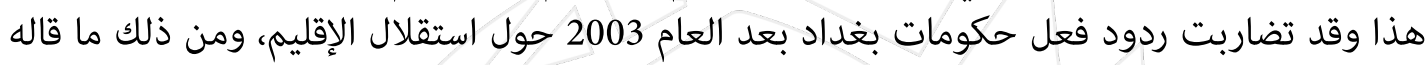

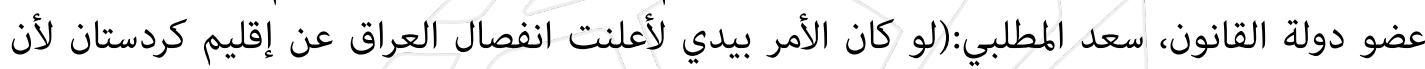

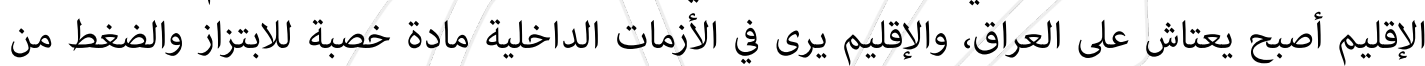

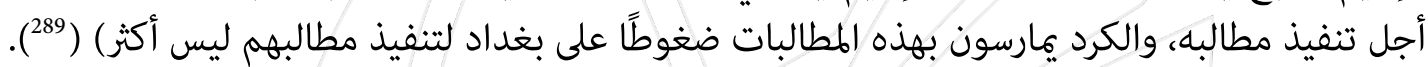

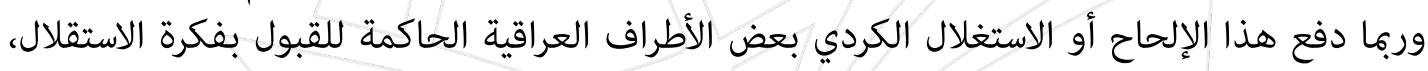

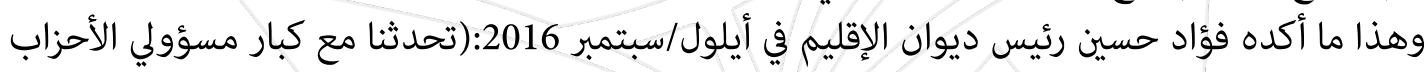

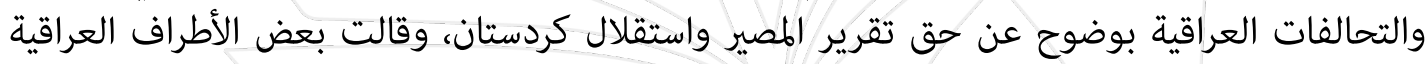

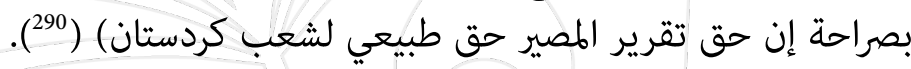

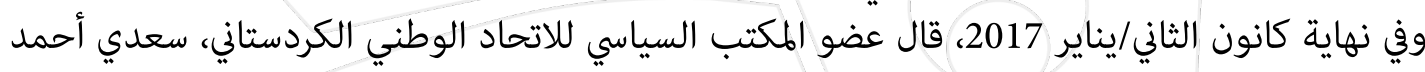

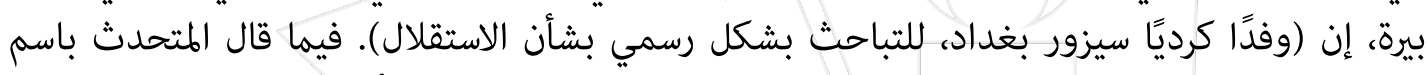

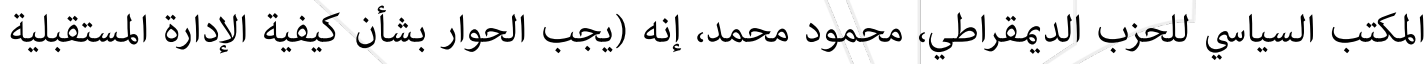

286 وهذا الحديث منقول من مذكركرات مكرم الطالباني، والطالباني عمل كوسيط بين حكومة بغداد والكرد لإنهاء الخلافات قبل الاحتلال،

كما ذكرت جريدة آوينة، العدد: (145).

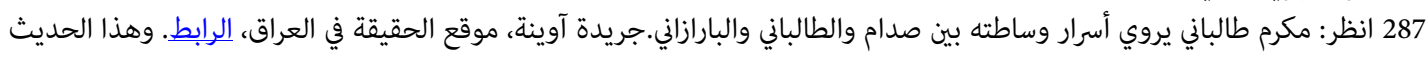

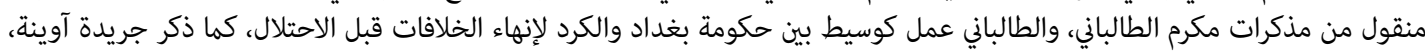


لهذا البلد، فنحن لم نستطع أن نتعايش معًا من خلال الحكم الذاتي ولا الحكم الفيدرالي، فماذا سيكون

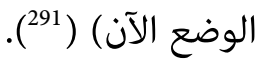
سادسًا: معوقات قيام الدولة الكردة الكردية: يُدرك القادة الكرد أن الطريق إلى تحقيق تطلعاتهم القومية ليست مفروشة بالورد، وأن هنالك شبه

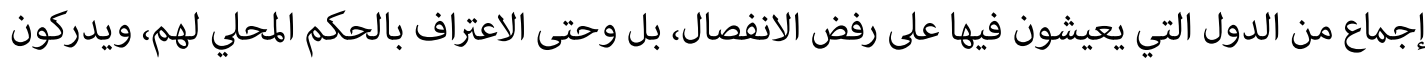

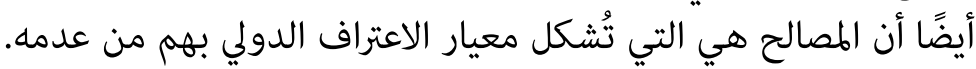

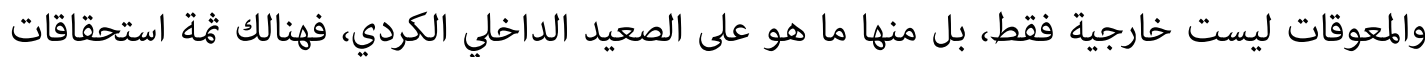

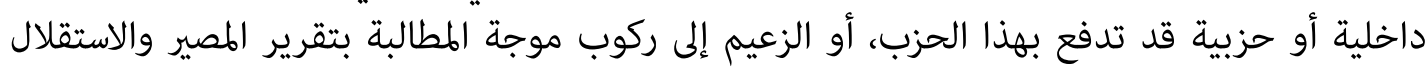

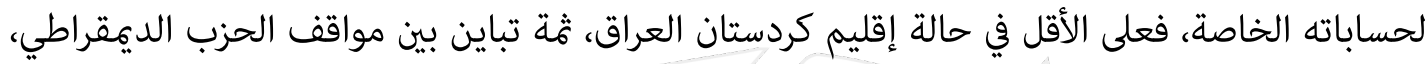

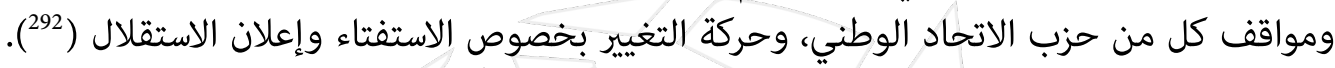

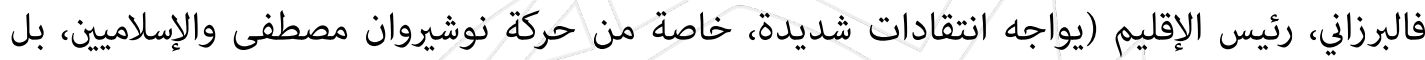

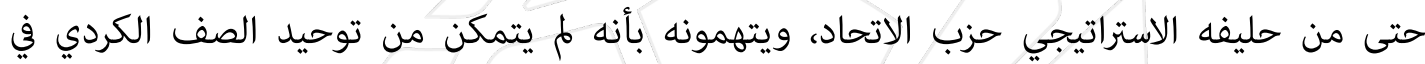
كردستان، رغم أولوية ذلك قبيل الاتجاه للإعلان عن الدولة) (293 (29).

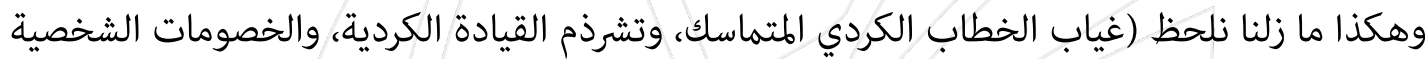

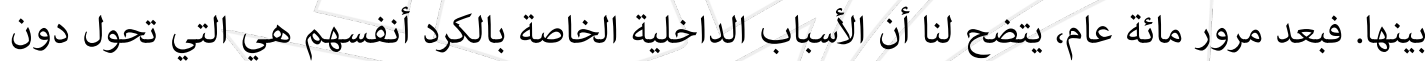
تشكيل دولة كردية مستقلة) (294). وقد ساهمت العوامل السياسية والاقتصادية والاجتماعية وتضارب المصالح في تشكيل أفكار انفصالية داخل الإقليم، خاصة في محافظات كركوك، والسليمانية، وسنجار، لتشكيل إقليم داخل إقليم كردستان

وعلى الرغم من أنه سيكون لدى هذه الدولة الكردية أكبر مخزون نفطي، أي أكثر من إيران والعراق وسوريا والكويت (296)، فإنها ستواجه معوقات اقتصادية، فمواردها الطبيعية قليلة، ووجود النفط وحده 
لا يكفي من دون مسرب إلى البحر لتصديره، خصوصًا أن الدولة الكردية ستكون محاطة بدول تعاديها

وكذلك سيواجه الإقليم (تقلصًا جذريًا في سوقه الهحلية، حيث سينخفض عدد الطستهلكين من أكثر من

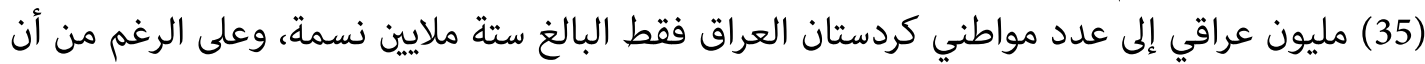

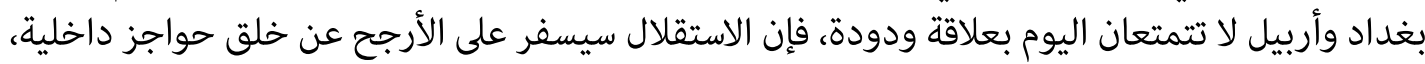

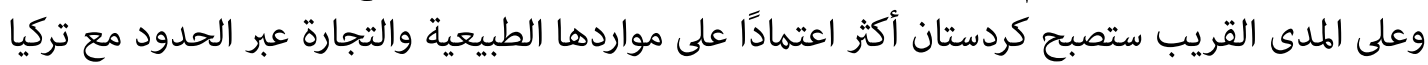
لتحقيق الملاءة المالية والبقاء) (298). وتشير (المشاريع الاقتصادية الفاشلة والسياسة النفطية الخاطئة والعجز عن بناء بنية تحتية استراتيجية

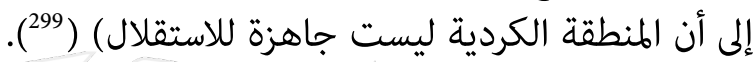

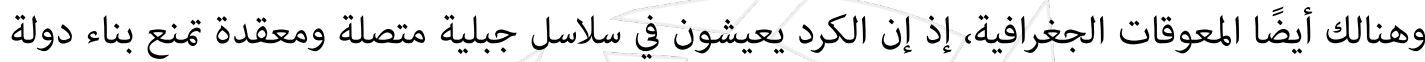

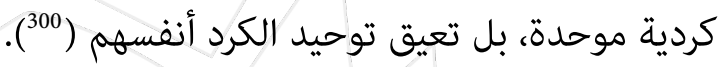

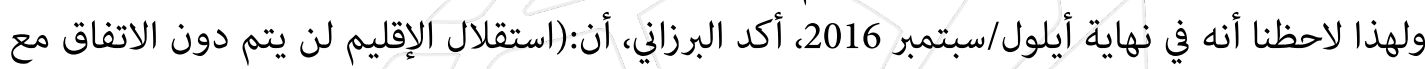

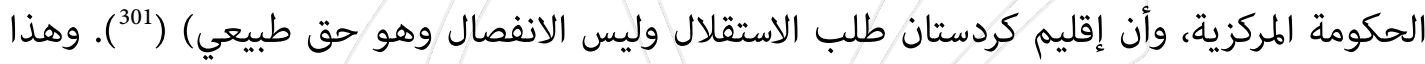
نوع من التراجع الضمني عن الانفراد بقرار إعلان الدولة الكردية.

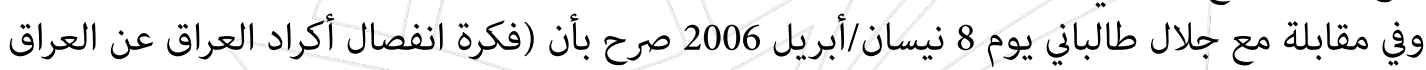

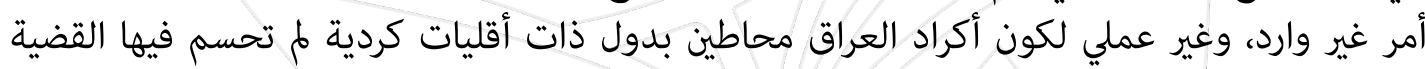
الكردية بعل، وإذا ما قررت هذه الدول غلق حدودها فإن ذلك الإجراء يكون كفيلًا بإسقاط الكيان

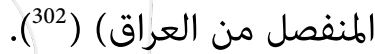

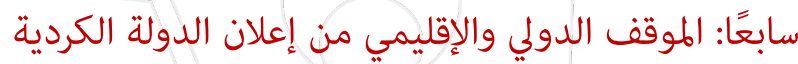
قبل تسعينيات القرن الماضي كانت دول الشرق الأوسط الأربع ذات التجمعات الإقلئ الكردية الكبيرة -تركيا

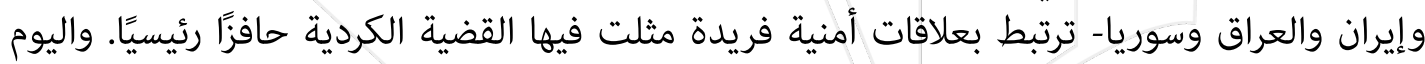

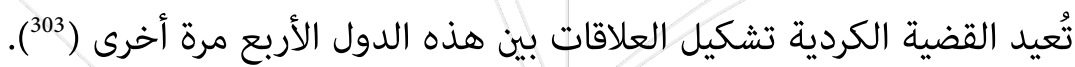

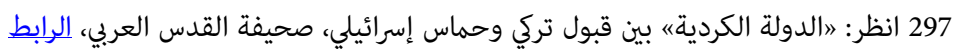

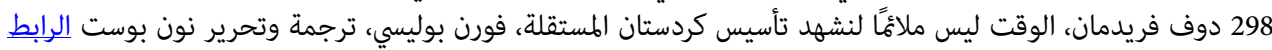

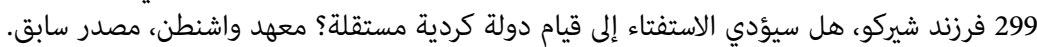

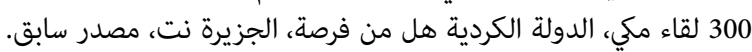

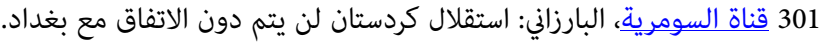

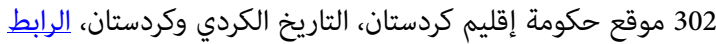
303 انظر: سونر حاغايتاي، جينز إسلاميك آفيرز آناليست، (الربيع العربي) يُشعل القضية الكردية الكردية، معهد واشنطن. 


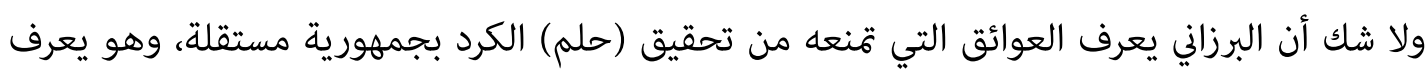

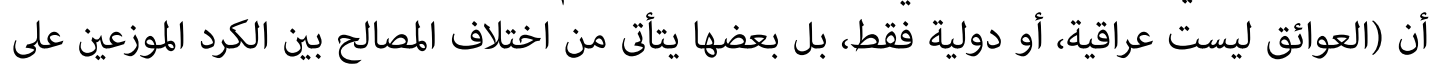

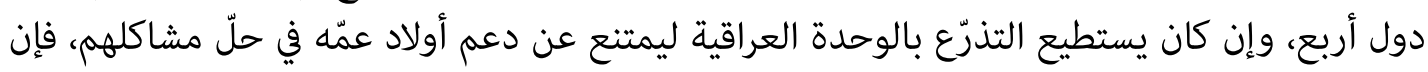

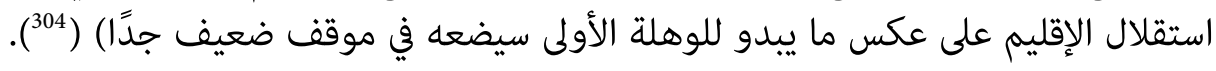

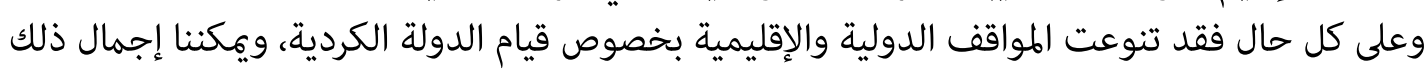

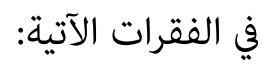

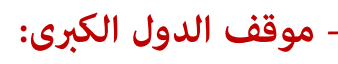
تأرجحت مواقف الدول الكبرى بخصوص استقلال الكرد، إذ ذكر (ملا بختيار) عضو المكتب السياسي

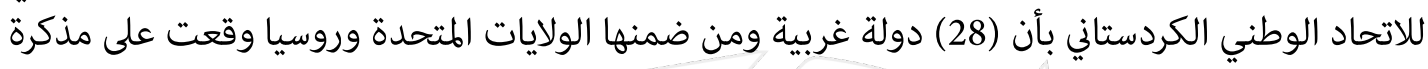

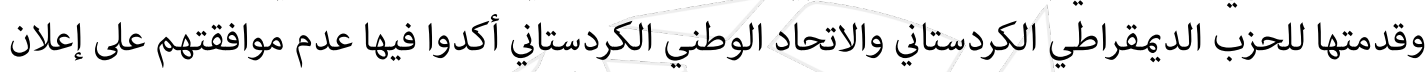
استقلال إقليم كردستان (205 (305).

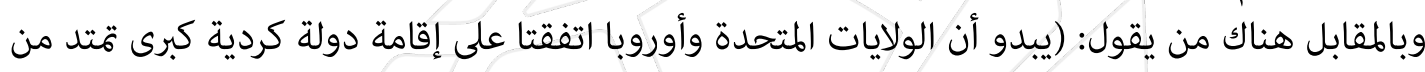

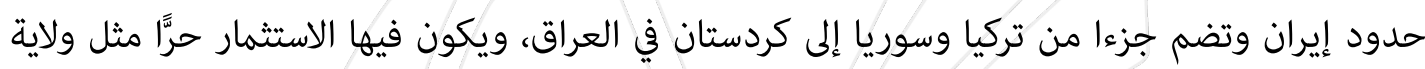

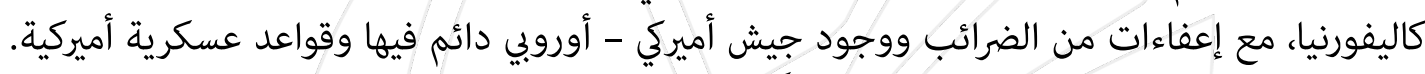

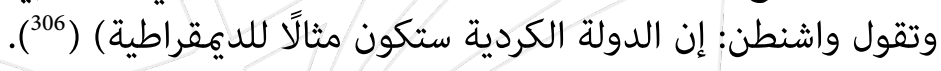

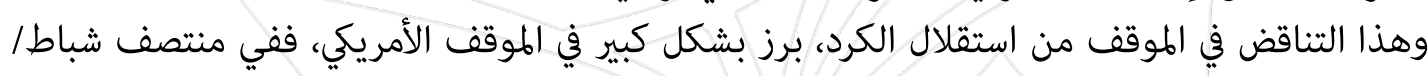

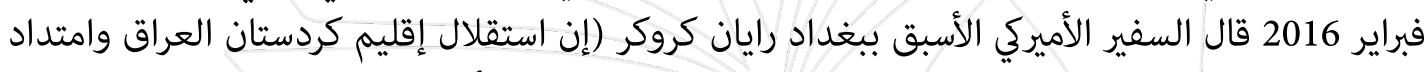

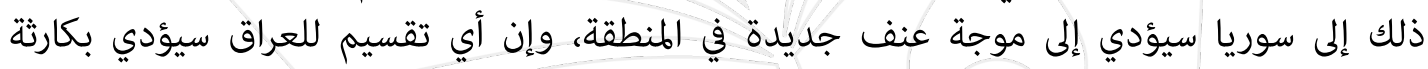
للمنطقة) (ذلى (ف07).

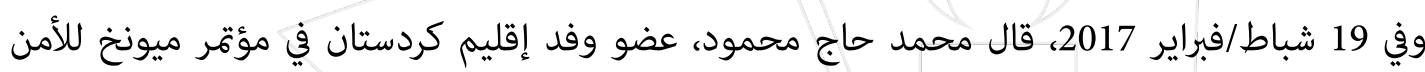

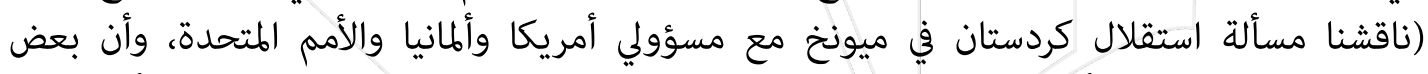

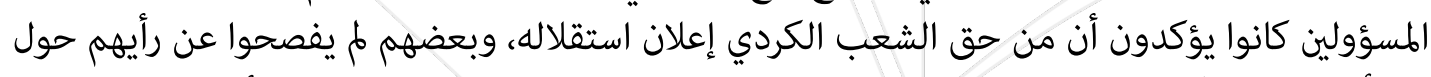

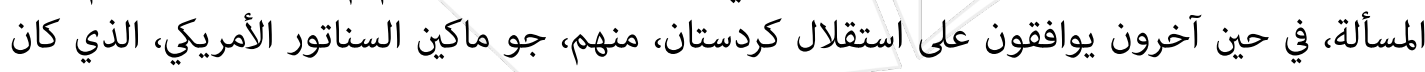

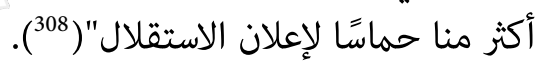

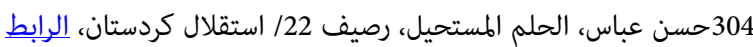

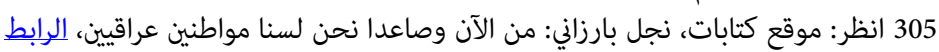

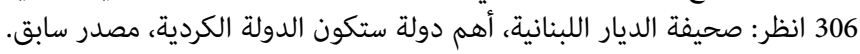

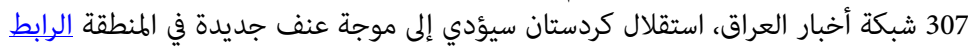

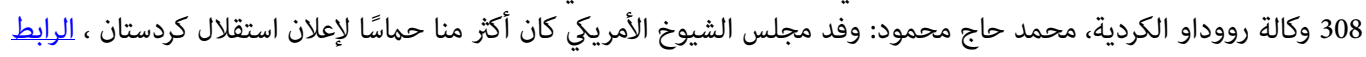




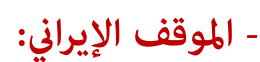

لا شك أن إيران تقف ضالئ ضد قيام الدولة الكردية، وهنالك العديد من التصريحات التي تؤكد هذه الحقيقة، الحيق،

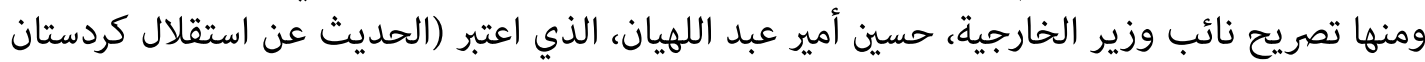

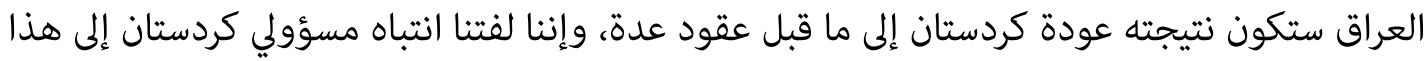

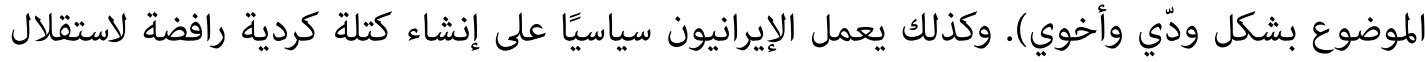

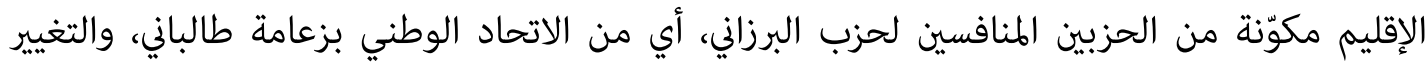

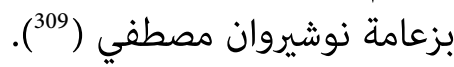

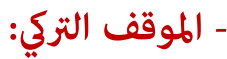
الموقف التركي الرسمي الرافض لإعلان الدولة الكردية أكده الرئيس رجب أردوغان، نهاية حزيران/يونيو

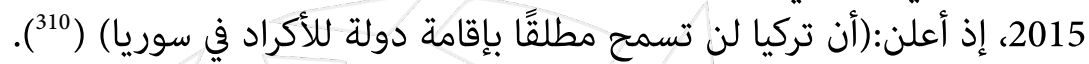

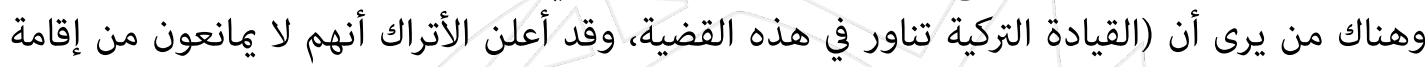

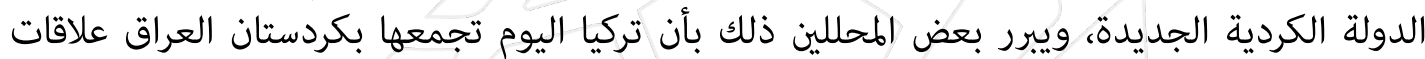

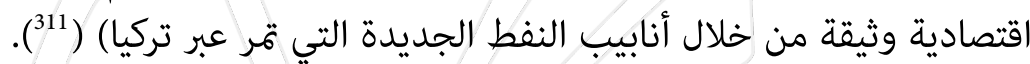

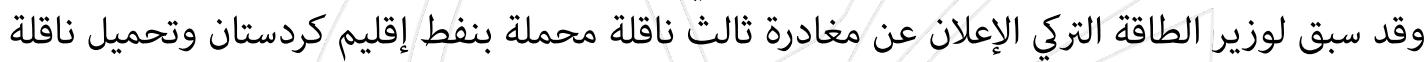

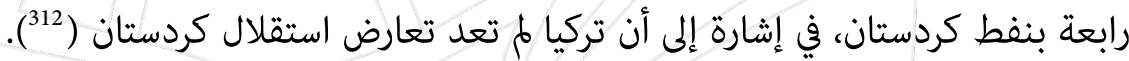

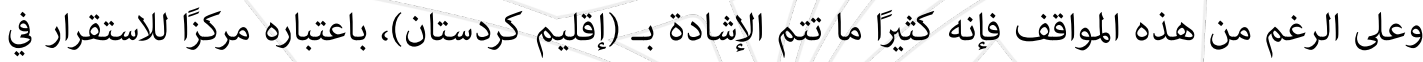

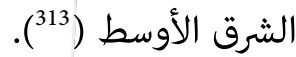

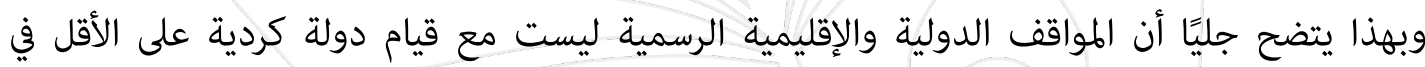

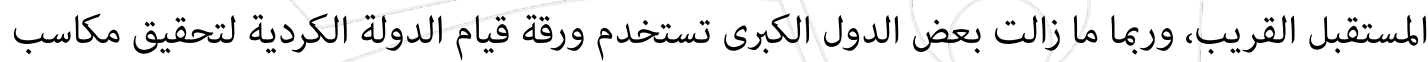

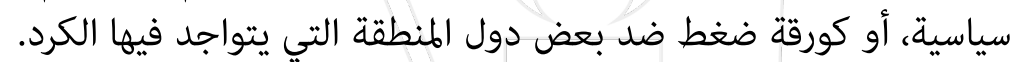

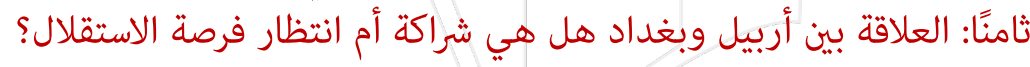

309حسن عباس، رصيف 22/ استقلال كردستان، الحلم المستحيل، مصدر سابق.

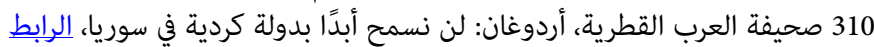

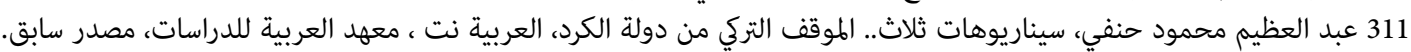

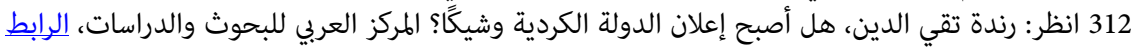

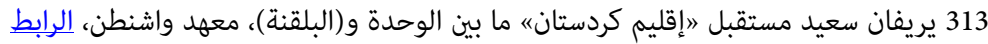


منذ مرحلة ما قبل الاحتلال الأمريكي للعراق كانت العلاقة بين الأطراف الفاعلة فيما يسمى بالمعارضة

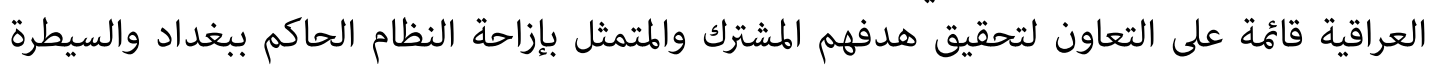

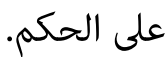

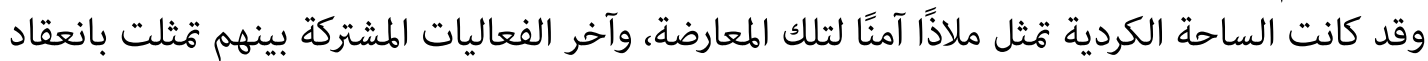

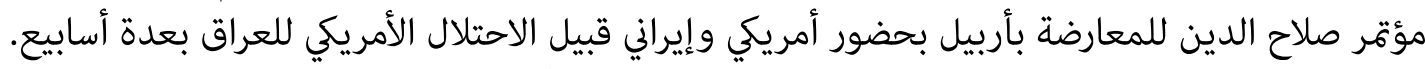

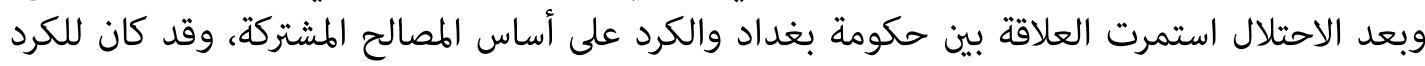

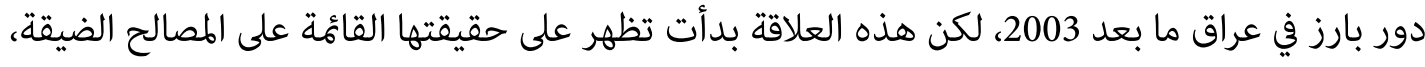
وليس على مصلحة الوطن العراقي الجامع للعرب والئ والكرد وغيرهم.

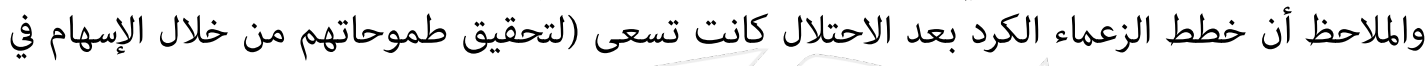

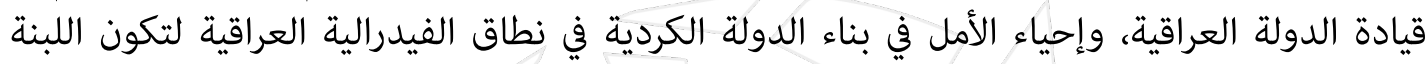

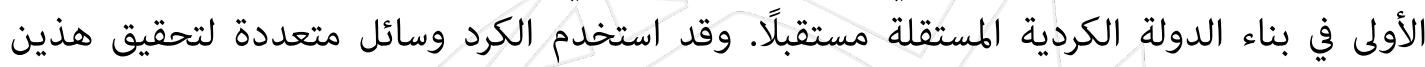

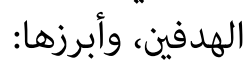

1. استخدام أسلوب القوة الناعمة في التعامل مع جميع الأطراف وتجنب التصعيد والمواجهات.

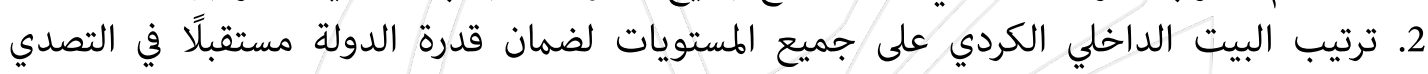
للتهديدات والتحديات والطحن التي تواجهها.

3. ممارسة الضغوط على التحديات والحكومة التي تواقية العاتية لاتخاذ قرارات في مصلحة الكرد.

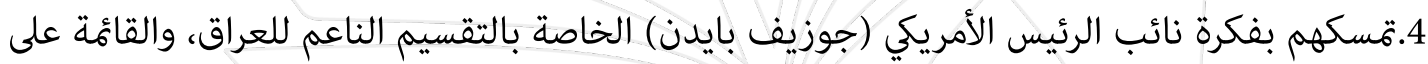

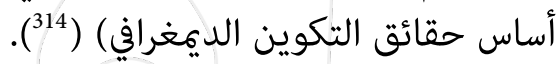

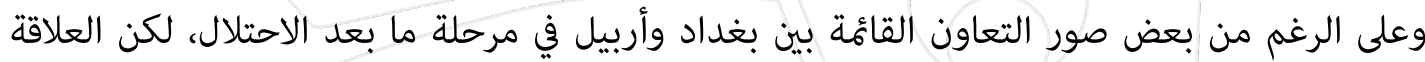

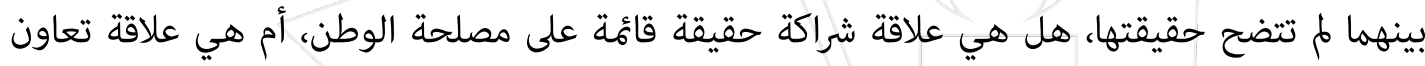

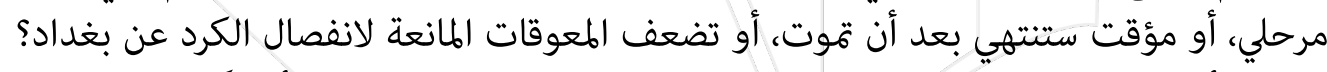

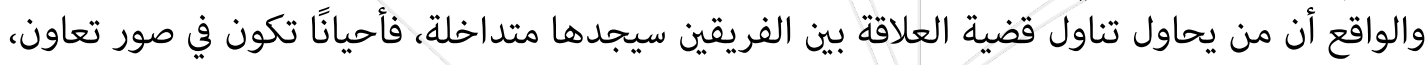

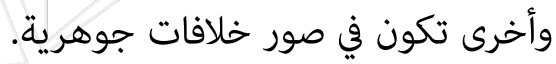

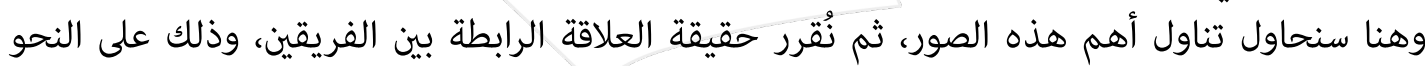
الآتي: صور الشراكة 
هنالك بعض صور الشراكة بين أربيل وبغداد، وأهمها:

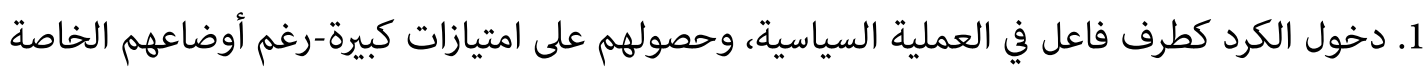

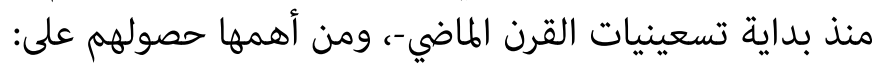

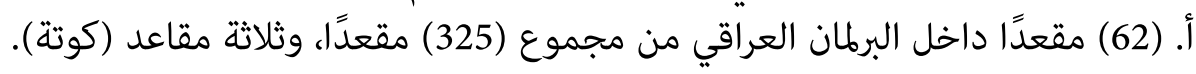

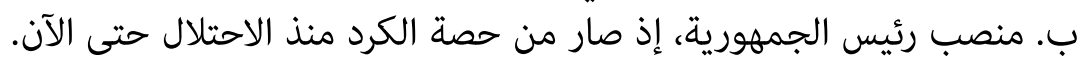
ج. منصب أحد نواب رئيس الوزراء، منذ الاحتلال حتى الآني الآن.

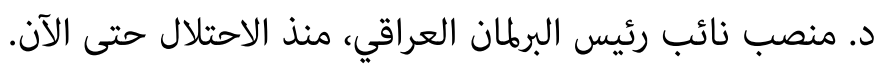

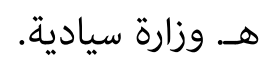

و. عشرات المناصب العليا الأخرى في عموم وزارات الدولة المدنية والعسكرية.

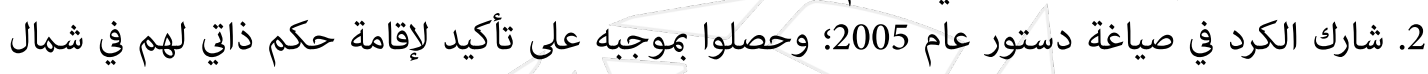

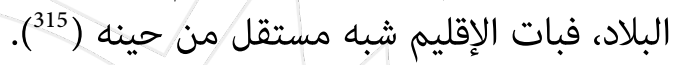

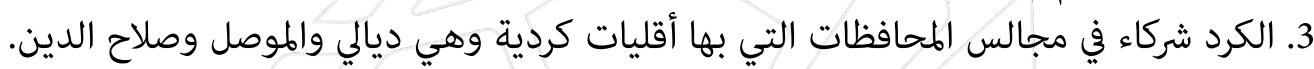

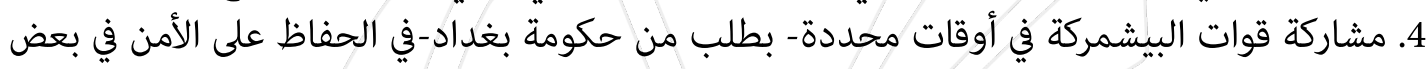

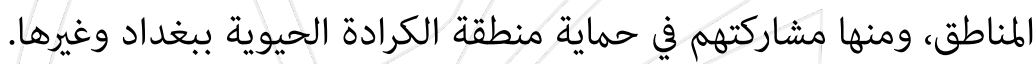

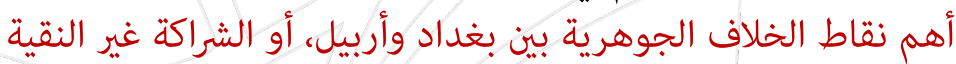

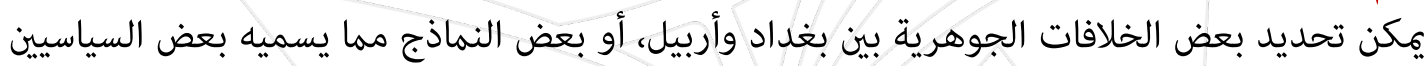

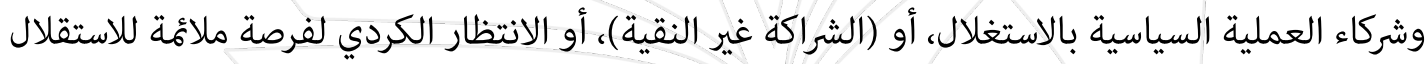

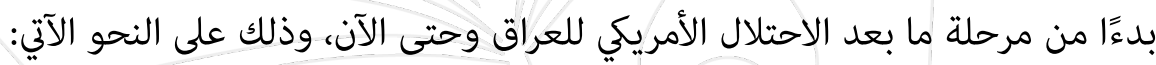

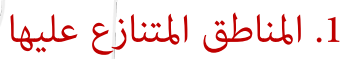
يُقصد بمصطلح (المناطق المتنازع عليها): المدن والبلدات والقرى الاستراتيجية ذات الأغلبية الكردية

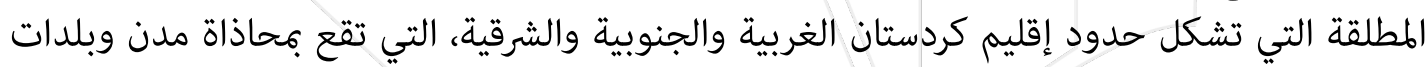
عربية (16).

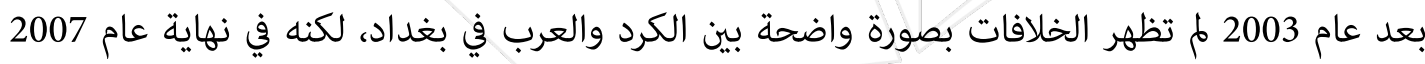

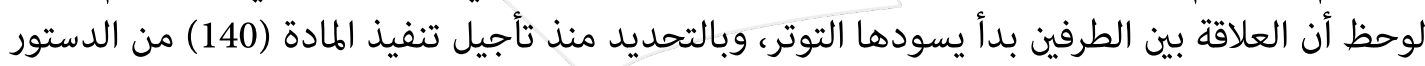

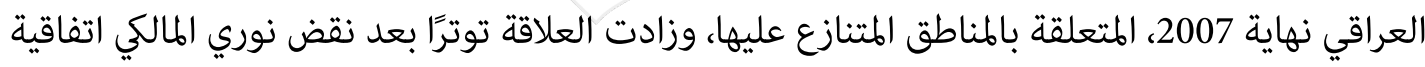

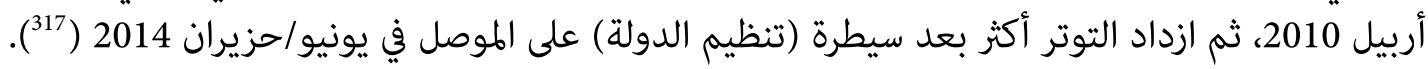


وفي 22 توز/يوليو 2008، أقر مجلس النواب العراقي قانون انتخابات مجالس المحافظات والأقضية

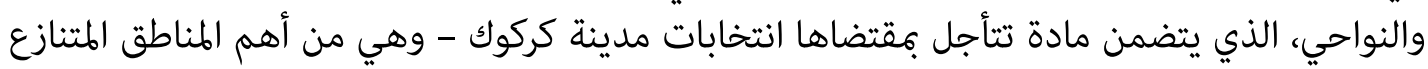

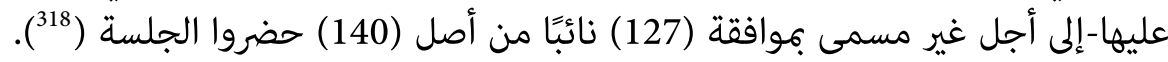

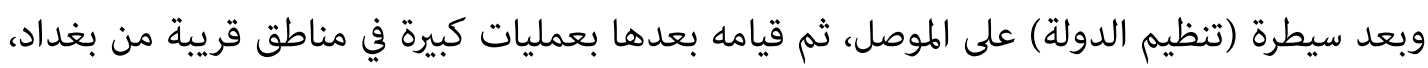

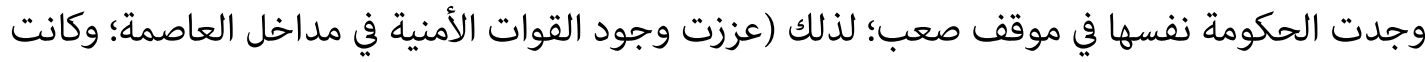

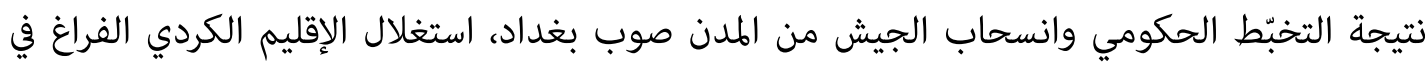

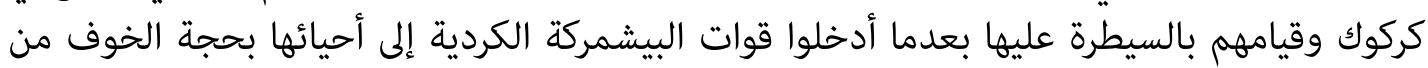

توغل المنظمات الإسلامية فيها) (319)

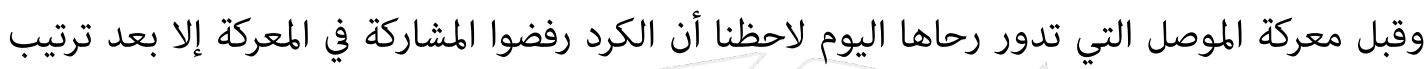

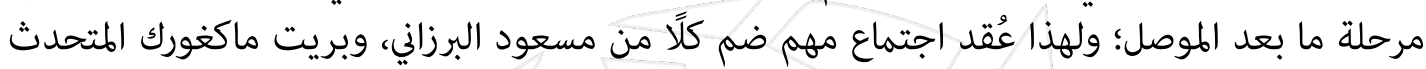

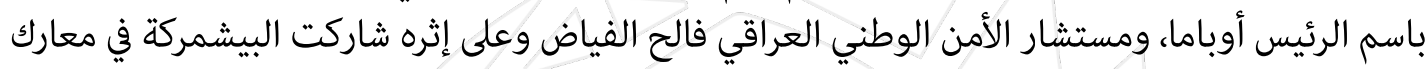

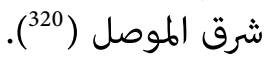

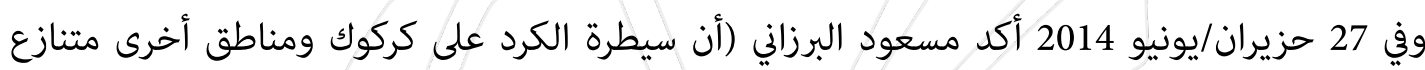

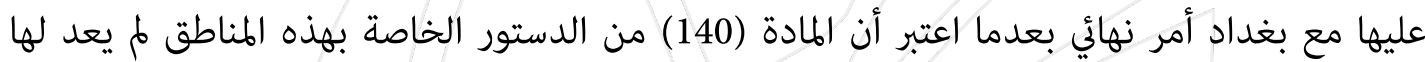
وجود) (

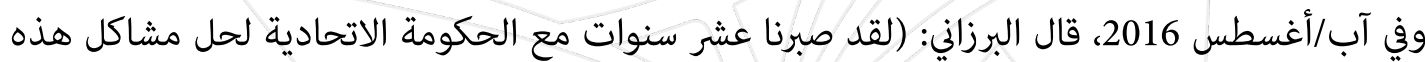

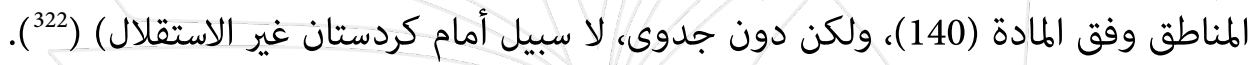

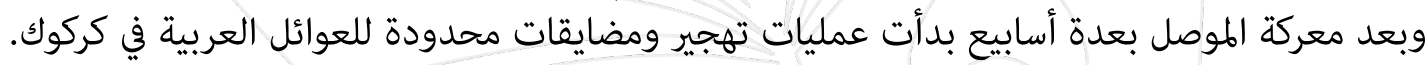

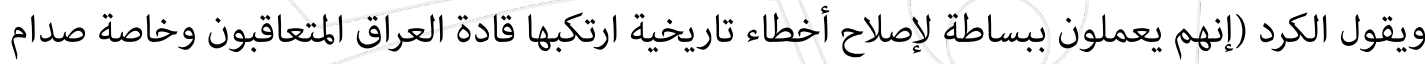

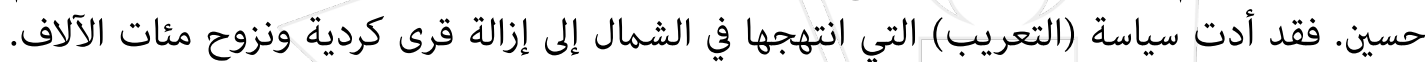

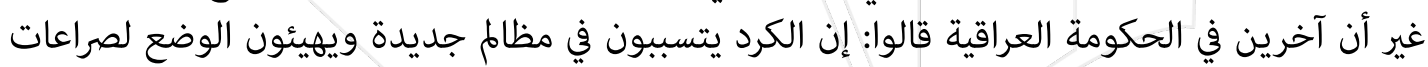

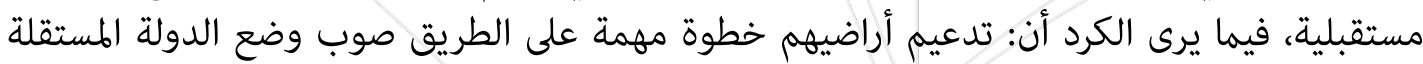
التي يسعون لإقامتها) (323).

318 انظر: راديو سوا، البرلمان يقر قانون انتخابات مجالس المحافظات، الرابط

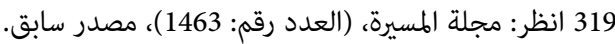

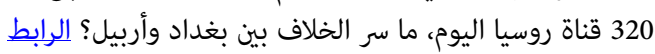

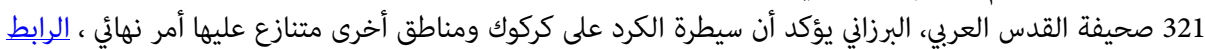

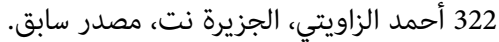
323 ايزابيل كولز وستيفن كالين، رويترز، في الحرب على الجني، الدولة الإسلامية.. الكرد يوسعون نطاق سيطرتهم، وكالة رويترز، الرابط 
وفي خطوة جديدة قرر مجلس محافظة كركوك نهاية آذار/ مارس 2017 رفع علم إقليم كردستان إلى إلى الى المان

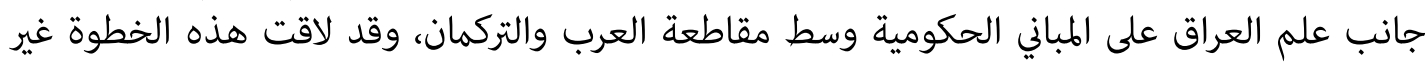

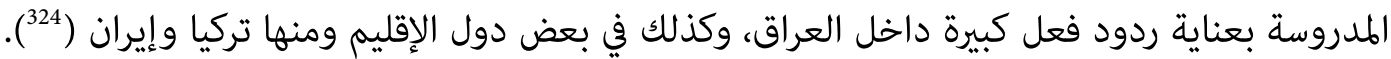

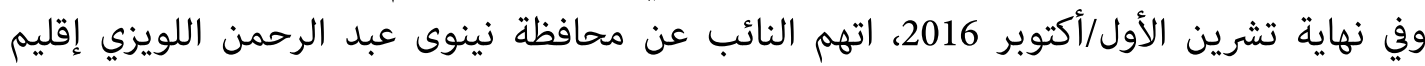

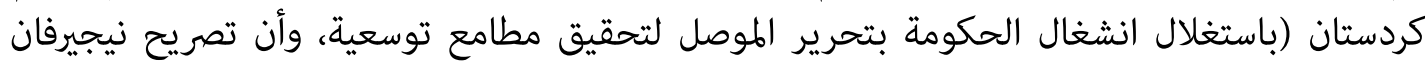

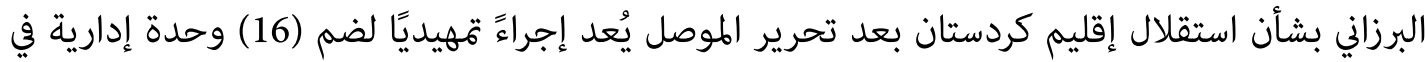

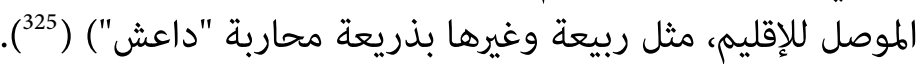

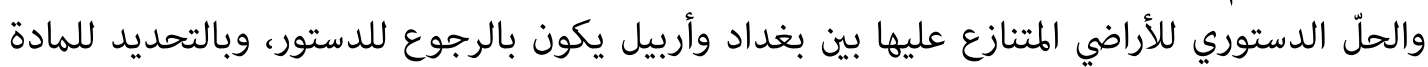

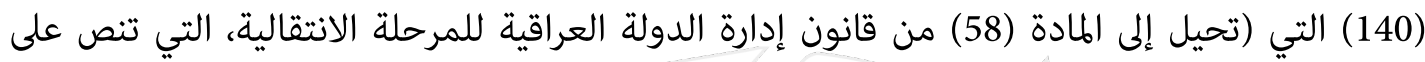

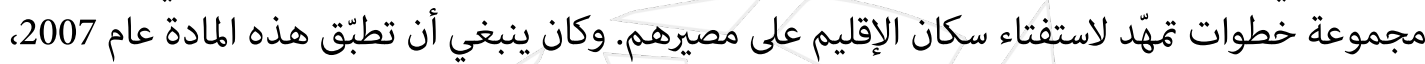

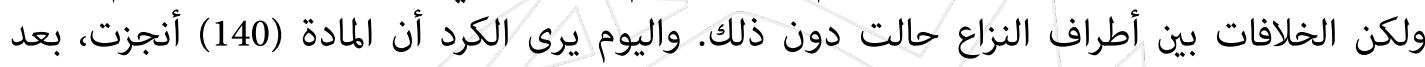

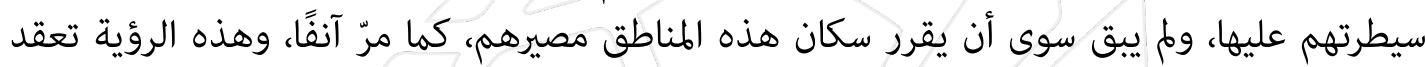

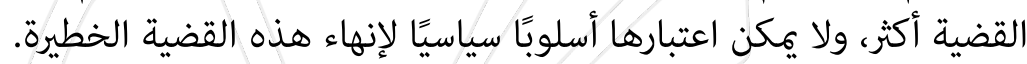

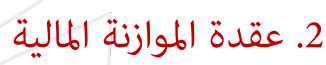
على الرغم من أن الكثيرين ينظرون لإقليم كردستان على أنه أنه (دولة) داخل الدولة العراقية، فإن الإقليم

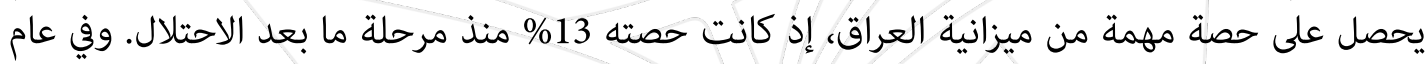

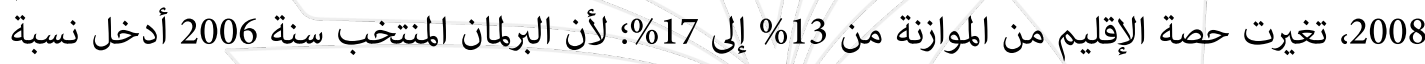

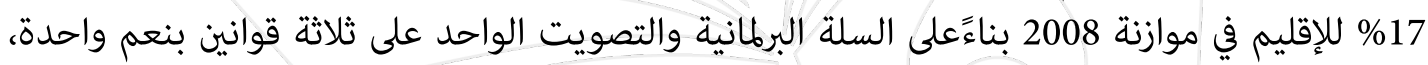

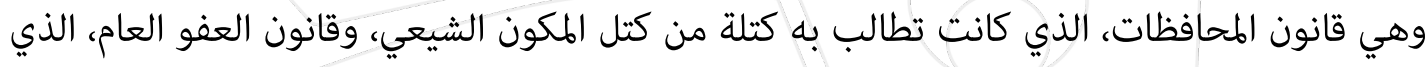

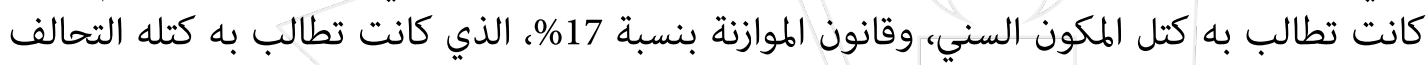

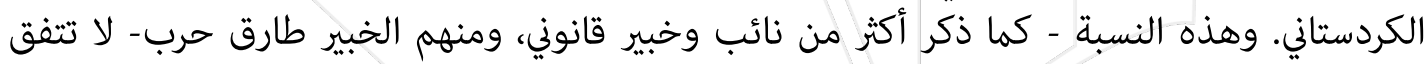

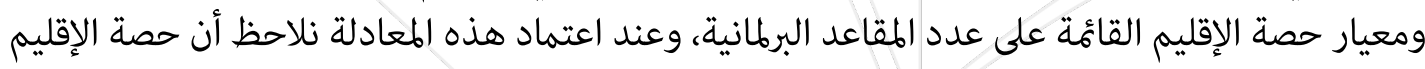

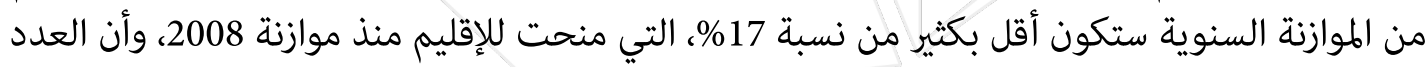

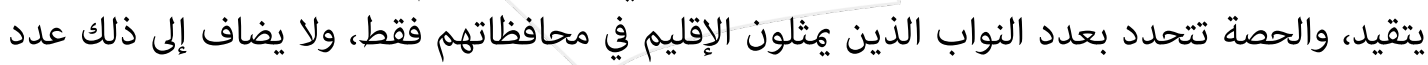

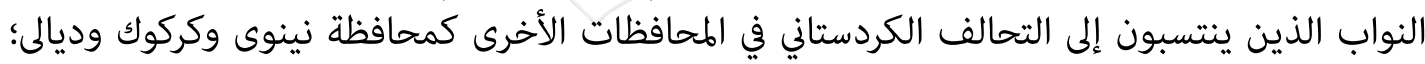

صحيفة رأي اليوم، أكراد كركوك يرفعون علم كردستنا على المباني الرسمية، الرابط324

325 وكالة كنوز ميديا، نائب يتهم كردستان باستغلال انشغال الحكومة بعركة الموصل لتحقيق (مطامع توسعية)، الرابط 
وذلك لأن سكان المحافظات الكردستانيين في هذه المحافظات يكون استحقاقهم من موازنة هذه الهحافظات، وليس من موازنة محافظات الإقليم(326).

وفي نهاية عام 2016، دعا رئيس كتلة الدعوة النيابية خلف عبد الصمد إلى تخفيض حصة الإقليم من

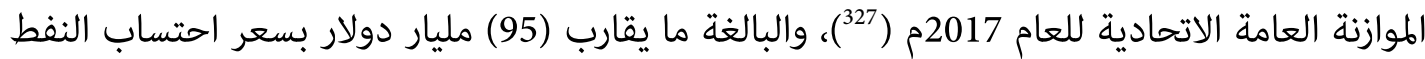

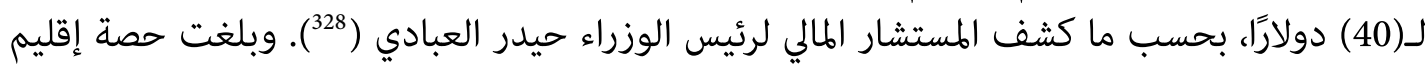
كردستان في موازنة عام 2017، (17\%) (على أن تكون مستحقات الشركات النفطية في الإقليم من ضمنها)

وعلى الرغم من إقرار الموازنة بحضور النواب الكرد فإن حكومة الإقليم أعلنت في كانون الأول/ديسمبر 2016 عن رفضها لقانون الموازنة الذي صادق عليه مجلس النواب، وأكدت بأن:(ما جاء ضمن الفراء الفقرات المتعلقة بإقليم كردستان من قانون الموازنة العامة لسنة 2017، مؤامرة سياسية خطيرة ضد الإقليم، وفي وفي ماني أفضل الأحوال سيصل مبلغ (496) مليار دينار إلى الإقليم من الحكومة العراقية، في الوقت الذئ الذي تصل

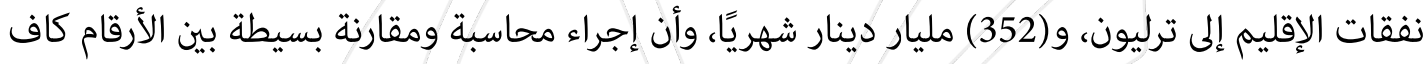

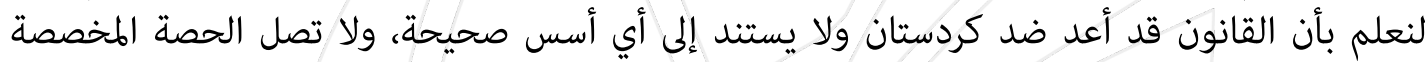

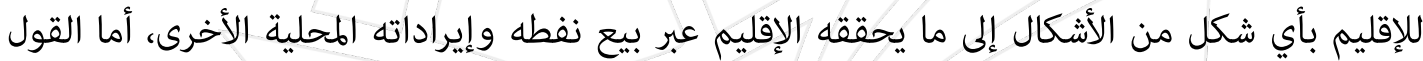

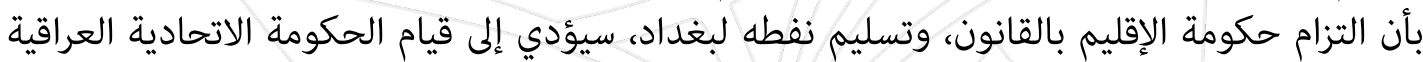
بدفع رواتب موظفيه، فذلك كذب)( وأرى أن الخروج من هذه العقدة المرتبطة بنسبة كل محافظة من محافظات العراق، - بها فيها محافظات الإقليم-يتطلب إجراء تعداد سكاني؛ لأن النسب اليوم غير دقيقة بسبب عدم عدم وجود إحصاء سكاني منذ

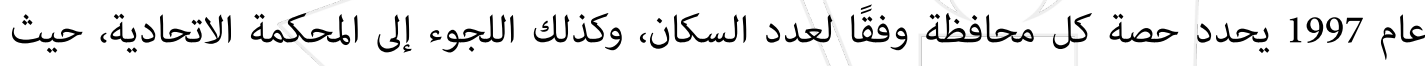

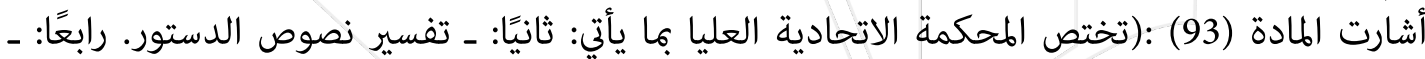

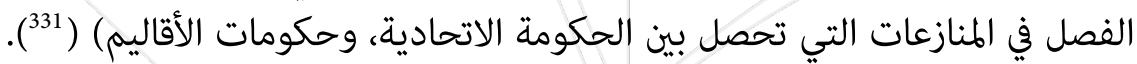
3. بيع الإقليم للنفط دون موافقة بغداد المياد

326 انظر: طارق حرب، مقاعد الإقليم تحدد حصته في الموازنة، جريدة الزمان، الرابط

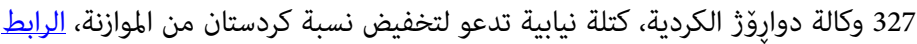

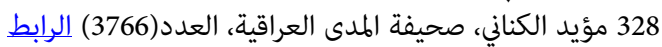

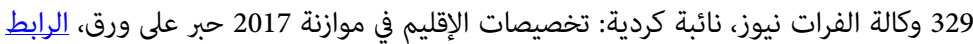

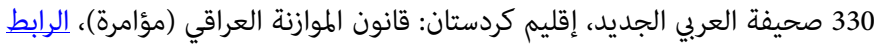

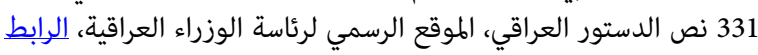


ما يزال الإقليم-شأنه شأن بقية أجزاء العراق- يعتمد في إيراداته على الصادرات النفطية بشكل شبه

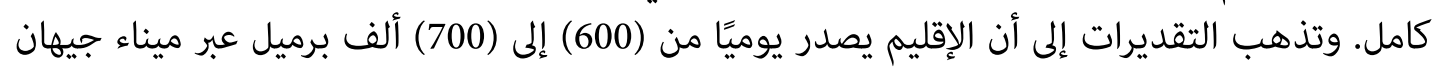

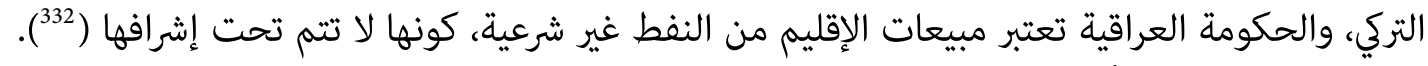

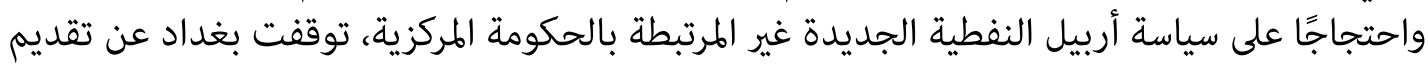
حصة الميزانية المخصصة لأربيل، مما خلق أزمة مالية في القطاع العام التابع لحكومة الإقليم خلال العامين

2015

وكان وزير الثروات لإقليم كردستان آشتي هورامي قد أكد أن (عائدات بيع النفط من الإقليم بشكل

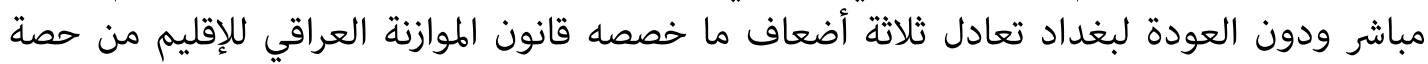
مالية، وأن استمرار الإقليم ببيع نفطه بشكل مستقل أفضل من الالتزام بقانون الموازنة) (3) (334). وأعتقد أن الحل الأمثل لهذه القضية يكون بالعودة للدستور العراقي، الذي أكد بحسب الغبن المادة (111):

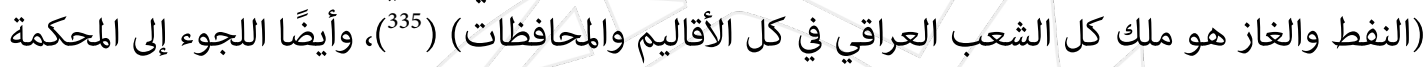

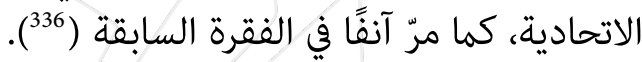
4. 1 موازنة البيشمركة تُعد قضية رواتب قوات البيشمركة الكردية واحدة من المشاكل المتجددة بين بغداد وأربيل، إلا أنها في موازنة 2017 كانت حاضرة بقوة، وذلك بعد مشاركة قوات البيشمركة في معارك الموصل الطستمرة الآن.

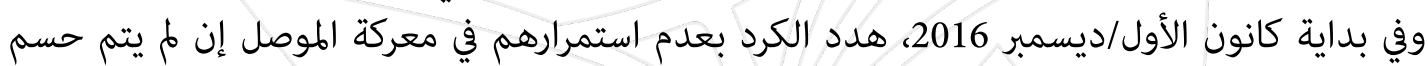
ملف رواتب البيشمركة، وأكد مستشار مجلس أمن الإقليم مسرور البرزاني، أن (دور قوات البيشمركة في

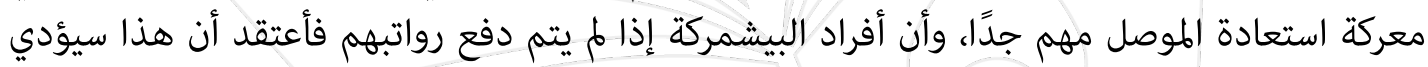

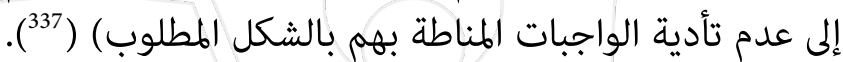
وكان رئيس كتلة الدعوة النيابية علي الأديب، أكد أن (حرس الإقليم وفق الدستور لا يأقتر بأمره القائد

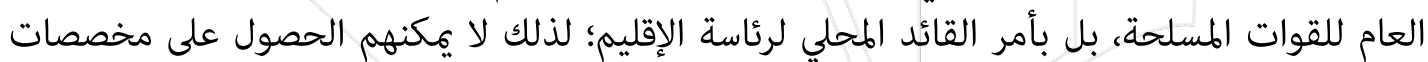

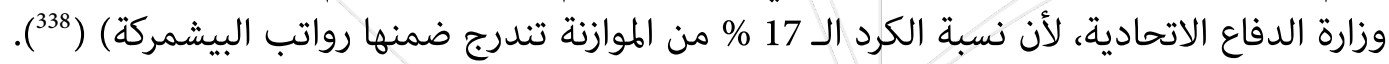

332 وكالة DW، كردستان العراق - من الازدهار إلى حافة الإفلاس!، الرابط

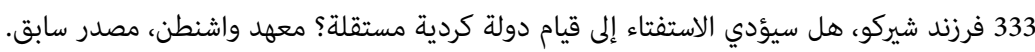

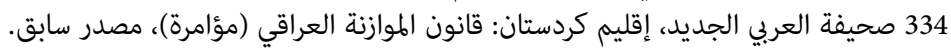

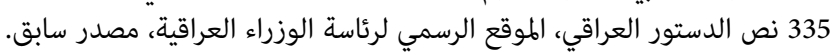
336 المصدر السابق. 337 وكالة سكاي برس، البرزاني يفجرها: إذا ما تدفع بغداد رواتب البيشمركة فلن يؤدوا واجباتهم المناطة لهم، الرابط 338 المصدر السابق. 
وفي نهاية 2016، صوَّت مجلس النواب على المادة (9) - تعديل فقرة خامسًا المتعلقة بتخصيص نسبة من

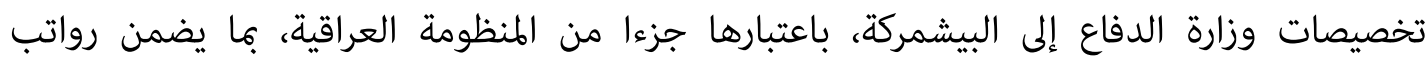

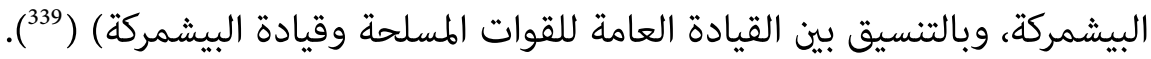

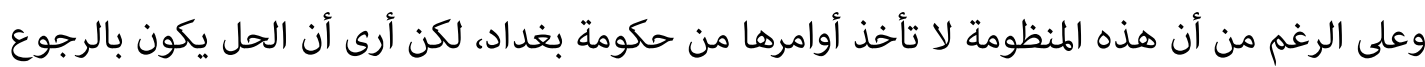

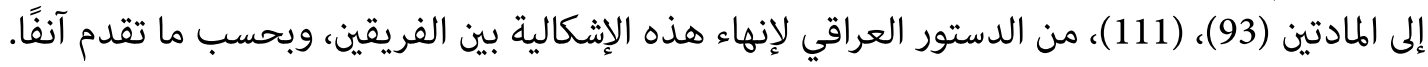

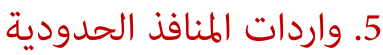

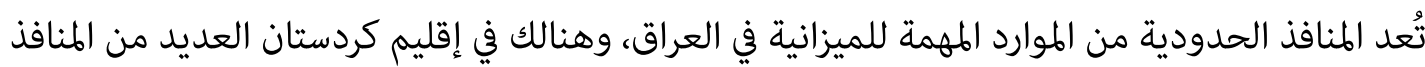

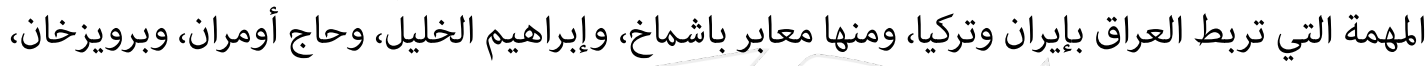

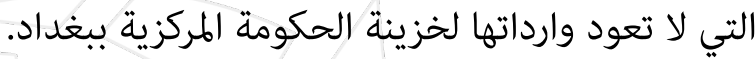

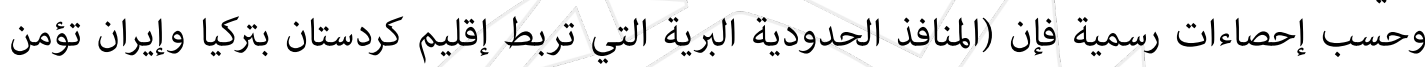

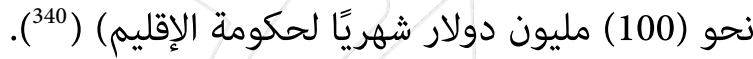

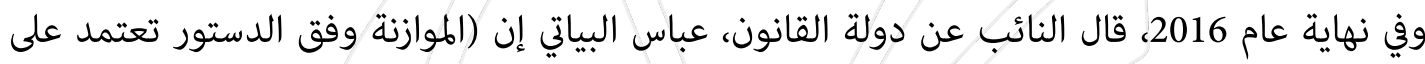

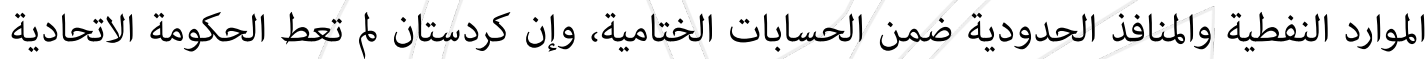

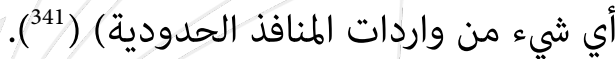

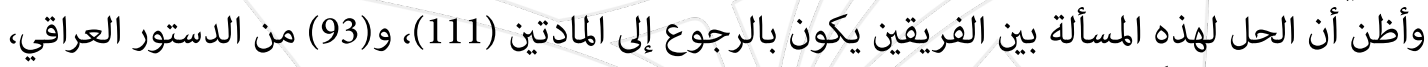
بحسب ما تقدم آنفًا.

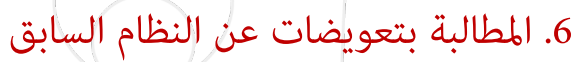

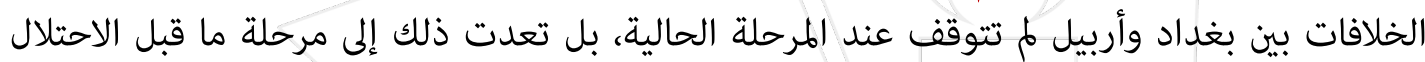

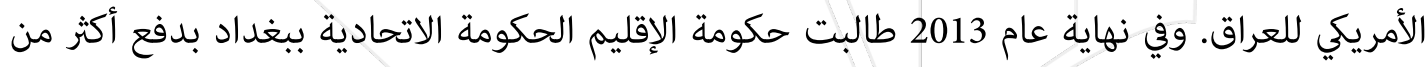

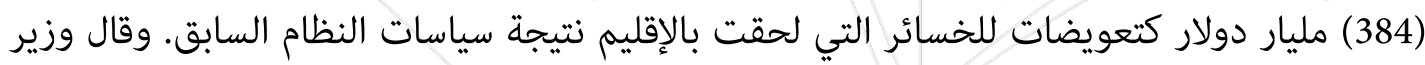

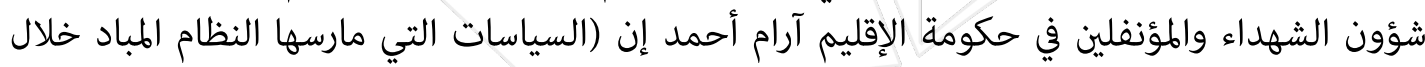

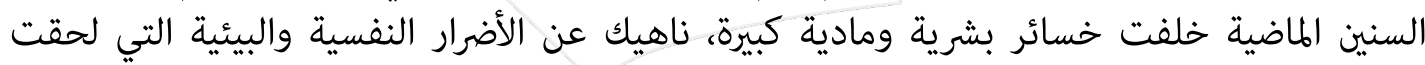


بالشعب الكردي؛ وكون الحكومة الاتحادية الحالية وريثة النظام السابق، فعليها تعويض هذه الأضرار)

وفي المقابل انتقد سامي العسكري النائب عن ائتلاف رئيس الوزراء - حينها- نوري المالكي مطالبة الإقليم

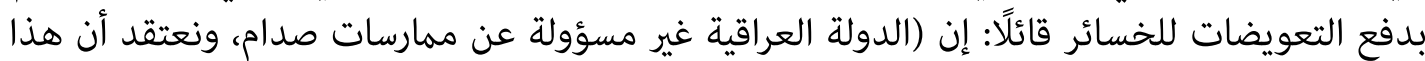

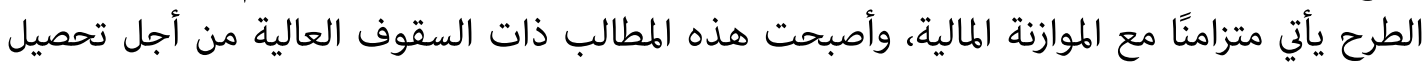

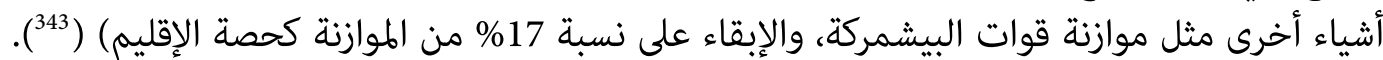

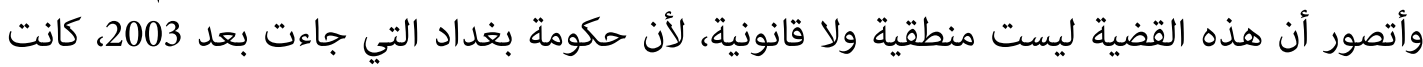

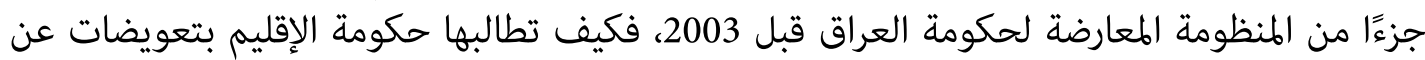
مرحلة ما قبل الاحتلال، وفي كل الأحوال يمكن اللجوء للمحكمة الاتحادية المختصة بالفصل الفصل في الخلافات

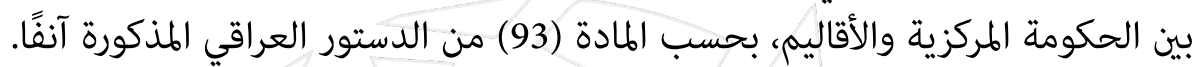

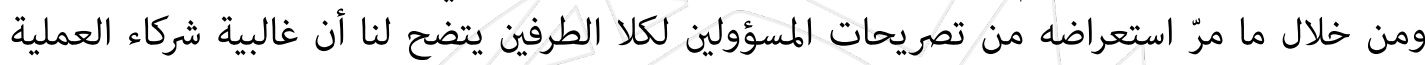
السياسية ينظرون للمواقف الكردية على أنها استغلال لظروف غير صحية يمر بهر بها العراق، وهذا مؤشر خطير، ويؤكد فرضية أن العلاقات بين الفريقين غير دائة، وإفا هي مرحلية تنتهي بانتهاء الظروف المئه المانعة لاستقلال الكرد، أو إعلان دولتهم. ثامناً: مستقبل العراق في ضوء العلاقات العربية العلان دولثه الكردية في ضوء ما تقدم نلاحظ أن الكرد مقتنعون بضرورة الاستقلال، لكن يبدو أن الظروف الداخلية والخارجية لم توفر لهم الأرضية الصالحة لهذا الإعلان. إذن - في ظل اقتناع الكرد بعدم وجود أرضية صالحة لإعلان دولتهم- فإن ذلك يدفعهم للتعايش المرحلي،

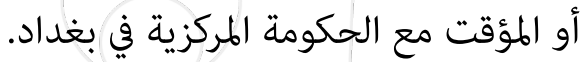

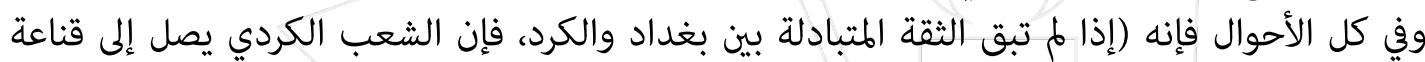

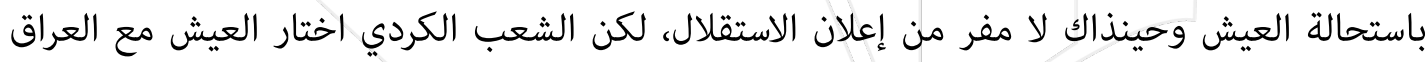

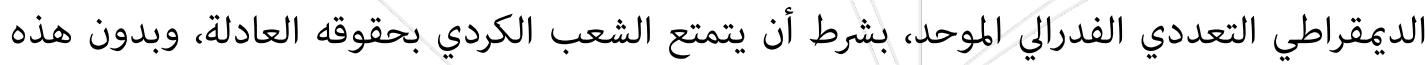

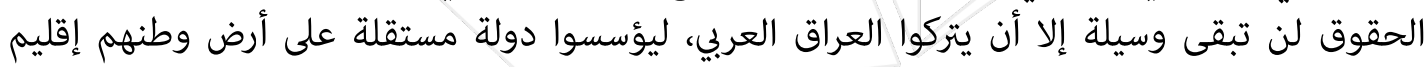

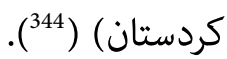
ورغم بقاء حالة التعايش (المرحلي) بين الفريقين إلا أننا نلاحظ أن الكرد حققوا الكثير من الخطوات المشجعة لانفصالهم، ومن أبرزهاء 
1. بناء مؤسسات الدولة المستقلة المتمثلة في حكومة الإقليم ووزاراته وبرمانه المنتخب ودستوره وجيشه المكون من "البيشمركة".

2. سعي الكرد لتحديد حدود إقليمهم متضمنة كركوك بوصفها الركيزة الاقتصادية لتطلبات الدولة مستقبلًا.

3. إصدار دستور لإقليم كردستان وإقراره في حزيران 2009، الذي يحتوي على الأسس والركائز التي تحقق أمل الكرد في إقامة دولتهم المستقلة.

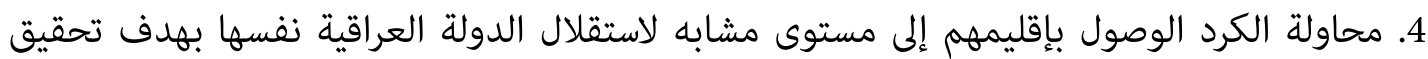

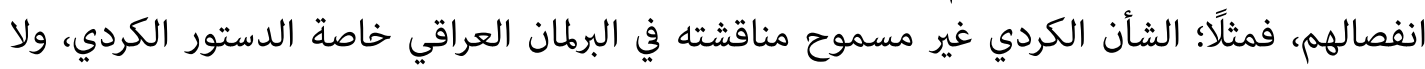
يحق للحكومة المركزية إصدار قرارات بشأن الإقليم ولا تصديق قرارات الحئان الحكومة الحة الكردية. 5. تأسيس دائرة للعلاقات الخارجية خاصة بإقليم كردستان، وقد تم فتح أكثر من (14) ممثلية إصنات للإقليم

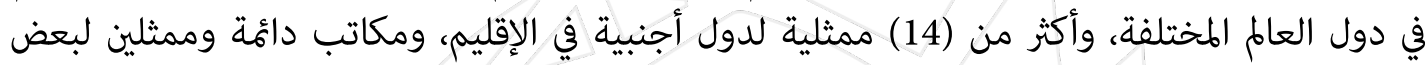
المنظمات الدولية. 6. إبرام كثير من الاتفاقات الدولية التجارية والنفطية، وتبادل الزيارات الخارجية مع عدد كبير من الدول،

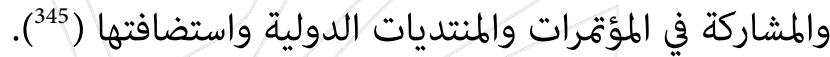
المشكلة في العراق اليوم هي: أن بعض الموكات دعاة الفدرالية لا يريدون إقامة حكومة فيدرالية، كما هو حال

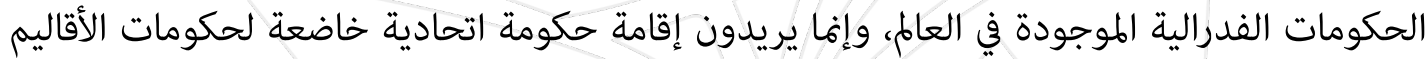

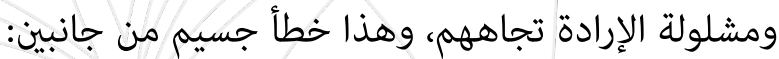

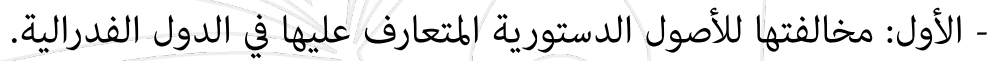
- الثاني: البيئة الإقليمية للعراق تقتضي وجود حكومة قوية تتخذ إجراءات حازمة في حماية الأمن والوحدة

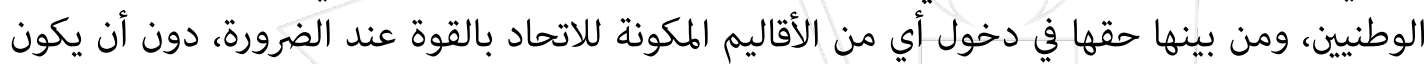

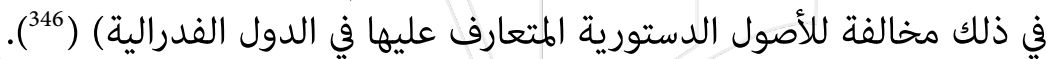

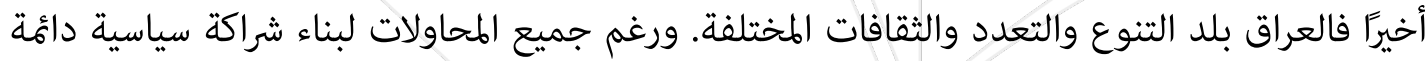

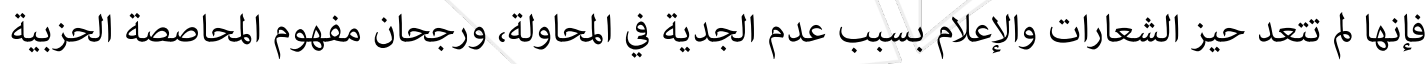
بصبغة طائفية على جميع اللفاهيم، وهو ما أدى إلى عدم وجود شراكة سياسية حقيقية في العراق ( 
وفي كل الأحوال فإن القيادة الكردية تسعى للانفصال بعد توفر الظروف الموضوعية لذلك، وانتهاء

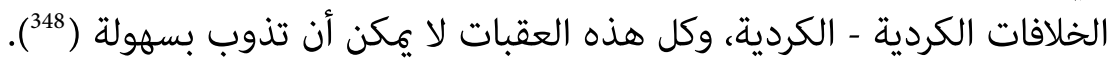

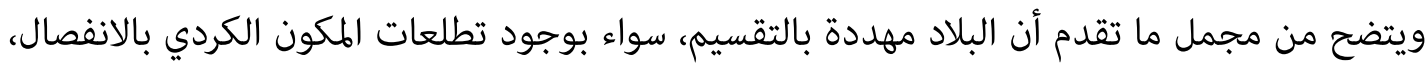

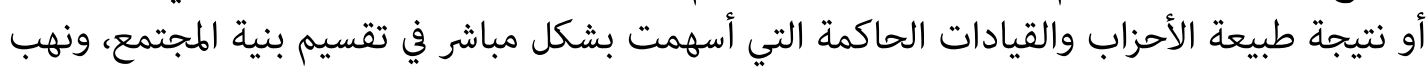

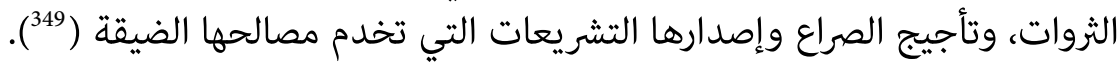

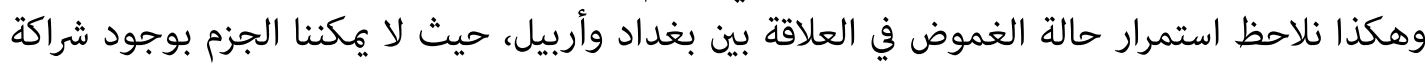

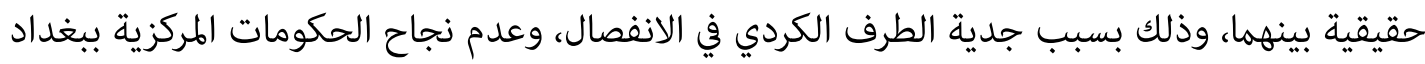
باستيعاب الحالة الكردية الخاصة داخل إطار الدولة العراقية، ذات الأغلبية العربية الطية.

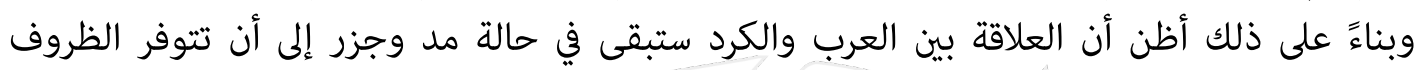
الموضوعية لتحقيق الحلم الكردي بإعلان دولتهم القومية.

خاقة:

من خلال القراءة التاريخية للعلاقات بين الحكومات التي تناوبت على حكم العراق والكرد، ومن خلال

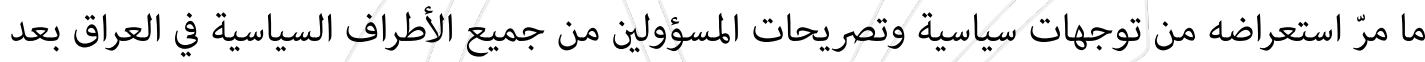

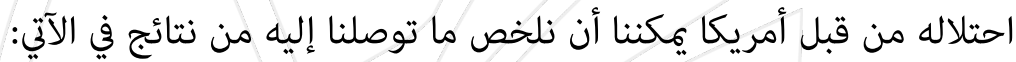
1. نشأت عند الكرد في أوائل القرن العشرين الميلادي فكرة القومية الكردية؛ وتسمية شمال العراق بكردستان العراق ترجع إلى القرن السابع عشر، ويقدر عدد سكان إقليم كردستان العراق بأكثر من (5.2)

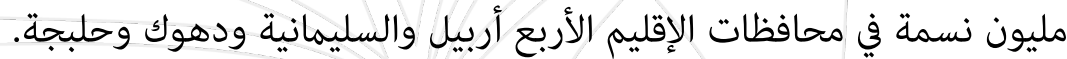

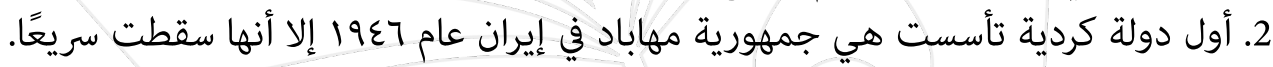

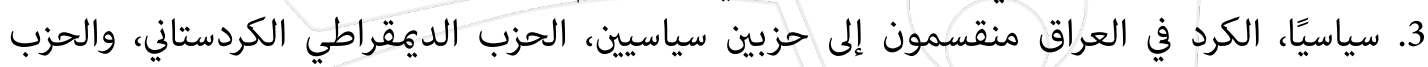

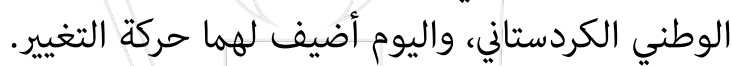

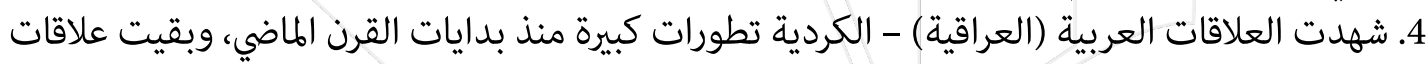

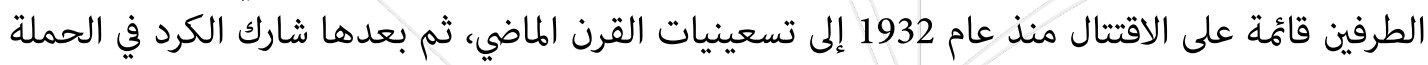
الأمريكية لاحتلال العراق عام 2003.

5. بعد الاحتلال الأمريكي للعراق عام 2003 فم يتوقف الساسة الكرد عن دعواتهم بالدولة الكردية.

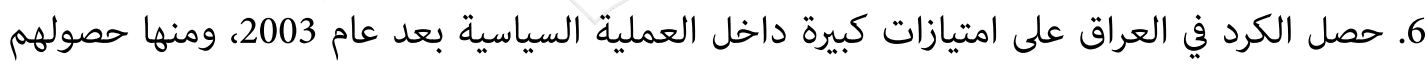
على (62) مقعدًا داخل البركلان العراقي، وعلى مناصب مهمة منها: منصب رئيس الجمهورية، ونائب 
رئيس الوزراء، ونائب رئيس البرلان، ووزارة سيادية واحدة، وعشرات المناصب العليا الأخرى في عموم

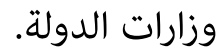
7. شارك الكرد في دستور عام 2005 وحصلوا بموجبه على تأكيد لإقامة حكم ذاتي.

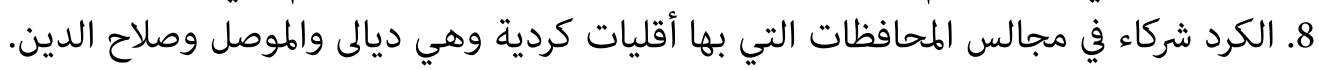

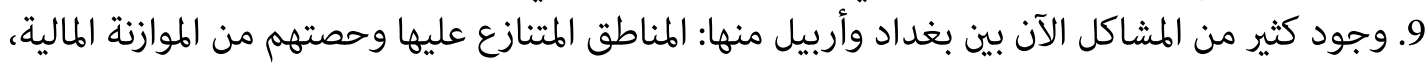

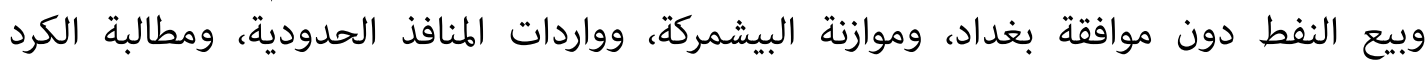
بتعويضات عن مرحلة النظام السابق. 10. الحل لجميع المسائل العالقة بين بغداد النظاد وأربيل يكون بالرجوع إلى المادتين (111) و(93) من الدستور

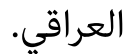

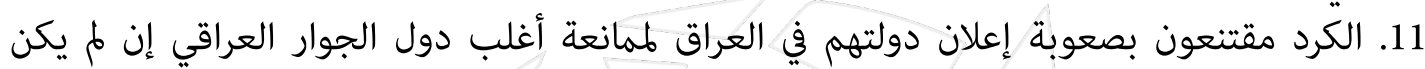

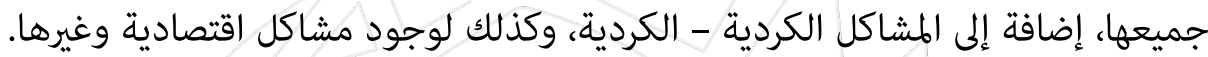

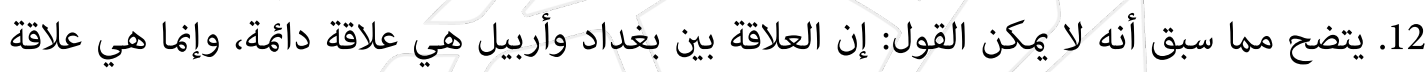
مرحلية، ستنتهي بكجرد توفّر الظروف الموضوعية لإعلان الدولة الكرن الكردية.

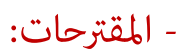

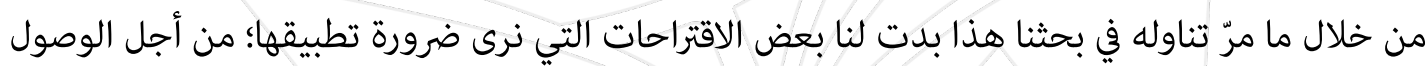

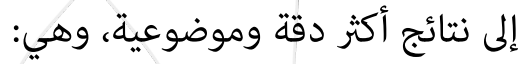

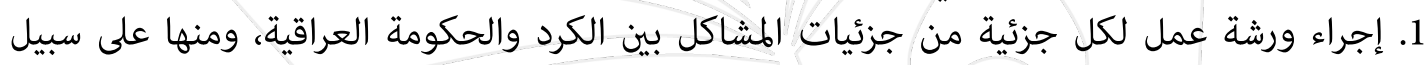

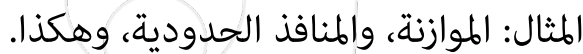
2. ورشة عمل تدرس قضية مفهوم الفيدرالية، هل هو دولة مستقلة مقامًا داخل الدولة الأم، أم هي جزء الماء منها؟ 3. ضرورة توجيه دعوات رسمية للأطراف في حكومتي بغداد وأربيل للمشاركة في أي حوارات تتعلق

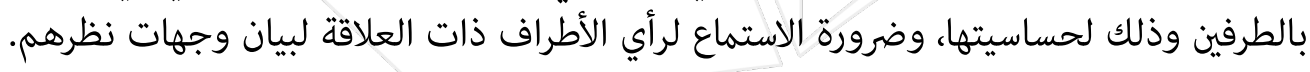




\section{مجلة المعشد المصرى . EGYPT INSTITUTE JOURNAL}

\section{كيف تصنع رمزاً: باسم يوسف نموذجاً

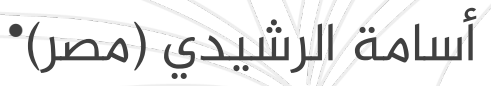




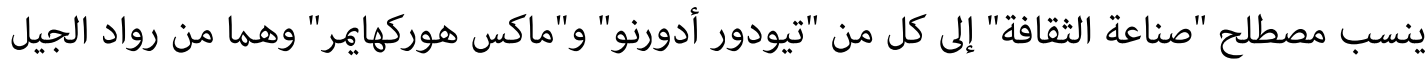

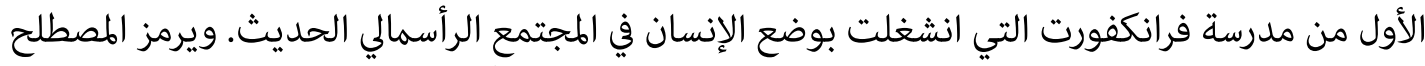

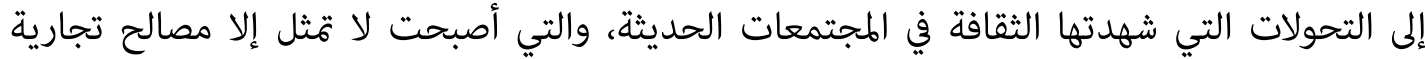

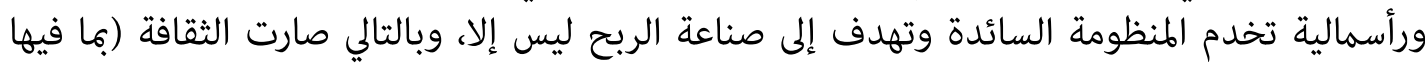

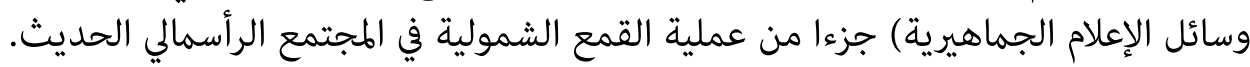

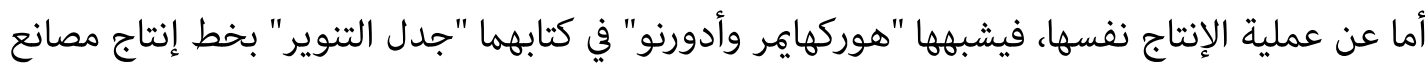

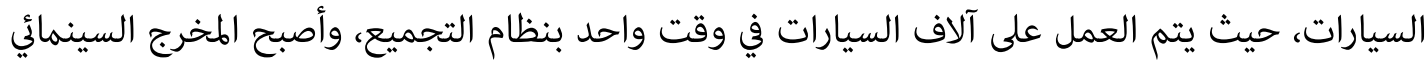

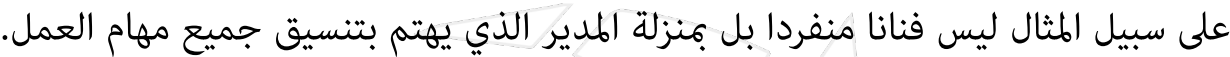

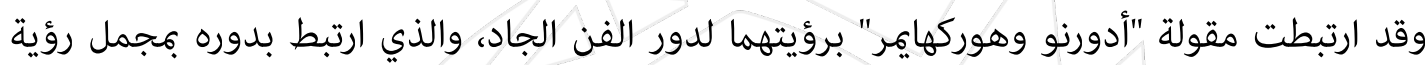

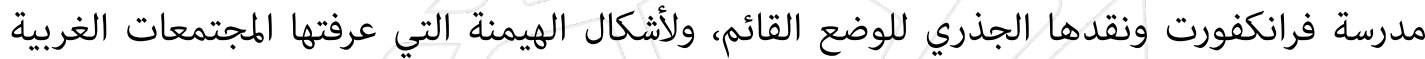

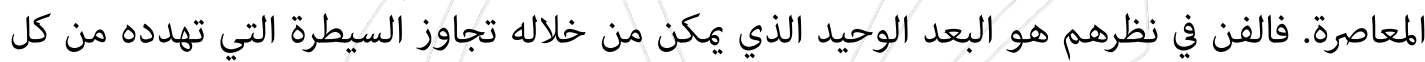

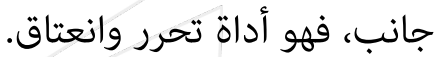

يقول "هوركهاير" في مقالة الفن والثقافة الجماهيرية، إن الفن الأصيل هو "فن قاوم الجراحة التهر التجميلية

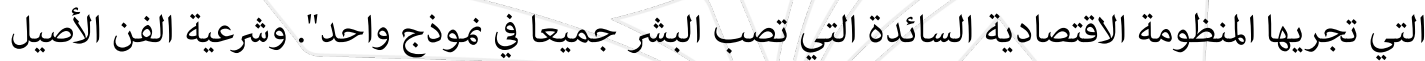

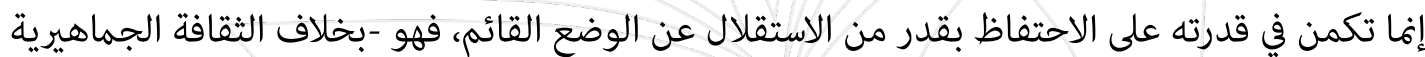

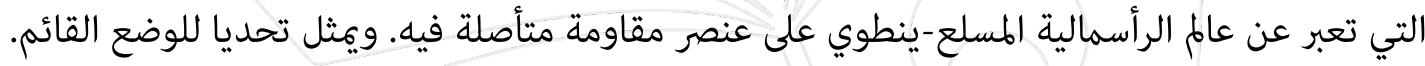

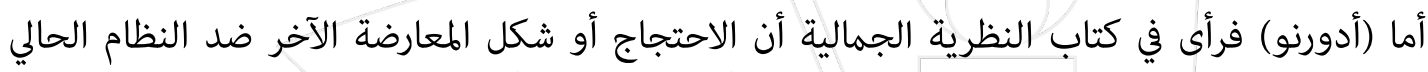

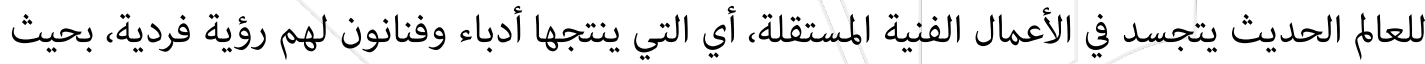

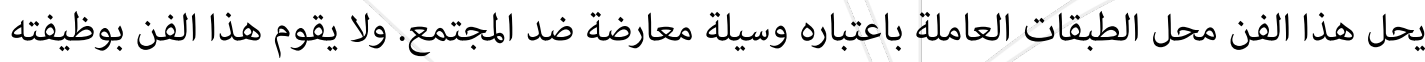

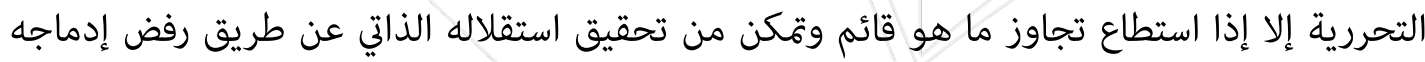
بالواقع القائم أو اختزاله إلى انعكاس للواقعاع.

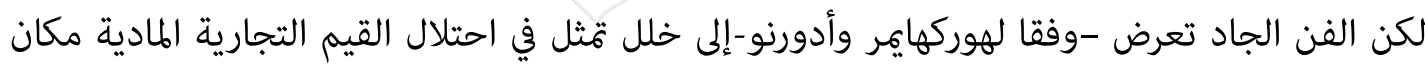

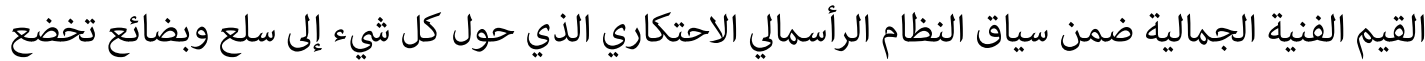

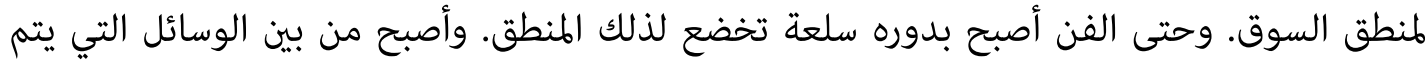

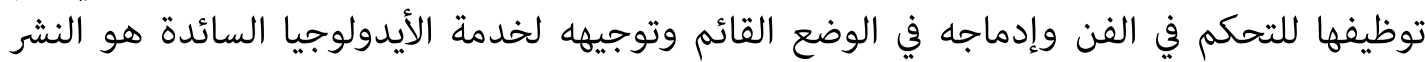

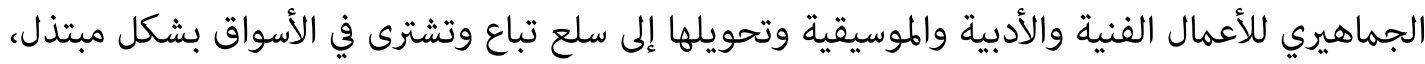
وأصبح يغلب عليها الطابع التجاري والنفعي الذي وادية والفيعد الفن عن وظيفته الحقيقية. 
كما انتقد (أدورنو) و(هوركهايمر) إخضاع الفن للمؤسسات الاقتصادية والسياسية والثقافية وتوظيفه

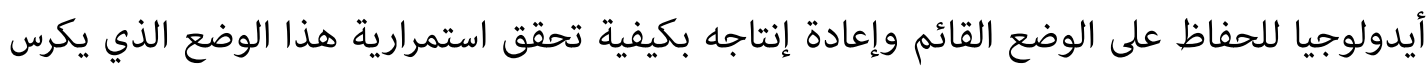

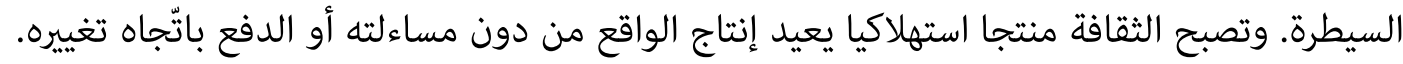

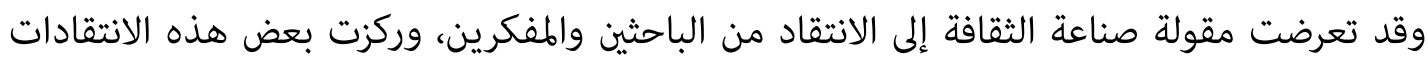

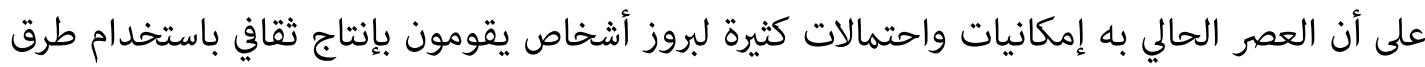

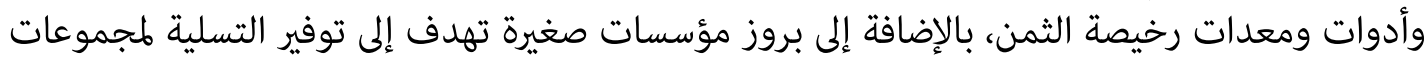

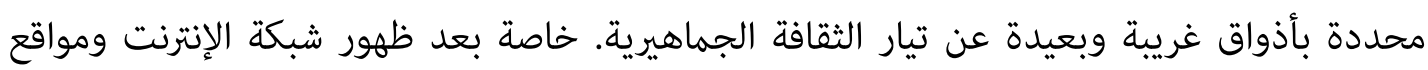

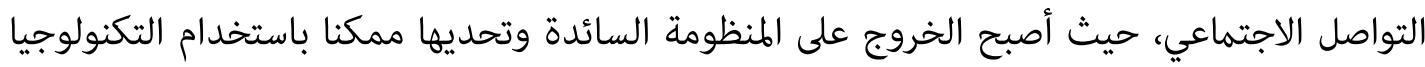

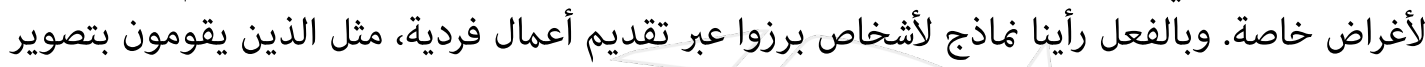

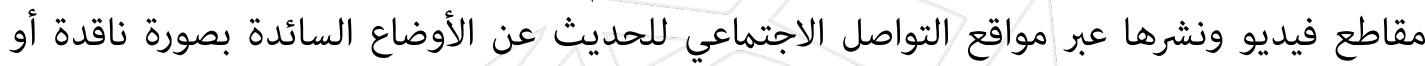

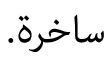

لكن في هذا البحث سنرى كيف أن ظاهرة المذيع المصري "باسم يوسف" تحولت من تحدٍ للوضع القائم

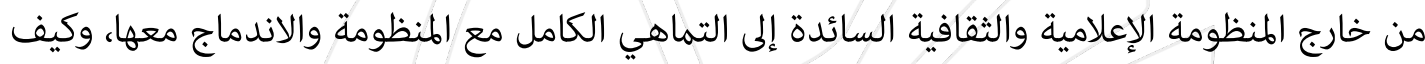

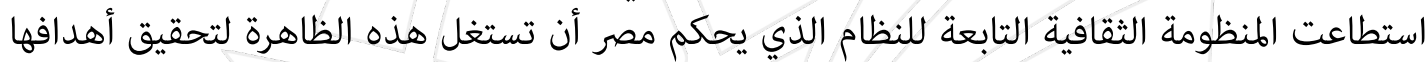
ثم تخلصت منه في النهاية.

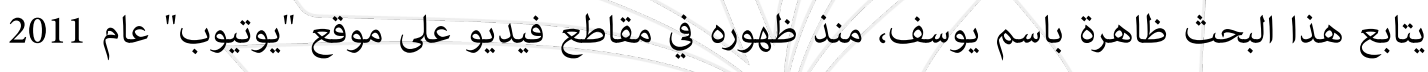

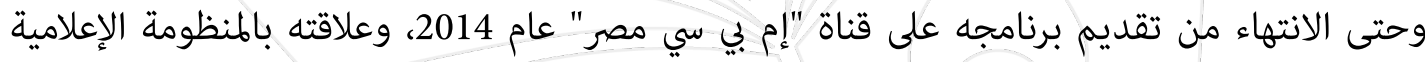

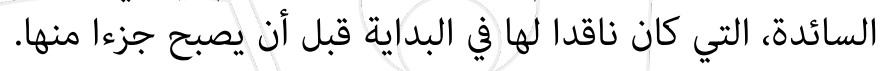

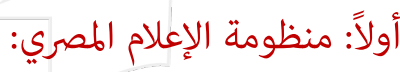

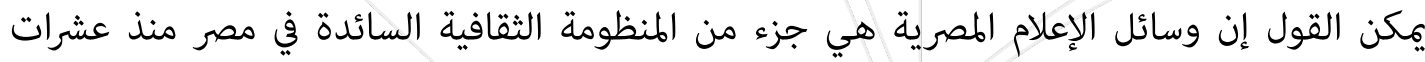

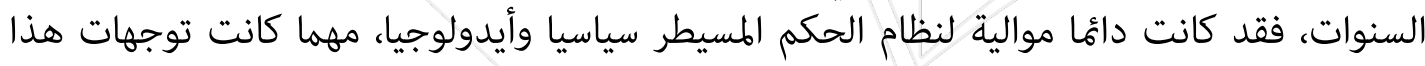

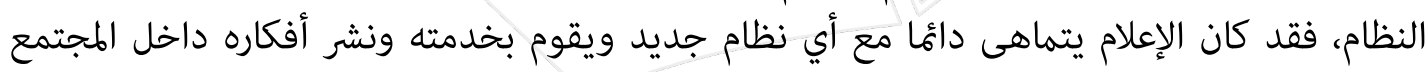
وإقناع الجماهير بها.

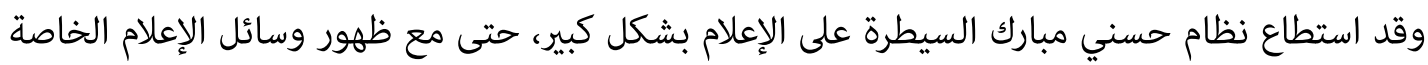

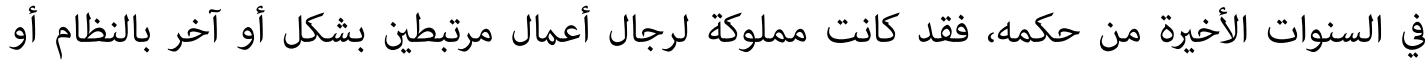

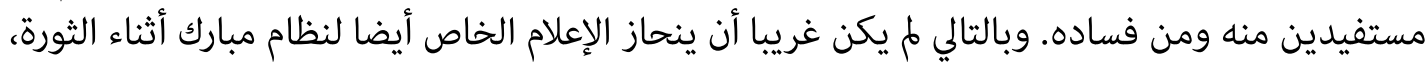

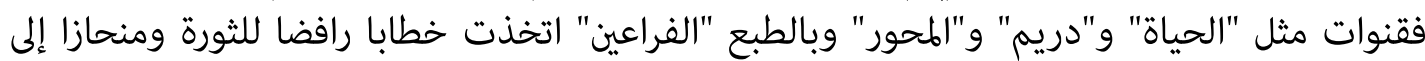

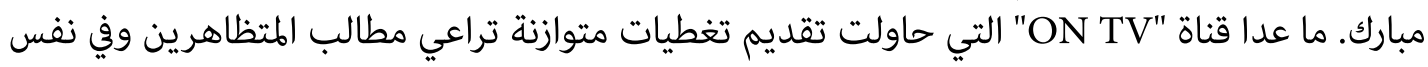
الوقت لا تغضب النظام بالشكل الذي يدفعه إلى إغلاقها. 
رغم فقدان وسائل الإعلام تلك المصداقية عقب الثورة مباشرة، إلا أن المنظومة الإعلامية التابعة لعهد

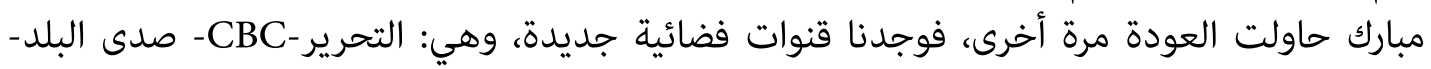

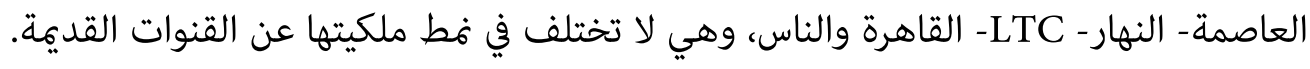
قامت وسائل الإعلام تلك بعملية احتواء لبعض الشخصيات المحسوبة على الثورة عن طريق التعاقد معها

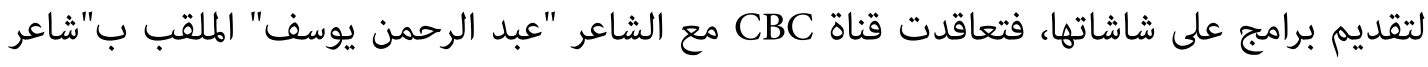

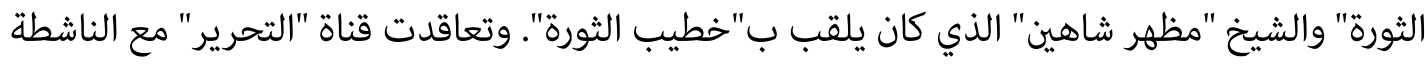
السياسية "نوارة نجم" والصحفي "إبراهيم عيسى" الذي كان يعتبر معارضا لبارك.

كانت ملكية قناة التحرير في ذلك الوقت تعود إلى عدد من المحسوبين على ثورة يناير، قبل أن يتم بيعها

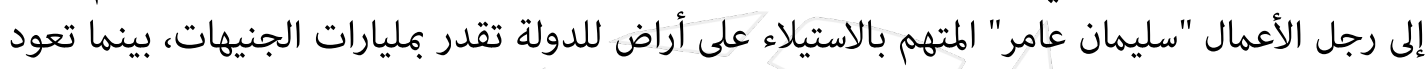
قناة CBC إلى رجل الأعمال "محمد الأمين" الذي تربطه علاقة قوية برمئ برموز نظام مبارك. وجمع في قناته

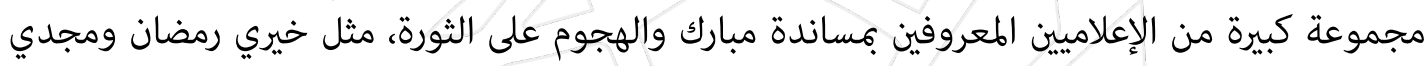

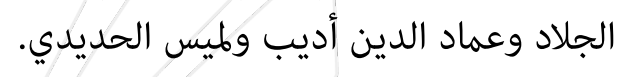
ثانيا: باسم يوسف ومراحل الخضوع

مر "باسم يوسف" خلال عملية تصنيعه، بثلاث مراحل أساسية: الأولى على موقع يوتيوب، والثانية بدأ

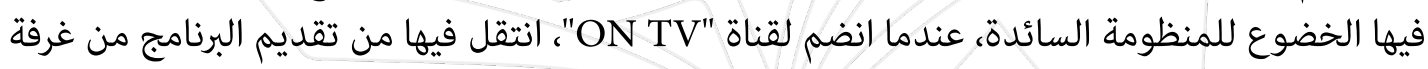
شقته إلى ستوديو، والثالثة عند انتقاله لقناة "CBC" ثم قناة "MBC مصر" التي مثلت نقلة أخدر أخرى من الاستوديو إلى "المسرح" ولكل مرحلة مواصفاتها التي قيزيزها عن الأخرى.

المرحلة الأولي: مرحلة "الغرفة"

ظهر باسم يوسف للمرة الأولى عبر موقع "يوتيوب" في الثامن من مارس عام 2011، في حلقة ساخرة بثها على قناته الشخصية على الموقع، تناول فيها محاولات نظام مبارك إخلاء ميدان التحرير من المتظاهرين. وكانت تلك الحلقة تسخر من مجموعة من الشخصيات المرتبطة بنظام مبارك، أغلبهم من الإعلاميين. كانت الأجواء التي ظهر فيها باسم تتمثل في نجاح المتظاهرين في خلع حسني مبارك، بعد ثورة شعبية دعا إليها مجموعات من الشباب على مواقع التواصل الاجتماعي، واستطاعوا عبرها التغلب إنب على الإعلام

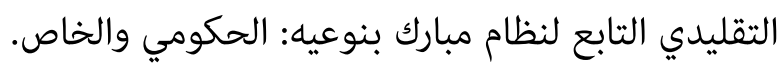
وكان الخطاب السائد وقتها هو التمجيد من قوة الإعلام الجديد وقدرته على إحداث التغيير السياسي

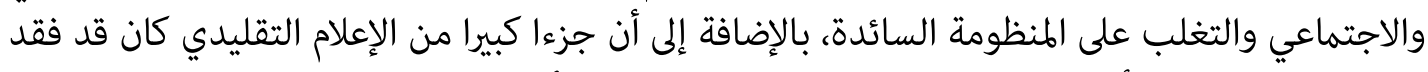

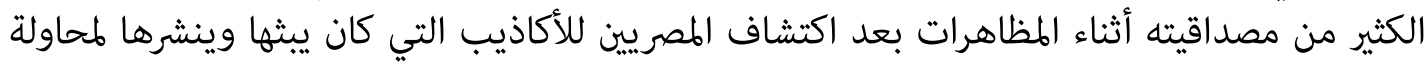

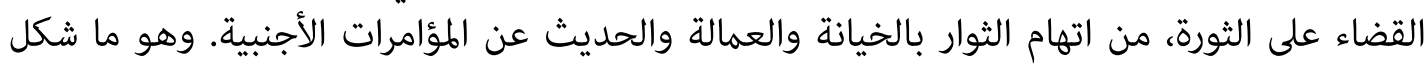
دفعة قوية لبرنامج باسم الجديد في الانتشار واكتساب جماهيرية كبيرة وسط شرائح اجتماعية عديدة. 
بعد هذا النجاح بدأ باسم يظهر في قنوات تلفزيونية في الإعلام التقليدي كضيف في المرة الأولى ليتحدث

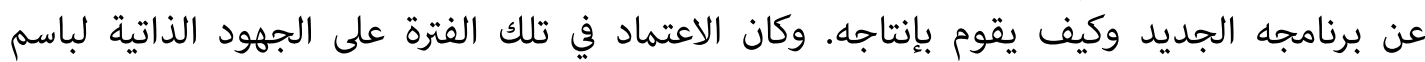

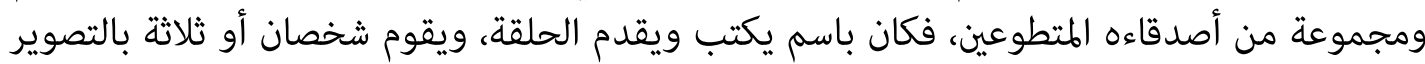

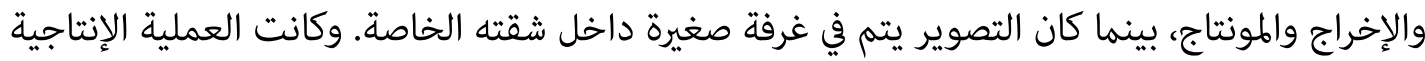

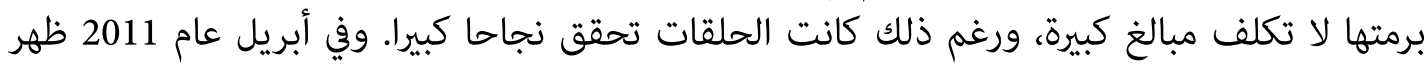

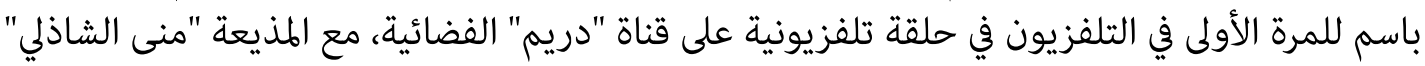
ليتحدث عن برنامجه.

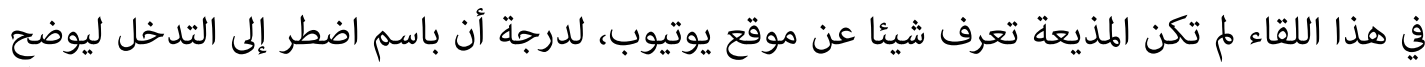

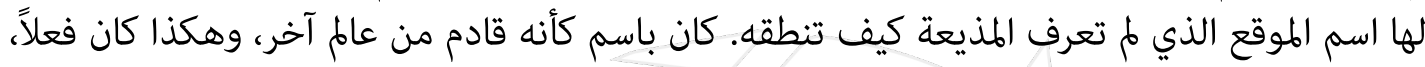

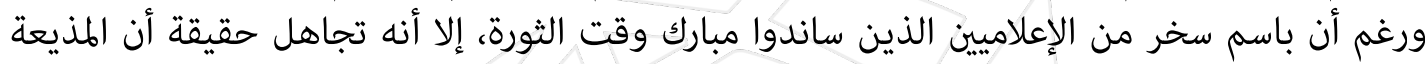

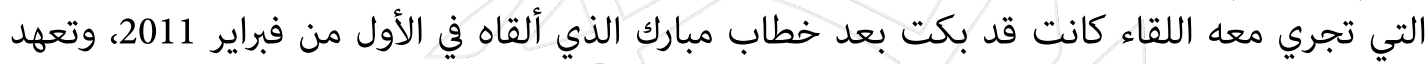

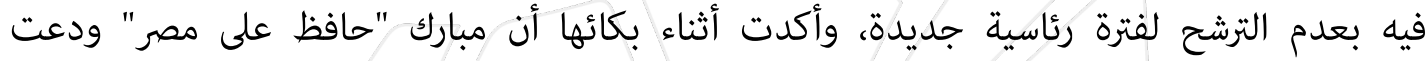

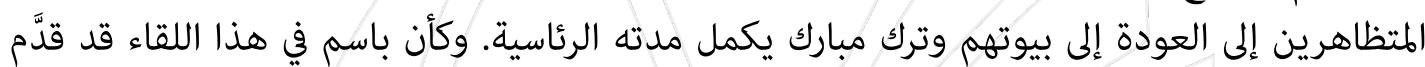

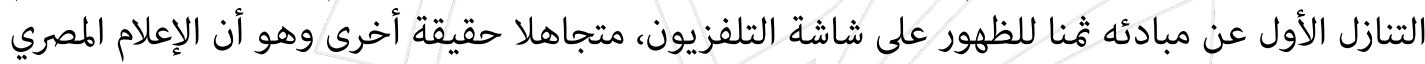
م ميتغير.

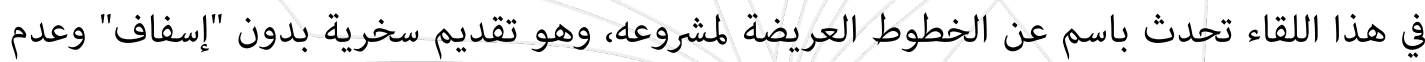

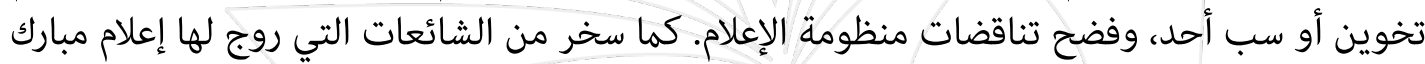

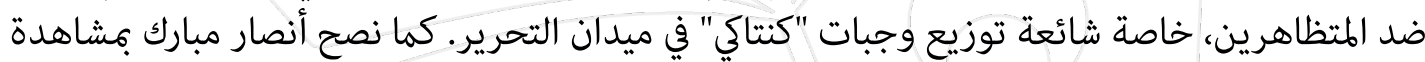
قناة الجزيرة وبي بي سي وأي قنوات أخرى غير مصرية لئوني ليعرفوا "الحقيقة".

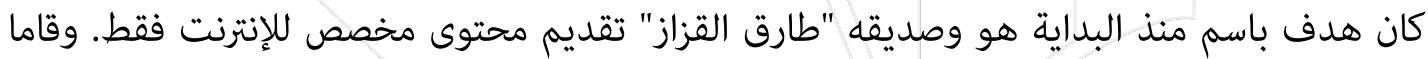

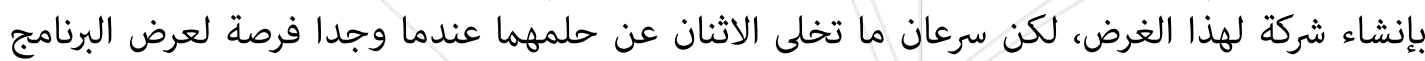

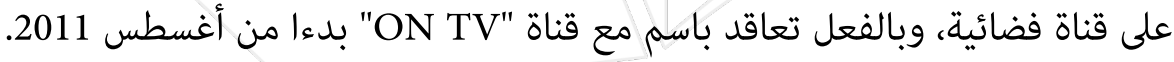
المرحلة الثانية: مرحلة الاستوديو: 
سبق أن نوهنا إلى أن قناة "ON TV" كانت الوحيدة ضمن الإعلام التلفزيوني الخاص التي قدمت خطابا

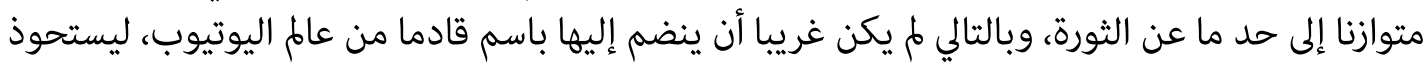

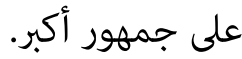

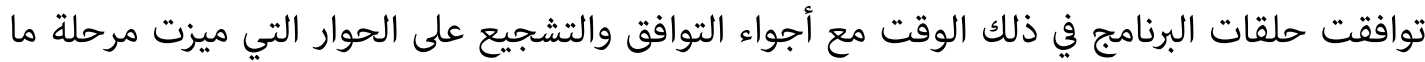

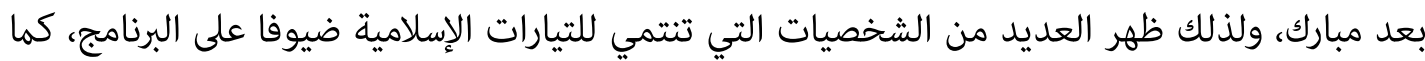

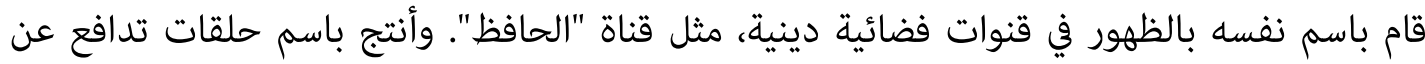

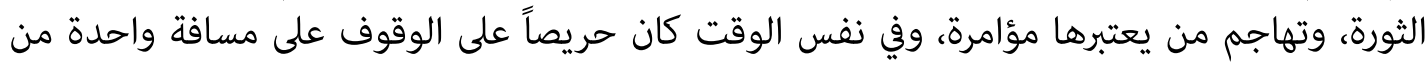

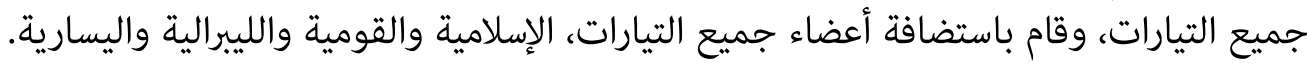

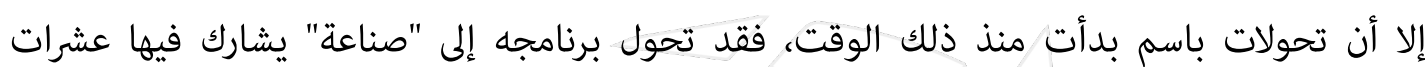

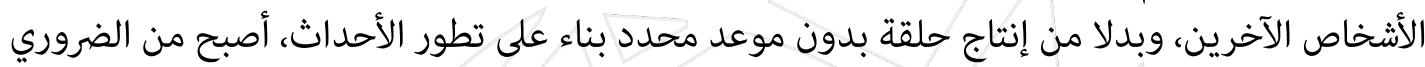

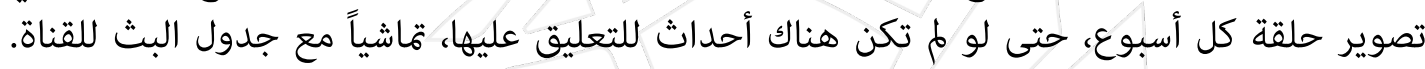

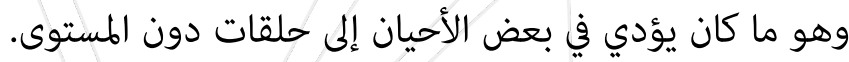

وتحول برنامج باسم إلى نوع من الفن الجماهيري، فقد كانت شبكة الإنترنت محدودة في النهاية ولا

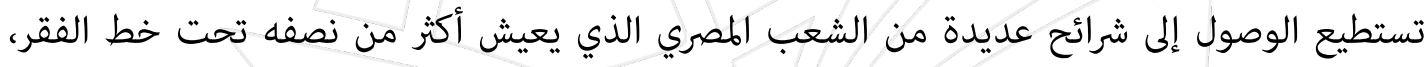

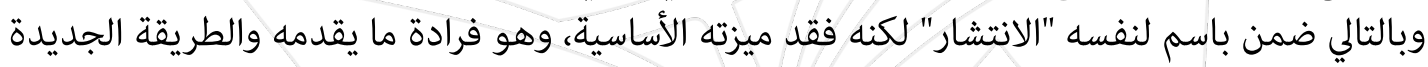
التي ظهر من خلالها.

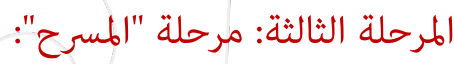

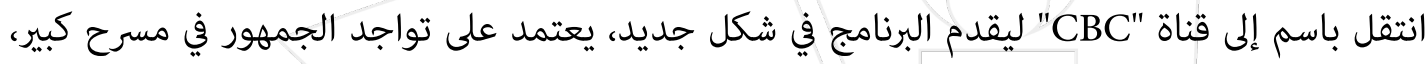

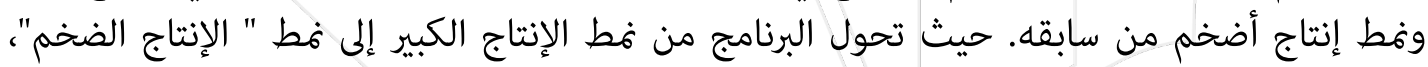

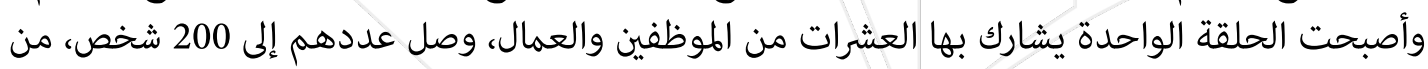

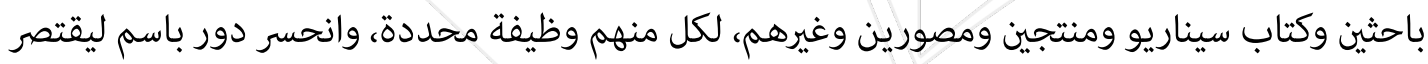

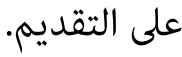

منذ بدايته أعلن باسم أنه يتخذ من المذيع الأمريكي "جون ستيوارت" قدوة له، وظهر واضحا في الشكل

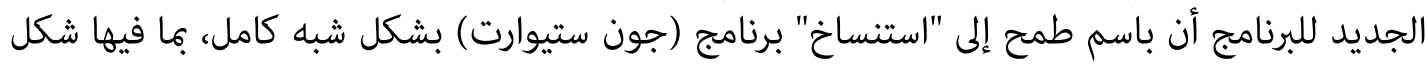

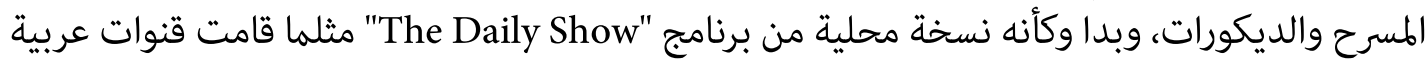

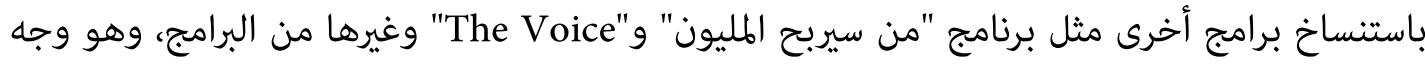

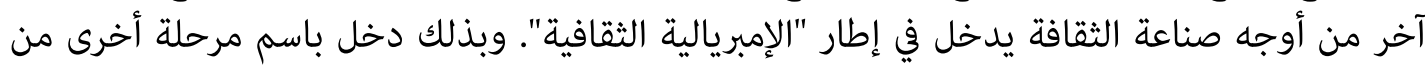

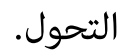
منذ الحلقة الأولى على قناة "CBC" واجهت البرنامج أول أزمة تتعلق بمحتواه، لكنها لم تكن من النظام الحاكم آنذاك، وإفا من أحد زملاء باسم في القناة الجديدة. 
ففي هذه الحلقة سخر باسم من المذيع "عماد أديب" الذي غضب من المان تلك السخرية وتوعد بمقاضاة

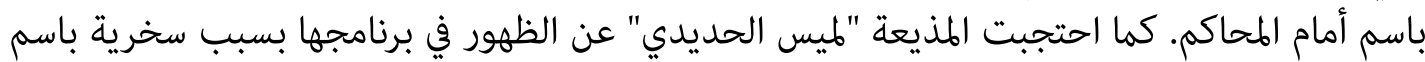

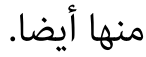

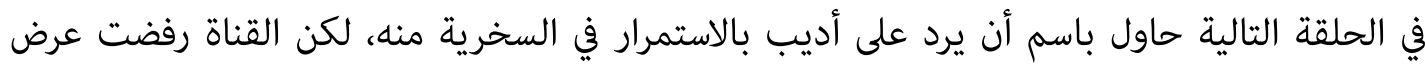

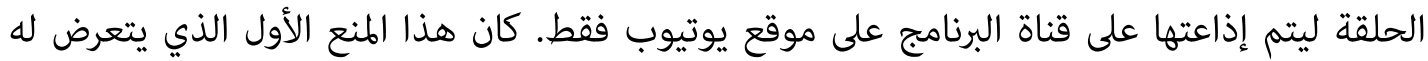

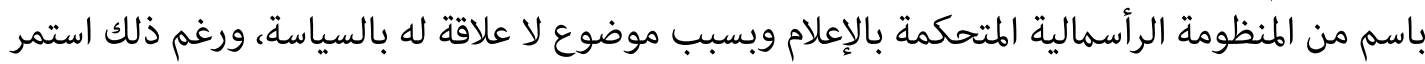

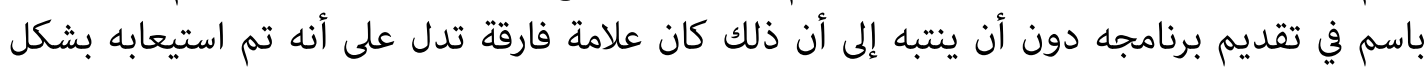

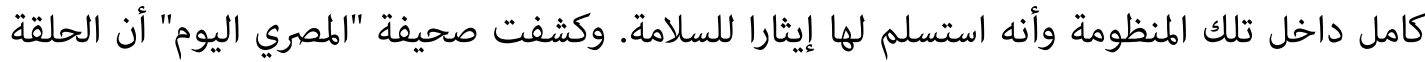

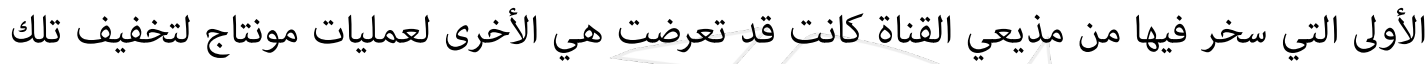

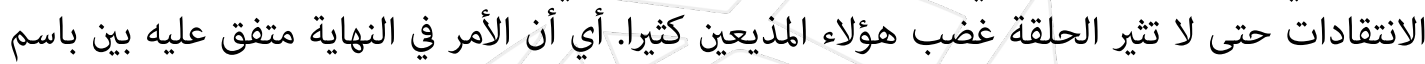

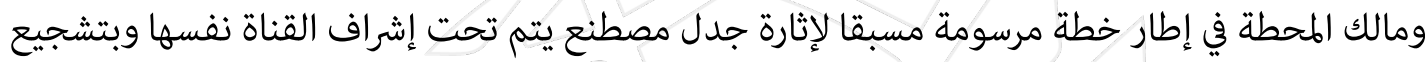
منها وبالقدر الذي تسمح به.

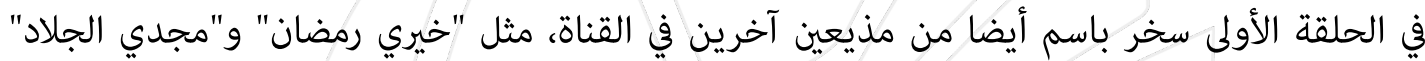

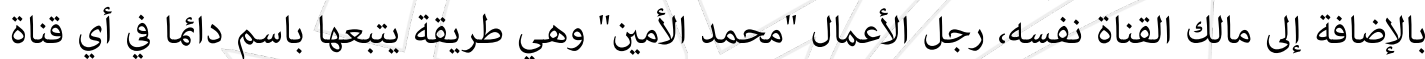

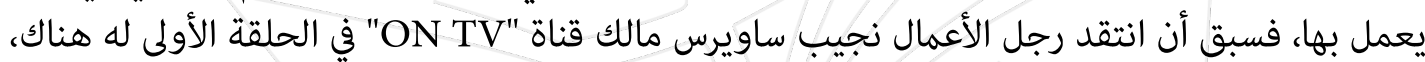

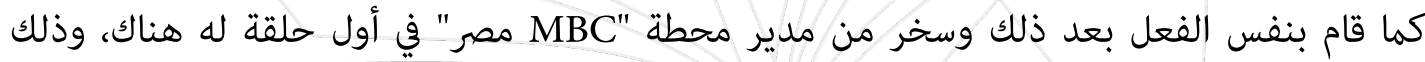

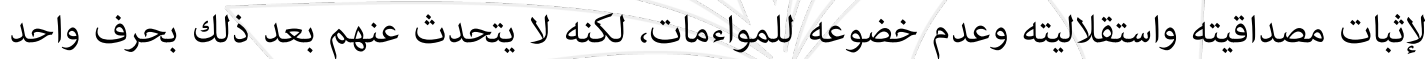

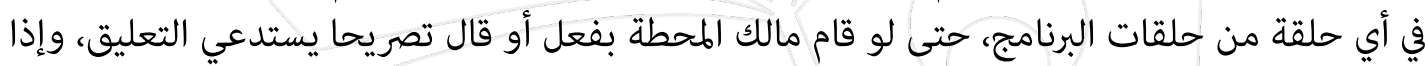

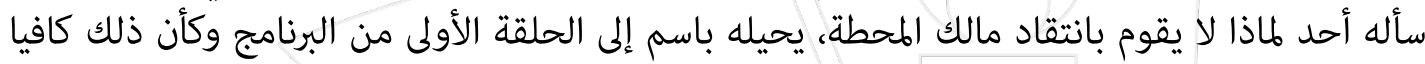

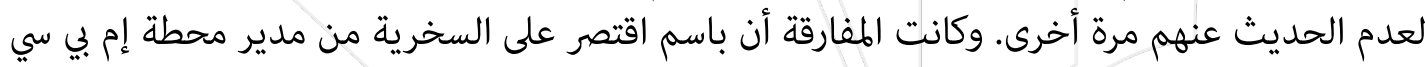
مصر وليس من مالك القناة نفسه (رجل الأعمال السعودي وليد العنديد الإبراهيم).

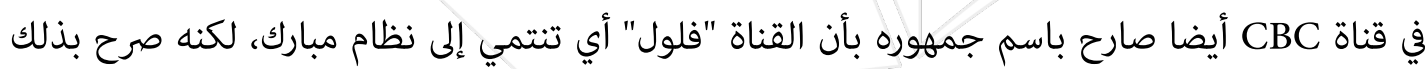

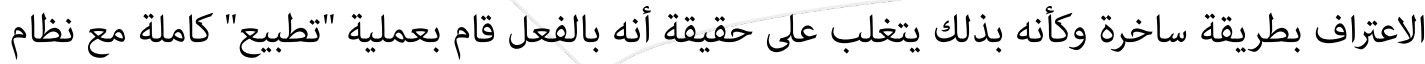
مبارك الإعلامي والسياسي والاقتصادي، ممثلا في القناة ومذيعيها ومالكها وسياستهانها بلتها التحريرية.

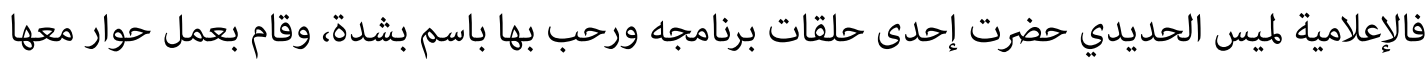

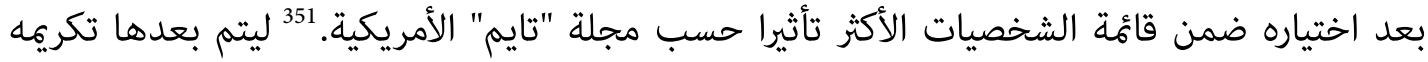


من القناة بحفل كبير دعيت إليه شخصيات كثيرة تنتمي إلى نظام مبارك دون أن يجد باسم في نفسه

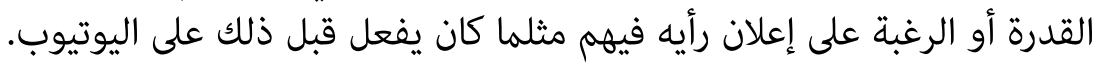

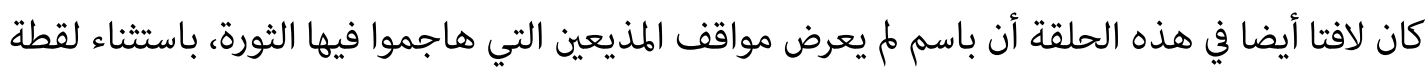

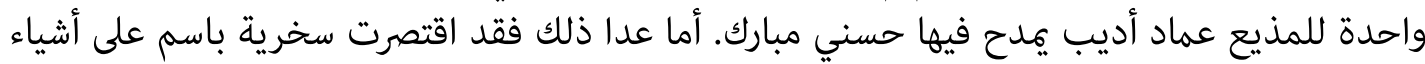

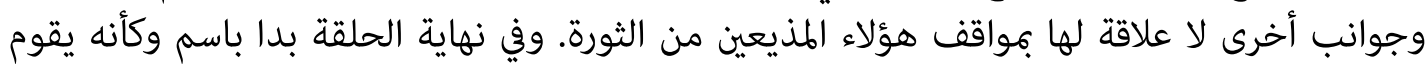

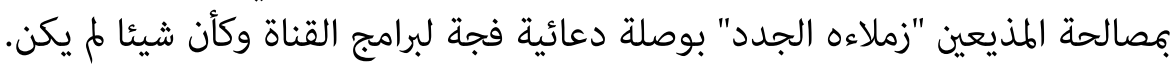
حقق البرنامج في هذه الفترة نجاحا غير مسبوق، سواء من ناحية التأثير السياسي أو الأرباح المالية للقناة،

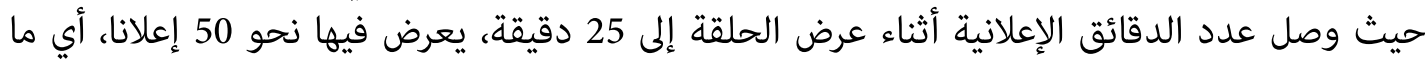

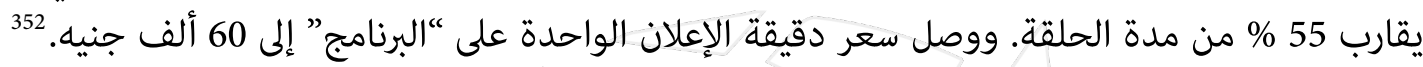

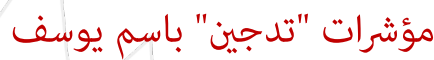

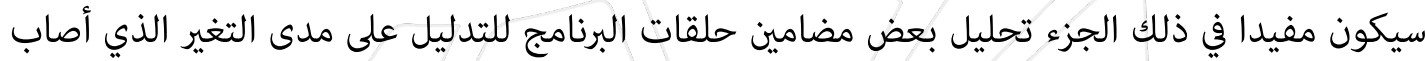

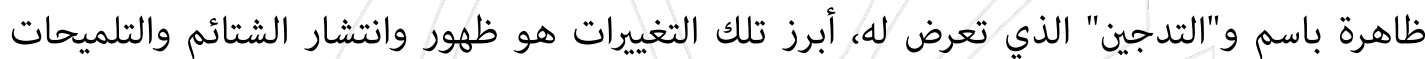

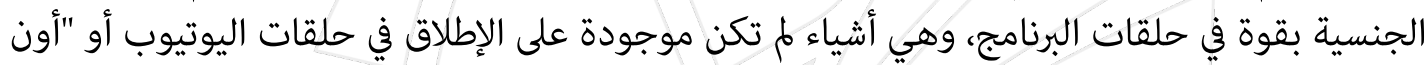

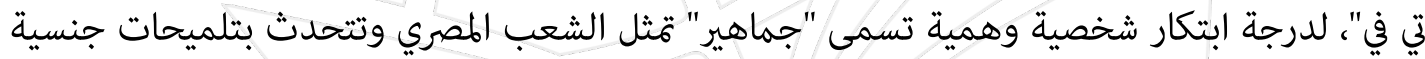
عن علاقة الجماهير بالحكام.

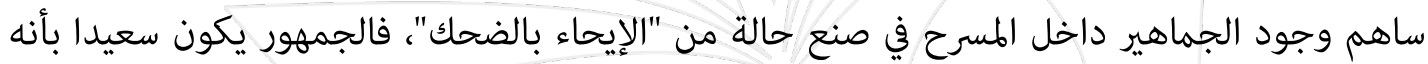

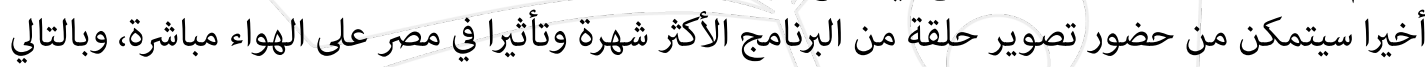

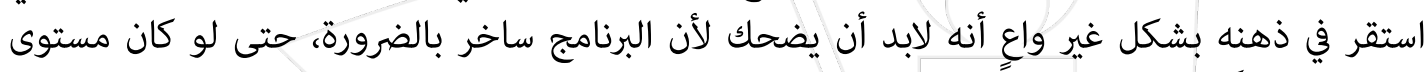
الحلقة سخيفاً ولا يبعث على ذئه الضحك. هذه الحالة من الضحك امتدت إلى مشاهدي البرنامج عبر التلفزيون، فقد أدى ظهور الشتاء الشتائم على لسان

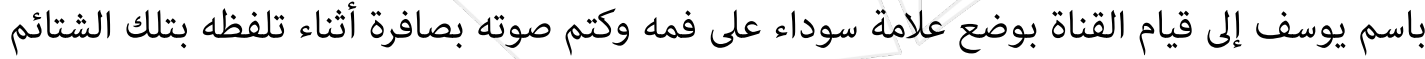

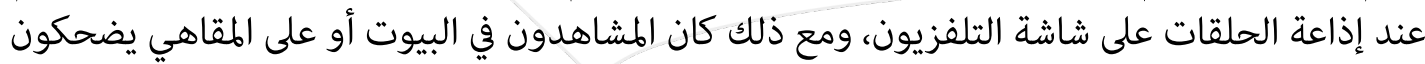
على تلك الشتائم، رغم أنهم مل يعرفوا بالضبط ماذا قال المّل الذيع، لكن صوت الجمهور الذي يضحك يدفعهم 
إلى الضحك أو يرغمهم عليه، مفترضين أنه قال شيئا يدفع إلى الضحك بالضرورة. وربها كان بعضهم يحسد جمهور المسرح على قكنهم من سماع تلك الشتائم. وقع باسم في تلك الفترة في فخ الدعاية السياسية ضد نظام مرسي، فأثناء العام الأول من حكم الدكتور

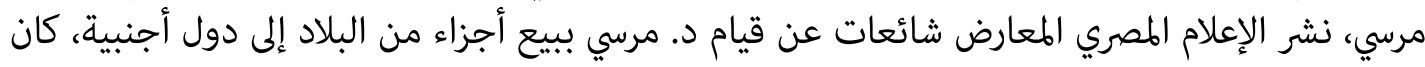

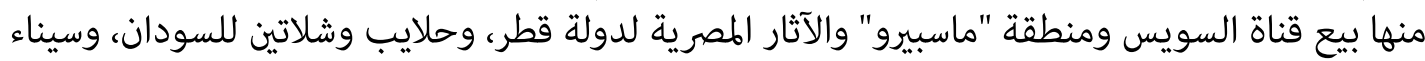
لإقامة دولة فلسطينية. وهي شائعات استسلم لها "باسم يوسف" وقاة وقام بعمل أوبريت غنائي بعنوان "قطري حبيبي". ويمكن القول إن حلقات باسم يوسف قد تبدو من الناحية الظاهرية "معارضة" للوضع الذي كان قائما،

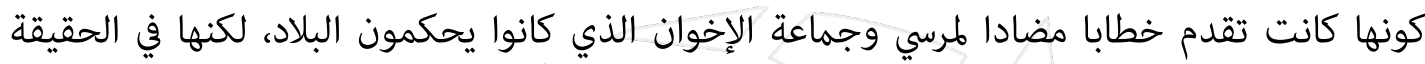
كانت تدفع دفعا إلى عودة النظام القديم مرة أخرى، والذي كان مازال يسيطر على كانى كافة جواني النب التهان الحياة

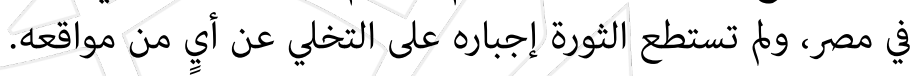
توقف البرنامج في نهاية يونيو 2013، وعاد في أكتوبر 2013 بعد الانقلاب العسكري في الثالث من يوليو من نفس العام، وقد حاول باسم يوسف أن يكرر ما فعله مع مرسي بعد عزل عزل الأخير، لكن بسقف منف منخفض

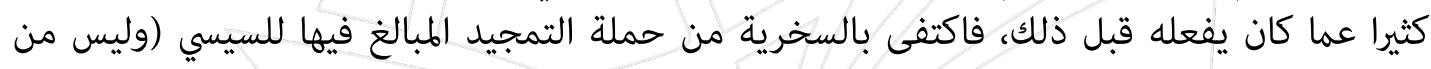

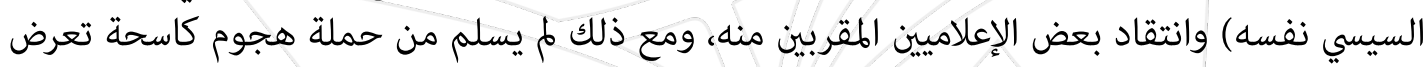
لها بعد الحلقة الأولى بعد عودته.

وحاصر العشرات من مؤيدي السيسي المسرح الذي يقدم فيه البرنامج وهاجموه بشدة. أما عن الإعلاميين

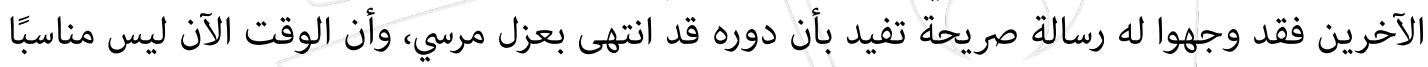

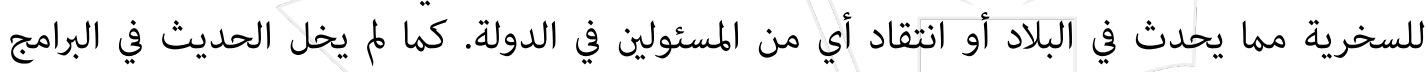

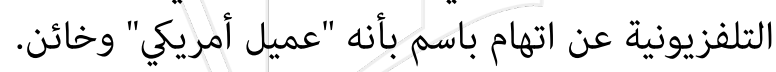

وسرعان ما تخلت قناة CBC عن مذيعها المفضل، إذ أصدرت بيانا أكدت فيه رفضها لبعض محتويات

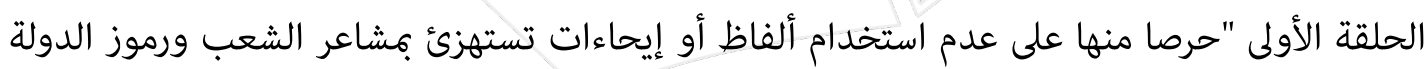

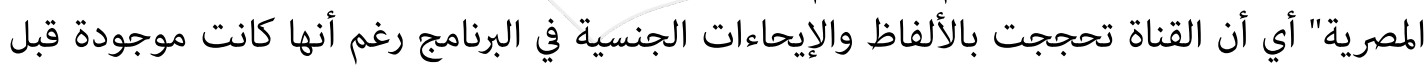

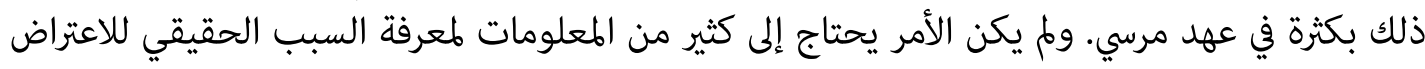

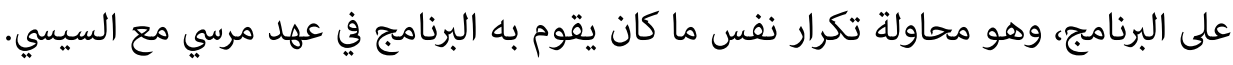




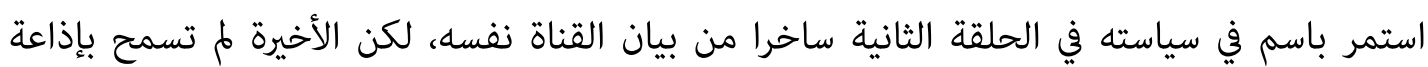

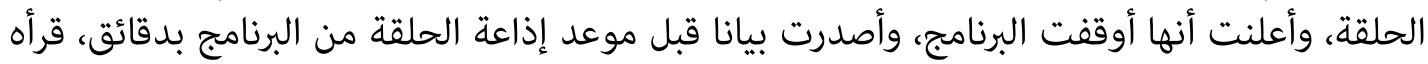

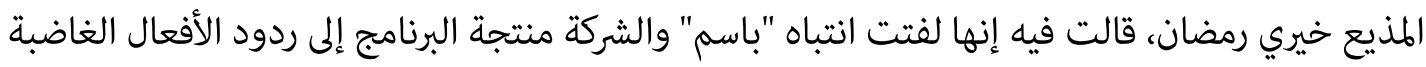

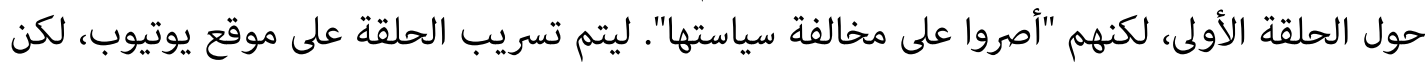

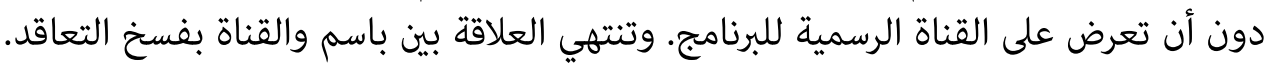

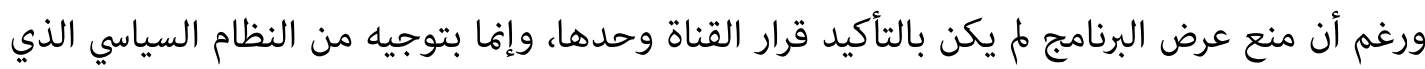

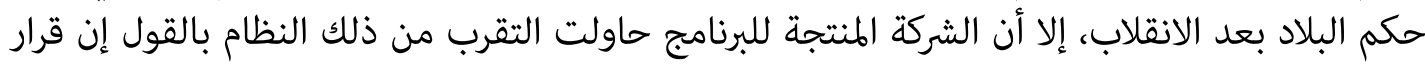

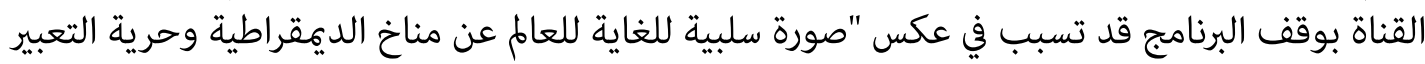

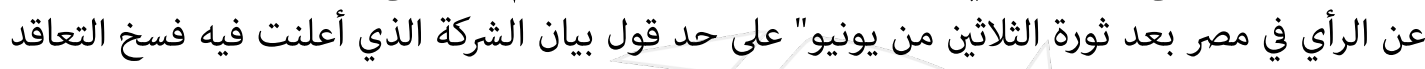
مع القناة.

ثالثا: نهاية التصنيع

كانت المرحلة الأخيرة لباسم على قناة "MBC مصر". حيث بدأ في تقديم الحلقة الأولى في فبراير عام

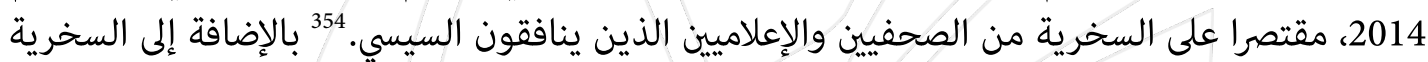

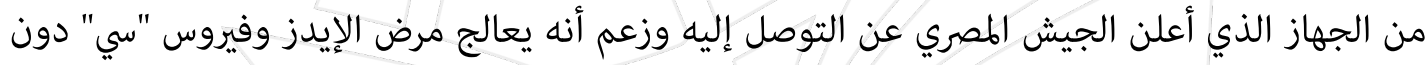

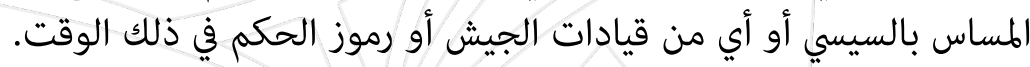
المفارقة أن تلك الحلقة أذيعت بعد أيام قليلة من مقتل أكثر من 60 متظاهرا أثناء الذكرى الثالثة لثورة الثنا

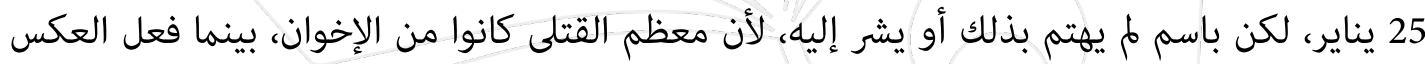

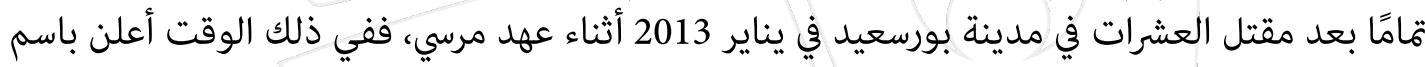

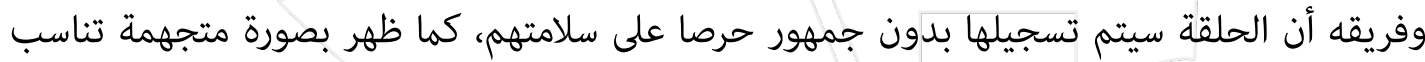

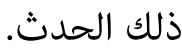

استمر باسم في برنامجه لمدة 4 أشهر، قدم خلالها 11 حلقة، وكان من المقرر أن يحصل على إجازة ويعود

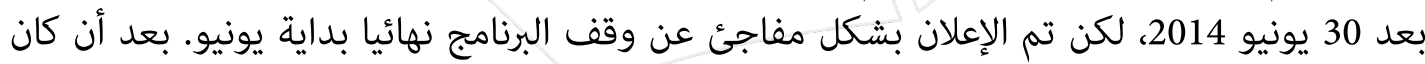

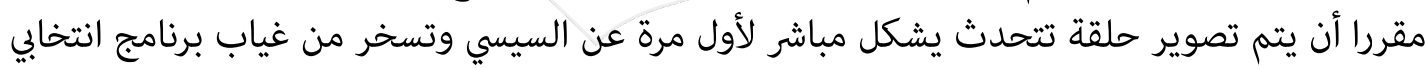

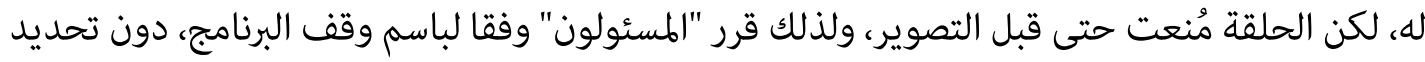




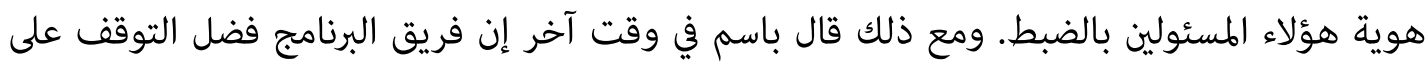
أن يقوم بتقليل سقفه حتى يستمر.

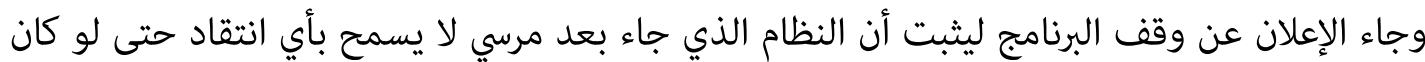

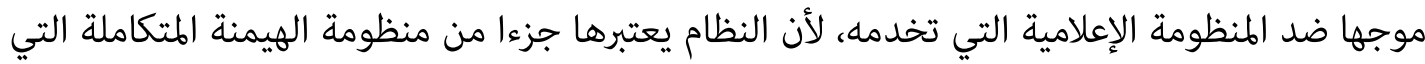
قام ببنائها ولن يسمح بالمساس بها.

وقال باسم صراحة في تصريحات تلفزيونية إنه أوقف البرنامج ببساطة لأن النظام الحالي "نجح في إسكاته" إنها

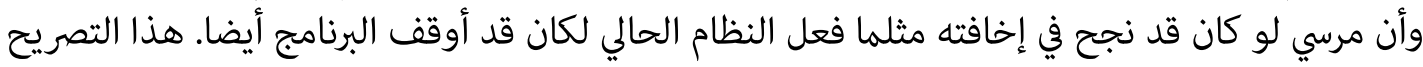

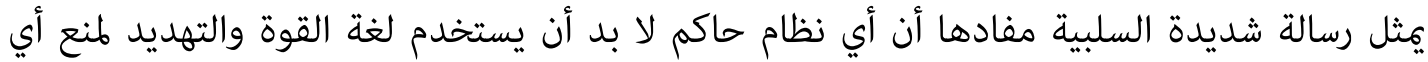

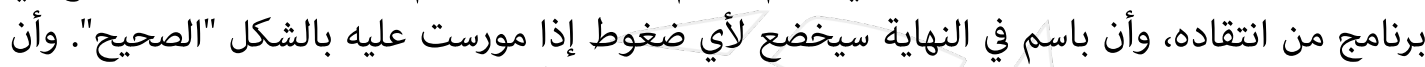
خطأ مرسي الوحيد أنه مل يبذل جهدا بادما كافيا لمنعه.

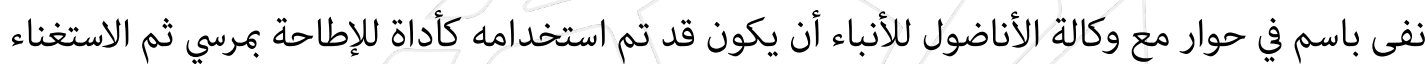

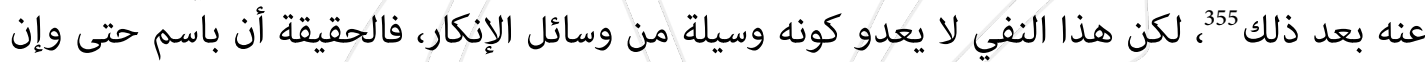

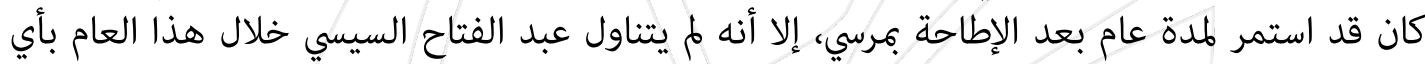

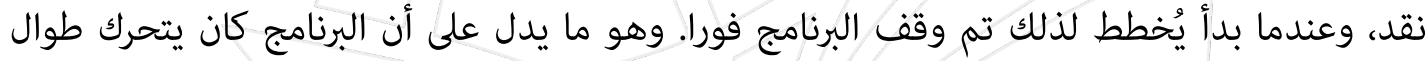

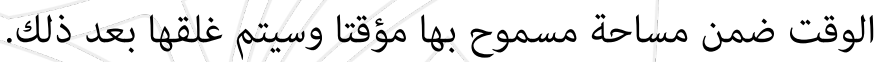

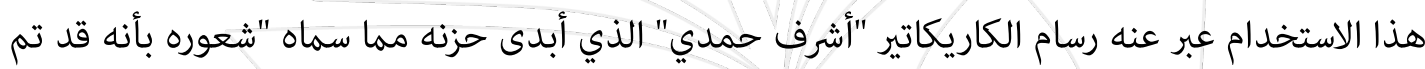

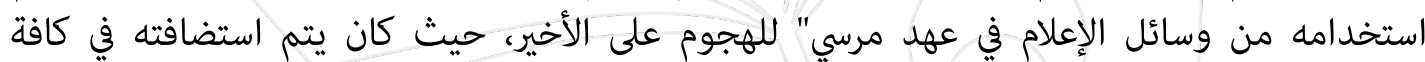

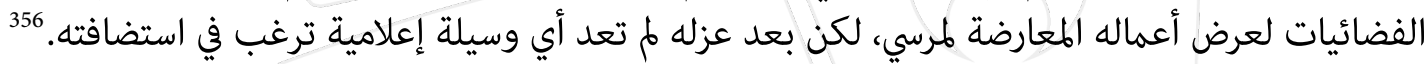
رابعا: من الثورة إلى السياسة إلى "التناقض" فرتسي

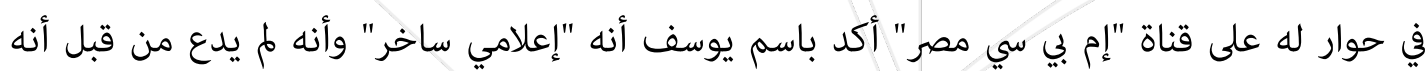

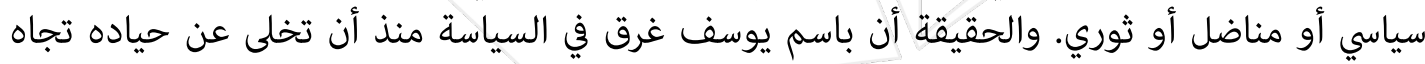

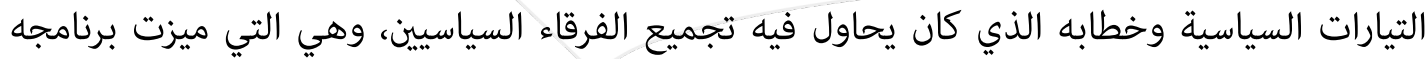

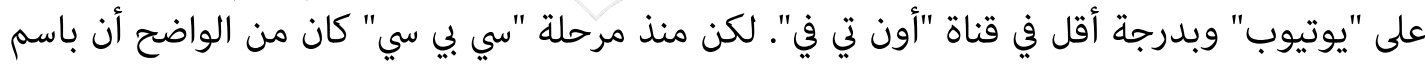

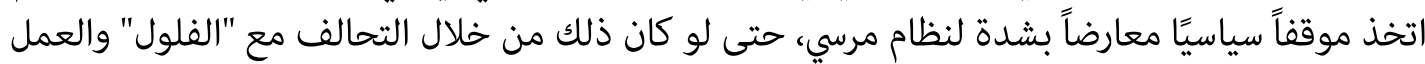

355 "باسم يوسف: لم استخدم كأداة للإطاحة بحكم مرسي"، الجزيرة مباشر، 29 نوفمبر/ تشرين الثاني 2015. 356 "رسام كارتون: في عهد السيسي .. دوري انتهى مثل باسم يوسف"، المصريون، 9 أغسطس/ آب 2015. 
من خلال قنواتهم، وكان باسم يحرص في نهاية كل فقرة من فقرات برنامجه على إلقاء ما يشبه الخطاب السياسي الصريح الذي يجمل فيه موقفه من الأحداث السياسية.

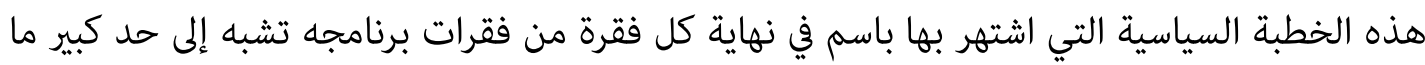

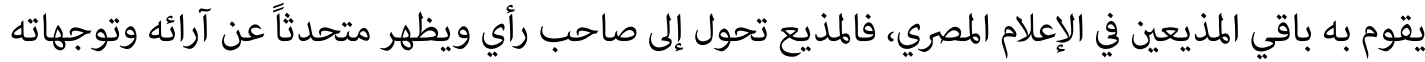

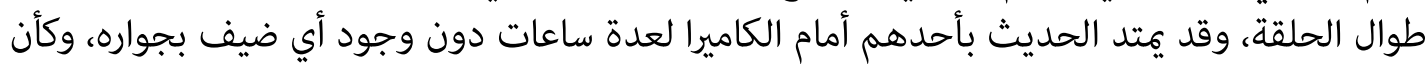

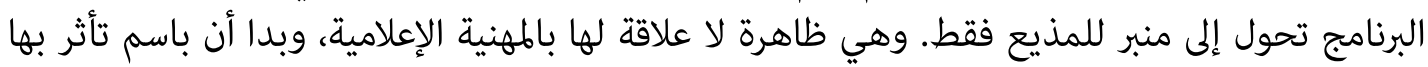

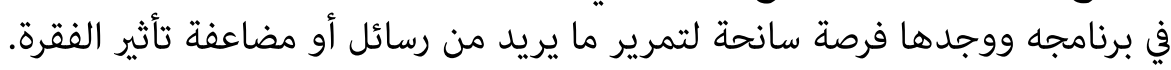

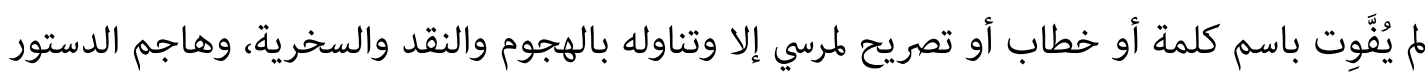

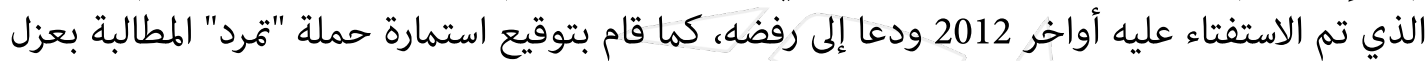

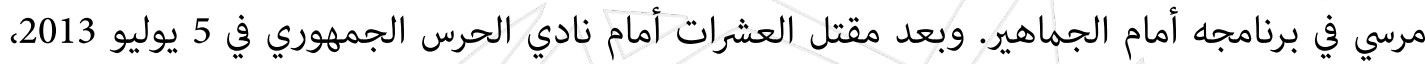

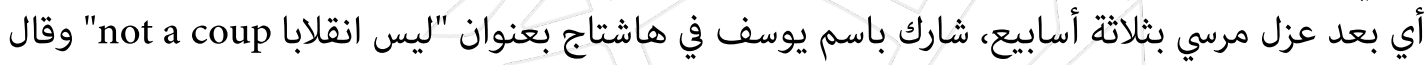

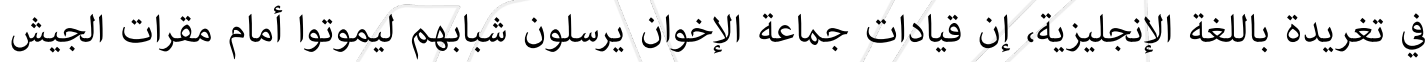

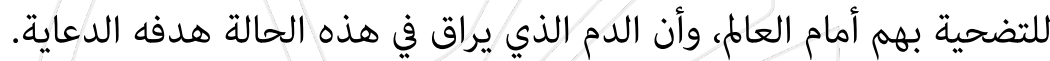
حتى مقالاته في صحيفة الشروق كان موضوعها الأساسي هو السياسة بالدرجة الأولى، مُكرراً مضامين

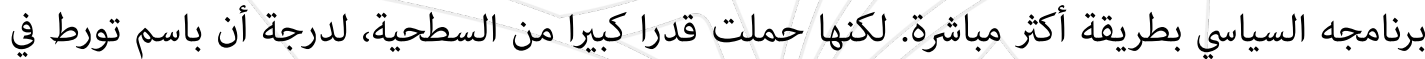

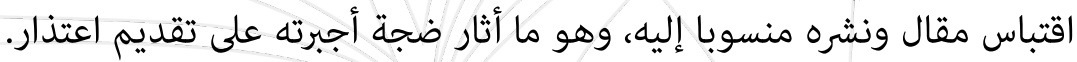

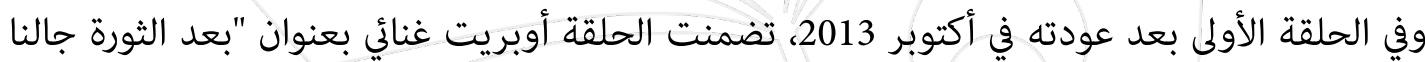

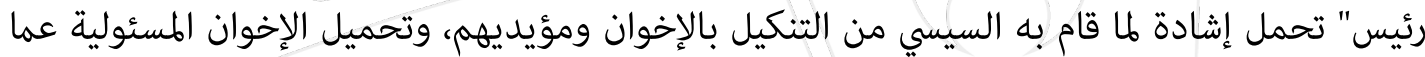

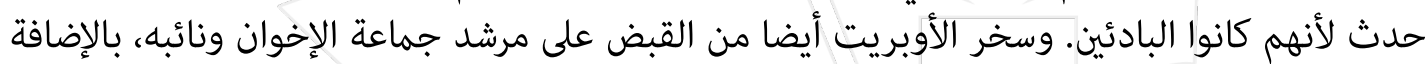

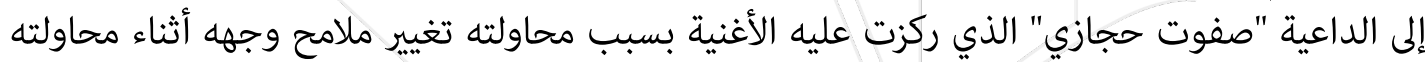

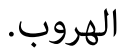

ورغم إشادته في ذلك الأوبريت بما قام به عبد الفتاح السيسي من انقلاب وتنكيل بالإخوان وأنصارهم،

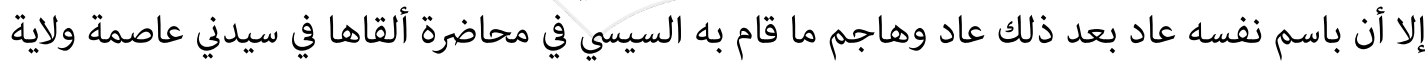

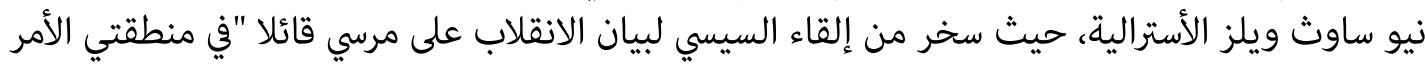

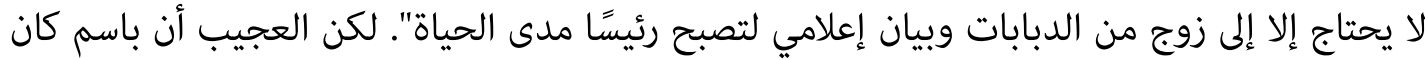


قد أشاد بهذا البيان نفسه في الأوبريت الغنائي الذي قدمه في برنامجه. (والسيسي طلع بيان.. قرر يفشخ الإخوان) (والسيسي لعبها صح.. والإخوان ابتدوا بالدح).

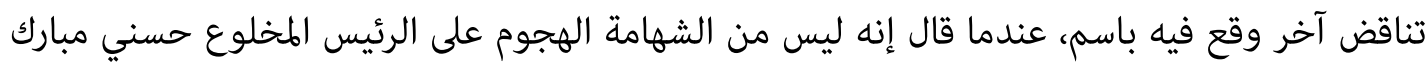

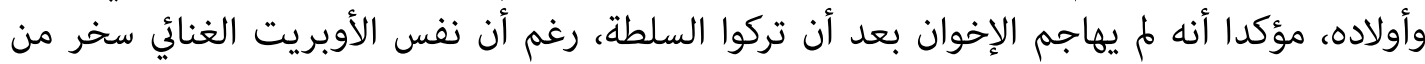

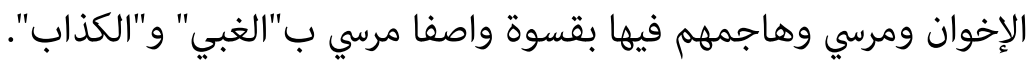

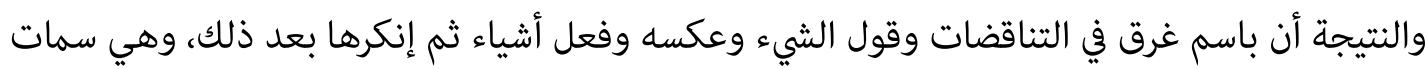

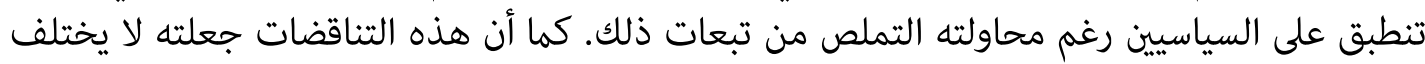
كثيرا عن الإعلاميين الآخرين الذين كان يسخر من تناقضاتهم كما قال في بداية مشواره النئ الإعلامي.

خلاصة

بعد توقف البرنامج انتشرت عدة شائعات على مدى فترات زمنية متفاوتة تؤكد أن باسم سيعود إلى إنتاج

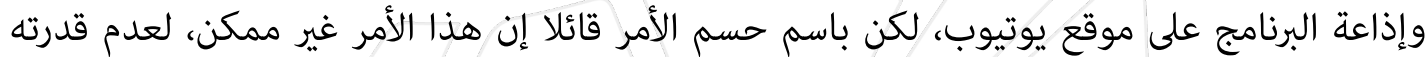

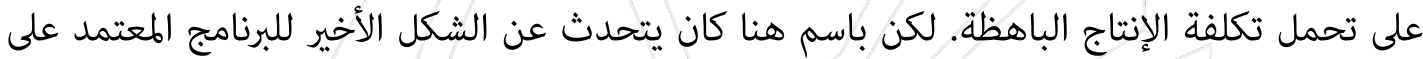

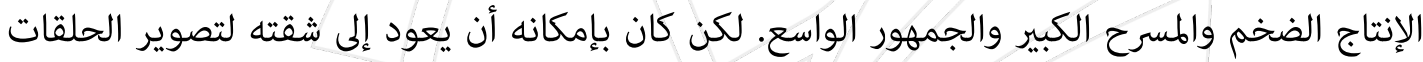

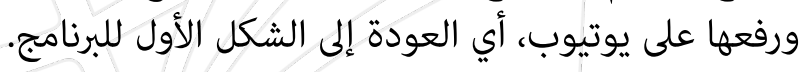

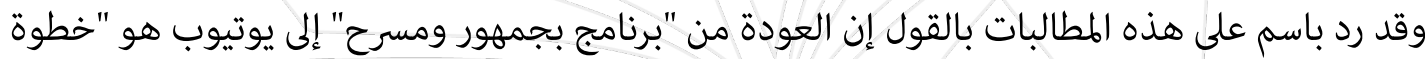

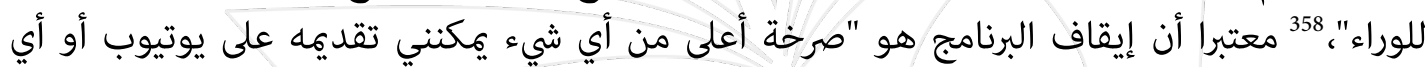

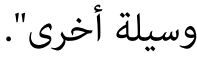

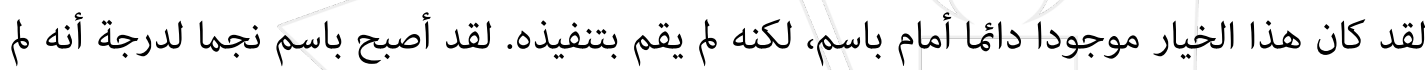

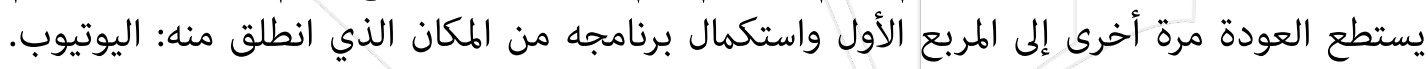

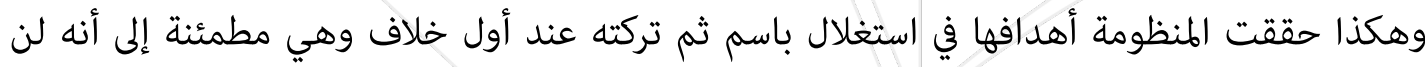

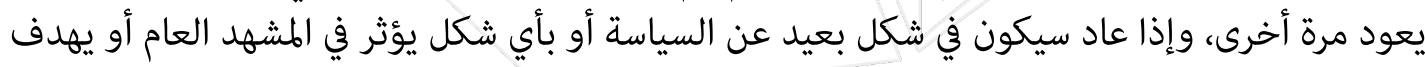
إلى تغييره.

357 مثل شعبي مصري استخدمه باسم يوسف في الأغنية لتحميل الإخوان المسئولية عما حدث في فض ميدان رابعة العدوية في 14 أغطس/ آب 2013. 358 "الإعلامي المصري الساخر باسم يوسف: لست نادما على انتقاد محمد مرسي"، أرابيان بيزنس، 23 فبراير / شباط 2015. 
أما من جانبه، فإن باسم يدرك الفارق جيدا بين إذاعة برنامج على يوتيوب، لن يحصل في أحسن الأحوال

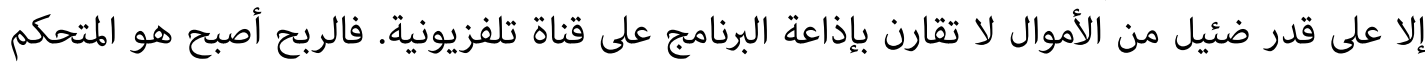

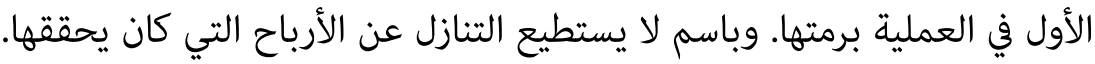

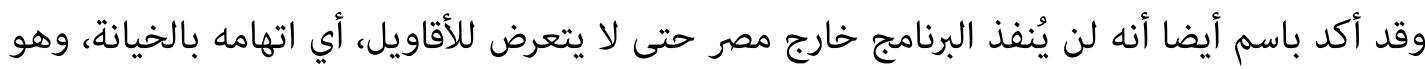

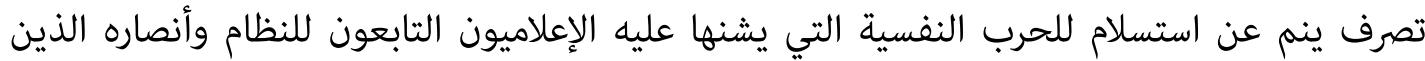

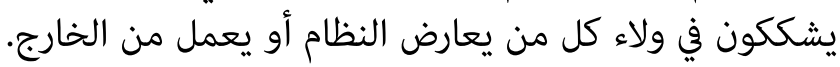
وفي المؤتمر الصحفي الذي عقده باسم يوسف للإعلان عن وقف برنامجه، قال إن هذا الإيقاف ليس رسالة

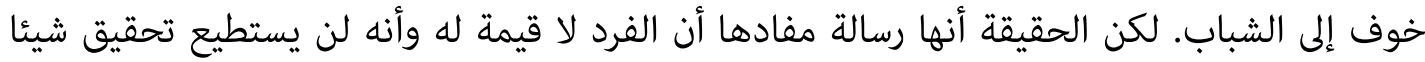

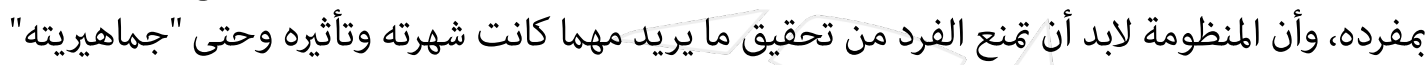

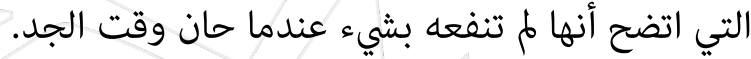

تقبل باسم إذن توقيف برنامجه في هدوء لا يناسب الصخب والضجيج الذي مارسه في عهد مرسي عندما

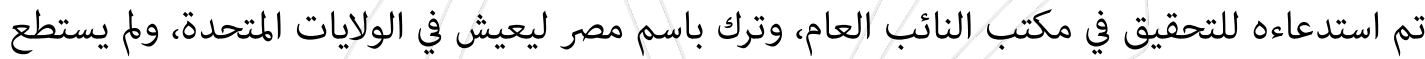

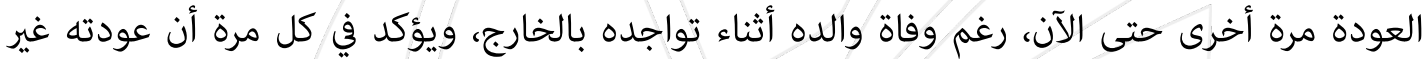

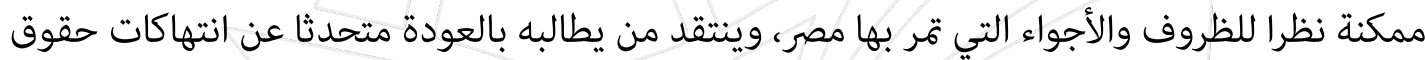
الإنسان في مصر والتي يتعرض لها الكثراء لنيرون.

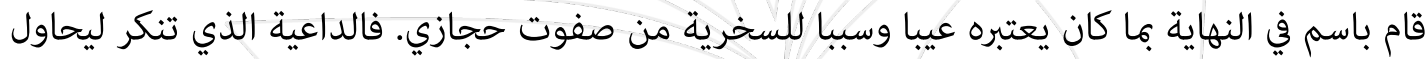

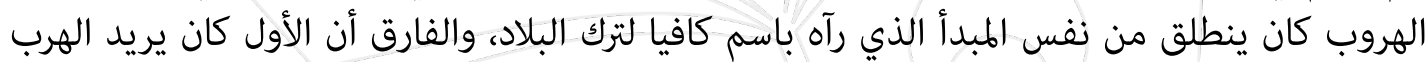

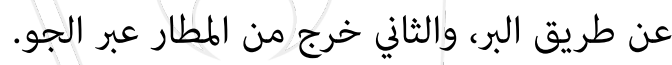

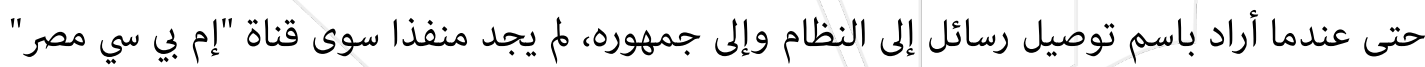

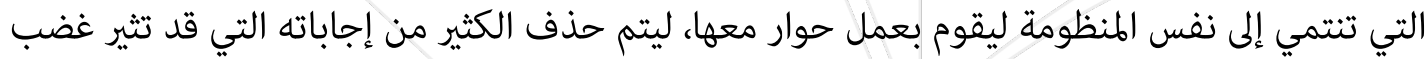

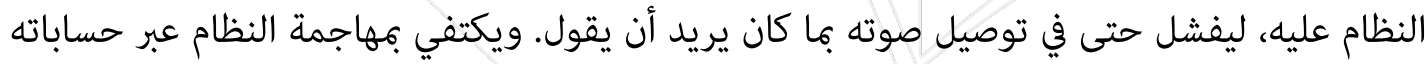
وصفحاته على مواقع التواصل الاجتماعي، أو حلقات معدودة يظهر فئه فيها ضيفا في في فضائيات في غير في مصرية.

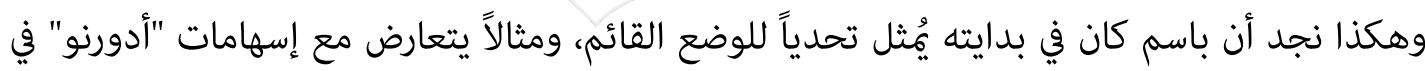

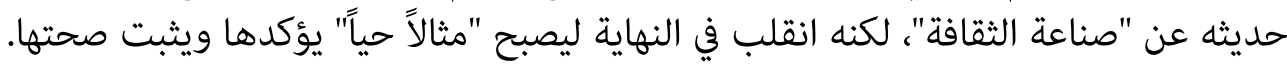




\section{مجلة المعهد المصرى}

EGYPT INSTITUTE JOURNAL

حقوق الطبع والنشر والتوزيع محفوظة

\section{المعد المصره للدراسات}

EGYPTIAN INSTITUTE FOR STUDIES

www.eipss-eg.org

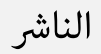

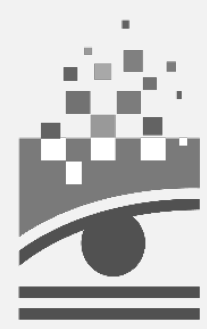

المرصد للنـشْر والصحافْةٌ والإعلام ALMARSAD FOR PUBLISHING, PRESS \& MEDIA

www.almarsad.co.uk 


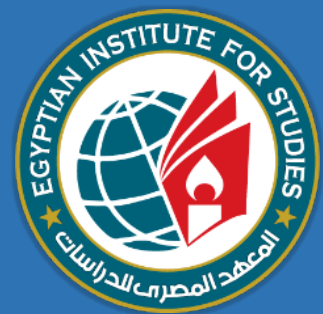

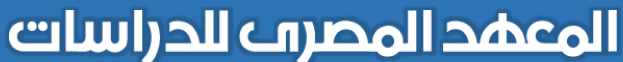
EGYPTIAN INSTITUTE FOR STUDIES

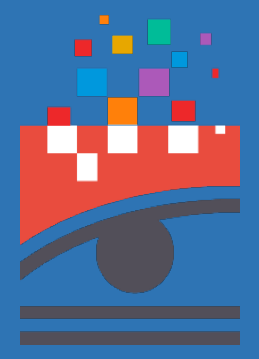

المرصد للنشُر والصحافة والإعلامم almarsad.co.uk 